\title{
Volatility Risk and Stock Return Predictability
}

\author{
on Global Financial Crises
}

\author{
Worawuth Kongsilp
}

The thesis submitted is partial fulfilment of the requirements of the University of Greenwich to the degree of Doctor of Philosophy

University of Greenwich, London, U.K Business School

March 2017 


\section{DECLARATION}

I certify that the work contained in this thesis, or any part of it, has not been accepted in substance for any previous degree awarded to me, and is not concurrently being submitted for any degree other than that of Doctor of Philosophy being studied at the University of Greenwich. I also declare that this work is the result of my own investigations, except where otherwise identified by references and that the contents are not the outcome of any form of research misconduct.

Candidate: Worawuth Kongsilp

First Supervisor : Dr. Cesario Mateus

Second Supervisor : Dr. Alex Stojanovic

March 2017 


\section{Table of Contents}

Page

$\begin{array}{ll}\text { Abstract } & 7\end{array}$

$\begin{array}{lr}\text { List of Tables and Figures } & 8\end{array}$

$\begin{array}{ll}\text { Chapter 1: Introduction } & 11\end{array}$

$\begin{array}{ll}\text { Chapter 2: Literature Review } & 15\end{array}$

2.1.Introduction $\quad 15$

2.2. Implied Volatility and Future Realized Returns 16

2.3. Implied Volatility versus ARCH Models as Future Volatility Predictors 18

2.4. Cross-Section Volatility and Expected Returns 19

2.5. Implied and Realized volatility 21

2.6. Option Prices and Stock Returns 24

2.7. Implied Volatility and Cross-section equity returns 31

2.8. Historical and Implied volatilities effect on future volatility 32

2.9. Financial Crises and Structural Break

2.10. Earnings announcement surprises 37

Chapter 3: Volatility Risk and Stock Return Predictability on Global Financial 41 Crises

3.1.1. Abstract 41

3.1.2. Background and Review 42

3.2. Data and methodology 45

3.2.1. Sample $\quad 45$

3.2.2. Methodology 46

3.2.2.1 Beta, Implied and Realized idiosyncratic volatilities 46

3.2.2.1.1. Beta Calculation 46

3.2.2.1.2 Implied idiosyncratic volatility calculation 47

3.2.2.1.3.Realized idiosyncratic volatility calculation 48

3.2.2. GARCH and $\mathrm{AR}(2) \quad 48$ 
3.2.2.3. Short-sale and liquidity

3.2.2.4 Realized volatility prediction $\quad 50$

3.2.2.4.1. Implied volatility $\quad 50$

3.2.2.4.2. Implied idiosyncratic volatility 51

3.2.2.5. Predictive Regressions 51

3.2.2.5.1. Fama-Macbeth (1973) 51

3.2.2.6. Breakpoints by Chow Test 52

3.3. Data sources and description $\quad 53$

3.4. Empirical Results $\quad 54$

3.4.1. Descriptive statistics $\quad 54$

3.4.2. Breakpoints in Financial Crises

3.4.3. Preliminary analysis $\quad 60$

3.4.4. Predictive regressions $\quad 67$

3.4.4.1. Future realized volatility $\quad 67$

$\begin{array}{ll}\text { 3.4.4.2. Realized returns } & 70\end{array}$

$\begin{array}{lr}\text { 3.5. Conclusions } & 82\end{array}$

$\begin{array}{ll}\text { References } & 84\end{array}$

Chapter 4: Volatility Risk, Global Financial Crises and Industry Specific Effects 86

4.1.1. Abstract 86

$\begin{array}{ll}\text { 4.1.2. Background } & 87\end{array}$

4.2. Data and Methodology 92

4.2.1. Sample $\quad 92$

4.2.2. Methodology 93

4.2.2.1 Beta, Implied and Realized idiosyncratic volatilities 93

4.2.2.1.1. Beta Calculation 93

4.2.2.1.2 Implied idiosyncratic volatility calculation 93

4.2.2.1.3.Realized idiosyncratic volatility calculation 94

4.2.2.2. EGARCH and $\mathrm{AR}(2) \quad 94$

4.2.2.3. Short-sale and liquidity 95

4.2.2.4 Realized volatility prediction 96

4.2.2.4.1. Implied volatility 96 
4.2.2.4.2. Implied idiosyncratic volatility 96

4.2.2.5. Predictive Regressions 97

4.2.2.5.1. Fama-Macbeth (1973) 97

4.2.2.6. Breakpoints by Chow Test 98

4.3. Data sources and description 99

4.4. Empirical Results 100

$\begin{array}{ll}\text { 4.4.1. Descriptive statistics } & 100\end{array}$

4.4.2. Breakpoints in Financial Crises 102

$\begin{array}{ll}\text { 4.4.3. Preliminary analysis } & 110\end{array}$

4.4.4. Predictive regressions 147

4.4.4.1. Future realized volatility 147

$\begin{array}{ll}\text { 4.4.4.2. Realized returns } & 170\end{array}$

4.5. Conclusions 246

$\begin{array}{ll}\text { References } & 248\end{array}$

Chapter 5: Volatility Risk and Earnings Announcement Surprises 250

$\begin{array}{ll}\text { 5.1.1. Abstract } & 250\end{array}$

5.1.2. Background 255

5.2. Data and Methodology 255

5.2.1. Sample 255

5.2.1.1. Implied idiosyncratic volatility 256

5.2.1.2. Earning Announcements and Standardized Unexpected Earnings 257

$\begin{array}{ll}\text { 5.2.2. Methodology } & 258\end{array}$

5.2.2.1. Beta, and Implied idiosyncratic volatility 258

$\begin{array}{ll}\text { 5.2.2.1.1. Beta Calculation } & 258\end{array}$

5.2.2.1.2 Implied idiosyncratic volatility calculation 258

5.2.2.2. Standardized Unexpected Earnings 259

5.2.2.3. Relationship Between SUE and the implied idiosyncratic volatility 259

5.2.2.3.1. The Correlation test 260

5.2.2.3.2. The Equal Mean Statictical test 261

5.2.2.3.3. The Equal Median Statictical test 262

5.3. Data sources and description 263 


\subsection{Empirical Results}

5.4.1. Descriptive statistics

5.4.2.The implied idiosyncratic volatility $\left(\sigma_{I V}\right.$ idio $)$ and Standardized Unexpected Earnings (SUE)

5.4.2.1. The correlation test

5.4.2.2. The Equal Mean and Median tests 276

5.5. Conclusions

References 


\begin{abstract}
This dissertation provides three self-contained empirical studies for investigating the role of volatility risk on stock return predictability specified on two global financial crises: the dot-com bubble and recent financial crisis. Using a broad sample of stock options traded at the American Stock Exchange and the Chicago Board Options Exchange (CBOE) from January 2001 to December 2010, three essays are simultaneously researched. The first essay contributes to the existing literature on volatility measures, volatility risk and stock return predictability in Global Financial Crises. We examine "different idiosyncratic volatility forecasting measures on future stock returns in four different periods (Bear and Bull markets)". First we find clear and robust empirical evidence that the implied idiosyncratic volatility is the best stock return predictor for every sub-period both in Bear and Bull markets. Second, the evidence of cross-section firm-specific characteristics on stock returns has mixed positive and negative effects on Bear and Bull markets. Third, short selling constraints impact negatively on stock returns for only a Bull market and liquidity is meaningless for both Bear and Bull markets after the recent financial crisis.

The second essay is enlarged to contribute to the literature of volatility measures and risk on stock return in term of industry specific effects during Global Financial Crises. First, the clear and robust empirical evidence indicates that the implied idiosyncratic volatility is the best stock return predictor for all sub periods both Bear and Bull markets in entire industries as same as all stock sectors which are not weak form, namely Consumer Goods, Healthcare, Services, and Technology except Basic Materials, Utilities, Industrial Goods, and Financial. Second, the cross-section firm-specific characteristics influence on stock returns forecast with mixed positive and negative effects for Bear and Bull markets for entire sectors and every eight stock sectors. Third, short selling constraints and liquidity are meaningless to impact on future stock returns for all sectors both Bull and Bull markets after sector classification.

The third essay contributes to the scarce literature of earnings announcement surprises affected by implied idiosyncratic volatility of option prices over periods of two global financial crises, We examine "earnings announcement surprises imbedded in option prices (via implied idiosyncratic volatility) prior to the announcement.." At the end, we find clear and robust empirical evidence that the implied idiosyncratic volatility at the end of month can forecast Standardized Unexpected Earnings (SUE) in the stock group of earning announcement date from 11th till end of next month.

Keywords: Options, Risk Premium, stock, volatility, Standardized Unexpected Earnings JEL Classification: G10; G12; C53
\end{abstract}




\section{List of Tables and Figures \\ Essay 1: Volatility Risk and Stock Return Predictability \\ on Global Financial Crises}

Table 1: $\quad$ Number of firms per industry 46

Table 2: $\quad$ Data Sources and Description 53

Table 3: Implied Volatility statistics $\quad 54$

Table 4: Historical Volatility statistics $\quad 55$

Figure 1: Monthly Implied Volatility 55

Figure 2: Monthly Historical Volatility 56

Table 5: Model Summary on breakpoints by Chow Test 57

Figure 3.1: Monthly Implied Volatility 58

Figure 3.2: Monthly Historical Volatility 59

Table 6: $\quad$ Testing Historical vs. Implied volatility 61

Table 7: $\quad$ Testing alternative idiosyncratic volatility measures 62

$\begin{array}{lll}\text { Table 8: } & \text { Summary statistics } & 64\end{array}$

Table 9: $\quad$ Correlation matrix $\quad 65$

$\begin{array}{lll}\text { Table 10: } & \text { Future Realized Volatility forecast } & 67\end{array}$

$\begin{array}{ll}\text { Table 11: } & \text { Realized idiosyncratic Volatility forecast }\end{array}$

$\begin{array}{ll}\text { Table 12: } & \text { Fama-Macbeth future returns estimation }\end{array}$

Table 13: Fama-Macbeth Future returns estimation with firm-specific characteristics $\quad 73$

Table 14: Forecast model of implied, realized, EGARCH and AR(2) idiosyncratic 79 volatilities.

Table 15: The short-sales constraint and liquidity or open-interest variables $\left(O R W_{\text {ratio }}, O I\right) \quad 80$

Table 16: The cross-section firm-specific characteristics variables ( $\log S I Z E$, and $\log B M) \quad 81$ 


\section{Essay 2: Volatility Risk, Global Financial Crises and Industry Specific Effects}

Table 1: $\quad$ Number of firms per industry 92

Table 2: $\quad$ Data Sources and Description 99

Table 3: $\quad$ Implied Volatility statistics 100

$\begin{array}{lll}\text { Table 4: } & \text { Historical Volatility statistics } & 101\end{array}$

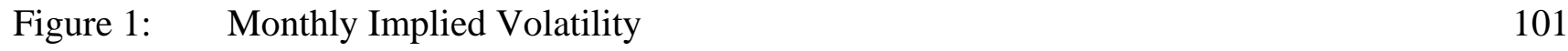

Figure 2: $\quad$ Monthly Historical Volatility 102

Table 5: $\quad$ Model Summary on breakpoints by Chow Test 104

$\begin{array}{lll}\text { Figure 3.1: } & \text { Monthly Implied Volatility } & 108\end{array}$

Figure 3.2: $\quad$ Monthly Historical Volatility 109

Table 6: $\quad$ Testing Historical vs. Implied volatility 111

Table 7: $\quad$ Testing alternative idiosyncratic volatility measures 117

Table 8: $\quad$ Summary statistics 125

Table 9: $\quad$ Correlation matrix 139

Table 10: $\quad$ Future Realized Volatility forecast 148

Table 11: $\quad$ Realized idiosyncratic Volatility forecast 157

Table 12: $\quad$ Fama-Macbeth future returns estimation 171

Table 13: Fama-Macbeth Future returns estimation with firm-specific characteristics 176

Table 14: Forecast model of implied, realized, EGARCH and AR(2) idiosyncratic 216 volatilities.

Table 15: The short-sales constraint and liquidity or open-interest variables $\left(\right.$ ORW $W_{\text {ratio }}$, OI $) 225$

Table 16: The cross-section firm-specific characteristics variable in term of log SIZE 229

Table 17: The cross-section firm-specific characteristics variable in term of $\log B M \quad 233$

Table 18: $\quad$ Variable in term of Beta $(\beta) \quad 238$ 


\section{Essay 3: Volatility Risk and Earnings Announcement Surprises}

Table 1.1: $\quad$ Number of firms per industry 255

Table 1.2: $\quad$ Earnings announcements monthly period, year and industry 257

Table 2: $\quad$ Data Sources and Description 263

Table 3: $\quad$ Implied Volatility statistics 264

Figure 1: $\quad$ Monthly Implied Volatility 265

Table 4: $\quad$ Implied idiosyncratic volatility and Standardized Unexpected Earnings 265

(Panel A) Panel A: Earning announcement from the1st to 10th of the month

Table 4: $\quad$ Implied idiosyncratic volatility and Standardized Unexpected Earnings 268

(Panel B) Panel B: Earnings announcement from 11th to 20th of the month

Table 4: $\quad$ Implied idiosyncratic volatility and Standardized Unexpected Earnings 270

(Panel C) Panel C: Earnings announcement from 21st until the end of the month

Table 5: $\quad$ Correlation Test of Implied idiosyncratic volatility and SUE 273

(Panel A) Panel A: Earnings announcement from the1st to 10th of the month

Table 5: $\quad$ Correlation Test of Implied idiosyncratic volatility and SUE 274

(Panel B) Panel B: Earnings announcement from $11^{\text {th }}$ to $20^{\text {th }}$ of the month

Table 5: $\quad$ Correlation Test of Implied idiosyncratic volatility and SUE 275

(Panel C) Panel C: Earning announcement from $21^{\text {st }}$ until the end of the month

Table 6: $\quad$ Equal Mean and Median Tests 276

(Panel A) Panel A: Earnings announcement from the $1^{\text {st }}$ to $10^{\text {th }}$ of the month

Table 6: $\quad$ Equal Mean and Median Tests 277

(Panel B) Panel B: Earnings announcement from $11^{\text {th }}$ to $20^{\text {th }}$ of the month

$\begin{array}{lll}\text { Table 5: } & \text { Equal Mean and Median Tests } & 278\end{array}$

(Panel C) Panel C: Earning announcement from $21^{\text {st }}$ until the end of the month 


\section{Chapter 1: Introduction}

Volatility is recognized to be central in asset pricing. An accurate forecast of future volatility delivers important information to market participants and consequently options can be essentially bets on volatility. Financial market volatility is not only important to option pricing but also a vital input for investment and financial market regulation. The volatile market environment and depressed expected returns of the past several years have increased the use of volatility strategies. No investor wants to be exposed to unnecessary risks that are not compensated by a return premium. There is an extensive literature on volatility prediction and broadly the best forecast of future volatility is the market's prediction imbedded in implied volatility. Volatility is not merely a measure for the level of uncertainty prevailing in financial markets. In particular, investors are looking to diversify their portfolio strategy in recent years, becoming volatility a new asset class. Due to its complexity, a wide range of investment opportunities is offered and a niche investment strategy for institutional investors has been developed by making volatility as an asset class accessible in the form of structured products and certificates for retail investors.

Poon and Granger (2003) provide an extended literature review comparing volatility forecasting performance of two main approaches; historical volatility models and volatility implied from options. Ang et al (2006), Doran and Ronn (2005) and Coval and Shumway (2001) among others, examine the predicting power of implied volatility finding that implied volatility is a bias predictor of future realized volatility. Other authors analyze whether other volatility forecast models such as $G A R C H, E G A R C H$ and autoregressive model in $2^{\text {nd }}$ order are better predictors than implied volatility obtained by inverting the Black and Scholes model.

Although the time-series relation between the expected returns and market volatility has been considerable addressed in the literature Glosten, Jagannathan, and Runkle (1993), and Campbell and Hentschel (1992), among others the question of how the cross-section of expected stock returns are affected by aggregate volatility has gathered less attention. Ang et al. (2006) find that low average returns are due to stocks with high idiosyncratic volatility. Cross-sectional effects such as liquidity risk were also documented by Pastor and Stambaugh (2003), momentum by Jegadeesh and Titman (1993), and the size and value factors from Fama and French (1993), can be controlled by crosssection of stock returns. In fact these cross-sectional risk factors are not controlled by option pricing studies. 
In another strand of literature Giot (2005) explores the stock returns prediction by the information content of implied volatility stating that higher future returns tend to be associated with higher levels of volatility. Several authors Malkiel and Xu (2006), Jones and Rhodes-Kropf (2003) and Barberis and Huang, (2001), among others, examined and find cross-section association between idiosyncratic risk and stock return.

In this dissertation, we examine the role of volatility risk in stock returns predictability for 596 stock options traded at the American Stock Exchange and the Chicago Board Options Exchange (CBOE) for the full period from January 2001 to December 2010 including two global financial crises (Dotcom Bubble and recent financial crisis). In summary, we study and research in three simultaneous essays. In the first empirical essay, we examine "different idiosyncratic volatility forecasting measures on future stock returns in four different periods (bear and bull markets)". The second empirical essay extended in term of industry specific effects, we examine "different idiosyncratic volatility forecasting measures on future stock returns in four different periods (bear and bull markets) with eight stock sector classification". Meanwhile, third empirical essay in term of earnings announcement surprises, we further study and examine "earnings announcement surprises imbedded in option prices (via implied idiosyncratic volatility prior to the announcement." as the robust results from our previous research parts that implied volatility might also contain information about future earnings.

According to the first essay, we extended previous research to determine three breakpoints comprised of December 2002 (31/12/2002), December 2007 (31/12/2007), and December 2008 (31/12/2008), then they are examined by Chow test on the key regression of Fama-Macbeth (1973) future returns estimation with firm-specific characteristics. The results show strong statistical significance at 1 percent level for divide full periods into 4 sub periods with two main market characteristics consisted of "Bear markets" and "Bull markets". At last, four different periods are determined to be Phase 1 (between 2001 and 2002), Phase 2 (between 2003 and 2007) in Dotcom Bubble, Phase 3 (in 2008) and Phase 4 (between 2009 and 2010) in recent financial crisis. This study of first essay aims to contribute to the existing literature on volatility measures, volatility risk and stock return predictability in a number of ways for sub periods in two global financial crises. First, to our knowledge, it is the first research analyzing the effect of different idiosyncratic volatility measures for a period that involves both the dotcom bubble and the recent financial crisis with sub 
period extension. This will shed light to the relation between idiosyncratic volatility and stock prices in sub periods when S\&P500 drop at least 20 percent in Bear markets and also recover in Bull markets. Second, the empirical findings will disclose more information on the best idiosyncratic volatility measure to be implemented in both Bear and Bull markets. Third, this research will extend the work of Ang et al. (2006) by including and analyzing firm-specific characteristics on both market characteristics which are Bear and Bull. Fourth, we control for possible short-sale constraints and liquidity issues effect on stock returns over both Bear and Bull markets. At the end, the results of $1^{\text {st }}$ essay can be summarized as follows for four sub periods divided both Bear and Bull markets over two global financial crises. First, we find strong statistically significant evidence of idiosyncratic volatility on stock returns predictability. Second, the results show that implied idiosyncratic volatility is the best predictor among the different volatility measures used. There is clear evidence of a return premium for carrying idiosyncratic volatility risk. Third, we provide evidence of cross-section firmspecific characteristics on stock returns for different periods (bear and bull markets). Finally, we confirm that short selling constraints and liquidity is meaningless on stock returns for both bear and bull markets after the recent financial crisis.

As shown in the second empirical essay, we extend from the first essay with eight stock sector classification and keep for divide full periods into 4 sub periods with two main market characteristics consisted of "Bear markets" and "Bull markets" such as Phase 1 (between 2001 and 2002), Phase 2 (between 2003 and 2007) in Dotcom Bubble, Phase 3 (in 2008) and Phase 4 (between 2009 and 2010) in recent financial crisis. This second essay aims contribute to the existing literature on volatility measures, volatility risk and stock return predictability in a number of ways for sub periods divided from full periods in two global financial crises with stock sector classification. First, to our knowledge, it is the first research analyzing the effect of different idiosyncratic volatility measures and industry effect by stock sector classification for a period that involves both the dotcom bubble and the recent financial crisis with sub period extension. This will shed light to the relation between idiosyncratic volatility and stock prices in sub periods when S\&P500 drop at least 20 percent in Bear markets and also recover in Bull markets. Second, the empirical findings will disclose more information on the best idiosyncratic volatility measure to be implemented in both Bear and Bull markets. Third, this research will extend the work of Ang et al. (2006) by including and analyzing firm-specific characteristics on both market characteristics which are Bear and Bull. Fourth, we control for possible short-sale constraints and liquidity issues effect on stock returns over both Bear and Bull markets. By last, the results of second essay are summarized as follows for four sub periods 
divided both Bear and Bull markets over two global financial crises in term of industry effect with stock sector classification. First we find clear and robust empirical evidence that the implied idiosyncratic volatility is the best stock return predictor for every sub periods both bear and bull markets among different sectors. Second, the cross-section firm-specific characteristics uncertainly effect on stock returns forecast in mixed positive and negative effects for different sectors in bear and bull markets. Third, we provide evidence that short selling constraints and liquidity are meaningless to impact on future stock returns after sector classification.

In the third and last empirical essay, we examine the role of volatility risk in stock returns predictability in the term of earnings announcement surprises imbedded in option prices (via implied idiosyncratic volatility) prior to the announcement. This third essay aims to contribute to the existing literature and previous research on volatility risk, future earnings contained in implied volatility, earnings per share (EPS) announcement surprises and predictability in a number of ways. First, to our knowledge, it is the first research analyzing the effect of the implied idiosyncratic volatility which can predict earnings per share (EPS) announcement surprises for a period that involves both the dotcom bubble and the recent financial crisis. This will shed light to the relation between the implied idiosyncratic volatility and EPS announcement surprises in term of Standardized Unexpected Earnings (SUE) in periods when S\&P500 drop at least 20 percent. Second, the empirical findings will disclose more information on the best period of earning announcement date to be implemented by the result of implied idiosyncratic volatility predictability. In fact, the result summary of third essay is as follows. First, we find strong statistically significant evidence of implied idiosyncratic volatility on earnings per share (EPS) announcement surprises predictability. Second, the results show that the best monthly period of earning announcement date spanning $11^{\text {th }}$ to end of month indicates the impact and predictability of implied idiosyncratic volatility on Standardized Unexpected Earnings(SUE). There is clear evidence of earnings announcement surprises carried by the idiosyncratic volatility risk.

Within each chapter of all essays is organized as following sections. First section addresses the empirical essay introduction and background of the study. The next section discusses the theoretical framework and empirical evidence on volatility risk in different terms. Further section presents the data sources and discusses sample selection and methodology implemented. Before the last section, we test different empirical methods and analysis, and the final section concludes the study. 


\section{Chapter 2: Literature Review}

\subsection{Introduction}

Volatility is recognized to be central to the pricing of options. The Black and Scholes (1973) model implies a correspondence between the volatility of the underlying asset and the price of the option. An estimate of the volatility is possible to obtain by inverting Black and Scholes pricing formula given the option price. After that the result is estimated and generally determined to be the implied volatility, which represents the market's anticipation of the underlying future volatility over the life of the option if markets are efficient. We can back out the volatility, which is called the implied volatility for the asset by using an algorithmic procedure and inverting the option price. Implied volatility properties and its reaction to events have been focused by prior studies; especially importance is that implied volatility forecasting power for future realized volatility is analyzed by previous studies and to a lesser extent, for future realized returns. Since an accurate forecasting of future volatility delivers important economic information to traders, Options can be essentially bets on volatility. As the result, there is an extensive literature on predicting volatility. For instance Poon and Granger (2003) survey the existing literature and broadly discover that the best prediction of future volatility is the market's prediction imbedded in implied volatility. Volatility has become a keyword of the recent financial crisis with realized volatilities of asset prices rising and volatilities implied by option prices (e.g. measured by volatilities indices such as the EURO STOXX 50, Volatility Index (VSTOXX), VDAX or VSMI) reaching unprecedented levels, reflecting the increasing cost of buying downside protection in the form of options during the market turmoil.

Volatility is not merely a measure for the level of uncertainty prevailing in financial markets. In particular, investors are looking to diversify their portfolio strategy in recent years, becoming volatility a new asset class. Due to its complexity, a wide range of investment opportunities is offered and a niche investment strategy for institutional investors has been developed by making volatility as an asset class accessible in the form of structured products and certificates for retail investors. Volatility is traded in the form of OTC and listed derivatives, especially on the Nikkei, SMI, DAX, FTSE 100, EURO STOXX 50, and the S\&P500 for institutional investors. It is essential to know volatility basic characteristic descriptions before the strategies discussion of various investment for volatility investments: 1) There is no direct returns such as interest or dividends created by Volatility; 2) When markets of equity are falling and vice versa, volatility is typically high i.e. a negative correlation occurs between the underlying equity market and volatility; 3) Long term upwards equity trends are not illustrated by volatility, but periods of high volatility occurring within a short period of time (i.e. volatility "jumps") are typically shown and then a downward trend to return to the long 
run medium level is appeared. In the term of mathematics pronouncing this cause is due to the equity return's heteroscedasticity property, i.e. the variance of the underlying probability distribution varying itself in time are stochastic with equity returns; 4) It illustrates a property recognized to be mean reversion in the long run, i.e. tends towards a medium level in the long run whereas volatility cannot grow to arbitrary low or high levels, and, 5) On average, realized volatilities tend to be lower than implied volatilities.

Overall, volatility is a most crucial concept in finance for both the practice and theory. It is commonly defined as the standard deviation of the returns of the said financial instrument within a set time span and is a measure of the uncertainty about a financial instrument's probability distribution of returns. Especially volatility is the central element that influences financial behavior and inseparably connected to the fundamental concept of risk.

\subsection{Implied Volatility and Future Realized Returns}

Implied volatility represents the expected volatility of a stock over the life of its option and refers to the market's assessment of future volatility. It is directly influenced by the supply and demand of the underlying options and by the market's expectation of the share price's direction. Realized volatility (sometimes referred to as the historical volatility) measures what actually happened in the past. Banerjee, Doran and Peterson (2007) find that the forecasting power of implied volatility to returns is higher for higher beta portfolios and for longer horizon holding periods and reported fewer evidence in prior studies of the forecasting power of implied volatility for future realized returns. This is explained by the assumption that returns are unforescastable in efficient markets. However, if we start with the assumption that implied volatility is a risk factor added to or separated from realized volatility, this could be incorrect. Conversely, a number of studies examine and discover the prediction power of $\mathrm{VIX}^{1}$ for future returns leads to generally conclude that the competence of VIX to forecast future realized returns.

Copeland and Copeland (1999) test if the VIX deviation from its mean provides predicting power for indices based on a measure of value versus growth or the market value of equity. Their findings are that large and value firms based indices performed well when VIX is high. This outcome is attributed by them to investors exploring "safe" portfolios after high VIX. Giot (2005) divided the

\footnotetext{
${ }^{1}$ VIX is a measure of market expectations of stock index return volatility over the next 30 calendar days. Starting in 2003, VIX is calculated from the S\&P 500 index option prices and based on a wide range of strike prices and is independent of any option pricing model.
} 
VIX value history into twenty percentiles and analyze the predicting capability of the VIX for the S\&P 100 index. The findings are that future returns are always positive, when VIX is very high, and future returns are always negative, when VIX is very low. The cause for the predicting power of VIX to future realized returns might be due to risk correlation. Furthermore the modern asset pricing literature has been trying to address the question of whether there is a volatility risk premium in addition to the traditional price risk premium.

In what respects to the price risk premium, the option pricing literature states an apparent existence of a separate volatility risk premium. Buraschi and Jackeworth (2001) find that the optionpricing essence cannot be covered by the underlying asset and the risk free interest rate, and the existence of other risk premiums is implied. Coval and Shumway (2001) find that at-the-money straddle positions result in zero-beta and average losses of approximately three percent per week. This implies that option returns are priced in some additional factor, such as systematic stochastic volatility. Bakshi and Kapadia (2003) apply strategies of option- trading and find that the volatility risk of market price is actually negative. Ang et al (2006) notice that there are low cross-sectional returns for stocks with high sensitivity to changes in VIX being one of the causes of this phenomenon the negative price of volatility risk attributed to them. Additionally, Branger and Schlag (2004) realize that the sign of volatility risk premium may be indeterminate for discrete time hedging errors. In the sense of Merton (1973), a price risk factor in intertemporal relation between expected volatility and expected returns in a time series context may be cause by implied volatility. If an efficient forecast of future realized volatility is implied volatility, Bali and Peng (2006) illustrate that expected volatility in the Merton (1973) relation can be applied by implied volatility. However, the feasibility that implied volatility could also be related to the volatility risk premium is not accounted. Doran and Ronn (2005) find that implied volatility is given rise to the bias by the negative price of volatility risk. Also, part of the risk of VIX may also be the mean reversion of VIX; it is likely to be higher in the future, if VIX is improperly low. 


\subsection{Implied Volatility versus ARCH Models as Future Volatility Predictors}

Banerjee and Peterson (2007) states that most studies about volatility address whether an efficient and unbiased prediction of future realized volatility is implied volatility. The underlying dogma is that all relevant information about future realized volatility should be limited by implied volatility and no other additional information subjects if option markets are proficient informationally. Lamoureux and Lastrapes (1993) provide evidence for stock options that if past volatility is existing information then an inefficient forecasting of future realized volatility is the implied volatility. Therefore, the benefit of implied volatility in future realized volatility prediction is limited. In contrary, Christensen and Prabhala (1998), applying non-overlapping data and longer sample periods, discover that the information content of past volatility is included in implied volatility. Fleming, Ostidiek and Whaley (1995) Blair, Poon and Taylor (2001) find that the future realized volatility is predicted by the VIX. Consistent with Doran and Ronn (2005) the literature supports that implied volatility has predicting power for future realized volatility but also that it is a biased forecaster of future realized volatility. In particular, implied volatility is used by most of the previous literature as a prediction of future realized volatility by testing the incremental forecasting power of implied volatility versus some prediction of future volatility (like historical volatility or a GARCH8 type forecast). For instance, Christensen and Prabhala (1998) illustrate that future realized volatility is dependent on historical realized volatility and historical implied volatility. Lamoureux and Lastrapes (1993) apply GARCH model for predicting volatility including implied volatility as an exogenous variable in the volatility regression. In some way, the volatility of broad market indices are supported by this literature but portfolios formed on the basis of important firm characteristics are not. In addition, previous literature explores if bearish and bullish market sentiment has predicting power for future volatility. Lee, Jiang and Indro (2002) report that an impact on the conditional volatility of equity returns is an existing institutional survey measure of sentiment about future equity market conditions. In contrary, Wang, Keswani and Taylor (2005) report that a sentiment indicator, such as the ARMS index (predictor of future price movements in the market primarily on an intraday basis) has limited predicting power for future realized volatility. Therefore, previous literature establish that future realized volatility can be predicted by a good proxy for bullish and bearish investor market sentiment and that VIX can be used for future realized volatility prediction. 


\subsection{Cross-Section Volatility and Expected Returns}

Ang et al. (2006) explored the pricing in the cross-section of equity returns for the aggregate volatility risk. Their findings are that low average returns are demonstrated by stocks with high sensitivities to innovations in aggregate volatility. Moreover, low average returns are due to stocks with high idiosyncratic volatility related to the model of Fama and French (1993). However, exposure to aggregate volatility risk cannot describe this phenomenon. Book-to-market, size, liquidity effects, and momentum cannot account for either the low average returns of stocks with high idiosyncratic volatility or for the low average returns earned by stocks with high exposure to systematic volatility risk. It is known that the equity returns' volatility alters over time. While the time-series relation between the expected returns and market volatility has been considerable addressed in the literature (Glosten, Jagannathan, and Runkle 1993, and Campbell and Hentschel 1992, among others) the question of how the cross-section of expected stock returns are affected by aggregate volatility has gathered less attention. In particular changes in the investment opportunity set by changing the riskreturn trade-off and the expectation of future market returns are induced by time-varying market volatility. Furthermore, a factor model predicts that aggregate volatility or the arbitrage pricing theory should also be priced in the cross-section of stocks, if the volatility of the market return is a systematic risk factor. In Ang et al. (2006) it is examined how the cross-section of expected stock returns price the stochastic volatility of the market. It is addressed whether the volatility of the market estimate the price of aggregate volatility risk is a priced risk factor. A negative price of market volatility risk using options on individual stocks or on aggregate market index has been found in several studies. Moreover, portfolios of stocks that have different sensitivities to market volatility can be created by using the cross-section of stock returns rather than market options. Stocks with large positive sensitivities to volatility risk should have lower average returns, if the price of aggregate volatility risk is negative. Cross-sectional effects such as liquidity risk documented by Pastor and Stambaugh (2003), momentum by Jegadeesh and Titman (1993), and the size and value factors from Fama and French (1993), can be controlled by cross-section of stock returns. In fact these cross-sectional risk factors are not controlled by option pricing studies. The economic theory presents several reasons why the price of market volatility risk is negative. For instance, since increasing volatility represents deterioration in investment opportunities, Ang and Chen (2002) and Campbell (1993, 1996) claim that investor's want to hedge against changes in market volatility. Stocks that hedge against this risk are demanded by risk-averse agents. Downward market movements also tend to coincide with periods of high volatility. (see, Campbell and Hentschel 1992 and French, Schwert, and Stambaugh 1987). Kapadia and Bakshi (2003) state that hedging against market downside risk is provided by 
assets with high sensitivity to market volatility risk. Eventually, stocks that do well when volatility rises tend to have positively skewed returns. Ang et al. (2006) additionally investigate the crosssectional relationship between expected returns and idiosyncratic volatility. Forming portfolios sorted by idiosyncratic volatility will obviously provide no difference in average returns if the Fama and French (1993) model is correct. However, sorting in this way potentially provides a set of assets that may have different exposures to aggregate volatility and hence different average returns, if the Fama and French model is not correct. Their logic is the following. The sensitivity of stocks to aggregate volatility times the movement in aggregate volatility will show up in the residuals of the Fama and French model. Therefore, everything else being equal, larger idiosyncratic volatilities relative to the Fama and French (1993) model should exist to firms with greater sensitivities to aggregate volatility. This relation will be noisy and made by differences in the volatilities of firms' true idiosyncratic errors, which are not priced. Furthermore if aggregate volatility risk is priced, constructing portfolios of stocks should be able to be averaged out this noise by them to reveal that larger idiosyncratic volatilities relative to the Fama and French (1993) model correspond to greater sensitivities to movements in aggregate volatility and different average returns. Economic theory states that expected returns should be positively related to idiosyncratic volatility and low expected returns tends to be produced by high exposure to aggregate volatility risk. If compensation for being unable to diversify risk is demanded by investors (Jones and Rhodes-Kropf, 2003 and Malkiel and $\mathrm{Xu}$ 2002) then a premium for holding stocks with high idiosyncratic volatility will be demanded by agents. Moreover, Merton (1987) advises that higher average returns are required in an informationsegmented market, investors should hold stocks with larger firm-specific variances to compensate investors for holding imperfectly diversified portfolios. Some behavioral models, such as in Barberis and Huang (2001), also forecast that higher expected returns should be earned by higher idiosyncratic volatility stocks. Their findings are that low average returns exist from stocks with low idiosyncratic volatility. Especially a strongly substantial difference of $-1.06 \%$ per month occurs between the quintile portfolio with the lowest idiosyncratic volatility stocks and the average returns of the quintile portfolio with the highest idiosyncratic volatility stocks. In contrary to their outcomes, earlier researchers either fail to find any statistically significant relation between average returns and idiosyncratic volatility or find a substantially positive relation between average returns and idiosyncratic volatility. Nevertheless, Lehmann (1990) find statistically positive significant coefficient on idiosyncratic volatility. Likewise, Malkiel and Xu (2002) and Tinic and West (1986) unambiguously discover that higher average returns are existing in portfolios with higher idiosyncratic volatility. In contrast Longstaff (1989) find an insignificant negative sign carried by a 
cross-sectional regression coefficient on entire variance for size-sorted portfolios. There is difference between the results of previous studies either past academic papers does not directly sort stocks into portfolios or does not investigate idiosyncratic volatility at the firm level. As an example, Malkiel and $\mathrm{Xu}$ (2002) sorted 100 portfolios on market beta and size while in Tinic and West (1986) 20 portfolios were sorted just by market beta. Moreover, the idiosyncratic volatility of each of the 100 beta/size portfolios to which a stock belongs to proxy for stock's idiosyncratic risk is only used by Malkiel and Xu (2002) and, thus, they do not investigate firm-level idiosyncratic volatility. Hence, without directly estimate differences in average returns between stocks with high and low idiosyncratic volatilities prior studies failure to find the strong negative relation between average returns and idiosyncratic volatility in their results. Stocks with high idiosyncratic volatility may have high exposure to aggregate volatility risk, which lowers their average returns. The idiosyncratic volatility outcomes are also vital to control for momentum effects, dispersion of analysts' predictions, volume, size, liquidity, and value. In particular, the robust effect of different formation periods and holding periods for computing idiosyncratic volatility are important, as well as, bear and bull markets, expansions and, recessions and periods of stable and volatile. Therefore, a substantive puzzle arises from idiosyncratic volatility.

\subsection{Implied and Realized volatility}

Zhang and Shu (2010) investigates the relationship between realized and implied volatility using daily S\&P 500 index option prices over the period January 1995 to December 1999. They analyze how different measurement errors affect the stability of the relationship between implied and realized volatility. A couple of sources of measurement errors were identified. The measurement error in realized volatility is the first one. The analysis was performed for four different estimators: the standard deviation of daily returns, the square root of intraday returns (Andersen, 2000), the range estimator (Yang and Zhang 2000) and the extreme value volatility estimator Parkinson (1980). The model specification is the second source of error. The calculation of implied volatility from calibrated Heston (1993) stochastic volatility option-pricing model is compared with that from Black-Scholes (1973) model. Zhang and Shu, (2010) find that the forecast ability of implied volatility can be significantly developed by the improvement of the measurement of realized volatility, being the estimation of realized volatility from intraday return data the most predictable. Additionally, there is no substantial difference in predicting realized volatility applying implied volatility either from Heston (1993) or from Black-Scholes (1973) models. However, when both historical and implied volatilities are applied to predict realized volatility, their findings is that implied volatility 
outperforms historical volatility and even when historical volatility information is included. This outcome holds for all measures of implied volatility and realized volatility. Frequently option markets are examined for trading volatility markets. Then it follows that a good predictor of subsequent observed volatility is likely to be implied volatility backed out from option prices if the option pricing model is correct and the option market is efficient. The predicting ability of historical volatility computed from past return information is often compared with the predicting ability of implied volatility. Since traders are commonly institutional traders and more information exist, it is also anticipated that historical volatility is worse in predicting volatility than implied volatility.

The investigation of the relationship between future realized volatility and the implied volatility has been subject for several studies (Fleming, 1998, Christensen and Prabhala 1998, Canina and Figlewski 1993; among others). A formal investigation of information efficiency of the option market is also established by the examination between realized and implied volatility. Hull and White (1987) illustrate that when volatility is constant the expected future realized volatility during the option life approximately equals to the Black-Scholes implied volatility of an ATM (at the-money) option. This presents that the implied future volatility should form an unbiased prediction of future realized volatility over the option life, if option market is information efficient in reflecting underlying asset market. However, quite mixed outcomes are presented by the regression between implied and realized volatility. Canina and Figlewski (1993) discover that no information about future volatility is contained by implied volatility of S\&P100 index option. The basis of option pricing theory is affected by this conclusion. Nevertheless, it is unreasonable that the implied volatility from option market has no relationship with the volatility of the underlying asset unless the index option market is inefficient, since option price is based on the underlying asset price. However, one has to eliminate other factors that could possibly distort the relation between realized and implied volatility, if one wants to reach this conclusion. For instance, Christensen and Prabhala (1998) illustrate that the predicting ability of historical volatility will be substantially overestimated by the application of daily overlapping data. In substitution, a new sampling at monthly level is recommended by them in order to avoid data over lapping problems. They find that monthly implied volatility outperforms historical volatility in predicting future volatility and even includes the information content of historical volatility in some specifications. In particular the GMM (Generalized Method of Moments) estimation procedure applied by Fleming (1998) corrects the serial impendence problem. Furthermore, the implied volatility measurement error pointed in Fleming (1998) is also raised by the application of Black-Scholes (1973) model to compute American options, so a modified binominal model developed by Fleming and Whaley (1994) is applied to 
estimate option model prices that accounts for the early exercise problems. Additionally, it was found that the application of implied volatility is better than the historical volatility in the prediction of future realized volatility of S\&P100 returns when the S\&P100 index options were used. However, the implied volatility is still an upward biased predicting of realized volatility. Taylor and Xu (1997) compare the predicting ability of historical volatility and implied volatility using Deutschemark/Dollar foreign exchange rate data. They conclude that when daily data is applied to construct historical and realized volatility, historical volatility is dominated by the implied volatility in predicting realized volatility. When historical and realized volatilities are constructed by intraday 5-minute return, the historical volatility outperforms implied volatility in predicting realized volatility. Their outcomes recommend that the improvement of the accuracy measurement of realized volatility could provide a better predicting ability. The existing literature supports that the econometric models, the measurement of realized volatility, the measurement of implied volatility, and even the data set used tend to affect the correlation between realized and implied volatility. Taylor and $\mathrm{Xu}$ (1997) paper main objective is to examine the factors that affect the relationship between realized and implied volatilities. The error in measuring realized volatility is the first one. According to their interpretation, the ex-post observed volatility is incorrect, but the ex-ante volatility forecasts are unbiased and efficient, relative to their true distributions, so that it apparent that the exante forecast is biased. In particular, constructing more accurate measurement of realized volatility can improve the predicting capability of implied volatility, if this hypothesis is true. Therefore, comparing the predicting performance of implied volatility with different measurements of historical volatility and realized volatility might be the optimal way of measuring realized volatility. More specifically, four different measurements of realized volatility are examined by them: 1) the integrated volatility used by Anderson (2000); 2) multi-period range estimator newly developed by Yang and Zhang (2000), 3) the Parkinson (1980) extreme value volatility estimator and 4) the classical volatility, calculated as the standard deviation of asset returns during the computation period. The measuring of the implied volatility is the second error source. 
According to Canina and Figlewski (1993) the poor predicting aptitude of implied volatility is partly attributed to the misspecification of the Black-Scholes model. The Black-Scholes model constant volatility assumption is incorrect in reflecting the true volatility process perceived by the market although the option market does contain information in predicting future realized volatility. Therefore, the market expectation of future volatility cannot be reflected by the implied volatility supported from the Black-Scholes model. This is why virtually realized volatility has no relationship with implied volatility. Since the constant volatility assumption is the main bias associated with the Black-Scholes model is natural to examine whether the predicting capibility of the implied volatility can be improved by estimating the implied volatility from more sophisticated stochastic volatility models. This can be done by comparing the predicting competence of implied volatility applied either from the Heston stochastic volatility model or from Black-Scholes model.

\subsection{Option Prices and Stock Returns}

Moll (2010) investigates the information content of implied volatility. The seasonality in stock and option returns (especially around the turn of the year) was investigated by prior studies. Especially for small firms, stock returns in January are abnormally high when compared to the remainder of the year (the so-called January effect), was documented by Keim (1983), Rozeff and Kinney (1976), Wachtel (1942) among others. The most common reasons include risk shifting, taxloss- selling, and window dressing for the continued existence of the January effect.

Wachtel (1942) proposes the tax-loss selling hypothesis which continues to be developed by Roll (1983) mentioning that lower stock prices are the result of investors wishing to realize capital losses for tax bill reductions (sell losers at the end of the year). In particular, an upward spike in the stock prices of former losers leading to the January effect is a result after the turn-of-the-year, the relaxation of selling pressure and investors purchasing perceived undervalued stocks. The January effect influences the strongest small firms. The evidence supporting window dressing as an explanation for the January effect, is provided by Ng and Wang (2004), Lakonishok, Shleifer, Thaler, and Vishny (1991), Haugen and Lakonishok (1987), and Ritter and Chopra (1989). The window dressing hypothesis mentions that before the end of the year selling pressure causes the prices of such losers to fall. This is leading by financial institutions that sell losers in an attempt to avoid reporting them among their holdings at the end of the year. At the turn-of-the-year a January effect is caused from institutions reestablish positions in the former losers. However the result of higher risk in January may be from the abnormally high returns in January. Rogalski and Tinic (1986) reported that 
small firms have the highest risk in January. Tinic and West (1984) and Rozeff and Kinney (1976) find that the relation between stock returns and beta is larger in January than other month. Ritter and Chopra (1989) provide evidence that when portfolios are value-weighted and the risk-return relation no longer displays a January seasonal, the higher return - risk relation in January is a phenomenon for small-firms. They also reported that even when the market return is negative the returns for small firms are positive in January.

In addition, higher betas in January would imply that negative market returns would correspond to strongly negative small-firm returns in January, hence this is inconsistent with a higher level of beta risk in January.

Stock returns seasonality from the perspective of the options markets are investigated in other studies. The fact that the implied stock return volatility from options increases leading up to the turn of the year, with the increase most pronounced for January expiring options was reported by Maloney and Rogalski (1989). Jones and Singh (1997) find that the increase in implied volatility is due to portfolio rebalancing and not a seasonal risk premium after analyzed call and put options implied volatility around the turn-of-the-year. The information content of both implied and historical volatility is addressed in the literature to as future volatility predictors. Canina and Figlewski (1993) discover that the predicting power of historical volatility includes implied volatility and that implied volatility is a biased and inefficient prediction of future volatility. Christensen and Prabhala (1998) find that historical volatility contains less information than implied volatility about future volatility. Their outcomes illustrate that an unbiased and efficient forecast of future volatility is implied volatility. Doran and Ronn (2006) investigate the bias of implied volatility of energy and equity markets. Consistent with Jackwerth and Rubinstein (1996), their findings is that implied volatility is a lower variance with historically higher than realized volatility. Doran and Ronn (2006) using an instrumental variables approach similar to Christensen and Prabhala (1998) illustrate that a negative volatility risk premium is consistent with the upward bias in the Black-Scholes model and argue that due to a different sample period the difference between those of Christensen and Prabhala (1998) and their outcomes may be existing.

In another strand of literature Giot (2005) explores the stock returns prediction by the information content of implied volatility. Giot (2005) investigates the Nasdaq 100 and the S\&P 100 indices and report a negative correlation between returns of the underlying indices and levels of market implied volatility proxied by the VIX. The negative relation with implied volatility perceived as proposed by Whaley (2000) as a measure of the investor "fear gauge" recommends that times of greater market turmoil correspond to higher levels of volatility. The evidence with the overreaction 
hypothesis also addressed by Giot (2005) states that higher future returns tend to be associated with higher levels of volatility. Additionally, times of greater market turmoil correspond to high levels of implied volatility under the overreaction hypothesis. Moreover, selling financial assets to limit losses and raise cash is overreacted by investors during such times of high market turmoil. A sign to patient investors to buy underpriced assets and hold them until the financial turmoil is solved can occur when it is seen high levels of implied volatility. However, the volatility of the market as a systematic risk factor is another reason for the relation between returns and implied volatility. Banerjee, Doran and Peterson (2007) examine the correlation between future portfolio returns and levels of variations in market implied volatility. Their findings are that both innovations and VIX levels are positively related to future portfolio returns with the strongest relation for high beta portfolios. Although returns and future volatility forecast ability clearly exist in implied volatility, the feasibility that these relations have January seasonality is not explored. Some important contributions are made by Banerjee, Doran and Peterson, (2007). First, they address the information content of implied volatility for realized volatility with seasonal effects. Previous studies report that even upward biased predictor of realized volatility the implied volatility is an efficient. However, the possibility of seasonal patterns in the relation between realized and implied volatility is failed to explore by previous literature. Evidence of changes of volatility around the turn-of-the-year and the correlation between realized and implied volatility at the same time was reported by Ritter and Chopra (1989), Rogalski and Tinic (1986), Rozeff and Kinney (1976), and Tinic and West (1984). None of these studies examines the possible seasonal in the correlation between realized and implied volatility, as reported in Jones and Singh (1997) and Maloney and Rogalski (1989). Using individual firms the relation between implied and realized volatility is performed by time-series regressions of realized volatility on implied volatility and interaction terms and seasonal dummies. It was found that there are slope coefficients and significant shifts in December intercepts on implied volatility. In addition, it is illustrated that January slope coefficients significantly shift. The bias in implied volatility is lower in January and higher in December, when compare to February through November. Hence, volatility in December is significantly overestimated and volatility in January is done the best job of assessing by the market. The results recommend that little (substantial) downside protection in January (December) is demanded by investors. Additionally, the turn-of-the-year impacts on the information content of implied volatility for forecasting future stock returns. Banerjee, Doran and Peterson (2007) and Giot (2005) examined the relation between portfolio returns and future index and market implied volatility without allowing for seasonal shifts. Since different turn-of-the-year behavior is exhibited by stock returns, seasonal correlations between future portfolio returns and the market volatility risk 
premium were investigated. When defined as the implied volatility observed at time t-1 less the realized volatility over month t-1 an assessment of market volatility risk expected in the coming month is provided by the market volatility risk premium. Their findings are that the correlation between future portfolio returns and the market volatility risk premium is statistically insignificant from February through November.

There is a significant correlation between future portfolio returns and the market volatility risk premium in December and January. Furthermore, the correlation is dependent upon firm size, whereas the correlation between the volatility risk premium and future portfolio returns is positive (negative) for the smallest firms in January (December). In addition the relation between the market volatility risk premium and future portfolio returns is negative (positive) for the middle-size portfolios in January (December). Overall, there is evidence that the correlation between the market volatility risk premium and future portfolio returns is stronger in December and January seasonal. Next, it is analyzed whether the seasonal relation between the market volatility risk premium and portfolio returns hold in the cross-section. Especially, a Fama and MacBeth (1973) cross-sectional regression approach is applied to investigate whether firm loadings on VIX levels and innovations are priced (either priced characteristics or priced risk factors). There appears to be a negative correlation between risk-adjusted returns and firm loadings on two-month VIX variations in January to November prior to restriction return momentum, size, and B/M. This correlation disappears in December.

The outcomes are consistent with a seasonal correlation between VIX innovation loadings and risk-adjusted returns. However, appears to be no correlation between risk-adjusted returns and firm loadings on VIX levels. This is true for whole seasonal subsamples. Moreover the correlation between VIX loadings and risk-adjusted returns becomes insignificant in entire seasonal subsamples after restriction for return momentum, firm size, and B/M.

The embedded risk-premia contained in derivative prices specifically single stock future and option prices, is modeled and also investigated. The role of derivatives in the price discovery process has been focused by an extensive amount of literature. Furthermore the literature recommends that traders should see price discovery in the derivative markets, if traders are informed to trade derivatives, possibly due to higher leverage and or lower costs. In particular price discovery is a method of determination the price for a specific security or commodity through basic demand and supply factors connected to the market. Black (1975) argued that a more effective lower-cost avenue for informed trading can be provided by greater financial leverage in the derivative markets. Easley, O'Hara and Srinivas (1998) claimed that a unidirectional linkage between underlying stocks and 
derivative prices is only valid in complete markets. Especially, the ability of informed traders to trade in derivative markets implies that there is no redundancy in derivative markets, if information is stored into prices via trading. Moreover, they present evidence corresponding with the hypothesis that options markets are a venue for information-based trading. John, Koticha, Narayanan and Subrahmanyam, (2003) argue that option prices and trades contain valuable information making the options market non-redundant when investors hold private information about the underlying stock and can choose to trade in the stock or the option. Chakravarty, Gulen and Mayhew (2004) findings are that the options market contributes in the underlying stocks on average nearly $18 \%$ of the price discovery.

The role that the futures market plays in price discovery of the underlying asset is addressed by a large strand of literature. In particular, it is expected that futures markets support in the price discovery process much the same as options markets do given that futures are derivatives like options. Shastri, Thirumalai and Zutter, (2008) point out that futures markets are for informed traders a superior venue for trading compared to the options market due to having a premium associated with options that is not related with futures. Chan (1992), Kawaller, Koch, and Koch (1987), and Stoll and Whaley (1990) investigate the S\&P 500 index cash markets and index futures and find an asymmetric lag lead relation between them. The strong evidence provided by them is that the cash market is led by the futures market and only weak evidence that the futures market is led by the cash market. Tse (1999) investigates the lag - lead relation between cash markets and the DJIA futures finding that terms of price discovery the DJIA index is dominated by the DJIA futures market. In particular, cash price information accounts for $11.7 \%$ compared to the $88.3 \%$ information attributed to the futures price. This evidence supporting the critical role in the price discovery process of the future markets is also presented in other studies. Hence, the general consensus is that price movement of the underlying index in the cash market is systematically led by price movements in the index futures market, concluding that the futures and cash markets are not equal in their competence to broadcast information about asset prices.

The literature on the topic $\mathrm{SSF}^{2}$ (single-stock futures) is sparse since SFF only has been trading since 2002. With the exception of Shasrti, Thirumalai and Zutter (2008), SSF studies have

\footnotetext{
2 On December 15, 2000, the Commodity Futures Modernization Act of 2000 passed by Congress, repealed the ShadJohnson Accord and made it legal to trade single-stock futures (SSF). On November 8, 2002, SSF began trading with 21 SSF listed on One Chicago and 10 listed on NQLX in the United States. On October 25, 2004, One Chicago the sole market made for SSF due to NQLX suspended trading. Currently futures are listed in One Chicago on more than 500 well known stocks.
} 
primarily concentrated on how SSF affect market efficiency, the development of the SSF market, and listing selection. Shasrti, Thirumalai and Zutter (2008) investigate the price discovery role of SSF in the United States with an error correction model and find that the information included in the SSF market is statistically significant and economically large. They illustrate that SSF, contribute more to information revelation than make either options markets or non-NYSE trades, on average. The development of the literature has illustrated that future markets and derivatives markets are not redundant. In fact, it has been illustrated that a leading role in the price discovery process is played by futures markets where the information disseminating is quicker than the underlying cash markets. Several of the academic papers studies regarding information dissemination are done via investigation of the correlation between price changes in the cash markets and price changes in the futures markets. A separate strand of futures pricing literature - the correlation between liquidity and the futures/cash basis spread - are investigated by previous studies. As argued by Kumar and Seppi (1994) the basis spread may be affected by liquidity as arbitrage opportunities tend to disappear in liquid markets. Following the results from Kumar and Seppi (1994), Roll, Schwartz and Subrahmanyam (2007) prove that liquidity predicts and is predicted by deviations from the noarbitrage correlation (i.e. their finding is that liquidity can predict, and is predicted by the absolute basis). They particularly discover that spreads are contemporaneously correlated with innovations to the absolute basis. An important contribution made by of Kumar and Seppi (1994) and Roll, Schwartz and Subrahmanyam (2007) is that the correlation at the firm level fails to be estimated by the role that liquidity plays in the relation between index futures and index spot prices.

The correlation between returns and liquidity has been investigated by an extensive number of academic papers employing the bid-ask spread as a measure of liquidity. Amihud and Mendelson (1986) find that a significant premium for the quoted spread is contained by asset returns. However, since the bid-ask spread occurred outside (inside) a number of large (small) trades makes it a rather noisy measure of illiquidity (Lee, Mucklow and Ready 1993). Furthermore, the liquidity effect of asymmetric information is most likely captured in the variable components of the trading costs or the price impact of the trade, as recommended by theoretical models of Easley and O'Hara (1987) and Kyle (1985) and the outcomes of Glosten and Harris (1988).

Several other studies find a negative correlation between liquidity and expected stock returns (i.e. lower liquidity is associated with higher returns). Additionally, Roll, Schwartz and Subrahmanyam (2007) demonstrate that liquidity is related to futures mispricing. Moll (2010) makes a couple of crucial contributions in this area. Firstly, examines the information content of the implied 
risk-premia embedded in SSF prices for portfolio returns and future stock returns using a sample of firms with actively traded SSF. In particular it is examined the correlation between future stock returns and the discount rate implied in the cost-of-carry model. Secondly, the analysis using options is reiterated. The implied risk-premia embedded in deviations from put-call parity is examined and how future stock returns are related to them. Due the higher leverage of derivatives and/or the relatively lower transaction costs the information by trading in these securities (leading to price discovery in derivative securities) may be best exploited by informed traders. As such, important information content for future stock returns and portfolio returns could be provided by the implied risk-premia embedded in SSF and option prices.

According to the cost-of-carry model, the risk free rate of return is equal to the discount rate. However, the risk-free rate may not equal to the implied discount rate. Instead, a lot of embedded risk premia may be discovered within the discount rate, namely a liquidity risk premium. Therefore, relevant information to future stock returns may be contained in the implied discount rate.

Moll (2010) uses a sample of firms with listed SSF to investigate whether future stock returns can be forecast by deviations from the cost-of-carry relation possibly due to embedded risk-premia. Specifically, using the cost-of-carry futures pricing model, the implied discount rate is backed out and examined whether future stock returns can be predicted by the discount rate. This study is the first to analyze the deviations of information content of the future stock returns from the cost-of-carry model. Since the put-call parity is a pricing correlation applied commonly to model the relation between call and put prices for European options, violations of call -put parity are considered as arbitrage opportunities. ${ }^{3}$ Using a sample of firms with both listed options and listed SSF, put-call parity is used to back out an implied risk premium for options and to examine whether any information content for future stock returns is contained by this risk premium. Applying both crosssectional and time- series methods the examination is if future stock returns can be forecasted by employing the implied risk premium. As with the SSF contracts, it could be that other risk-premiasuch as a liquidity risk premium - may be caused by the implied risk premium embedded in option prices.

\footnotetext{
${ }^{3}$ For American options the call -put parity is not anticipated to exactly hold. As originally Merton (1973) argues the violations of put-call parity for American options are frequent and are commonly thought to represent an early exercise premium.
} 


\subsection{Implied Volatility and Cross-section equity returns}

The standard asset pricing models comprised of Ross (1976) arbitrage pricing theorem (APT) and Sharpe- Lintner (Sharpe 1964 and Lintner 1965) capital asset pricing model (CAPM) represents the certain association between return and systematic risk. The systematic risk as risk inherent to the entire market or an entire market segment is the perspective of whole risk connected to returns. Several papers examined the cross-section association between idiosyncratic risk and stock returns. Malkiel and Xu (2006), Jones and Rhodes-Kropf (2003), Barberis and Huang (2001), and Merton (1987), expand asset pricing models and find that the idiosyncratic risk function is dependable to returns. Malkiel Xu and (2006) find a link among idiosyncratic risk and returns. Chua, Goh and Zhang (2005) employed an autoregressive model while Spiegel and Wang (2007) and Fu (2009) use models of EGARCH to forecast anticipated idiosyncratic volatility. They all encounter that anticipated idiosyncratic volatility are effectively connected to anticipated returns. Conversely, an association cross-section bias between idiosyncratic risk and returns were found by, Ang et al. (2006). These outcomes are strong independently of different market conditions and other independent variables. Ang et al. (2006) notice that their investigation are turning back to argument via theory that investors prefer supplementary return for standing unsystematic risk and previous experimental pronouncement of a productive association between idiosyncratic risk and returns. Cakici and Bali (2007) illustrate that no vigorousness in significant association between anticipated returns of stocks in cross-section and idiosyncratic volatility.

As Miller (1977) poses big restrictions on short sale would cause smaller future returns. Duan, $\mathrm{Hu}$ and McLean (2007) and Boehme, Danielsen, Kumar and Sorescu (2006) find proportions of short interest related to the association between idiosyncratic risk and returns. Stocks with low (high) short interest and without (with) traded options have high (low) constraints of short sale. Boehme et al. (2006) find a negative (positive) correlation between idiosyncratic risk and returns for stocks with high (low) constraints of short sale.

No evidence was found by Battalio and Schultz (2006) regarding Internet stocks with short sales restrictions in early period of 2000's. The crucial evidence of non-existing restrictions of short sales is illustrated for stocks underlying proficiently traded options. Ang et al. (2006) explored a broad spectrum of stocks from whole of U.S. markets such the NYSE, AMEX and Nasdaq and reported a bias correlation between stock returns and idiosyncratic risk.

The uniformity of the correlation in cross-section returns and idiosyncratic risk is ambiguous at this present. One of the weaknesses from earlier researches is the measurement application of historical risk. The best anticipation of market for the future volatility on the terminology of the 
option is defined to be the options implied volatility. As a result, the predictive and forecasting power of implied volatility is investigated in multiple papers. Christensen and Prabhala (1998) find that for the future S\&P100 index option prices prediction implied volatility outperforms past volatility. Doran and Ronn (2006) report that this estimation is negative and might be correlated to the volatility risk premium. Besides, a number of researchers investigate the forecasting competence of the $\mathrm{CBOE}$ volatility index, or VIX for stock returns. Giot (2005) find that there is a benefit of VIX for forecasting the S\&P 100's returns. Furthermore, Copeland and Copeland (1999) report that the VIX levels forecast returns on various indices formed on growth and size against value characteristics. Banerjee, Doran and Peterson (2007) stated that VIX innovations and levels forecast the benefits of characteristic based portfolios.

\subsection{Historical and implied volatilities effect on future volatility}

The volatility forecast is a very interesting topic explored by a number of researchers/investors for valuation purposes (risk management, or/and portfolio selection) or forming trading strategies such as volatility arbitrage. In order to achieve that a couple of predictors are focused on historical volatility as previous realized volatility and on implied volatility, defined and formally born in 1973 with the formation of CBOE (the Chicago Board Options Exchange). Implied volatility is derived from option prices applying models such as Black-Scholes while historical volatility is straightly calculate from previous market data. One issue to address is the common financial principles such as mean-reversion as the logic behind the application of historical volatility Furthermore the meaning of common historical volatility is an unconditional estimator that overlooks the most recent available public data. Moreover, historical volatility falls to reflect the feasible forecasting ability of true volatility when standard statistical techniques are applied to calculate. Conversely, implied volatility is extensively encountered as the market's estimation of future volatility and it should illustrate whole available information in an assigned period, including that containing in historical volatility (if markets are efficient). Merton and Bodie (1995) look to the period that passes the Persian Gulf War in 1991 and showed show the superiority of implied volatility beyond historical volatility in estimating the future volatility. It is shared among financial operators that implied volatility is truly a much more superior predictor than historical volatility. However, researchers have produced quite different results about whether implied volatility certainly predicts future volatility or whether it does not do so effectively. One of the first studies, Latane and Rendleman (1976) reported that the weighted implied volatility is commonly a much more superior 
estimator of future volatility than historical volatility. They examined the correlation between subsequent realized volatility and an average of implied volatilities using closing stock prices and call option of 24 companies traded on the CBOE (Chicago Board Options Exchange).

Moreover, Chiras and Manaster (1978) come across the same results, even though they find there is no substantial difference between the indicating or predicting characteristics of implied volatility and historical volatility in the first of 9 months overlaid by their research they report that implied volatility becomes a much more superior estimator of future volatility in the following 14 months. Beckers (1981) stated that implied volatility incorporates and outperforms the estimating information of historical volatility using static cross-sectional regression approach due to the absence of large time-series data.

Due to applying time-series data in a dynamic setting, further researches came across with different results after analyzing actively-traded OEX options on the S\&P100 index. Day and Lewis (1992) analyzed options between 1983 and 1989 and find that even though some information about subsequent volatility may be contained in implied volatility it is still outperformed by time-series models of conditional volatility, such as the EGARCH and $G A R C H$ models. However the findings from Lamoureux and Lastrapes (1993) are that the information contained in historical volatility is superior to that contained in implied volatility. Canina and Figlewski (1993) find a more radical result arguing that implied volatility has truly no correlation with future volatility and that it does not compile the information contained in recent observed volatility. However, Christensen and Prabhala (1998) contribute to the idea that dramatic information about future volatility is not only carried by implied volatility, but that implied volatility is also more forecasting than historical volatility. Christensen and Prabhala (1998) investigate OEX options with longer time series and nonoverlapping data overlaying the period between November 1983 and May 1995. They reported that implied volatility is an unbiased and efficient predictor of subsequent volatility and that, in some cases, implied volatility includes the information carried in past realized volatility. Hansen (1999) analyzed the Danish option and stock markets and conclude can that a good predictor of subsequent realized volatility is implied volatility, that its bias is insignificant and that it compiles the information of historical volatility. Moreover, Christensen and Hansen (2002) following Christensen and Prabhala (1998) for a more recent period confirmed previous results. Additionally, they expanded to put options and find that put implied volatility is not as much as call implied volatility as future volatility predictor. Shu and Zhang (2003) subsequent research of the S\&P500 index and its options further contribute that implied volatility is a superior estimator of future volatility. Furthermore, Szakmary et al. (2003) analyze 35 options markets and reported that implied volatility outperforms 
historical volatility in predicting the volatility of the underlying prices for a large majority of commodities. More recently, Li and Yang (2009) analyses the S\&P/ASX 200 index options traded on the Australian Stock Exchange finding that the implied volatilities of both puts and calls are more superior then historical volatility at prior subsequent volatility. Additionally, their also find that the volatility implied in call options is a nearly unbiased predictor of future volatility. In contrary to previous findings, recent studies notifies the extensively - shared trust that implied volatility does carry some information about future volatility and it is superb in this respect to historical volatility.

To summarize, markets for trading volatility are distinct from option markets. Furthermore a good estimator of subsequent observed volatility is probably to be implied volatility backed out from option price, if the option pricing model is correct and the option market is effective. In particular the indicative power and predicting competence is always compared between implied volatility and historical volatility computed from information of previous returns. Due to the fact that option traders who are generally institutional traders, have a great deal of information, hence, implied volatility is also anticipated to be a much more superior indicative power and predicting the future volatility than historical volatility.

\subsection{Financial Crises and Structural Breaks}

The term financial crisis is applied broadly to a variety of situations in which some financial assets suddenly lose a large part of their nominal value. In the 19th and early 20th centuries, many financial crises were associated with banking panics, and many recessions coincided with these panics. Other situations that are often called financial crises include stock market crashes and the bursting of other financial bubbles, currency crises, and sovereign defaults. Financial crises directly result in a loss of paper wealth but do not necessarily result in changes in the real economy.

The process of financial globalization has given rise to an increase in the frequency of financial crises. With it, there has also been a surge in research about financial crises. One of the key questions in this area is whether crises are triggered by fundamentals or come as a result of panic. Observing real-world events, many prominent researchers, including Friedman and Schwartz (1963) and Kindleberger (1978), concluded that financial crises are so strong and sudden that there must be an element of panic in them. Yet, a large empirical literature has been able to establish a fairly strong link between crises and fundamentals. Theoretically, the panic-based approach to banking crises was formalized by Bryant (1980) and Diamond and Dybvig (1983). In the Diamond-Dybvig model,when investors withdraw money from a bank, they deplete the bank's capital, reducing the amount 
available for investors who come in the future. This creates strategic complementarities, such that investors wish to withdraw when they think others will do so. The result is multiplicity of equilibria. There is an equilibrium in which all the investors withdraw and an equilibrium in which none of them does. Crises are then self-fulfilling; they occur only because investors believe they will occur. In the Diamond-Dybvig model, the occurrence of a crisis cannot be linked to fundamentals. The fundamental-based (or information-based) approach has been modeled as well, for example, in Chari and Jagannathan (1988), Jacklin and Bhattacharya (1988), and Allen and Gale (1998). The basic idea is simple. Bad fundamentals (or negative information about fundamentals) lead banks balance sheets to deteriorate, inducing investors to run. The tension between the self-fulfilling approach and the fundamental approach to crises exists also in the currency-attack literature. The two classic approaches are presented by Krugman (1979) and Obstfeld (1996). According to Krugman (1979), the crisis is an inevitable result of a government that runs a fiscal policy which isinconsistent with the exchange rate regime, and hence the currency collapse is predictable by fundamentals. On the other hand, in Obstfeld (1996), the currency collapse might be self-fulfilling. If enough speculators choose to attack the currency, they will weaken the ability of the government to maintain the fixed exchange rate regime, leading to the collapse of the currency. Krugman himself later admitted that the fundamental approach is unable to explain the Asian crisis of the late 1990s, and in Krugman (1999), he proposed a model that is based on self-fulfilling beliefs and multiple equilibria. Differentiating between panic-based and fundamental based crises is crucial for policy purposes. Many of the policies adopted against financial crises - such as deposit insurance, lender of last resort, and suspension of convertibility - are predicated on the idea that crises are panic-based and result from a coordination failure. Hence, it is not surprising that many empirical papers have tried to distinguish the two types of crises in the data.

A structural break is a concept in econometrics. A structural break appears when we see an unexpected shift in a (macroeconomic) time series. This can lead to huge forecasting errors and unreliability of the model in general. Especially, the CUSUM (cumulative sum) and CUSUM-sq (CUSUM squared) tests can be used to test the constancy of the coefficients in a model. The bounds test can also be used. For a linear model with one known single break in mean, the Chow test is often used.

The Chow test is a statistical and econometric test of whether the coefficients in two linear regressions on different data sets are equal. The Chow test was invented by economist Gregory Chow in 1960. In econometrics, the Chow test is most commonly used in time series analysis to test for the presence of a structural break. In program evaluation, the Chow test is often used to determine 
whether the independent variables have different impacts on different subgroups of the population. Chow test looks forthe following. Whether splitting data from the possible break point and estimating two generated sub-samples separately by least square gives significantly better fit than using the whole sample at once; if the answer is yes, the null hypothesis of no break is rejected. The resulting statistics would be; F-statistics, log likelihood ratio or the Wald statistic.

Single Break Estimators: For the unknown break date, Quandt $(1958,1960)$ proposed likelihood ratio test statistics for an unknown change point, called Supremum (Max)-Test, while Andrews (1993) supplied analogous Wald and Lagrange Multiplier test statistics for it. Then Andrews and Ploberger (1994) developed Exponential (LR, Wald and LM) and Average (LR, Wald and LM) tests. These tests are calculated by using individual Chow Statistics for each date of the data except from some trimmed portion from both ends of it. While the Supremum test is calculated for and fnds the date that maximizes Chow Statistics, the most possible break point, the Average and Exponential tests use all the Chow statistic values and are only informative about existence of the break but not its date. The deficiencies of the Supremum test are, however, as follows. It only has power if one break occurs under the alternative hypothesis, and is valid as long as residuals from the regression follow i.i.d.. This means they do not show heterogeneity before and after the break, as is also a necessary condition for the Chow test. But even this is quite informative for suggesting this is not always the case. Heteroscedasticity and autocorrelation robust version of this test (also called Quandt Likelihood Ratio or Andrews-Quandt statistics, which is the estimator used most commonly) can be used, even though it still gives the most possible break date (it is so because of small sample properties). It also strongly suffers from large confidence intervals around the break date. Finally, and again for the single break model, Bai, Lumsdaine and Stock (1998) use quasi likelihood estimation in a VAR setting and show that with common breaks across equations, the precision of the estimates increases with the number of equations in the system. However, their methodology obviously can only be carried out as long as equations are expected to show a break in the same time period. This could be the case when several variables are co-integrated, as in their study (they also use output, consumption and investment data). Besides, this test is designed for a single break and there could be more than one break date in the data, in which case these test exhibits non-monotonic power function (Vogelsang 1997, 1999). 


\subsection{Earnings announcement surprises}

The examination is whether information about earnings announcement surprises is imbedded in option prices prior to the announcement. Much work has been done on post-earnings-announcement drift (PEAD) ${ }^{4}$, and PEAD appears to be an enduring feature of stock returns. ${ }^{5}$ However, the existing literature seems to be more concerned with the differences in stock returns between option and nonoption firms, rather than the differences in returns to various option based strategies formed around earnings announcements. In particular, Jennings and Starks (1986) examine the stock price adjustment to the release of quarterly earnings using samples of firms with and without listed options. They find the two samples exhibit different adjustment processes, with the non-option firms requiring substantially more time to adjust. Their findings are consistent with the hypothesis that the common stock of firms with exchange listed options is associated with a different price adjustment process than that of non-option firms. Overall, the Jennings and Starks (1986) results support the argument that option markets are useful in disseminating earnings news and improving market efficiency.

Along similar lines, Skinner (1990) examines whether a firm's listing on an options exchange is associated with changes in the information content of its accounting earnings releases. For the majority of firms in the study, the size of the stock-price reaction to accounting earnings releases is smaller after exchange-traded options are listed on the respective stocks. Skinner argues that this evidence is consistent with the view that options listing improves the 'informational efficiency' of the market for the underlying stock. One interpretation of this evidence is that options listing causes these firms to be more 'closely followed' after options listing, thus reducing the potential information content of their public information releases. The author points out, however, that it is difficult to draw causal inferences since the incentives of the options exchanges make it unlikely that they select stocks randomly. Therefore, it is plausible that the observed changes in informational efficiency are simply a function of the way that options exchanges choose stocks, rather than reflecting the informational effects of options trading itself.

Ho (1993) essentially extends and complements the work of Skinner (1990) and Jennings and Starks (1986). She documents differences in the price-earnings relation between firms with and without listed options. In particular, she finds that the surprise associated with quarterly earnings announcements is greater for non-option firms than for option firms, and that the security prices of option firms anticipate earnings changes earlier than those of non-option firms. However, she is

\footnotetext{
${ }^{4}$ Post-earnings-announcement drift is the tendency for a stock's price to drift in the direction of an earnings surprise following an earnings announcement.

${ }^{5}$ See Foster, Olsen, Shevlin (1984), Bernard and Thomas (1989, 1990), and Freeman and Tse (1989).
} 
careful to conclude that her results simply suggest an association between option trading and return behavior in conjunction with earnings announcements.

Mendenhall and Fehrs (1999) reexamine the issue of the effect of option listing on the stockprice response to earnings announcements. Their analysis extends prior studies by examining a more recent time period and by considering additional factors. They attempt to control for changing market conditions that tend to affect the earnings response of all firms (not just those listing options) and to correct for firm size. Their results suggest that both of these factors may be important. However, contrary to prior studies using earlier data, they find that firms initiating option trading after 1986 fail to exhibit a significant decline in the response rate to earnings surprises. In fact, they find evidence that option listing may actually increase the stock-price response rate to earnings, but no evidence that listing reduces the response rate. A possible explanation for this last result is posited by the authors. They argue that if informed traders can take larger and less expensive positions in option firms than they can in non-option firms, and if the total response to earnings is not complete for several months following the announcement, then their results might represent a more complete announcement-day response for option firms that is caused by the actions of informed traders. Thus, their results, though different, might still imply that option listing increases stock market efficiency.

However, Mendenhall (2004) believes that PEAD is attributable to investors who underreact to earnings surprises and arbitrage does not eliminate the drift because the required trades are risky. In fact, he controls for a wide range of firm-specific characteristics and finds that the magnitude of PEAD is significantly positively related to the risk faced by an arbitrageur who takes a position in the mispriced stock and tries to hedge the position using various market indexes. He also finds some evidence that the magnitude of the drift is positively related to transactions costs and concludes that these results represent new evidence that PEAD reflects under reaction to earnings information and that arbitrage risk and transactions costs impede arbitrageurs who attempt to profit from it.

Finally, Battallio and Mendenhall (2005) consider earnings expectations and the return relationship to investor trade size. They find that smaller, less sophisticated investors ignore earnings signals based on analysts' forecasts and respond to signals of a less accurate time-series model. Large traders, on the other hand, use a more complete information set that incorporates time-series signals along with other information reflected in analysts' forecasts. They conclude, as hypothesized by Bernard and Thomas (1990), that the actions of these smaller unsophisticated investors is what gives rise to PEAD.

One limitation of the previous research discussed is that it does not investigate trading on options markets. Instead, it focuses on changes in the market for the underlying stock. On the other 
hand, Amin and Lee (1997) examine trading behavior on both the options and stock markets around the time of earnings announcements. They find that trading volume in options increases by more than $10 \%$ in the four days before quarterly earnings announcements, while trading volume in stocks increases by less than $5 \%^{6}$. Interestingly, they show that the direction of this preannouncement trading in options foreshadows subsequent earnings news. Specifically, they find that option traders initiate a greater proportion of long (short) positions immediately before good (bad) earnings news. This suggests that informed traders may prefer to deal in options when they have an important piece of information.

This point is made by Black (1975), who argues that traders with private information prefer to exploit that information by trading on the options market. He argues that options markets provide lower short selling costs and higher leverage, and that many potential information traders will trade on the options market when they wouldn't bother to trade at all if the options market didn't exist. A large amount of research has investigated the links between options and equity markets, but the evidence is inconclusive as to which of the two markets reflects new information earlier. Early support for Black's arguments is found by Manaster and Rendelman (1982) who posit that option markets may provide a preferred outlet for informed investors. They find that the closing prices of listed call options contain information about equilibrium stock prices that is not contained in the closing prices of underlying stocks. They offer two potential explanations for their finding. The simplest is that closing option and stock transactions do not always take place at the same time. The alternative is that closing option prices reflect fundamental information about the equilibrium values of underlying stocks that is not contained in closing stock prices. To test this they use the Black and Scholes (1973) option pricing model to calculate implied stock prices to compare with observed stock prices 24 hours later. They wait 24 hours to allow time for the nonsynchronous data effect to be absorbed into observed stock prices. However, their analysis reveals that the implied prices still contain information regarding equilibrium stock prices that is not fully reflected in observed stock prices a day later. Thus, they conclude that option prices do reflect information not already present in stock prices.

Sheikh and Ronn (1994) examine option return patterns, and argue that differences between these and equity market returns are evidence of information based trades in options. In particular they find that option returns contain systematic patterns even after adjusting for patterns in the means and variances of the underlying assets. This is consistent with the hypothesis that informed trading in

\footnotetext{
${ }^{6}$ Abnormal trading volume is measured as the percentage deviation from the daily mean for each firm and averaged across all firms. Their results for options (stocks) are statistically significant (insignificant) at the $5 \%$ level.
} 
options can make the options market informative about the value of the underlying asset. Easley, O'Hara, and Srinivas (1998) investigate the informational role of transactions volume in options markets by developing and testing an asymmetric information model in which informed traders may trade in option or equity markets. Their main empirical result is that negative and positive option volumes contain information about future stock prices. In particular, they find that certain option volumes lead stock price changes, thus supporting the notion that options markets are an important venue for information based trading. Additionally, Diavatopoulos, Doran, and Peterson, (2011) and Diavatopoulos D., Doran, Fodor, and Peterson, (2012) investigate and find a positive relation between implied volatility in stock option and expected returns, somehow their results show the limited support about correlation between implied volatility skew and unexpected future earnings.

Overall, it appears that many studies are more concerned about the earnings announcement itself, rather than the effect on the options market. But a delay reaction to a surprise in the earnings announcement is an inefficiency in the market. One of encouragements for this research study is lighted up from findings in a previous research of Mateus and Konsilp, (2014) that option listing and subsequent trading do increase available information, and consequently implied volatility might also contain information about future earnings. Specifically, this research examines how the options price via the implied idiosyncratic volatility can anticipate unexpected earnings. Following this, the hypothesis is determined in this research that information about earnings announcement surprises is imbedded in option prices via implied idiosyncratic volatility prior to the announcement. As the result, the implied idiosyncratic volatility is tested whether the implied idiosyncratic volatility can predict earnings per share (EPS) announcement surprises in term of Standardized Unexpected Earnings (SUE). ${ }^{7}$

More specifically, stocks are sorted and divided into equal Quintiles based on the value of implied idiosyncratic volatility. The issue of 30 days prior is realized and used due to a reasonable starting point which earnings information may begin to appear in option prices. Moreover, it is anticipated that at 30 trading days prior to the earnings announcement information is not yet in stock prices. Somehow, we consider the 'transition' periods of 20 and 10 days prior to the announcement date because earnings information may not be priced into options 30 days before the announcement. Additionally, less 10 days before, earnings information may already be priced into both stock and option prices.

\footnotetext{
${ }^{7}$ Implied volatility is the volatility implied from an option price using the Black-Scholes or a similar model. The implied idiosyncratic volatility is computed from the implied volatility in its idiosyncratic part with the market implied volatility demonstrated to be a market volatility function.
} 


\title{
Chapter 3: Volatility Risk and Stock Return Predictability on Global Financial Crises
}

\begin{abstract}
This paper investigates the role of volatility risk on stock return predictability specified on two global financial crises: the dot-com bubble and recent financial crisis. Using a broad sample of stock options traded on the American Stock Exchange and the Chicago Board Options Exchange (CBOE) from January 2001 to December 2010, we examine the effect of different idiosyncratic volatility forecasting measures on future stock returns in four different periods (Bear and Bull markets). First we find clear and robust empirical evidence that the implied idiosyncratic volatility is the best stock return predictor for every sub-period both in Bear and Bull markets. Second, the crosssection firm-specific characteristics are important when it comes to stock returns forecasts, as the latter have mixed positive and negative effects on Bear and Bull markets. Third, we provide evidence that short selling constraints impact negatively on stock returns for only a Bull market and that liquidity is meaningless for both Bear and Bull markets after the recent financial crisis.
\end{abstract}

Keywords: Options, Risk Premium, stock, volatility

JEL Classification: G10; G12; C53 


\subsection{Background and Review}

Bollerslev, Tauchen, and Zhou (2009) present a strong evidence that the difference between implied and realized variation, or the variance risk premium (VRP), has a significantly positive predictability for a nontrivial fraction of the time-series variation in post-1990 aggregate stock market returns. Indeed, the magnitude of predictability is particularly strong at the intermediate quarterly return horizon. Even though, VRP is positively related to the future stock and market returns and their results are strong as similar as our research, their models and methodologies including outcome terms are different to our research. In fact, Bollerslev et al. (2009) examine the effect of market or systematic risk model on the market returns, whereas our research apply different idiosyncratic or unsystematic volatility forecasting models affected on future firm stock returns. Bali and Hovakimian, (2009), show a significant relation between the cross-sectional variation in expected stock returns and volatility spreads for "the realized-implied volatility spread" and "the call-put implied volatility spread". However, their results are mixed with significantly negative premium for the realized-implied volatility spread in the cross- sectional pricing of individual stock and a highly positive call-put implied volatility spreads or jump risks for higher jump stock returns. Additionally, these results do not present the effect of idiosyncratic components extracted from their volatility spread models. In fact, their examined volatility models are still considered to include both terms of market and firm level risks to predict the stock returns. In contrary, our research separates the idiosyncratic risk from all volatility forecasting models and examines the idiosyncratic risk component which should be the direct firm level impact for expected stock returns. Finally, we find a clear strong evidence that the implied idiosyncratic volatility from stock options can show the strongest positive statistical significance and be the best predictability beyond other idiosyncratic volatility models for the future stock returns.

In terms of methodology, Merton (1973) studied an intertemporal model for the capital market and the conditional excess return on the market portfolio. Their outcomes report that unlike the one-period model, current demands for assets are affected by the possibility of uncertain changes in future investment opportunities. As such, this is an evidence presented that the term of implied volatility from future uncertain market changes in investment opportunities impacts current asset demands. In addition, after aggregating demands and market cleared to the equilibrium, the finding is relationships among expected returns. Indeed, the conclusion come from these results that the implied volatility affects expected returns. Furthermore, as derived by Campbell (1993) from a standard intertemporal asset pricing model (ICAPM) that consumption-wealth ratio depends on the elasticity of intertemporal substitution in consumption. In fact, this elasticity is an evidence of the 
effect of volatility. Following this, asset risk premia are determined by the coefficient of relative risk aversion being this risk aversion connected with the implied volatility in our research due to the fact that the implied volatility is a sentiment term for the market's best guess of the future volatility and market uncertainty over the term of the option. Risk aversion is the action exposed after market uncertainty occurred to attempt to reduce the market uncertainty predicted by the implied volatility. The risk premia are related to the covariances of asset returns with market return and with news about the discounted value of all future market returns. In conclusion, if the testing method and model for expected future market and asset returns is considered, the implied volatility should be a crucial factor included as same as our research due to its effect. In a following research Campbell (1996) displays that a main factor determining excess stock returns is affected by aggregate market risk. As a result, it contributes that future stock returns can be forecasted by the systematic risk or volatility. Especially, his main contribution shows that expected returns on assets are determined by covariance with "an aggregate stock index" which its return is correlated with the return on human capital and with shifts in the investment opportunity set. Consequently, the conditional excess return on the market portfolio is related to its conditional variance as well as the conditional covariance between “excess market portfolio's returns affected by the aggregate stock index" and "the innovations in stated variables that impact the stochastic investment opportunity set". To summarise, these relevant covariances are evidences shown that the stock market volatility is directly connected with the excess stock returns as consistent as our research.

More specifically, our research defines more particular methodology than Campbell (1993) AER (1996) and Merton (1973) to get the implied idiosyncratic variance in the firm level from the total implied variance subtracted by the implied market variance. After that, we examine the effect of implied idiosyncratic volatility on future stock returns. Our results show the robust contribution about the relationship between implied idiosyncratic volatility and expected stock returns that the implied idiosyncratic volatility can predict these expected returns the best among different volatility measures for both in Bear and Bull markets.

Rapach, Strauss, and Zhou (2009) present "a combining individual forecasting model” to deliver statistically and economically significant out-of-sample gains relative to the historical average consistently over time. This is resulted by the forecasting ability of individual predictive regression models seriously impaired from the effect of model uncertainty and instability. In accordance withHenkel, Martin, and Nardari (2011), the historical average out-of-sample for performance of aggregate return can be forecasted by applying the regime-switching vector autoregression (RSVAR) model to match the time-varying dynamics of predictors. Their results are outperformed for the U.S. 
market and mixed for G7 countries. Moreover, they show that this predictability is related to countercyclical risk premiums as well as the time-variation in the dynamics of predictors. As can be seen from Dangland and Halling (2012), out-of-sample predictive models with constant coefficients are dominated by "models with time-varying coefficients". Moreover, out-of-sample predictability for S\&P 500 index's monthly returns is statistically and economically related to an investor using the historic mean, and their methodology with time-varying coefficients. Additionally, it can have earned consistently positive utility gains. Indeed, a strong connection between out-of-sample predictability and the business cycle, is found. As shown byHuang, Jiang, Tu, and Zhou (2015), "the new investor sentiment index" is proposed to be aligned for an aggregate stock market predictor base on 6 sentiment proxies by using the partial least squares (PLS) method. In term of the aggregate stock market return, it is calculated as the excess return as usual for the S\&P 500 index (including dividends). Moreover, they present that this new index which is eliminated noise in sentiment proxies can predict much greater than existing sentiment indices for both in- and out-of-samples. Specifically, this predictability becomes both statistically and economically significant for cross-sectional stock returns sorted by industry, size, value, and momentum. Economically, they find that the return predictability of investor sentiment seems to come from investors' biased belief about future cash flows rather than discount rates. Following this, Huang, Jiang, Tu, and Zhou (2016) present that "a state-dependent predictive regression model" is proposed to be a risk premium predictability for stock market returns. Furthermore, a market momentum predictor forecasts the excess market return negatively in good times and positively in bad times. Particularly, the concentration of return predictability in bad times is largely due to the assumption of the traditional one-state predictive regression model. They use 200-day moving average or 6-month average market return to date good and bad market states, which is easy to implement, somehow it cannot be indicated that the 200-day moving average is the most precise method or more accurate than others due to higher day moving average, for instance 300 or 400 day average resulting higher indication strength.

In summary, our research is consistent with outcomes from these researches Rapach et al. (2009), Henkel et al. (2011), Dangland and Halling (2012), Huang et al. (2015), and Huang, Jiang, $\mathrm{Tu}$, and Zhou, (2016) presenting different stock market return predictability models included analysis for the correlation between out-of-sample predictability and the time variation or business cycle. Indeed, all previous research present the stock return predictability in term of the market level which is mostly engaged to a systematic risk, on the other hand our research shows evidences in the different level of firm which is relevant to the idiosyncratic part and able to represent the U.S. stock market's returns as our evidence. More specifically, our methodology uses Chow structural break 
test Chow (1960) which is a broadly reliable and acceptable method to define different impacts of independent variables on different subgroups contributing to divide equity business cycles (Bull and Bear markets). Following this, the outcome of breaking point test is similar as those researches to classify between good and bad times. However, our research aim is illustrating only that the best volatility measure or implied idiosyncratic volatility can predict in both market characteristics such as Bull and Bear markets. Additionally, the Chow test is used to only present that four phase situations as breaking points are different market characteristics in either Bear or Bull market. Indeed, the objective for our structural break test is for only classify two different market characteristics (Bear and Bull markets) during the periods covering two financial crises considered.

The rest of the paper is organised as follows. The next section presents data sources, sample selection and methodology implemented. In Section 4, we test the different volatility forecast models and the predictive power of idiosyncratic volatility on future stock returns for all sub periods over two financial crises; finally Section 5 concludes the study.

\subsection{Data and methodology}

\subsubsection{Sample}

Our sample represents the U.S. equity option market as it comprises the stock options traded on the American Stock Exchange and the Chicago Board Options Exchange (CBOE) for the period spanning January 2001 to December 2010. The data used for the research is collected from different sources. 1) The daily implied volatility for each individual company and the option open interest are collected from Tick Data and OptionMetrics; 2) Stock returns, share prices, and the number of shares outstanding are from Tick Data and CRSP and equity book value are from Tick Data and Compustat; 3) daily returns for the the Carhart (1997) momentum factor (UMD) and three Fama and French (1993) factors (MKT, SMB, HML) are collected from Kenneth French's website ${ }^{8}$. In fact, the three Fama and French risk factors can explain a lot of the variation in stock returns-exposures to size, value, and market risk.

\footnotetext{
${ }^{8}$ Refer to Fama, E. F.; French, K. R. (1993) "Common risk factors in the returns on stocks and bonds", Journal of Financial Economics. 33: 3

Kenneth French's website is http://mba.tuck.dartmouth.edu/pages/faculty/ken.french/Data_Library/f-f_factors.html The Fama/French factors are constructed using the 6 value-weight portfolios formed on size and book-to-market. Firstly, SMB (Small Minus Big) is the average return on the three small portfolios minus the average return on the three big portfolios. Nextly, HML (High Minus Low) is the average return on the two value portfolios minus the average return on the two growth portfolios. Finally, Rm-Rf, the excess return on the market, value-weight return of all CRSP firms incorporated in the US and listed on the NYSE, AMEX, or NASDAQ that have a CRSP share code of 10 or 11 at the beginning of month $t$, good shares and price data at the beginning of $t$, and good return data for $t$ minus the one-month Treasury bill rate (from Ibbotson Associates).
} 
From CRSP, it is clear that the full data comprises 2,596 Tickers (or unique firms) for the period spanning January 2001 to December 2010. We impose the following sample selection criteria: 1) Full information (daily basis) for trade options, 2) Daily stock returns for at least the five previous years. ${ }^{9}$ In order to confirm whether our sample represents the U.S. market as a whole, the sample average daily return is computed and the correlation between this average and the market return is calculated. The result reveals a $90 \%$ correlation, thus meanings that the data can represent the U.S. market asa whole ${ }^{10}$

Table 1 reports the initial number of firms per industry available in CRSP for the period January 2001 and December 2010 as well as the number of sampling firms after the previous presented selection criteria.

Table 1: Number of firms per industry

\begin{tabular}{|c|c|c|c|}
\hline Industry & Full Sample & $\begin{array}{c}\text { Number unique } \\
\text { Firms }\end{array}$ & $\begin{array}{c}\text { Sample/Full Data } \\
(\%)\end{array}$ \\
\hline Basic Materials & 275 & 62 & 22.5 \\
\hline Consumer Goods & 268 & 64 & 23.9 \\
\hline Financials & 352 & 79 & 22.4 \\
\hline Healthcare & 270 & 63 & 23.3 \\
\hline Industrial Goods & 216 & 50 & 23.1 \\
\hline Services & 520 & 117 & 22.5 \\
\hline Technology & 603 & 141 & 23.4 \\
\hline Utilities & 92 & 20 & 21.7 \\
\hline Total & 2,596 & 596 & 22.9 \\
\hline
\end{tabular}

Overall there are 596 unique firms in our sample representing $22.9 \%$ of the full data available in CRSP. There is no evidence that a single industry is more represented in the sample. In fact, the percentage of unique firms per industry presented in the sample is very similar to values between 21.7 and $23.9 \%$ for Utilities and Consumer Goods, respectively.

\subsubsection{Methodology}

\subsubsection{Beta, Implied and Realized idiosyncratic volatilities}

\subsection{Beta Calculation}

The firm's beta for each of the unique firms selected is calculated on a 60 months rolling basis. The Firm j's beta is estimated by analysing the effect of regression of stock returns r on market returns for each month with the use of the previous 60 months:

\footnotetext{
${ }^{9}$ This condition is essential for the calculation of idiosyncratic realized, implied volatility and the firm's beta.

${ }^{10}$ Results are available upon request.
} 


$$
r_{j, t}=\alpha_{j}+\beta_{j} \text { Mret }_{t}+\varepsilon_{j, t}
$$

where, Mret is the S\&P 500 value-weighted monthly returns collected from CRSP, $r$ is the stock monthly returns, $\alpha$ represents the constant term and $\varepsilon$ is the error term. Furthermore, the beta calculation robustness is verified by applying the Fama and French (1993) three factor model and a beta portfolio computed following Fu (2009). More specifically, further robustness tests can be considered to apply by Cahart (1997) and Florackis, Gregoriou, \& Kostakis (2011) for further research as well. This creates equal-weighted returns in a rolling monthly estimation for portfolios of $10 \times 10$ depending on firm number and size betas. Following this, the regression of these portfolio returns is performed on the S\&P 500 value-weighted monthly returns with one-month lag to determine portfolio betas for the individual firms based on their beta level and size.

\subsection{Implied idiosyncratic volatility calculation}

Data is gathered in accordance with OptionMetrics employing European and American models upon appropriation. In fact, an American option can be exercised at any time, whereas a European option can only be exercised at the expiration date. This added flexibility of American options increases their value over European options in certain situations. Therefore, we can state that American Options $=$ European Options ${ }^{11}+$ Premium where the Premium is greater than or equal to zero.

Furthermore, the standardized implied volatility is estimated by using the option nearest to 30 days maturity and at-the-money for both puts and calls to deduct the measurement error related to the conversion to attain implied volatilities from option prices. ${ }^{12}$

Analogous to Stivers, Mayhew and Dennis (2006) for the computation of the implied volatility in its idiosyncratic part the market implied volatility is demonstrated to be a market volatility function:

$$
\sigma_{I V j, t}^{2}=\beta_{j}^{2} \sigma_{I V}^{2}+\sigma_{I V}^{2} \text { idio,j,t }
$$

\footnotetext{
${ }^{11}$ Theoretically, a European option has lower value than an otherwise equivalent American option. It is because a European option does not provide the convenience that arises from flexibility in timing of exercise.

Value of a European Call Option $=\max [0$, Asset Price - Exercise Price $]$ and

Value of a European Put Option $=\max [0$, Exercise Price - Asset Price] , when Asset price is the price of the underlying financial asset at the exercise date and Exercise price or Strike price is the price at which the option entitles its holder to sell or purchase the underlying financial asset.

${ }^{12}$ For details see Hentschel (2003).
} 
where, $\sigma_{I V}^{2}$ is the VIX implied market variance for day $t, \sigma_{I V}^{2}$ is is the total implied variance at time $t$ for firm $j, \beta^{2}{ }_{j}$ is the squared market beta from equation (1) and $\sigma_{I V i d i o, j, t}^{2}$ is the implied variance in the idiosyncratic part at time $t$ for firm $j$. Thus, the measurement of implied idiosyncratic volatility is the square root of the implied variance of the idiosyncratic part. In theory, this value would not be equal to zero or negative due to mathematical outcome that square root of average squared deviation can not be negative. In addition, volatility is size, consequently if there is no fluctuation or volatility in the worst case, it will be able to be only zero and never be negative. However, it is possible that this will occur empirically. ${ }^{13}$

\subsection{Realized idiosyncratic volatility calculation}

The annualized realized volatility is calculated for each month and firm as the annualized standard deviation of daily returns. The realized idiosyncratic volatility part is calculated through equation (1) using daily observations. The realized idiosyncratic risk $\sigma_{R V i d i o, j, t}$, is calculated using daily residuals standard deviation for each month and firm, such that:

$$
\sigma_{R V_{i d i o, j, t}}=\sqrt{\frac{1}{N} \sum_{n=1}^{N}\left(\varepsilon_{j, t, n}-\bar{\varepsilon}_{j, t}\right)^{2}}
$$

where, $N$ is the number of trading days in each month, $\varepsilon_{j, t, n}$ is the residual for firm $j$ on day $n$ for

month $t$ and $\bar{\varepsilon}_{j, t}$ is the mean residual in month $t$ over the $N$ days for firm $j$. The $\sigma_{R V}$ idio,j,t is measured in annual basis.

\subsubsection{EGARCH and $A R(2)$}

The advantage of the EGARCH versus the GARCH model is that, with the former, there is no requirement to restrict the parameters so as to assure a non-negative variance. This function is formed as:

$$
R_{i, t}=\alpha_{j}+\beta_{M K T, j} M K T_{M, t}+\beta_{S M B, j} S M B_{t}+\beta_{H M L j} H M L_{t}+\varepsilon_{j, t}, \quad \varepsilon_{j, t} \sim N\left(0, \sigma_{j, t}^{2}\right)
$$

${ }^{13}$ The small values are set equal to zero and there are non-positive values. 
Where the monthly returns are calculated following the Fama and French (1993) 3-factor model in equation (4) and the conditional variance for firm $j \sigma_{E G_{i d i o, j, t}}^{2}$ is a function of the past $p$ residual variances and $q-$ period stock returns.

$$
\ln \sigma_{E G_{i d i o, j, t}}^{2}=\alpha_{i}+\sum b_{j, \phi} \ln \sigma_{j, t-1}^{2}+\sum c_{j, \phi}\left\{\theta\left(\varepsilon_{j, t-k} / \sigma_{j, t-k}\right)+\gamma\left[\left|\left(\varepsilon_{j, t-k} / \sigma_{j, t-k}\right)\right|-\sqrt{(2 / \pi)}\right]\right\}
$$

Equations (4) and (5) are computed at least for 60 monthly returns for each stock. The idiosyncratic volatility is calculated as the square root of the conditional variance.

For the autoregressive model in $2^{\text {nd }}$ order, $A R(2)$ for the idiosyncratic volatility estimation we follow Chua, Goh and Zhang (2005). Applying equation (4) to calculate the square residual, the idiosyncratic variance for firm $j$ is calculated as:

$$
\sigma_{A R \text { idio }, j, t}=\lambda_{1, j}+\lambda_{2, j} \varepsilon_{j, t-1}+\lambda_{3, j} \varepsilon_{j, t-2}+\eta_{j, t}
$$

The idiosyncratic volatility is defined as the square root of the idiosyncratic variance.

\subsubsection{Short-sale and liquidity}

Additionally we control for possible short-sale constraints or liquidity issues. Particularly, highly liquid stocks are less likely to encounter market frictions and consequently this has an important impact on traded options. The liquidity measure open-interest is calculated as one plus the option open-interest logarithm, where open-interest is compiled for each firm across the all options. For the measure of short-sale constraint we follow Ofek, Richardson, and Whitelaw (2004) as:

$$
\text { ORW Ratio }=100 \times \ln [S / S *]
$$

Where $S *$ is the theoretical price computed from the call-put relation including the put of last exercise premium $^{14}$ and $\mathrm{S}$ is the current stock price. The ORW Ratio should exceed zero if a short-sale constraint exists.

In summary the control for possible short-sale constraints or liquidity issues is performed to

\footnotetext{
${ }^{14}$ Refer to Ofek, Richardson and Whitelaw (2004).
} 
test the hypothesis regarding whether short-sale constraints and/or higher liquidity impact prices differently in response to volatility when compared with those from more restricted companies.

\subsubsection{Realized volatility prediction}

\subsection{Implied volatility}

The effectiveness with which well does implied volatility (IV) predict future realized volatility (RV) is measured at both individual (firm) and market levels. The following regressions are performed:

$$
\sigma_{R V M, t+1}=\alpha_{t}+\xi_{1} \sigma_{I V, t}+\xi_{2} \sigma_{R V_{M, t}}+\varepsilon_{j+1}
$$

and,

$$
\sigma_{R V, t+1}=\alpha_{j, t}+\xi_{1, j} \sigma_{I V}+t+\xi_{2, j} \sigma_{R V}+t
$$

where, $\sigma_{R V_{M, t}}$ is the annualized realized monthly volatility in month $t$ for the S\&P 500 index, $\sigma_{I V_{M, t}}$ is the VIX index in month $t, \alpha$ is the constant term, $\xi_{1}$ and $\xi_{2}$ are estimated coefficients and $\varepsilon$ is the error term. The regression specification at individual/firm level is shown in equation (9). The equation is performed to each firm independently, whilst the mean and median coefficients are presented as well respective significance. $\sigma_{R V}{ }_{j, t}$, represents the annualized realized monthly volatility in month $t$ for each unique firm, $\sigma_{I V}$ it is the implied volatility for each firm in month $t, \alpha$ is the constant term, $\xi_{1}$ and $\xi_{2}$ are estimated coefficients and $\varepsilon$ is the error term. 


\subsection{Implied idiosyncratic volatility}

We also test the power of implied idiosyncratic volatility, and EGARCH and AR(2) volatility forecast models to predict realized idiosyncratic volatility. The following regression is estimated:

$$
\sigma_{R V i d i o, j, t+1}=\alpha_{j}+\psi_{1, j} \sigma_{I V i d i o, j, t}+\psi_{2, j} \sigma_{E G_{i d i o, j, t}}+\psi_{3, j} \sigma_{A R i d i o, j, t}+\psi_{4, j} \sigma_{R V i d i o, j, t}+\varepsilon_{j, t+1}
$$

where, $\sigma_{R V_{i d i o, j, t}}$ represents the realized idiosyncratic volatility in month $t$ for firm $j, \sigma_{I V i d i o, j, t}$ is the implied variance in its idiosyncratic part at month $t$ for firm $j, \sigma_{E G_{i d i o, j, t}}$, is conditional variance for firm $j$ in month $t$ is, $\sigma_{A R}$ idio,,,$t$, is the idiosyncratic volatility estimation following Chua, Goh and Zhang (2005) autoregressive model in $2^{\text {nd }}$ order, $A R(2), \alpha$ is the constant term, $\psi$ 's estimated coefficients and $\varepsilon$ is the error term.

\subsubsection{Predictive Regressions}

\subsection{Fama-Macbeth (1973)}

The final step is to examine the relation between idiosyncratic risk and firm future returns. We extend the study of Ang et al (2006) by including firm specific characteristics in our analysis. As a result, we assess, on a monthly basis and at firm level the relation between idiosyncratic volatility and future stock returns, applying firm-specific controls and following the procedure put forth by Fama and Macbeth (1973) procedure. The following regression is estimated:

$r_{j, t+1}=\alpha_{j}+\lambda_{1} \sigma_{R V i d i o, j, t}+\lambda_{2} \log S I Z E_{j, t}+\lambda_{3} \log B M_{j, t}+\lambda_{4} r_{j, t}+\lambda_{5} r_{j, t-11: t-1}+\lambda_{6} r_{j, t-35: t-12}+\lambda_{7} \beta_{j, t}+\varepsilon_{j, t+1}$

where, $r_{j, t}$ represents the stock return for firm for firm $j$ in month $t, \sigma_{R V \text { idio }, j, t}$, is the realized idiosyncratic volatility in month $t$ for firm $j, \log S I Z E_{j, t}$, is the logarithm of market value of equity (calculated by multiplying the company's current stock price by its number of outstanding shares.), $\log B M_{j, t}$, is the logarithm of the book-to-market ratio which can be negative, especially there are around $60 \%$ of sample for $\log B M_{j, t}$, which their values are minus, $r_{j, t-11: t-1}$ and $r_{j, t-35: t-12}$,represents the stock return for firm $j$ one and three years before the current month, $\beta_{j, t}$, is firm $j$ equity Beta, $\alpha$ is the constant term, $\lambda$ 's estimated coefficients and $\varepsilon$ is the error term.

Additionally, the previous equation is modified by including the idiosyncratic volatility forecasts (implied volatility, EGARCH and $\mathrm{AR}(2)$ ), short-sale constraints and liquidity issues. The regression will proceed as follow: 


$$
\begin{aligned}
& r_{j, t+1}=\alpha_{j}+\lambda_{1} \sigma_{R V_{i d i o, j, t}}+\lambda_{2} \log S I Z E_{j, t}+\lambda_{3} \log B M_{j, t}+\lambda_{4} r_{j, t}+\lambda_{5} r_{j, t-11: t-1}+\lambda_{6} r_{j, t-35: t-12}+\lambda_{7} \beta_{j, t}+ \\
& +\lambda_{8} \sigma_{I V}+{ }_{i d i o, j, t}+\lambda_{9} \sigma_{E G_{i d i o, j, t}}+\lambda_{10} \sigma_{A R 2 i d i o, j, t}+\lambda_{11} O R W_{\text {ratio }_{j, t}}+\lambda_{12} O I_{j, t}+\varepsilon_{j, t+1}
\end{aligned}
$$

where, $r_{j, t}$ represents the stock return for firm for firm $j$ in month $t, \sigma_{R V_{i d i o, j, t}}$, is the realized idiosyncratic volatility in month $t$ for firm $j, \log S I Z E_{j, t}$, is the logarithm of market value of equity (calculated by multiplying the company's current stock price by its number of outstanding shares.), $\log B M_{j, t}$, is the logarithm of the book-to-market ratio, $r_{j, t-11: t-1}$ and $r_{j, t-35: t-12}$, represents the stock return for firm $j$ one and three years before the current month, $\beta_{j, t}$, is firm $j$ equity Beta, $\sigma_{I V} i d i o, j, t$, is the implied variance in its idiosyncratic part at month $t$ for firm $j, \sigma_{E G_{i d i o, j, t}}$, is conditional variance for firm $j$ in month $t$ is, $\sigma_{A R}$ idio,j,t , is the idiosyncratic volatility estimation following Chua, Goh and Zhang (2005) autoregressive model in $2^{\text {nd }}$ order, $A R(2)$ which is chosen due to being suitable for our data and higher-order autoregressive models include more lagged terms as predictors with the autoregressive coefficients on lags 1 and 2, ORW ratio $_{j, t}$, is the ORW Ratio following Ofek, Richardson, and Whitelaw (2004), $O I_{j, t}$, is the liquidity measure open-interest, $\alpha$ is the constant term, $\lambda$ 's estimated coefficients and $\varepsilon$ is the error term.

\subsubsection{Breakpoints by Chow Test}

The aim of this study is to analyse and enlarge the effect of idiosyncratic volatility on stock return predictability during the dot-com bubble and the recent financial crisis over sub periods for both the Bear and Bull markets. We perform a Chow structural break test Chow, (1960) for the entire periods spanning January 2001 to December 2010 over the two previously mentioned financial crises. This is done in order to examine, and draw conclusions regarding, appropriate breakpoints with definite time intervals for every sub period. By definition, the Chow test which was invented by economist Gregory Chow in 1960 following Chow, (1960) is a statistical and econometric test of whether the coefficients in two linear regressions on different data sets are equal. In econometrics, the Chow test is most commonly used in time series analysis with various types of data including panel data to test for the presence of a structural break. It is also often used to determine whether the independent variables have different impacts on different subgroups of the population.

Suppose that we model our data as

$$
y_{t}=a+b x_{1 t}+c x_{2 t}+\varepsilon
$$

If we split our data into two groups, then we have 


$$
y_{t}=a_{1}+b_{1} x_{1 t}+c_{1} x_{2 t}+\varepsilon
$$

and

$$
y_{t}=a_{2}+b_{2} x_{1 t}+c_{2} x_{2 t}+\varepsilon
$$

The null hypothesis of the Chow test asserts that $a_{1}=a_{2}, b_{1}=b_{2}$, and $c_{1}=c_{2}$, and there is the assumption that the model errors $\varepsilon$ are independent and identically distributed from a normal distribution with unknown variance.

Let $S_{C}$ be the sum of squared residuals from the combined data, $S_{1}$ be the sum of squared residuals from the first group, and $S_{2}$ be the sum of squared residuals from the second group. $N_{1}$ and $N_{2}$ are the number of observations in each group and $\mathrm{k}$ is the total number of parameters. Then the Chow test statistic is

$$
\frac{\left(S_{C}-\left(S_{1}+S_{2}\right)\right) /(k)}{\left(S_{1}+S_{2}\right) /\left(N_{1}+N_{2}-2 k\right)}
$$

The test statistic follows the F distribution with $\mathrm{k}$ and $N_{1}+N_{2}-2 \mathrm{k}$ degrees of freedom. Moreover, the global sum of squares (SSE) if often called Restricted Sum of Squares (RSSM) as we basically test a constrained model where we have $2 \mathrm{~K}$ assumptions (with $\mathrm{K}$ the number of regressors).

\subsection{Data sources and description}

Table 2 below summarizes the data sources and equations description for each of the previously detailed research steps detailed previously.

Table 2: Data Sources and Description

\begin{tabular}{llc}
\hline & \multicolumn{1}{c}{ Variable } & Source and Description \\
\hline 1. & Index Return & CRSP \\
2. & Stock return & CRSP \\
3. & Realized Volatility Index & CRSP \\
4. & Realized Stock Volatility & OptionMetrics \\
5. & Implied Stock Volatility & OptionMetrics \\
6. & Realize Idiosyncratic Volatility & Calculated with (Stock Beta, Realized and Implied Stock Volatility) \\
7. & Implied Idiosyncratic Volatility & [Equations (3) and (4)] \\
& & Fama French and Liquidity Factors [Equation (5)] \\
8. & EGARCH Idiosyncratic Volatility & Fama French and Liquidity Factors [Equation (6)] \\
9. & AR(2) Idiosyncratic Volatility & OptionMetric (Use to calculate log SIZE) \\
10. & Market Value & Compustat (Use with equation of 10, to calculate log $B M)$ \\
11. & Firm's Equity & OptionMetrics (Use to calculate Option Interest) \\
12. & Option Volume &
\end{tabular}




\subsection{Empirical Results}

We first start by examining breakpoints using the Chow test to determine the sub periods over two financial crises, namely the dotcom bubble in 2002 and the recent financial crisis in 2008. Furthermore, in comparison to previous research, this study is somewhat larger and deals with the entire period spanning2001 to 2010 by dividing it into four sub periods. These breakpoints are tested by using the Chow method in both the Bear and Bull markets. Following this, we present a brief overview of summary statistics for the variables used in this study followed by preliminary tests to establish whether lagged historical/implied volatilities or EGARCH and AR(2) models better explain realized volatility. Finally, we finish with the Predictive Regressions analysis for every sub period, followed by a conclusion.

The sample represents the U.S. equity option market as it comprises the stock options traded on the American Stock Exchange and the Chicago Board Options Exchange (CBOE) for the period spanning January 2001 to December 2010. Our sample comprises 596 unique firms. To ensure that the sample represents the US market as a whole, the correlation between the average daily return per stock and the market return (proxied by S\&P500) is calculated. The correlation between the average sample returns and market return is above $90 \%$, thus indicating that our sample properly represents the U.S. market as a whole.

In fact, all empirical results in entire tables from Table 3 to Table 16 are illustrated to be independent or separately in whole following parts, namely Descriptive statistics, Breakpoints in Financial Crises, Preliminary analysis, Predictive regressions, and others.

\subsubsection{Descriptive statistics}

Table 3 reports per year summary statistics for the 596 unique firms analysed. We can highlight the increased volatility in 2001-2002 (dotcom bubble) ${ }^{15}$ and 2008-2009 (recent financial crisis). Additionally, the implied volatility annual standard deviation increases in the two cited periods, this is clear evidence of the non- homogeneous increase in volatility among the different stocks in our sample, which also supports the notion that differences in firms and industry sectors do exist.

Table 3: Implied Volatility statistics

\begin{tabular}{cccccc}
\hline Year & $\begin{array}{c}\text { Implied Volatility } \\
\text { (Average monthly) }\end{array}$ & $\begin{array}{c}\text { Implied Volatility } \\
\text { (Median monthly) }\end{array}$ & $\begin{array}{c}\text { Std. Deviation Implied } \\
\text { Volatility }\end{array}$ & Maximum & Minimum \\
\hline 2001 & 0.567 & 0.510 & 0.231 & 1.672 & 0.085 \\
2002 & 0.533 & 0.482 & 0.223 & 1.953 & 0.111 \\
2003 & 0.435 & 0.396 & 0.179 & 1.751 & 0.134 \\
2004 & 0.366 & 0.333 & 0.137 & 1.002 & 0.122
\end{tabular}

${ }^{15}$ S\&P500 index drops by 13.04 and 23.37 percent in 2001 and 2002, respectively. 


\begin{tabular}{llllll}
2005 & 0.337 & 0.311 & 0.125 & 1.746 & 0.117 \\
2006 & 0.334 & 0.316 & 0.117 & 1.147 & 0.116 \\
2007 & 0.356 & 0.332 & 0.131 & 1.616 & 0.117 \\
2008 & 0.544 & 0.494 & 0.222 & 2.114 & 0.137 \\
2009 & 0.574 & 0.532 & 0.221 & 1.988 & 0.167 \\
2010 & 0.465 & 0.444 & 0.151 & 1.436 & 0.135 \\
\hline
\end{tabular}

Table 4 presents the same analysis regarding the historical volatility. In fact historical volatility is higher on 2001-2002 and 2008-2009 periods. We can also detect a higher average implied volatility comparing with historical volatility in our sample possible indicating that options are overvalued. ${ }^{16}$

Table 4: Historical Volatility statistics

\begin{tabular}{cccccc}
\hline Year & $\begin{array}{c}\text { Historical Volatility } \\
\text { (Average monthly) }\end{array}$ & $\begin{array}{c}\text { Historical Volatility } \\
\text { (Median monthly) }\end{array}$ & $\begin{array}{c}\text { Std Deviation Implied } \\
\text { Volatility }\end{array}$ & Maximum & Minimum \\
\hline 2001 & 0.514 & 0.432 & 0.314 & 3.594 & 0.072 \\
2002 & 0.493 & 0.417 & 0.311 & 5.289 & 0.082 \\
2003 & 0.355 & 0.306 & 0.210 & 3.305 & 0.058 \\
2004 & 0.295 & 0.251 & 0.161 & 1.776 & 0.069 \\
2005 & 0.268 & 0.235 & 0.155 & 4.321 & 0.065 \\
2006 & 0.275 & 0.243 & 0.152 & 3.369 & 0.050 \\
2007 & 0.297 & 0.262 & 0.159 & 2.418 & 0.054 \\
2008 & 0.581 & 0.469 & 0.379 & 3.996 & 0.086 \\
2009 & 0.508 & 0.425 & 0.336 & 5.101 & 0.054 \\
2010 & 0.325 & 0.292 & 0.166 & 2.178 & 0.049 \\
\hline
\end{tabular}

In Figures 1 and 2 it is presented the average monthly implied and historical volatilities per industry.

Figure 1: Monthly Implied Volatility

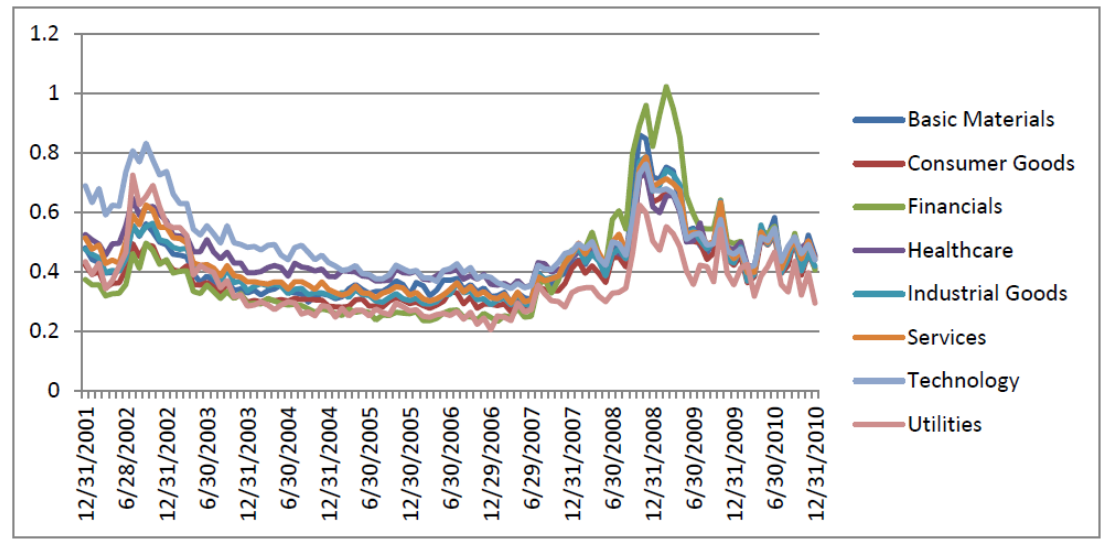

The volatility increase in the years 2001-2002 and 2008-2009 is observed independently of

\footnotetext{
${ }^{16}$ When implied volatility is greater than historical volatility, options are thought to be overvalued, and when implied volatility is less than historical volatility, options are considered to be undervalued.
} 
the industry analysed. However, there is clear evidence of higher volatility (both implied and historical) of technology firms in the period 2001-2002 and the financial crisis period of 2008-2009.

Figure 2: Monthly Historical Volatility

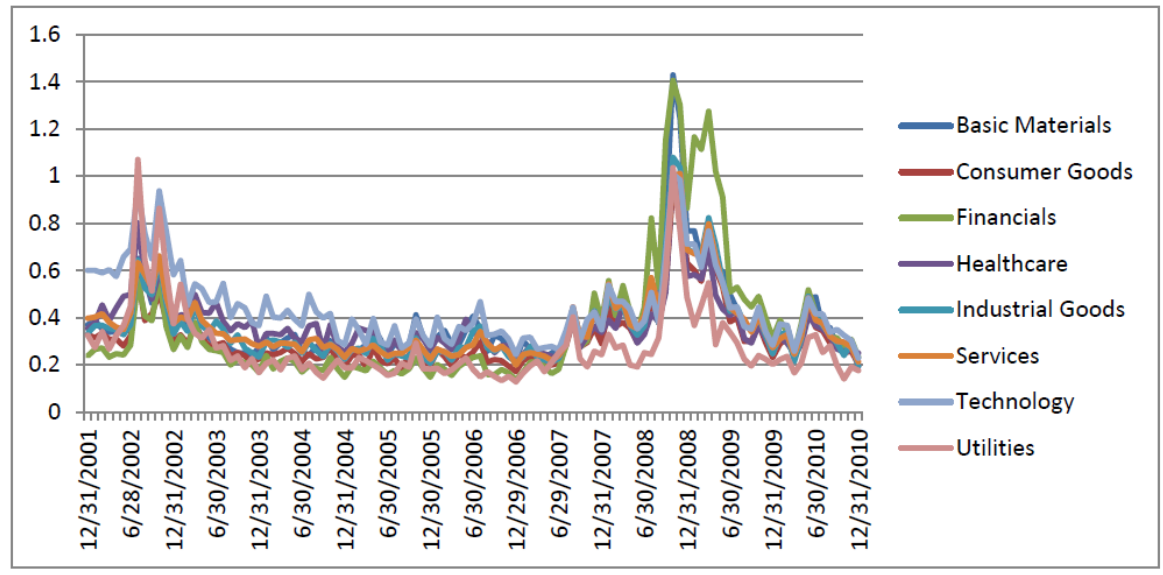

\subsubsection{Breakpoints in Financial Crises}

Table 5 details the Chow test for three main breakpoints, namely 31/12/2002 (December 2002), 31/12/2207 (December 2007), and 31/12/2008 (December 2008) in both financial crises (dotcom bubble and recent financial crisis) between 2001 and 2010. These are used on the key regression of Fama-Macbeth future returns estimation with firm-specific characteristics as shown by equation 12 from a previous research study in Mateus and Konsilp (2014). Our analysis applies the Chow test and monthly cross-sectional regressions using Fama-Macbeth (1973) with different combinations for the independent variables (models 1 to 10 ).

$$
\begin{aligned}
& r_{j, t+1}=\alpha_{j}+\lambda_{1} \sigma_{R V_{i d i o, j, t}}+\lambda_{2} \log S I Z E_{j, t}+\lambda_{3} \log B M_{j, t}+\lambda_{4} r_{j, t}+\lambda_{5} r_{j, t-11: t-1}+\lambda_{6} r_{j, t-35: t-12}+\lambda_{7} \beta_{j, t}+ \\
& +\lambda_{8} \sigma_{I V i d i o, j, t}+\lambda_{9} \sigma_{E G_{i d i o, j, t}}+\lambda_{10} \sigma_{A R 2 i d i o, j, t}+\lambda_{11} O R W_{\text {ratio } j, t}+\lambda_{12} O I_{j, t}+\varepsilon_{j, t+1}
\end{aligned}
$$

Finally, we conclude that breakpoints are assigned to be three of 31/12/2002, 31/12/2207, and 31/12/2008. The statistical test following the F distribution for every model is statistically significant at $1 \%$ level. In summary, this shows that coefficients examined and obtained from Table 12 (Fama-Macbeth future returns estimation with firm-specific characteristics) from a previous study Mateus \& Konsilp, (2014) are not consistent. As a result, these breakpoints can be strongly effective and the sub periods are divided into four intervals called "Phases" for further examination as follows.

1. Phase 1 is between February 2001 and December 2002 (01/02/2001 and 31/12/2002).

2. Phase 2 is between January 2003 and December 2007 (01/01/2003 and 31/12/2007). 
3. Phase 3 is between January 2008 and December 2008 (01/01/2008 and 31/12/2008).

4. Phase 4 is between January 2009 and December 2010 (01/01/2009 and 31/12/2010).

The Chow method is examined for three breakpoints including 31/12/2002, 31/12/2007, and 31/12/2008 on the key regression of Fama-Macbeth future returns estimation with firm-specific characteristics

$$
\begin{aligned}
& r_{j, t+1}=\alpha_{j}+\lambda_{1} \sigma_{R V_{i d i o j, t}}+\lambda_{2} \log S I Z E_{j, t}+\lambda_{3} \log B M_{j, t}+\lambda_{4} r_{j, t}+\lambda_{5} r_{j, t-11: t-1}+\lambda_{6} r_{j, t-35: t-12}+\lambda_{7} \beta_{j, t}+ \\
& +\lambda_{8} \sigma_{I V i d i o, j, t}+\lambda_{9} \sigma_{E G_{i d i o, j, t}}+\lambda_{10} \sigma_{A R 2} i_{\text {dio }, j, t}+\lambda_{11} O R W_{\text {ratio } j, t}+\lambda_{12} O I_{j, t}+\varepsilon_{j, t+1}
\end{aligned}
$$

\begin{tabular}{|c|c|c|c|}
\hline Model & Variables & F-statistic & Probability \\
\hline Model 1 & $\log S I Z E, \log B M, r_{t}, r_{j, t-11: t-1}, r_{j, t-35: t-12}$ & $9,332.193 * * *$ & 0.0000 \\
\hline Model 2 & $\log S I Z E, \log B M, r_{t}, r_{j, t-11: t-1}, r_{j, t-35: t-12}, \beta_{j}$ & $8,054.095^{* * *}$ & 0.0000 \\
\hline Model 3 & $\log S I Z E, \log B M, r_{t}, r_{j, t-11: t-1}, r_{j, t-35: t-12}, \beta_{j}, \sigma_{R V \text { idio }}$ & $7,114.296^{* * *}$ & 0.0000 \\
\hline Model 4 & $\log S I Z E, \log B M, r_{t}, r_{j, t-11: t-1}, r_{j, t-35: t-12}, \beta_{j}, \sigma_{I V}$ idio & $7,092.780 * * *$ & 0.0000 \\
\hline Model 5 & $\log S I Z E, \log B M, r_{t}, r_{j, t-11: t-1}, r_{j, t-35: t-12}, \beta_{j}, \sigma_{R V_{i d i o}}, \sigma_{I V \text { idio }}$ & $6,314.868 * * *$ & 0.0000 \\
\hline Model 6 & $\log S I Z E, \log B M, r_{t}, r_{j, t-11: t-1}, r_{j, t-35: t-12}, \beta_{j}, \sigma_{R V_{i d i o}}, \sigma_{E G_{i d i o, j, t}}$ & $6,336.049 * * *$ & 0.0000 \\
\hline Model 7 & $\log S I Z E, \log B M, r_{t}, r_{j, t-11: t-1}, r_{j, t-35: t-12}, \beta_{j}, \sigma_{R V_{i d i o}}, \sigma_{A R_{i d i o}, j, t}$ & $6325.632 * * *$ & 0.0000 \\
\hline Model 8 & $\log S I Z E, \log B M, r_{t}, r_{j, t-11: t-1}, r_{j, t-35: t-12}, \beta_{j}, \sigma_{R V_{i d i o}}, \sigma_{I V i d i o}, \sigma_{E G_{i d i o}, j, t}, \sigma_{A R_{i d i o}, j, t}$ & $5,174.559 * * *$ & 0.0000 \\
\hline Model 9 & $\log S I Z E, \log B M, r_{t}, r_{j, t-11: t-1}, r_{j, t-35: t-12}, \beta_{j}, \sigma_{R V_{\text {idio }}}, \sigma_{\text {IV idio }}, O R W_{\text {ratio }}, O I$ & $5,168.078 * * *$ & 0.0000 \\
\hline Model10 & $\log B M, r_{t}, r_{j, t-11: t-1}, r_{j, t-35: t-12}, \beta_{j}, \sigma_{R V_{\text {idio }}}, \sigma_{I V_{\text {idio }}}, O R W_{\text {ratio }}, O I$ & $5,679.965 * * *$ & 0.0000 \\
\hline
\end{tabular}

Table 5: Model Summary on breakpoints by Chow Test

After completing the Chow test performance over breakpoints, there are four sub timeframes defined as below, these descriptions are for the two previously-mentioned financial crises between 2001 and 2010 on three breakpoints, namely 31/12/2002 (December 2002), 31/12/2207 (December 2007), and 31/12/2008 (December 2008).

1. Phase 1 is "Bear markets" during the periods of (1/02/2001-31/12/2002) in the dotcom bubble;

2. Phase 2 is "Bull markets" during the periods of (1/12/2003 -31/12/2007) after the dotcom bubble;

3. Phase 3 is "Bear markets" during the periods of $(01 / 01 / 2008-31 / 12 / 2008)$ in the recent financial crisis;

4. Phase 4 is "Bull markets" during the periods of (01/01/2009-31/12/2010) after the recent financial crisis.

By definition, "Bear market" is a characteristic which is associated with general declines in the stock 
market. These declines are characterizing by significantly increasing volatility, conversely "Bull market" is an event generally rising stock price with volatility declination.

Figure 3: Breakpoints and Sub periods in a couple of financial crises.

Figure 3.1: Monthly Implied Volatility

Figure 3.1.a: Monthly Implied Volatility

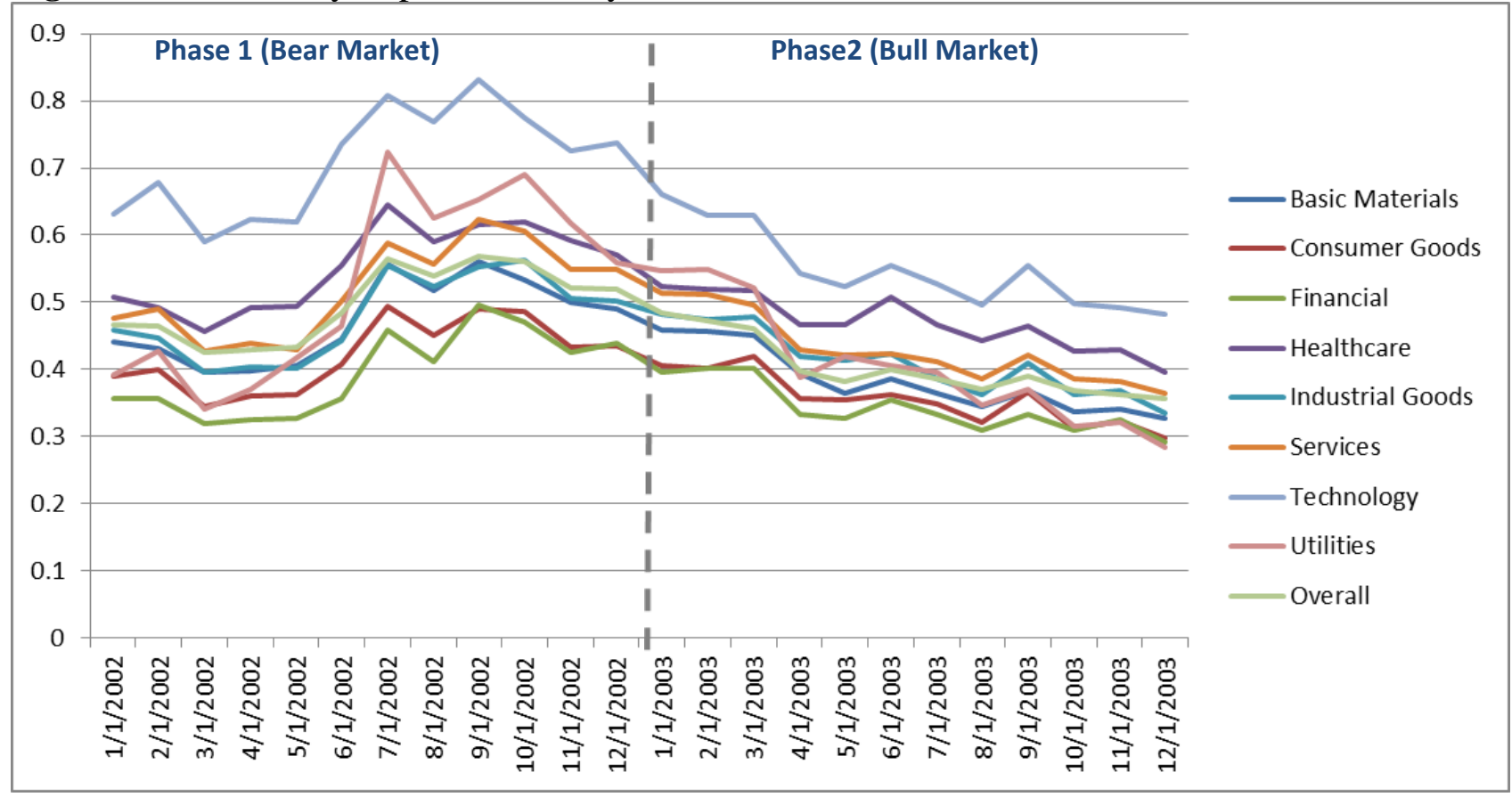

Figure 3.1.b : Monthly Implied Volatility

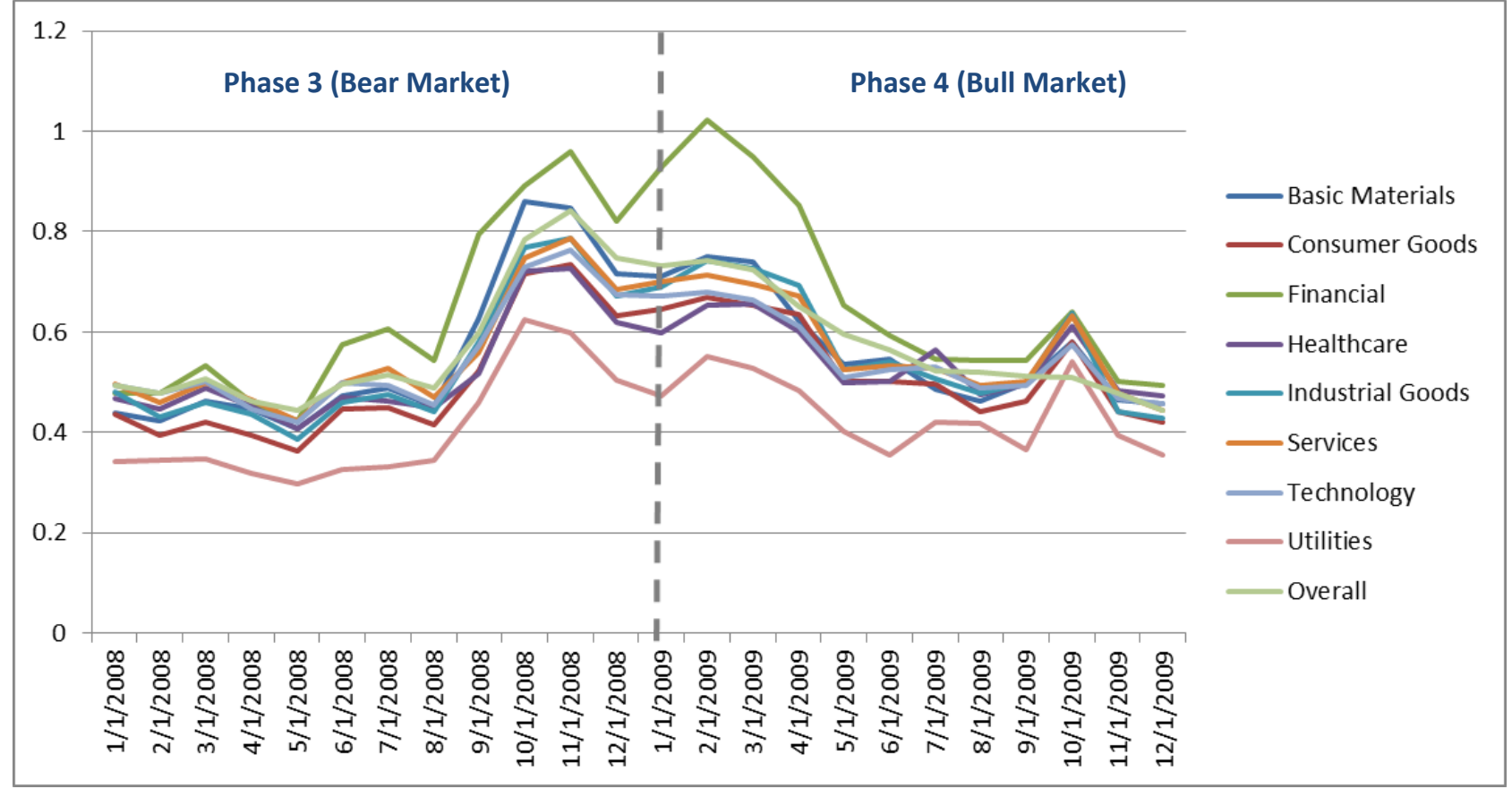


Figure 3.2: Monthly Historical Volatility Figure 3.2.a: Monthly Historical Volatility

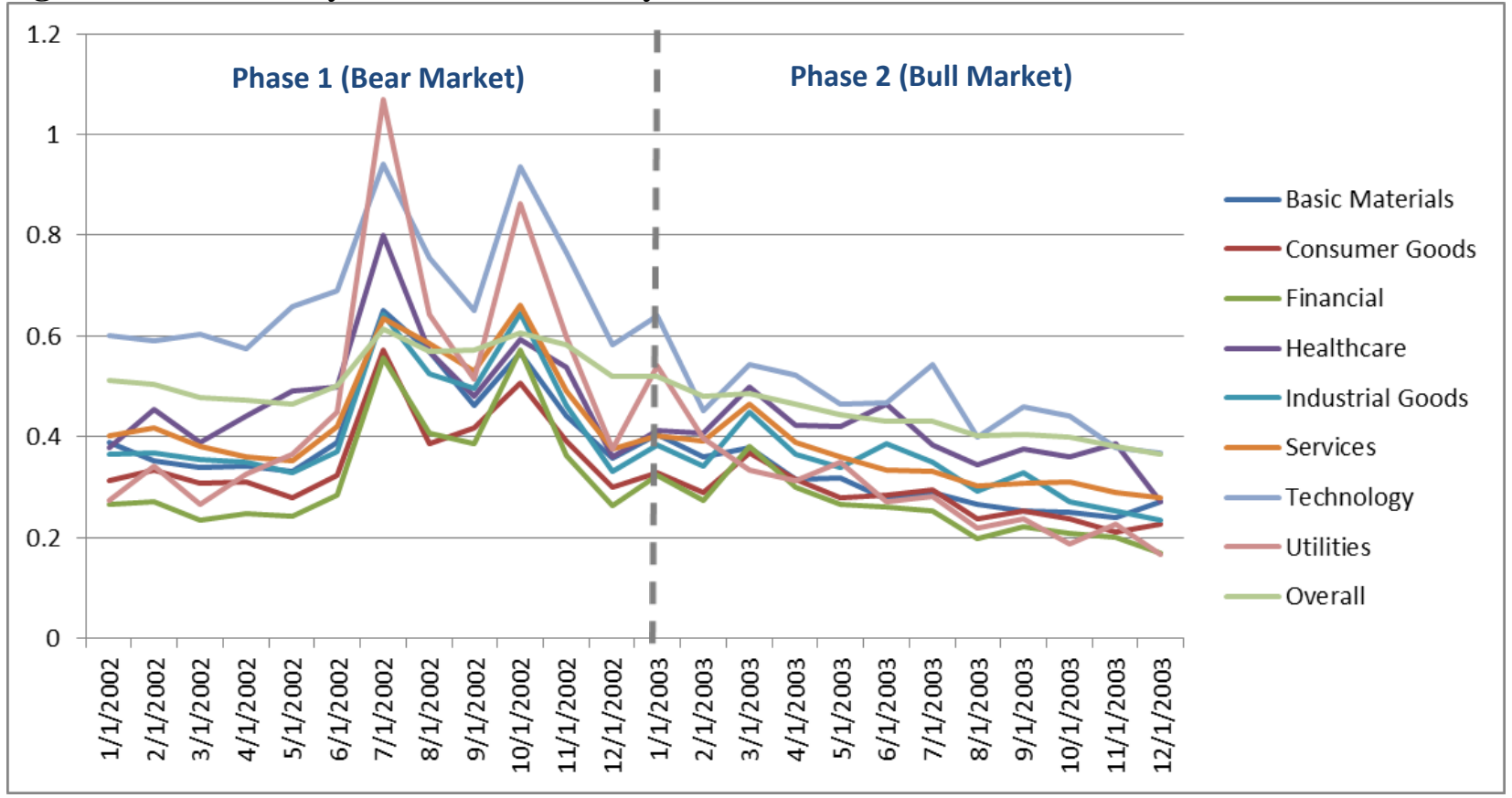

Figure 3.2.b: Monthly Historical Volatility

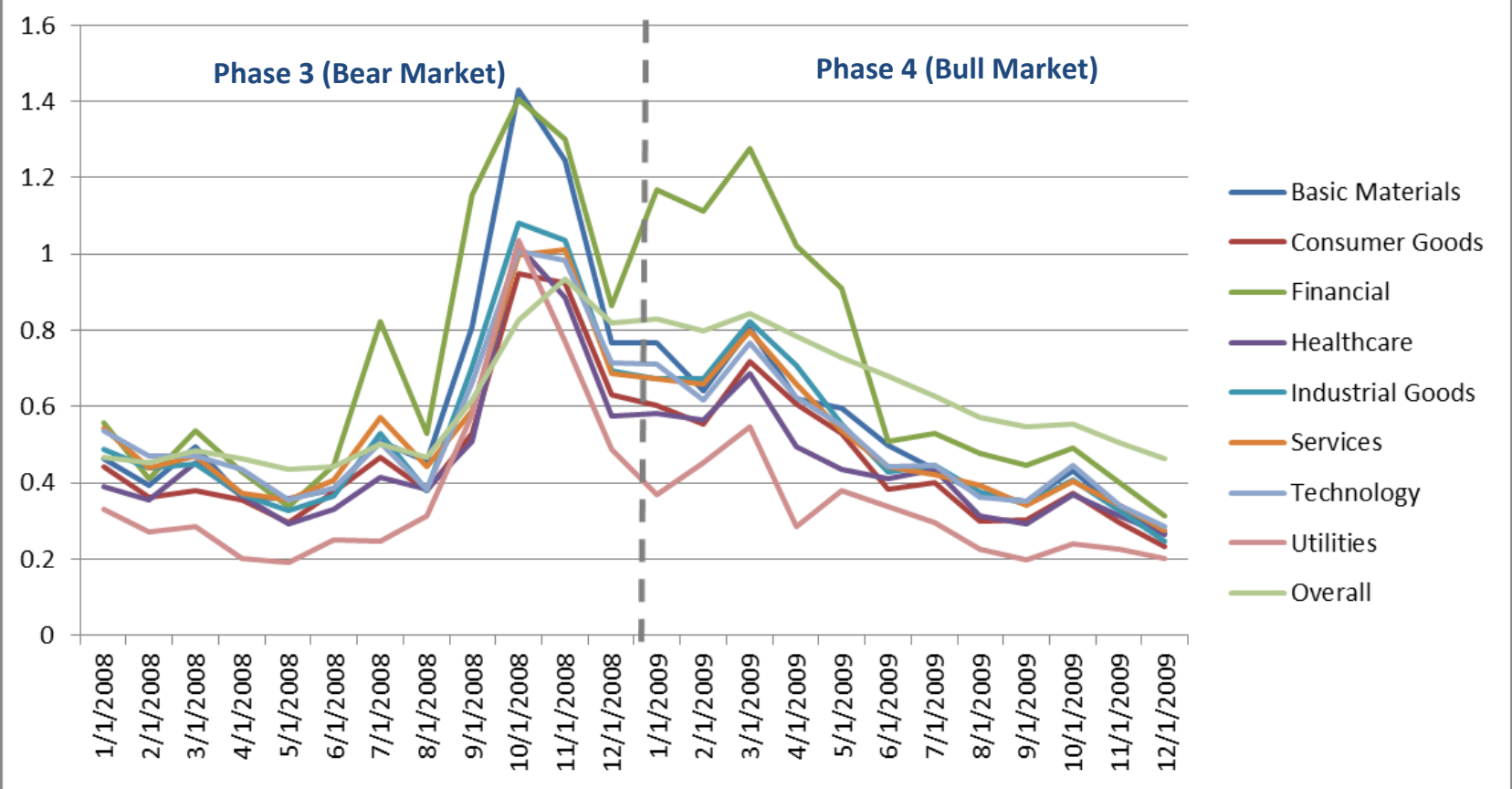




\subsubsection{Preliminary analysis}

To examine the predictive power of realized and implied volatility, we test the forecast accuracy of both. This is done by performing time series regression at firm level of historical volatility lagged one day and with one-day lag of implied volatility.

$$
R V_{j, t+1}=\alpha_{i}+\beta I V_{j, t}+\beta R V_{j, t}+\varepsilon_{j, t+1}
$$

where, $R V$ is the stacked vector of the dependent variable representing the realized volatility for each of the 596 stocks for the period January 2001 to December 2010, $\alpha$ is the constant term, $I V$ and $R V$ are vectors with the implied and realized volatility one month before for each of the 506 stocks, respectively, and $\varepsilon$ is the error term.

Table 6 shows a summary of outcomes divided into four sub periods or phases covering two Bear markets and two Bull markets (dotcom bubble and recent financial crisis) from the 596 unique regressions during the full periods. Overall, and for the most part, implied and historical volatilities in each phase have hardly been able to forecast the realized volatility in the next period. With this said however, there is evidence relating to a high percentage of firms which shows that implied volatility can forecast future realized volatility in Phase 2 which is the longest period between 2003 and 2007 in the Bull market. This finding is statistically significant at the $10 \%$ level for $72.76 \%$ of stocks or 350 regressions (average coefficient 0.493 ). However, we find that historical volatility can not forecast the future realized volatility for every sub period. Indeed, the conclusion derived from these results would not be strong due to less observations in other phases, indeed additional tests for forecasting accuracy will be performed in the next predictive regression sessions. 
Table 6 : Testing Historical vs. Implied volatility

\begin{tabular}{cccccc}
\hline Phase & Confidence level & \multicolumn{2}{c}{ Historical Volatility } & \multicolumn{2}{c}{ Implied Volatility } \\
\hline \multirow{4}{*}{ Phase 1 } & $90 \%$ & 44 & $9.1476 \%$ & 137 & $28.4823 \%$ \\
& $95 \%$ & 21 & $4.3659 \%$ & 85 & $17.6715 \%$ \\
& $99 \%$ & 2 & $0.4158 \%$ & 36 & $7.4844 \%$ \\
& Average Coefficient & & 0.034389 & & 0.449243 \\
& Median Coefficient & & 0.011002 & & 0.415327 \\
\hline \multirow{5}{*}{ Phase 2 } & $90 \%$ & 149 & $30.9771 \%$ & 350 & $72.7651 \%$ \\
& $95 \%$ & 106 & $22.0374 \%$ & 309 & $64.2412 \%$ \\
& $99 \%$ & 56 & $11.6424 \%$ & 219 & $45.5301 \%$ \\
& Average Coefficient & & 0.112348 & & 0.492740 \\
& Median Coefficient & & 0.105152 & & 0.475408 \\
\hline \multirow{5}{*}{ Phase 3 } & $90 \%$ & 90 & $18.7110 \%$ & 96 & $19.9584 \%$ \\
& $95 \%$ & 50 & $10.3950 \%$ & 74 & $15.3846 \%$ \\
& $99 \%$ & 11 & $2.2869 \%$ & 33 & $6.8607 \%$ \\
& Average Coefficient & & 0.257868 & & 0.629067 \\
& Median Coefficient & & 0.264091 & & 0.568795 \\
\hline Phase 4 & $90 \%$ & 270 & $56.1331 \%$ & 208 & $43.2432 \%$ \\
& $95 \%$ & 228 & $47.4012 \%$ & 174 & $36.1746 \%$ \\
& 99\% & 159 & $33.0561 \%$ & 106 & $22.0374 \%$ \\
& Average Coefficient & & 0.345819 & & 0.539694 \\
Median Coefficient & & 0.378074 & & 0.413986 \\
\hline
\end{tabular}

In Table 7, we extend the analysis and test the forecast accuracy of the alternative idiosyncratic volatility measures used in this paper. We compare the historical, implied and the EGARCH and AR(2) volatility forecast models, running time series regressions at firm level for the period spanning January 2001 to December 2010, which divided into four sub periods. We tackle every phases using equation 10 , where:

$$
\sigma_{R V_{i d i o, j, t+1}}=\alpha_{j}+\psi_{1, j}+\sigma_{I V_{i d i o, j, t}}+\psi_{2, j} \sigma_{E G_{i d i o, j, t}}+\psi_{3, j} \sigma_{A R i d i o, j, t}+\psi_{4, j} \sigma_{R V_{i d i o, j, t}}+\varepsilon_{j, t+1}
$$

The results presented in Table 7, are similar to those in Table 6. It is found that implied volatility is a good predictor of realized volatility in the next period (month). Indeed, only Phase 2 has statistical significance at the $10 \%$ level for $66 \%$ of stock amount, whereas historical, EGARCH and $\operatorname{AR}(2)$ volatilities have low and statistically significant or meaningless effects for every phase. In particular, due to less observations in other phases, conclusions derived from these results would not be strong, and thus we implement additional tests of forecasting accuracy later when the stock returns predictive regressions Fama and Macbeth (1973) are applied. 
Table 7: Testing alternative idiosyncratic volatility measures

\begin{tabular}{ccccccccc}
\hline \multicolumn{7}{c}{ Phase 1 } \\
\hline Confidence level & \multicolumn{1}{c}{ Historical Volatility } & \multicolumn{2}{c}{ Implied Volatility } & EGARCH Volatility & \multicolumn{2}{c}{ AR Volatility } \\
\hline $90 \%$ & 50 & $10.3950 \%$ & 122 & $25.3638 \%$ & 68 & $14.1372 \%$ & 58 & $12.0582 \%$ \\
$95 \%$ & 27 & $5.6133 \%$ & 76 & $15.8004 \%$ & 37 & $7.6923 \%$ & 34 & $7.0686 \%$ \\
$99 \%$ & 2 & $0.4158 \%$ & 33 & $6.8607 \%$ & 10 & $2.0790 \%$ & 11 & $2.2869 \%$ \\
Average & & & & & & & $\mathbf{2 . 0 4 7 2 4 3}$ & $\mathbf{6 . 5 0 3 2 4 9}$ \\
Coefficient & $\mathbf{0 . 0 0 8 4 0 2}$ & & $\mathbf{0 . 4 5 5 4 7 1}$ & & & $\mathbf{0 . 8 6 8 4 1 2}$ & $\mathbf{0 . 8 3 9 6 4 9}$ \\
Median Coefficient & $\mathbf{- 0 . 0 1 7 1 8 3}$ & $\mathbf{0 . 4 0 3 4 0 3}$ & & & &
\end{tabular}

\begin{tabular}{ccccccccc}
\hline \multicolumn{7}{c}{ Phase 2 } \\
\hline Confidence level & \multicolumn{10}{c}{ Historical Volatility } & \multicolumn{2}{c}{ Implied Volatility } & EGARCH Volatility & \multicolumn{2}{c}{ AR Volatility } \\
\hline $90 \%$ & 147 & $30.5613 \%$ & 321 & $66.7360 \%$ & 104 & $21.6216 \%$ & 72 & $14.9688 \%$ \\
$95 \%$ & 91 & $18.9189 \%$ & 269 & $55.9252 \%$ & 69 & $14.3451 \%$ & 46 & $9.5634 \%$ \\
$99 \%$ & 44 & $9.1476 \%$ & 186 & $38.6694 \%$ & 29 & $6.0291 \%$ & 15 & $3.1185 \%$ \\
Average & & & & & & & & \\
Coefficient & $\mathbf{0 . 0 9 2 2 9 7}$ & $\mathbf{0 . 4 6 6 6 7 6}$ & $\mathbf{2 . 7 2 9 9 8 9}$ & $\mathbf{- 0 . 7 6 5 9 2 5}$ \\
Median Coefficient & $\mathbf{0 . 0 8 5 8 8 5}$ & $\mathbf{0 . 4 5 1 6 1 9}$ & $\mathbf{1 . 5 8 7 9 6 6}$ & $\mathbf{- 0 . 0 0 6 3 6 0}$ \\
\hline
\end{tabular}

Phase 3

\begin{tabular}{ccrrrrrrr}
\hline Confidence level & \multicolumn{2}{c}{ Historical Volatility } & \multicolumn{2}{c}{ Implied Volatility } & EGARCH Volatility & \multicolumn{2}{c}{ AR Volatility } \\
\hline $90 \%$ & 85 & $17.6715 \%$ & 100 & $20.7900 \%$ & 65 & $13.5135 \%$ & 67 & $13.9293 \%$ \\
$95 \%$ & 41 & $8.5239 \%$ & 69 & $14.3451 \%$ & 42 & $8.7318 \%$ & 40 & $8.3160 \%$ \\
$99 \%$ & 13 & $2.7027 \%$ & 17 & $3.5343 \%$ & 9 & $1.8711 \%$ & 11 & $2.2869 \%$ \\
Average & & & & & & & \\
Coefficient & $\mathbf{0 . 2 0 8 2 2 7}$ & $\mathbf{0 . 6 2 4 0 8 0}$ & $\mathbf{1 3 . 0 6 3 0 4 6}$ & $\mathbf{- 4 . 0 8 9 4 2 4}$ \\
Median Coefficient & $\mathbf{0 . 1 7 6 1 8 6}$ & $\mathbf{0 . 5 9 1 1 2 0}$ & $\mathbf{3 . 0 5 8 6 6 4}$ & $\mathbf{- 0 . 3 8 4 7 0 4}$ \\
\hline
\end{tabular}

Phase 4

\begin{tabular}{ccccccccc}
\hline Confidence level & \multicolumn{2}{c}{ Historical Volatility } & \multicolumn{2}{c}{ Implied Volatility } & EGARCH Volatility & \multicolumn{2}{c}{ AR Volatility } \\
\hline $90 \%$ & 231 & $48.0249 \%$ & 192 & $39.9168 \%$ & 94 & $19.5426 \%$ & 76 & $15.8004 \%$ \\
$95 \%$ & 192 & $39.9168 \%$ & 142 & $29.5218 \%$ & 54 & $11.2266 \%$ & 47 & $9.7713 \%$ \\
$99 \%$ & 112 & $23.2848 \%$ & 85 & $17.6715 \%$ & 18 & $3.7422 \%$ & 15 & $3.1185 \%$ \\
Average & & & & & & & \\
Coefficient & $\mathbf{0 . 3 1 2 5 0 2}$ & $\mathbf{0 . 5 1 9 1 0 5}$ & $\mathbf{8 . 2 4 5 5 4 2}$ & $\mathbf{0 . 6 3 7 0 3 6}$ \\
Median Coefficient & $\mathbf{0 . 3 3 2 0 6 4}$ & $\mathbf{0 . 3 5 2 8 2 6}$ & $\mathbf{0 . 9 4 8 4 0 7}$ & $\mathbf{0 . 2 7 2 6 8 7}$ \\
\hline
\end{tabular}


As can be seen from the summary of variable statistics in Table 8, there are a number of volatility measures, including implied volatility $\left(\sigma_{I V}\right)$, realized volatility $\left(\sigma_{R V}\right)$, and idiosyncratic volatilities such as implied $\left(\sigma_{I V_{\text {idio }}}\right)$, realized $\left(\sigma_{R V_{\text {idio }}}\right)$, EGARCH $\left(\sigma_{E G_{\text {idio }}}\right)$, and $\operatorname{AR}(2)\left(\sigma_{A R_{\text {idio }}}\right)$ in four sub periods. These are classified into Bear and Bull markets from two financial crises, namely the dotcom bubble and the recent financial crisis between January 2001 and December 2010. We find evidence that every all volatilities are lowest in Phase 2, which is a long period Bull market from January 2003 to December 2007 before the recent financial crisis. It is implied that when the market is Bull or upward trending over a long period, stock prices mostly consist of low idiosyncratic components or are close to the real fundamental value. Additionally, the implied idiosyncratic volatility is highest among other idiosyncratic volatilities and around 50 to $60 \%$ on entire implied volatility for all phases.

Meanwhile, the book-to-market ratio (BM) tends to increase all full periods, since investors are more conservative in the long term due to a higher number of firm choices and the fact that there is no need to invest in the high price stock; in addition to this, investors may not be sure whether or not to purchase expensive stocks owing to less qualified firms. Otherwise it can be implied that most companies in the U.S. market reach the mature stage, thus leading to less of difference between Book and Market values. In the variable of Equity Beta $(\beta)$, the tendency is higher from Phase 1 to Phase 4, since stocks in the market are higher due to their effect on the increasing systematic risk as CAPM or investors turn to speculate through passive investment strategies, this causes most stocks to move in the same direction due to the increasing systematic risk of stocks and their higher moving relation to the market.

Furthermore, there is an evidence that short sale constraint (ORW_Ratio) tends to decrease in the long term from Phase 1 to 4; this most likely happens because investors speculate more in the option market and affect the option price, thus also moving ahead the stock price or the price of put - call parity moving ahead the stock price and causing $\mathrm{S}^{*}$ (which is the theoretical price computed from the call-put relation including the put of last exercise premium as Ofek, Richardson and Whitelaw (2004)) more than $S$ (which is the current stock price) or ORW Ratio $=100 \times \ln [S / S *]$ turns out to be more negative, which results from option price moving ahead of stock price. Indeed, this shows that the option market is more liquid. As a result, option interest is higher and this is an indicator that investors speculate more higher on options, thus leading to higher liquidity in the option market. 
Table 8: Summary statistics

\begin{tabular}{|c|c|c|c|c|}
\hline & \multicolumn{4}{|c|}{ Phase 1} \\
\hline Variables & Mean & Median & $5^{\text {th }}$ percentile & $95^{\text {th }}$ percentile \\
\hline Implied Volatility $\left(\sigma_{I V}\right)$ & 0.531551 & 0.486300 & 0.280340 & 0.931149 \\
\hline Realized Volatility $\left(\sigma_{R V}\right)$ & 0.488521 & 0.416417 & 0.183281 & 1.026349 \\
\hline Implied idiosyncratic volatility $\left(\sigma_{I V}\right.$ idio $)$ & 0.324692 & 0.236217 & 0.078368 & 0.866283 \\
\hline Realized idiosyncratic volatility $\left(\sigma_{R V \text { idio }}\right)$ & 0.104131 & 0.089358 & 0.039908 & 0.218325 \\
\hline EGARCH idiosyncratic volatility $\left(\sigma_{E G_{i d i o}}\right)$ & 0.096818 & 0.083222 & 0.041565 & 0.196411 \\
\hline $\operatorname{AR}(2)$ idiosyncratic volatility $\left(\sigma_{A R_{\text {idio }}}\right)$ & 0.096082 & 0.082639 & 0.043676 & 0.185482 \\
\hline Book-to-market ratio (BM) & -0.271709 & -0.490281 & -2.480661 & 2.250164 \\
\hline Equity Beta $(\beta)$ & 1.035259 & 0.854315 & 0.115710 & 2.510474 \\
\hline ORW_Ratio (ORW) & 0.031536 & -0.232299 & -1.717131 & 0.505772 \\
\hline \multirow[t]{2}{*}{ Open-Interest $(O I)$} & 4.441537 & 4.510860 & 0.000000 & 8.637034 \\
\hline & \multicolumn{4}{|c|}{ Phase 2} \\
\hline Variables & Mean & Median & $5^{\text {th }}$ percentile & $95^{\text {th }}$ percentile \\
\hline Implied Volatility $\left(\sigma_{I V}\right)$ & 0.360858 & 0.332360 & 0.201366 & 0.623243 \\
\hline Realized Volatility $\left(\sigma_{R V}\right)$ & 0.293059 & 0.255351 & 0.123832 & 0.579778 \\
\hline Implied idiosyncratic volatility $\left(\sigma_{I V}\right.$ idio $)$ & 0.149149 & 0.110375 & 0.040511 & 0.388217 \\
\hline Realized idiosyncratic volatility $\left(\sigma_{R V \text { idio }}\right)$ & 0.065831 & 0.057353 & 0.025836 & 0.133977 \\
\hline EGARCH idiosyncratic volatility $\left(\sigma_{E G_{i d i o}}\right)$ & 0.080956 & 0.072286 & 0.036263 & 0.154477 \\
\hline $\mathrm{AR}(2)$ idiosyncratic volatility $\left(\sigma_{A R_{\text {idio }}}\right)$ & 0.084517 & 0.076033 & 0.040430 & 0.155092 \\
\hline Book-to-market ratio (BM) & -0.252042 & -0.475146 & -2.295010 & 2.238256 \\
\hline Equity Beta $(\beta)$ & 1.177448 & 0.971968 & 0.104920 & 2.924964 \\
\hline ORW_Ratio (ORW) & -0.015187 & -0.029672 & -1.384019 & 0.432497 \\
\hline \multirow[t]{2}{*}{ Open-Interest $(O I)$} & 5.222747 & 5.351858 & 0.000000 & 9.246151 \\
\hline & \multicolumn{4}{|c|}{ Phase 3} \\
\hline Variables & Mean & Median & $5^{\text {th }}$ percentile & $9^{\text {th }}$ percentile \\
\hline Implied Volatility $\left(\sigma_{I V}\right)$ & 0.518071 & 0.472227 & 0.271660 & 0.918412 \\
\hline Realized Volatility $\left(\sigma_{R V}\right)$ & 0.543894 & 0.428779 & 0.201449 & 1.263246 \\
\hline Implied idiosyncratic volatility $\left(\sigma_{I V}\right.$ idio $)$ & 0.310857 & 0.222443 & 0.073635 & 0.839298 \\
\hline Realized idiosyncratic volatility $\left(\sigma_{R V_{\text {idio }}}\right)$ & 0.128099 & 0.097855 & 0.038544 & 0.334627 \\
\hline EGARCH idiosyncratic volatility $\left(\sigma_{E G_{i d i o}}\right)$ & 0.089579 & 0.078034 & 0.039194 & 0.176408 \\
\hline $\operatorname{AR}(2)$ idiosyncratic volatility $\left(\sigma_{A R_{\text {idio }}}\right)$ & 0.092276 & 0.080515 & 0.041837 & 0.169900 \\
\hline Book-to-market ratio (BM) & -0.171280 & -0.369290 & -2.455845 & 2.383829 \\
\hline Equity Beta $(\beta)$ & 1.215179 & 1.122366 & 0.352093 & 2.339395 \\
\hline ORW_Ratio $(O R W)$ & -0.344274 & -0.315325 & -2.744194 & 0.356216 \\
\hline \multirow[t]{2}{*}{ Open-Interest $(O I)$} & 5.802992 & 5.958425 & 0.693147 & 9.474948 \\
\hline & Phase 4 & & & \\
\hline Variables & Mean & Median & $5^{\text {th }}$ percentile & $95^{\text {th }}$ percentile \\
\hline Implied Volatility $\left(\sigma_{I V}\right)$ & 0.526437 & 0.491755 & 0.282407 & 0.888934 \\
\hline Realized Volatility $\left(\sigma_{R V}\right)$ & 0.432082 & 0.359857 & 0.154124 & 0.944228 \\
\hline Implied idiosyncratic volatility $\left(\sigma_{I V}\right.$ idio $)$ & 0.314330 & 0.241609 & 0.079636 & 0.788822 \\
\hline Realized idiosyncratic volatility $\left(\sigma_{R V_{\text {idio }}}\right)$ & 0.097694 & 0.079187 & 0.029161 & 0.229289 \\
\hline EGARCH idiosyncratic volatility $\left(\sigma_{E G_{i d i o}}\right)$ & 0.089877 & 0.076481 & 0.037392 & 0.184259 \\
\hline $\operatorname{AR}(2)$ idiosyncratic volatility $\left(\sigma_{A R_{\text {idio }}}\right)$ & 0.096485 & 0.080656 & 0.041594 & 0.187441 \\
\hline Book-to-market ratio (BM) & 0.109891 & -0.122105 & -2.056135 & 2.857757 \\
\hline Equity Beta $(\beta)$ & 1.231860 & 1.119788 & 0.399756 & 2.470065 \\
\hline ORW_Ratio $(O R W)$ & -1.251827 & -0.760058 & -5.355122 & 0.265308 \\
\hline Open-Interest $(O I)$ & 5.721334 & 6.054439 & 0.000000 & 9.590467 \\
\hline
\end{tabular}


As shown by the correlation matrix in Table 9, the following correlation (univariate relationships) among the independent variables used in the Fama \& Macbeth, "Risk, Return, and Equilibrium: Empirical Tests", (1973) predictive regressions can be highlighted after they are divided into four phases (Bear and Bull markets). Indeed, analysis revealed that all variables of idiosyncratic volatility have highly positive correlations with each other or that similarly unsystematic volatilities tend to learn in the same direction for all volatility models as CAPM or Fama French(1993). In particular, there is a highly negative correlation between idiosyncratic volatilities and $\log S I Z E$, which implies that larger firms have higher returns as theories than smaller firms due to lower idiosyncratic volatilities.

Additionally, $\log B M$ variables are linked to idiosyncratic volatilities with a positive effect and this indicates that high Book to Market firms (cheaper price) which have mostly lower price than theoretical price, experience higher idiosyncratic volatilities. Meanwhile, we find evidence that short sales constraints $\left(O R W_{\text {ratio }}\right)$ and liquidities $(O I)$ have no correlation with idiosyncratic volatilities. Especially, short sales constraints are slightly correlated with all variables, whereas liquidities have a positive correlation with $\log S I Z E$ and are linked to $\log B M$ with a strong negative effect. As such, the options of larger firms whichare greater in $S I Z E$ and have lower Book to Market, are more liquid than smaller firms' options for all phases (both Bear and Bull markets) examined.

Table 9: Correlation matrix

\begin{tabular}{|c|c|c|c|c|c|c|c|c|c|c|}
\hline \multicolumn{11}{|c|}{ Phase 1} \\
\hline & $\sigma_{R V_{i d i o}}$ & $\log S I Z E$ & $\log B M$ & $r_{t}$ & $\beta_{j}$ & $\sigma_{I V_{i d i o, j, t}}$ & $\sigma_{E G_{i d i o, j, t}}$ & $\sigma_{\text {AR }}$ idio, $, \mathrm{t}, t$ & ORW $W_{\text {ratio }}$ & $O I$ \\
\hline$\sigma_{R V_{i d i o}}$ & 1.000000 & & & & & & & & & \\
\hline $\log S I Z E$ & & & & & & & & & & \\
\hline & $0.335 / 82$ & 1.000000 & & & & & & & & \\
\hline $\log B M$ & 0.293447 & -0.756434 & 1.000000 & & & & & & & \\
\hline & 0.042069 & 0.005235 & 0.024967 & 1.000000 & & & & & & \\
\hline$\beta_{j}$ & 0.552285 & -0.250312 & 0.208888 & 0.003540 & 1.000000 & & & & & \\
\hline$\sigma_{I V} i d i o, j, t$ & 0.729891 & -0.382005 & 0.322742 & 0.107314 & 0.632926 & 1.000000 & & & & \\
\hline$\sigma_{E G_{i d i o, j, t}}$ & 0.536530 & -0.381054 & 0.303962 & 0.057620 & 0.469300 & 0.620011 & 1.000000 & & & \\
\hline$\sigma_{A R}$ idio, $j, t$ & 0.467605 & -0.351022 & 0.280803 & 0.049456 & 0.405397 & 0.550420 & 0.712094 & 1.000000 & & \\
\hline$O R W_{\text {ratio }}$ & $0.036215^{-}$ & 0.081919 & $0.049332^{-}$ & 0.010195 & 0.018353 & -0.059939 & -0.026468 & -0.022656 & 1.000000 & \\
\hline 01 & 0.155201 & 0.474205 & 0.332564 & 0.005421 & 0.195101 & 0.165374 & 0.112807 & 0.086332 & 0.058854 & 1.000000 \\
\hline
\end{tabular}




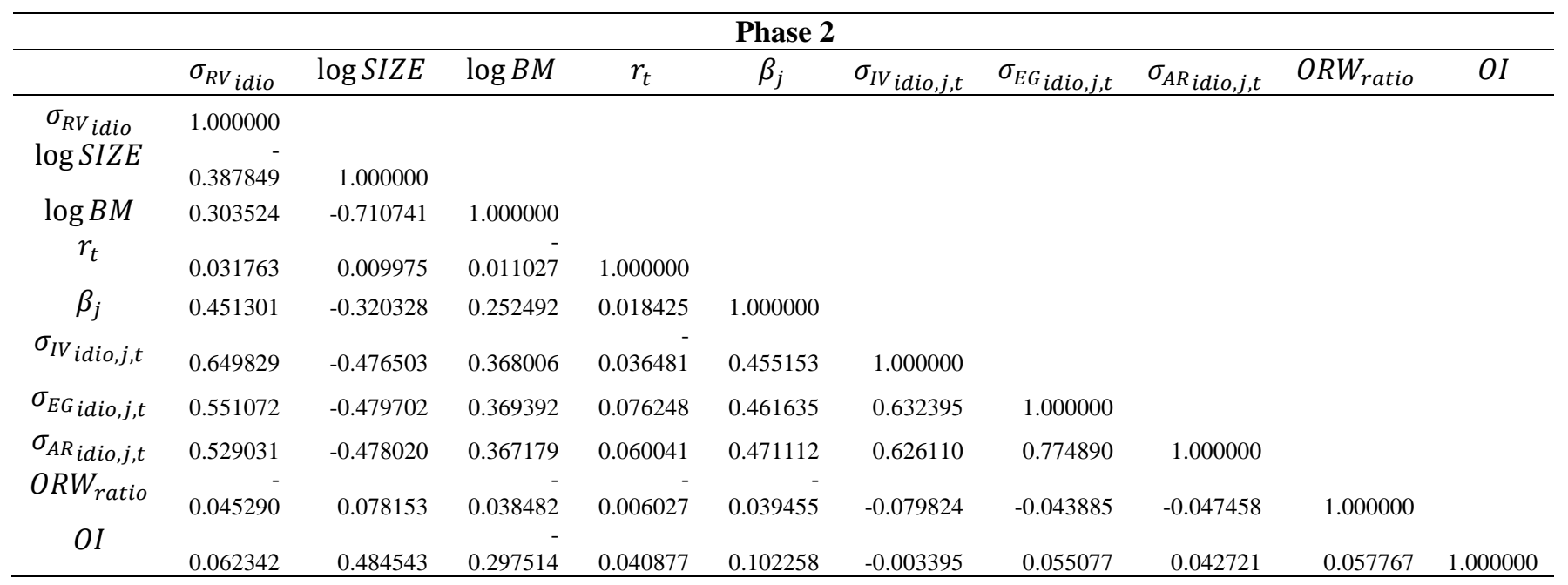

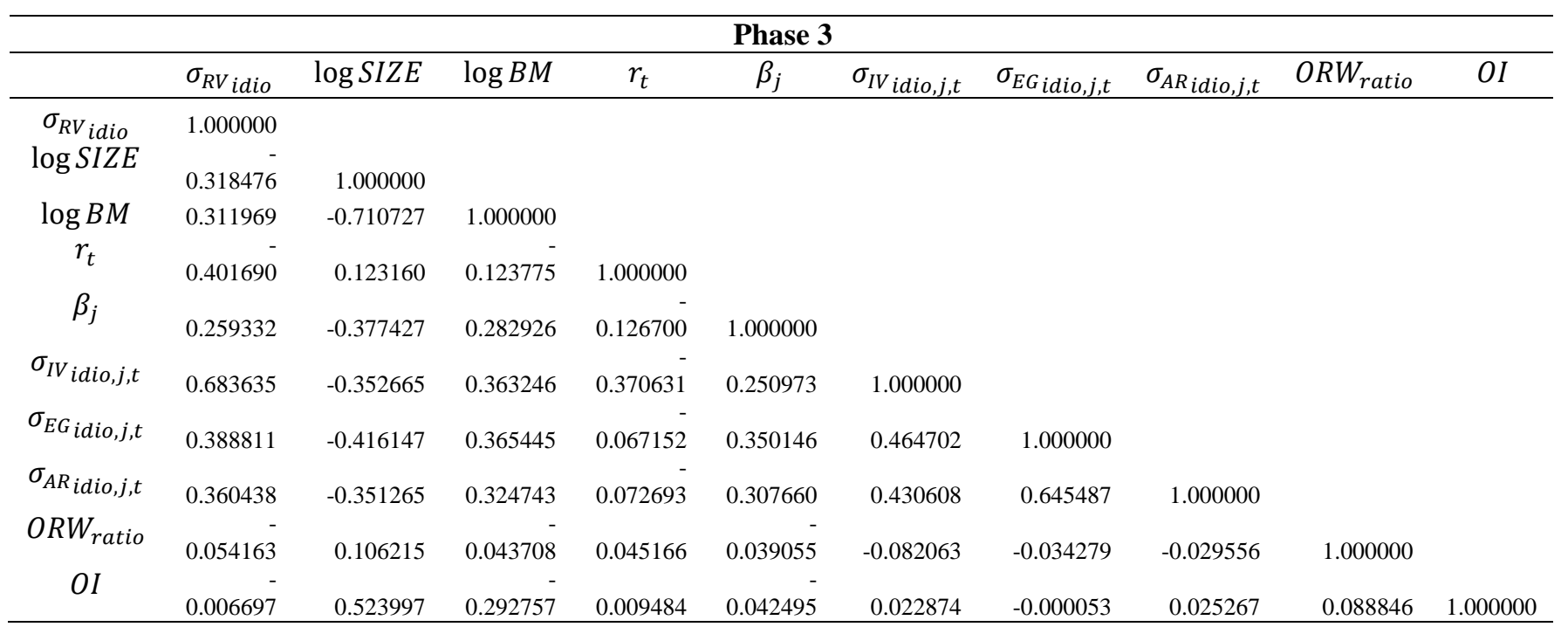

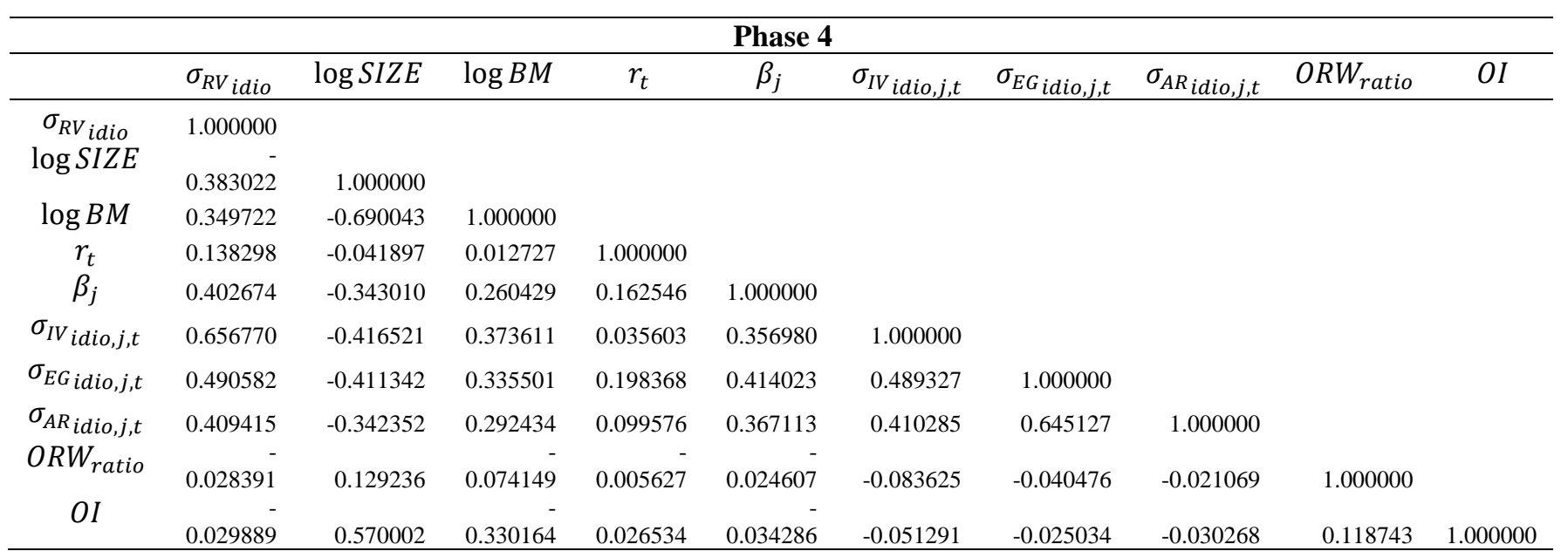




\subsubsection{Predictive regressions}

\subsubsection{Future realized volatility}

We start by examining whether implied and realized volatilities from a specific month explain the realized volatility one month ahead. We test this relationship at both market (proxied by VIX and S\&P500) and firm level. We apply equation 8 and 9, where:

$$
\sigma_{R V_{M, t+1}}=\alpha_{t}+\xi_{1} \sigma_{I V_{M, t}}+\xi_{2} \sigma_{R V_{M, t}}+\varepsilon_{j_{t+1}}
$$

and,

$$
\sigma_{R V}{ }_{j, t+1}=\alpha_{j, t}+\xi_{1, j} \sigma_{I V}{ }_{j, t}+\xi_{2, j} \sigma_{R V_{j, t}}+\varepsilon_{j, t+1}
$$

\begin{tabular}{|c|c|c|c|c|c|c|c|c|}
\hline \multicolumn{9}{|c|}{ Phase 1} \\
\hline & \multicolumn{4}{|c|}{ Panel A } & \multicolumn{4}{|c|}{ Panel B } \\
\hline & \multicolumn{4}{|c|}{ Market Estimates } & \multicolumn{4}{|c|}{ Firm-level estimates } \\
\hline \multirow[t]{2}{*}{$\sigma_{I V}$} & 0.781837 & $* *$ & 1.421075 & $* *$ & 0.962613 & $* * *$ & 0.780697 & $* * *$ \\
\hline & $(2.344392)$ & & $(2.347302)$ & & $(102.944400)$ & & $(51.861480)$ & \\
\hline \multirow[t]{2}{*}{$\sigma_{R V}$} & --- & & -0.428699 & & --- & & 0.163594 & $* * *$ \\
\hline & & & $(1.257767)$ & & & & $(15.321170)$ & \\
\hline \multirow[t]{2}{*}{ Constant } & 0.067211 & & -0.065573 & & -0.034625 & $* * *$ & -0.017846 & $* * *$ \\
\hline & $(0.365152)$ & & $(0.312212)$ & & $(6.494222)$ & & $(3.311848)$ & \\
\hline$R$-Squared & 0.207433 & & 0.265529 & & 0.489301 & & 0.499915 & \\
\hline
\end{tabular}

Table 10: Future Realized Volatility forecast

\begin{tabular}{|c|c|c|c|c|c|c|c|c|}
\hline \multicolumn{9}{|c|}{ Phase 2} \\
\hline & \multicolumn{4}{|c|}{ Panel A } & \multicolumn{4}{|c|}{ Panel B } \\
\hline & \multicolumn{4}{|c|}{ Market Estimates } & \multicolumn{4}{|c|}{ Firm-level estimates } \\
\hline \multirow[t]{2}{*}{$\sigma_{I V}$} & 0.790700 & $* * *$ & 0.842444 & $* * *$ & 0.807053 & $* * *$ & 0.663152 & $* * *$ \\
\hline & $(9.063170)$ & & $(5.274629)$ & & $(154.842700)$ & & $(90.802990)$ & \\
\hline \multirow[t]{2}{*}{$\sigma_{R V}$} & --- & & -0.058818 & & --- & & 0.168679 & $* * *$ \\
\hline & & & $(0.388002)$ & & & & $(27.757400)$ & \\
\hline \multirow[t]{2}{*}{ Constant } & 0.007289 & & 0.005845 & & 0.001032 & & 0.003527 & $*$ \\
\hline & $(0.224974)$ & & $(0.177928)$ & & $(0.512632)$ & & $(1.772907)$ & \\
\hline$R$-Squared & 0.586131 & & 0.587221 & & 0.453802 & & 0.468006 & \\
\hline
\end{tabular}

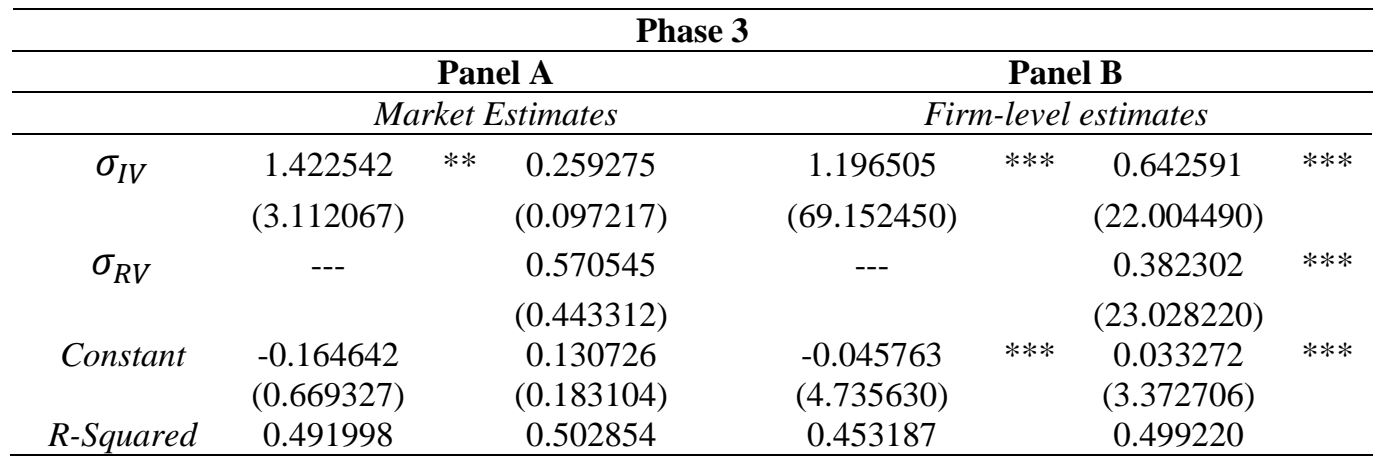




\begin{tabular}{|c|c|c|c|c|c|c|c|c|}
\hline \multicolumn{9}{|c|}{ Phase 4} \\
\hline & \multicolumn{4}{|c|}{ Panel A } & \multicolumn{4}{|c|}{ Panel B } \\
\hline & \multicolumn{3}{|c|}{ Market Estimates } & \multicolumn{5}{|c|}{ Firm-level estimates } \\
\hline$\sigma_{I V}$ & $\begin{array}{c}1.459938 \\
(9.428729)\end{array}$ & $* * *$ & $\begin{array}{c}0.836533 \\
(2.511405)\end{array}$ & $* *$ & $\begin{array}{c}1.021783 \\
(112.619100)\end{array}$ & $* * *$ & $\begin{array}{c}0.462939 \\
(38.859300)\end{array}$ & $* * *$ \\
\hline$\sigma_{R V}$ & --- & & $\begin{array}{c}0.413593 \\
(2.076705)\end{array}$ & $*$ & --- & & $\begin{array}{c}0.509561 \\
(62.347510)\end{array}$ & $* * *$ \\
\hline Constant & $\begin{array}{c}-0.357857 \\
(4.285214)\end{array}$ & $* * *$ & $\begin{array}{c}-0.207794 \\
(1.956251)\end{array}$ & $*$ & $\begin{array}{c}-0.125965 \\
(24.744030)\end{array}$ & $* * *$ & $\begin{array}{c}-0.051941 \\
(11.389500)\end{array}$ & $* * *$ \\
\hline$R$-Squared & 0.801625 & & 0.835423 & & 0.523551 & & 0.643595 & \\
\hline
\end{tabular}

$* * *, * * *$ Statistical significant for 1,5 , and 10 percent levels

Table 10 presents our results. The evidence found in panel A (Market estimates) that implied volatility is a good predictor of next period realized volatility with strong statistical significance for every phase except only Phase 3 which has less observations. These results are still aligned with Zhang and Shu (2010) who analyse the relationship between implied and realized volatility by using daily S\&P 500 index option prices over the period spanning January and December 1995. In contrast, realized volatility is meaningless when it comes to forecasting realized volatility in the next period for all phases. Moreover, at market level, the results of implied volatility for all phases support Christiansen and Prabhala (1998) findings that implied volatility is a proficient forecaster of future realized volatility, even in the presence of past realized volatility. The implied volatility coefficient diverges from one result that implied volatility is an upward biased forecaster of future realized volatility which highlights the existence of a robust volatility risk premium.

In panel B (firm-level estimates), we find that at firm level, implied and realized volatilities are strongly statistically significant predictors (at the $1 \%$ level) of future realized volatility for all phases. This is, especially evident when looking at the R-Squared shown in the model which includes realized volatility higher than excluding. Indeed, this indicates that when implied and realized volatilities are mutually employed, forecasting accuracy is higher. However, our results diverge from Bakshi and Kapadia (2003) and Stivers, Mayhew and Dennis (2006) who claim that implied volatility is an unbiased and proficient predictor of future realized volatility. In our study we find evidence that implied volatility is an upward biased forecaster of future volatility at both market and firm-level. 
We next regress the idiosyncratic volatility into its different formulations with the realized volatility one month ahead; we apply equation 10 for all phases as below:

$$
\sigma_{R V i d i o, j, t+1}=\alpha_{j}+\psi_{1, j} \sigma_{I V i d i o, j, t}+\psi_{2, j} \sigma_{E G_{i d i o, j, t}}+\psi_{3, j} \sigma_{A R i d i o, j, t}+\psi_{4, j} \sigma_{R V i d i o, j, t}+\varepsilon_{j, t+1}
$$

Table 11: Realized idiosyncratic Volatility forecast

\begin{tabular}{|c|c|c|c|c|c|c|c|c|}
\hline \multicolumn{9}{|c|}{ Phase 1} \\
\hline & \multicolumn{2}{|l|}{ Model 1} & \multicolumn{2}{|c|}{ Model 2} & \multicolumn{2}{|l|}{ Model 3} & \multicolumn{2}{|l|}{ Model 4} \\
\hline$\sigma_{I V}$ idio,j,t & $\begin{array}{c}0.572904 \\
(56.000480)\end{array}$ & $* * *$ & --- & & --- & & $\begin{array}{c}0.504026 \\
(45.240560)\end{array}$ & $* * *$ \\
\hline$\sigma_{R V_{i d i o, j, t}}$ & $\begin{array}{c}0.873904 \\
(18.549220)\end{array}$ & $* * *$ & $\begin{array}{c}2.073832 \\
(50.240610)\end{array}$ & **** & $\begin{array}{c}2.297399 \\
(57.444860)\end{array}$ & $* * *$ & $\begin{array}{c}0.760849 \\
(16.100740)\end{array}$ & $* * *$ \\
\hline$\sigma_{E G_{i d i o, j, t}}$ & --- & & $\begin{array}{c}1.412067 \\
(32.770730)\end{array}$ & $* * *$ & --- & & $\begin{array}{c}0.532370 \\
(10.279920)\end{array}$ & $* * *$ \\
\hline$\sigma_{A R}$ idio, $j, t$ & --- & & --- & & $\begin{array}{c}1.068144 \\
(26.854310)\end{array}$ & $* * *$ & $\begin{array}{c}0.150897 \\
(3.272950)\end{array}$ & $* * *$ \\
\hline Constant & $\begin{array}{c}0.200036 \\
(51.618690)\end{array}$ & $* * *$ & $\begin{array}{c}0.124390 \\
(27.162250)\end{array}$ & $* * *$ & $\begin{array}{c}0.135194 \\
(29.137450)\end{array}$ & $* * *$ & $\begin{array}{c}0.168131 \\
(38.049140)\end{array}$ & $* * *$ \\
\hline$R$-Squared & 0.491569 & & 0.405163 & & 0.387351 & & 0.501656 & \\
\hline \multicolumn{9}{|c|}{ Phase 2} \\
\hline & \multicolumn{2}{|l|}{ Model 1} & \multicolumn{2}{|c|}{ Model 2} & \multicolumn{2}{|l|}{ Model 3} & \multicolumn{2}{|l|}{ Model 4} \\
\hline$\sigma_{I V_{i d i o, j, t}}$ & $\begin{array}{c}0.624508 \\
(90.698020)\end{array}$ & $* * *$ & --- & & --- & & $\begin{array}{c}0.502710 \\
(65.544040)\end{array}$ & $* * *$ \\
\hline$\sigma_{R V_{i d i o, j, t}}$ & $\begin{array}{c}0.872257 \\
(34.391840)\end{array}$ & $* * *$ & $\begin{array}{c}1.501428 \\
(61.279330)\end{array}$ & $* * *$ & $\begin{array}{c}1.596980 \\
(65.762020)\end{array}$ & $* * *$ & $\begin{array}{c}0.654867 \\
(25.503260)\end{array}$ & $* * *$ \\
\hline$\sigma_{E G_{i d i o, j, t}}$ & --- & & $\begin{array}{c}1.455255 \\
(64.111930)\end{array}$ & $* * *$ & --- & & $\begin{array}{c}0.580922 \\
(19.806420)\end{array}$ & $* * *$ \\
\hline$\sigma_{A R_{i d i o}, j, t}$ & --- & & --- & & $\begin{array}{c}1.265207 \\
(59.942540)\end{array}$ & $* * *$ & $\begin{array}{c}0.268404 \\
(9.891467)\end{array}$ & $* * *$ \\
\hline Constant & $\begin{array}{c}0.141697 \\
(96.901990)\end{array}$ & $* * *$ & $\begin{array}{c}0.075612 \\
(41.613710)\end{array}$ & $* * *$ & $\begin{array}{c}0.080202 \\
(44.017680)\end{array}$ & $* * *$ & $\begin{array}{c}0.104461 \\
(57.670400)\end{array}$ & $* * *$ \\
\hline$R$-Squared & 0.446765 & & 0.377696 & & 0.367777 & & 0.468091 & \\
\hline \multicolumn{9}{|c|}{ Phase 3} \\
\hline & \multicolumn{2}{|l|}{ Model 1} & \multicolumn{2}{|l|}{ Model 2} & \multicolumn{2}{|l|}{ Model 3} & \multicolumn{2}{|c|}{ Model 4} \\
\hline$\sigma_{I V}$ idio,j,t & $\begin{array}{c}0.446582 \\
(27.675490)\end{array}$ & $* * *$ & --- & & --- & & $\begin{array}{c}0.393634 \\
(23.308770)\end{array}$ & $* * *$ \\
\hline$\sigma_{R V}$ idio,j,t & $\begin{array}{c}1.550368 \\
(31.479530)\end{array}$ & $* * *$ & $\begin{array}{c}2.225497 \\
(54.811380)\end{array}$ & $* * *$ & $\begin{array}{c}2.272649 \\
(56.404670)\end{array}$ & $* * *$ & $\begin{array}{c}1.492521 \\
(30.333490)\end{array}$ & $* * *$ \\
\hline$\sigma_{E G_{i d i o, j, t}}$ & --- & & $\begin{array}{c}1.234816 \\
(16.258970)\end{array}$ & $* * *$ & --- & & $\begin{array}{c}0.526031 \\
(5.786933)\end{array}$ & $* * *$ \\
\hline$\sigma_{A R} i d i o, j, t$ & --- & & --- & & $\begin{array}{c}0.921802 \\
(14.427510)\end{array}$ & $* * *$ & $\begin{array}{c}0.259472 \\
(3.435549)\end{array}$ & $* * *$ \\
\hline Constant & $\begin{array}{c}0.236688 \\
(40.674380)\end{array}$ & $* * *$ & $\begin{array}{c}0.178414 \\
(23.227730)\end{array}$ & $* * *$ & $\begin{array}{c}0.197927 \\
(27.247730)\end{array}$ & $* * *$ & $\begin{array}{c}0.189493 \\
(25.242050)\end{array}$ & $* * *$ \\
\hline$R$-Squared & 0.489641 & & 0.447213 & & 0.442015 & & 0.498065 & \\
\hline
\end{tabular}




\begin{tabular}{|c|c|c|c|c|c|c|c|c|}
\hline \multicolumn{9}{|c|}{ Phase 4} \\
\hline & \multicolumn{2}{|c|}{ Model 1} & \multicolumn{2}{|l|}{ Model 2} & \multicolumn{2}{|l|}{ Model 3} & \multicolumn{2}{|l|}{ Model 4} \\
\hline$\sigma_{I V}$ idio,j,t & $\begin{array}{c}0.478751 \\
(59.845630)\end{array}$ & $* * *$ & --- & & --- & & $\begin{array}{c}0.449392 \\
(54.574980)\end{array}$ & $* * *$ \\
\hline$\sigma_{R V_{i d i o, j, t}}$ & $\begin{array}{c}1.515019 \\
(51.118960)\end{array}$ & $* * *$ & $\begin{array}{c}2.333792 \\
(81.559390)\end{array}$ & $* * *$ & $\begin{array}{c}2.456548 \\
(89.079370)\end{array}$ & $* * *$ & $\begin{array}{c}1.405566 \\
(46.053200)\end{array}$ & $* * *$ \\
\hline$\sigma_{E G_{i d i o, j, t}}$ & --- & & $\begin{array}{c}0.888353 \\
(24.655490)\end{array}$ & $* * *$ & --- & & $\begin{array}{c}0.339361 \\
(8.650755)\end{array}$ & $* * *$ \\
\hline$\sigma_{A R} i d i o, j, t$ & --- & & --- & & $\begin{array}{c}0.485259 \\
(19.782410)\end{array}$ & $* * *$ & $\begin{array}{c}0.105746 \\
(4.042883)\end{array}$ & $* * *$ \\
\hline Constant & $\begin{array}{c}0.113446 \\
(40.909300)\end{array}$ & $* * *$ & $\begin{array}{c}0.104101 \\
(29.338530)\end{array}$ & $* * *$ & $\begin{array}{c}0.125130 \\
(37.958430)\end{array}$ & $* * *$ & $\begin{array}{c}0.092664 \\
(29.242130)\end{array}$ & $* * *$ \\
\hline$R$-Squared & 0.608795 & & 0.513042 & & 0.504205 & & 0.614812 & \\
\hline
\end{tabular}

$* * *, * *, *$ Statistical significant for 1,5 , and 10 percent levels

Table 11 reports the results. After examining on all models, it is clear that the results from all phases are similar to all types of idiosyncratic volatilities, namely are implied, realized, EGARCH, and $\operatorname{AR}(2)$. These can be predictors and have strong statistically significant effects at the $1 \%$ level with future realized idiosyncratic volatility. Furthermore, $R$-Squared values from every model are similar for all phases. Model 4 has the highest R-Squared, while Model 1, 2, and 3 are lower respectively. This is evidence that for every sub period, the most accurate forecasting measures of idiosyncratic volatility are all implied, realized, EGARCH, and AR Additionally, implied and realized idiosyncratic volatility predictors are more precise than realized and EGARCH idiosyncratic volatility measures. Lastly, realized and AR idiosyncratic volatilities are the least accurate measure.

\subsubsection{Realized returns}

In the following step we analyse in Table 12 the predicting power of realized idiosyncratic volatility, other firm-specific characteristics and previous firm returns for all phases. We achieve this by applying monthly cross-sectional regressions using (Fama \& Macbeth, "Risk, Return, and Equilibrium: Empirical Tests", 1973). As previously referred the variables SIZE and B/M ratio are calculated at the end of each month and the return variables are lagged 1, 11 and 36 months. 
Table 12: Fama-Macbeth Future returns estimation

$$
r_{j, t+1}=\alpha_{j}+\lambda_{1} \sigma_{R V_{i d i o, j, t}}+\lambda_{2} \log S I Z E_{j, t}+\lambda_{3} \log B M_{j, t}+\lambda_{4} r_{j, t}+\lambda_{5} r_{j, t-11: t-1}+\lambda_{6} r_{j, t-35: t-12}+\lambda_{7} \beta_{j, t}+\varepsilon_{j, t+1}
$$

\begin{tabular}{|c|c|c|c|c|c|c|c|c|}
\hline \multirow{2}{*}{$\begin{array}{c}\text { Variables } \\
\sigma_{R V_{\text {idio }}}\end{array}$} & \multicolumn{2}{|c|}{ Phase 1} & \multicolumn{2}{|c|}{ Phase 2} & \multicolumn{2}{|c|}{ Phase 3} & \multicolumn{2}{|l|}{ Phase 4} \\
\hline & $\begin{array}{c}0.291920 \\
(10.132080)\end{array}$ & $* * *$ & $\begin{array}{c}0.168545 \\
(9.858261)\end{array}$ & $* * *$ & $\begin{array}{c}-0.127858 \\
(5.288850)\end{array}$ & $* * *$ & $\begin{array}{c}0.189341 \\
(9.141333)\end{array}$ & $* * *$ \\
\hline $\log S I Z E$ & $\begin{array}{l}-0.005992 \\
(4.268441)\end{array}$ & $* * *$ & $\begin{array}{c}-0.000994 \\
(1.844362)\end{array}$ & $*$ & $\begin{array}{c}-0.001928 \\
(1.030843)\end{array}$ & & $\begin{array}{l}-0.004765 \\
(4.154561)\end{array}$ & $* * *$ \\
\hline $\log B M$ & $\begin{array}{c}0.000729 \\
(0.506018)\end{array}$ & & $\begin{array}{c}0.001870 \\
(3.470189)\end{array}$ & $* * *$ & $\begin{array}{c}0.003691 \\
(1.942716)\end{array}$ & $*$ & $\begin{array}{c}0.000835 \\
(0.723582)\end{array}$ & \\
\hline$r_{t}$ & $\begin{array}{l}-0.050759 \\
(5.560232)\end{array}$ & $* * *$ & $\begin{array}{c}0.027218 \\
(4.674157)\end{array}$ & $* * *$ & $\begin{array}{c}0.071918 \\
(4.504718)\end{array}$ & $* * *$ & $\begin{array}{c}0.007004 \\
(0.786936)\end{array}$ & \\
\hline$r_{j, t-11: t-1}$ & $\begin{array}{c}0.023106 \\
(3.049270)\end{array}$ & $* * *$ & $\begin{array}{c}-0.044020 \\
(8.590745)\end{array}$ & $* * *$ & $\begin{array}{c}0.029384 \\
(1.179529)\end{array}$ & & $\begin{array}{c}0.094323 \\
(12.154550)\end{array}$ & $* * *$ \\
\hline$r_{j, t-35: t-12}$ & $\begin{array}{c}0.043225 \\
(4.939103)\end{array}$ & $* * *$ & $\begin{array}{c}-0.006195 \\
(1.684910)\end{array}$ & $*$ & $\begin{array}{c}0.045947 \\
(1.953752)\end{array}$ & $*$ & $\begin{array}{c}-0.069414 \\
(4.470857)\end{array}$ & $* * *$ \\
\hline$\beta_{j}$ & $\begin{array}{c}-0.026065 \\
(11.314260)\end{array}$ & $* * *$ & $\begin{array}{l}-0.002223 \\
(3.131686)\end{array}$ & $* * *$ & $\begin{array}{c}0.007454 \\
(2.127991)\end{array}$ & $* *$ & $\begin{array}{c}0.010630 \\
(4.672868)\end{array}$ & $* * *$ \\
\hline Constant & $\begin{array}{c}0.083783 \\
(3.823555)\end{array}$ & $* * *$ & $\begin{array}{c}0.021985 \\
(2.524333)\end{array}$ & $* *$ & $\begin{array}{c}0.006373 \\
(0.207829)\end{array}$ & & $\begin{array}{c}0.071702 \\
(3.821571)\end{array}$ & $* * *$ \\
\hline$R$-Squared & 0.024769 & & 0.010528 & & 0.015199 & & 0.040853 & \\
\hline
\end{tabular}

$* * *, * *, *$ Statistical significant for 1,5 , and 10 percent levels

According to the results reported in Table 12, realized idiosyncratic volatility has a statistical significance at the $1 \%$ level with future stock returns for all phases. In particular, it has a negative effect during Phase 3 and positive effects during Phase 1, 2, and 4. If realized idiosyncratic volatility is higher, the stock return will be further away from the fundamental price as CAPM. These results show that Phase 1, which is a Bear market with positive effect of realized idiosyncratic volatility, presents a lower idiosyncratic part that becomes steady following the market's downward slope. In contrast a positive effect in Phase 2, which is the Bull market, represents an upward market with an increasing idiosyncratic part or an event which investors chase to buy stocks; indeed, this results in a higher stock price compared with fundamental price as CAPM. After this, the next cycle of the recent financial crisis occurs in Phase 3 which is a Bear market with a negative effect. Following this, the idiosyncratic range continues to increase, even though the market is downward. This shows that investors hurry to sell their stocks, and then stock prices decline substantially, much more so than fundamental prices as CAPM. Finally, after the recent crisis, the market again turns to Bull in Phase 4 with a positive effect; as such, the idiosyncratic part is increasing again in an upward market, or investors hurry to buy stocks until these stock prices are higher than the fundamental CAPM prices at the end. 
As previously stated, the variables SIZE and B/M ratio are calculated at the end of each month, and the return variables are lagged 1, 11 and 36 months. We find that Size has a $1 \%$ statistical significance in terms of its effect on future stock returns for Phase 1 and 4, which are Bull markets. In contrast, Phase 2 shows a negative statistically significant effect at $10 \%$ level. This is evidence that when stocks are overvalued, then these stocks are larger and the returns in the next period decrease due to replacement and speculation from investors that stock prices will decline.. More specifically, this type of investor behaviour happens in Phase 1 and 4. Meanwhile, B/M ratio has a statistical significance at the $1 \%$ level for only Phase 2, which is a long term Bull market, and at 10 $\%$ level in Phase 3. This shows that investors try to hurry into the Bull market to buy higher B/M ratio stocks which are also cheaper. Furthermore, the equity beta can serve as a forecasting measure of future stock returns as well as for the dotcom crisis in Phase 1 and 2 with negative effects at $1 \%$ statistical significance and the recent financial crisis of Phase 3 and 4 with positive coefficients at the 5 and $1 \%$ levels respectively. It is highly probable that investment characteristic turns from less passive management in Phase 1 and 2 to higher passive management in Phase 3 and 4 . As a result of this, beta direction is changed and market movement is also turned and related to systematic risk in positive terms.

Table 13 reports on our analysis, which is divided into four sub periods. This is achieved by applying monthly cross-sectional regressions using Fama-Macbeth (1973) as equation 12 with different combinations for the independent variables (models 1 to 10). The results present an overall of variable statistics, and show that there is a statistical significance in a number of variables from entire models for only certain phases. More specifically, there are both highly positive and negative statistical significances that appear in these sub periods. Moreover, these are related and contribute to the Chow test results. Said results indicate that when each model is examined and divided into sub periods among assigned breakpoints, coefficients differ between positive and negative during those sub periods. As a result, evidence has emerged to indicate that there exist different variable relations in sub periods (embedded in the summary outcome in Table 12) Indeed, Table 12 is tested for the full period in previous studies, which is not totally complete. This leads to further analysis, as they are broken down into sub periods in this paper. Additionally, we enlarge three groups of the highlighted results so as to show the effects of the forecast model on future stock returns for all sub periods compared with the full period, such as a group of implied, realized, EGARCH and AR(2) idiosyncratic volatilities $\left(\sigma_{I V}\right.$ idio $\left., \sigma_{R V_{i d i o}}, \sigma_{E G_{i d i o}}, \sigma_{A R i d i o}\right)$ in table 14 , the short-sales constraint and open-interest variables $\left(O R W_{\text {ratio }}, O I\right)$ in table 15, and cross-section firm-specific characteristics 
for a couple of variables $(\log S I Z E, \log B M)$ in table 16 respectively.

Table 13: Fama-Macbeth future returns estimation with firm-specific characteristics

$$
\begin{aligned}
r_{j, t+1}=\alpha_{j}+ & \lambda_{1} \sigma_{R V_{\text {idio }, j, t}}+\lambda_{2} \log S I Z E_{j, t}+\lambda_{3} \log B M_{j, t}+\lambda_{4} r_{j, t}+\lambda_{5} r_{j, t-11: t-1}+\lambda_{6} r_{j, t-35: t-12}+\lambda_{7} \beta_{j, t}+ \\
& +\lambda_{8} \sigma_{I V} V_{\text {idio }, j, t}+\lambda_{9} \sigma_{E G_{\text {idio } j, t}}+\lambda_{10} \sigma_{A R 2} \text { idio }, j, t+\lambda_{11} O R W_{\text {ratio }_{j, t}}+\lambda_{12} O I_{j, t}+\varepsilon_{j, t+1}
\end{aligned}
$$




\begin{tabular}{|c|c|c|c|c|c|c|c|c|c|c|}
\hline \multicolumn{11}{|c|}{ Phase 1} \\
\hline Variables & Model 1 & Model 2 & Model 3 & Model 4 & Model 5 & Model 6 & Model 7 & Model 8 & Model 9 & Model 10 \\
\hline$\sigma_{R V_{i d i o, j, t}}$ & --- & --- & $\begin{array}{l}0.291920 * * * \\
(10.132080)\end{array}$ & --- & $\begin{array}{l}0.205231 * * * \\
(5.924928)\end{array}$ & $\begin{array}{l}0.346996 * * * \\
(11.379150)\end{array}$ & $\begin{array}{l}0.330026 * * * \\
(11.029950)\end{array}$ & $\begin{array}{l}0.237842 * * * \\
(6.833052)\end{array}$ & $\begin{array}{l}0.211890 * * * \\
(6.084883)\end{array}$ & $\begin{array}{l}0.218440 * * * \\
(6.291719)\end{array}$ \\
\hline $\log S I Z E$ & $\begin{array}{l}-0.006333 * * * \\
(4.566421)\end{array}$ & $\begin{array}{l}-0.007799 * * * \\
-(5.575965)\end{array}$ & $\begin{array}{l}-0.005992 * * * \\
(4.268441)\end{array}$ & $\begin{array}{l}-0.005476 * * * \\
(3.869415)\end{array}$ & $\begin{array}{l}-0.005187 * * * \\
(3.668969)\end{array}$ & $\begin{array}{l}-0.007292 * * * \\
(5.127706)\end{array}$ & $\begin{array}{l}-0.006993 * * * \\
(4.928729)\end{array}$ & $\begin{array}{l}-0.006800 * * * \\
(4.771048)\end{array}$ & $\begin{array}{l}-0.003791 * * \\
(2.360036)\end{array}$ & --- \\
\hline $\log B M$ & $\begin{array}{l}0.001212 \\
(0.837813)\end{array}$ & $\begin{array}{l}0.001529 \\
(1.058501)\end{array}$ & $\begin{array}{l}0.000729 \\
(0.506018)\end{array}$ & $\begin{array}{l}0.000950 \\
(0.659420)\end{array}$ & $\begin{array}{l}0.000632 \\
(0.439171)\end{array}$ & $\begin{array}{l}0.000718 \\
(0.498940)\end{array}$ & $\begin{array}{l}0.000743 \\
(0.516558)\end{array}$ & $\begin{array}{l}0.000570 \\
(0.397289)\end{array}$ & $\begin{array}{l}0.000738 \\
(0.512926)\end{array}$ & $\begin{array}{l}0.002932 * * * \\
(2.668525)\end{array}$ \\
\hline$r_{t}$ & $\begin{array}{l}-0.054854 * * * \\
(5.974814)\end{array}$ & $\begin{array}{l}-0.055188 * * * \\
-(6.024664)\end{array}$ & $\begin{array}{l}-0.050759 * * * \\
(5.560232)\end{array}$ & $\begin{array}{l}-0.042951 * * * \\
(4.659656)\end{array}$ & $\begin{array}{l}-0.045011 * * * \\
(4.887134)\end{array}$ & $\begin{array}{l}-0.046134 * * * \\
(5.038460)\end{array}$ & $\begin{array}{l}-0.047552 * * * \\
(5.199112)\end{array}$ & $\begin{array}{l}-0.034176 * * * \\
(3.678409)\end{array}$ & $\begin{array}{l}-0.044334 * * * \\
(4.810354)\end{array}$ & $\begin{array}{l}-0.043081 * * * \\
(4.681179)\end{array}$ \\
\hline$r_{j, t-11: t-1}$ & $\begin{array}{l}0.025825 * * * \\
(3.386796)\end{array}$ & $\begin{array}{l}0.024160 * * * \\
(3.174169)\end{array}$ & $\begin{array}{l}0.023106 * * * \\
(3.049270)\end{array}$ & $\begin{array}{l}0.021349 * * * \\
(2.813534)\end{array}$ & $\begin{array}{l}0.021796 * * * \\
(2.876775)\end{array}$ & $\begin{array}{l}0.023615^{* * * *} \\
(3.120307)\end{array}$ & $\begin{array}{l}0.023566^{* * *} \\
(3.112579)\end{array}$ & $\begin{array}{l}0.021858 * * * \\
(2.892598)\end{array}$ & $\begin{array}{l}0.022240 * * * \\
(2.935031)\end{array}$ & $\begin{array}{l}0.022646 * * * \\
(2.988718)\end{array}$ \\
\hline$r_{j, t-35: t-12}$ & $\begin{array}{l}0.031677 * * * \\
(3.669388)\end{array}$ & $\begin{array}{l}0.044267 * * * \\
(5.035380)\end{array}$ & $\begin{array}{l}0.043225 * * * \\
(4.939103)\end{array}$ & $\begin{array}{l}0.044142 * * * \\
(5.040896)\end{array}$ & $\begin{array}{l}0.043462 * * * \\
(4.970486)\end{array}$ & $\begin{array}{l}0.042301 * * * \\
(4.838887)\end{array}$ & $\begin{array}{l}0.042116^{* * *} \\
(4.815085)\end{array}$ & $\begin{array}{l}0.041825 * * * \\
(4.794095)\end{array}$ & $\begin{array}{l}0.043317 * * * \\
(4.953963)\end{array}$ & $\begin{array}{l}0.042722 * * * \\
(4.886971)\end{array}$ \\
\hline$\beta_{j}$ & --- & $\begin{array}{l}-0.014299 * * * \\
-(7.153939)\end{array}$ & $\begin{array}{l}-0.026065 * * * \\
(11.314260)\end{array}$ & $\begin{array}{l}-0.028151 * * * \\
(11.350170)\end{array}$ & $\begin{array}{l}-0.030567 * * * \\
(12.179150)\end{array}$ & $\begin{array}{l}-0.023065 * * * \\
(9.750653)\end{array}$ & $\begin{array}{l}-0.024019 * * * \\
(10.251820)\end{array}$ & $\begin{array}{l}-0.028676 * * * \\
(11.400560)\end{array}$ & $\begin{array}{l}-0.029906^{* * *} \\
(11.807820)\end{array}$ & $\begin{array}{l}-0.029493 * * * \\
(11.670100)\end{array}$ \\
\hline$\sigma_{I V_{i d i o, j, t}}$ & --- & --- & --- & $\begin{array}{l}0.064703 * * * \\
(9.365323)\end{array}$ & $\begin{array}{l}0.037350 * * * \\
(4.499655)\end{array}$ & --- & --- & $\begin{array}{l}0.060546 * * * \\
(6.880003)\end{array}$ & $\begin{array}{l}0.039230 * * * \\
(4.644812)\end{array}$ & $\begin{array}{l}0.043071 * * * \\
(5.195970)\end{array}$ \\
\hline$\sigma_{E G_{i d i o, j, t}}$ & --- & --- & --- & --- & --- & $\begin{array}{l}-0.167107 * * * \\
(5.454972)\end{array}$ & --- & $\begin{array}{l}-0.180006 * * * \\
(4.723379)\end{array}$ & --- & --- \\
\hline$\sigma_{A R i d i o, j, t}$ & --- & --- & --- & --- & --- & --- & $\begin{array}{l}-0.127876^{* * *} \\
(4.665243)\end{array}$ & $\begin{array}{l}-0.091022 * * * \\
(2.706575)\end{array}$ & --- & --- \\
\hline$O R W_{\text {ratio }}$ & --- & --- & --- & --- & --- & --- & --- & --- & $\begin{array}{l}-0.000425 * \\
(1.777338)\end{array}$ & $\begin{array}{l}-0.000446 * \\
(1.865765)\end{array}$ \\
\hline$O I$ & --- & --- & --- & --- & --- & --- & --- & --- & $\begin{array}{l}-0.001128 \\
(1.635540)\end{array}$ & $\begin{array}{l}-0.001896 * * * \\
(3.117237)\end{array}$ \\
\hline Constant & $\begin{array}{l}0.092784 * * * \\
(4.428626)\end{array}$ & $\begin{array}{l}0.129807 * * * \\
(6.027836)\end{array}$ & $\begin{array}{l}0.083783 * * * \\
(3.823555)\end{array}$ & $\begin{array}{l}0.087501 * * * \\
(3.991622)\end{array}$ & $\begin{array}{l}0.073029 * * * \\
(3.316006)\end{array}$ & $\begin{array}{l}0.110987 * * * \\
(4.944884)\end{array}$ & $\begin{array}{l}0.105294 * * * \\
(4.706481)\end{array}$ & $\begin{array}{l}0.110967 * * * \\
(4.930951)\end{array}$ & $\begin{array}{l}0.054742 * * \\
(2.270611)\end{array}$ & $\begin{array}{l}-0.001536 \\
(0.432756)\end{array}$ \\
\hline
\end{tabular}




\begin{tabular}{|c|c|c|c|c|c|c|c|c|c|c|}
\hline \multicolumn{11}{|c|}{ Phase 2} \\
\hline Variables & Model 1 & Model 2 & Model 3 & Model 4 & Model 5 & Model 6 & Model 7 & Model 8 & Model 9 & Model 10 \\
\hline$\sigma_{R V i d i o, j, t}$ & --- & --- & $\begin{array}{l}0.168545^{* * *} \\
(9.858261)\end{array}$ & --- & $\begin{array}{l}0.048465 * * \\
(2.447680)\end{array}$ & $\begin{array}{l}0.124883 * * * \\
(6.818701)\end{array}$ & $\begin{array}{l}0.144164 * * * \\
(7.974071)\end{array}$ & $\begin{array}{l}0.040702 * * \\
(2.024659)\end{array}$ & $\begin{array}{l}0.060062 * * * \\
(3.007447)\end{array}$ & $\begin{array}{l}0.053582 * * * \\
(2.701313)\end{array}$ \\
\hline $\log S I Z E$ & $\begin{array}{l}-0.002085 * * * \\
(4.024005)\end{array}$ & $\begin{array}{l}-0.002021 * * * \\
(3.814836)\end{array}$ & $\begin{array}{l}-0.000994 * \\
(1.844362)\end{array}$ & $\begin{array}{l}0.000272 \\
(0.496900)\end{array}$ & $\begin{array}{l}0.000351 \\
(0.639686)\end{array}$ & $\begin{array}{l}-0.000172 \\
(0.312069)\end{array}$ & $\begin{array}{l}-0.000477 \\
(0.862624)\end{array}$ & $\begin{array}{l}0.000516 \\
(0.924077)\end{array}$ & $\begin{array}{l}0.001761 * * * \\
(2.765191)\end{array}$ & --- \\
\hline $\log B M$ & $\begin{array}{l}0.002048 * * * \\
(3.799296)\end{array}$ & $\begin{array}{l}0.002036 * * * \\
(3.774618)\end{array}$ & $\begin{array}{l}0.001870 * * * \\
(3.470189)\end{array}$ & $\begin{array}{l}0.001741 * * * \\
(3.239065)\end{array}$ & $\begin{array}{l}0.001721 * * * \\
(3.201688)\end{array}$ & $\begin{array}{l}0.001778 * * * \\
(3.300654)\end{array}$ & $\begin{array}{l}0.001816 * * * \\
(3.370267)\end{array}$ & $\begin{array}{l}0.001701 * * * \\
(3.162711)\end{array}$ & $\begin{array}{l}0.001870 * * * \\
(3.471454)\end{array}$ & $\begin{array}{l}0.000992 * * \\
(2.279644)\end{array}$ \\
\hline$r_{t}$ & $\begin{array}{l}0.029187 * * * \\
(5.008131)\end{array}$ & $\begin{array}{l}0.029103 * * * \\
(4.992225)\end{array}$ & $\begin{array}{l}0.027218 * * * \\
(4.674157)\end{array}$ & $\begin{array}{l}0.033497 * * * \\
(5.762026)\end{array}$ & $\begin{array}{l}0.032540 * * * \\
(5.585377)\end{array}$ & $\begin{array}{l}0.023954 * * * \\
(4.101939)\end{array}$ & $\begin{array}{l}0.025716^{* * * *} \\
(4.408810)\end{array}$ & $\begin{array}{l}0.031001 * * * \\
(5.282720)\end{array}$ & $\begin{array}{l}0.033540 * * * \\
(5.753612)\end{array}$ & $\begin{array}{l}0.033198 * * * \\
(5.695586)\end{array}$ \\
\hline$r_{j, t-11: t-1}$ & $\begin{array}{l}-0.043222 * * * \\
(8.424386)\end{array}$ & $\begin{array}{l}-0.043295 * * * \\
(8.436120)\end{array}$ & $\begin{array}{l}-0.044020 * * * \\
(8.590745)\end{array}$ & $\begin{array}{l}-0.041769 * * * \\
(8.169919)\end{array}$ & $\begin{array}{l}-0.042121 * * * \\
(8.236298)\end{array}$ & $\begin{array}{l}-0.044121 * * * \\
(8.616679)\end{array}$ & $\begin{array}{l}-0.043662 * * * \\
(8.521988)\end{array}$ & $\begin{array}{l}-0.042481 * * * \\
(8.305798)\end{array}$ & $\begin{array}{l}-0.041338 * * * \\
(8.080417)\end{array}$ & $\begin{array}{l}-0.041482 * * * \\
(8.108045)\end{array}$ \\
\hline$r_{j, t-35: t-12}$ & $\begin{array}{l}-0.004675 \\
(1.270540)\end{array}$ & $\begin{array}{l}-0.004673 \\
(1.269976)\end{array}$ & $\begin{array}{l}-0.006195 * \\
(1.684910)\end{array}$ & $\begin{array}{l}-0.007552 * * \\
(2.057838)\end{array}$ & $\begin{array}{l}-0.007718 * * \\
(2.102922)\end{array}$ & $\begin{array}{l}-0.006361 * \\
(1.731186)\end{array}$ & $\begin{array}{l}-0.006358 * \\
(1.729542)\end{array}$ & $\begin{array}{l}-0.007651 * * \\
(2.084928)\end{array}$ & $\begin{array}{l}-0.007567 * * \\
(2.062171)\end{array}$ & $\begin{array}{l}-0.007612 * * \\
(2.074329)\end{array}$ \\
\hline$\beta_{j}$ & --- & $\begin{array}{l}0.000387 \\
(0.587167)\end{array}$ & $\begin{array}{l}-0.002223 * * * \\
(3.131686)\end{array}$ & $\begin{array}{l}-0.003543 * * * \\
(5.021758)\end{array}$ & $\begin{array}{l}-0.003923 * * * \\
(5.430824)\end{array}$ & $\begin{array}{l}-0.003399 * * * \\
(4.648020)\end{array}$ & $\begin{array}{l}-0.003033 * * * \\
(4.119503)\end{array}$ & $\begin{array}{l}-0.004134 * * * \\
(5.576672)\end{array}$ & $\begin{array}{l}-0.003300 * * * \\
(4.482498)\end{array}$ & $\begin{array}{l}-0.003624 * * * \\
(4.984525)\end{array}$ \\
\hline$\sigma_{I V_{i d i o, j, t}}$ & --- & --- & --- & $\begin{array}{l}0.074021 * * * \\
(15.301850)\end{array}$ & $\begin{array}{l}0.067038 * * * \\
(11.938020)\end{array}$ & --- & --- & $\begin{array}{l}0.063349 * * * \\
(10.448500)\end{array}$ & $\begin{array}{l}0.069728 * * * \\
(12.321510)\end{array}$ & $\begin{array}{l}0.066094 * * * \\
(12.006240)\end{array}$ \\
\hline$\sigma_{E G_{i d i o, j, t}}$ & --- & --- & --- & --- & --- & $\begin{array}{l}0.118054 * * * \\
(6.615325)\end{array}$ & --- & $\begin{array}{l}0.074297 * * * \\
(3.246410)\end{array}$ & --- & --- \\
\hline$\sigma_{A R i d i o, j, t}$ & --- & --- & --- & --- & --- & --- & $\begin{array}{l}0.068558 * * * \\
(4.138064)\end{array}$ & $\begin{array}{l}-0.036860 * \\
(1.735467)\end{array}$ & --- & --- \\
\hline$O R W_{\text {ratio }}$ & --- & --- & --- & --- & --- & --- & --- & --- & $\begin{array}{l}-0.000054 \\
(0.477174)\end{array}$ & $\begin{array}{l}-0.000046 \\
(0.402319)\end{array}$ \\
\hline$O I$ & --- & --- & --- & --- & --- & --- & --- & --- & $\begin{array}{l}-0.001137 * * * \\
(4.332350)\end{array}$ & $\begin{array}{l}-0.000771 * * * \\
(3.401832)\end{array}$ \\
\hline Constant & $\begin{array}{l}0.047451 * * * \\
(5.933197)\end{array}$ & $\begin{array}{l}0.045989 * * * \\
(5.490517)\end{array}$ & $\begin{array}{l}0.021985 * * \\
(2.524333)\end{array}$ & $\begin{array}{l}0.003738 \\
(0.425322)\end{array}$ & $\begin{array}{l}0.000821 \\
(0.092593)\end{array}$ & $\begin{array}{l}0.003911 \\
(0.428748)\end{array}$ & $\begin{array}{l}0.010700 \\
(1.172735)\end{array}$ & $\begin{array}{l}-0.003322 \\
(0.360064)\end{array}$ & $\begin{array}{l}-0.017089 * \\
(1.750207)\end{array}$ & $\begin{array}{l}0.009572 * * * \\
(6.208561)\end{array}$ \\
\hline
\end{tabular}




\begin{tabular}{|c|c|c|c|c|c|c|c|c|c|c|}
\hline \multicolumn{11}{|c|}{ Phase 3} \\
\hline Variables & Model 1 & Model 2 & Model 3 & Model 4 & Model 5 & Model 6 & Model 7 & Model 8 & Model 9 & Model 10 \\
\hline$\sigma_{R V i d i o, j, t}$ & --- & --- & $\begin{array}{l}-0.127858 * * * \\
(5.288850)\end{array}$ & --- & $\begin{array}{l}-0.248338 * * * \\
(8.464513)\end{array}$ & $\begin{array}{l}-0.140092 * * * \\
(5.556416)\end{array}$ & $\begin{array}{l}-0.116249 * * * \\
(4.642675)\end{array}$ & $\begin{array}{l}-0.242326^{* * *} \\
(8.222168)\end{array}$ & $\begin{array}{l}-0.247445 * * * \\
(8.429103)\end{array}$ & $\begin{array}{l}-0.247554 * * * \\
(8.446389)\end{array}$ \\
\hline $\log S I Z E$ & $\begin{array}{l}-0.001705 \\
(0.947211)\end{array}$ & $\begin{array}{l}-0.001021 \\
(0.546702)\end{array}$ & $\begin{array}{l}-0.001928 \\
(1.030843)\end{array}$ & $\begin{array}{l}-0.000507 \\
(0.270584)\end{array}$ & $\begin{array}{l}-0.001209 \\
(0.648174)\end{array}$ & $\begin{array}{l}-0.001413 \\
(0.745837)\end{array}$ & $\begin{array}{l}-0.002272 \\
(1.208421)\end{array}$ & $\begin{array}{l}-0.001411 \\
(0.748519)\end{array}$ & $\begin{array}{l}0.000147 \\
(0.067337)\end{array}$ & --- \\
\hline $\log B M$ & $\begin{array}{l}0.002609 \\
(1.379068)\end{array}$ & $\begin{array}{l}0.002552 \\
(1.349055)\end{array}$ & $\begin{array}{l}0.003691 * \\
(1.942716)\end{array}$ & $\begin{array}{l}0.001685 \\
(0.879603)\end{array}$ & $\begin{array}{l}0.002103 \\
(1.104268)\end{array}$ & $\begin{array}{l}0.003444 * \\
(1.808067)\end{array}$ & $\begin{array}{l}0.003975 * * \\
(2.085124)\end{array}$ & $\begin{array}{l}0.002423 \\
(1.271660)\end{array}$ & $\begin{array}{l}0.002259 \\
(1.179494)\end{array}$ & $\begin{array}{l}0.002182 \\
(1.418333)\end{array}$ \\
\hline$r_{t}$ & $\begin{array}{l}0.099986 * * * \\
(6.727794)\end{array}$ & $\begin{array}{l}0.102139 * * * \\
(6.835583)\end{array}$ & $\begin{array}{l}0.071918 * * * \\
(4.504718)\end{array}$ & $\begin{array}{l}0.116676 * * * \\
(7.390376)\end{array}$ & $\begin{array}{l}0.088017 * * * \\
(5.482953)\end{array}$ & $\begin{array}{l}0.068685^{* * * *} \\
(4.272875)\end{array}$ & $\begin{array}{l}0.074505 * * * \\
(4.648303)\end{array}$ & $\begin{array}{l}0.092036 * * * \\
(5.660245)\end{array}$ & $\begin{array}{l}0.088808 * * * \\
(5.525969)\end{array}$ & $\begin{array}{l}0.088755 * * * \\
(5.529669)\end{array}$ \\
\hline$r_{j, t-11: t-1}$ & $\begin{array}{l}0.044196 * \\
(1.788592)\end{array}$ & $\begin{array}{l}0.040091 \\
(1.610914)\end{array}$ & $\begin{array}{l}0.029384 \\
(1.179529)\end{array}$ & $\begin{array}{l}0.045968 * \\
(1.841812)\end{array}$ & $\begin{array}{l}0.037316 \\
(1.503018)\end{array}$ & $\begin{array}{l}0.029091 \\
(1.167953)\end{array}$ & $\begin{array}{l}0.029330 \\
(1.177575)\end{array}$ & $\begin{array}{l}0.037409 \\
(1.508362)\end{array}$ & $\begin{array}{l}0.036395 \\
(1.465338)\end{array}$ & $\begin{array}{l}0.036523 \\
(1.474979)\end{array}$ \\
\hline$r_{j, t-35: t-12}$ & $\begin{array}{l}0.043325 * \\
(1.838271)\end{array}$ & $\begin{array}{l}0.043253 * \\
(1.835341)\end{array}$ & $\begin{array}{l}0.045947 * \\
(1.953752)\end{array}$ & $\begin{array}{l}0.041776 * \\
(1.773342)\end{array}$ & $\begin{array}{l}0.043958 * \\
(1.877227)\end{array}$ & $\begin{array}{l}0.044902 * \\
(1.909013)\end{array}$ & $\begin{array}{l}0.045197 * \\
(1.921927)\end{array}$ & $\begin{array}{l}0.040443 * \\
(1.727551)\end{array}$ & $\begin{array}{l}0.045141 * \\
(1.926559)\end{array}$ & $\begin{array}{l}0.045184 * \\
(1.929290)\end{array}$ \\
\hline$\beta_{j}$ & --- & $\begin{array}{l}0.004791 \\
(1.378917)\end{array}$ & $\begin{array}{l}0.007454 * * \\
(2.127991)\end{array}$ & $\begin{array}{l}0.003591 \\
(1.026484)\end{array}$ & $\begin{array}{c}0.006282 * \\
(1.799363)\end{array}$ & $\begin{array}{l}0.006261 * \\
(1.753010)\end{array}$ & $\begin{array}{l}0.008517 * * \\
(2.397071)\end{array}$ & $\begin{array}{l}0.007503 * * \\
(2.106105)\end{array}$ & $\begin{array}{l}0.007050 * * \\
(1.990188)\end{array}$ & $\begin{array}{l}0.006980 * * \\
(2.061557)\end{array}$ \\
\hline$\sigma_{I V_{i d i o, j, t}}$ & --- & --- & --- & $\begin{array}{l}0.022574 * * * \\
(2.837421)\end{array}$ & $\begin{array}{l}0.069223 * * * \\
(7.181937)\end{array}$ & --- & --- & $\begin{array}{l}0.074597 * * * \\
(7.424203)\end{array}$ & $\begin{array}{l}0.071626 * * * \\
(7.319587)\end{array}$ & $\begin{array}{l}0.071542 * * * \\
(7.371840)\end{array}$ \\
\hline$\sigma_{E G_{i d i o, j, t}}$ & --- & --- & --- & --- & --- & $\begin{array}{c}0.078449 * \\
(1.705747)\end{array}$ & --- & $\begin{array}{l}0.101265 * \\
(1.855544)\end{array}$ & --- & --- \\
\hline$\sigma_{A R i d i o, j, t}$ & --- & --- & --- & --- & --- & --- & $\begin{array}{l}-0.066373 * \\
(1.775507)\end{array}$ & $\begin{array}{l}-0.178140 * * * \\
(4.041649)\end{array}$ & --- & --- \\
\hline$O R W_{\text {ratio }}$ & --- & --- & --- & --- & --- & --- & --- & --- & $\begin{array}{l}0.000231 \\
(0.701062)\end{array}$ & $\begin{array}{l}0.000232 \\
(0.706157)\end{array}$ \\
\hline$O I$ & --- & --- & --- & --- & --- & --- & --- & --- & $\begin{array}{l}-0.001327 \\
(1.299058)\end{array}$ & $\begin{array}{l}-0.001291 \\
(1.477470)\end{array}$ \\
\hline Constant & $\begin{array}{l}-0.003486 \\
(0.124900)\end{array}$ & $\begin{array}{l}-0.019880 \\
(0.655398)\end{array}$ & $\begin{array}{l}0.006373 \\
(0.207829)\end{array}$ & $\begin{array}{l}-0.032998 \\
(1.076099)\end{array}$ & $\begin{array}{l}-0.009115 \\
(0.297805)\end{array}$ & $\begin{array}{l}-0.005828 \\
(0.185107)\end{array}$ & $\begin{array}{l}0.015235 \\
(0.490446)\end{array}$ & $\begin{array}{l}-0.002283 \\
(0.072830)\end{array}$ & $\begin{array}{l}-0.024210 \\
(0.725264)\end{array}$ & $\begin{array}{l}-0.022009 * * * \\
(3.224938)\end{array}$ \\
\hline
\end{tabular}




\begin{tabular}{|c|c|c|c|c|c|c|c|c|c|c|}
\hline \multicolumn{11}{|c|}{ Phase 4} \\
\hline Variables & Model 1 & Model 2 & Model 3 & Model 4 & Model 5 & Model 6 & Model 7 & Model 8 & Model 9 & Model 10 \\
\hline$\sigma_{R V i d i o, j, t}$ & --- & --- & $\begin{array}{l}0.189341 * * * \\
(9.141333)\end{array}$ & & $\begin{array}{l}0.128283 * * * \\
(5.160828)\end{array}$ & $\begin{array}{l}0.158108 * * * \\
(7.258908)\end{array}$ & $\begin{array}{l}0.178162 * * * \\
(8.347293)\end{array}$ & $\begin{array}{l}0.113180 * * * \\
(4.488124)\end{array}$ & $\begin{array}{l}0.128555 * * * \\
(5.146721)\end{array}$ & $\begin{array}{l}0.136239 * * * \\
(5.474639)\end{array}$ \\
\hline $\log S I Z E$ & $\begin{array}{l}-0.008258 * * * \\
(7.426012)\end{array}$ & $\begin{array}{l}-0.006241 * * * \\
(5.476990)\end{array}$ & $\begin{array}{l}-0.004765^{* * *} \\
(4.154561)\end{array}$ & $\begin{array}{l}-0.004393 * * * \\
(3.802923)\end{array}$ & $\begin{array}{l}-0.004117 * * * \\
(3.564101)\end{array}$ & $\begin{array}{l}-0.003893 * * * \\
(3.352105)\end{array}$ & $\begin{array}{l}-0.004494 * * * \\
(3.896330)\end{array}$ & $\begin{array}{l}-0.003508 * * * \\
(3.007551)\end{array}$ & $\begin{array}{l}-0.004703 * * * \\
(3.377720)\end{array}$ & --- \\
\hline $\log B M$ & $\begin{array}{l}0.002511 * * \\
(2.181987)\end{array}$ & $\begin{array}{l}0.002164 * \\
(1.883715)\end{array}$ & $\begin{array}{l}0.000835 \\
(0.723582)\end{array}$ & $\begin{array}{l}0.000891 \\
(0.771785)\end{array}$ & $\begin{array}{l}0.000489 \\
(0.423467)\end{array}$ & $\begin{array}{l}0.000632 \\
(0.547909)\end{array}$ & $\begin{array}{l}0.000716 \\
(0.620002)\end{array}$ & $\begin{array}{l}0.000392 \\
(0.339431)\end{array}$ & $\begin{array}{l}0.000459 \\
(0.396110)\end{array}$ & $\begin{array}{l}0.002616^{* * * *} \\
(2.705519)\end{array}$ \\
\hline$r_{t}$ & $\begin{array}{l}0.025481 * * * \\
(2.894562)\end{array}$ & $\begin{array}{l}0.014612 \\
(1.643092)\end{array}$ & $\begin{array}{l}0.007004 \\
(0.786936)\end{array}$ & $\begin{array}{l}0.015908 * \\
(1.794399)\end{array}$ & $\begin{array}{l}0.010245 \\
(1.148180)\end{array}$ & $\begin{array}{l}0.001223 \\
(0.136194)\end{array}$ & $\begin{array}{l}0.006425 \\
(0.721688)\end{array}$ & $\begin{array}{l}0.004673 \\
(0.516845)\end{array}$ & $\begin{array}{l}0.009774 \\
(1.095118)\end{array}$ & $\begin{array}{l}0.010315 \\
(1.155385)\end{array}$ \\
\hline$r_{j, t-11: t-1}$ & $\begin{array}{l}0.092340 * * * \\
(11.853940)\end{array}$ & $\begin{array}{l}0.090215^{* * *} \\
(11.603280)\end{array}$ & $\begin{array}{l}0.094323 * * * \\
(12.154550)\end{array}$ & $\begin{array}{l}0.095848 * * * \\
(12.325570)\end{array}$ & $\begin{array}{l}0.096424 * * * \\
(12.412110)\end{array}$ & $\begin{array}{l}0.095399 * * * \\
(12.298300)\end{array}$ & $\begin{array}{l}0.095192 * * * \\
(12.252060)\end{array}$ & $\begin{array}{l}0.096843 * * * \\
(12.461200)\end{array}$ & $\begin{array}{l}0.096279 * * * \\
(12.395570)\end{array}$ & $\begin{array}{l}0.096501 * * * \\
(12.419010)\end{array}$ \\
\hline$r_{j, t-35: t-12}$ & $\begin{array}{l}-0.069118 * * * \\
(4.424739)\end{array}$ & $\begin{array}{l}-0.068860 * * * \\
(4.419401)\end{array}$ & $\begin{array}{l}-0.069414 * * * \\
(4.470857)\end{array}$ & $\begin{array}{l}-0.072837 * * * \\
(4.687945)\end{array}$ & $\begin{array}{l}-0.071654 * * * \\
(4.616405)\end{array}$ & $\begin{array}{l}-0.068264 * * * \\
(4.400057)\end{array}$ & $\begin{array}{l}-0.069060 * * * \\
(4.448535)\end{array}$ & $\begin{array}{l}-0.070325 * * * \\
(4.531971)\end{array}$ & $\begin{array}{l}-0.069727 * * * \\
(4.487939)\end{array}$ & $\begin{array}{l}-0.071862 * * * \\
(4.627143)\end{array}$ \\
\hline$\beta_{j}$ & --- & $\begin{array}{l}0.016824 * * * \\
(7.719649)\end{array}$ & $\begin{array}{l}0.010630 * * * \\
(4.672868)\end{array}$ & $\begin{array}{l}0.011884 * * * \\
(5.294686)\end{array}$ & $\begin{array}{l}0.009624 * * * \\
(4.212796)\end{array}$ & $\begin{array}{l}0.008393 * * * \\
(3.610606)\end{array}$ & $\begin{array}{l}0.009619 * * * \\
(4.142805)\end{array}$ & $\begin{array}{l}0.008014 * * * \\
(3.424556)\end{array}$ & $\begin{array}{l}0.009410 * * * \\
(4.084812)\end{array}$ & $\begin{array}{l}0.011000 * * * \\
(4.875696)\end{array}$ \\
\hline$\sigma_{I V_{i d i o, j, t}}$ & --- & --- & --- & $\begin{array}{l}0.048715 * * * \\
(8.750052)\end{array}$ & $\begin{array}{l}0.029623 * * * \\
(4.434916)\end{array}$ & --- & --- & $\begin{array}{l}0.024599 * * * \\
(3.605404)\end{array}$ & $\begin{array}{l}0.027727 * * * \\
(4.113254)\end{array}$ & $\begin{array}{l}0.031491 * * * \\
(4.734616)\end{array}$ \\
\hline$\sigma_{E G_{i d i o, j, t}}$ & --- & --- & --- & --- & --- & $\begin{array}{l}0.128469 * * * \\
(4.597452)\end{array}$ & --- & $\begin{array}{l}0.114318 * * * \\
(3.485283)\end{array}$ & --- & --- \\
\hline$\sigma_{A R i d i o, j, t}$ & -- & -- & -- & -- & -- & -- & $\begin{array}{l}0.039717 * * \\
(2.164567)\end{array}$ & $\begin{array}{l}-0.008297 \\
(0.389240)\end{array}$ & -- & --- \\
\hline ORW $W_{\text {ratio }}$ & -- & -- & -- & -- & -- & -- & -- & -- & $\begin{array}{l}-0.000467 * * \\
(2.382324)\end{array}$ & $\begin{array}{l}-0.000502 * * \\
(2.562173)\end{array}$ \\
\hline$O I$ & -- & -- & -- & -- & -- & -- & -- & -- & $\begin{array}{l}0.000692 \\
(1.115787)\end{array}$ & $\begin{array}{l}-0.000464 \\
(0.898057)\end{array}$ \\
\hline Constant & $\begin{array}{l}0.156371 * * * \\
(9.052806)\end{array}$ & $\begin{array}{l}0.104947 * * * \\
(5.681326)\end{array}$ & $\begin{array}{l}0.071702 * * * \\
(3.821571)\end{array}$ & $\begin{array}{l}0.067373 * * * \\
(3.563526)\end{array}$ & $\begin{array}{l}0.059575 * * * \\
(3.144516)\end{array}$ & $\begin{array}{l}0.052721 * * * \\
(2.746577)\end{array}$ & $\begin{array}{l}0.066067 * * * \\
(3.488379)\end{array}$ & $\begin{array}{l}0.045919 * * \\
(2.380363)\end{array}$ & $\begin{array}{l}0.064892 * * * \\
(3.070787)\end{array}$ & $\begin{array}{l}-0.005107 \\
(1.234926)\end{array}$ \\
\hline
\end{tabular}


Table 14 reports the effect of implied idiosyncratic volatility on future stock returns; indeed, all of these effects are positive at a strong statistically significant at $1 \%$ level for every model in both the full period and every sub period. In fact a $1 \%$ increase in the implied idiosyncratic volatility increases future returns by between 0.02 and $0.07 \%$ depending on the model specification and sub periods. This is also evidence that there exists a premium for carrying implied idiosyncratic volatility and that higher returns are partially due to idiosyncratic volatility risk.

Meanwhile, realized idiosyncratic volatility which is meaningless for all model specifications in the full period (as seen in previous studies, can show strong statistical significance for all models in every sub period. In particular, there is a strong negative statistical significance at the $1 \%$ level for Phase 3, whereas other coefficients are positive for the three remaining phases. As a result, the summary of whole periods is offset to be null from all effects which have both positive and negative statistically significant relations in sub periods or are meaningless at the end.

Additionally, we find evidence that the EGARCH volatility forecast has no relation during the full period, as only model 8 is affected from the off set during sub periods. In fact, there is only a negative statistically significant relation at the $1 \%$ level in Phase 1 , while the remaining periods have a positive statistically significant relation. However, model 6 shows that this EGARCH volatility can forecast a stock return in a full period with lower effect and significance than implied idiosyncratic volatility, especially as there is only a negative statistically significant relation in Phase 1 and positive statistical significance for all other sub periods.

In terms of the $A R(2)$ volatility forecast model, there is also no relation in the full period for only model 8 , although we find a negative statistical significance at the $1 \%$ level for Phase 1 and 3 (Bear markets) and at $10 \%$ level for Phase 2; in addition, there is no relation for only Phase 4, which pulls results from three sub periods to be meaningless in the full period at the end. Inversely, AR(2) volatility can forecast a stock return in the full period for model 7, with a lower effect and significance than implied idiosyncratic volatility; in contrast there is a negative statistical significance in Phase 1 and 3 (Bear markets) and a positive statistical significance for Phase 2 and 4 (Bull markets).

Finally, these outcomes as shown in Table 14 are also related to and fully support the result of the Chow test, namely that the relation is not consistent during the entire full period, or there are different impacts on and relations between different subgroups in sub periods. As such, a further step in analysis is to divide the full period by breakpoints to examine the relation in each sub period. 
Table 14: Forecast model of implied, realized, EGARCH and $A R(2)$ idiosyncratic volatilities.

\begin{tabular}{|c|c|c|c|c|c|c|c|c|c|c|c|}
\hline Variables & Model & Phase 1 & & Phase 2 & & Phase 3 & & Phase 4 & & \multicolumn{2}{|c|}{ Full Periods } \\
\hline \multirow[t]{14}{*}{$\sigma_{R V}$ idio } & Model3 & 0.291920 & $* * *$ & 0.168545 & $* * *$ & -0.127858 & $* * *$ & 0.189341 & $* * *$ & \multirow{2}{*}{\multicolumn{2}{|c|}{$\begin{array}{l}0.0116 \\
(1.30)\end{array}$}} \\
\hline & & (10.132080) & & $(9.858261)$ & & $(5.288850)$ & & (9.141333) & & & \\
\hline & Model5 & 0.205231 & $* * *$ & 0.048465 & $* *$ & -0.248338 & $* * *$ & 0.128283 & *** & \multicolumn{2}{|l|}{-0.0021} \\
\hline & & (5.924928) & & $(2.447680)$ & & $(8.464513)$ & & (5.160828) & & \multicolumn{2}{|l|}{$(0.43)$} \\
\hline & Model6 & 0.346996 & $* * *$ & 0.124883 & $* * *$ & -0.140092 & $* * *$ & 0.158108 & $* * *$ & \multirow{2}{*}{\multicolumn{2}{|c|}{$\begin{array}{l}0.1000 \\
(0.69)\end{array}$}} \\
\hline & & (11.379150) & & $(6.818701)$ & & $(5.556416)$ & & (7.258908) & & & \\
\hline & Model7 & 0.330026 & $* * *$ & 0.144164 & $* * *$ & -0.116249 & $* * *$ & 0.178162 & **** & \multirow{2}{*}{\multicolumn{2}{|c|}{$\begin{array}{l}0.0092 \\
(1.58)\end{array}$}} \\
\hline & & (11.029950) & & (7.974071) & & $(4.642675)$ & & (8.347293) & & & \\
\hline & Model8 & 0.237842 & $* * *$ & 0.040702 & $* *$ & -0.242326 & $* * *$ & 0.113180 & $* * *$ & \multirow{2}{*}{\multicolumn{2}{|c|}{$\begin{array}{l}-0.0026 \\
(0.55)\end{array}$}} \\
\hline & & $(6.833052)$ & & $(2.024659)$ & & $(8.222168)$ & & $(4.488124)$ & & & \\
\hline & Model9 & 0.211890 & $* * *$ & 0.060062 & $* * *$ & -0.247445 & $* * *$ & 0.128555 & $* * *$ & \multirow{2}{*}{\multicolumn{2}{|c|}{$\begin{array}{l}-0.0036 \\
(0.75)\end{array}$}} \\
\hline & & $(6.084883)$ & & (3.007447) & & $(8.429103)$ & & $(5.146721)$ & & & \\
\hline & Model10 & 0.218440 & $* * *$ & 0.053582 & $* * *$ & -0.247554 & $* * *$ & 0.136239 & $* * *$ & \multirow{2}{*}{\multicolumn{2}{|c|}{$\begin{array}{l}0.0007 \\
(0.14)\end{array}$}} \\
\hline & & $(6.291719)$ & & $(2.701313)$ & & $(8.446389)$ & & $(5.474639)$ & & & \\
\hline \multirow{10}{*}{$\sigma_{I V i d i o, j, t}$} & Model4 & 0.064703 & $* * *$ & 0.074021 & $* * *$ & 0.022574 & $* * *$ & 0.048715 & $* * *$ & 0.0350 & $* * *$ \\
\hline & & (9.365323) & & $(15.301850)$ & & $(2.837421)$ & & $(8.750052)$ & & \multicolumn{2}{|l|}{$(4.20)$} \\
\hline & Model5 & 0.037350 & $* * *$ & 0.067038 & $* * *$ & 0.069223 & $* * *$ & 0.029623 & $* * *$ & 0.0371 & $* * *$ \\
\hline & & $(4.499655)$ & & (11.938020) & & (7.181937) & & $(4.434916)$ & & \multicolumn{2}{|l|}{$(5.67)$} \\
\hline & Model8 & 0.060546 & $* * *$ & 0.063349 & $* * *$ & 0.074597 & $* * *$ & 0.024599 & $* * *$ & 0.0352 & $* * *$ \\
\hline & & (6.880003) & & (10.448500) & & $(7.424203)$ & & (3.605404) & & \multicolumn{2}{|l|}{$(5.56)$} \\
\hline & Model9 & 0.039230 & $* * *$ & 0.069728 & $* * *$ & 0.071626 & $* * *$ & 0.027727 & $* * *$ & & $* * *$ \\
\hline & & $(4.644812)$ & & (12.321510) & & (7.319587) & & (4.113254) & & \multicolumn{2}{|l|}{$(4.92)$} \\
\hline & Model10 & 0.043071 & $* * *$ & 0.066094 & $* * *$ & 0.071542 & $* * *$ & 0.031491 & $* * *$ & 0.0426 & $* * *$ \\
\hline & & $(5.195970)$ & & $(12.006240)$ & & $(7.371840)$ & & $(4.734616)$ & & \multicolumn{2}{|l|}{$(5.77)$} \\
\hline \multirow[t]{4}{*}{$\sigma_{E G_{i d i o, j, t}}$} & Model6 & -0.167107 & $* * *$ & 0.118054 & $* * *$ & 0.078449 & $*$ & 0.128469 & $* * *$ & \multirow{2}{*}{\multicolumn{2}{|c|}{$\begin{array}{l}0.0124 \\
(2.20)\end{array}$}} \\
\hline & & $(5.454972)$ & & $(6.615325)$ & & $(1.705747)$ & & $(4.597452)$ & & & \\
\hline & Model8 & -0.180006 & $* * *$ & 0.074297 & $* * *$ & 0.101265 & $*$ & 0.114318 & $* * *$ & \multirow{2}{*}{\multicolumn{2}{|c|}{$\begin{array}{l}0.0031 \\
(0.45)\end{array}$}} \\
\hline & & $(4.723379)$ & & $(3.246410)$ & & $(1.855544)$ & & $(3.485283)$ & & & \\
\hline \multirow[t]{4}{*}{$\sigma_{A R_{i d i o, j, t}}$} & Model7 & -0.127876 & $* * *$ & 0.068558 & $* * *$ & -0.066373 & * & 0.039717 & $* *$ & 0.0128 & $* * *$ \\
\hline & & $(4.665243)$ & & (4.138064) & & (1.775507) & & $(2.164567)$ & & \multicolumn{2}{|l|}{$(2.42)$} \\
\hline & Model8 & -0.091022 & $* * *$ & -0.036860 & $*$ & -0.178140 & $* * *$ & -0.008297 & & \multirow{2}{*}{\multicolumn{2}{|c|}{$\begin{array}{l}0.0034 \\
(0.46)\end{array}$}} \\
\hline & & $(2.706575)$ & & $(1.735467)$ & & (4.041649) & & $(0.389240)$ & & & \\
\hline
\end{tabular}

Table 15 presents the following results. The short-sales constraint $\left(O R W_{\text {ratio }}\right)$ has a strong negative impact (statistically significant at the $1 \%$ level in full periods), whereas there is no relation between Phase 1, 2, and 3, and the beginning of the effect is in Phase 4 (Bull market after recent financial crisis). Indeed, in terms of the latter, it is a negative statistically significant coefficient or when the constraint is higher, then the return is lower. This shows that investors in the U.S. equity 
market anticipate to speculate more on call options, and therefore the price of the call option dedicates the price of the stock and results in lower short-sales constraint This demonstrates that investors in the U.S. equity market anticipate to speculate more on call options, and therefore the price of the call option dictates the price of the stock and results in lower short-sales constraint. Somehow, the higher stock price is not directly affected by the short-sales constraint. It is strongly related to results of higher implied idiosyncratic volatility in Phase 4 (as shown in Table 14), since investors are highly speculative in options. In relation to the open-interest variable (OI) as a proxy for liquidity we find a positive statistically significant effect of stock returns in full periods,although this is meaningless for Phase 3 and 4 as there is enough high liquidity in the option market afterward for investors. As a result, the liquidity is not affected by the stock return from investment after Phase 3 and 4 .

Table 15: The short-sales constraint and liquidity or open-interest variables $\left(O R W_{\text {ratio }}, O I\right)$

\begin{tabular}{|c|c|c|c|c|c|c|c|c|c|c|}
\hline \multirow{3}{*}{$\frac{\text { Variables }}{O R W_{\text {ratio }}}$} & \multirow{2}{*}{$\frac{\text { Model }}{\text { Model } 9}$} & \multicolumn{2}{|l|}{ Phase 1} & \multicolumn{2}{|l|}{ Phase 2} & \multirow{2}{*}{$\begin{array}{l}\text { Phase } 3 \\
0.000231\end{array}$} & \multicolumn{2}{|l|}{ Phase 4} & \multicolumn{2}{|c|}{ Full Periods } \\
\hline & & -0.000425 & $*$ & -0.000054 & & & -0.000467 & ** & -0.0027 & $* * *$ \\
\hline & & (1.777338) & & $(0.477174)$ & & $(0.701062)$ & $(2.382324)$ & & $(4.43)$ & \\
\hline & Model10 & -0.000446 & $*$ & -0.000046 & & 0.000232 & -0.000502 & $* *$ & -0.0027 & $* * *$ \\
\hline & & $(1.865765)$ & & $(0.402319)$ & & $(0.706157)$ & $(2.562173)$ & & $(4.33)$ & \\
\hline \multirow[t]{4}{*}{$O I$} & Model 9 & -0.001128 & & -0.001137 & $* * *$ & -0.001327 & 0.000692 & & 0.0026 & $* * *$ \\
\hline & & $(1.635540)$ & & $(4.332350)$ & & (1.299058) & (1.115787) & & $(4.17)$ & \\
\hline & Model10 & -0.001896 & $* * *$ & -0.000771 & $* * *$ & -0.001291 & -0.000464 & & -0.0001 & \\
\hline & & $(3.117237)$ & & (3.401832) & & (1.477470) & $(0.898057)$ & & $(0.18)$ & \\
\hline
\end{tabular}

The last table (16) in our analysis presents, evidence with regard to firm-specific characteristics variables (log SIZE and $\log$ BM), specifically that the coefficient of $\log$ SIZE has a strong negative statistical significance for all models in full periods. However, Size has a strong negative effect (at a $1 \%$ statistical significance) on the next month's returns for only Phase 1 and 4. This should affect when stocks are overvalued, as Size is bigger. Following this, returns are lower in the next period, since investors turn to speculate on lower price stocks instead. Meanwhile, $\log B M$ has a strong positive statistically significant relation for all models in full periods, whereas every model has a strong positive statistically significant effect for only Phase 2, which is the Bull market, over a long period between 2003 and 2007 It is implied that investors chase to acquire stocks with higher B/M ratio or cheaper price in the event of a long term Bull market. 
Table 16: The cross-section firm-specific characteristics variables ( $\log S I Z E$, and $\log B M$ )

\begin{tabular}{|c|c|c|c|c|c|c|c|c|c|c|c|}
\hline \multirow[t]{2}{*}{ Variables } & \multirow{2}{*}{$\begin{array}{l}\text { Model } \\
\text { Model } 1\end{array}$} & \multicolumn{2}{|l|}{ Phase 1} & \multicolumn{2}{|c|}{ Phase 2} & \multicolumn{2}{|l|}{ Phase 3} & \multicolumn{2}{|c|}{ Phase 4} & \multicolumn{2}{|c|}{ Full Periods } \\
\hline & & -0.006333 & $* * *$ & -0.002085 & $* * *$ & -0.001705 & & -0.008258 & $* * *$ & -0.0048 & $* * *$ \\
\hline \multirow{17}{*}{$\log S I Z E$} & & $(4.566421)$ & & $(4.024005)$ & & $(0.947211)$ & & $(7.426012)$ & & $(4.54)$ & \\
\hline & Model2 & -0.007799 & $* * *$ & -0.002021 & $* * *$ & -0.001021 & & -0.006241 & $* * *$ & -0.0040 & $* * *$ \\
\hline & & -(5.575965) & & $(3.814836)$ & & $(0.546702)$ & & $(5.476990)$ & & $(4.39)$ & \\
\hline & Model3 & -0.005992 & $* * *$ & -0.000994 & * & -0.001928 & & -0.004765 & $* * *$ & -0.0035 & $* * *$ \\
\hline & & $(4.268441)$ & & $(1.844362)$ & & $(1.030843)$ & & $(4.154561)$ & & $(4.20)$ & \\
\hline & Model4 & -0.005476 & $* * *$ & 0.000272 & & -0.000507 & & -0.004393 & $* * *$ & -0.0019 & $* *$ \\
\hline & & $(3.869415)$ & & $(0.496900)$ & & $(0.270584)$ & & (3.802923) & & $(2.31)$ & \\
\hline & Model5 & -0.005187 & $* * *$ & 0.000351 & & -0.001209 & & -0.004117 & $* * *$ & -0.0018 & $* *$ \\
\hline & & (3.668969) & & $(0.639686)$ & & $(0.648174)$ & & $(3.564101)$ & & $(2.18)$ & \\
\hline & Model6 & -0.007292 & $* * *$ & -0.000172 & & -0.001413 & & -0.003893 & $* * *$ & -0.0032 & $* * *$ \\
\hline & & $(5.127706)$ & & $(0.312069)$ & & $(0.745837)$ & & (3.352105) & & $(3.88)$ & \\
\hline & Model7 & -0.006993 & $* * *$ & -0.000477 & & -0.002272 & & -0.004494 & $* * *$ & -0.0030 & $* * *$ \\
\hline & & (4.928729) & & $(0.862624)$ & & $(1.208421)$ & & $(3.896330)$ & & $(3.59)$ & \\
\hline & Model8 & -0.006800 & $* * *$ & 0.000516 & & -0.001411 & & -0.003508 & $* * *$ & -0.0018 & $* *$ \\
\hline & & $(4.771048)$ & & $(0.924077)$ & & (0.748519) & & $(3.007551)$ & & $(2.23)$ & \\
\hline & Mode19 & -0.003791 & $* *$ & 0.001761 & $* * *$ & 0.000147 & & -0.004703 & $* * *$ & -0.0050 & $* * *$ \\
\hline & & $(2.360036)$ & & $(2.765191)$ & & $(0.067337)$ & & $(3.377720)$ & & $(5.09)$ & \\
\hline \multirow{20}{*}{$\log B M$} & Model 1 & 0.001212 & & 0.002048 & $* * *$ & 0.002609 & & 0.002511 & $* *$ & 0.0530 & $* * *$ \\
\hline & & $(0.837813)$ & & (3.799296) & & (1.379068) & & (2.181987) & & $(4.11)$ & \\
\hline & Model2 & 0.001529 & & 0.002036 & $* * *$ & 0.002552 & & 0.002164 & $*$ & 0.0058 & $* * *$ \\
\hline & & $(1.058501)$ & & (3.774618) & & (1.349055) & & $(1.883715)$ & & $(4.00)$ & \\
\hline & Model3 & 0.000729 & & 0.001870 & $* * *$ & 0.003691 & $*$ & 0.000835 & & 0.0059 & $* * *$ \\
\hline & & $(0.506018)$ & & $(3.470189)$ & & (1.942716) & & $(0.723582)$ & & $(4.52)$ & \\
\hline & Model4 & 0.000950 & & 0.001741 & $* * *$ & 0.001685 & & 0.000891 & & 0.0065 & $* * *$ \\
\hline & & $(0.659420)$ & & $(3.239065)$ & & $(0.879603)$ & & $(0.771785)$ & & $(5.00)$ & \\
\hline & Model5 & 0.000632 & & 0.001721 & $* * *$ & 0.002103 & & 0.000489 & & 0.0064 & $* * *$ \\
\hline & & $(0.439171)$ & & (3.201688) & & (1.104268) & & $(0.423467)$ & & $(5.05)$ & \\
\hline & Model6 & 0.000718 & & 0.001778 & $* * *$ & 0.003444 & $*$ & 0.000632 & & 0.0049 & $* * *$ \\
\hline & & $(0.498940)$ & & $(3.300654)$ & & (1.808067) & & $(0.547909)$ & & $(4.92)$ & \\
\hline & Model7 & 0.000743 & & 0.001816 & $* * *$ & 0.003975 & $* *$ & 0.000716 & & 0.0049 & $* * *$ \\
\hline & & $(0.516558)$ & & (3.370267) & & (2.085124) & & $(0.620002)$ & & $(5.07)$ & \\
\hline & Model8 & 0.000570 & & 0.001701 & $* * *$ & 0.002423 & & 0.000392 & & 0.0051 & $* * *$ \\
\hline & & $(0.397289)$ & & $(3.162711)$ & & $(1.271660)$ & & $(0.339431)$ & & $(5.43)$ & \\
\hline & Mode19 & 0.000738 & & 0.001870 & $* * *$ & 0.002259 & & 0.000459 & & 0.0049 & $* * *$ \\
\hline & & $(0.512926)$ & & (3.471454) & & (1.179494) & & $(0.396110)$ & & $(5.17)$ & \\
\hline & Model10 & 0.002932 & $* * *$ & 0.000992 & $* *$ & 0.002182 & & 0.002616 & $* * *$ & 0.0063 & $* * *$ \\
\hline & & $(2.668525)$ & & $(2.279644)$ & & (1.418333) & & $(2.705519)$ & & $(6.29)$ & \\
\hline
\end{tabular}




\subsection{Conclusions}

This dissertation investigates, the role of volatility risk on stock returns predictability for 596 stock options traded on the American Stock Exchange and the Chicago Board Options Exchange (CBOE) for the full period spanning January 2001 to December 2010. Using a time period that incorporates both the dotcom bubble and the recent financial crisis we expand to divide it into four different periods (Bear and Bull markets) after completing the Chow examination in three breakpoints, including December 2002 (31/12/2002), December 2007(31/12/2007), and December 2008(31/12/2008). This is done on the key regression of Fama-Macbeth (1973) future returns estimation, including firm-specific characteristics. In particular, we shed light on the relation between idiosyncratic volatility and stock prices in all four sub periods over two financial crises when S\&P500 drops at least $20 \%$ in the Bear market and recovers in the Bull market.

The findings confirm the impact of idiosyncratic volatility on stock returns predictability; the best predictor among the different volatility measures used is the implied idiosyncratic volatility during every different period both the Bear and Bull markets over two financial crises. Definitely, there is clear evidence of a return premium for carrying idiosyncratic volatility risk in all sub periods. Indeed, a $1 \%$ increase in the implied idiosyncratic volatility increases future returns by between 0.02 and $0.07 \%$. Furthermore, the realized idiosyncratic volatility forecasts future stock returns for different periods of Bear and Bull markets with mixed positive and negative effects, whereas they can be offset to be null for entire periods as shown in previous studies. We find evidence that the EGARCH and AR(2) volatilities can be a stock return predictor with lower effect and significance than implied idiosyncratic volatility in entire periods; indeed, this has been shown in previous studies, different Bear and Bull periods present positive and negative statistically significant effects without certain direction as well.

We also discover that cross-section firm-specific characteristics are important for stock returns forecast, and have mixed positive and negative effects for Bear and Bull markets. In addition, we provide evidence that short selling constraints impact negatively on stock returns for only a Bull market and liquidity is meaningless for both Bear and Bull markets after the recent financial crisis.

Overall, we claim that this research provides a significant contribution to the existing evidence on volatility measures, volatility risk and stock return predictability. To our knowledge, it is the first time that a period including both the dotcom bubble and the recent financial crisis is 
analysed and divided into different periods, namely Bear and Bull markets.

The volatile market environment and depressed expected returns of the past several years have increased the use of volatility strategies. Now that volatility has emerged not only as a concept but as an investment in its own right, this study brings to light the accuracy of different forecast models in idiosyncratic volatility calculation and their effect on future stock returns.

This research is conducted by examining the effect of idiosyncratic volatility on stock returns predictability in different periods of Bear and Bull markets. This study can be extended in future, perhaps to industry specific effects on volatility risk and stock returns predictability 


\section{References}

Ang, A., Hodrick, R. J., Xing, Y., \& Zhang, X. (2006). "The cross-section of volatility and expected returns". Journal of Finance, 61, 259-299.

Bakshi, G., \& Kapadia, N. (2003). "Delta-Hedged Gains and the Negative Market Volatility Risk Premium". Review of Financial Studies, 16(2), 527-566.

Bali, T. G., \& Cakici, N. (2008). "Idiosyncratic Volatility and the Cross Section of Expected Returns". Journal of Financial and Quantitative Analysis, 43(01), 29.

Barberis, N., \& Huang, M. (2001). "Mental Accounting, Loss Aversion, and Individual Stock Returns". The Journal of Finance, 56(4), 1247-1292.

Campbell, J. Y., \& Hentsche, L. (1992). "No news is good news: An asymmetric model of changing volatility in stock returns". Journal of Financial Economics, 31(3), 281-318.

Carhart, Mark M. (1997) "On Persistence In Mutual Fund Performance".The Journal of Finance $52(1), 57-82$.

Chow, G. C. (1960). "Tests of Equality Between Sets of Coefficients in Two Linear Regressions". Econometrica, 28(3), 591-605.

Christensen, B., \& Prabhala, N. (1998). "The relation between implied and realized volatility". Journal of Financial Economics, 50(2), 125-150.

Chua, C. T., Goh, J., \& Zhang, Z. (2010). "Expected Volatility, Unexpected Volatility, And The Cross-Section Of Stock Returns". Journal of Financial Research, 33(2), 103-123.

Coval, J. D., \& Shumway, T. (2001). "Expected Option Returns". The Journal of Finance, 56(3), 983-1009.

Dennis, P., Mayhew, S., \& Stivers, C. (2006). "Stock Returns, Implied Volatility Innovations, and the Asymmetric Volatility Phenomenon". Journal of Financial and Quantitative Analysis, 41(02), 381-406.

Doran, J. S., \& Ronn, E. I. (2006). "The bias in Black-Scholes/Black implied volatility: An analysis of equity and energy markets". Review of Derivatives Research, 8(3), 177-198.

Fama, E. F., \& French, K. R. (1993). "Common risk factors in the returns on stocks and bonds". Journal of Financial Economics, 33(1), 3-56.

Fama, E. F., \& Macbeth, J. D. (1973). "Risk, Return, and Equilibrium: Empirical Tests". Journal of Political Economy, 81(3), 607-636.

Florackis, C, Gregoriou, A \& Kostakis, A (2011), 'Trading frequency and asset pricing on the London Stock Exchange: Evidence from a new price impact ratio", Journal of Banking and Finance, 35(12), 3335-3350.

$\mathrm{Fu}$, F. (2009). "Idiosyncratic risk and the cross-section of expected stock returns". Journal of Financial Economics, 9(1), 24-37.

Giot, P. (2005). "Relationships Between Implied Volatility Indexes and Stock Index Returns". The Journal of Portfolio Management, 31(3), 92-100.

Glosten, L. R., Jagannathan, R., \& Runkle, D. E. (1993). "On the Relation between the Expected Value and the Volatility of the Nominal Excess Return on Stocks". The Journal of Finance, 48(5), 1779-1801.

Goyal, A., \& Santa-Clara, P. (2003). "Idiosyncratic Risk Matters!". The Journal of Finance, 58(3), 975-1007.

Hentschel, L. (2003). "Errors in Implied Volatility Estimation". The Journal of Financial and Quantitative Analysis, 38(4), 779-810.

Jegadeesh, N., \& Titman, S. (1993). "Returns to Buying Winners and Selling Losers: Implications for Stock Market Efficiency". The Journal of Finance, 48(1), 65-91.

Jones, C. M., \& Rhodes-Kropf, M. (2003). "The Price of Diversifiable Risk in Venture Capital and Private Equity". SSRN Journal, Working paper, Columbia University. 
Mateus, C., \& Konsilp, W. (2014). Implied Idiosyncratic Volatility and Stock Return Predictability. JMF Journal of Mathematical Finance, 04(05), 338-352.

Ofek, E., Richardson, M., \& Whitelaw, R. F. (2004). "Limited arbitrage and short sales restrictions: evidence from the options markets". Journal of Financial Economics, 74(2), 305-342.

Pástor, L., \& Stambaugh, R. F. (2003). "Liquidity Risk and Expected Stock Returns". Journal of Political Economy, 111(3), 642-685.

Poon, S.-H., \& Granger, C. W. (2003). "Forecasting volatility in financial markets: A review". Journal of Economic Literature, 41(2), 478-539.

Xu, Y., \& Malkiel, B. G. (2006). "Idiosyncratic Risk and Security Returns". SSRN Journal, Working paper,University of Texas at Dallas.

Zhang, J. E., Shu, J., \& Brenner, M. (2010). "The new market for volatility trading". Journal of Futures Markets, 30(9), 809-833. 


\title{
Chapter 4: Volatility Risk, Global Financial Crises and Industry Specific Effects
}

\begin{abstract}
In this paper it is analyzed the role of volatility risk on stock return predictability incorporating industry specific effects for the period that includes two global financial crises: the dot-com bubble and recent financial crisis. We examine alternative idiosyncratic volatility forecasting measures on future stock returns in four different periods (Bear and Bull markets) for eight different industry sectors.

Our empirical results crucially depend on the use of eight stock sector classification from a broad sample of stock options traded at the American Stock Exchange and the Chicago Board Options Exchange (CBOE) from January 2001 to December 2010. The clear and robust empirical evidence points that the implied idiosyncratic volatility is the best stock return predictor for all sub periods both Bear and Bull markets. Specifically, our results strongly support the same predictability outcomes obtained from all sectors before divide and certain sectors which are divided and are not weak form efficient, namely Consumer Goods, Healthcare, Services and Technology. Whereas, other sectors which are weak form efficient, namely Basic Materials, Utilities, Industrial Goods, and Financials, cannot be predicted by all volatility measures, that is realized, $E G A R C H, A R(2)$, and implied idiosyncratic volatilities. In fact, the cross-section firm-specific characteristics is ineligible for future stock return forecast and give inconsistent outcomes in mixed positive and negative effects for all different sectors in Bear and Bull markets. At last, short selling constraints and liquidity show meaningless to impact on future stock returns for all sectors both Bear and Bull markets after sector classification.
\end{abstract}

Keywords: Options, Risk Premium, stock, volatility

JEL Classification: G10; G12; C53 


\subsection{Background}

Implied volatility represents the expected volatility of a stock over the life of its option and refers to the market's assessment of future volatility (Canina and Figlewski, 1993). In fact, Conrad (1989) finds that it is directly influenced by the supply and demand of the underlying options and by the market's expectation of the share price's direction. Moreover, Mateus and Konsilp (2014) examine the relation between different measures and expected stock returns and find that implied idiosyncratic volatility is the best future stock return predictor among the different volatility measures used, namely realized volatility, EGARCH and the autoregressive model. This shows that implied volatility is a measure to indicate what future volatility is. On the other hand, realized volatility (referred as well as the historical volatility) measures what actually happened in the past. Specifically, Ryu (2012) presents the properties and information contents of an implied volatility index based on Korea's index options contract for forecasting future realized volatilities. As well, Banerjee, doran and Peterson (2007) find that the forecasting power of implied volatility to returns is higher for higher beta portfolios and for longer horizon holding periods and reported fewer evidence in prior studies of the forecasting power of implied volatility for future realized returns. This is explained by the assumption that returns are unforecastable in efficient markets. However, if we start with the assumption that implied volatility is a risk factor added to or separated from realized volatility, this could be incorrect. Conversely, a number of studies examine and discover the prediction power of VIX ${ }^{17}$ for future returns leads to generally conclude that the competence of VIX to forecast future realized returns. Copeland and Copeland (1999) test VIX deviation from its mean provides predicting power for indices based on a measure of value versus growth or the market value of equity. Their findings are that large and value firms based indices performed well when VIX is high. This outcome is attributed by them to investors exploring "safe" portfolios after high VIX. Giot (2005) divided the VIX value history into twenty percentiles and analyze the predicting capability of the VIX for the S\&P 100 index. The findings are that future returns are always positive, when VIX is very high, and future returns are always negative, when VIX is very low. The cause for the predicting power of VIX to future realized returns might be due to risk correlation. Furthermore the modern asset pricing literature has been trying to address the question of whether there is a volatility risk premium in addition to the traditional price risk premium. In the sense of Merton (1973) a price risk factor in intertemporal relation between expected volatility and expected returns in a time series context may

\footnotetext{
${ }^{17}$ VIX is a measure of market expectations of stock index return volatility over the next 30 calendar days. Starting in 2003, VIX is calculated from the S\&P 500 index option prices and based on a wide range of strike prices and is independent of any option pricing model.
} 
be cause by implied volatility. If an efficient forecast of future realized volatility is implied volatility, Bali and Peng (2006) illustrate that expected volatility in the Merton (1973) relation can be applied by implied volatility. However, the feasibility that implied volatility could also be related to the volatility risk premium is not accounted. Doran and Ronn (2006) find that implied volatility is given rise to the bias by the negative price of volatility risk. As well, part of the risk of VIX may be the mean reversion of VIX. It is likely to be higher in the future, if VIX is improperly low. Indeed, as a previous research (Mateus and Konsilp, 2014), the implied volatility is applied from its option, and find the robust result that the implied idiosyncratic volatility is the best stock return predictor among the different volatility measures used over a period that involves two global financial crises: the dotcom bubble and recent financial crisis. As the result, one of encouragements for this further study is lighted up whether the implied idiosyncratic volatility would be still able to be the best stock return predictor for every sub periods both Bear and Bull markets after divide into different sectors or industries.

According to different market contexts, namely Bear and Bull markets, there is finance literature (Chauvet and Ptter, 200) introducing that Bull and Bear markets are as longer periods of price rise and price decline, respectively. Teeuwen (2012) examines the forecasting behavior of investors in Bull and Bear markets. Finally, the forecasts of the expected price cange of other investors are studied. It resulted in positive forecasts in Bull and Bear markets, which significantly differ in magnitude from the expectations of investors' own forecasts in Bear markets, however are equal to the expectations of investors' own forecasts in Bull markets. Bondt (1991) simplifies the two terms as similar as Teeuwen (2012) and defines Bull and Bear markets as two market trends with respectively a positive and negative return. Many authors, such as Cunado, Gil-Alana (2008) studied stock market volatility in Bull and Bear markets and found that the volatility is higher during Bear than Bull markets. They analysed the difference in volatility in Bull and Bear markets in the United States and conclude, similar to previous literature, volatility to be significantly higher in Bear than in bull markets. Grobys (2012) studied the volatility in Bull and Bear markets as well and found that the volatility in bear markets is almost twice as in Bull markets. Two possible explanations for higher volatility during Bear markets are given by Jones, Walker and Wilson (2004). The first states that in volatility markets equity values decline, reflecting a higher risk in the market, which is associated by an increased uncertainty. Second, investors react more quickly to news in times of uncertainty, which increases the stock price volatility. Chordia, Roll and Subrahmanyam (2001) argue that declining markets attract less investors, which leaves the markets to be subject to falling liquidity and therefore more uncertain and volatility. 
In term of "industry effect", a few papers have also found that some industry portfolios may be able to lead the stock market (Eleswarapu and Ashish, 1996 and Pollet, 2002). In particular, Pollet (2002) finds that oil can predict stock returns and most interestingly that the Norwegian stock market (which is dominated by oil) leads the world stock market. His finding regarding the Norwegian market fits especially nicely with our gradual- information-diffusion hypothesis since the Norwegian market is likely to be off the radar screen of investors who trade the world market index. Hong, Torous and Valkanov (2007) investigate whether the returns of industry portfolios are able to predict the movements of stock markets. Their finding is that out of thirty-four industry portfolios in the U.S., fourteen including commercial real estate, petroleum, metal, transportation, utilities, retail and financial can predict the stock market by up to two months. Importantly, the ability of an industry to lead the market is strongly correlated with its propensity to forecast indicators of economic activity such as industrial production growth. When they extend their analysis to the eight largest stock markets outside of the U.S., the findings are remarkably similar patterns. These findings indicate that markets incorporate information contained in industry returns about their fundamentals only with a lag because information diffuses gradually across asset markets. The logic of their hypothesis suggests that the gradual diffusion of information across asset markets ought to be pervasive. As a result, they would expect to find cross- asset return predictability in many contexts beyond industry portfolios and the broad market index. The key to finding such cross-predictability is to first identify sets of assets whose payoffs are likely correlated. As such, other contexts for interesting empirical work include looking at whether returns of stocks from one industry predict those in another or at stocks and the options listed on them. Indeed, a number of papers following theirs have taken up this task and found confirming results. For instance, Menzly and Oguzhan (2004) find that industry returns do lead and lag each other according to their place in the supply chain and Pan and Poteshman (2004) find that information may diffuse slowly from option markets to stock markets as option volume seems to be able to predict stock price movements. But much more work remains to be done on this topic.

More specifically, Alber (2013) aims at analyzing the "industry effect" on stock market reaction to global financial crisis. This has been conducted using a sample of four stock markets, and covering the period from 2007 to 2011. Kruskal-Wallis tests indicated that we could accept hypotheses regarding the effects of "industry effect" on stock market reaction to global financial crisis in Egyptian, Kuwaiti, American and British stock markets for all the research period and for the during- crisis period. As well, they referred to the need to reject the hypotheses regarding these effects in all stock markets, for the pre-crisis period. Tests indicated that hypotheses could be 
accepted regarding the effects of "country effect" on stock market reaction to global financial crisis in banking, insurance and real estate sectors. Results of "country effect" tests are consistent with those of "industry effect" in periods and sectors. Tests of the two hypotheses could be considered as robustness checks for each other. In summary, these researches, namely Hong, Torous and Valkanov (2007), Menzly and Oguzhan (2004), Pan and Poteshman (2004) and Alber (2013) encourage us to further study whether "the effect of industry" would occur on the stock return predictability of implied idiosyncratic volatility among different industry portfolios in Bear and Bull markets over the period of two global financial crises.

In this paper we investigate the role of volatility risk on stock returns predictability over the period of Global Financial Crises (included the dot-com bubble and recent financial crisis) with "Industry Specific Effects" during "Different market phases" both Bear and Bull markets from January 2001 to December 2010, for 596 sample stock options traded at the American Stock Exchange and the Chicago Board Options Exchange (CBOE). In fact, industries are classified into eight sectors, namely Basic Materials, Utilities, Industrial Goods, Financial, Consumer Goods, Healthcare, Services, and Technology.

To our knowledge, it is the first research analyzing the effect of different idiosyncratic volatility measures and industry effect by stock sector classification for a period that involves both the dotcom bubble and the recent financial crisis with sub period extension. We shed light to the relation between idiosyncratic volatility and stock prices in all different sectors and periods both Bear and Bull markets over two financial crises when S\&P500 drop at least 20 percent.

The findings confirm that after sector separation, the best stock return predictor among different volatility measures used is the implied idiosyncratic volatility which is analogous to previous study before all sectors divided. Although, evidence is not shown its forecast for all sectors, it can effectively affect for most sectors which are not weak form market efficiency such as Consumer Goods, Healthcare, Services, and Technology with estimation to be over 65 percent of stocks examined. Unfortunately, other remaining sectors which are weak form, namely Basic Materials, Utilities, Industrial Goods, and Financial, cannot be predicted by all volatility measures including implied idiosyncratic volatility. Furthermore, there is a clear evidence of a return premium for carrying idiosyncratic volatility risk among different sectors and periods. Indeed, a one percent increase in the implied idiosyncratic volatility increases future returns between 0.01 and 0.08 percent. 
The rest of the paper is organised as follows. The next section presents data sources, sample selection and methodology implemented. In Section 3, we test the different volatility forecast models and the predictive power of idiosyncratic volatility on future stock returns for all sub periods over two financial crises and for eight different industries; finally Section 4 concludes the study. 


\subsection{Data and methodology}

\subsubsection{Sample}

Our sample represents the U.S. equity option market by comprising the stock options traded at the American Stock Exchange and the Chicago Board Options Exchange (CBOE) for the period from January 2001 to December 2010. The data to undertake the research was collected from different sources. 1) The daily implied volatility for each individual company and the option open interest were collected from Tick Data and OptionMetrics; 2) Stock returns, share prices, and the number of shares outstanding are from Tick Data and CRSP and equity book value are from Tick Data and Compustat; 3) daily returns for the the Carhart (1997) momentum factor (UMD) and three Fama and French (1993) factors (MKT, SMB, HML) were collected from Kenneth French's website.

From CRSP the full data comprises 2,596 Tickers (or unique firms) for the period January 2001 to December 2010. We impose the following sample selection criteria: 1) Full information (daily basis) for trade options, 2) Daily stock returns for at least the five previous years. ${ }^{18}$ In order to confirm whether our sample represents the U.S. market as a whole, the sample average daily return was computed and the correlation between this average and the market return was calculated. The result shows a $90 \%$ of correlation which means that the data can represent the U.S. market as a whole ${ }^{19}$

Table 1 reports the initial number of firms per industry available in CRSP for the period January 2001 and December 2010 and the number of sampling firms after the previous presented selection criteria.

Table 1: Number of firms per industry (Sector)

\begin{tabular}{|c|c|c|c|}
\hline Industry & Full Sample & $\begin{array}{c}\text { Number unique } \\
\text { Firms }\end{array}$ & $\begin{array}{c}\text { Sample/Full Data } \\
(\%)\end{array}$ \\
\hline Basic Materials & 275 & 62 & 22.5 \\
\hline Consumer Goods & 268 & 64 & 23.9 \\
\hline Financials & 352 & 79 & 22.4 \\
\hline Healthcare & 270 & 63 & 23.3 \\
\hline Industrial Goods & 216 & 50 & 23.1 \\
\hline Services & 520 & 117 & 22.5 \\
\hline Technology & 603 & 141 & 23.4 \\
\hline Utilities & 92 & 20 & 21.7 \\
\hline Total & 2,596 & 596 & 22.9 \\
\hline
\end{tabular}

\footnotetext{
${ }^{18}$ This condition is essential for the calculation of idiosyncratic realized, implied volatility and the firm's beta.

${ }^{19}$ Results are available upon request.
} 
Overall there are 596 unique firms in our sample which represents 22.9 percent of full data available in CRSP. There is no evidence of a single industry to be more represented in the sample. In fact, the percentage of unique firms per industry presented in the sample is very similar with values between 21.7 and 23.9 percent for Utilities and Consumer Goods, respectively.

\subsubsection{Methodology}

\subsubsection{Beta, Implied and Realized idiosyncratic volatilities}

\subsection{Beta Calculation}

The firm's beta for each of the unique firms selected is calculated in a 60 months rolling basis. The Firm $j$ 's beta is estimated by the regression of stock returns $r$ on market returns Mret for each month with the use of the previous 60 months:

$$
r_{j, t}=\alpha_{j}+\beta_{j} \operatorname{Mret}_{t}+\varepsilon_{j, t}
$$

where, Mret is the S\&P 500 value-weighted monthly returns collected from CRSP, $r$ is the stock monthly returns, $\alpha$ represents the constant term and $\varepsilon$ is the error term. Furthermore, the beta calculation robustness is verified by applying the Fama and French (1993) three factor model and a beta portfolio computed following Fu (2009) creating equal-weighted returns in a rolling monthly estimation for portfolios of $10 \times 10$ depending on firm's number and size betas. Then, the regression of these portfolios returns are performed on the S\&P 500 value-weighted monthly returns with onemonth lag to determine portfolio betas for the individual firms based on their beta level and size.

\subsection{Implied idiosyncratic volatility calculation}

Data is gathered as refereed from OptionMetrics employing European and American models upon appropriated. The standardized implied volatility is estimated by using the option nearest to 30 days to maturity and at-the-money for both puts and calls to deduct the measurement error related to the conversion to attain implied volatilities from option prices. ${ }^{20}$

Analogous to Stivers, Mayhew and Dennis (2006) for the computation of the implied volatility in its idiosyncratic part the market implied volatility is demonstrated to be a market volatility function:

\footnotetext{
${ }^{20}$ For details see Hentschel (2003).
} 


$$
\sigma_{I V}^{2}, t=\beta_{j}^{2} \sigma_{I V, t}^{2}+\sigma_{I V}^{2}{ }_{i d i o, j, t}
$$

where, $\sigma_{I V}^{2}$ is the VIX implied market variance for day $t, \sigma_{I V}^{2}$ is is the total implied variance at time $t$ for firm $j, \beta^{2}{ }_{j}$ is the squared market beta from equation (1) and $\sigma_{I V}^{2}{ }_{i d i o, j, t}$ is the implied variance in the idiosyncratic part at time $t$ for firm $j$. Thus, the measurement of implied idiosyncratic volatility is the square root of the implied variance of the idiosyncratic part. In theory, this value would not be equal to zero or negative but it is possible empirically to occur. ${ }^{21}$

\subsection{Realized idiosyncratic volatility calculation}

The annualized realized volatility is calculated for each month and firm as the annualized standard deviation of daily returns. The realized idiosyncratic volatility part is calculated through equation (1) using daily observations. The realized idiosyncratic risk $\sigma_{R V_{i d i o, j, t}}$, is calculated from daily residuals standard deviation for each month and firm, such that:

$$
\sigma_{R V_{i d i o, j, t}}=\sqrt{\frac{1}{N} \sum_{n=1}^{N}\left(\varepsilon_{j, t, n}-\bar{\varepsilon}_{j, t}\right)^{2}}
$$

where, $N$ is the number of trading days in each month, $\varepsilon_{j, t, n}$ is the residual for firm $j$ on day $n$ for

month $t$ and $\bar{\varepsilon}_{j, t}$ is the mean residual in month $t$ over the $N$ days for firm $j$. The $\sigma_{R V_{i d i o, j, t}}$ is measured in annual basis.

\subsubsection{EGARCH and $A R(2)$}

The advantage of the EGARCH versus the GARCH model is the no requirement to restrict the parameters to assure a non-negative variance. This function is formed as:

$$
R_{i, t}=\alpha_{j}+\beta_{M K T, j} M K T_{M, t}+\beta_{S M B, j} S M B_{t}+\beta_{H M L j} H M L_{t}+\varepsilon_{j, t}, \quad \varepsilon_{j, t} \sim N\left(0, \sigma_{j, t}^{2}\right)
$$

Where the monthly returns are calculated following the Fama and French (1993) 3-factor model in

${ }^{21}$ The small values are set equal to zero and there are non-positive values. 
equation (4) and the conditional variance for firm $j \sigma_{E G_{i d i o, j, t}}^{2}$ is a function of the past $p$ residual variances and $q-$ period stock returns.

$$
\ln {\sigma^{2}}_{E G_{i d i o, j, t}}=\alpha_{i}+\sum b_{j, \phi} \ln \sigma_{j, t-1}^{2}+\sum c_{j, \phi}\left\{\theta\left(\varepsilon_{j, t-k} / \sigma_{j, t-k}\right)+\gamma\left[\left|\left(\varepsilon_{j, t-k} / \sigma_{j, t-k}\right)\right|-\sqrt{(2 / \pi)}\right]\right\}
$$

Equations (4) and (5) are computed at least for 60 monthly returns for each stock. The idiosyncratic volatility is calculated as the square root of the conditional variance.

For the autoregressive model in $2^{\text {nd }}$ order, $A R(2)$ for the idiosyncratic volatility estimation we follow Chua, Goh and Zhang (2005). Applying equation (4) to calculate the square residual, the idiosyncratic variance for firm $j$ is calculated as:

$$
\sigma_{A R i d i o, j, t}=\lambda_{1, j}+\lambda_{2, j} \varepsilon_{j, t-1}+\lambda_{3, j} \varepsilon_{j, t-2}+\eta_{j, t}
$$

The idiosyncratic volatility is defined as the square root of the idiosyncratic variance.

\subsubsection{Short-sale and liquidity}

Additionally we control for possible short-sale constraints or liquidity issues. Particularly, highly liquid stocks are less likely to get market frictions and consequently this has an important impact in traded options. The liquidity measure open-interest is calculated as one plus the option open-interest logarithm, where open-interest is compiled for each firm across the all options. For the measure of short-sale constraint we follow Ofek, Richardson, and Whitelaw (2004) as:

$$
\text { ORW Ratio }=100 \times \ln [S / S *]
$$

Where $S^{*}$ is the theoretical price computed from the call-put relation including the put of last exercise premium $^{22}$ and $\mathrm{S}$ is the current stock price. The ORW Ratio should exceed zero if a short-sale constraint exists. Consequently, we estimate premium for call and put options daily with different strike price from OptionMetrics. Options are selected at the end of each month. The strike price, which closes to the stock price and stand in the at-the-money option, is used to calculate $S^{*}$ by put-

\footnotetext{
${ }^{22}$ Refer to Ofek, Richardson and Whitelaw (2004).
} 
call Parity as Call - Put + Strike price * $\operatorname{EXP}(0.1 \mathrm{t})$ and 0.1 is risk-free-rate of Treasury Bill. At last, ORW Ratio can be determinded by monthly stock price and $S^{*}$ as the above equation.

In summary the control for possible short-sale constraints or liquidity issues are performed to test the hypothesis whether short-sale constraints and/or higher liquidity impacts prices differently in response to volatility than those from more restricted companies.

\subsubsection{Realized volatility prediction}

\subsection{Implied volatility}

How well does implied volatility (IV) predict future realized volatility (RV) is measured at both individual (firm) and market levels. The following regressions are performed:

$$
\sigma_{R V_{M, t+1}}=\alpha_{t}+\xi_{1} \sigma_{I V_{M, t}}+\xi_{2} \sigma_{R V_{M, t}}+\varepsilon_{j_{t+1}}
$$

and,

$$
\sigma_{R V j, t+1}=\alpha_{j, t}+\xi_{1, j} \sigma_{I V}+t+\xi_{2, j} \sigma_{R V}+\varepsilon_{j, t+1}
$$

where, $\sigma_{R V_{M, t}}$ is the annualized realized monthly volatility in month $t$ for the S\&P 500 index, $\sigma_{I V}{ }_{M, t}$ is the VIX index in month $t, \alpha$ is the constant term, $\xi_{1}$ and $\xi_{2}$ are estimated coefficients and $\varepsilon$ is the error term. The regression specification at individual/firm level is shown in equation (9). The equation is performed to each firm independently, whilst the mean and median coefficients are presented as well respective significance. $\sigma_{R V}, t$, represents the annualized realized monthly volatility in month $t$ for each unique firm, $\sigma_{I V}, t$ is the implied volatility for each firm in month $t, \alpha$ is the constant term, $\xi_{1}$ and $\xi_{2}$ are estimated coefficients and $\varepsilon$ is the error term.

\subsection{Implied idiosyncratic volatility}

We will additionally test the power of implied idiosyncratic volatility, and EGARCH and $\mathrm{AR}(2)$ volatility forecast models to predict realized idiosyncratic volatility. The following regression is estimated:

$$
\sigma_{R V i d i o, j, t+1}=\alpha_{j}+\psi_{1, j} \sigma_{I V i d i o, j, t}+\psi_{2, j} \sigma_{E G_{i d i o, j, t}}+\psi_{3, j} \sigma_{A R i d i o, j, t}+\psi_{4, j} \sigma_{R V i d i o, j, t}+\varepsilon_{j, t+1}
$$

where, $\sigma_{R V_{i d i o, j, t}}$ represents the realized idiosyncratic volatility in month $t$ for firm $j, \sigma_{I V} i d i o, j, t$, is 
the implied variance in its idiosyncratic part at month $t$ for firm $j, \sigma_{E G_{i d i o, j, t}}$, is conditional variance for firm $j$ in month $t$ is, $\sigma_{A R}$ idio,j,t , is the idiosyncratic volatility estimation following Chua, Goh and Zhang (2005) autoregressive model in $2^{\text {nd }}$ order, $A R(2), \alpha$ is the constant term, $\psi$ 's estimated coefficients and $\varepsilon$ is the error term.

\subsubsection{Predictive Regressions}

\subsection{Fama-Macbeth (1973)}

The final step is to examine the relation between idiosyncratic risk and firm future returns. We extend the study of Ang et al (2006) by including firm specific characteristics in our analysis. As a result we assess in a monthly basis and at firm level the relation between idiosyncratic volatility and future stock returns, applying firm-specific controls and following Fama and Macbeth (1973) procedure. The following regression is estimated:

$r_{j, t+1}=\alpha_{j}+\lambda_{1} \sigma_{R V \text { idio }, j, t}+\lambda_{2} \log S I Z E_{j, t}+\lambda_{3} \log B M_{j, t}+\lambda_{4} r_{j, t}+\lambda_{5} r_{j, t-11: t-1}+\lambda_{6} r_{j, t-35: t-12}+\lambda_{7} \beta_{j, t}+\varepsilon_{j, t+1}$

where, $r_{j, t}$ represents the stock return for firm for firm $j$ in month $t, \sigma_{R V_{i d i o, j, t}}$, is the realized idiosyncratic volatility in month $t$ for firm $j, \log S I Z E_{j, t}$, is the logarithm of market value of equity (calculated by multiplying the company's current stock price by its number of outstanding shares.), $\log B M_{j, t}$, is the logarithm of the book-to-market ratio, $r_{j, t-11: t-1}$ and $r_{j, t-35: t-12}$, represents the stock return for firm $j$ one and three years before the current month, $\beta_{j, t}$, is firm $j$ equity Beta, $\alpha$ is the constant term, $\lambda$ 's estimated coefficients and $\varepsilon$ is the error term.

Additionally, the previous equation is modified by including the idiosyncratic volatility forecasts (implied volatility, EGARCH and $\mathrm{AR}(2)$ ), short-sale constraints and liquidity issues. The regression will proceed as follow:

$$
\begin{aligned}
& r_{j, t+1}=\alpha_{j}+\lambda_{1} \sigma_{R V_{i d i o, j, t}}+\lambda_{2} \log S I Z E_{j, t}+\lambda_{3} \log B M_{j, t}+\lambda_{4} r_{j, t}+\lambda_{5} r_{j, t-11: t-1}+\lambda_{6} r_{j, t-35: t-12}+\lambda_{7} \beta_{j, t}+ \\
& +\lambda_{8} \sigma_{I V_{\text {idio }, j, t}}+\lambda_{9} \sigma_{E G_{\text {idio }, j, t}}+\lambda_{10} \sigma_{\text {AR2 }} \text { idio, }, t, t \\
& +\lambda_{11} O R W_{\text {ratio }_{j, t}}+\lambda_{12} O I_{j, t}+\varepsilon_{j, t+1}
\end{aligned}
$$

where, $r_{j, t}$ represents the stock return for firm for firm $j$ in month $t, \sigma_{R V}$ idio,j,t , is the realized idiosyncratic volatility in month $t$ for firm $j, \log S I Z E_{j, t}$, is the logarithm of market value of equity (calculated by multiplying the company's current stock price by its number of outstanding shares.), 
$\log B M_{j, t}$, is the logarithm of the book-to-market ratio, $r_{j, t-11: t-1}$ and $r_{j, t-35: t-12}$, represents the stock return for firm $j$ one and three years before the current month, $\beta_{j, t}$, is firm $j$ equity Beta, $\sigma_{I V} i d i o, j, t$, is the implied variance in its idiosyncratic part at month $t$ for firm $j, \sigma_{E G_{i d i o, j, t}}$, is conditional variance for firm $j$ in month $t$ is, $\sigma_{A R}$ idio,j,t , is the idiosyncratic volatility estimation following Chua, Goh and Zhang (2005) autoregressive model in $2^{\text {nd }}$ order, $A R(2), O R W_{\text {ratio } j, t}$, is the $O R W$ Ratio following Ofek, Richardson, and Whitelaw (2004), $O I_{j, t}$, is the liquidity measure open-interest, $\alpha$ is the constant term, $\lambda$ 's estimated coefficients and $\varepsilon$ is the error term.

\subsubsection{Breakpoints by Chow Test}

To analyse and enlarge the effect of idiosyncratic volatility on stock return predictability during the dot-com bubble and the recent financial crisis over sub periods for both bear and bull markets. We will perform structural break test by Chow's test for whole periods from January 2001 to December 2010 over two mentioned financial crises to conclude appropriate breakpoints and definite time interval for every sub-periods. By definition, the Chow test is a statistical and econometric test of whether the coefficients in two linear regressions on different data sets are equal. In econometrics, the Chow test is most commonly used in time series analysis with various types of data including panel to test for the presence of a structural break and often used to determine whether the independent variables have different impacts on different subgroups of the population.

Suppose that we model our data as

$$
y_{t}=a+b x_{1 t}+c x_{2 t}+\varepsilon
$$

If we split our data into two groups, then we have

$$
y_{t}=a_{1}+b_{1} x_{1 t}+c_{1} x_{2 t}+\varepsilon
$$

and

$$
y_{t}=a_{2}+b_{2} x_{1 t}+c_{2} x_{2 t}+\varepsilon
$$

The null hypothesis of the Chow test asserts that $a_{1}=a_{2}, b_{1}=b_{2}$, and $c_{1}=c_{2}$, and there is the assumption that the model errors $\varepsilon$ are independent and identically distributed from a normal distribution with unknown variance. Let $S_{C}$ be the sum of squared residuals from the combined data, $S_{1}$ be the sum of squared residuals from the first group, and $S_{2}$ be the sum of squared residuals from the second group. $N_{1}$ and $N_{2}$ are the number of observations in each group and $\mathrm{k}$ is the total number of parameters. Then the Chow test statistic is:

$$
\frac{\left(S_{C}-\left(S_{1}+S_{2}\right)\right) /(k)}{\left(S_{1}+S_{2}\right) /\left(N_{1}+N_{2}-2 k\right)}
$$


The test statistic follows the F distribution with $\mathrm{k}$ and $N_{1}+N_{2}-2 \mathrm{k}$ degrees of freedom. Moreover, the global sum of squares (SSE) if often called Restricted Sum of Squares (RSSM) as we basically test a constrained model where we have $2 \mathrm{~K}$ assumptions (with $\mathrm{K}$ the number of regressors).

\subsection{Data sources and description}

Table 2 below summarizes the data sources and equations description for each of the research steps detailed previously.

Table 2: Data Sources and Description

\begin{tabular}{llc}
\hline & \multicolumn{1}{c}{ Variable } & Source and Description \\
\hline 1. & Index Return & CRSP \\
2. & Stock return & CRSP \\
3. & Realized Volatility Index & CRSP \\
4. & Realized Stock Volatility & OptionMetrics \\
5. & Implied Stock Volatility & OptionMetrics \\
6. & Realize Idiosyncratic Volatility & Calculated with (Stock Beta, Realized and Implied Stock Volatility) \\
7. & Implied Idiosyncratic Volatility & [Equations (3) and (4)] \\
& & Fama French and Liquidity Factors [Equation (5)] \\
8. & EGARCH Idiosyncratic Volatility & Fama French and Liquidity Factors [Equation (6)] \\
9. & AR(2) Idiosyncratic Volatility & OptionMetric (Use to calculate log SIZE) \\
10. & Market Value & Compustat (Use with equation of 10, to calculate log BM) \\
11. & Firm's Equity & OptionMetrics (Use to calculate Option Interest) \\
12. & Option Volume &
\end{tabular}




\subsection{Empirical Results}

Our empirical analysis is divided in several steps. First, we start by examining breakpoints by Chow test to determine what sub-periods are over two financial crises which are Dotcom Bubble in 2002 and recent financial crisis in 2008. Therefore, we extend previous research showing full periods from 2001 to 2010 by divide into 4 sub periods as breakpoints tested by Chow method both Bear and Bull markets. Then, we present a brief overview of summary statistics for the variables used in this study followed by preliminary tests whether lagged historical/implied volatilities or EGARCH and AR(2) models better explain realized volatility. Finally, we finish with the predictive Regressions analysis for every sub periods and conclusion.

The sample represents the U.S. equity option market by comprising the stock options traded at the American Stock Exchange and the Chicago Board Options Exchange (CBOE) for the period from January 2001 to December 2010. Our sample comprises 596 unique firms. To ensure that the sample represents the US market as a whole, the correlation between the average daily return per stock and the market return (proxied by S\&P500) was calculated. The correlation between the average sample returns and market return is above $90 \%$ showing that our sample represents properly the U.S. market as a whole.

\subsubsection{Descriptive statistics}

Table 3 reports per year summary statistics for the 596 unique firms analysed. We can highlight the increased volatility in 2001-2002 (dotcom bubble) ${ }^{23}$ and 2008-2009 (recent financial crisis). Additionally the implied volatility annual standard deviation increases in the two cited periods, a clear evidence of the no homogeneous increase in volatility among the different stocks in our sample, supporting that differences in firms and industry sectors do exist.

Table 3: Implied Volatility statistics

\begin{tabular}{cccccc}
\hline Year & $\begin{array}{c}\text { Implied Volatility } \\
\text { (Average monthly) }\end{array}$ & $\begin{array}{c}\text { Implied Volatility } \\
\text { (Median monthly) }\end{array}$ & $\begin{array}{c}\text { Std. Deviation Implied } \\
\text { Volatility }\end{array}$ & Maximum & Minimum \\
\hline 2001 & 0.567 & 0.510 & 0.231 & 1.672 & 0.085 \\
2002 & 0.533 & 0.482 & 0.223 & 1.953 & 0.111 \\
2003 & 0.435 & 0.396 & 0.179 & 1.751 & 0.134 \\
2004 & 0.366 & 0.333 & 0.137 & 1.002 & 0.122 \\
2005 & 0.337 & 0.311 & 0.125 & 1.746 & 0.117 \\
2006 & 0.334 & 0.316 & 0.117 & 1.147 & 0.116 \\
2007 & 0.356 & 0.332 & 0.131 & 1.616 & 0.117 \\
2008 & 0.544 & 0.494 & 0.222 & 2.114 & 0.137 \\
2009 & 0.574 & 0.532 & 0.221 & 1.988 & 0.167 \\
2010 & 0.465 & 0.444 & 0.151 & 1.436 & 0.135 \\
\hline
\end{tabular}

${ }^{23}$ S\&P500 index drops by 13.04 and 23.37 percent in 2001 and 2002, respectively. 
Table 4 presents the same analysis regarding the historical volatility. In fact historical volatility is higher on 2001-2002 and 2008-2009 periods. We can also detect a higher average implied volatility comparing with historical volatility in our sample possible indicating that options are overvalued. ${ }^{24}$

Table 4: Historical Volatility statistics

\begin{tabular}{cccccc}
\hline Year & $\begin{array}{c}\text { Historical Volatility } \\
\text { (Average monthly) }\end{array}$ & $\begin{array}{c}\text { Historical Volatility } \\
\text { (Median monthly) }\end{array}$ & $\begin{array}{c}\text { Std Deviation Implied } \\
\text { Volatility }\end{array}$ & Maximum & Minimum \\
\hline 2001 & 0.514 & 0.432 & 0.314 & 3.594 & 0.072 \\
2002 & 0.493 & 0.417 & 0.311 & 5.289 & 0.082 \\
2003 & 0.355 & 0.306 & 0.210 & 3.305 & 0.058 \\
2004 & 0.295 & 0.251 & 0.161 & 1.776 & 0.069 \\
2005 & 0.268 & 0.235 & 0.155 & 4.321 & 0.065 \\
2006 & 0.275 & 0.243 & 0.152 & 3.369 & 0.050 \\
2007 & 0.297 & 0.262 & 0.159 & 2.418 & 0.054 \\
2008 & 0.581 & 0.469 & 0.379 & 3.996 & 0.086 \\
2009 & 0.508 & 0.425 & 0.336 & 5.101 & 0.054 \\
2010 & 0.325 & 0.292 & 0.166 & 2.178 & 0.049 \\
\hline
\end{tabular}

In Figures 1 and 2 it is presented the average monthly implied and historical volatilities per industry.

Figure 1: Monthly Implied Volatility

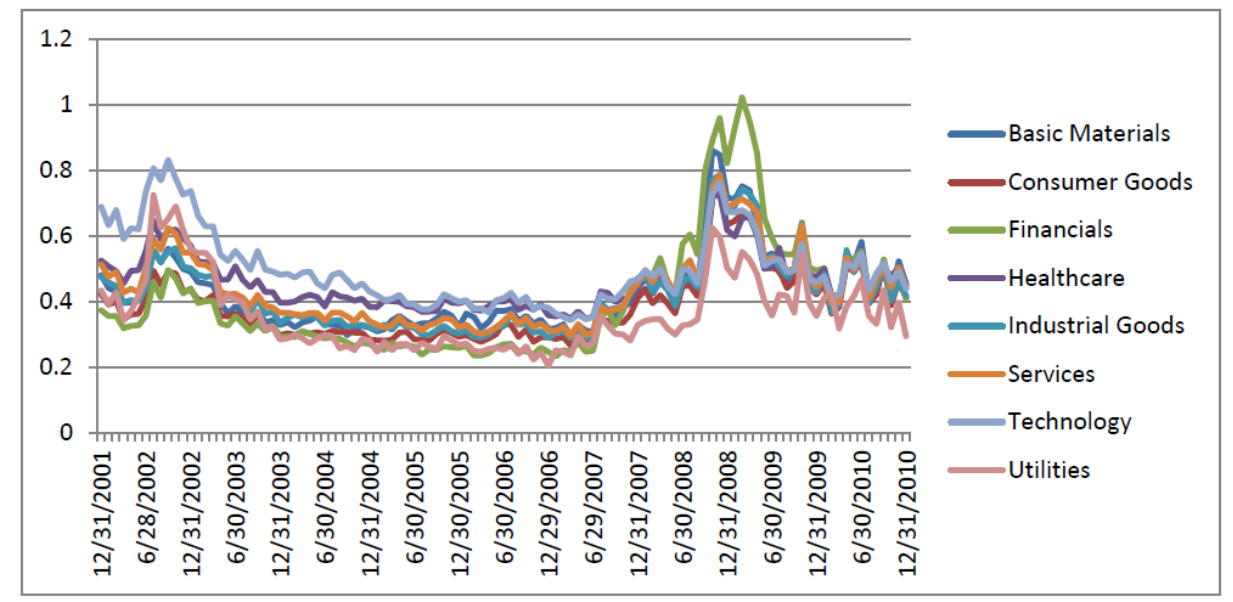

The volatility increase in the years 2001-2002 and 2008-2009 is observed independently of the industry analysed. However, there is a clear evidence of higher volatility (both implied and historical) of technology firms in the period 2001-2002 and Financials in 2008-2009.

\footnotetext{
${ }^{24}$ When implied volatility is greater than historical volatility, options are thought to be overvalued, and when implied volatility is less than historical volatility, options are considered to be undervalued.
} 
Figure 2: Monthly Historical Volatility

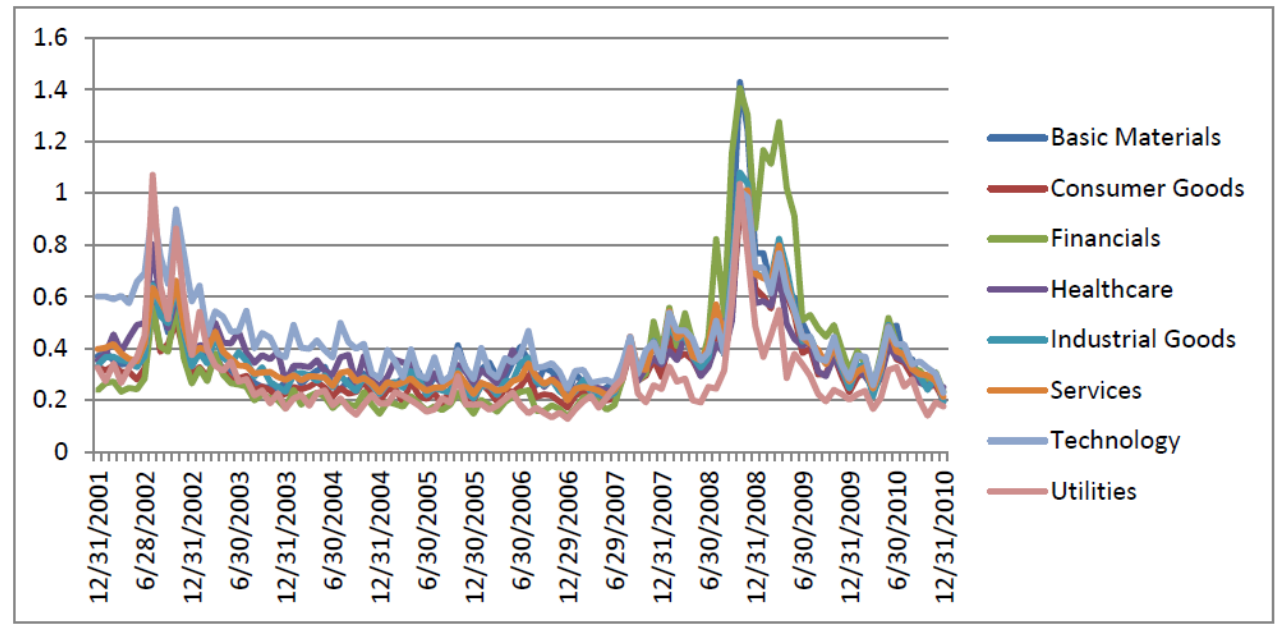

\subsubsection{Breakpoints in Financial Crises}

Kristoufek (2013), show that NASDAQ as primarily a technological index was most severely hit by the Dot Com bubble at the break of the millennium and it plummeted from its highs around 5000 points down to 1000 points at the end of 2002. As the result, we apply "31/12/2002 (December 2002)" to be "the first breakpoint" for testing. Moreover, Gorton, Metrick, and Xie (2015), define financial crisis as a common econometric breakpoint in the characteristics of different forms of bankproduced money. They use this methodology to document the recent financial crisis of 2007-2009. Specifically, their finding is that the subprime shock occurs on January 4, 2007. In fact, the real economy is affected starting on January 3, 2008. The crisis then evolves. Consequently, "the second breakpoint", which is "31/12/2007 (December 2007)", is considered and employed for testing. Furthermore, Xiong, Sun, Wang, Wang, and Liu (2016) show that December 2008 is the most observable breakpoint through the selection data with U.S. weekly leading index $\mathrm{WLI}^{25}$ changes in different breakpoint periods. They find that December 2008 became the most observable structural mutation point was that the financial crisis in 2008. The financial crisis led to economic recession throughout the world, and made investors lose confidence to invest. Finally, we employ "the third breakpoint” as “31/12/2008 (December 2008)" for examination.

Table 5 (table 5.1 to 5.8) reports analysis by Chow structural break test; (Chow, 1960) for the entire periods spanning January 2001 to December 2010 over the two previously mentioned financial

\footnotetext{
${ }^{25} \mathrm{WLI}$ is a forward-looking composite leading index that anticipates cyclical turning points in U.S. economic ability by 2 - 3 quarters. The data are calculated by Economic Cycle Research Institute (ECRI). WLI is a useful tool for investors and government to predict the future dollar index. WLI is easier to get than dollar index, and dollar index is hysteretic. In fact, the U.S. dollar index is a sign of confidence from the market for the US economy.
} 
crises. This is done in order to examine, and draw conclusions regarding, appropriate breakpoints with definite time intervals for every sub period. In fact, Chow test is used for every sectors on the key regression of Fama-Macbeth future returns estimation with firm-specific characteristics as shown in Konsilp W. and Mateus C. (2014). Our analysis is applied Chow test and monthly cross-sectional regressions using Fama-Macbeth (1973) with different combinations for the independent variables (models 1 to 10). Finally, we find that three main breakpoints comprised of 31/12/2002 (December 2002), 31/12/2007 (December 2007), and 31/12/2008 (December 2008) are able to give those strong results for every models following the $\mathrm{F}$ distribution at $1 \%$ level of statistical significance during both financial crises (Dotcom Bubble and recent financial crisis) between 2001 and 2010.

$$
\begin{aligned}
& r_{j, t+1}=\alpha_{j}+\lambda_{1} \sigma_{R V_{i d i o, j, t}}+\lambda_{2} \log S I Z E_{j, t}+\lambda_{3} \log B M_{j, t}+\lambda_{4} r_{j, t}+\lambda_{5} r_{j, t-11: t-1}+\lambda_{6} r_{j, t-35: t-12}+\lambda_{7} \beta_{j, t}+ \\
& +\lambda_{8} \sigma_{I V i d i o, j, t}+\lambda_{9} \sigma_{E G_{\text {idio }, j, t}}+\lambda_{10} \sigma_{\text {AR2 } i \text { idio }, j, t}+\lambda_{11} O R W_{\text {ratio }_{j, t}}+\lambda_{12} O I_{j, t}+\varepsilon_{j, t+1}
\end{aligned}
$$

where, represents the stock return for firm for firm $j$ in month $t, \sigma_{R V i d i o, j, t}$, is the realized idiosyncratic volatility in month $t$ for firm $j, \log S I Z E_{j, t}$, is the $\log$ arithm of market value of equity (calculated by multiplying the company's current stock price by its number of outstanding shares.), $\log B M_{j, t}$, is the logarithm of the book-to-market ratio, $r_{j, t-11: t-1}$ and $r_{j, t-35: t-12}$,represents the stock return for firm $j$ one and three years before the current month, $\beta_{j, t}$, is firm $j$ equity Beta, $\sigma_{I V} i d i o, j, t$, is the implied variance in its idiosyncratic part at month $t$ for firm $j, \sigma_{E G_{i d i o, j, t}}$, is conditional variance for firm $j$ in month $t$ is, $\sigma_{A R}$ idio,j,t , is the idiosyncratic volatility estimation following Chua, Goh and Zhang (2005) autoregressive model in $2^{\text {nd }}$ order, $A R(2), O R W_{\text {ratio }_{j, t}}$, is the $O R W$ Ratio following Ofek, Richardson, and Whitelaw (2004), $O I_{j, t}$, is the liquidity measure open-interest, $\alpha$ is the constant term, $\lambda$ 's estimated coefficients and $\varepsilon$ is the error term.

In summary, we find strong evidences when breakpoints are assigned to be three of $31 / 12 / 2002,31 / 12 / 2007$, and 31/12/2008 for Chow test, the statistical testing outcomes following to the $\mathrm{F}$ distribution for every models are statistical significance at 1 percent level for every sectors. In fact, this shows that coefficients examined and obtained from an above equation of Fama-Macbeth future returns estimation with firm-specific characteristics are not consistent, as the result "these breakpoints" can be strongly confirmed to be effective and the sub periods are divided into 4 intervals called "Phase" for further examinations in all sectors as following. 
1. Phase 1 is between February 2001 and December 2002 (01/02/2001 and 31/12/2002).

2. Phase 2 is between January 2003 and December 2007 (01/01/2003 and 31/12/2007).

3. Phase 3 is between January 2008 and December 2008 (01/01/2008 and 31/12/2008).

4. Phase 4 is between January 2009 and December 2010 (01/01/2009 and 31/12/2010).

Chow method is examined for all sectors with three Breakpoints such as 31/12/2002, 31/12/2007, and 31/12/2008 on the key regression of Fama-Macbeth future returns estimation with firm-specific characteristics with below results. To be concluded, those results strongly show that three main breakpoints, namely 31/12/2002 (December 2002), 31/12/2207 (December 2007), and 31/12/2008 (December 2008) present at 1\% level of statistical significance for every models during both financial crises (Dotcom Bubble and recent financial crisis) between 2001 and 2010.

$$
\begin{aligned}
& r_{j, t+1}=\alpha_{j}+\lambda_{1} \sigma_{R V i d i o, j, t}+\lambda_{2} \log S I Z E_{j, t}+\lambda_{3} \log B M_{j, t}+\lambda_{4} r_{j, t}+\lambda_{5} r_{j, t-11: t-1}+\lambda_{6} r_{j, t-35: t-12}+\lambda_{7} \beta_{j, t}+
\end{aligned}
$$

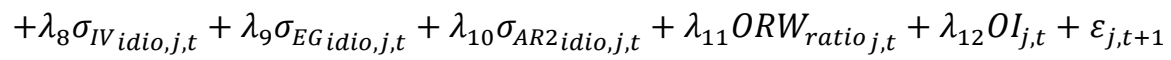

Table 5: Model Summary on breakpoints by Chow Test and sector classification

Table 5.1: Basic Materials Sector

\begin{tabular}{|c|c|c|c|c|}
\hline Model & Variables & \multicolumn{2}{|c|}{ F-statistic } & Probability \\
\hline Model 1 & $\log S I Z E, \log B M, r_{t}, r_{j, t-11: t-1}, r_{j, t-35: t-12}$ & 19.24189 & $* * *$ & 0.0000 \\
\hline Model 2 & $\log S I Z E, \log B M, r_{t}, r_{j, t-11: t-1}, r_{j, t-35: t-12}, \beta_{j}$ & 16.69213 & *** & 0.0000 \\
\hline Model 3 & $\log S I Z E, \log B M, r_{t}, r_{j, t-11: t-1}, r_{j, t-35: t-12}, \beta_{j}, \sigma_{R V \text { idio }}$ & 13.71677 & $* * *$ & 0.0000 \\
\hline Model 4 & $\log S I Z E, \log B M, r_{t}, r_{j, t-11: t-1}, r_{j, t-35: t-12}, \beta_{j}, \sigma_{I V \text { idio }}$ & 15.84812 & $* * *$ & 0.0000 \\
\hline Model 5 & $\log S I Z E, \log B M, r_{t}, r_{j, t-11: t-1}, r_{j, t-35: t-12}, \beta_{j}, \sigma_{R V_{i d i o}}, \sigma_{I V \text { idio }}$ & 12.5024 & $* * *$ & 0.0000 \\
\hline Model 6 & $\log S I Z E, \log B M, r_{t}, r_{j, t-11: t-1}, r_{j, t-35: t-12}, \beta_{j}, \sigma_{R V i d i o}, \sigma_{E G_{i d i o, j, t}}$ & 13.1492 & $* * *$ & 0.0000 \\
\hline Model 7 & $\log S I Z E, \log B M, r_{t}, r_{j, t-11: t-1}, r_{j, t-35: t-12}, \beta_{j}, \sigma_{R V_{i d i o}}, \sigma_{A R_{i d i o}, j, t}$ & 13.6702 & $* * *$ & 0.0000 \\
\hline Model 8 & $\log S I Z E, \log B M, r_{t}, r_{j, t-11: t-1}, r_{j, t-35: t-12}, \beta_{j}, \sigma_{R V_{i d i o}}, \sigma_{I V}{ }_{\text {idio }}, \sigma_{E G_{i d i o, j, t}}, \sigma_{A R_{i d i o, j, t}}$ & 11.69826 & $* * *$ & 0.0000 \\
\hline Model 9 & $\log S I Z E, \log B M, r_{t}, r_{j, t-11: t-1}, r_{j, t-35: t-12}, \beta_{j}, \sigma_{R V_{\text {idio }}}, \sigma_{I V \text { idio }}, O R W_{\text {ratio }}$, OI & 10.13269 & $* * *$ & 0.0000 \\
\hline Model10 & $\log B M, r_{t}, r_{j, t-11: t-1}, r_{j, t-35: t-12}, \beta_{j}, \sigma_{R V_{\text {idio }}}, \sigma_{I V_{\text {idio }}}, O R W_{\text {ratio }}, O I$ & 11.14864 & $* * *$ & 0.0000 \\
\hline
\end{tabular}


Table 5.2: Consumer Goods Sector

\begin{tabular}{|c|c|c|c|c|}
\hline Model & Variables & \multicolumn{2}{|c|}{ F-statistic } & Probability \\
\hline Model 1 & $\log S I Z E, \log B M, r_{t}, r_{j, t-11: t-1}, r_{j, t-35: t-12}$ & 13.66727 & $* * *$ & 0.0000 \\
\hline Model 2 & $\log S I Z E, \log B M, r_{t}, r_{j, t-11: t-1}, r_{j, t-35: t-12}, \beta_{j}$ & 12.52907 & $* * *$ & 0.0000 \\
\hline Model 3 & $\log S I Z E, \log B M, r_{t}, r_{j, t-11: t-1}, r_{j, t-35: t-12}, \beta_{j}, \sigma_{R V}$ idio & 14.87334 & $* * *$ & 0.0000 \\
\hline Model 4 & $\log S I Z E, \log B M, r_{t}, r_{j, t-11: t-1}, r_{j, t-35: t-12}, \beta_{j}, \sigma_{I V}$ idio & 12.26837 & $* * *$ & 0.0000 \\
\hline Model 5 & $\log S I Z E, \log B M, r_{t}, r_{j, t-11: t-1}, r_{j, t-35: t-12}, \beta_{j}, \sigma_{R V \text { idio }}, \sigma_{I V \text { idio }}$ & 12.5678 & $* * *$ & 0.0000 \\
\hline Model 6 & $\log S I Z E, \log B M, r_{t}, r_{j, t-11: t-1}, r_{j, t-35: t-12}, \beta_{j}, \sigma_{R V i d i o}, \sigma_{E G_{i d i o}, j, t}$ & 13.41202 & $* * *$ & 0.0000 \\
\hline Model 7 & $\log S I Z E, \log B M, r_{t}, r_{j, t-11: t-1}, r_{j, t-35: t-12}, \beta_{j}, \sigma_{R V_{i d i o}}, \sigma_{A R}$ idio $, j, t$ & 13.25409 & $* * *$ & 0.0000 \\
\hline Model 8 & $\log S I Z E, \log B M, r_{t}, r_{j, t-11: t-1}, r_{j, t-35: t-12}, \beta_{j}, \sigma_{R V_{\text {idio }}}, \sigma_{I V_{\text {idio }}}, \sigma_{E G_{i d i o, j, t}}, \sigma_{A R_{i d i o}, j, t}$ & 10.90817 & $* * *$ & 0.0000 \\
\hline Model 9 & $\log S I Z E, \log B M, r_{t}, r_{j, t-11: t-1}, r_{j, t-35: t-12}, \beta_{j}, \sigma_{R V_{\text {idio }}}, \sigma_{I V_{\text {idio }}}, O R W_{\text {ratio }}$, OI & 10.60654 & $* * *$ & 0.0000 \\
\hline Model10 & $\log B M, r_{t}, r_{j, t-11: t-1}, r_{j, t-35: t-12}, \beta_{j}, \sigma_{R V_{\text {idio }}}, \sigma_{I V_{\text {idio }}}, O R W_{\text {ratio }}$, OI & 11.58105 & $* * *$ & 0.0000 \\
\hline
\end{tabular}

Table 5.3: Financial Sector

\begin{tabular}{|c|c|c|c|c|}
\hline Model & Variables & F-statis & & Probability \\
\hline Model 1 & $\log S I Z E, \log B M, r_{t}, r_{j, t-11: t-1}, r_{j, t-35: t-12}$ & 7.582256 & $* * *$ & 0.0000 \\
\hline Model 2 & $\log S I Z E, \log B M, r_{t}, r_{j, t-11: t-1}, r_{j, t-35: t-12}, \beta_{j}$ & 7.028673 & $* * *$ & 0.0000 \\
\hline Model 3 & $\log S I Z E, \log B M, r_{t}, r_{j, t-11: t-1}, r_{j, t-35: t-12}, \beta_{j}, \sigma_{R V}$ idio & 6.176617 & $* * *$ & 0.0000 \\
\hline Model 4 & $\log S I Z E, \log B M, r_{t}, r_{j, t-11: t-1}, r_{j, t-35: t-12}, \beta_{j}, \sigma_{I V}$ idio & 6.851014 & $* * *$ & 0.0000 \\
\hline Model 5 & $\log S I Z E, \log B M, r_{t}, r_{j, t-11: t-1}, r_{j, t-35: t-12}, \beta_{j}, \sigma_{R V \text { idio }}, \sigma_{I V \text { idio }}$ & 5.929890 & $* * *$ & 0.0000 \\
\hline Model 6 & $\log S I Z E, \log B M, r_{t}, r_{j, t-11: t-1}, r_{j, t-35: t-12}, \beta_{j}, \sigma_{R V i d i o}, \sigma_{E G_{i d i o, j, t}}$ & 6.513381 & $* * *$ & 0.0000 \\
\hline Model 7 & $\log S I Z E, \log B M, r_{t}, r_{j, t-11: t-1}, r_{j, t-35: t-12}, \beta_{j}, \sigma_{R V i d i o}, \sigma_{A R i d i o, j, t}$ & 6.181357 & $* * *$ & 0.0000 \\
\hline Model 8 & $\log S I Z E, \log B M, r_{t}, r_{j, t-11: t-1}, r_{j, t-35: t-12}, \beta_{j}, \sigma_{R V_{i d i o}}, \sigma_{I V_{\text {idio }}}, \sigma_{E G_{i d i o, j, t}}, \sigma_{A R_{i d i o}, j, t}$ & 5.748324 & $* * *$ & 0.0000 \\
\hline Model 9 & $\log S I Z E, \log B M, r_{t}, r_{j, t-11: t-1}, r_{j, t-35: t-12}, \beta_{j}, \sigma_{R V_{\text {idio }}}, \sigma_{I V_{\text {idio }}}, O R W_{\text {ratio }}$, OI & 5.387800 & $* * *$ & 0.0000 \\
\hline Model10 & $\log B M, r_{t}, r_{j, t-11: t-1}, r_{j, t-35: t-12}, \beta_{j}, \sigma_{R V_{\text {idio }}}, \sigma_{I V_{\text {idio }}}, O R W_{\text {ratio }}$, OI & 5.831074 & $* * *$ & 0.0000 \\
\hline
\end{tabular}

Table 5.4: Healthcare Sector

\begin{tabular}{|c|c|c|c|c|}
\hline Model & Variables & \multicolumn{2}{|c|}{ F-statistic } & Probability \\
\hline Model 1 & $\log S I Z E, \log B M, r_{t}, r_{j, t-11: t-1}, r_{j, t-35: t-12}$ & 7.582256 & $* * *$ & 0.0000 \\
\hline Model 2 & $\log S I Z E, \log B M, r_{t}, r_{j, t-11: t-1}, r_{j, t-35: t-12}, \beta_{j}$ & 7.028673 & $* * *$ & 0.0000 \\
\hline Model 3 & $\log S I Z E, \log B M, r_{t}, r_{j, t-11: t-1}, r_{j, t-35: t-12}, \beta_{j}, \sigma_{R V}$ idio & 6.176617 & $* * *$ & 0.0000 \\
\hline Model 4 & $\log S I Z E, \log B M, r_{t}, r_{j, t-11: t-1}, r_{j, t-35: t-12}, \beta_{j}, \sigma_{I V \text { idio }}$ & 6.851014 & $* * *$ & 0.0000 \\
\hline Model 5 & $\log S I Z E, \log B M, r_{t}, r_{j, t-11: t-1}, r_{j, t-35: t-12}, \beta_{j}, \sigma_{R V_{\text {idio }}}, \sigma_{I V_{\text {idio }}}$ & 5.929890 & $* * *$ & 0.0000 \\
\hline Model 6 & $\log S I Z E, \log B M, r_{t}, r_{j, t-11: t-1}, r_{j, t-35: t-12}, \beta_{j}, \sigma_{R V}{ }_{i d i o}, \sigma_{E G_{i d i o}, j, t}$ & 6.513381 & $* * *$ & 0.0000 \\
\hline Model 7 & $\log S I Z E, \log B M, r_{t}, r_{j, t-11: t-1}, r_{j, t-35: t-12}, \beta_{j}, \sigma_{R V i d i o}, \sigma_{A R_{i d i o}, j, t}$ & 6.181357 & $* * *$ & 0.0000 \\
\hline Model 8 & $\log S I Z E, \log B M, r_{t}, r_{j, t-11: t-1}, r_{j, t-35: t-12}, \beta_{j}, \sigma_{R V \text { idio }}, \sigma_{I V \text { idio }}, \sigma_{E_{\text {idio }, j, t}}, \sigma_{A R_{\text {idio }, j, t}}$ & 5.748324 & $* * *$ & 0.0000 \\
\hline
\end{tabular}




\begin{tabular}{|c|c|c|c|c|}
\hline Model 9 & $\log S I Z E, \log B M, r_{t}, r_{j, t-11: t-1}, r_{j, t-35: t-12}, \beta_{j}, \sigma_{R V_{\text {idio }}}, \sigma_{\text {IV }}{ }_{\text {idio }}, O R W_{\text {ratio }}$, OI & 5.387800 & $* * *$ & 0.0000 \\
\hline Model10 & $\log B M, r_{t}, r_{j, t-11: t-1}, r_{j, t-35: t-12}, \beta_{j}, \sigma_{R V_{\text {idio }}}, \sigma_{I V_{\text {idio }}}, O R W_{\text {ratio }}, O I$ & 5.831074 & $* * *$ & 0.0000 \\
\hline
\end{tabular}

Table 5.5: Industrial Goods Sector

\begin{tabular}{|c|c|c|c|c|}
\hline \multirow{2}{*}{$\begin{array}{c}\text { Model } \\
\text { Model } 1\end{array}$} & \multirow{2}{*}{$\begin{array}{rr}\text { Variables } \\
\log S I Z E, \log B M, r_{t}, r_{j, t-11: t-1}, r_{j, t-35: t-12}\end{array}$} & \multicolumn{2}{|c|}{ F-statistic } & \multirow{2}{*}{$\begin{array}{c}\text { Probability } \\
0.0000\end{array}$} \\
\hline & & 10.153350 & $* * *$ & \\
\hline Model 2 & $\log S I Z E, \log B M, r_{t}, r_{j, t-11: t-1}, r_{j, t-35: t-12}, \beta_{j}$ & 9.170625 & $* * *$ & 0.0000 \\
\hline Model 3 & $\log S I Z E, \log B M, r_{t}, r_{j, t-11: t-1}, r_{j, t-35: t-12}, \beta_{j}, \sigma_{R V_{i d i o}}$ & 8.503555 & $* * *$ & 0.0000 \\
\hline Model 4 & $\log S I Z E, \log B M, r_{t}, r_{j, t-11: t-1}, r_{j, t-35: t-12}, \beta_{j}, \sigma_{I V}$ idio & 8.741119 & $* * *$ & 0.0000 \\
\hline Model 5 & $\log S I Z E, \log B M, r_{t}, r_{j, t-11: t-1}, r_{j, t-35: t-12}, \beta_{j}, \sigma_{R V i d i o}, \sigma_{I V i d i o}$ & 8.136652 & $* * *$ & 0.0000 \\
\hline Model 6 & $\log S I Z E, \log B M, r_{t}, r_{j, t-11: t-1}, r_{j, t-35: t-12}, \beta_{j}, \sigma_{R V}$ ddio,$\sigma_{E G_{i d i o, j, t}}$ & 8.197704 & $* * *$ & 0.0000 \\
\hline Model 7 & $\log S I Z E, \log B M, r_{t}, r_{j, t-11: t-1}, r_{j, t-35: t-12}, \beta_{j}, \sigma_{R V i d i o}, \sigma_{A R i d i o, j, t}$ & 8.498763 & $* * *$ & 0.0000 \\
\hline Model 8 & $\log S I Z E, \log B M, r_{t}, r_{j, t-11: t-1}, r_{j, t-35: t-12}, \beta_{j}, \sigma_{R V_{i d i o}}, \sigma_{I V_{i d i o}}, \sigma_{E G_{i d i o}, j, t}, \sigma_{A R i d i o, j, t}$ & 7.654321 & $* * *$ & 0.0000 \\
\hline Model 9 & $\log S I Z E, \log B M, r_{t}, r_{j, t-11: t-1}, r_{j, t-35: t-12}, \beta_{j}, \sigma_{R V_{i d i o}}, \sigma_{I V i d i o}, O R W_{\text {ratio }}, O I$ & 7.114454 & $* * *$ & 0.0000 \\
\hline Model10 & $\log B M, r_{t}, r_{j, t-11: t-1}, r_{j, t-35: t-12}, \beta_{j}, \sigma_{R V i d i o}, \sigma_{I V i d i o}, O R W_{\text {ratio }}, O I$ & 7.847012 & $* * *$ & 0.0000 \\
\hline
\end{tabular}

Table 5.6: Services Sector

\begin{tabular}{|c|c|c|c|c|}
\hline Model & Variables & \multicolumn{2}{|c|}{ F-statistic } & Probability \\
\hline Model 1 & $\log S I Z E, \log B M, r_{t}, r_{j, t-11: t-1}, r_{j, t-35: t-12}$ & 20.853560 & $* * *$ & 0.0000 \\
\hline Model 2 & $\log S I Z E, \log B M, r_{t}, r_{j, t-11: t-1}, r_{j, t-35: t-12}, \beta_{j}$ & 18.515430 & $* * *$ & 0.0000 \\
\hline Model 3 & $\log S I Z E, \log B M, r_{t}, r_{j, t-11: t-1}, r_{j, t-35: t-12}, \beta_{j}, \sigma_{R V}$ idio & 27.613220 & $* * *$ & 0.0000 \\
\hline Model 4 & $\log S I Z E, \log B M, r_{t}, r_{j, t-11: t-1}, r_{j, t-35: t-12}, \beta_{j}, \sigma_{I V}$ idio & 18.338870 & $* * *$ & 0.0000 \\
\hline Model 5 & $\log S I Z E, \log B M, r_{t}, r_{j, t-11: t-1}, r_{j, t-35: t-12}, \beta_{j}, \sigma_{R V \text { idio }}, \sigma_{I V \text { idio }}$ & 28.310450 & $* * *$ & 0.0000 \\
\hline Model 6 & $\log S I Z E, \log B M, r_{t}, r_{j, t-11: t-1}, r_{j, t-35: t-12}, \beta_{j}, \sigma_{R V i d i o}, \sigma_{E G_{i d i o, j, t}}$ & 24.768700 & $* * *$ & 0.0000 \\
\hline Model 7 & $\log S I Z E, \log B M, r_{t}, r_{j, t-11: t-1}, r_{j, t-35: t-12}, \beta_{j}, \sigma_{R V i d i o}, \sigma_{A R_{i d i o, j, t}}$ & 24.582170 & $* * *$ & 0.0000 \\
\hline Model 8 & $\log S I Z E, \log B M, r_{t}, r_{j, t-11: t-1}, r_{j, t-35: t-12}, \beta_{j}, \sigma_{R V_{i d i o}}, \sigma_{I V_{i d i o}}, \sigma_{E G_{i d i o}, j, t}, \sigma_{A R i d i o, j, t}$ & 24.361750 & $* * *$ & 0.0000 \\
\hline Model 9 & $\log S I Z E, \log B M, r_{t}, r_{j, t-11: t-1}, r_{j, t-35: t-12}, \beta_{j}, \sigma_{R V_{i d i o}}, \sigma_{I V \text { idio }}, O R W_{\text {ratio }}$, OI & 23.398310 & $* * *$ & 0.0000 \\
\hline Model10 & $\log B M, r_{t}, r_{j, t-11: t-1}, r_{j, t-35: t-12}, \beta_{j}, \sigma_{R V_{i d i o}}, \sigma_{I V i d i o}, O R W_{\text {ratio }}, O I$ & 25.528470 & $* * *$ & 0.0000 \\
\hline
\end{tabular}

Table 5.7: Technology Sector

\begin{tabular}{|c|c|c|c|c|}
\hline \multirow{2}{*}{$\begin{array}{c}\text { Model } \\
\text { Model } 1\end{array}$} & \multirow{2}{*}{$\begin{array}{r}\text { Variables } \\
\log S I Z E, \log B M, r_{t}, r_{j, t-11: t-1}, r_{j, t-35: t-12}\end{array}$} & & \multirow{2}{*}{$\begin{array}{c}\text { Probability } \\
0.0000\end{array}$} \\
\hline & & \multicolumn{2}{|c|}{$\frac{\text { F-statistic }}{24.424690 * * *}$} & \\
\hline Model 2 & $\log S I Z E, \log B M, r_{t}, r_{j, t-11: t-1}, r_{j, t-35: t-12}, \beta_{j}$ & 21.887190 & $* * *$ & 0.0000 \\
\hline Model 3 & $\log S I Z E, \log B M, r_{t}, r_{j, t-11: t-1}, r_{j, t-35: t-12}, \beta_{j}, \sigma_{R V \text { idio }}$ & 25.369460 & $* * *$ & 0.0000 \\
\hline Model 4 & $\log S I Z E, \log B M, r_{t}, r_{j, t-11: t-1}, r_{j, t-35: t-12}, \beta_{j}, \sigma_{I V i d i o}$ & 25.254350 & $* * *$ & 0.0000 \\
\hline Model 5 & $\log S I Z E, \log B M, r_{t}, r_{j, t-11: t-1}, r_{j, t-35: t-12}, \beta_{j}, \sigma_{R V_{i d i o}}, \sigma_{I V_{i d i o}}$ & 24.577930 & $* * *$ & 0.0000 \\
\hline Model 6 & $\log S I Z E, \log B M, r_{t}, r_{j, t-11: t-1}, r_{j, t-35: t-12}, \beta_{j}, \sigma_{R V i d i o}, \sigma_{E G_{i d i o}, j, t}$ & 24.343240 & $* * *$ & 0.0000 \\
\hline
\end{tabular}




\begin{tabular}{|c|c|c|c|c|}
\hline Model 7 & $\log S I Z E, \log B M, r_{t}, r_{j, t-11: t-1}, r_{j, t-35: t-12}, \beta_{j}, \sigma_{R V_{\text {idio }}}, \sigma_{A R_{\text {idio }, j, t}}$ & 23.204330 & **** & 0.0000 \\
\hline Model 8 & $\log S I Z E, \log B M, r_{t}, r_{j, t-11: t-1}, r_{j, t-35: t-12}, \beta_{j}, \sigma_{R V \text { idio }}, \sigma_{I V \text { idio }}, \sigma_{E G_{i d i o, j, t}}, \sigma_{A R i d i o, j, t}$ & 22.519850 & $* * *$ & 0.0000 \\
\hline Model 9 & $\log S I Z E, \log B M, r_{t}, r_{j, t-11: t-1}, r_{j, t-35: t-12}, \beta_{j}, \sigma_{R V_{\text {idio }}}, \sigma_{\text {IV idio }}, O R W_{\text {ratio }}$, OI & 20.349150 & $* * *$ & 0.0000 \\
\hline Model10 & $\log B M, r_{t}, r_{j, t-11: t-1}, r_{j, t-35: t-12}, \beta_{j}, \sigma_{R V_{\text {idio }}}, \sigma_{I V_{\text {idio }}}, O R W_{\text {ratio }}, O I$ & 22.268970 & $* * *$ & 0.0000 \\
\hline
\end{tabular}

Table 5.8: Utilities Sector

\begin{tabular}{|c|c|c|c|c|}
\hline Model & Variables & \multicolumn{2}{|c|}{ F-statistic } & Probability \\
\hline Model 1 & $\log S I Z E, \log B M, r_{t}, r_{j, t-11: t-1}, r_{j, t-35: t-12}$ & 6.194872 & $* * *$ & 0.0000 \\
\hline Model 2 & $\log S I Z E, \log B M, r_{t}, r_{j, t-11: t-1}, r_{j, t-35: t-12}, \beta_{j}$ & 6.710832 & $* * *$ & 0.0000 \\
\hline Model 3 & $\log S I Z E, \log B M, r_{t}, r_{j, t-11: t-1}, r_{j, t-35: t-12}, \beta_{j}, \sigma_{R V_{\text {idio }}}$ & 6.767289 & $* * *$ & 0.0000 \\
\hline Model 4 & $\log S I Z E, \log B M, r_{t}, r_{j, t-11: t-1}, r_{j, t-35: t-12}, \beta_{j}, \sigma_{I V \text { idio }}$ & 6.994893 & $* * *$ & 0.0000 \\
\hline Model 5 & $\log S I Z E, \log B M, r_{t}, r_{j, t-11: t-1}, r_{j, t-35: t-12}, \beta_{j}, \sigma_{R V}$ idio,$\sigma_{I V \text { idio }}$ & 6.316024 & $* * *$ & 0.0000 \\
\hline Model 6 & $\log S I Z E, \log B M, r_{t}, r_{j, t-11: t-1}, r_{j, t-35: t-12}, \beta_{j}, \sigma_{R V_{i d i o}}, \sigma_{E G_{i d i o, j, t}}$ & 7.165203 & $* * *$ & 0.0000 \\
\hline Model 7 & $\log S I Z E, \log B M, r_{t}, r_{j, t-11: t-1}, r_{j, t-35: t-12}, \beta_{j}, \sigma_{R V_{i d i o}}, \sigma_{A R i d i o, j, t}$ & 5.964787 & $* * *$ & 0.0000 \\
\hline Model 8 & $\log S I Z E, \log B M, r_{t}, r_{j, t-11: t-1}, r_{j, t-35: t-12}, \beta_{j}, \sigma_{R V_{\text {idio }}}, \sigma_{I V_{\text {idio }}}, \sigma_{E G_{i d i o, j, t}}, \sigma_{A R i d i o, j, t}$ & 6.283011 & $* * *$ & 0.0000 \\
\hline Model 9 & $\log S I Z E, \log B M, r_{t}, r_{j, t-11: t-1}, r_{j, t-35: t-12}, \beta_{j}, \sigma_{R V_{\text {idio }}}, \sigma_{\text {IV idio }}, O R W_{\text {ratio }}$, OI & 5.226013 & $* * *$ & 0.0000 \\
\hline Model10 & $\log B M, r_{t}, r_{j, t-11: t-1}, r_{j, t-35: t-12}, \beta_{j}, \sigma_{R V_{\text {idio }}}, \sigma_{I V_{\text {idio }}}, O R W_{\text {ratio }}$, OI & 5.662229 & $* * *$ & 0.0000 \\
\hline
\end{tabular}

As table 5 (table 5.1 to 5.8), after completed Chow test performance over breakpoints for every sectors, there are four sub timeframes defined as below descriptions for two mentioned financial crises between 2001 and 2010 on three breakpoints comprised of 31/12/2002 (December 2002), 31/12/2207 (December 2007), and 31/12/2008 (December 2008).

1. Phase 1 is "Bear markets" on periods of (1/02/2001-31/12/2002) in Dotcom Bubble

2. Phase 2 is "Bull markets" on periods of (1/12/2003 -31/12/2007) after Dotcom Bubble

3. Phase 3 is "Bear markets" on periods of (01/01/2008 -31/12/2008) in recent financial crisis

4. Phase 4 is "Bull markets" on periods of (01/01/2009 -31/12/2010) after recent financial crisis.

By meanings, "Bear market" is a characteristic which general declines in the stock market with characterizing by significantly increasing volatility, conversely "Bull market" is an event generally rising stock price with volatility declination. 
Figure 3: Breakpoints and sub periods with sector classification.

Figure 3.1: Monthly Implied Volatility
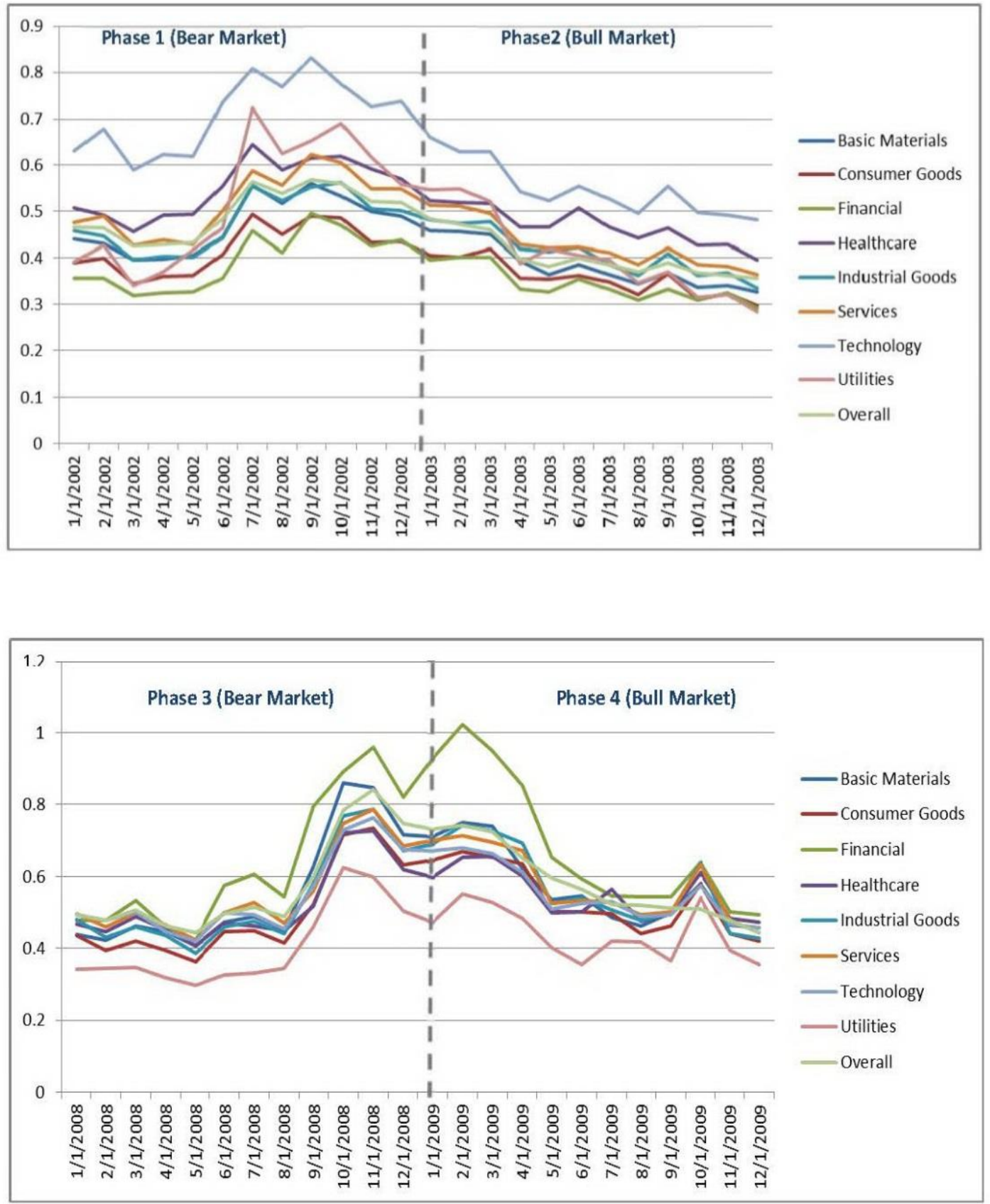
Figure 3.2: Monthly Historical Volatility
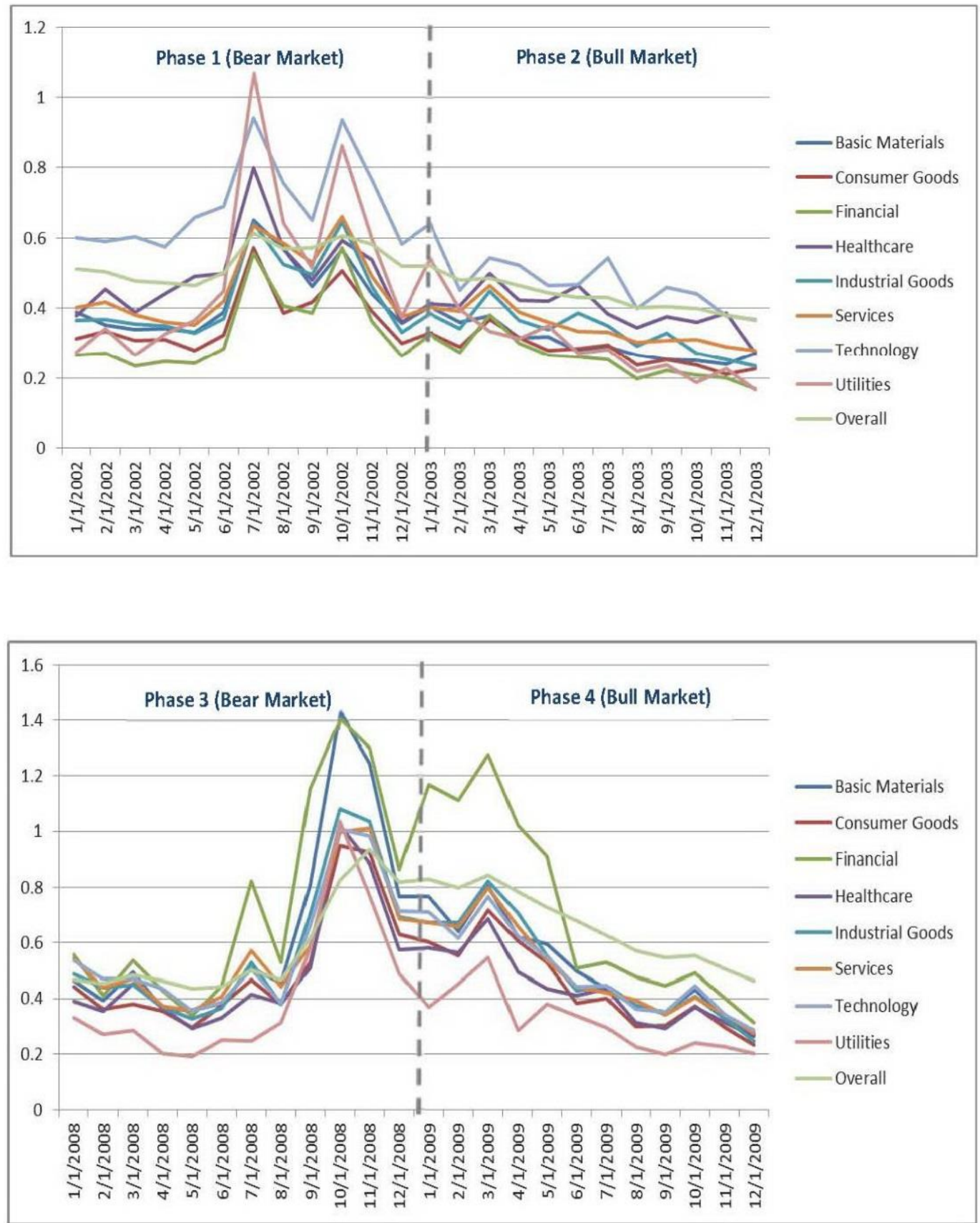


\subsubsection{Preliminary analysis}

To examine the predictive power of realized and implied volatility, we test the forecast accuracy of both by performing time series regression at firm level of historical volatility lagged one day and with one day lag of implied volatility.

$$
R V_{j, t+1}=\alpha_{i}+\beta I V_{j, t}+\beta R V_{j, t}+\varepsilon_{j, t+1}
$$

where, $R V$ is the stacked vector of the dependent variable representing the realized volatility for each of the 596 stocks for the period January 2001 to December 2010, $\alpha$ is the constant term, $I V$ and $R V$ are vectors with the implied and realized volatility one month before for each of the 506 stocks, respectively, and $\varepsilon$ is the error term.

Tables 6.1 to 6.8 ) shows a summary of results for every unique firm-level regressions classified into 8 sectors such as Basic Material, Consumer goods, Financial, Healthcare, Industrial Goods, Services, Technology, and Utilities in 4 phases for Bear and Bull markets on a couple of financial crises (Dotcom Bubble and recent financial crisis). Overall, from the results examined every sectors in full periods, the future realized volatility can be strongly forecasted as statistical significance at 1 percent level with average coefficients between just over 0.20 and 0.71 by both implied and historical volatilities, whereas after sector classification and 4 phase divide, mostly implied and historical volatilities are unable to predict the future realized volatility except phase 2 which the implied volatility is eligible to forecast at least 5 percent significant level for every sectors except Utility and phase 4 which the historical volatility is significance at least 10 percent level for every sectors, especially 5 percent significance is for Basic materials, Consumer Goods, Financial, and Industrial Goods. Even then, these results can be concluded more strongly with increasing observations, when additional tests for forecasting accuracy are performed in next predictive regression sessions. 
Table 6: Testing Historical vs. Implied volatility

Table 6.1: Basic Material Sector

\begin{tabular}{|c|c|c|c|c|c|}
\hline Phase & Confidence level & \multicolumn{2}{|c|}{ Historical Volatility } & \multicolumn{2}{|c|}{ Implied Volatility } \\
\hline \multirow{5}{*}{$\begin{array}{l}\text { Entire } \\
\text { Phases }\end{array}$} & $90 \%$ & 46 & $88.4615 \%$ & 38 & $73.0769 \%$ \\
\hline & $95 \%$ & 45 & $86.5385 \%$ & 33 & $63.4615 \%$ \\
\hline & $99 \%$ & 44 & $84.6154 \%$ & 25 & $48.0769 \%$ \\
\hline & Average Coefficient & \multicolumn{2}{|c|}{0.475034} & \multicolumn{2}{|c|}{0.416542} \\
\hline & Median Coefficient & \multicolumn{2}{|c|}{0.491238} & \multicolumn{2}{|c|}{0.369448} \\
\hline \multirow{5}{*}{ Phase 1} & $90 \%$ & 1 & $1.9231 \%$ & 10 & $19.2308 \%$ \\
\hline & $95 \%$ & 0 & $0.0000 \%$ & 5 & $9.6154 \%$ \\
\hline & $99 \%$ & 0 & $0.0000 \%$ & 2 & $3.8462 \%$ \\
\hline & Average Coefficient & \multicolumn{2}{|c|}{0.024905} & \multicolumn{2}{|c|}{0.402067} \\
\hline & Median Coefficient & \multicolumn{2}{|c|}{0.022206} & \multicolumn{2}{|c|}{0.347332} \\
\hline \multirow{5}{*}{ Phase 2} & $90 \%$ & 16 & $30.7692 \%$ & 32 & $61.5385 \%$ \\
\hline & $95 \%$ & 11 & $21.1538 \%$ & 26 & $50.0000 \%$ \\
\hline & $99 \%$ & 5 & $9.6154 \%$ & 14 & $26.9231 \%$ \\
\hline & Average Coefficient & \multicolumn{2}{|c|}{0.166366} & \multicolumn{2}{|c|}{0.390277} \\
\hline & Median Coefficient & \multicolumn{2}{|c|}{0.176330} & \multicolumn{2}{|c|}{0.364282} \\
\hline \multirow{5}{*}{ Phase 3} & $90 \%$ & 7 & $13.4615 \%$ & 4 & $7.6923 \%$ \\
\hline & $95 \%$ & 5 & $9.6154 \%$ & 4 & $7.6923 \%$ \\
\hline & $99 \%$ & 0 & $0.0000 \%$ & 0 & $0.0000 \%$ \\
\hline & Average Coefficient & \multicolumn{2}{|c|}{0.491748} & \multicolumn{2}{|c|}{0.410206} \\
\hline & Median Coefficient & \multicolumn{2}{|c|}{0.485712} & \multicolumn{2}{|c|}{0.408894} \\
\hline \multirow{5}{*}{ Phase 4} & $90 \%$ & 35 & $67.3077 \%$ & 22 & $42.3077 \%$ \\
\hline & $95 \%$ & 31 & $59.6154 \%$ & 18 & $34.6154 \%$ \\
\hline & $99 \%$ & 23 & $44.2308 \%$ & 11 & $21.1538 \%$ \\
\hline & Average Coefficient & \multicolumn{2}{|c|}{0.409801} & \multicolumn{2}{|c|}{0.512808} \\
\hline & Median Coefficient & \multicolumn{2}{|c|}{0.470823} & \multicolumn{2}{|c|}{0.404560} \\
\hline
\end{tabular}

Table 6.2: Consumer Goods Sector

\begin{tabular}{cccccc}
\hline Phase & Confidence level & \multicolumn{2}{c}{ Historical Volatility } & \multicolumn{2}{c}{ Implied Volatility } \\
\hline \multirow{5}{*}{ Entire } & $90 \%$ & 48 & $82.7586 \%$ & 52 & $89.6552 \%$ \\
Phases & $95 \%$ & 44 & $75.8621 \%$ & 49 & $84.4828 \%$ \\
& $99 \%$ & 38 & $65.5172 \%$ & 39 & $67.2414 \%$ \\
& Average Coefficient & & 0.338641 & & 0.453037 \\
& Median Coefficient & & 0.345017 & 0.427132 \\
\hline \multirow{5}{*}{ Phase 1 } & $90 \%$ & 9 & $15.5172 \%$ & 15 & $25.8621 \%$ \\
& $95 \%$ & 5 & $8.6207 \%$ & 6 & $10.3448 \%$ \\
& $99 \%$ & 0 & $0.0000 \%$ & 3 & $5.1724 \%$ \\
& Average Coefficient & & 0.010585 & & 0.352522 \\
Median Coefficient & & -0.005384 & & 0.281863 \\
\hline \multirow{5}{*}{ Phase 2 } & $90 \%$ & 17 & $29.3103 \%$ & 36 & $62.0690 \%$ \\
& $95 \%$ & 14 & $24.1379 \%$ & 30 & $51.7241 \%$ \\
& $99 \%$ & 9 & $15.5172 \%$ & 17 & $29.3103 \%$
\end{tabular}




\begin{tabular}{cccccc} 
& Median Coefficient & & 0.127520 & 0.342989 \\
\hline \multirow{4}{*}{ Phase 3 } & $90 \%$ & 6 & $10.3448 \%$ & 9 & $15.5172 \%$ \\
& $95 \%$ & 3 & $5.1724 \%$ & 7 & $12.0690 \%$ \\
& $99 \%$ & 1 & $1.7241 \%$ & 4 & $6.8966 \%$ \\
& Average Coefficient & & 0.078899 & & 0.897462 \\
& Median Coefficient & & 0.107219 & 0.625937 \\
\hline \multirow{5}{*}{ Phase 4 } & $36 \%$ & $62.0690 \%$ & 25 & $43.1034 \%$ \\
& $95 \%$ & 29 & $50.0000 \%$ & 21 & $36.2069 \%$ \\
& $99 \%$ & 16 & $27.5862 \%$ & 14 & $24.1379 \%$ \\
& Average Coefficient & & 0.354342 & & 0.457903 \\
& Median Coefficient & & 0.411000 & & 0.297269 \\
\hline
\end{tabular}

Table 6.3: Financial Sector

\begin{tabular}{|c|c|c|c|c|c|}
\hline Phase & Confidence level & \multicolumn{2}{|c|}{ Historical Volatility } & \multicolumn{2}{|c|}{ Implied Volatility } \\
\hline \multirow{5}{*}{$\begin{array}{l}\text { Entire } \\
\text { Phases }\end{array}$} & $90 \%$ & 42 & $75.0000 \%$ & 50 & $89.2857 \%$ \\
\hline & $95 \%$ & 41 & $73.2143 \%$ & 48 & $85.7143 \%$ \\
\hline & $99 \%$ & 37 & $66.0714 \%$ & 40 & $71.4286 \%$ \\
\hline & Average Coefficient & \multicolumn{2}{|c|}{0.389872} & \multicolumn{2}{|c|}{0.650980} \\
\hline & Median Coefficient & \multicolumn{2}{|c|}{0.417966} & \multicolumn{2}{|c|}{0.629160} \\
\hline \multirow{5}{*}{ Phase 1} & $90 \%$ & 5 & $8.9286 \%$ & 13 & $23.2143 \%$ \\
\hline & $95 \%$ & 3 & $5.3571 \%$ & 8 & $14.2857 \%$ \\
\hline & $99 \%$ & 0 & $0.0000 \%$ & 3 & $5.3571 \%$ \\
\hline & Average Coefficient & \multicolumn{2}{|c|}{0.074763} & \multicolumn{2}{|c|}{0.417378} \\
\hline & Median Coefficient & \multicolumn{2}{|c|}{0.034353} & \multicolumn{2}{|c|}{0.357272} \\
\hline \multirow{5}{*}{ Phase 2} & $90 \%$ & 33 & $58.9286 \%$ & 39 & $69.6429 \%$ \\
\hline & $95 \%$ & 30 & $53.5714 \%$ & 36 & $64.2857 \%$ \\
\hline & $99 \%$ & 17 & $30.3571 \%$ & 29 & $51.7857 \%$ \\
\hline & Average Coefficient & \multicolumn{2}{|c|}{0.258682} & \multicolumn{2}{|c|}{0.426705} \\
\hline & Median Coefficient & \multicolumn{2}{|c|}{0.275105} & \multicolumn{2}{|c|}{0.420042} \\
\hline \multirow{5}{*}{ Phase 3} & $90 \%$ & 18 & $32.1429 \%$ & 19 & $33.9286 \%$ \\
\hline & $95 \%$ & 11 & $19.6429 \%$ & 15 & $26.7857 \%$ \\
\hline & $99 \%$ & 4 & $7.1429 \%$ & 9 & $16.0714 \%$ \\
\hline & Average Coefficient & \multicolumn{2}{|c|}{0.218269} & \multicolumn{2}{|c|}{0.826174} \\
\hline & Median Coefficient & \multicolumn{2}{|c|}{0.242020} & \multicolumn{2}{|c|}{0.683901} \\
\hline \multirow{5}{*}{ Phase 4} & $90 \%$ & 33 & $58.9286 \%$ & 35 & $62.5000 \%$ \\
\hline & $95 \%$ & 28 & $50.0000 \%$ & 31 & $55.3571 \%$ \\
\hline & $99 \%$ & 22 & $39.2857 \%$ & 18 & $32.1429 \%$ \\
\hline & Average Coefficient & \multicolumn{2}{|c|}{0.334580} & \multicolumn{2}{|c|}{0.856809} \\
\hline & Median Coefficient & \multicolumn{2}{|c|}{0.425589} & \multicolumn{2}{|c|}{0.744520} \\
\hline
\end{tabular}


Table 6.4: Healthcare Sector

\begin{tabular}{|c|c|c|c|c|c|}
\hline Phase & Confidence level & \multicolumn{2}{|c|}{ Historical Volatility } & \multicolumn{2}{|c|}{ Implied Volatility } \\
\hline \multirow{5}{*}{$\begin{array}{l}\text { Entire } \\
\text { Phases }\end{array}$} & $90 \%$ & 33 & $68.7500 \%$ & 40 & $83.3333 \%$ \\
\hline & $95 \%$ & 31 & $64.5833 \%$ & 33 & $68.7500 \%$ \\
\hline & $99 \%$ & 21 & $43.7500 \%$ & 29 & $60.4167 \%$ \\
\hline & Average Coefficient & \multicolumn{2}{|c|}{0.260215} & \multicolumn{2}{|c|}{0.485582} \\
\hline & Median Coefficient & \multicolumn{2}{|c|}{0.256500} & \multicolumn{2}{|c|}{0.409244} \\
\hline \multirow{5}{*}{ Phase 1} & $90 \%$ & 9 & $18.7500 \%$ & 10 & $20.8333 \%$ \\
\hline & $95 \%$ & 5 & $10.4167 \%$ & 5 & $10.4167 \%$ \\
\hline & $99 \%$ & 1 & $2.0833 \%$ & 1 & $2.0833 \%$ \\
\hline & Average Coefficient & \multicolumn{2}{|c|}{0.080686} & \multicolumn{2}{|c|}{0.385184} \\
\hline & Median Coefficient & \multicolumn{2}{|c|}{0.045607} & \multicolumn{2}{|c|}{0.324331} \\
\hline \multirow{5}{*}{ Phase 2} & $90 \%$ & 8 & $16.6667 \%$ & 31 & $64.5833 \%$ \\
\hline & $95 \%$ & 4 & $8.3333 \%$ & 29 & $60.4167 \%$ \\
\hline & $99 \%$ & 3 & $6.2500 \%$ & 20 & $41.6667 \%$ \\
\hline & Average Coefficient & \multicolumn{2}{|c|}{0.049154} & \multicolumn{2}{|c|}{0.513227} \\
\hline & Median Coefficient & \multicolumn{2}{|c|}{0.028964} & \multicolumn{2}{|c|}{0.473923} \\
\hline \multirow{5}{*}{ Phase 3} & $90 \%$ & 10 & $20.8333 \%$ & 9 & $18.7500 \%$ \\
\hline & $95 \%$ & 6 & $12.5000 \%$ & 3 & $6.2500 \%$ \\
\hline & $99 \%$ & 2 & $4.1667 \%$ & 0 & $0.0000 \%$ \\
\hline & Average Coefficient & \multicolumn{2}{|c|}{0.325982} & \multicolumn{2}{|c|}{0.386652} \\
\hline & Median Coefficient & \multicolumn{2}{|c|}{0.329176} & \multicolumn{2}{|c|}{0.070651} \\
\hline \multirow{5}{*}{ Phase 4} & $90 \%$ & 25 & $52.0833 \%$ & 12 & $25.0000 \%$ \\
\hline & $95 \%$ & 20 & $41.6667 \%$ & 8 & $16.6667 \%$ \\
\hline & $99 \%$ & 14 & $29.1667 \%$ & 3 & $6.2500 \%$ \\
\hline & Average Coefficient & \multicolumn{2}{|c|}{0.349718} & \multicolumn{2}{|c|}{0.337060} \\
\hline & Median Coefficient & \multicolumn{2}{|c|}{0.373852} & \multicolumn{2}{|c|}{0.218865} \\
\hline
\end{tabular}

Table 6.5: Industrial Goods Sector

\begin{tabular}{cccccc}
\hline Phase & Confidence level & \multicolumn{2}{c}{ Historical Volatility } & \multicolumn{2}{c}{ Implied Volatility } \\
\hline \multirow{5}{*}{ Entire } & $90 \%$ & 37 & $88.0952 \%$ & 40 & $95.2381 \%$ \\
Phases & $95 \%$ & 36 & $85.7143 \%$ & 38 & $90.4762 \%$ \\
& $99 \%$ & 31 & $73.8095 \%$ & 31 & $73.8095 \%$ \\
& Average Coefficient & & 0.338542 & & 0.493311 \\
& Median Coefficient & & 0.348339 & & 0.433564 \\
\hline \multirow{5}{*}{ Phase 1 } & $90 \%$ & 4 & $9.5238 \%$ & 7 & $16.6667 \%$ \\
& $95 \%$ & 1 & $2.3810 \%$ & 5 & $11.9048 \%$ \\
& $99 \%$ & 0 & $0.0000 \%$ & 1 & $2.3810 \%$ \\
& Average Coefficient & & 0.022186 & & 0.260965 \\
& Median Coefficient & & 0.003911 & & 0.316375 \\
\hline \multirow{5}{*}{ Phase 2 } & $90 \%$ & 10 & $23.8095 \%$ & 34 & $80.9524 \%$ \\
& $95 \%$ & 4 & $9.5238 \%$ & 29 & $69.0476 \%$ \\
& $99 \%$ & 2 & $4.7619 \%$ & 22 & $52.3810 \%$ \\
& Average Coefficient & & 0.077871 & & 0.504741 \\
& Median Coefficient & & 0.085936 & & 0.536798 \\
\hline
\end{tabular}




\begin{tabular}{cccccc}
\hline \multirow{5}{*}{ Phase 3 } & $90 \%$ & 8 & $19.0476 \%$ & 10 & $23.8095 \%$ \\
& $95 \%$ & 1 & $2.3810 \%$ & 7 & $16.6667 \%$ \\
& $99 \%$ & 0 & $0.0000 \%$ & 3 & $7.1429 \%$ \\
& Average Coefficient & & 0.257920 & & 0.672088 \\
& Median Coefficient & & 0.236713 & & 0.690768 \\
\hline \multirow{4}{*}{ Phase 4 } & $90 \%$ & 27 & $64.2857 \%$ & 19 & $45.2381 \%$ \\
& $95 \%$ & 27 & $64.2857 \%$ & 16 & $38.0952 \%$ \\
& $99 \%$ & 21 & $50.0000 \%$ & 11 & $26.1905 \%$ \\
& Average Coefficient & & 0.405235 & & 0.550725 \\
& Median Coefficient & & 0.512862 & & 0.368286 \\
\hline
\end{tabular}

Table 6.6: Services Sector

\begin{tabular}{|c|c|c|c|c|c|}
\hline Phase & Confidence level & \multicolumn{2}{|c|}{ Historical Volatility } & \multicolumn{2}{|c|}{ Implied Volatility } \\
\hline \multirow{5}{*}{$\begin{array}{l}\text { Entire } \\
\text { Phases }\end{array}$} & $90 \%$ & 82 & $78.8462 \%$ & 96 & $92.3077 \%$ \\
\hline & $95 \%$ & 80 & $76.9231 \%$ & 91 & $87.5000 \%$ \\
\hline & $99 \%$ & 60 & $57.6923 \%$ & 76 & $73.0769 \%$ \\
\hline & Average Coefficient & \multicolumn{2}{|c|}{0.319170} & \multicolumn{2}{|c|}{0.511131} \\
\hline & Median Coefficient & \multicolumn{2}{|c|}{0.312039} & \multicolumn{2}{|c|}{0.496966} \\
\hline \multirow{5}{*}{ Phase 1} & $90 \%$ & 7 & $6.7308 \%$ & 25 & $24.0385 \%$ \\
\hline & $95 \%$ & 2 & $1.9231 \%$ & 17 & $16.3462 \%$ \\
\hline & $99 \%$ & 1 & $0.9615 \%$ & 6 & $5.7692 \%$ \\
\hline & Average Coefficient & \multicolumn{2}{|c|}{0.055913} & \multicolumn{2}{|c|}{0.403548} \\
\hline & Median Coefficient & \multicolumn{2}{|c|}{0.061545} & \multicolumn{2}{|c|}{0.311422} \\
\hline \multirow{5}{*}{ Phase 2} & $90 \%$ & 30 & $28.8462 \%$ & 80 & $76.9231 \%$ \\
\hline & $95 \%$ & 24 & $23.0769 \%$ & 66 & $63.4615 \%$ \\
\hline & $99 \%$ & 11 & $10.5769 \%$ & 48 & $46.1538 \%$ \\
\hline & Average Coefficient & \multicolumn{2}{|c|}{0.106529} & \multicolumn{2}{|c|}{0.520359} \\
\hline & Median Coefficient & \multicolumn{2}{|c|}{0.098066} & \multicolumn{2}{|c|}{0.494583} \\
\hline \multirow{5}{*}{ Phase 3} & $90 \%$ & 20 & $19.2308 \%$ & 21 & $20.1923 \%$ \\
\hline & $95 \%$ & 9 & $8.6538 \%$ & 18 & $17.3077 \%$ \\
\hline & $99 \%$ & 2 & $1.9231 \%$ & 7 & $6.7308 \%$ \\
\hline & Average Coefficient & \multicolumn{2}{|c|}{0.222301} & \multicolumn{2}{|c|}{0.488509} \\
\hline & Median Coefficient & \multicolumn{2}{|c|}{0.264347} & \multicolumn{2}{|c|}{0.569849} \\
\hline \multirow{5}{*}{ Phase 4} & $90 \%$ & 52 & $50.4854 \%$ & 49 & $47.5728 \%$ \\
\hline & $95 \%$ & 41 & $39.8058 \%$ & 40 & $38.8350 \%$ \\
\hline & $99 \%$ & 30 & $29.1262 \%$ & 24 & $23.3010 \%$ \\
\hline & Average Coefficient & \multicolumn{2}{|c|}{0.334799} & \multicolumn{2}{|c|}{0.491754} \\
\hline & Median Coefficient & \multicolumn{2}{|c|}{0.329429} & \multicolumn{2}{|c|}{0.421171} \\
\hline
\end{tabular}


Table 6.7: Technology Sector

\begin{tabular}{|c|c|c|c|c|c|}
\hline Phase & Confidence level & \multicolumn{2}{|c|}{ Historical Volatility } & \multicolumn{2}{|c|}{ Implied Volatility } \\
\hline \multirow{5}{*}{$\begin{array}{l}\text { Entire } \\
\text { Phases }\end{array}$} & $90 \%$ & 57 & $53.7736 \%$ & 103 & $97.1698 \%$ \\
\hline & $95 \%$ & 49 & $46.2264 \%$ & 98 & $92.4528 \%$ \\
\hline & $99 \%$ & 43 & $40.5660 \%$ & 93 & $87.7358 \%$ \\
\hline & Average Coefficient & \multicolumn{2}{|c|}{0.208826} & \multicolumn{2}{|c|}{0.714864} \\
\hline & Median Coefficient & \multicolumn{2}{|c|}{0.181384} & \multicolumn{2}{|c|}{0.708976} \\
\hline \multirow{5}{*}{ Phase 1} & $90 \%$ & 6 & $5.6604 \%$ & 53 & $50.0000 \%$ \\
\hline & $95 \%$ & 4 & $3.7736 \%$ & 36 & $33.9623 \%$ \\
\hline & $99 \%$ & 0 & $0.0000 \%$ & 20 & $18.8679 \%$ \\
\hline & Average Coefficient & \multicolumn{2}{|c|}{-0.008548} & \multicolumn{2}{|c|}{0.689723} \\
\hline & Median Coefficient & \multicolumn{2}{|c|}{-0.039671} & \multicolumn{2}{|c|}{0.696472} \\
\hline \multirow{5}{*}{ Phase 2} & $90 \%$ & 24 & $22.6415 \%$ & 91 & $85.8491 \%$ \\
\hline & $95 \%$ & 10 & $9.4340 \%$ & 86 & $81.1321 \%$ \\
\hline & $99 \%$ & 4 & $3.7736 \%$ & 65 & $61.3208 \%$ \\
\hline & Average Coefficient & \multicolumn{2}{|c|}{0.011517} & \multicolumn{2}{|c|}{0.625029} \\
\hline & Median Coefficient & \multicolumn{2}{|c|}{-0.028740} & \multicolumn{2}{|c|}{0.589033} \\
\hline \multirow{5}{*}{ Phase 3} & $90 \%$ & 19 & $17.9245 \%$ & 24 & $22.6415 \%$ \\
\hline & $95 \%$ & 13 & $12.2642 \%$ & 20 & $18.8679 \%$ \\
\hline & $99 \%$ & 2 & $1.8868 \%$ & 10 & $9.4340 \%$ \\
\hline & Average Coefficient & \multicolumn{2}{|c|}{0.208774} & \multicolumn{2}{|c|}{0.843872} \\
\hline & Median Coefficient & \multicolumn{2}{|c|}{0.196659} & \multicolumn{2}{|c|}{0.755589} \\
\hline \multirow{5}{*}{ Phase 4} & $90 \%$ & 54 & $50.9434 \%$ & 44 & $41.5094 \%$ \\
\hline & $95 \%$ & 45 & $42.4528 \%$ & 38 & $35.8491 \%$ \\
\hline & $99 \%$ & 30 & $28.3019 \%$ & 23 & $21.6981 \%$ \\
\hline & Average Coefficient & \multicolumn{2}{|c|}{0.301278} & \multicolumn{2}{|c|}{0.599472} \\
\hline & Median Coefficient & \multicolumn{2}{|c|}{0.328287} & \multicolumn{2}{|c|}{0.486223} \\
\hline
\end{tabular}

Table 6.8: Utilities Sector

\begin{tabular}{cccccc}
\hline Phase & Confidence level & \multicolumn{2}{c}{ Historical Volatility } & \multicolumn{2}{c}{ Implied Volatility } \\
\hline \multirow{5}{*}{ Entire } & $90 \%$ & 14 & $93.3333 \%$ & 10 & $66.6667 \%$ \\
Phases & $95 \%$ & 13 & $86.6667 \%$ & 8 & $53.3333 \%$ \\
& $99 \%$ & 12 & $80.0000 \%$ & 7 & $46.6667 \%$ \\
& Average Coefficient & & 0.367698 & & 0.366023 \\
& Median Coefficient & & 0.414422 & & 0.238246 \\
\hline & $90 \%$ & 3 & $20.0000 \%$ & 4 & $26.6667 \%$ \\
Phase 1 & $95 \%$ & 1 & $6.6667 \%$ & 3 & $20.0000 \%$ \\
& $99 \%$ & 0 & $0.0000 \%$ & 0 & $0.0000 \%$ \\
& Average Coefficient & & 0.048787 & & 0.455325 \\
& Median Coefficient & & -0.004314 & & 0.533662 \\
\hline \multirow{5}{*}{ Phase 2 } & $90 \%$ & 11 & $73.3333 \%$ & 7 & $46.6667 \%$ \\
& $95 \%$ & 9 & $60.0000 \%$ & 7 & $46.6667 \%$ \\
& $99 \%$ & 5 & $33.3333 \%$ & 4 & $26.6667 \%$ \\
& Average Coefficient & & 0.295067 & & 0.301040 \\
& Median Coefficient & & 0.323766 & & 0.218181 \\
\hline
\end{tabular}




\begin{tabular}{cccccc}
\hline \multirow{4}{*}{ Phase 3 } & $90 \%$ & 2 & $13.3333 \%$ & 0 & $0.0000 \%$ \\
& $95 \%$ & 2 & $13.3333 \%$ & 0 & $0.0000 \%$ \\
& $99 \%$ & 0 & $0.0000 \%$ & 0 & $0.0000 \%$ \\
& Average Coefficient & & 0.662359 & -0.274022 \\
& Median Coefficient & & 0.542306 & -0.530489 \\
\hline \multirow{4}{*}{ Phase 4 } & $90 \%$ & 8 & $53.3333 \%$ & 2 & $13.3333 \%$ \\
& $95 \%$ & 7 & $46.6667 \%$ & 2 & $13.3333 \%$ \\
& $99 \%$ & 3 & $20.0000 \%$ & 2 & $13.3333 \%$ \\
& Average Coefficient & & 0.344605 & & 0.289565 \\
& Median Coefficient & & 0.349866 & & 0.187093 \\
\hline
\end{tabular}

In tables 7.1 to 7.8 , we extend the analysis and test the forecast accuracy for the alternative idiosyncratic volatility measures used in this paper. We compare the historical, implied and the EGARCH and $\mathrm{AR}(2)$ volatility forecast models, running time series regressions at firm level for the period January 2001 to December 2010 divided into 4 phases with sector classification. We apply every phases and sectors by equation 10 , where:

$$
\sigma_{R V i d i o, j, t+1}=\alpha_{j}+\psi_{1, j}+\sigma_{I V i d i o, j, t}+\psi_{2, j} \sigma_{E G_{i d i o, j, t}}+\psi_{3, j} \sigma_{A R i d i o, j, t}+\psi_{4, j} \sigma_{R V i d i o, j, t}+\varepsilon_{j, t+1}
$$

From the results presented in tables 7.1 to 7.8 , they are same direction as tables 6.1 to 6.8 and found that the future realized idiosyncratic volatility is forecasted in full periods at strong statistical significance at 1 percent level around 50 percent of the firm-level regressions by both implied and historical volatilities for every sectors except Healthcare and Technology sectors which the historical idiosyncratic volatility is 5 percent significant level and Utilities sector which the implied idiosyncratic volatility is significance at 10 percent level. In fact, in the term of sub period, there is only phase 2 which the implied volatility is eligible to forecast at least 5 percent significant level for every sectors except Utilities. Particularly, other idiosyncratic volatility measures such realized, EGARCH and $A R(2)$ are not able to be strong and significant to predict for every sectors and sub periods. Somehow, hese results will be concluded more strongly with increasing observations, when additional tests of forecasting accuracy will be processed later with the stock returns predictive regressions applying Fama and Macbeth (1973) executed. 
Table 7: Testing alternative idiosyncratic volatility measures

Table 7.1: Basic Materials Sector

$$
\text { Entire Phases }
$$

\begin{tabular}{|c|c|c|c|c|c|c|c|c|}
\hline \multirow{2}{*}{$\begin{array}{c}\text { Confidence level } \\
90 \%\end{array}$} & \multicolumn{2}{|c|}{ Historical Volatility } & \multicolumn{2}{|c|}{ Implied Volatility } & \multicolumn{2}{|c|}{ EGARCH Volatility } & \multicolumn{2}{|c|}{ AR Volatility } \\
\hline & 46 & $88.4615 \%$ & 37 & $71.1538 \%$ & 6 & $11.5385 \%$ & 10 & $19.2308 \%$ \\
\hline $95 \%$ & 46 & $88.4615 \%$ & 31 & $59.6154 \%$ & 4 & $7.6923 \%$ & 5 & $9.6154 \%$ \\
\hline $99 \%$ & 44 & $84.6154 \%$ & 22 & $42.3077 \%$ & 1 & $1.9231 \%$ & 3 & $5.7692 \%$ \\
\hline Average & \multicolumn{2}{|c|}{0.469420} & \multicolumn{2}{|c|}{0.398863} & \multicolumn{2}{|c|}{0.728064} & \multicolumn{2}{|c|}{-0.113318} \\
\hline \multicolumn{9}{|l|}{ Coefficient } \\
\hline Median Coefficient & \multicolumn{2}{|c|}{0.486590} & \multicolumn{2}{|c|}{0.359444} & \multicolumn{2}{|c|}{0.349072} & \multicolumn{2}{|c|}{0.173243} \\
\hline
\end{tabular}

Phase 1

\begin{tabular}{|c|c|c|c|c|c|c|c|c|}
\hline \multirow{2}{*}{$\begin{array}{c}\text { Confidence level } \\
90 \%\end{array}$} & \multicolumn{2}{|c|}{ Historical Volatility } & \multicolumn{2}{|c|}{ Implied Volatility } & \multicolumn{2}{|c|}{ EGARCH Volatility } & \multicolumn{2}{|c|}{ AR Volatility } \\
\hline & 3 & $5.7692 \%$ & 7 & $13.4615 \%$ & 6 & $11.5385 \%$ & 9 & $17.3077 \%$ \\
\hline $95 \%$ & 2 & $3.8462 \%$ & 4 & $7.6923 \%$ & 1 & $1.9231 \%$ & 3 & $5.7692 \%$ \\
\hline $99 \%$ & 0 & $0.0000 \%$ & 2 & $3.8462 \%$ & 0 & $0.0000 \%$ & 1 & $1.9231 \%$ \\
\hline Average & \multicolumn{2}{|c|}{0.013444} & \multicolumn{2}{|c|}{0.383658} & \multicolumn{2}{|c|}{0.556640} & \multicolumn{2}{|c|}{-0.727114} \\
\hline \multicolumn{9}{|l|}{ Coefficient } \\
\hline Median Coefficient & \multicolumn{2}{|c|}{0.003215} & \multicolumn{2}{|c|}{0.344522} & \multicolumn{2}{|c|}{0.114227} & \multicolumn{2}{|c|}{-0.018063} \\
\hline
\end{tabular}

Phase 2

\begin{tabular}{|c|c|c|c|c|c|c|c|c|}
\hline \multirow{2}{*}{$\begin{array}{c}\text { Confidence level } \\
90 \%\end{array}$} & \multicolumn{2}{|c|}{ Historical Volatility } & \multicolumn{2}{|c|}{ Implied Volatility } & \multicolumn{2}{|c|}{ EGARCH Volatility } & \multicolumn{2}{|c|}{ AR Volatility } \\
\hline & 15 & $28.8462 \%$ & 29 & $55.7692 \%$ & 10 & $19.2308 \%$ & 7 & $13.4615 \%$ \\
\hline $95 \%$ & 8 & $15.3846 \%$ & 21 & $40.3846 \%$ & 6 & $11.5385 \%$ & 4 & $7.6923 \%$ \\
\hline $99 \%$ & 5 & $9.6154 \%$ & 13 & $25.0000 \%$ & 1 & $1.9231 \%$ & 3 & $5.7692 \%$ \\
\hline Average Coefficient & \multicolumn{2}{|c|}{0.148926} & \multicolumn{2}{|c|}{0.380843} & \multicolumn{2}{|c|}{0.450741} & \multicolumn{2}{|c|}{0.046922} \\
\hline Median Coefficient & \multicolumn{2}{|c|}{0.172887} & \multicolumn{2}{|c|}{0.359342} & \multicolumn{2}{|c|}{0.222603} & \multicolumn{2}{|c|}{-0.016329} \\
\hline \multicolumn{9}{|c|}{ Phase 3} \\
\hline Confidence level & \multicolumn{2}{|c|}{$\begin{array}{l}\text { Historical } \\
\text { Volatility }\end{array}$} & \multicolumn{2}{|c|}{ Implied Volatility } & \multicolumn{2}{|c|}{ EGARCH Volatility } & \multicolumn{2}{|c|}{ AR Volatility } \\
\hline $90 \%$ & 3 & $5.7692 \%$ & 8 & $15.3846 \%$ & 10 & $19.2308 \%$ & 8 & $15.3846 \%$ \\
\hline $95 \%$ & 3 & $5.7692 \%$ & 5 & $9.6154 \%$ & 4 & $7.6923 \%$ & 6 & $11.5385 \%$ \\
\hline $99 \%$ & 0 & $0.0000 \%$ & 0 & $0.0000 \%$ & 1 & $1.9231 \%$ & 4 & $7.6923 \%$ \\
\hline Average Coefficient & \multicolumn{2}{|c|}{0.406358} & \multicolumn{2}{|c|}{0.315457} & \multicolumn{2}{|c|}{6.155074} & \multicolumn{2}{|c|}{-0.373803} \\
\hline Median Coefficient & \multicolumn{2}{|c|}{0.326088} & \multicolumn{2}{|c|}{0.236944} & \multicolumn{2}{|c|}{3.641991} & \multicolumn{2}{|c|}{1.101721} \\
\hline \multicolumn{9}{|c|}{ Phase 4} \\
\hline Confidence level & \multicolumn{2}{|c|}{ Historical Volatility } & \multicolumn{2}{|c|}{ Implied Volatility } & \multicolumn{2}{|c|}{ EGARCH Volatility } & \multicolumn{2}{|c|}{ AR Volatility } \\
\hline $90 \%$ & 32 & $61.5385 \%$ & 21 & $40.3846 \%$ & 7 & $13.4615 \%$ & 6 & $11.5385 \%$ \\
\hline $95 \%$ & 28 & $53.8462 \%$ & 17 & $32.6923 \%$ & 7 & $13.4615 \%$ & 1 & $0.0000 \%$ \\
\hline $99 \%$ & 19 & $36.5385 \%$ & 10 & $19.2308 \%$ & 1 & $1.9231 \%$ & 0 & $0.0000 \%$ \\
\hline Average Coefficient & \multicolumn{2}{|c|}{0.383896} & \multicolumn{2}{|c|}{0.454272} & \multicolumn{2}{|c|}{1.711603} & \multicolumn{2}{|c|}{-0.165710} \\
\hline Median Coefficient & & 170654 & & 367812 & & 4303 & & 28073 \\
\hline
\end{tabular}


Table 7.2: Consumer Goods Sector

\begin{tabular}{|c|c|c|c|c|c|c|c|c|}
\hline \multicolumn{9}{|c|}{ Entire Phases } \\
\hline \multirow{2}{*}{$\begin{array}{c}\text { Confidence level } \\
90 \%\end{array}$} & \multicolumn{2}{|c|}{ Historical Volatility } & \multicolumn{2}{|c|}{ Implied Volatility } & \multicolumn{2}{|c|}{ EGARCH Volatility } & \multicolumn{2}{|c|}{ AR Volatility } \\
\hline & 49 & $84.4828 \%$ & 50 & $86.2069 \%$ & 14 & $24.1379 \%$ & 8 & $13.7931 \%$ \\
\hline $95 \%$ & 44 & $75.8621 \%$ & 47 & $81.0345 \%$ & 11 & $18.9655 \%$ & 6 & $10.3448 \%$ \\
\hline $99 \%$ & 37 & $63.7931 \%$ & 35 & $60.3448 \%$ & 7 & $12.0690 \%$ & 2 & $3.4483 \%$ \\
\hline $\begin{array}{l}\text { Average } \\
\text { Coefficient }\end{array}$ & \multicolumn{2}{|c|}{0.326078} & \multicolumn{2}{|c|}{0.435913} & \multicolumn{2}{|c|}{0.069411} & \multicolumn{2}{|c|}{0.231823} \\
\hline Median Coefficient & \multicolumn{2}{|c|}{0.361178} & \multicolumn{2}{|c|}{0.401064} & \multicolumn{2}{|c|}{0.118506} & \multicolumn{2}{|c|}{0.107599} \\
\hline \multicolumn{9}{|c|}{ Phase 1} \\
\hline Confidence level & \multicolumn{2}{|c|}{ Historical Volatility } & \multicolumn{2}{|c|}{ Implied Volatility } & \multicolumn{2}{|c|}{ EGARCH Volatility } & \multicolumn{2}{|c|}{ AR Volatility } \\
\hline $90 \%$ & 10 & $17.2414 \%$ & 13 & $22.4138 \%$ & 8 & $13.7931 \%$ & 6 & $10.3448 \%$ \\
\hline $95 \%$ & 7 & $12.0690 \%$ & 7 & $12.0690 \%$ & 5 & $8.6207 \%$ & 5 & $8.6207 \%$ \\
\hline $99 \%$ & 1 & $1.7241 \%$ & 3 & $5.1724 \%$ & 0 & $0.0000 \%$ & 2 & $3.4483 \%$ \\
\hline $\begin{array}{l}\text { Average } \\
\text { Coefficient }\end{array}$ & \multicolumn{2}{|c|}{0.001012} & \multicolumn{2}{|c|}{0.334628} & \multicolumn{2}{|c|}{-0.441722} & \multicolumn{2}{|c|}{0.165799} \\
\hline Median Coefficient & \multicolumn{2}{|c|}{-0.035222} & \multicolumn{2}{|c|}{0.301063} & \multicolumn{2}{|c|}{-0.201022} & \multicolumn{2}{|c|}{0.075806} \\
\hline & & & & Phase 2 & & & & \\
\hline Confidence level & Hist & cal Volatility & $\operatorname{Imp}$ & d Volatility & EGA & I Volatility & & Volatility \\
\hline $90 \%$ & 19 & $32.7586 \%$ & 34 & $58.6207 \%$ & 11 & $18.9655 \%$ & 5 & $8.6207 \%$ \\
\hline $95 \%$ & 11 & $18.9655 \%$ & 26 & $44.8276 \%$ & 6 & $10.3448 \%$ & 3 & $5.1724 \%$ \\
\hline $99 \%$ & 9 & $15.5172 \%$ & 13 & $22.4138 \%$ & 4 & $6.8966 \%$ & 1 & $1.7241 \%$ \\
\hline Average Coefficient & & 140499 & & 361780 & & 73068 & & 413781 \\
\hline Median Coefficient & & 133018 & & 324462 & & 59254 & & 258521 \\
\hline & & & & Phase 3 & & & & \\
\hline Confidence level & & $\begin{array}{l}\text { storical } \\
\text { llatility }\end{array}$ & Impl & Volatility & EGAR & Volatility & & olatility \\
\hline $90 \%$ & 6 & $10.3448 \%$ & 12 & $20.6897 \%$ & 5 & $8.6207 \%$ & 4 & $6.8966 \%$ \\
\hline $95 \%$ & 2 & $3.4483 \%$ & 8 & $13.7931 \%$ & 1 & $1.7241 \%$ & 4 & $6.8966 \%$ \\
\hline $99 \%$ & 1 & $1.7241 \%$ & 4 & $6.8966 \%$ & 0 & $0.0000 \%$ & 0 & $0.0000 \%$ \\
\hline Average Coefficient & & 015979 & & 05091 & & 9706 & & 01407 \\
\hline Median Coefficient & & 029812 & & 95821 & & 2451 & & 87624 \\
\hline & & & & Phase 4 & & & & \\
\hline Confidence level & Hist & cal Volatility & $\operatorname{Imp}$ & d Volatility & EGA & I Volatility & & Volatility \\
\hline $90 \%$ & 25 & $43.1034 \%$ & 23 & $39.6552 \%$ & 7 & $12.0690 \%$ & 11 & $18.9655 \%$ \\
\hline $95 \%$ & 23 & $39.6552 \%$ & 18 & $31.0345 \%$ & 3 & $5.1724 \%$ & 4 & $0.0000 \%$ \\
\hline $99 \%$ & 9 & $15.5172 \%$ & 7 & $12.0690 \%$ & 2 & $3.4483 \%$ & 1 & $1.7241 \%$ \\
\hline Average Coefficient & & 335689 & & 399595 & & 60964 & & 55198 \\
\hline Median Coefficient & & 347768 & & 292181 & & 63995 & & 110908 \\
\hline
\end{tabular}


Table 7.3: Financial Sector

\begin{tabular}{|c|c|c|c|c|c|c|c|c|}
\hline \multicolumn{9}{|c|}{ Entire Phases } \\
\hline Confidence level & \multicolumn{2}{|c|}{ Historical Volatility } & \multicolumn{2}{|c|}{ Implied Volatility } & \multicolumn{2}{|c|}{ EGARCH Volatility } & \multicolumn{2}{|c|}{ AR Volatility } \\
\hline $90 \%$ & 41 & $73.2143 \%$ & 47 & $83.9286 \%$ & 22 & $39.2857 \%$ & 14 & $25.0000 \%$ \\
\hline $95 \%$ & 41 & $73.2143 \%$ & 43 & $76.7857 \%$ & 16 & $28.5714 \%$ & 12 & $21.4286 \%$ \\
\hline $99 \%$ & 37 & $66.0714 \%$ & 36 & $64.2857 \%$ & 7 & $12.5000 \%$ & 8 & $14.2857 \%$ \\
\hline $\begin{array}{c}\text { Average } \\
\text { Coefficient }\end{array}$ & \multicolumn{2}{|c|}{0.379437} & \multicolumn{2}{|c|}{0.620486} & \multicolumn{2}{|c|}{0.608162} & \multicolumn{2}{|c|}{-0.223717} \\
\hline Median Coefficient & \multicolumn{2}{|c|}{0.412855} & \multicolumn{2}{|c|}{0.580690} & \multicolumn{2}{|c|}{0.626338} & \multicolumn{2}{|c|}{-0.111806} \\
\hline \multicolumn{9}{|c|}{ Phase 1} \\
\hline Confidence level & \multicolumn{2}{|c|}{ Historical Volatility } & \multicolumn{2}{|c|}{ Implied Volatility } & \multicolumn{2}{|c|}{ EGARCH Volatility } & \multicolumn{2}{|c|}{ AR Volatility } \\
\hline $90 \%$ & 5 & $8.9286 \%$ & 11 & $19.6429 \%$ & 9 & $16.0714 \%$ & 6 & $10.7143 \%$ \\
\hline $95 \%$ & 2 & $3.5714 \%$ & 8 & $14.2857 \%$ & 5 & $8.9286 \%$ & 4 & $7.1429 \%$ \\
\hline $99 \%$ & 1 & $1.7857 \%$ & 2 & $3.5714 \%$ & 2 & $3.5714 \%$ & 3 & $5.3571 \%$ \\
\hline $\begin{array}{c}\text { Average } \\
\text { Coefficient }\end{array}$ & \multicolumn{2}{|c|}{0.037298} & \multicolumn{2}{|c|}{0.483224} & \multicolumn{2}{|c|}{-0.717335} & \multicolumn{2}{|c|}{1.501741} \\
\hline Median Coefficient & \multicolumn{2}{|c|}{-0.002616} & \multicolumn{2}{|c|}{0.470350} & \multicolumn{2}{|c|}{-1.000634} & \multicolumn{2}{|c|}{0.691236} \\
\hline \multicolumn{9}{|c|}{ Phase 2} \\
\hline Confidence level & Hist & cal Volatility & $\operatorname{Imp}$ & d Volatility & EGA & H Volatility & & Volatility \\
\hline $90 \%$ & 30 & $53.5714 \%$ & 36 & $64.2857 \%$ & 15 & $26.7857 \%$ & 9 & $16.0714 \%$ \\
\hline $95 \%$ & 25 & $44.6429 \%$ & 33 & $58.9286 \%$ & 11 & $19.6429 \%$ & 6 & $10.7143 \%$ \\
\hline $99 \%$ & 11 & $19.6429 \%$ & 26 & $46.4286 \%$ & 3 & $5.3571 \%$ & 1 & $1.7857 \%$ \\
\hline Average Coefficient & & .221971 & & 425984 & & 69736 & & 386600 \\
\hline Median Coefficient & & .249664 & & 421642 & & 04387 & & 165227 \\
\hline & & & & Phase 3 & & & & \\
\hline Confidence level & & $\begin{array}{l}\text { istorical } \\
\text { olatility }\end{array}$ & Impl & Volatility & EGAR & Volatility & & olatility \\
\hline $90 \%$ & 12 & $21.4286 \%$ & 15 & $26.7857 \%$ & 10 & $17.8571 \%$ & 9 & $16.0714 \%$ \\
\hline $95 \%$ & 6 & $10.7143 \%$ & 12 & $21.4286 \%$ & 7 & $12.5000 \%$ & 4 & $7.1429 \%$ \\
\hline $99 \%$ & 3 & $5.3571 \%$ & 2 & $3.5714 \%$ & 2 & $3.5714 \%$ & 0 & $0.0000 \%$ \\
\hline Average Coefficient & & .252524 & & 88579 & & 1971 & & 72318 \\
\hline Median Coefficient & & 149874 & & 72141 & & 7398 & & 71204 \\
\hline & & & & Phase 4 & & & & \\
\hline Confidence level & Hist & cal Volatility & Imp & d Volatility & EGA & H Volatility & & Volatility \\
\hline $90 \%$ & 26 & $46.4286 \%$ & 28 & $50.0000 \%$ & 12 & $21.4286 \%$ & 11 & $19.6429 \%$ \\
\hline $95 \%$ & 21 & $37.5000 \%$ & 21 & $37.5000 \%$ & 7 & $12.5000 \%$ & 8 & $0.0000 \%$ \\
\hline $99 \%$ & 12 & $21.4286 \%$ & 11 & $19.6429 \%$ & 3 & $5.3571 \%$ & 4 & $7.1429 \%$ \\
\hline Average Coefficient & & .267020 & & 775162 & & 18129 & & 145545 \\
\hline Median Coefficient & & .321833 & & 538180 & & 44627 & & 283356 \\
\hline
\end{tabular}


Table 7.4: Healthcare Sector

\begin{tabular}{|c|c|c|c|c|c|c|c|c|}
\hline \multicolumn{9}{|c|}{ Entire Phases } \\
\hline \multirow{2}{*}{$\begin{array}{c}\text { Confidence level } \\
90 \%\end{array}$} & \multicolumn{2}{|c|}{ Historical Volatility } & \multicolumn{2}{|c|}{ Implied Volatility } & \multicolumn{2}{|c|}{ EGARCH Volatility } & \multicolumn{2}{|c|}{ AR Volatility } \\
\hline & 32 & $66.6667 \%$ & 37 & $77.0833 \%$ & 11 & $22.9167 \%$ & 9 & $18.7500 \%$ \\
\hline $95 \%$ & 30 & $62.5000 \%$ & 33 & $68.7500 \%$ & 8 & $16.6667 \%$ & 2 & $4.1667 \%$ \\
\hline $99 \%$ & 19 & $39.5833 \%$ & 27 & $56.2500 \%$ & 3 & $6.2500 \%$ & 0 & $0.0000 \%$ \\
\hline $\begin{array}{c}\text { Average } \\
\text { Coefficient }\end{array}$ & \multicolumn{2}{|c|}{0.246199} & \multicolumn{2}{|c|}{0.474549} & \multicolumn{2}{|c|}{0.142824} & \multicolumn{2}{|c|}{0.194534} \\
\hline Median Coefficient & \multicolumn{2}{|c|}{0.240238} & \multicolumn{2}{|c|}{0.430243} & \multicolumn{2}{|c|}{-0.037474} & \multicolumn{2}{|c|}{-0.170056} \\
\hline
\end{tabular}

Phase 1

\begin{tabular}{|c|c|c|c|c|c|c|c|c|}
\hline \multirow{2}{*}{$\begin{array}{c}\text { Confidence level } \\
90 \%\end{array}$} & \multicolumn{2}{|c|}{ Historical Volatility } & \multicolumn{2}{|c|}{ Implied Volatility } & \multicolumn{2}{|c|}{ EGARCH Volatility } & \multicolumn{2}{|c|}{ AR Volatility } \\
\hline & 8 & $16.6667 \%$ & 9 & $18.7500 \%$ & 3 & $6.2500 \%$ & 5 & $10.4167 \%$ \\
\hline $95 \%$ & 3 & $6.2500 \%$ & 4 & $8.3333 \%$ & 3 & $6.2500 \%$ & 4 & $8.3333 \%$ \\
\hline $99 \%$ & 0 & $0.0000 \%$ & 1 & $2.0833 \%$ & 1 & $2.0833 \%$ & 0 & $0.0000 \%$ \\
\hline Average Coefficient & \multicolumn{2}{|c|}{0.043074} & \multicolumn{2}{|c|}{0.407298} & \multicolumn{2}{|c|}{0.385867} & \multicolumn{2}{|c|}{-0.624515} \\
\hline Median Coefficient & \multicolumn{2}{|c|}{0.020619} & \multicolumn{2}{|c|}{0.276066} & \multicolumn{2}{|c|}{-0.371042} & \multicolumn{2}{|c|}{-0.289613} \\
\hline \multicolumn{9}{|c|}{ Phase 2} \\
\hline Confidence level & \multicolumn{2}{|c|}{ Historical Volatility } & \multicolumn{2}{|c|}{ Implied Volatility } & \multicolumn{2}{|c|}{ EGARCH Volatility } & \multicolumn{2}{|c|}{ AR Volatility } \\
\hline $90 \%$ & 9 & $18.7500 \%$ & 28 & $58.3333 \%$ & 8 & $16.6667 \%$ & 8 & $16.6667 \%$ \\
\hline $95 \%$ & 5 & $10.4167 \%$ & 25 & $52.0833 \%$ & 3 & $6.2500 \%$ & 6 & $12.5000 \%$ \\
\hline $99 \%$ & 2 & $4.1667 \%$ & 19 & $39.5833 \%$ & 1 & $2.0833 \%$ & 3 & $6.2500 \%$ \\
\hline Average Coefficient & \multicolumn{2}{|c|}{0.038972} & \multicolumn{2}{|c|}{0.487334} & \multicolumn{2}{|c|}{0.341302} & \multicolumn{2}{|c|}{0.021951} \\
\hline Median Coefficient & \multicolumn{2}{|c|}{-0.002343} & \multicolumn{2}{|c|}{0.461308} & \multicolumn{2}{|c|}{0.528499} & \multicolumn{2}{|c|}{-0.130779} \\
\hline \multicolumn{9}{|c|}{ Phase 3} \\
\hline Confidence level & \multicolumn{2}{|c|}{$\begin{array}{l}\text { Historical } \\
\text { Volatility }\end{array}$} & \multicolumn{2}{|c|}{ Implied Volatility } & \multicolumn{2}{|c|}{ EGARCH Volatility } & \multicolumn{2}{|c|}{ AR Volatility } \\
\hline $90 \%$ & 11 & $22.9167 \%$ & 9 & $18.7500 \%$ & 5 & $10.4167 \%$ & 8 & $16.6667 \%$ \\
\hline $95 \%$ & 8 & $16.6667 \%$ & 6 & $12.5000 \%$ & 2 & $4.1667 \%$ & 4 & $8.3333 \%$ \\
\hline $99 \%$ & 2 & $4.1667 \%$ & 2 & $4.1667 \%$ & 1 & $2.0833 \%$ & 2 & $4.1667 \%$ \\
\hline Average Coefficient & & .303523 & & 46545 & & 2393 & & 1616 \\
\hline Median Coefficient & & 433429 & & 02552 & & 0332 & & 2122 \\
\hline & & & & Phase 4 & & & & \\
\hline Confidence level & Hist & cal Volatility & $\operatorname{Imp}$ & d Volatility & EGA & I Volatility & & olatility \\
\hline $90 \%$ & 20 & $41.6667 \%$ & 12 & $25.0000 \%$ & 11 & $22.9167 \%$ & 10 & $20.8333 \%$ \\
\hline $95 \%$ & 17 & $35.4167 \%$ & 8 & $16.6667 \%$ & 8 & $16.6667 \%$ & 6 & $0.0000 \%$ \\
\hline $99 \%$ & 8 & $16.6667 \%$ & 4 & $8.3333 \%$ & 3 & $6.2500 \%$ & 1 & $2.0833 \%$ \\
\hline Average Coefficient & & .306884 & & 383627 & & 6247 & & 82212 \\
\hline Median Coefficient & & .300194 & & 241242 & & 27692 & & 97915 \\
\hline
\end{tabular}


Table 7.5: Industrial Goods Sector

\begin{tabular}{|c|c|c|c|c|c|c|c|c|}
\hline \multicolumn{9}{|c|}{ Entire Phases } \\
\hline Confidence level & \multicolumn{2}{|c|}{ Historical Volatility } & \multicolumn{2}{|c|}{ Implied Volatility } & \multicolumn{2}{|c|}{ EGARCH Volatility } & \multicolumn{2}{|c|}{ AR Volatility } \\
\hline $90 \%$ & 35 & $83.3333 \%$ & 38 & $90.4762 \%$ & 10 & $23.8095 \%$ & 6 & $14.2857 \%$ \\
\hline $95 \%$ & 33 & $78.5714 \%$ & 34 & $80.9524 \%$ & 7 & $16.6667 \%$ & 1 & $2.3810 \%$ \\
\hline $99 \%$ & 28 & $66.6667 \%$ & 30 & $71.4286 \%$ & 3 & $7.1429 \%$ & 0 & $0.0000 \%$ \\
\hline $\begin{array}{c}\text { Average } \\
\text { Coefficient }\end{array}$ & \multicolumn{2}{|c|}{0.323428} & \multicolumn{2}{|c|}{0.501205} & \multicolumn{2}{|c|}{0.027692} & \multicolumn{2}{|c|}{-0.096112} \\
\hline Median Coefficient & \multicolumn{2}{|c|}{0.342263} & \multicolumn{2}{|c|}{0.422728} & \multicolumn{2}{|c|}{-0.026619} & \multicolumn{2}{|c|}{-0.004422} \\
\hline \multicolumn{9}{|c|}{ Phase 1} \\
\hline Confidence level & \multicolumn{2}{|c|}{ Historical Volatility } & \multicolumn{2}{|c|}{ Implied Volatility } & \multicolumn{2}{|c|}{ EGARCH Volatility } & \multicolumn{2}{|c|}{ AR Volatility } \\
\hline $90 \%$ & 4 & $0.8316 \%$ & 7 & $16.6667 \%$ & 4 & $9.5238 \%$ & 4 & $9.5238 \%$ \\
\hline $95 \%$ & 2 & $0.4158 \%$ & 5 & $11.9048 \%$ & 2 & $4.7619 \%$ & 3 & $7.1429 \%$ \\
\hline $99 \%$ & 1 & $0.2079 \%$ & 2 & $4.7619 \%$ & 0 & $0.0000 \%$ & 2 & $4.7619 \%$ \\
\hline $\begin{array}{c}\text { Average } \\
\text { Coefficient }\end{array}$ & \multicolumn{2}{|c|}{$-\mathbf{0 . 0 2 1 1 9 7}$} & \multicolumn{2}{|c|}{0.350804} & \multicolumn{2}{|c|}{-0.250477} & \multicolumn{2}{|c|}{-0.340666} \\
\hline Median Coefficient & \multicolumn{2}{|c|}{-0.028351} & \multicolumn{2}{|c|}{0.420369} & \multicolumn{2}{|c|}{0.037990} & \multicolumn{2}{|c|}{0.034100} \\
\hline \multicolumn{9}{|c|}{ Phase 2} \\
\hline Confidence level & Hist & cal Volatility & $\operatorname{Imp}$ & d Volatility & EGA & H Volatility & & olatility \\
\hline $90 \%$ & 8 & $19.0476 \%$ & 32 & $76.1905 \%$ & 10 & $23.8095 \%$ & 7 & $16.6667 \%$ \\
\hline $95 \%$ & 5 & $11.9048 \%$ & 26 & $61.9048 \%$ & 6 & $14.2857 \%$ & 6 & $14.2857 \%$ \\
\hline $99 \%$ & 1 & $2.3810 \%$ & 21 & $50.0000 \%$ & 1 & $2.3810 \%$ & 1 & $2.3810 \%$ \\
\hline Average Coefficient & & 066701 & & 479724 & & 23931 & & 61451 \\
\hline Median Coefficient & & .068690 & & 487913 & & 24044 & & 76148 \\
\hline & & & & Phase 3 & & & & \\
\hline Confidence level & & $\begin{array}{l}\text { istorical } \\
\text { olatility }\end{array}$ & Impl & Volatility & EGAR & Volatility & & olatility \\
\hline $90 \%$ & 8 & $19.0476 \%$ & 9 & $21.4286 \%$ & 5 & $11.9048 \%$ & 4 & $9.5238 \%$ \\
\hline $95 \%$ & 3 & $7.1429 \%$ & 6 & $14.2857 \%$ & 3 & $7.1429 \%$ & 2 & $4.7619 \%$ \\
\hline $99 \%$ & 0 & $0.0000 \%$ & 3 & $7.1429 \%$ & 2 & $4.7619 \%$ & 1 & $2.3810 \%$ \\
\hline Average Coefficient & & 215715 & & 71372 & & 0827 & & 36652 \\
\hline Median Coefficient & & .286103 & & 74127 & & 7004 & & 68695 \\
\hline & & & & Phase 4 & & & & \\
\hline Confidence level & Hist & cal Volatility & $\operatorname{Imp}$ & d Volatility & EGA & H Volatility & & olatility \\
\hline $90 \%$ & 23 & $54.7619 \%$ & 20 & $47.6190 \%$ & 5 & $11.9048 \%$ & 3 & $7.1429 \%$ \\
\hline $95 \%$ & 19 & $45.2381 \%$ & 17 & $40.4762 \%$ & 1 & $2.3810 \%$ & 2 & $0.0000 \%$ \\
\hline $99 \%$ & 16 & $38.0952 \%$ & 12 & $28.5714 \%$ & 1 & $2.3810 \%$ & 1 & $2.3810 \%$ \\
\hline Average Coefficient & & .325894 & & 635245 & & 74988 & & 949217 \\
\hline Median Coefficient & & 384050 & & 418384 & & 85169 & & 487741 \\
\hline
\end{tabular}


Table 7.6: Services Sector

\begin{tabular}{|c|c|c|c|c|c|c|c|c|}
\hline \multicolumn{9}{|c|}{ Entire Phases } \\
\hline Confidence level & \multicolumn{2}{|c|}{ Historical Volatility } & \multicolumn{2}{|c|}{ Implied Volatility } & \multicolumn{2}{|c|}{ EGARCH Volatility } & \multicolumn{2}{|c|}{ AR Volatility } \\
\hline $90 \%$ & 78 & $75.0000 \%$ & 95 & $91.3462 \%$ & 24 & $23.0769 \%$ & 14 & $13.4615 \%$ \\
\hline $95 \%$ & 73 & $70.1923 \%$ & 87 & $83.6538 \%$ & 15 & $14.4231 \%$ & 9 & $8.6538 \%$ \\
\hline $99 \%$ & 56 & $53.8462 \%$ & 73 & $70.1923 \%$ & 8 & $7.6923 \%$ & 3 & $2.8846 \%$ \\
\hline Average Coefficient & \multicolumn{2}{|c|}{0.301945} & \multicolumn{2}{|c|}{0.486783} & \multicolumn{2}{|c|}{0.088875} & \multicolumn{2}{|c|}{0.433404} \\
\hline Median Coefficient & \multicolumn{2}{|c|}{0.281788} & \multicolumn{2}{|c|}{0.466062} & \multicolumn{2}{|c|}{0.078786} & \multicolumn{2}{|c|}{0.206749} \\
\hline \multicolumn{9}{|c|}{ Phase 1} \\
\hline Confidence level & \multicolumn{2}{|c|}{ Historical Volatility } & \multicolumn{2}{|c|}{ Implied Volatility } & \multicolumn{2}{|c|}{ EGARCH Volatility } & \multicolumn{2}{|c|}{ AR Volatility } \\
\hline $90 \%$ & 8 & $1.6632 \%$ & 25 & $24.0385 \%$ & 21 & $20.1923 \%$ & 11 & $10.5769 \%$ \\
\hline $95 \%$ & 3 & $0.6237 \%$ & 14 & $13.4615 \%$ & 14 & $13.4615 \%$ & 10 & $9.6154 \%$ \\
\hline $99 \%$ & 0 & $0.0000 \%$ & 7 & $6.7308 \%$ & 3 & $2.8846 \%$ & 3 & $2.8846 \%$ \\
\hline Average Coefficient & \multicolumn{2}{|c|}{0.027376} & \multicolumn{2}{|c|}{0.403240} & \multicolumn{2}{|c|}{-0.903066} & \multicolumn{2}{|c|}{3.330796} \\
\hline Median Coefficient & \multicolumn{2}{|c|}{0.052455} & \multicolumn{2}{|c|}{0.321781} & \multicolumn{2}{|c|}{-0.235043} & \multicolumn{2}{|c|}{0.619501} \\
\hline \multicolumn{9}{|c|}{ Phase 2} \\
\hline Confidence level & Hist & rical Volatility & $\operatorname{Imp}$ & d Volatility & EGA & I Volatility & & olatility \\
\hline $90 \%$ & 30 & $28.8462 \%$ & 73 & $70.1923 \%$ & 22 & $21.1538 \%$ & 13 & $12.5000 \%$ \\
\hline $95 \%$ & 22 & $21.1538 \%$ & 61 & $58.6538 \%$ & 17 & $16.3462 \%$ & 7 & $6.7308 \%$ \\
\hline $99 \%$ & 9 & $8.6538 \%$ & 43 & $41.3462 \%$ & 8 & $7.6923 \%$ & 0 & $0.0000 \%$ \\
\hline Average Coefficient & & 0.083451 & & 505932 & & 26809 & & 28284 \\
\hline Median Coefficient & & 0.071853 & & 463624 & & 36514 & & 14990 \\
\hline & & & & hase 3 & & & & \\
\hline Confidence level & & $\begin{array}{l}\text { Historical } \\
\text { Volatility }\end{array}$ & Impl & Volatility & EGAR & Volatility & & olatility \\
\hline $90 \%$ & 17 & $16.3462 \%$ & 19 & $18.2692 \%$ & 7 & $6.7308 \%$ & 5 & $4.8077 \%$ \\
\hline $95 \%$ & 8 & $7.6923 \%$ & 14 & $13.4615 \%$ & 2 & $1.9231 \%$ & 1 & $0.9615 \%$ \\
\hline $99 \%$ & 2 & $1.9231 \%$ & 3 & $2.8846 \%$ & 0 & $0.0000 \%$ & 1 & $0.9615 \%$ \\
\hline Average Coefficient & & 0.170757 & & 64926 & & 5616 & & 6387 \\
\hline Median Coefficient & & 0.149552 & & 40043 & & 7038 & & 93752 \\
\hline & & & & hase 4 & & & & \\
\hline Confidence level & Hist & rical Volatility & Imp & d Volatility & EGA & I Volatility & & olatility \\
\hline $90 \%$ & 44 & $42.3077 \%$ & 49 & $47.1154 \%$ & 18 & $17.3077 \%$ & 14 & $13.4615 \%$ \\
\hline $95 \%$ & 36 & $34.6154 \%$ & 34 & $32.6923 \%$ & 7 & $6.7308 \%$ & 7 & $0.0000 \%$ \\
\hline $99 \%$ & 21 & $20.1923 \%$ & 21 & $20.1923 \%$ & 1 & $0.9615 \%$ & 2 & $1.9231 \%$ \\
\hline Average Coefficient & & 0.291103 & & 483840 & & 38622 & & 96706 \\
\hline Median Coefficient & & 0.300509 & & 428128 & & 12420 & & 09689 \\
\hline
\end{tabular}


Table 7.7: Technology Sector

\begin{tabular}{|c|c|c|c|c|c|c|c|c|}
\hline \multicolumn{9}{|c|}{ Entire Phases } \\
\hline Confidence level & \multicolumn{2}{|c|}{ Historical Volatility } & \multicolumn{2}{|c|}{ Implied Volatility } & \multicolumn{2}{|c|}{ EGARCH Volatility } & \multicolumn{2}{|c|}{ AR Volatility } \\
\hline $90 \%$ & 56 & $52.8302 \%$ & 100 & $94.3396 \%$ & 29 & $27.3585 \%$ & 16 & $15.0943 \%$ \\
\hline $95 \%$ & 51 & $48.1132 \%$ & 98 & $92.4528 \%$ & 26 & $24.5283 \%$ & 12 & $11.3208 \%$ \\
\hline $99 \%$ & 37 & $34.9057 \%$ & 86 & $81.1321 \%$ & 12 & $11.3208 \%$ & 4 & $3.7736 \%$ \\
\hline $\begin{array}{c}\text { Average } \\
\text { Coefficient }\end{array}$ & \multicolumn{2}{|c|}{0.189886} & \multicolumn{2}{|c|}{0.671830} & \multicolumn{2}{|c|}{0.339154} & \multicolumn{2}{|c|}{-0.079491} \\
\hline Median Coefficient & \multicolumn{2}{|c|}{0.167039} & \multicolumn{2}{|c|}{0.663497} & \multicolumn{2}{|c|}{0.388312} & \multicolumn{2}{|c|}{0.097147} \\
\hline \multicolumn{9}{|c|}{ Phase 1} \\
\hline Confidence level & \multicolumn{2}{|c|}{ Historical Volatility } & \multicolumn{2}{|c|}{ Implied Volatility } & \multicolumn{2}{|c|}{ EGARCH Volatility } & \multicolumn{2}{|c|}{ AR Volatility } \\
\hline $90 \%$ & 9 & $8.4906 \%$ & 48 & $45.2830 \%$ & 17 & $16.0377 \%$ & 13 & $12.2642 \%$ \\
\hline $95 \%$ & 2 & $1.8868 \%$ & 34 & $32.0755 \%$ & 7 & $6.6038 \%$ & 9 & $8.4906 \%$ \\
\hline $99 \%$ & 0 & $0.0000 \%$ & 17 & $16.0377 \%$ & 0 & $0.0000 \%$ & 2 & $1.8868 \%$ \\
\hline $\begin{array}{c}\text { Average } \\
\text { Coefficient }\end{array}$ & \multicolumn{2}{|c|}{-0.038490} & \multicolumn{2}{|c|}{0.667663} & \multicolumn{2}{|c|}{0.403029} & \multicolumn{2}{|c|}{-0.882166} \\
\hline Median Coefficient & \multicolumn{2}{|c|}{-0.057625} & \multicolumn{2}{|c|}{0.618519} & \multicolumn{2}{|c|}{0.273791} & \multicolumn{2}{|c|}{0.080371} \\
\hline \multicolumn{9}{|c|}{ Phase 2} \\
\hline Confidence level & Hist & cal Volatility & $\operatorname{Imp}$ & ed Volatility & EGAl & H Volatility & & Volatility \\
\hline $90 \%$ & 25 & $23.5849 \%$ & 84 & $79.2453 \%$ & 23 & $21.6981 \%$ & 19 & $17.9245 \%$ \\
\hline $95 \%$ & 9 & $8.4906 \%$ & 74 & $69.8113 \%$ & 17 & $16.0377 \%$ & 12 & $11.3208 \%$ \\
\hline $99 \%$ & 3 & $2.8302 \%$ & 53 & $50.0000 \%$ & 6 & $5.6604 \%$ & 5 & $4.7170 \%$ \\
\hline Average Coefficient & & .008837 & & .573676 & & 44227 & & 047475 \\
\hline Median Coefficient & & .028431 & & .555216 & & 24106 & & 81964 \\
\hline & & & & Phase 3 & & & & \\
\hline Confidence level & & $\begin{array}{l}\text { istorical } \\
\text { olatility }\end{array}$ & Impl & d Volatility & EGAR & I Volatility & & olatility \\
\hline $90 \%$ & 17 & $16.0377 \%$ & 29 & $27.3585 \%$ & 21 & $19.8113 \%$ & 16 & $15.0943 \%$ \\
\hline $95 \%$ & 6 & $5.6604 \%$ & 19 & $17.9245 \%$ & 13 & $12.2642 \%$ & 9 & $8.4906 \%$ \\
\hline $99 \%$ & 4 & $3.7736 \%$ & 3 & $2.8302 \%$ & 1 & $0.9434 \%$ & 3 & $2.8302 \%$ \\
\hline Average Coefficient & & 130071 & & 37558 & & 9084 & & 73646 \\
\hline Median Coefficient & & 093114 & & 305849 & & 3031 & & 4510 \\
\hline & & & & Phase 4 & & & & \\
\hline Confidence level & Hist & cal Volatility & Imp & ed Volatility & EGAI & H Volatility & & Volatility \\
\hline $90 \%$ & 48 & $45.2830 \%$ & 38 & $35.8491 \%$ & 17 & $16.0377 \%$ & 19 & $17.9245 \%$ \\
\hline $95 \%$ & 44 & $41.5094 \%$ & 26 & $24.5283 \%$ & 12 & $11.3208 \%$ & 14 & $0.0000 \%$ \\
\hline $99 \%$ & 23 & $21.6981 \%$ & 16 & $15.0943 \%$ & 2 & $1.8868 \%$ & 4 & $3.7736 \%$ \\
\hline Average Coefficient & & .290722 & & .587898 & & 50870 & & 330216 \\
\hline Median Coefficient & & .296810 & & .457957 & & 22099 & & 67411 \\
\hline
\end{tabular}


Table 7.8: Utilities Sector

\begin{tabular}{|c|c|c|c|c|c|c|c|c|}
\hline \multicolumn{9}{|c|}{ Entire Phases } \\
\hline \multirow{2}{*}{$\begin{array}{c}\text { Confidence level } \\
90 \%\end{array}$} & \multicolumn{2}{|c|}{ Historical Volatility } & \multicolumn{2}{|c|}{ Implied Volatility } & \multicolumn{2}{|c|}{ EGARCH Volatility } & \multicolumn{2}{|c|}{ AR Volatility } \\
\hline & 14 & $93.3333 \%$ & 9 & $60.0000 \%$ & 2 & $13.3333 \%$ & 1 & $6.6667 \%$ \\
\hline $95 \%$ & 13 & $86.6667 \%$ & 7 & $46.6667 \%$ & 1 & $6.6667 \%$ & 0 & $0.0000 \%$ \\
\hline $99 \%$ & 12 & $80.0000 \%$ & 4 & $26.6667 \%$ & 0 & $0.0000 \%$ & 0 & $0.0000 \%$ \\
\hline $\begin{array}{l}\text { Average } \\
\text { Coefficient }\end{array}$ & \multicolumn{2}{|c|}{0.363145} & \multicolumn{2}{|c|}{0.304382} & \multicolumn{2}{|c|}{0.592050} & \multicolumn{2}{|c|}{0.460317} \\
\hline Median Coefficient & \multicolumn{2}{|c|}{0.402301} & \multicolumn{2}{|c|}{0.227298} & \multicolumn{2}{|c|}{0.640871} & \multicolumn{2}{|c|}{-0.224469} \\
\hline \multicolumn{9}{|c|}{ Phase 1} \\
\hline Confidence level & \multicolumn{2}{|c|}{ Historical Volatility } & \multicolumn{2}{|c|}{ Implied Volatility } & \multicolumn{2}{|c|}{ EGARCH Volatility } & \multicolumn{2}{|c|}{ AR Volatility } \\
\hline $90 \%$ & 2 & $0.4158 \%$ & 3 & $20.0000 \%$ & 0 & $0.0000 \%$ & 0 & $0.0000 \%$ \\
\hline $95 \%$ & 2 & $0.4158 \%$ & 2 & $13.3333 \%$ & 0 & $0.0000 \%$ & 0 & $0.0000 \%$ \\
\hline $99 \%$ & 0 & $0.0000 \%$ & 1 & $6.6667 \%$ & 0 & $0.0000 \%$ & 0 & $0.0000 \%$ \\
\hline $\begin{array}{l}\text { Average } \\
\text { Coefficient }\end{array}$ & \multicolumn{2}{|c|}{0.029611} & \multicolumn{2}{|c|}{0.386093} & \multicolumn{2}{|c|}{-0.543133} & \multicolumn{2}{|c|}{1.719032} \\
\hline Median Coefficient & \multicolumn{2}{|c|}{-0.035824} & \multicolumn{2}{|c|}{0.364093} & \multicolumn{2}{|c|}{-1.402156} & \multicolumn{2}{|c|}{0.486160} \\
\hline & & & & Phase 2 & & & & \\
\hline Confidence level & Hist & cal Volatility & & d Volatility & EGA & I Volatility & & olatility \\
\hline $90 \%$ & 10 & $66.6667 \%$ & 6 & $40.0000 \%$ & 3 & $20.0000 \%$ & 1 & $6.6667 \%$ \\
\hline $95 \%$ & 7 & $46.6667 \%$ & 4 & $26.6667 \%$ & 3 & $20.0000 \%$ & 1 & $6.6667 \%$ \\
\hline $99 \%$ & 4 & $26.6667 \%$ & 3 & $20.0000 \%$ & 1 & $6.6667 \%$ & 0 & $0.0000 \%$ \\
\hline Average Coefficient & & 267429 & & 245048 & & 1653 & & 75532 \\
\hline Median Coefficient & & 266712 & & 158517 & & 50066 & & 38871 \\
\hline & & & & hase 3 & & & & \\
\hline Confidence level & & $\begin{array}{l}\text { storical } \\
\text { olatility }\end{array}$ & $\operatorname{Imp}$ & Volatility & EGAI & Volatility & & latility \\
\hline $90 \%$ & 2 & $13.3333 \%$ & 0 & $0.0000 \%$ & 0 & $0.0000 \%$ & 1 & $6.6667 \%$ \\
\hline $95 \%$ & 0 & $0.0000 \%$ & 0 & $0.0000 \%$ & 0 & $0.0000 \%$ & 0 & $0.0000 \%$ \\
\hline $99 \%$ & 0 & $0.0000 \%$ & 0 & $0.0000 \%$ & 0 & $0.0000 \%$ & 0 & $0.0000 \%$ \\
\hline Average Coefficient & & 662223 & & 31553 & & 4529 & & 9748 \\
\hline Median Coefficient & & 497537 & & 59548 & & 9095 & & 8990 \\
\hline & & & & Phase 4 & & & & \\
\hline Confidence level & Hist & cal Volatility & & d Volatility & EGA & I Volatility & & olatility \\
\hline $90 \%$ & 8 & $53.3333 \%$ & 2 & $13.3333 \%$ & 2 & $13.3333 \%$ & 3 & $20.0000 \%$ \\
\hline $95 \%$ & 5 & $33.3333 \%$ & 2 & $13.3333 \%$ & 2 & $13.3333 \%$ & 1 & $0.0000 \%$ \\
\hline $99 \%$ & 2 & $13.3333 \%$ & 1 & $6.6667 \%$ & 0 & $0.0000 \%$ & 0 & $0.0000 \%$ \\
\hline Average Coefficient & & 343974 & & 228703 & & 59627 & & 27543 \\
\hline Median Coefficient & & 386487 & & 072544 & & 28116 & & 17731 \\
\hline
\end{tabular}


Tables 8.1 to 8.10 provides summary of variable statistics for a number of volatility measures; including implied volatility $\left(\sigma_{I V}\right)$, realized volatility $\left(\sigma_{R V}\right)$, and idiosyncratic volatilities, such as implied $\left(\sigma_{I V_{\text {idio }}}\right)$, realized $\left(\sigma_{R V_{\text {idio }}}\right)$, EGARCH $\left(\sigma_{E G_{\text {idio }}}\right), \operatorname{AR}(2)\left(\sigma_{A R_{\text {idio }}}\right)$, the book-to-market ratio $(\mathrm{BM})$, Equity Beta $(\beta)$, short sale constraint (ORW_Ratio), and open-Interest (OI) in four sub periods. These are classified as sectors into Bear and Bull markets for four sub periods from two financial crises, namely the dotcom bubble and the recent financial crisis between January 2001 and December 2010.

Table 8: Summary statistics

Table 8.1: Implied Volatility $\left(\sigma_{I V}\right)$

\begin{tabular}{|c|c|c|c|c|}
\hline \multicolumn{5}{|c|}{ Basic Materials Sector } \\
\hline Phase & Mean & Median & $5^{\text {th }}$ percentile & $95^{\text {th }}$ percentile \\
\hline Entire Phases & 0.434012 & 0.398450 & 0.233882 & 0.760384 \\
\hline Phase 1 & 0.478211 & 0.460496 & 0.287409 & 0.720953 \\
\hline Phase 2 & 0.355379 & 0.337910 & 0.214061 & 0.557662 \\
\hline Phase 3 & 0.530456 & 0.473201 & 0.305737 & 0.936583 \\
\hline Phase 4 & 0.540012 & 0.507372 & 0.317427 & 0.843214 \\
\hline \multicolumn{5}{|c|}{ Consumer Goods Sector } \\
\hline Phase & Mean & Median & $5^{\text {th }}$ percentile & $95^{\text {th }}$ percentile \\
\hline Entire Phases & 0.387110 & 0.352555 & 0.198212 & 0.695371 \\
\hline Phase 1 & 0.431771 & 0.404227 & 0.248108 & 0.699002 \\
\hline Phase 2 & 0.312558 & 0.295918 & 0.183968 & 0.496316 \\
\hline Phase 3 & 0.467979 & 0.436570 & 0.228709 & 0.797543 \\
\hline Phase 4 & 0.490256 & 0.460194 & 0.242487 & 0.828072 \\
\hline \multicolumn{5}{|c|}{ Financial Sector } \\
\hline Phase & Mean & Median & $5^{\text {th }}$ percentile & $9^{\text {th }}$ percentile \\
\hline Entire Phases & 0.408552 & 0.350573 & 0.192437 & 0.858900 \\
\hline Phase 1 & 0.398829 & 0.379476 & 0.240879 & 0.617950 \\
\hline Phase 2 & 0.293123 & 0.272730 & 0.178728 & 0.470848 \\
\hline Phase 3 & 0.606945 & 0.508826 & 0.298406 & 1.149716 \\
\hline Phase 4 & 0.607248 & 0.536800 & 0.309929 & 1.156305 \\
\hline \multicolumn{5}{|c|}{ Healthcare Sector } \\
\hline Phase & Mean & Median & $5^{\text {th }}$ percentile & $9^{\text {th }}$ percentile \\
\hline Entire Phases & 0.478977 & 0.424593 & 0.228297 & 0.901210 \\
\hline Phase 1 & 0.574715 & 0.514572 & 0.302515 & 1.012365 \\
\hline Phase 2 & 0.417343 & 0.353566 & 0.215872 & 0.798181 \\
\hline Phase 3 & 0.514374 & 0.459987 & 0.248478 & 0.915504 \\
\hline Phase 4 & 0.523616 & 0.479605 & 0.270754 & 0.919921 \\
\hline \multicolumn{5}{|c|}{ Industrial Goods Sector } \\
\hline Phase & Mean & Median & $5^{\text {th }}$ percentile & $9^{\text {th }}$ percentile \\
\hline Entire Phases & 0.424231 & 0.383900 & 0.222821 & 0.778488 \\
\hline Phase 1 & 0.473658 & 0.437830 & 0.302329 & 0.757749 \\
\hline Phase 2 & 0.345635 & 0.313469 & 0.208406 & 0.574275 \\
\hline Phase 3 & 0.515616 & 0.452386 & 0.269678 & 0.969861 \\
\hline Phase 4 & 0.527662 & 0.491066 & 0.303996 & 0.881721 \\
\hline \multicolumn{5}{|c|}{ Services Sector } \\
\hline Phase & Mean & Median & $5^{\text {th }}$ percentile & $95^{\text {th }}$ percentile \\
\hline Entire Phases & 0.437500 & 0.400522 & 0.236215 & 0.763429 \\
\hline Phase 1 & 0.518836 & 0.493037 & 0.305205 & 0.838051 \\
\hline Phase 2 & 0.352960 & 0.331730 & 0.220479 & 0.561527 \\
\hline Phase 3 & 0.524792 & 0.491537 & 0.291105 & 0.875083 \\
\hline Phase 4 & 0.527257 & 0.498062 & 0.290454 & 0.851773 \\
\hline
\end{tabular}




\begin{tabular}{ccccc}
\hline \multicolumn{5}{c}{ Technology Sector } \\
\hline Phase & Mean & Median & $\mathbf{5}^{\text {th }}$ percentile & $\mathbf{9 5}^{\text {th }}$ percentile \\
\hline Entire Phases & 0.509518 & 0.471230 & 0.268104 & 0.877085 \\
Phase 1 & 0.710326 & 0.697431 & 0.407543 & 1.061744 \\
Phase 2 & 0.427271 & 0.403849 & 0.245186 & 0.686998 \\
Phase 3 & 0.512985 & 0.482298 & 0.319718 & 0.797845 \\
Phase 4 & 0.520962 & 0.496207 & 0.311629 & 0.819465 \\
\hline \multicolumn{5}{c}{ Utilities Sector } \\
\hline Phase & Mean & Median & $\mathbf{5}^{\text {th }}$ percentile & $\mathbf{9 5}^{\text {th }}$ percentile \\
\hline Entire Phases & 0.327466 & 0.287363 & 0.167407 & 0.624211 \\
Phase 1 & 0.446571 & 0.379218 & 0.213669 & 0.959617 \\
Phase 2 & 0.266791 & 0.237864 & 0.157231 & 0.489909 \\
Phase 3 & 0.345079 & 0.308663 & 0.234576 & 0.579836 \\
Phase 4 & 0.356204 & 0.343415 & 0.198970 & 0.566976 \\
\hline
\end{tabular}

We report in table 8.1 that the implied volatility $\left(\sigma_{I V}\right)$ is lowest for every sectors in Phase 2 which is a longest period Bull market from January 2003 to December 2007 before the recent financial crisis. Moreover, they are higher in Phase 1, 3 and 4 respectively for every sectors except Healthcare, Technology, and Utilities which have the highest implied volatility in Phase 1 throughout Dotcom Bubble. In particular, this straightly affects Technology sector, meanwhile Healthcare is also resulted due to impact of business related to the medical technology. Even though, Utilities sector is consisted of various business types, firms involved to teachnology are affected. Additionally, the highest implied volatility is shown between 60 and 70 percents in both Financial and Technology sectors which mainly cause crises during period of Dotcom Bubble in Phase 1 and recent financial crisis in Phase 3 and 4.

Table 8.2: Realized Volatility $\left(\sigma_{R V}\right)$

\begin{tabular}{ccccc}
\hline \multicolumn{5}{c}{ Basic Materials Sector } \\
\hline Phase & Mean & Median & $\mathbf{5}^{\text {th }}$ percentile & $\mathbf{9 5}^{\text {th }}$ percentile \\
\hline Entire Phases & 0.390229 & 0.331821 & 0.163918 & 0.815435 \\
Phase 1 & 0.431264 & 0.392307 & 0.200289 & 0.737261 \\
Phase 2 & 0.304806 & 0.280679 & 0.150342 & 0.540357 \\
Phase 3 & 0.606837 & 0.454434 & 0.238799 & 1.533279 \\
Phase 4 & 0.456158 & 0.395683 & 0.194207 & 0.906243 \\
\hline \multicolumn{5}{c}{ Consumer Goods Sector } \\
\hline Phase & Median & $\mathbf{5}^{\text {th }}$ percentile & $\mathbf{9 5}^{\text {th }}$ percentile \\
\hline Entire Phases & 0.319949 & 0.266373 & 0.116309 & 0.706480 \\
Phase 1 & 0.378270 & 0.332937 & 0.168284 & 0.764838 \\
Phase 2 & 0.245246 & 0.218414 & 0.107689 & 0.477543 \\
Phase 3 & 0.469655 & 0.394050 & 0.166977 & 1.059451 \\
Phase 4 & 0.375964 & 0.314846 & 0.125634 & 0.850248 \\
\hline \multicolumn{5}{c}{ Financial Sector } \\
\hline Phase & Mean & Median & $\mathbf{5}^{\text {th }}$ percentile & $\mathbf{9 5}^{\text {th }}$ percentile \\
\hline Entire Phases & 0.360738 & 0.254543 & 0.117854 & 1.042393 \\
Phase 1 & 0.332456 & 0.290194 & 0.142053 & 0.666000 \\
Phase 2 & 0.219704 & 0.191149 & 0.106007 & 0.433355 \\
Phase 3 & 0.700075 & 0.508291 & 0.224999 & 1.696135 \\
Phase 4 & 0.570758 & 0.417446 & 0.173809 & 1.544905 \\
\hline \multicolumn{5}{c}{}
\end{tabular}




\begin{tabular}{|c|c|c|c|c|}
\hline \multicolumn{5}{|c|}{ Healthcare Sector } \\
\hline Phase & Mean & Median & $5^{\text {th }}$ percentile & $95^{\text {th }}$ percentile \\
\hline Entire Phases & 0.391956 & 0.311861 & 0.136888 & 0.897805 \\
\hline Phase 1 & 0.513960 & 0.430710 & 0.193413 & 1.073344 \\
\hline Phase 2 & 0.329801 & 0.267510 & 0.127476 & 0.710431 \\
\hline Phase 3 & 0.485017 & 0.370501 & 0.167059 & 1.137197 \\
\hline Phase 4 & 0.383890 & 0.315254 & 0.140730 & 0.834373 \\
\hline \multicolumn{5}{|c|}{ Industrial Goods Sector } \\
\hline Phase & Mean & Median & $5^{\text {th }}$ percentile & $95^{\text {th }}$ percentile \\
\hline Entire Phases & 0.369156 & 0.307659 & 0.144738 & 0.808799 \\
\hline Phase 1 & 0.431578 & 0.372174 & 0.201742 & 0.792907 \\
\hline Phase 2 & 0.285196 & 0.249683 & 0.132461 & 0.526122 \\
\hline Phase 3 & 0.544823 & 0.423647 & 0.202405 & 1.288274 \\
\hline Phase 4 & 0.431405 & 0.379483 & 0.171933 & 0.905419 \\
\hline \multicolumn{5}{|c|}{ Services Sector } \\
\hline Phase & Mean & Median & $5^{\text {th }}$ percentile & $95^{\text {th }}$ percentile \\
\hline Entire Phases & 0.371721 & 0.312471 & 0.151958 & 0.776824 \\
\hline Phase 1 & 0.465057 & 0.413898 & 0.211464 & 0.871295 \\
\hline Phase 2 & 0.283393 & 0.254338 & 0.141094 & 0.518116 \\
\hline Phase 3 & 0.536864 & 0.450693 & 0.228062 & 1.152617 \\
\hline Phase 4 & 0.420522 & 0.354122 & 0.157947 & 0.877605 \\
\hline \multicolumn{5}{|c|}{ Technology Sector } \\
\hline Phase & Mean & Median & $5^{\text {th }}$ percentile & $95^{\text {th }}$ percentile \\
\hline Entire Phases & 0.462128 & 0.390017 & 0.172970 & 0.990611 \\
\hline Phase 1 & 0.706466 & 0.651339 & 0.302856 & 1.296857 \\
\hline Phase 2 & 0.362935 & 0.325474 & 0.157646 & 0.685698 \\
\hline Phase 3 & 0.534302 & 0.434815 & 0.225132 & 1.109820 \\
\hline Phase 4 & 0.439866 & 0.381743 & 0.180416 & 0.876640 \\
\hline \multicolumn{5}{|c|}{ Utilities Sector } \\
\hline Phase & Mean & Median & $5^{\text {th }}$ percentile & $95^{\text {th }}$ percentile \\
\hline Entire Phases & 0.251501 & 0.190916 & 0.102183 & 0.622845 \\
\hline Phase 1 & 0.396531 & 0.275015 & 0.139857 & 1.012297 \\
\hline Phase 2 & 0.188751 & 0.159650 & 0.093659 & 0.373510 \\
\hline Phase 3 & 0.331990 & 0.233088 & 0.145444 & 0.892130 \\
\hline Phase 4 & 0.229142 & 0.198589 & 0.103948 & 0.466706 \\
\hline
\end{tabular}

Table 8.2 in regard to the realized volatility $\left(\sigma_{R V}\right)$, the lowest value is exhibited in Phase 2 for every sectors, in contrary almost sectors show the highest value in Phase 3 between recent financial crisis except Healthcare, Technology, and Utilities which present a top in Phase 1 occurred Dotcom Bubble. Especially, main cause sectors such as Financial and Technology show a peak above 70 percent during crisis periods in Phase 3 and 1 in order. 
Table 8.3: Implied idiosyncratic volatility $\left(\sigma_{I V}\right.$ idio $)$

\begin{tabular}{|c|c|c|c|c|}
\hline \multicolumn{5}{|c|}{ Basic Materials Sector } \\
\hline Phase & Mean & Median & $5^{\text {th }}$ percentile & $95^{\text {th }}$ percentile \\
\hline Entire Phases & 0.215666 & 0.158626 & 0.054665 & 0.577980 \\
\hline Phase 1 & 0.252733 & 0.211770 & 0.082556 & 0.519623 \\
\hline Phase 2 & 0.139638 & 0.113963 & 0.045752 & 0.310805 \\
\hline Phase 3 & 0.319597 & 0.223425 & 0.093323 & 0.873111 \\
\hline Phase 4 & 0.318246 & 0.257078 & 0.100665 & 0.709535 \\
\hline \multicolumn{5}{|c|}{ Consumer Goods Sector } \\
\hline Phase & Mean & Median & $5^{\text {th }}$ percentile & $95^{\text {th }}$ percentile \\
\hline Entire Phases & 0.175333 & 0.124155 & 0.039232 & 0.482814 \\
\hline Phase 1 & 0.209250 & 0.163148 & 0.061540 & 0.488082 \\
\hline Phase 2 & 0.107711 & 0.087484 & 0.033833 & 0.246147 \\
\hline Phase 3 & 0.254096 & 0.190248 & 0.052303 & 0.634276 \\
\hline Phase 4 & 0.272505 & 0.211581 & 0.058785 & 0.684809 \\
\hline \multicolumn{5}{|c|}{ Financial Sector } \\
\hline Phase & Mean & Median & $5^{\text {th }}$ percentile & $9^{\text {th }}$ percentile \\
\hline Entire Phases & 0.215310 & 0.122705 & 0.036992 & 0.737199 \\
\hline Phase 1 & 0.173620 & 0.143698 & 0.057906 & 0.381287 \\
\hline Phase 2 & 0.095531 & 0.074361 & 0.031936 & 0.221522 \\
\hline Phase 3 & 0.450385 & 0.258371 & 0.088894 & 1.317704 \\
\hline Phase 4 & 0.437176 & 0.287987 & 0.095982 & 1.335745 \\
\hline \multicolumn{5}{|c|}{ Healthcare Sector } \\
\hline Phase & Mean & Median & $5^{\text {th }}$ percentile & $9^{\text {th }}$ percentile \\
\hline Entire Phases & 0.277042 & 0.180160 & 0.052103 & 0.811152 \\
\hline Phase 1 & 0.383475 & 0.264701 & 0.091494 & 1.024289 \\
\hline Phase 2 & 0.211495 & 0.124980 & 0.046585 & 0.637059 \\
\hline Phase 3 & 0.318410 & 0.211489 & 0.061701 & 0.833582 \\
\hline Phase 4 & 0.318229 & 0.229924 & 0.073298 & 0.846016 \\
\hline \multicolumn{5}{|c|}{ Industrial Goods Sector } \\
\hline Phase & Mean & Median & $5^{\text {th }}$ percentile & $95^{\text {th }}$ percentile \\
\hline Entire Phases & 0.211509 & 0.147134 & 0.049599 & 0.604335 \\
\hline Phase 1 & 0.246839 & 0.191183 & 0.091284 & 0.571479 \\
\hline Phase 2 & 0.138605 & 0.098019 & 0.043323 & 0.329501 \\
\hline Phase 3 & 0.312400 & 0.203710 & 0.072669 & 0.937611 \\
\hline Phase 4 & 0.309464 & 0.240846 & 0.092346 & 0.777088 \\
\hline \multicolumn{5}{|c|}{ Services Sector } \\
\hline Phase & Mean & Median & $5^{\text {th }}$ percentile & $95^{\text {th }}$ percentile \\
\hline Entire Phases & 0.220273 & 0.160247 & 0.055730 & 0.581496 \\
\hline Phase 1 & 0.296338 & 0.242747 & 0.092872 & 0.700471 \\
\hline Phase 2 & 0.136852 & 0.109941 & 0.048549 & 0.315067 \\
\hline Phase 3 & 0.308081 & 0.241053 & 0.084588 & 0.762396 \\
\hline Phase 4 & 0.312024 & 0.247980 & 0.084329 & 0.723892 \\
\hline \multicolumn{5}{|c|}{ Technology Sector } \\
\hline Phase & Mean & Median & $5^{\text {th }}$ percentile & $95^{\text {th }}$ percentile \\
\hline Entire Phases & 0.296061 & 0.221665 & 0.071788 & 0.768117 \\
\hline Phase 1 & 0.544288 & 0.485832 & 0.165561 & 1.124526 \\
\hline Phase 2 & 0.202057 & 0.162912 & 0.060063 & 0.471585 \\
\hline Phase 3 & 0.287736 & 0.232203 & 0.101978 & 0.631516 \\
\hline Phase 4 & 0.297352 & 0.245216 & 0.097028 & 0.671104 \\
\hline \multicolumn{5}{|c|}{ Utilities Sector } \\
\hline Phase & Mean & Median & $5^{\text {th }}$ percentile & $95^{\text {th }}$ percentile \\
\hline Entire Phases & 0.134280 & 0.082563 & 0.028012 & 0.389383 \\
\hline Phase 1 & 0.259178 & 0.143795 & 0.045640 & 0.920835 \\
\hline Phase 2 & 0.083926 & 0.056571 & 0.024718 & 0.239911 \\
\hline Phase 3 & 0.133265 & 0.095214 & 0.054986 & 0.335772 \\
\hline Phase 4 & 0.140979 & 0.117904 & 0.039585 & 0.321405 \\
\hline
\end{tabular}


Table 8.4: Realized idiosyncratic volatility $\left(\sigma_{R V \text { idio }}\right)$

\begin{tabular}{|c|c|c|c|c|}
\hline \multicolumn{5}{|c|}{ Basic Materials Sector } \\
\hline Phase & Mean & Median & $5^{\text {th }}$ percentile & $95^{\text {th }}$ percentile \\
\hline Entire Phases & 0.087321 & 0.073696 & 0.033229 & 0.185863 \\
\hline Phase 1 & 0.097539 & 0.087883 & 0.044973 & 0.171623 \\
\hline Phase 2 & 0.068388 & 0.062920 & 0.030050 & 0.123695 \\
\hline Phase 3 & 0.136493 & 0.102204 & 0.043891 & 0.364514 \\
\hline Phase 4 & 0.100276 & 0.084212 & 0.036171 & 0.218727 \\
\hline \multicolumn{5}{|c|}{ Consumer Goods Sector } \\
\hline Phase & Mean & Median & $5^{\text {th }}$ percentile & $95^{\text {th }}$ percentile \\
\hline Entire Phases & 0.071580 & 0.059755 & 0.025233 & 0.157464 \\
\hline Phase 1 & 0.083821 & 0.074478 & 0.037107 & 0.160855 \\
\hline Phase 2 & 0.055154 & 0.048460 & 0.023320 & 0.109827 \\
\hline Phase 3 & 0.108740 & 0.085963 & 0.034670 & 0.287784 \\
\hline Phase 4 & 0.082332 & 0.069500 & 0.025712 & 0.192167 \\
\hline \multicolumn{5}{|c|}{ Financial Sector } \\
\hline Phase & Mean & Median & $5^{\text {th }}$ percentile & $95^{\text {th }}$ percentile \\
\hline Entire Phases & 0.080547 & 0.058884 & 0.025016 & 0.219935 \\
\hline Phase 1 & 0.075097 & 0.065769 & 0.033695 & 0.149133 \\
\hline Phase 2 & 0.051728 & 0.044964 & 0.022190 & 0.102733 \\
\hline Phase 3 & 0.151179 & 0.105672 & 0.043772 & 0.405668 \\
\hline Phase 4 & 0.122500 & 0.089556 & 0.032476 & 0.334651 \\
\hline \multicolumn{5}{|c|}{ Healthcare Sector } \\
\hline Phase & Mean & Median & $5^{\text {th }}$ percentile & $95^{\text {th }}$ percentile \\
\hline Entire Phases & 0.084177 & 0.067215 & 0.028150 & 0.195275 \\
\hline Phase 1 & 0.107017 & 0.090890 & 0.042611 & 0.221487 \\
\hline Phase 2 & 0.070578 & 0.056769 & 0.026564 & 0.154053 \\
\hline Phase 3 & 0.107175 & 0.082532 & 0.036338 & 0.261009 \\
\hline Phase 4 & 0.084785 & 0.068916 & 0.026873 & 0.194784 \\
\hline \multicolumn{5}{|c|}{ Industrial Goods Sector } \\
\hline Phase & Mean & Median & $5^{\text {th }}$ percentile & $95^{\text {th }}$ percentile \\
\hline Entire Phases & 0.084413 & 0.069708 & 0.029411 & 0.195862 \\
\hline Phase 1 & 0.094220 & 0.083161 & 0.039860 & 0.182133 \\
\hline Phase 2 & 0.065502 & 0.057524 & 0.026897 & 0.128253 \\
\hline Phase 3 & 0.131332 & 0.099566 & 0.037269 & 0.320775 \\
\hline Phase 4 & 0.098832 & 0.081600 & 0.030659 & 0.223748 \\
\hline \multicolumn{5}{|c|}{ Services Sector } \\
\hline Phase & Mean & Median & $5^{\text {th }}$ percentile & $95^{\text {th }}$ percentile \\
\hline Entire Phases & 0.083402 & 0.069040 & 0.031097 & 0.181367 \\
\hline Phase 1 & 0.099630 & 0.087712 & 0.044075 & 0.195010 \\
\hline Phase 2 & 0.063897 & 0.056762 & 0.028943 & 0.122843 \\
\hline Phase 3 & 0.125883 & 0.100563 & 0.042409 & 0.301041 \\
\hline Phase 4 & 0.095372 & 0.078209 & 0.030123 & 0.212255 \\
\hline \multicolumn{5}{|c|}{ Technology Sector } \\
\hline Phase & Mean & Median & $5^{\text {th }}$ percentile & $95^{\text {th }}$ percentile \\
\hline Entire Phases & 0.104772 & 0.088098 & 0.034911 & 0.231258 \\
\hline Phase 1 & 0.143792 & 0.132819 & 0.053051 & 0.274361 \\
\hline Phase 2 & 0.081604 & 0.073484 & 0.031924 & 0.159433 \\
\hline Phase 3 & 0.141614 & 0.108425 & 0.044039 & 0.368825 \\
\hline Phase 4 & 0.106876 & 0.089815 & 0.033554 & 0.239080 \\
\hline \multicolumn{5}{|c|}{ Utilities Sector } \\
\hline Phase & Mean & Median & $5^{\text {th }}$ percentile & $95^{\text {th }}$ percentile \\
\hline Entire Phases & 0.051211 & 0.038877 & 0.020642 & 0.120948 \\
\hline Phase 1 & 0.083355 & 0.062790 & 0.030412 & 0.197347 \\
\hline Phase 2 & 0.038581 & 0.032896 & 0.019165 & 0.074797 \\
\hline Phase 3 & 0.065447 & 0.050611 & 0.027697 & 0.169296 \\
\hline Phase 4 & 0.044863 & 0.038020 & 0.019530 & 0.096404 \\
\hline
\end{tabular}


Table 8.3 in term of implied idiosyncratic volatility $\left(\sigma_{I V \text { idio }}\right)$ and table 8.4 regarding realized idiosyncratic volatility $\left(\sigma_{R V_{i d i o}}\right)$, Phase 2 presents the bottom for every sectors as well, because the idiosyncratic component comes to equilibrium or is close to the actual fundamental value of stock price. In addition, the implied idiosyncratic volatility $\left(\sigma_{I V}\right.$ idio $)$ for Financial in Phase 3 and Technology in Phase 1 is analogous and present peak around 75 percent on the entire implied volatility. Meanwhile, outcomes of the realized idiosyncratic volatility $\left(\sigma_{R V}\right.$ idio $)$ from same sectors and phases are also analogous to the entire realized volatility.

Table 8.5: EGARCH idiosyncratic volatility $\left(\sigma_{E G_{i d i o}}\right)$

\begin{tabular}{|c|c|c|c|c|}
\hline \multicolumn{5}{|c|}{ Basic Materials Sector } \\
\hline Phase & Mean & Median & $5^{\text {th }}$ percentile & $95^{\text {th }}$ percentile \\
\hline Entire Phases & 0.089374 & 0.083097 & 0.040907 & 0.168938 \\
\hline Phase 1 & 0.090757 & 0.085983 & 0.042501 & 0.164379 \\
\hline Phase 2 & 0.085665 & 0.080365 & 0.040983 & 0.152028 \\
\hline Phase 3 & 0.095754 & 0.090183 & 0.041591 & 0.176803 \\
\hline Phase 4 & 0.094128 & 0.085171 & 0.038965 & 0.184114 \\
\hline \multicolumn{5}{|c|}{ Consumer Goods Sector } \\
\hline Phase & Mean & Median & $5^{\text {th }}$ percentile & $9^{\text {th }}$ percentile \\
\hline Entire Phases & 0.073315 & 0.064764 & 0.034140 & 0.132691 \\
\hline Phase 1 & 0.079823 & 0.068017 & 0.037160 & 0.148028 \\
\hline Phase 2 & 0.069231 & 0.062972 & 0.033216 & 0.126991 \\
\hline Phase 3 & 0.075599 & 0.065200 & 0.034811 & 0.138038 \\
\hline Phase 4 & 0.076143 & 0.065649 & 0.033810 & 0.145345 \\
\hline \multicolumn{5}{|c|}{ Financial Sector } \\
\hline Phase & Mean & Median & $5^{\text {th }}$ percentile & $9^{\text {th }}$ percentile \\
\hline Entire Phases & 0.071936 & 0.060107 & 0.030030 & 0.150710 \\
\hline Phase 1 & 0.067630 & 0.060751 & 0.032319 & 0.127373 \\
\hline Phase 2 & 0.059518 & 0.054508 & 0.028254 & 0.102716 \\
\hline Phase 3 & 0.094565 & 0.073472 & 0.031415 & 0.233822 \\
\hline Phase 4 & 0.095790 & 0.074421 & 0.032035 & 0.257625 \\
\hline \multicolumn{5}{|c|}{ Healthcare Sector } \\
\hline Phase & Mean & Median & $5^{\text {th }}$ percentile & $95^{\text {th }}$ percentile \\
\hline Entire Phases & 0.101204 & 0.085544 & 0.039770 & 0.217007 \\
\hline Phase 1 & 0.107353 & 0.093644 & 0.043622 & 0.216650 \\
\hline Phase 2 & 0.099714 & 0.082503 & 0.040604 & 0.215115 \\
\hline Phase 3 & 0.099279 & 0.085593 & 0.040561 & 0.204562 \\
\hline Phase 4 & 0.099997 & 0.083506 & 0.036372 & 0.230376 \\
\hline \multicolumn{5}{|c|}{ Industrial Goods Sector } \\
\hline Phase & Mean & Median & $5^{\text {th }}$ percentile & $9^{\text {th }}$ percentile \\
\hline Entire Phases & 0.080723 & 0.069317 & 0.035844 & 0.154036 \\
\hline Phase 1 & 0.088261 & 0.071764 & 0.043554 & 0.188132 \\
\hline Phase 2 & 0.077257 & 0.067683 & 0.034071 & 0.142533 \\
\hline Phase 3 & 0.081006 & 0.070868 & 0.036988 & 0.138609 \\
\hline Phase 4 & 0.082022 & 0.069620 & 0.034840 & 0.154940 \\
\hline
\end{tabular}




\begin{tabular}{ccccc}
\hline \multicolumn{5}{c}{ Services Sector } \\
\hline Phase & Mean & Median & $\mathbf{5}^{\text {th }}$ percentile & $\mathbf{9 5}^{\text {th }}$ percentile \\
\hline Entire Phases & 0.085277 & 0.076288 & 0.042324 & 0.159801 \\
Phase 1 & 0.092834 & 0.082774 & 0.046372 & 0.169741 \\
Phase 2 & 0.079045 & 0.072816 & 0.041322 & 0.140380 \\
Phase 3 & 0.089214 & 0.078805 & 0.042373 & 0.169789 \\
Phase 4 & 0.091644 & 0.078817 & 0.041552 & 0.171568 \\
\hline \multicolumn{5}{c}{ Technology Sector } \\
\hline Phase & Mean & Median & $\mathbf{5}^{\text {th }}$ percentile & $\mathbf{9 5}^{\text {th }}$ percentile \\
\hline Entire Phases & 0.102041 & 0.089654 & 0.046726 & 0.188473 \\
Phase 1 & 0.129523 & 0.113961 & 0.055242 & 0.251395 \\
Phase 2 & 0.095555 & 0.086407 & 0.046485 & 0.166593 \\
Phase 3 & 0.096777 & 0.085301 & 0.046425 & 0.174390 \\
Phase 4 & 0.094554 & 0.081985 & 0.044234 & 0.179109 \\
\hline \multicolumn{5}{c}{ Utilities Sector } \\
\hline Phase & Mean & Median & $\mathbf{5}^{\text {th }}$ percentile & $\mathbf{9 5}^{\text {th }}$ percentile \\
\hline Entire Phases & 0.055777 & 0.046407 & 0.030262 & 0.109441 \\
Phase 1 & 0.079263 & 0.061367 & 0.036469 & 0.209362 \\
Phase 2 & 0.050400 & 0.043482 & 0.030190 & 0.096399 \\
Phase 3 & 0.048242 & 0.044865 & 0.030784 & 0.074958 \\
Phase 4 & 0.050481 & 0.045704 & 0.028940 & 0.086489 \\
\hline \multicolumn{5}{c}{}
\end{tabular}

Furthermore, table 8.5 in regard to $\mathrm{EGARCH}\left(\sigma_{E G_{\text {idio }}}\right)$, and table 8.6 about $\operatorname{AR}(2)\left(\sigma_{A R}\right.$ idio $)$ idiosyncratic volatilities are same direction as implied and realized idiosyncratic volatilities for every sectors with lowest value in Phase 2 which stock price has a low idiosyncratic component and is close to the actual fundamental part.

Table 8.6: $A R(2)$ idiosyncratic volatility $\left(\sigma_{A R}\right.$ idio $)$

\begin{tabular}{ccccc}
\hline \multicolumn{5}{c}{ Basic Materials Sector } \\
\hline Phase & Mean & Median & $\mathbf{5}^{\text {th }}$ percentile & $\mathbf{9 5}^{\text {th }}$ percentile \\
\hline Entire Phases & 0.091120 & 0.083955 & 0.044395 & 0.158435 \\
Phase 1 & 0.093119 & 0.086302 & 0.046221 & 0.158244 \\
Phase 2 & 0.086846 & 0.081538 & 0.043928 & 0.148094 \\
Phase 3 & 0.097535 & 0.088682 & 0.043969 & 0.167052 \\
Phase 4 & 0.096680 & 0.085830 & 0.044531 & 0.176052 \\
\hline \multicolumn{5}{c}{ Consumer Goods Sector } \\
\hline Phase & Median & $\mathbf{5}^{\text {th }}$ percentile & $\mathbf{9 5}^{\text {th }}$ percentile \\
\hline Entire Phases & 0.074740 & 0.065440 & 0.037196 & 0.128918 \\
Phase 1 & 0.081472 & 0.068533 & 0.038706 & 0.140598 \\
Phase 2 & 0.071115 & 0.064513 & 0.036736 & 0.123020 \\
Phase 3 & 0.074549 & 0.066274 & 0.038622 & 0.128193 \\
Phase 4 & 0.077447 & 0.065799 & 0.036858 & 0.138762 \\
\hline Phase & Financial Sector & \\
\hline Entire Phases & Mean & Median & $\mathbf{5}^{\text {th }}$ percentile & $\mathbf{9 5}^{\text {th }}$ percentile \\
Phase 1 & 0.077239 & 0.060824 & 0.036259 & 0.164322 \\
Phase 2 & 0.070240 & 0.061762 & 0.036921 & 0.127266 \\
Phase 3 & 0.062516 & 0.057155 & 0.034153 & 0.108533 \\
Phase 4 & 0.100917 & 0.071019 & 0.038464 & 0.244448 \\
\hline \multicolumn{5}{c}{0.070599} \\
\hline
\end{tabular}




\begin{tabular}{|c|c|c|c|c|}
\hline \multicolumn{5}{|c|}{ Healthcare Sector } \\
\hline Phase & Mean & Median & $5^{\text {th }}$ percentile & $95^{\text {th }}$ percentile \\
\hline Entire Phases & 0.104205 & 0.086695 & 0.044631 & 0.202293 \\
\hline Phase 1 & 0.109019 & 0.092242 & 0.046304 & 0.209013 \\
\hline Phase 2 & 0.102814 & 0.085601 & 0.044441 & 0.200371 \\
\hline Phase 3 & 0.103054 & 0.086331 & 0.044604 & 0.200039 \\
\hline Phase 4 & 0.103644 & 0.086660 & 0.043754 & 0.199970 \\
\hline \multicolumn{5}{|c|}{ Industrial Goods Sector } \\
\hline Phase & Mean & Median & $5^{\text {th }}$ percentile & $95^{\text {th }}$ percentile \\
\hline Entire Phases & 0.082835 & 0.068247 & 0.039941 & 0.161474 \\
\hline Phase 1 & 0.089311 & 0.071484 & 0.044298 & 0.187318 \\
\hline Phase 2 & 0.078495 & 0.066322 & 0.038448 & 0.143238 \\
\hline Phase 3 & 0.083644 & 0.068556 & 0.036821 & 0.157792 \\
\hline Phase 4 & 0.087074 & 0.070018 & 0.038705 & 0.176448 \\
\hline \multicolumn{5}{|c|}{ Services Sector } \\
\hline Phase & Mean & Median & $5^{\text {th }}$ percentile & $95^{\text {th }}$ percentile \\
\hline Entire Phases & 0.087781 & 0.078948 & 0.047684 & 0.152380 \\
\hline Phase 1 & 0.090947 & 0.081890 & 0.049604 & 0.159340 \\
\hline Phase 2 & 0.083226 & 0.078032 & 0.046810 & 0.140382 \\
\hline Phase 3 & 0.087895 & 0.078732 & 0.047963 & 0.156324 \\
\hline Phase 4 & 0.096074 & 0.079258 & 0.046708 & 0.174621 \\
\hline \multicolumn{5}{|c|}{ Technology Sector } \\
\hline Phase & Mean & Median & $5^{\text {th }}$ percentile & $95^{\text {th }}$ percentile \\
\hline Entire Phases & 0.106945 & 0.098232 & 0.054423 & 0.179257 \\
\hline Phase 1 & 0.122844 & 0.107854 & 0.056200 & 0.234729 \\
\hline Phase 2 & 0.101753 & 0.096268 & 0.053917 & 0.166879 \\
\hline Phase 3 & 0.102765 & 0.095612 & 0.054619 & 0.166561 \\
\hline Phase 4 & 0.106777 & 0.094932 & 0.054728 & 0.176813 \\
\hline \multicolumn{5}{|c|}{ Utilities Sector } \\
\hline Phase & Mean & Median & $5^{\text {th }}$ percentile & $95^{\text {th }}$ percentile \\
\hline Entire Phases & 0.061356 & 0.048800 & 0.034314 & 0.121524 \\
\hline Phase 1 & 0.083366 & 0.054469 & 0.035839 & 0.208543 \\
\hline Phase 2 & 0.055846 & 0.046548 & 0.033870 & 0.103525 \\
\hline Phase 3 & 0.056269 & 0.049294 & 0.035067 & 0.104429 \\
\hline Phase 4 & 0.056580 & 0.048829 & 0.035172 & 0.099597 \\
\hline
\end{tabular}

Table 8.7: Book-to-market ratio (BM)

\begin{tabular}{ccccc}
\hline \multicolumn{5}{c}{ Basic Materials Sector } \\
\hline Phase & Mean & Median & $\mathbf{5}^{\text {th }}$ percentile & $\mathbf{9 5}^{\text {th }}$ percentile \\
\hline Entire Phases & -0.121771 & -0.494957 & -1.631376 & 2.212425 \\
Phase 1 & -0.009450 & -0.475985 & -1.522952 & 2.259543 \\
Phase 2 & -0.176350 & -0.540580 & -1.682369 & 2.172351 \\
Phase 3 & -0.408344 & -0.709727 & -1.818971 & 1.892452 \\
Phase 4 & 0.050322 & -0.337071 & -1.382513 & 2.326907 \\
\hline \multicolumn{5}{c}{ Consumer Goods Sector } \\
\hline Phase & Mean & Median & $\mathbf{5}^{\text {th }}$ percentile & $\mathbf{9 5}^{\text {th }}$ percentile \\
\hline Entire Phases & -0.532171 & -0.726762 & -3.091677 & 2.543991 \\
Phase 1 & -0.571720 & -0.783409 & -2.724796 & 2.489070 \\
Phase 2 & -0.594759 & -0.740507 & -3.208997 & 2.156492 \\
Phase 3 & -0.515233 & -0.688899 & -3.103112 & 2.655975 \\
Phase 4 & -0.346269 & -0.569112 & -2.753165 & 3.031580 \\
\hline
\end{tabular}




\begin{tabular}{|c|c|c|c|c|}
\hline \multicolumn{5}{|c|}{ Financial Sector } \\
\hline Phase & Mean & Median & $5^{\text {th }}$ percentile & $95^{\text {th }}$ percentile \\
\hline Entire Phases & 0.331949 & 0.137205 & -1.568337 & 2.853452 \\
\hline Phase 1 & -0.010008 & -0.348287 & -1.956818 & 2.474692 \\
\hline Phase 2 & 0.111295 & -0.226670 & -1.698462 & 2.366673 \\
\hline Phase 3 & 0.599888 & 0.360227 & -1.321532 & 3.043646 \\
\hline Phase 4 & 1.077323 & 0.833943 & -0.871713 & 3.449950 \\
\hline \multicolumn{5}{|c|}{ Healthcare Sector } \\
\hline Phase & Mean & Median & $5^{\text {th }}$ percentile & 95 $5^{\text {th }}$ percentile \\
\hline Entire Phases & 0.160307 & -0.177832 & -2.132943 & 3.386982 \\
\hline Phase 1 & -0.053597 & -0.220794 & -2.535806 & 3.304772 \\
\hline Phase 2 & 0.154857 & -0.128389 & -1.950531 & 3.266827 \\
\hline Phase 3 & 0.183045 & -0.228547 & -2.038821 & 3.826528 \\
\hline Phase 4 & 0.367554 & -0.179047 & -1.671333 & 3.643009 \\
\hline \multicolumn{5}{|c|}{ Industrial Goods Sector } \\
\hline Phase & Mean & Median & $5^{\text {th }}$ percentile & $95^{\text {th }}$ percentile \\
\hline Entire Phases & -0.201158 & -0.460962 & -1.940502 & 1.947866 \\
\hline Phase 1 & -0.099702 & -0.472528 & -1.788965 & 2.166388 \\
\hline Phase 2 & -0.270699 & -0.611024 & -1.875852 & 1.965475 \\
\hline Phase 3 & -0.369109 & -0.532940 & -2.171403 & 1.595042 \\
\hline Phase 4 & -0.040558 & -0.202481 & -1.982054 & 1.973918 \\
\hline \multicolumn{5}{|c|}{ Services Sector } \\
\hline Phase & Mean & Median & $5^{\text {th }}$ percentile & $95^{\text {th }}$ percentile \\
\hline Entire Phases & -0.425804 & -0.551384 & -2.187244 & 1.721652 \\
\hline Phase 1 & -0.540798 & -0.583508 & -2.548996 & 1.646285 \\
\hline Phase 2 & -0.487819 & -0.620905 & -2.235422 & 1.577166 \\
\hline Phase 3 & -0.398010 & -0.567234 & -2.153397 & 1.716139 \\
\hline Phase 4 & -0.174461 & -0.365939 & -1.894138 & 2.041902 \\
\hline \multicolumn{5}{|c|}{ Technology Sector } \\
\hline Phase & Mean & Median & $5^{\text {th }}$ percentile & $95^{\text {th }}$ percentile \\
\hline Entire Phases & -0.147286 & -0.235315 & -3.265810 & 2.389129 \\
\hline Phase 1 & -0.261984 & -0.379227 & -3.149504 & 2.167781 \\
\hline Phase 2 & -0.222156 & -0.325244 & -3.351049 & 2.234253 \\
\hline Phase 3 & -0.108476 & -0.126619 & -3.396847 & 2.359550 \\
\hline Phase 4 & 0.130404 & -0.027966 & -3.162784 & 2.696755 \\
\hline \multicolumn{5}{|c|}{ Utilities Sector } \\
\hline Phase & Mean & Median & $5^{\text {th }}$ percentile & $95^{\text {th }}$ percentile \\
\hline Entire Phases & -0.318276 & -0.320927 & -0.898798 & 0.326910 \\
\hline Phase 1 & -0.380446 & -0.380935 & -1.004230 & 0.129578 \\
\hline Phase 2 & -0.372049 & -0.352757 & -0.892860 & 0.212038 \\
\hline Phase 3 & -0.350287 & -0.246764 & -1.048078 & 0.118402 \\
\hline Phase 4 & -0.108256 & -0.072730 & -0.699783 & 0.532694 \\
\hline
\end{tabular}

Table 8.7 presents the book-to-market ratio (BM) in log term for entire phases are mostly negative for every sectors except Financial and Healthcare sectors. In the positive group is implied to be a cheap stock price owing to the fact that the book value is higher than market value. Conversely, the negative group or market value higher than book value is an expensive stock price for instance Consumer Goods, Industrial Goods Services, Technology, and Utilities due to investor's perspective to anticipate high growth in the future. 
Table 8.8: Equity Beta $(\beta)$

\begin{tabular}{|c|c|c|c|c|}
\hline \multicolumn{5}{|c|}{ Basic Materials Sector } \\
\hline Phase & Mean & Median & $5^{\text {th }}$ percentile & $95^{\text {th }}$ percentile \\
\hline Entire Phases & 1.051168 & 0.957465 & 0.324404 & 2.067192 \\
\hline Phase 1 & 0.867202 & 0.767797 & 0.417311 & 1.597466 \\
\hline Phase 2 & 0.937873 & 0.823534 & 0.160174 & 1.979929 \\
\hline Phase 3 & 1.269122 & 1.152263 & 0.593597 & 2.355253 \\
\hline Phase 4 & 1.401732 & 1.277371 & 0.680179 & 2.671842 \\
\hline \multicolumn{5}{|c|}{ Consumer Goods Sector } \\
\hline Phase & Mean & Median & $5^{\text {th }}$ percentile & $95^{\text {th }}$ percentile \\
\hline Entire Phases & 0.828195 & 0.749002 & 0.028104 & 1.893393 \\
\hline Phase 1 & 0.656533 & 0.639607 & 0.047906 & 1.465237 \\
\hline Phase 2 & 0.747580 & 0.691727 & -0.037430 & 1.869382 \\
\hline Phase 3 & 0.971993 & 0.876291 & 0.227960 & 2.084155 \\
\hline Phase 4 & 1.122341 & 1.100067 & 0.280981 & 2.315103 \\
\hline \multicolumn{5}{|c|}{ Financial Sector } \\
\hline Phase & Mean & Median & $5^{\text {th }}$ percentile & $9^{\text {th }}$ percentile \\
\hline Entire Phases & 0.936582 & 0.831155 & 0.190125 & 2.076004 \\
\hline Phase 1 & 0.757993 & 0.669186 & 0.148087 & 1.457542 \\
\hline Phase 2 & 0.821458 & 0.665370 & 0.159859 & 1.785187 \\
\hline Phase 3 & 1.033262 & 1.005691 & 0.363540 & 1.896957 \\
\hline Phase 4 & 1.347200 & 1.207443 & 0.411285 & 2.810916 \\
\hline \multicolumn{5}{|c|}{ Healthcare Sector } \\
\hline Phase & Mean & Median & $5^{\text {th }}$ percentile & $95^{\text {th }}$ percentile \\
\hline Entire Phases & 0.932418 & 0.713612 & 0.070513 & 2.401867 \\
\hline Phase 1 & 1.021959 & 0.724277 & 0.195624 & 2.356029 \\
\hline Phase 2 & 0.913614 & 0.607739 & -0.028996 & 2.562447 \\
\hline Phase 3 & 0.916769 & 0.840681 & 0.061263 & 2.124789 \\
\hline Phase 4 & 0.901441 & 0.821643 & 0.351166 & 2.058492 \\
\hline \multicolumn{5}{|c|}{ Industrial Goods Sector } \\
\hline Phase & Mean & Median & $5^{\text {th }}$ percentile & $9^{\text {th }}$ percentile \\
\hline Entire Phases & 1.075112 & 0.979142 & 0.212808 & 2.266119 \\
\hline Phase 1 & 0.771380 & 0.738800 & 0.144489 & 1.382938 \\
\hline Phase 2 & 1.025169 & 0.927359 & 0.054957 & 2.426302 \\
\hline Phase 3 & 1.300529 & 1.237107 & 0.485225 & 2.288851 \\
\hline Phase 4 & 1.378334 & 1.280746 & 0.618116 & 2.476353 \\
\hline \multicolumn{5}{|c|}{ Services Sector } \\
\hline Phase & Mean & Median & $5^{\text {th }}$ percentile & $9^{\text {th }}$ percentile \\
\hline Entire Phases & 1.053258 & 0.971598 & 0.223154 & 2.166116 \\
\hline Phase 1 & 0.893268 & 0.807538 & 0.211414 & 1.894236 \\
\hline Phase 2 & 1.041890 & 0.934370 & 0.201234 & 2.160673 \\
\hline Phase 3 & 1.138086 & 1.076140 & 0.442654 & 1.956580 \\
\hline Phase 4 & 1.192587 & 1.091305 & 0.332664 & 2.556659 \\
\hline \multicolumn{5}{|c|}{ Technology Sector } \\
\hline Phase & Mean & Median & $5^{\text {th }}$ percentile & $95^{\text {th }}$ percentile \\
\hline Entire Phases & 1.876243 & 1.798382 & 0.718606 & 3.359237 \\
\hline Phase 1 & 1.861379 & 1.871216 & 0.646164 & 3.010838 \\
\hline Phase 2 & 2.125358 & 2.138849 & 0.693056 & 3.546592 \\
\hline Phase 3 & 1.672357 & 1.538916 & 0.783848 & 3.000313 \\
\hline Phase 4 & 1.369641 & 1.199025 & 0.753328 & 2.555235 \\
\hline
\end{tabular}




\begin{tabular}{ccccc}
\hline \multicolumn{5}{c}{ Utilities Sector } \\
\hline Phase & Mean & Median & $\mathbf{5}^{\text {th }}$ percentile & $\mathbf{9 5}^{\text {th }}$ percentile \\
\hline Entire Phases & 0.451075 & 0.379766 & -0.221822 & 1.911137 \\
Phase 1 & 0.045353 & -0.122412 & -0.242624 & 1.465761 \\
Phase 2 & 0.511098 & 0.347928 & -0.228861 & 2.196091 \\
Phase 3 & 0.667377 & 0.587155 & 0.309852 & 1.407778 \\
Phase 4 & 0.581683 & 0.559961 & 0.265400 & 1.373677 \\
\hline
\end{tabular}

Table 8.8 in the variable of Equity Beta $(\beta)$, the tendency is higher from Phase 1 to Phase 4 for every sectors except Healthcare, Technology, and Utilities, since the increasing relation of stocks in market affects to the higher systematic risk as CAPM. As of this consequence, most investors turn to speculate by passive investment strategies resulting stocks to move into same directions and highly follow to the market direction. Then, the stock's systematic risk increases. Although the beta tendency of Healthcare and Technology is not higher, the value for Healthcare is around 0.9 close to 1. This shows that it moves following to the market. Meanwhile, Technology's beta is over 1 with highest average in entire phases compared to every sectors, even though its tendency is decreasing. Additionally, Utilities sector is different to other sectors due to quite small Beta value. Consequently, Utilities' Beta moves independently and is not affected by the stock market.

Table 8.9: ORW_Ratio $(O R W)$

\begin{tabular}{|c|c|c|c|c|}
\hline \multicolumn{5}{|c|}{ Basic Materials Sector } \\
\hline Phase & Mean & Median & $5^{\text {th }}$ percentile & $95^{\text {th }}$ percentile \\
\hline Entire Phases & -0.087510 & -0.061054 & -1.988601 & 0.437378 \\
\hline Phase 1 & 0.159190 & -0.171818 & -1.705669 & 0.505425 \\
\hline Phase 2 & 0.020678 & 0.054002 & -0.801898 & 0.445978 \\
\hline Phase 3 & 0.038425 & -0.097209 & -1.676637 & 0.443865 \\
\hline Phase 4 & -0.657369 & -0.541469 & -4.027996 & 0.313084 \\
\hline \multicolumn{5}{|c|}{ Consumer Goods Sector } \\
\hline Phase & Mean & Median & $5^{\text {th }}$ percentile & $95^{\text {th }}$ percentile \\
\hline Entire Phases & -0.306971 & -0.127995 & -2.281460 & 0.425396 \\
\hline Phase 1 & -0.185973 & -0.137486 & -1.713674 & 0.488339 \\
\hline Phase 2 & 0.016591 & 0.000000 & -1.041714 & 0.442577 \\
\hline Phase 3 & -0.339528 & -0.298684 & -2.150731 & 0.368659 \\
\hline Phase 4 & -1.215553 & -0.688792 & -5.148031 & 0.298931 \\
\hline \multicolumn{5}{|c|}{ Financial Sector } \\
\hline Phase & Mean & Median & $5^{\text {th }}$ percentile & $95^{\text {th }}$ percentile \\
\hline Entire Phases & -0.045313 & -0.136328 & -2.755219 & 0.450231 \\
\hline Phase 1 & 0.122476 & -0.119290 & -1.006491 & 0.570778 \\
\hline Phase 2 & 0.297049 & 0.042231 & -1.007897 & 0.477665 \\
\hline Phase 3 & 0.070528 & -0.517924 & -4.049405 & 0.354839 \\
\hline Phase 4 & -1.119936 & -0.957275 & -5.635215 & 0.211528 \\
\hline
\end{tabular}




\begin{tabular}{|c|c|c|c|c|}
\hline \multicolumn{5}{|c|}{ Healthcare Sector } \\
\hline Phase & Mean & Median & $5^{\text {th }}$ percentile & $95^{\text {th }}$ percentile \\
\hline Entire Phases & -0.402072 & -0.153694 & -3.058707 & 0.429896 \\
\hline Phase 1 & 0.217999 & -0.156189 & -1.837724 & 0.607440 \\
\hline Phase 2 & -0.099375 & -0.023390 & -1.913857 & 0.445954 \\
\hline Phase 3 & -0.938214 & -0.319540 & -3.386655 & 0.311042 \\
\hline Phase 4 & -1.484977 & -0.720064 & -5.252880 & 0.330368 \\
\hline \multicolumn{5}{|c|}{ Industrial Goods Sector } \\
\hline Phase & Mean & Median & $5^{\text {th }}$ percentile & $95^{\text {th }}$ percentile \\
\hline Entire Phases & -0.237555 & -0.073546 & -2.168781 & 0.442530 \\
\hline Phase 1 & 0.075016 & -0.204737 & -1.543799 & 0.478608 \\
\hline Phase 2 & 0.014665 & 0.065082 & -0.996905 & 0.471582 \\
\hline Phase 3 & -0.331873 & -0.181576 & -2.230108 & 0.405515 \\
\hline Phase 4 & -1.120490 & -0.653251 & -4.268891 & 0.257419 \\
\hline \multicolumn{5}{|c|}{ Services Sector } \\
\hline Phase & Mean & Median & $5^{\text {th }}$ percentile & $95^{\text {th }}$ percentile \\
\hline Entire Phases & -0.403502 & -0.183536 & -2.360018 & 0.394974 \\
\hline Phase 1 & -0.168539 & -0.294849 & -1.709314 & 0.469935 \\
\hline Phase 2 & -0.080521 & -0.038727 & -1.216495 & 0.421479 \\
\hline Phase 3 & -0.336112 & -0.286580 & -2.017070 & 0.312655 \\
\hline Phase 4 & -1.469822 & -0.747275 & -5.239680 & 0.257881 \\
\hline \multicolumn{5}{|c|}{ Technology Sector } \\
\hline Phase & Mean & Median & $5^{\text {th }}$ percentile & $95^{\text {th }}$ percentile \\
\hline Entire Phases & -0.378455 & -0.369726 & -2.986652 & 0.341377 \\
\hline Phase 1 & 0.093821 & -0.389515 & -1.941837 & 0.519911 \\
\hline Phase 2 & -0.113768 & -0.226407 & -1.766166 & 0.354130 \\
\hline Phase 3 & -0.503339 & -0.505686 & -2.959537 & 0.272697 \\
\hline Phase 4 & -1.430330 & -1.009528 & -6.513871 & 0.197183 \\
\hline \multicolumn{5}{|c|}{ Utilities Sector } \\
\hline Phase & Mean & Median & $5^{\text {th }}$ percentile & $95^{\text {th }}$ percentile \\
\hline Entire Phases & -0.175888 & -0.088873 & -1.724384 & 0.415613 \\
\hline Phase 1 & 0.319153 & -0.197672 & -1.671374 & 0.602266 \\
\hline Phase 2 & -0.092640 & 0.036482 & -1.199971 & 0.446686 \\
\hline Phase 3 & -0.304555 & -0.150156 & -1.611945 & 0.413391 \\
\hline Phase 4 & -0.794091 & -0.377645 & -3.146872 & 0.295032 \\
\hline
\end{tabular}

Furthermore, table 8.9 show an evidence that short sale constraint (ORW_Ratio) tends to decrease in the long term from Phase 1 to 4 for every sectors, whereas this would cause by investors who speculate more in option market and affect the option price moving ahead the stock price or the price of put - call parity moving ahead the stock price and causing $\mathrm{S}^{*}$ (which is the theoretical price computed from the call-put relation including the put of last exercise premium as Ofek, Richardson and Whitelaw (2004) more than S (which is the current stock price) or ORW Ratio = $100 \times \ln [S / S *]$ turns to be more negative causing from option price moving ahead stock price and shows that option market is higher liquidity. 
Table 8.10: Open-Interest (OI)

\begin{tabular}{|c|c|c|c|c|}
\hline \multicolumn{5}{|c|}{ Basic Materials Sector } \\
\hline Phase & Mean & Median & $5^{\text {th }}$ percentile & $95^{\text {th }}$ percentile \\
\hline Entire Phases & 5.877089 & 6.202536 & 0.000000 & 9.415116 \\
\hline Phase 1 & 4.347109 & 4.615121 & 0.000000 & 8.037703 \\
\hline Phase 2 & 5.833504 & 6.191335 & 0.000000 & 9.315303 \\
\hline Phase 3 & 6.843271 & 7.103265 & 3.470352 & 9.526897 \\
\hline Phase 4 & 6.969192 & 7.132879 & 3.258097 & 9.927935 \\
\hline \multicolumn{5}{|c|}{ Consumer Goods Sector } \\
\hline Phase & Mean & Median & $5^{\text {th }}$ percentile & $95^{\text {th }}$ percentile \\
\hline Entire Phases & 4.818691 & 4.912655 & 0.000000 & 8.951816 \\
\hline Phase 1 & 3.914353 & 3.931826 & 0.000000 & 8.060860 \\
\hline Phase 2 & 4.772154 & 4.844187 & 0.000000 & 8.996379 \\
\hline Phase 3 & 5.506092 & 5.566432 & 1.098612 & 9.192949 \\
\hline Phase 4 & 5.457989 & 5.589118 & 0.000000 & 9.431120 \\
\hline \multicolumn{5}{|c|}{ Financial Sector } \\
\hline Phase & Mean & Median & $5^{\text {th }}$ percentile & $9^{\text {th }}$ percentile \\
\hline Entire Phases & 4.562602 & 4.672829 & 0.000000 & 8.864160 \\
\hline Phase 1 & 3.573477 & 3.688879 & 0.000000 & 7.873940 \\
\hline Phase 2 & 4.301379 & 4.406719 & 0.000000 & 8.667318 \\
\hline Phase 3 & 5.508061 & 5.680167 & 0.000000 & 9.359657 \\
\hline Phase 4 & 5.690839 & 6.086772 & 0.000000 & 9.779816 \\
\hline \multicolumn{5}{|c|}{ Healthcare Sector } \\
\hline Phase & Mean & Median & $5^{\text {th }}$ percentile & $95^{\text {th }}$ percentile \\
\hline Entire Phases & 5.647566 & 5.891644 & 0.000000 & 9.335681 \\
\hline Phase 1 & 4.823538 & 4.908965 & 0.000000 & 8.526746 \\
\hline Phase 2 & 5.820421 & 6.074195 & 0.000000 & 9.428588 \\
\hline Phase 3 & 5.936022 & 6.110328 & 1.791759 & 9.603057 \\
\hline Phase 4 & 5.860894 & 6.195421 & 0.000000 & 9.384600 \\
\hline \multicolumn{5}{|c|}{ Industrial Goods Sector } \\
\hline Phase & Mean & Median & $5^{\text {th }}$ percentile & $9^{\text {th }}$ percentile \\
\hline Entire Phases & 5.145106 & 5.382196 & 0.000000 & 8.915452 \\
\hline Phase 1 & 3.756342 & 3.784190 & 0.000000 & 7.969322 \\
\hline Phase 2 & 5.232452 & 5.446737 & 0.000000 & 8.855939 \\
\hline Phase 3 & 5.969863 & 6.188256 & 1.609438 & 9.225024 \\
\hline Phase 4 & 5.845265 & 6.111467 & 1.098612 & 9.296693 \\
\hline \multicolumn{5}{|c|}{ Services Sector } \\
\hline Phase & Mean & Median & $5^{\text {th }}$ percentile & $9^{\text {th }}$ percentile \\
\hline Entire Phases & 5.135694 & 5.320565 & 0.000000 & 8.790497 \\
\hline Phase 1 & 4.354934 & 4.477337 & 0.000000 & 8.156094 \\
\hline Phase 2 & 5.042234 & 5.147494 & 0.000000 & 8.803041 \\
\hline Phase 3 & 5.817361 & 5.986449 & 1.464395 & 9.075794 \\
\hline Phase 4 & 5.776739 & 6.083359 & 0.693147 & 9.057414 \\
\hline \multicolumn{5}{|c|}{ Technology Sector } \\
\hline Phase & Mean & Median & $5^{\text {th }}$ percentile & $95^{\text {th }}$ percentile \\
\hline Entire Phases & 5.514110 & 5.749393 & 0.000000 & 9.846268 \\
\hline Phase 1 & 5.495959 & 5.725216 & 0.000000 & 9.682617 \\
\hline Phase 2 & 5.634864 & 5.817111 & 0.000000 & 9.839636 \\
\hline Phase 3 & 5.564733 & 5.647211 & 0.000000 & 9.964807 \\
\hline Phase 4 & 5.204308 & 5.638355 & 0.000000 & 9.901822 \\
\hline
\end{tabular}




\begin{tabular}{ccccc}
\hline \multicolumn{5}{c}{ Utilities Sector } \\
\hline Phase & Mean & Median & $\mathbf{5}^{\text {th }}$ percentile & $\mathbf{9 5}^{\text {th }}$ percentile \\
\hline Entire Phases & 4.642832 & 4.820282 & 0.693147 & 7.494207 \\
Phase 1 & 3.893449 & 3.912023 & 0.000000 & 7.044731 \\
Phase 2 & 4.687037 & 4.799906 & 1.098612 & 7.602245 \\
Phase 3 & 5.136915 & 5.344721 & 2.297317 & 7.582209 \\
Phase 4 & 5.003440 & 5.310737 & 1.386294 & 7.584951 \\
\hline
\end{tabular}

Table 8.10 illustrates that option interest $(O I)$ is higher for every sectors and an indicator which implies investors speculating higher in option and affecting to higher liquidity in option market. In particular, a number of sectors which are Consumer Goods, Healthcare, Industrial Goods, Services, and Utilities, show that the maximum option interest is in Phase 3 during recent financial crisis due to higher speculation through option in these sectors.

Tables 9.1 to 9.8 show the correlation matrix classified by sectors, the following correlation (univariate relationships) among the independent variables used in the Fama and Macbeth predictive regressions can be highlight after divide into 4 phases (Bear and Bull markets) and analysis that every variables of idiosyncratic volatility for every sectors and phases have highly positive correlations each other or similarly unsystematic volatilities are tended to be same direction for whole volatility models as CAPM or Fama French(1973). In particular, there is a highly negative correlation between idiosyncratic volatilities and $\log S I Z E$ which is implied that larger firms have higher returns as theories than smaller firms due to lower idiosyncratic volatilities.

Additionally, $\log B M$ (Book to market value) variables are associated to idiosyncratic volatilities with a positive effect for every sectors except Financial in Phase 1 and 2 and this indicates that high Book to Market firms (cheaper price) which have mostly lower price than theoretical price, result in probably high idiosyncratic volatilities. Somehow, financial sector has an average positive $\log \mathrm{BM}$ resulting a group of cheap stock price. Its $\log \mathrm{BM}$ would not associate to idiosyncratic volatilities.

Meanwhile, we find an evidence that short sales constraints $\left(O R W_{\text {ratio }}\right)$ are slightly correlated to all variables for every sectors except Utilities sector which is low Beta and differently moves from the stock market. In addition, liquidities (OI ) have a highly positive correlation with $\log S I Z E$ for every phases and sectors examined, therefore options of large firms which have vigorous $\log S I Z E$, are higher liquidity than smaller firms' options. 
Table 9: Correlation matrix

Table 9.1: Basic Materials Sector

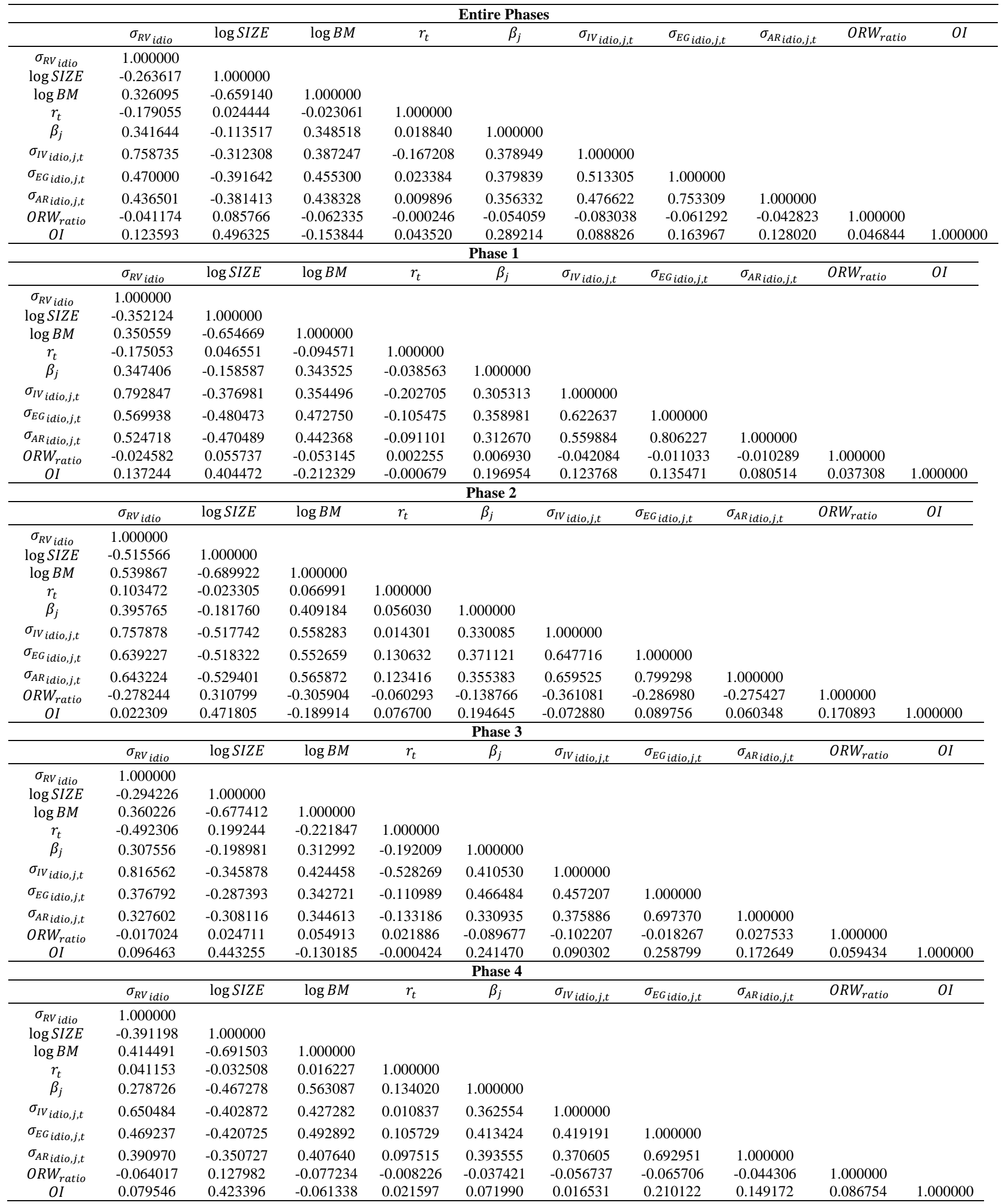


Table 9.2: Consumer Goods Sector

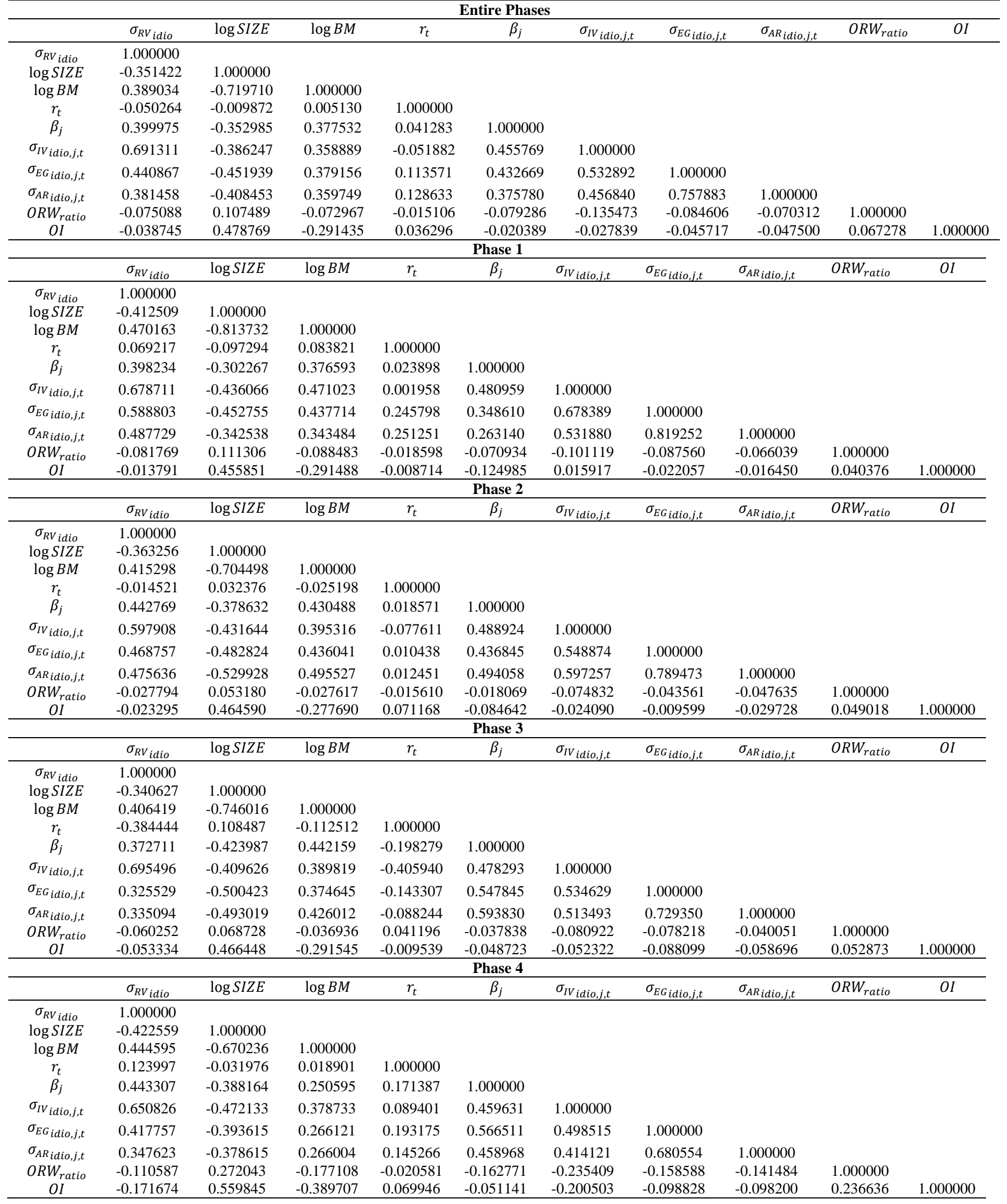


Table 9.3: Financial Sector

\begin{tabular}{|c|c|c|c|c|c|c|c|c|c|c|}
\hline \multicolumn{11}{|c|}{ Entire Phases } \\
\hline & $\sigma_{R V_{\text {idio }}}$ & $\log S I Z E$ & $\log B M$ & $r_{t}$ & $\beta_{j}$ & $\sigma_{I V_{i d i o, j, t}}$ & $\sigma_{E G_{i d i o, j, t}}$ & $\sigma_{A R_{\text {idio }, j, t}}$ & $O R W_{\text {ratio }}$ & $O I$ \\
\hline$\sigma_{R V_{i d i o}}$ & 1.000000 & & & & & & & & & \\
\hline $\log S I Z E$ & -0.215675 & 1.000000 & & & & & & & & \\
\hline $\log B M$ & 0.291297 & -0.607258 & 1.000000 & & & & & & & \\
\hline$r_{t}$ & -0.094584 & 0.019577 & -0.028758 & 1.000000 & & & & & & \\
\hline$\beta_{j}$ & 0.304994 & 0.010731 & 0.146960 & 0.053402 & 1.000000 & & & & & \\
\hline$\sigma_{I V}$ idio $, j, t$ & 0.809659 & -0.242215 & 0.324813 & -0.165412 & 0.327798 & 1.000000 & & & & \\
\hline$\sigma_{E G_{i d i o, j, t}}$ & 0.585900 & -0.264772 & 0.302312 & 0.083321 & 0.338437 & 0.620322 & 1.000000 & & & \\
\hline$\sigma_{A R_{i d i o, j, t}}$ & 0.486548 & -0.204285 & 0.242435 & 0.037882 & 0.269356 & 0.524267 & 0.671443 & 1.000000 & & \\
\hline$O R W_{\text {ratio }}$ & -0.053971 & 0.134579 & -0.073474 & 0.011856 & -0.065503 & -0.076566 & -0.050269 & -0.044884 & 1.000000 & \\
\hline OI & 0.209948 & 0.471896 & -0.116423 & 0.026069 & 0.233187 & 0.210398 & 0.175992 & 0.163412 & 0.076907 & 1.0000 \\
\hline \multicolumn{11}{|c|}{ Phase 1} \\
\hline & $\sigma_{R V_{\text {idio }}}$ & $\log S I Z E$ & $\log B M$ & $r_{t}$ & $\beta_{j}$ & $\sigma_{I V_{i d i o, j, t}}$ & $\sigma_{E G_{i d i o, j, t}}$ & $\sigma_{\text {AR }}$ idio $, j, t$ & $O R W_{\text {ratio }}$ & $O I$ \\
\hline$\sigma_{R V_{i d i o}}$ & 1.000000 & & & & & & & & & \\
\hline $\log S I Z E$ & -0.098444 & 1.000000 & & & & & & & & \\
\hline $\log B M$ & 0.087609 & -0.662402 & 1.000000 & & & & & & & \\
\hline$r_{t}$ & -0.186323 & -0.027446 & -0.007288 & 1.000000 & & & & & & \\
\hline$\beta_{j}$ & 0.325656 & -0.067883 & 0.087380 & -0.025417 & 1.000000 & & & & & \\
\hline$\sigma_{I V}$ idio,j,t & 0.563888 & -0.179955 & 0.144500 & -0.200925 & 0.502061 & 1.000000 & & & & \\
\hline$\sigma_{E G_{i d i o, j, t}}$ & 0.304905 & -0.129205 & 0.156097 & 0.035196 & 0.386338 & 0.461873 & 1.000000 & & & \\
\hline$\sigma_{A R_{i d i o, j, t}}$ & 0.223879 & -0.071118 & 0.081047 & 0.008931 & 0.195042 & 0.342451 & 0.633223 & 1.000000 & & \\
\hline ORW $W_{\text {ratio }}$ & -0.060334 & 0.074710 & -0.063741 & 0.018909 & -0.018773 & -0.074639 & -0.029233 & -0.027394 & 1.000000 & \\
\hline$O I$ & 0.062879 & 0.448100 & -0.233307 & 0.003586 & 0.109641 & 0.080835 & 0.060873 & 0.050807 & 0.054584 & 1.000000 \\
\hline \multicolumn{11}{|c|}{ Phase 2 } \\
\hline & $\sigma_{R V_{\text {idio }}}$ & $\log S I Z E$ & $\log B M$ & $r_{t}$ & $\beta_{j}$ & $\sigma_{I V_{i d i o, j, t}}$ & $\sigma_{E G_{i d i o, j, t}}$ & $\sigma_{\text {AR } i d i o, j, t}$ & ORW $W_{\text {ratio }}$ & $O I$ \\
\hline$\sigma_{R V_{\text {idio }}}$ & 1.000000 & & & & & & & & & \\
\hline $\log S I Z E$ & -0.179378 & 1.000000 & & & & & & & & \\
\hline $\log B M$ & 0.158881 & -0.591409 & 1.000000 & & & & & & & \\
\hline$r_{t}$ & -0.085976 & 0.009062 & -0.028826 & 1.000000 & & & & & & \\
\hline$\beta_{j}$ & 0.298289 & 0.107771 & 0.027274 & 0.038499 & 1.000000 & & & & & \\
\hline$\sigma_{I V} V_{i d i o, j, t}$ & 0.579133 & -0.233965 & 0.185996 & -0.139041 & 0.286021 & 1.000000 & & & & \\
\hline$\sigma_{E G_{i d i o, j, t}}$ & 0.354391 & -0.217493 & 0.188455 & 0.046716 & 0.277221 & 0.453827 & 1.000000 & & & \\
\hline$\sigma_{A R_{i d i o, j, t}}$ & 0.334387 & -0.266747 & 0.214420 & 0.012219 & 0.212111 & 0.475693 & 0.678627 & 1.000000 & & \\
\hline ORW $W_{\text {ratio }}$ & -0.042656 & 0.105774 & -0.046389 & 0.003670 & -0.034621 & -0.081537 & -0.059482 & -0.054301 & 1.000000 & \\
\hline$O I$ & 0.078177 & 0.558251 & -0.253963 & 0.025781 & 0.157944 & 0.015255 & 0.048495 & -0.011354 & 0.082654 & 1.000000 \\
\hline \multicolumn{11}{|c|}{ Phase 3} \\
\hline & $\sigma_{R V \text { idio }}$ & $\log S I Z E$ & $\log B M$ & $r_{t}$ & $\beta_{j}$ & $\sigma_{I V_{i d i o, j, t}}$ & $\sigma_{E G_{i d i o, j, t}}$ & $\sigma_{\text {AR }}$ idio $, j, t$ & $O R W_{\text {ratio }}$ & $O I$ \\
\hline$\sigma_{R V \text { idio }}$ & 1.000000 & & & & & & & & & \\
\hline $\log S I Z E$ & -0.275661 & 1.000000 & & & & & & & & \\
\hline $\log B M$ & 0.292164 & -0.578299 & 1.000000 & & & & & & & \\
\hline$r_{t}$ & -0.258126 & 0.082518 & -0.082815 & 1.000000 & & & & & & \\
\hline$\beta_{j}$ & 0.256330 & -0.111993 & 0.070314 & -0.219142 & 1.000000 & & & & & \\
\hline$\sigma_{I V_{i d i o, j, t}}$ & 0.771918 & -0.301174 & 0.326399 & -0.386346 & 0.311481 & 1.000000 & & & & \\
\hline$\sigma_{E G_{i d i o, j, t}}$ & 0.508261 & -0.316800 & 0.320433 & 0.020977 & 0.237470 & 0.533082 & 1.000000 & & & \\
\hline$\sigma_{A R}$ idio $, j, t$ & 0.386195 & -0.174229 & 0.203090 & -0.024773 & 0.134330 & 0.386452 & 0.544209 & 1.000000 & & \\
\hline$O R W_{\text {ratio }}$ & -0.032228 & 0.241037 & -0.074790 & 0.088167 & -0.079818 & -0.058609 & -0.017422 & -0.017198 & 1.000000 & \\
\hline$O I$ & 0.152642 & 0.497608 & -0.126438 & -0.050872 & 0.017656 & 0.186201 & 0.193391 & 0.165927 & 0.178666 & 1.000000 \\
\hline \multicolumn{11}{|c|}{ Phase 4} \\
\hline & $\sigma_{R V_{\text {idio }}}$ & $\log S I Z E$ & $\log B M$ & $r_{t}$ & $\beta_{j}$ & $\sigma_{I V_{i d i o, j, t}}$ & $\sigma_{E G_{i d i o, j, t}}$ & $\sigma_{A R_{i d i o, j, t}}$ & ORW $W_{\text {ratio }}$ & $O I$ \\
\hline$\sigma_{R V}$ idio & 1.000000 & & & & & & & & & \\
\hline $\log S I Z E$ & -0.276796 & 1.000000 & & & & & & & & \\
\hline $\log B M$ & 0.319305 & -0.623004 & 1.000000 & & & & & & & \\
\hline$r_{t}$ & 0.054950 & 0.043076 & -0.053013 & 1.000000 & & & & & & \\
\hline$\beta_{j}$ & 0.185802 & 0.081999 & 0.037193 & 0.160679 & 1.000000 & & & & & \\
\hline$\sigma_{I V}$ idio,j,t & 0.794143 & -0.313398 & 0.345735 & -0.076660 & 0.192927 & 1.000000 & & & & \\
\hline$\sigma_{E G_{i d i o, j, t}}$ & 0.612860 & -0.351024 & 0.325840 & 0.169302 & 0.292346 & 0.625307 & 1.000000 & & & \\
\hline$\sigma_{A R_{i d i o, j, t}}$ & 0.491354 & -0.263635 & 0.255646 & 0.095808 & 0.293884 & 0.521447 & 0.703168 & 1.000000 & & \\
\hline ORW $W_{\text {ratio }}$ & -0.032412 & 0.140204 & -0.065071 & -0.013404 & -0.054993 & -0.053239 & -0.029651 & -0.029945 & 1.000000 & \\
\hline$O I$ & 0.215815 & 0.485670 & -0.149406 & 0.079619 & 0.227308 & 0.189441 & 0.170251 & 0.204403 & 0.102003 & 1.000000 \\
\hline
\end{tabular}


Table 9.4: Healthcare Sector

\begin{tabular}{|c|c|c|c|c|c|c|c|c|c|c|}
\hline \multicolumn{11}{|c|}{ Entire Phases } \\
\hline & $\sigma_{R V \text { idio }}$ & $\log S I Z E$ & $\log B M$ & $r_{t}$ & $\beta_{j}$ & $\sigma_{I V_{i d i o, j, t}}$ & $\sigma_{\text {EG }}{ }_{i d i o, j, t}$ & $\sigma_{\text {ARidio,j,t }}$ & ORW $W_{\text {ratio }}$ & $O I$ \\
\hline$\sigma_{R V \text { idio }}$ & 1.000000 & & & & & & & & & \\
\hline $\log S I Z E$ & -0.473823 & 1.000000 & & & & & & & & \\
\hline $\log B M$ & 0.356828 & -0.711546 & 1.000000 & & & & & & & \\
\hline$r_{t}$ & -0.020186 & -0.001366 & 0.001308 & 1.000000 & & & & & & \\
\hline$\beta_{j}$ & 0.453733 & -0.591906 & 0.393433 & 0.014905 & 1.000000 & & & & & \\
\hline$\sigma_{I V_{i d i o, j, t}}$ & 0.701507 & -0.589366 & 0.415614 & -0.060488 & 0.564997 & 1.000000 & & & & \\
\hline$\sigma_{E G_{i d i o, j, t}}$ & 0.548399 & -0.575868 & 0.383231 & 0.070577 & 0.513079 & 0.621188 & 1.000000 & & & \\
\hline$\sigma_{\text {AR idio }, j, t}$ & 0.489962 & -0.544998 & 0.378513 & 0.048865 & 0.474665 & 0.562568 & 0.805336 & 1.000000 & & \\
\hline$O R W_{\text {ratio }}$ & -0.101243 & 0.178603 & -0.138225 & -0.014906 & -0.097741 & -0.135803 & -0.113016 & -0.103571 & 1.000000 & \\
\hline$O I$ & -0.122683 & 0.614839 & -0.486450 & 0.025766 & -0.207775 & -0.141691 & -0.087979 & -0.102023 & 0.090597 & 1.000000 \\
\hline \multicolumn{11}{|c|}{ Phase 1} \\
\hline & $\sigma_{R V_{\text {idio }}}$ & $\log S I Z E$ & $\log B M$ & $r_{t}$ & $\beta_{j}$ & $\sigma_{I V_{i d i o, j, t}}$ & $\sigma_{E G_{i d i o, j, t}}$ & $\sigma_{\text {AR }}{ }_{\text {idio }, j, t}$ & ORW $W_{\text {ratio }}$ & $O I$ \\
\hline$\sigma_{R V_{i d i o}}$ & 1.000000 & & & & & & & & & \\
\hline $\log S I Z E$ & -0.504346 & 1.000000 & & & & & & & & \\
\hline $\log B M$ & 0.462485 & -0.785053 & 1.000000 & & & & & & & \\
\hline$r_{t}$ & -0.149455 & 0.026824 & -0.024271 & 1.000000 & & & & & & \\
\hline$\beta_{j}$ & 0.578188 & -0.650213 & 0.417943 & -0.031937 & 1.000000 & & & & & \\
\hline$\sigma_{I V i d i o, j, t}$ & 0.726831 & -0.605344 & 0.522171 & -0.140469 & 0.653917 & 1.000000 & & & & \\
\hline$\sigma_{E G_{i d i o, j, t}}$ & 0.605798 & -0.603334 & 0.490933 & -0.027468 & 0.614166 & 0.712661 & 1.000000 & & & \\
\hline$\sigma_{A R_{i d i o, j, t}}$ & 0.538433 & -0.570072 & 0.460107 & -0.024324 & 0.573242 & 0.643752 & 0.813751 & 1.000000 & & \\
\hline ORW $W_{\text {ratio }}$ & -0.070270 & 0.142553 & -0.091616 & -0.034502 & -0.067138 & -0.076618 & -0.049620 & -0.028431 & 1.000000 & \\
\hline$O I$ & -0.133007 & 0.662339 & -0.586542 & -0.006652 & -0.285170 & -0.173921 & -0.207697 & -0.208818 & 0.106733 & 1.000000 \\
\hline \multicolumn{11}{|c|}{ Phase 2} \\
\hline & $\sigma_{R V_{i d i o}}$ & $\log S I Z E$ & $\log B M$ & $r_{t}$ & $\beta_{j}$ & $\sigma_{I V_{i d i o, j, t}}$ & $\sigma_{E G_{i d i o, j, t}}$ & $\sigma_{\text {ARidio }, j, t}$ & ORW $W_{\text {ratio }}$ & $O I$ \\
\hline$\sigma_{R V_{i d i o}}$ & 1.000000 & & & & & & & & & \\
\hline $\log S I Z E$ & -0.467990 & 1.000000 & & & & & & & & \\
\hline $\log B M$ & 0.353802 & -0.728371 & 1.000000 & & & & & & & \\
\hline$r_{t}$ & 0.166530 & -0.008738 & 0.011434 & 1.000000 & & & & & & \\
\hline$\beta_{j}$ & 0.488142 & -0.628385 & 0.450704 & 0.036866 & 1.000000 & & & & & \\
\hline$\sigma_{I V_{i d i o, j, t}}$ & 0.665062 & -0.609768 & 0.401628 & 0.015978 & 0.665636 & 1.000000 & & & & \\
\hline$\sigma_{E G_{i d i o, j, t}}$ & 0.580912 & -0.569147 & 0.383031 & 0.108842 & 0.544476 & 0.678195 & 1.000000 & & & \\
\hline$\sigma_{\text {AR }}$ idio, $, t, t$ & 0.495800 & -0.520859 & 0.362148 & 0.083312 & 0.492677 & 0.604260 & 0.789259 & 1.000000 & & \\
\hline$O R W_{\text {ratio }}$ & -0.098682 & 0.153125 & -0.105245 & -0.009985 & -0.117234 & -0.136860 & -0.125159 & -0.110147 & 1.000000 & \\
\hline$O I$ & -0.034754 & 0.576221 & -0.491981 & 0.026800 & -0.180290 & -0.054866 & -0.025777 & -0.042587 & 0.074500 & 1.000000 \\
\hline \multicolumn{11}{|c|}{ Phase 3} \\
\hline & $\sigma_{R V \text { idio }}$ & $\log S I Z E$ & $\log B M$ & $r_{t}$ & $\beta_{j}$ & $\sigma_{I V_{i d i o, j, t}}$ & $\sigma_{E G_{i d i o, j, t}}$ & $\sigma_{\text {ARidio }, j, t}$ & ORW $W_{\text {ratio }}$ & $O I$ \\
\hline$\sigma_{R V \text { idio }}$ & 1.000000 & & & & & & & & & \\
\hline $\log S I Z E$ & -0.434341 & 1.000000 & & & & & & & & \\
\hline $\log B M$ & 0.402136 & -0.745281 & 1.000000 & & & & & & & \\
\hline$r_{t}$ & -0.441845 & 0.103465 & -0.072770 & 1.000000 & & & & & & \\
\hline$\beta_{j}$ & 0.324706 & -0.548920 & 0.477007 & -0.139582 & 1.000000 & & & & & \\
\hline$\sigma_{I V_{i d i o, j, t}}$ & 0.680657 & -0.557932 & 0.463241 & -0.323186 & 0.446593 & 1.000000 & & & & \\
\hline$\sigma_{E G_{i d i o, j, t}}$ & 0.482019 & -0.566245 & 0.456016 & -0.059330 & 0.362548 & 0.565302 & 1.000000 & & & \\
\hline$\sigma_{A R_{i d i o, j, t}}$ & 0.469278 & -0.593272 & 0.488264 & -0.085976 & 0.371543 & 0.553309 & 0.856324 & 1.000000 & & \\
\hline$O R W_{\text {ratio }}$ & -0.174027 & 0.281977 & -0.232641 & 0.043030 & -0.155003 & -0.210206 & -0.189448 & -0.203524 & 1.000000 & \\
\hline$O I$ & -0.146717 & 0.620459 & -0.456755 & 0.065375 & -0.242877 & -0.127973 & -0.047965 & -0.097260 & 0.131962 & 1.000000 \\
\hline \multicolumn{11}{|c|}{ Phase 4} \\
\hline & $\sigma_{R V_{i d i o}}$ & $\log S I Z E$ & $\log B M$ & $r_{t}$ & $\beta_{j}$ & $\sigma_{I V_{i d i o, j, t}}$ & $\sigma_{E G_{i d i o, j, t}}$ & $\sigma_{\text {AR }}{ }_{\text {idio }, j, t}$ & ORW $W_{\text {ratio }}$ & $O I$ \\
\hline$\sigma_{R V_{\text {idio }}}$ & 1.000000 & & & & & & & & & \\
\hline $\log S I Z E$ & -0.555444 & 1.000000 & & & & & & & & \\
\hline $\log B M$ & 0.349509 & -0.603361 & 1.000000 & & & & & & & \\
\hline$r_{t}$ & 0.162618 & -0.076844 & 0.021398 & 1.000000 & & & & & & \\
\hline$\beta_{j}$ & 0.440033 & -0.454877 & 0.125459 & 0.144628 & 1.000000 & & & & & \\
\hline$\sigma_{I V_{i d i o, j, t}}$ & 0.694556 & -0.638915 & 0.417529 & 0.117629 & 0.424661 & 1.000000 & & & & \\
\hline$\sigma_{E G_{i d i o, j, t}}$ & 0.567570 & -0.575183 & 0.276204 & 0.152585 & 0.358468 & 0.566989 & 1.000000 & & & \\
\hline$\sigma_{A R_{i d i o, j, t}}$ & 0.566204 & -0.583351 & 0.329447 & 0.106841 & 0.351172 & 0.547095 & 0.829565 & 1.000000 & & \\
\hline ORW $W_{\text {ratio }}$ & -0.173098 & 0.356528 & -0.272299 & 0.005701 & -0.143068 & -0.244957 & -0.212294 & -0.220616 & 1.000000 & \\
\hline$O I$ & -0.190568 & 0.669389 & -0.480820 & 0.006351 & -0.188316 & -0.191306 & -0.134120 & -0.164852 & 0.210507 & 1.000000 \\
\hline
\end{tabular}


Table 9.5: Industrial Goods Sector

\begin{tabular}{|c|c|c|c|c|c|c|c|c|c|c|}
\hline \multicolumn{11}{|c|}{ Entire Phases } \\
\hline & $\sigma_{R V_{\text {idio }}}$ & $\log S I Z E$ & $\log B M$ & $r_{t}$ & $\beta_{j}$ & $\sigma_{I V_{i d i o, j, t}}$ & $\sigma_{E G_{i d i o, j, t}}$ & $\sigma_{\text {AR idio }, j, t}$ & $O R W_{\text {ratio }}$ & $O I$ \\
\hline$\sigma_{R V_{\text {idio }}}$ & 1.000000 & & & & & & & & & \\
\hline $\log S I Z E$ & -0.456349 & 1.000000 & & & & & & & & \\
\hline $\log B M$ & 0.359382 & -0.653306 & 1.000000 & & & & & & & \\
\hline$r_{t}$ & -0.127550 & 0.000637 & -0.016357 & 1.000000 & & & & & & \\
\hline$\beta_{j}$ & 0.355209 & -0.326160 & 0.173442 & 0.016971 & 1.000000 & & & & & \\
\hline$\sigma_{I V_{i d i o, j, t}}$ & 0.738273 & -0.485267 & 0.387517 & -0.088512 & 0.339421 & 1.000000 & & & & \\
\hline$\sigma_{E G_{i d i o}, j, t}$ & 0.384757 & -0.443588 & 0.345874 & 0.050045 & 0.331350 & 0.438009 & 1.000000 & & & \\
\hline$\sigma_{\text {AR idio }, j, t}$ & 0.450788 & -0.510266 & 0.387829 & 0.019144 & 0.418142 & 0.533344 & 0.711844 & 1.000000 & & \\
\hline ORW $W_{\text {ratio }}$ & -0.089242 & 0.124855 & -0.065573 & -0.016413 & -0.137995 & -0.146852 & -0.078376 & -0.080089 & 1.000000 & \\
\hline$O I$ & -0.049580 & 0.593668 & -0.246573 & 0.001720 & 0.009240 & -0.038021 & -0.084183 & -0.081071 & 0.072033 & 1.000000 \\
\hline \multicolumn{11}{|c|}{ Phase 1} \\
\hline & $\sigma_{R V_{\text {idio }}}$ & $\log S I Z E$ & $\log B M$ & $r_{t}$ & $\beta_{j}$ & $\sigma_{I V_{i d i o, j, t}}$ & $\sigma_{E G_{i d i o, j, t}}$ & $\sigma_{\text {AR idio }, j, t}$ & $O R W_{\text {ratio }}$ & $O I$ \\
\hline$\sigma_{R V}$ idio & 1.000000 & & & & & & & & & \\
\hline $\log S I Z E$ & -0.522809 & 1.000000 & & & & & & & & \\
\hline $\log B M$ & 0.475716 & -0.741991 & 1.000000 & & & & & & & \\
\hline$r_{t}$ & -0.205433 & 0.028773 & -0.037123 & 1.000000 & & & & & & \\
\hline$\beta_{j}$ & 0.395395 & -0.326828 & 0.139410 & -0.038269 & 1.000000 & & & & & \\
\hline$\sigma_{I V i d i o, j, t}$ & 0.714348 & -0.564344 & 0.514579 & -0.186434 & 0.481901 & 1.000000 & & & & \\
\hline$\sigma_{E G_{i d i o, j, t}}$ & 0.515803 & -0.473198 & 0.459269 & -0.007909 & 0.399921 & 0.634416 & 1.000000 & & & \\
\hline$\sigma_{A R_{i d i o, j, t}}$ & 0.477897 & -0.504658 & 0.460620 & -0.061274 & 0.413294 & 0.604145 & 0.806583 & 1.000000 & & \\
\hline ORW $W_{\text {ratio }}$ & -0.053641 & 0.094535 & -0.032595 & -0.004482 & -0.095900 & -0.109236 & -0.050769 & -0.044954 & 1.000000 & \\
\hline$O I$ & -0.142043 & 0.611637 & -0.323898 & 0.011761 & -0.174456 & -0.139307 & -0.100019 & -0.133337 & 0.093658 & 1.000000 \\
\hline \multicolumn{11}{|c|}{ Phase 2} \\
\hline & $\sigma_{R V_{i d i o}}$ & $\log S I Z E$ & $\log B M$ & $r_{t}$ & $\beta_{j}$ & $\sigma_{I V_{i d i o, j, t}}$ & $\sigma_{E G_{i d i o, j, t}}$ & $\sigma_{\text {ARidio }, j, t}$ & ORW $W_{\text {ratio }}$ & $O I$ \\
\hline$\sigma_{R V_{i d i o}}$ & 1.000000 & & & & & & & & & \\
\hline $\log S I Z E$ & -0.607378 & 1.000000 & & & & & & & & \\
\hline $\log B M$ & 0.457498 & -0.683073 & 1.000000 & & & & & & & \\
\hline$r_{t}$ & 0.169038 & -0.067524 & 0.025361 & 1.000000 & & & & & & \\
\hline$\beta_{j}$ & 0.521420 & -0.439112 & 0.216044 & 0.100236 & 1.000000 & & & & & \\
\hline$\sigma_{I V_{i d i o, j, t}}$ & 0.729199 & -0.604458 & 0.468384 & 0.098124 & 0.547306 & 1.000000 & & & & \\
\hline$\sigma_{E G_{i d i o, j, t}}$ & 0.647154 & -0.565774 & 0.469795 & 0.173373 & 0.554384 & 0.721756 & 1.000000 & & & \\
\hline$\sigma_{\text {AR idio }, j, t}$ & 0.609561 & -0.524537 & 0.396039 & 0.166886 & 0.561500 & 0.689810 & 0.762757 & 1.000000 & & \\
\hline ORW $W_{\text {ratio }}$ & -0.107148 & 0.174350 & -0.091802 & -0.043812 & -0.198193 & -0.129298 & -0.145195 & -0.109345 & 1.000000 & \\
\hline$O I$ & -0.211010 & 0.605700 & -0.295427 & 0.023565 & -0.214258 & -0.200370 & -0.129799 & -0.102143 & 0.134376 & 1.000000 \\
\hline \multicolumn{11}{|c|}{ Phase 3} \\
\hline & $\sigma_{R V \text { idio }}$ & $\log S I Z E$ & $\log B M$ & $r_{t}$ & $\beta_{j}$ & $\sigma_{I V}$ idio,j,t & $\sigma_{E G_{i d i o, j, t}}$ & $\sigma_{\text {ARidio }, j, t}$ & ORW $W_{\text {ratio }}$ & $O I$ \\
\hline$\sigma_{R V \text { idio }}$ & 1.000000 & & & & & & & & & \\
\hline $\log S I Z E$ & -0.471186 & 1.000000 & & & & & & & & \\
\hline $\log B M$ & 0.394536 & -0.625711 & 1.000000 & & & & & & & \\
\hline$r_{t}$ & -0.394411 & 0.087281 & -0.124665 & 1.000000 & & & & & & \\
\hline$\beta_{j}$ & 0.271091 & -0.436797 & 0.290137 & -0.109079 & 1.000000 & & & & & \\
\hline$\sigma_{I V_{i d i o, j, t}}$ & 0.751641 & -0.546002 & 0.451651 & -0.279852 & 0.199335 & 1.000000 & & & & \\
\hline$\sigma_{E G_{i d i o, j, t}}$ & 0.204235 & -0.342655 & 0.178536 & 0.018241 & 0.210245 & 0.291941 & 1.000000 & & & \\
\hline$\sigma_{A R_{i d i o, j, t}}$ & 0.417601 & -0.535640 & 0.336998 & -0.056916 & 0.339870 & 0.511593 & 0.544707 & 1.000000 & & \\
\hline ORW $W_{\text {ratio }}$ & -0.178599 & 0.172683 & -0.088022 & 0.017516 & -0.067548 & -0.214832 & -0.069143 & -0.153279 & 1.000000 & \\
\hline$O I$ & -0.024361 & 0.531872 & -0.164373 & 0.030688 & -0.136058 & 0.074105 & -0.079076 & -0.043737 & 0.034639 & 1.000000 \\
\hline \multicolumn{11}{|c|}{ Phase 4} \\
\hline & $\sigma_{R V_{\text {idio }}}$ & $\log S I Z E$ & $\log B M$ & $r_{t}$ & $\beta_{j}$ & $\sigma_{I V_{i d i o, j, t}}$ & $\sigma_{E G_{i d i o, j, t}}$ & $\sigma_{\text {AR }}$ idio $, j, t$ & ORW $W_{\text {ratio }}$ & $O I$ \\
\hline$\sigma_{R V_{i d i o}}$ & 1.000000 & & & & & & & & & \\
\hline $\log S I Z E$ & -0.479868 & 1.000000 & & & & & & & & \\
\hline $\log B M$ & 0.371259 & -0.610314 & 1.000000 & & & & & & & \\
\hline$r_{t}$ & 0.073375 & -0.007687 & -0.038437 & 1.000000 & & & & & & \\
\hline$\beta_{j}$ & 0.406580 & -0.363774 & 0.178191 & 0.134011 & 1.000000 & & & & & \\
\hline$\sigma_{I V_{i d i o, j, t}}$ & 0.711278 & -0.437208 & 0.320733 & 0.046308 & 0.327265 & 1.000000 & & & & \\
\hline$\sigma_{E G_{i d i o, j, t}}$ & 0.322463 & -0.342898 & 0.286193 & 0.081015 & 0.269647 & 0.242393 & 1.000000 & & & \\
\hline$\sigma_{A R_{i d i o, j, t}}$ & 0.405786 & -0.450161 & 0.320327 & 0.037495 & 0.397599 & 0.395999 & 0.657216 & 1.000000 & & \\
\hline ORW $W_{\text {ratio }}$ & -0.031221 & 0.183196 & -0.087115 & -0.019231 & -0.196032 & -0.128743 & -0.086106 & -0.052572 & 1.000000 & \\
\hline$O I$ & -0.001553 & 0.582695 & -0.207334 & -0.006553 & -0.052917 & 0.010059 & -0.026528 & -0.042010 & 0.194985 & 1.000000 \\
\hline
\end{tabular}


Table 9.6: Services Sector

\begin{tabular}{|c|c|c|c|c|c|c|c|c|c|c|}
\hline \multicolumn{11}{|c|}{ Entire Phases } \\
\hline & $\sigma_{R V_{\text {idio }}}$ & $\log S I Z E$ & $\log B M$ & $r_{t}$ & $\beta_{j}$ & $\sigma_{I V i d i o, j, t}$ & $\sigma_{E G_{i d i o, j, t}}$ & $\sigma_{\text {AR }}$ idio, $, j, t$ & ORW $W_{\text {ratio }}$ & $O I$ \\
\hline$\sigma_{R V_{\text {idio }}}$ & 1.000000 & & & & & & & & & \\
\hline $\log S I Z E$ & -0.352166 & 1.000000 & & & & & & & & \\
\hline $\log B M$ & 0.285325 & -0.694332 & 1.000000 & & & & & & & \\
\hline$r_{t}$ & -0.026471 & 0.002347 & -0.011463 & 1.000000 & & & & & & \\
\hline$\beta_{j}$ & 0.287045 & -0.232458 & 0.213652 & 0.050869 & 1.000000 & & & & & \\
\hline$\sigma_{I V_{i d i o, j, t}}$ & 0.646179 & -0.417720 & 0.316572 & -0.068134 & 0.339555 & 1.000000 & & & & \\
\hline$\sigma_{E G_{i d i o, j, t}}$ & 0.429691 & -0.432068 & 0.330641 & 0.120679 & 0.351894 & 0.470243 & 1.000000 & & & \\
\hline$\sigma_{\text {AR }}$ idio, $, \mathrm{t}, t$ & 0.369650 & -0.399131 & 0.295041 & 0.090952 & 0.334664 & 0.432870 & 0.689351 & 1.000000 & & \\
\hline ORW ratio & -0.082745 & 0.146189 & -0.101873 & -0.009511 & -0.098545 & -0.182564 & -0.088273 & -0.060633 & 1.000000 & \\
\hline$O I$ & -0.013870 & 0.541709 & -0.297278 & 0.014640 & 0.056399 & -0.021785 & -0.051294 & -0.049513 & 0.067380 & 1.0000 \\
\hline \multicolumn{11}{|c|}{ Phase 1} \\
\hline & $\sigma_{R V \text { idio }}$ & $\log S I Z E$ & $\log B M$ & $r_{t}$ & $\beta_{j}$ & $\sigma_{I V i d i o, j, t}$ & $\sigma_{E G_{i d i o, j, t}}$ & $\sigma_{\text {AR }}$ idio $, j, t$ & ORW $W_{\text {ratio }}$ & $O I$ \\
\hline$\sigma_{R V}$ idio & 1.000000 & & & & & & & & & \\
\hline $\log S I Z E$ & -0.326238 & 1.000000 & & & & & & & & \\
\hline $\log B M$ & 0.290043 & -0.726494 & 1.000000 & & & & & & & \\
\hline$r_{t}$ & -0.086259 & -0.011401 & -0.019047 & 1.000000 & & & & & & \\
\hline$\beta_{j}$ & 0.399376 & -0.155494 & 0.150812 & -0.004125 & 1.000000 & & & & & \\
\hline$\sigma_{I V i d i o, j, t}$ & 0.643630 & -0.394716 & 0.286373 & -0.112661 & 0.499392 & 1.000000 & & & & \\
\hline$\sigma_{E G_{i d i o, j, t}}$ & 0.371463 & -0.332840 & 0.200211 & 0.092238 & 0.165709 & 0.402737 & 1.000000 & & & \\
\hline$\sigma_{A R_{i d i o, j, t}}$ & 0.395344 & -0.403324 & 0.221076 & 0.104652 & 0.199128 & 0.443049 & 0.625773 & 1.000000 & & \\
\hline ORW $W_{\text {ratio }}$ & -0.075509 & 0.163463 & -0.117798 & -0.005168 & -0.032170 & -0.092058 & -0.027552 & -0.001358 & 1.000000 & \\
\hline$O I$ & 0.082871 & 0.503327 & -0.359763 & 0.007994 & 0.122835 & 0.085011 & 0.025411 & 0.002854 & 0.106300 & 1.000000 \\
\hline \multicolumn{11}{|c|}{ Phase 2 } \\
\hline & $\sigma_{R V_{\text {idio }}}$ & $\log S I Z E$ & $\log B M$ & $r_{t}$ & $\beta_{j}$ & $\sigma_{I V_{i d i o, j, t}}$ & $\sigma_{E G_{i d i o, j, t}}$ & $\sigma_{\text {AR }}$ idio, $, t, t$ & ORW $W_{\text {ratio }}$ & $O I$ \\
\hline$\sigma_{R V_{\text {idio }}}$ & 1.000000 & & & & & & & & & \\
\hline $\log S I Z E$ & -0.358847 & 1.000000 & & & & & & & & \\
\hline $\log B M$ & 0.285529 & -0.700876 & 1.000000 & & & & & & & \\
\hline$r_{t}$ & 0.014225 & 0.007855 & -0.002970 & 1.000000 & & & & & & \\
\hline$\beta_{j}$ & 0.303858 & -0.158468 & 0.150831 & 0.023271 & 1.000000 & & & & & \\
\hline$\sigma_{I V} i d i o, j, t$ & 0.551383 & -0.458280 & 0.352082 & -0.082708 & 0.357913 & 1.000000 & & & & \\
\hline$\sigma_{E G_{i d i o, j, t}}$ & 0.468229 & -0.477913 & 0.400036 & 0.044345 & 0.389479 & 0.521241 & 1.000000 & & & \\
\hline$\sigma_{\text {AR }}$ idio, $j, t$ & 0.455696 & -0.479643 & 0.379474 & 0.057514 & 0.376392 & 0.562138 & 0.719465 & 1.000000 & & \\
\hline ORW $W_{\text {ratio }}$ & -0.054097 & 0.102950 & -0.056847 & -0.003119 & -0.048637 & -0.142406 & -0.069869 & -0.070620 & 1.000000 & \\
\hline$O I$ & -0.013126 & 0.562437 & -0.330023 & 0.017088 & 0.096419 & -0.097845 & -0.049040 & -0.054021 & 0.068179 & 1.000000 \\
\hline \multicolumn{11}{|c|}{ Phase 3} \\
\hline & $\sigma_{R V \text { idio }}$ & $\log S I Z E$ & $\log B M$ & $r_{t}$ & $\beta_{j}$ & $\sigma_{I V_{\text {idio }, j, t}}$ & $\sigma_{E G_{i d i o, j, t}}$ & $\sigma_{\text {AR }}$ idio $, j, t$ & ORW $W_{\text {ratio }}$ & $O I$ \\
\hline$\sigma_{R V \text { idio }}$ & 1.000000 & & & & & & & & & \\
\hline $\log S I Z E$ & -0.396753 & 1.000000 & & & & & & & & \\
\hline $\log B M$ & 0.315270 & -0.617417 & 1.000000 & & & & & & & \\
\hline$r_{t}$ & -0.405452 & 0.187883 & -0.194934 & 1.000000 & & & & & & \\
\hline$\beta_{j}$ & 0.196946 & -0.372777 & 0.271229 & -0.178777 & 1.000000 & & & & & \\
\hline$\sigma_{I V_{i d i o, j, t}}$ & 0.702931 & -0.468578 & 0.367876 & -0.371030 & 0.292774 & 1.000000 & & & & \\
\hline$\sigma_{E G_{i d i o, j, t}}$ & 0.400168 & -0.527012 & 0.411146 & -0.119008 & 0.414627 & 0.522189 & 1.000000 & & & \\
\hline$\sigma_{A R_{i d i o, j, t}}$ & 0.339405 & -0.465230 & 0.333487 & -0.044882 & 0.379335 & 0.494876 & 0.759939 & 1.000000 & & \\
\hline ORW $W_{\text {ratio }}$ & -0.088689 & 0.106422 & -0.034494 & 0.078435 & -0.063094 & -0.128372 & -0.084399 & -0.080190 & 1.000000 & \\
\hline$O I$ & -0.066231 & 0.542066 & -0.206972 & 0.041492 & -0.122437 & -0.027050 & -0.063660 & -0.041798 & 0.023936 & 1.000000 \\
\hline \multicolumn{11}{|c|}{ Phase 4} \\
\hline & $\sigma_{R V_{\text {idio }}}$ & $\log S I Z E$ & $\log B M$ & $r_{t}$ & $\beta_{j}$ & $\sigma_{I V_{i d i o, j, t}}$ & $\sigma_{E G_{i d i o, j, t}}$ & $\sigma_{A R_{i d i o}, j, t}$ & ORW $W_{\text {ratio }}$ & $O I$ \\
\hline$\sigma_{R V_{i d i o}}$ & 1.000000 & & & & & & & & & \\
\hline $\log S I Z E$ & -0.430656 & 1.000000 & & & & & & & & \\
\hline $\log B M$ & 0.361484 & -0.702475 & 1.000000 & & & & & & & \\
\hline$r_{t}$ & 0.237053 & -0.058239 & 0.033203 & 1.000000 & & & & & & \\
\hline$\beta_{j}$ & 0.394695 & -0.425901 & 0.338108 & 0.192500 & 1.000000 & & & & & \\
\hline$\sigma_{I V i d i o, j, t}$ & 0.547557 & -0.484006 & 0.371555 & 0.084754 & 0.420681 & 1.000000 & & & & \\
\hline$\sigma_{E G_{i d i o, j, t}}$ & 0.460002 & -0.448266 & 0.358334 & 0.272637 & 0.481469 & 0.459442 & 1.000000 & & & \\
\hline$\sigma_{A R_{i d i o, j, t}}$ & 0.373381 & -0.371930 & 0.293275 & 0.129053 & 0.405109 & 0.401432 & 0.709432 & 1.000000 & & \\
\hline ORW $W_{\text {ratio }}$ & -0.079207 & 0.238282 & -0.153887 & -0.014503 & -0.256608 & -0.323385 & -0.163842 & -0.070665 & 1.000000 & \\
\hline OI & -0.138939 & 0.591371 & -0.336853 & 0.012541 & -0.167478 & -0.129039 & -0.135659 & -0.110249 & 0.187165 & 1.000000 \\
\hline
\end{tabular}


Table 9.7: Technology Sector

\begin{tabular}{|c|c|c|c|c|c|c|c|c|c|c|}
\hline \multicolumn{11}{|c|}{ Entire Phases } \\
\hline $\log S I Z E$ & -0.278796 & 1.000000 & & & & & & & & \\
\hline$r_{t}$ & -0.046439 & 0.015846 & -0.018030 & 1.000000 & & & & & & \\
\hline$\beta_{j}$ & 0.238373 & -0.293468 & 0.304066 & 0.023460 & 1.000000 & & & & & \\
\hline$\sigma_{I V_{i d i o, j, t}}$ & 0.628066 & -0.339077 & 0.292754 & -0.088128 & 0.238785 & 1.000000 & & & & \\
\hline ORW $W_{\text {ratio }}$ & -0.010471 & 0.046106 & -0.024899 & 0.007715 & 0.037982 & -0.029373 & 0.029366 & 0.016538 & 1.000000 & \\
\hline$O I$ & 0.016389 & 0.534883 & -0.390670 & 0.021794 & 0.097137 & -0.040998 & -0.010918 & -0.028075 & 0.069856 & 1.000000 \\
\hline \multicolumn{11}{|c|}{ Phase 1} \\
\hline & $\sigma_{R V \text { idio }}$ & $\log S I Z E$ & $\log B M$ & $r_{t}$ & $\beta_{j}$ & $\sigma_{I V i d i o, j, t}$ & $\sigma_{E G_{i d i o, j, t}}$ & $\sigma_{\text {AR }}$ idio, $j, t$ & ORW $W_{\text {ratio }}$ & $O I$ \\
\hline$\sigma_{R V_{\text {idio }}}$ & 1.000000 & & & & & & & & & \\
\hline $\log S I Z E$ & -0.265021 & 1.000000 & & & & & & & & \\
\hline$\sigma_{E G_{i d i o, j, t}}$ & 0.415344 & -0.317802 & 0.291492 & 0.080949 & 0.363236 & 0.516665 & 1.000000 & & & \\
\hline$\sigma_{A R_{i d i o, j, t}}$ & 0.345401 & -0.263812 & 0.253575 & 0.035484 & 0.323671 & 0.445540 & 0.604764 & 1.000000 & & \\
\hline ORW ratio & -0.000328 & 0.025701 & -0.005148 & 0.039861 & 0.002560 & -0.052750 & -0.008418 & -0.013281 & 1.000000 & \\
\hline$O I$ & 0.155094 & 0.538610 & -0.380569 & 0.024040 & 0.231648 & 0.139135 & 0.098260 & 0.091210 & 0.043719 & 1.000000 \\
\hline \multicolumn{11}{|c|}{ Phase 2 } \\
\hline & $\sigma_{R V_{\text {idio }}}$ & $\log S I Z E$ & $\log B M$ & $r_{t}$ & $\beta_{j}$ & $\sigma_{I V_{i d i o, j, t}}$ & $\sigma_{E G_{i d i o, j, t}}$ & $\sigma_{\text {ARidio }, j, t}$ & $O R W_{\text {ratio }}$ & $O I$ \\
\hline$\sigma_{R V_{\text {idio }}}$ & 1.000000 & & & & & & & & & \\
\hline $\log S I Z E$ & -0.325095 & 1.000000 & & & & & & & & \\
\hline $\log B M$ & 0.272720 & -0.827502 & 1.000000 & & & & & & & \\
\hline$r_{t}$ & -0.024837 & 0.030295 & -0.039298 & 1.000000 & & & & & & \\
\hline$\beta_{j}$ & 0.404964 & -0.365572 & 0.393305 & 0.009789 & 1.000000 & & & & & \\
\hline$\sigma_{I V} i d i o, j, t$ & 0.612318 & -0.454785 & 0.406121 & -0.078191 & 0.396006 & 1.000000 & & & & \\
\hline $\log B M$ & 0.242022 & -0.870940 & 1.000000 & & & & & & & \\
\hline$r_{t}$ & -0.452147 & 0.109093 & -0.104965 & 1.000000 & & & & & & \\
\hline$\beta_{j}$ & 0.149765 & -0.378451 & 0.356211 & 0.003994 & 1.000000 & & & & & \\
\hline$\sigma_{I V_{i d i o, j, t}}$ & 0.545470 & -0.288995 & 0.287282 & -0.395086 & 0.156235 & 1.000000 & & & & \\
\hline$\sigma_{E G_{i d i o, j, t}}$ & 0.349308 & -0.450826 & 0.461528 & -0.104073 & 0.385705 & 0.331641 & 1.000000 & & & \\
\hline$\sigma_{A R_{i d i o, j, t}}$ & 0.346162 & -0.457313 & 0.460762 & -0.135287 & 0.423255 & 0.351332 & 0.768884 & 1.000000 & & \\
\hline ORW $W_{\text {ratio }}$ & -0.069323 & 0.059867 & -0.038275 & 0.019162 & 0.014683 & -0.087145 & 0.004688 & -0.001575 & 1.000000 & \\
\hline OI & -0.041860 & 0.548419 & -0.411550 & 0.006477 & -0.038825 & -0.043768 & -0.127423 & -0.083951 & 0.089466 & 1.000000 \\
\hline \multicolumn{11}{|c|}{ Phase 4} \\
\hline & $\sigma_{R V_{\text {idio }}}$ & $\log S I Z E$ & $\log B M$ & $r_{t}$ & $\beta_{j}$ & $\sigma_{I V_{i d i o, j, t}}$ & $\sigma_{E G_{i d i o}, j, t}$ & $\sigma_{A R_{\text {idio }, j, t}}$ & ORW $W_{\text {ratio }}$ & $O I$ \\
\hline$\sigma_{R V_{\text {idio }}}$ & 1.000000 & & & & & & & & & \\
\hline $\log S I Z E$ & -0.347966 & 1.000000 & & & & & & & & \\
\hline $\log B M$ & 0.294219 & -0.866567 & 1.000000 & & & & & & & \\
\hline$r_{t}$ & 0.164685 & -0.055501 & 0.052832 & 1.000000 & & & & & & \\
\hline$\beta_{j}$ & 0.511186 & -0.396228 & 0.334359 & 0.160644 & 1.000000 & & & & & \\
\hline$\sigma_{I V i d i o, j, t}$ & 0.553559 & -0.457844 & 0.365264 & 0.066984 & 0.416483 & 1.000000 & & & & \\
\hline$\sigma_{E G_{i d i o, j, t}}$ & 0.460996 & -0.415860 & 0.396706 & 0.260660 & 0.479206 & 0.431670 & 1.000000 & & & \\
\hline$\sigma_{A R_{i d i o, j, t}}$ & 0.320687 & -0.281616 & 0.285312 & 0.075665 & 0.359213 & 0.263261 & 0.461525 & 1.000000 & & \\
\hline ORW $W_{\text {ratio }}$ & 0.023090 & 0.064139 & -0.037357 & 0.005225 & 0.118939 & -0.016595 & 0.051459 & 0.038581 & 1.000000 & \\
\hline$O I$ & -0.068779 & 0.596112 & -0.471768 & 0.017146 & -0.097322 & -0.195267 & -0.101159 & -0.097427 & 0.099893 & 1.000000 \\
\hline
\end{tabular}


Table 9.8: Utilities Sector

\begin{tabular}{|c|c|c|c|c|c|c|c|c|c|c|}
\hline \multicolumn{11}{|c|}{ Entire Phases } \\
\hline & $\sigma_{R V \text { idio }}$ & $\log S I Z E$ & $\log B M$ & $r_{t}$ & $\beta_{j}$ & $\sigma_{I V i d i o, j, t}$ & $\sigma_{E G_{i d i o, j, t}}$ & $\sigma_{\text {AR }}$ idio,j,t & $O R W_{\text {ratio }}$ & $O I$ \\
\hline$\sigma_{R V}$ idio & 1.000000 & & & & & & & & & \\
\hline $\log S I Z E$ & -0.316165 & 1.000000 & & & & & & & & \\
\hline $\log B M$ & 0.293465 & -0.617471 & 1.000000 & & & & & & & \\
\hline$r_{t}$ & -0.238836 & 0.042500 & -0.061345 & 1.000000 & & & & & & \\
\hline$\beta_{j}$ & 0.153556 & -0.186307 & 0.252820 & 0.017082 & 1.000000 & & & & & \\
\hline$\sigma_{I V_{i d i o, j, t}}$ & 0.779288 & -0.375947 & 0.408397 & -0.188002 & 0.194340 & 1.000000 & & & & \\
\hline$\sigma_{E G_{i d i o, j, t}}$ & 0.667172 & -0.398954 & 0.362774 & 0.034885 & 0.306434 & 0.750505 & 1.000000 & & & \\
\hline$\sigma_{\text {AR }}$ idio, $, \mathrm{t}, t$ & 0.476321 & -0.260769 & 0.287666 & 0.097135 & 0.324961 & 0.568692 & 0.704673 & 1.000000 & & \\
\hline ORW ratio & -0.108603 & 0.126211 & -0.131614 & -0.029256 & -0.122571 & -0.144197 & -0.103404 & -0.096307 & 1.000000 & \\
\hline$O I$ & 0.090849 & 0.463249 & -0.050814 & -0.029785 & 0.180623 & 0.090612 & 0.070289 & 0.111680 & -0.053610 & 1.00000 \\
\hline \multicolumn{11}{|c|}{ Phase 1} \\
\hline & $\sigma_{R V \text { idio }}$ & $\log S I Z E$ & $\log B M$ & $r_{t}$ & $\beta_{j}$ & $\sigma_{I V_{i d i o, j, t}}$ & $\sigma_{E G_{\text {idio }, j, t}}$ & $\sigma_{\text {ARidio }, j, t}$ & ORW $W_{\text {ratio }}$ & $O I$ \\
\hline$\sigma_{R V_{\text {idio }}}$ & 1.000000 & & & & & & & & & \\
\hline $\log S I Z E$ & -0.345788 & 1.000000 & & & & & & & & \\
\hline $\log B M$ & 0.449467 & -0.576627 & 1.000000 & & & & & & & \\
\hline$r_{t}$ & -0.340594 & 0.109012 & -0.146788 & 1.000000 & & & & & & \\
\hline$\beta_{j}$ & 0.544506 & -0.251018 & 0.252587 & -0.160238 & 1.000000 & & & & & \\
\hline$\sigma_{I V i d i o, j, t}$ & 0.808485 & -0.485359 & 0.599432 & -0.259010 & 0.631717 & 1.000000 & & & & \\
\hline$\sigma_{E G_{i d i o, j, t}}$ & 0.698784 & -0.321842 & 0.448400 & -0.044140 & 0.748796 & 0.780558 & 1.000000 & & & \\
\hline$\sigma_{A R_{i d i o, j, t}}$ & 0.461421 & -0.264790 & 0.381617 & 0.116441 & 0.647119 & 0.587218 & 0.784977 & 1.000000 & & \\
\hline ORW $W_{\text {ratio }}$ & -0.137376 & 0.116703 & -0.054936 & -0.026598 & -0.057474 & -0.131329 & -0.106805 & -0.094191 & 1.000000 & \\
\hline$O I$ & 0.382186 & 0.299177 & -0.019368 & -0.145633 & 0.306948 & 0.317957 & 0.356866 & 0.259506 & -0.106725 & 1.000000 \\
\hline \multicolumn{11}{|c|}{ Phase 2 } \\
\hline & $\sigma_{R V_{\text {idio }}}$ & $\log S I Z E$ & $\log B M$ & $r_{t}$ & $\beta_{j}$ & $\sigma_{I V_{i d i o, j, t}}$ & $\sigma_{E G_{i d i o, j, t}}$ & $\sigma_{\text {AR }}$ idio $, j, t$ & ORW $W_{\text {ratio }}$ & $O I$ \\
\hline$\sigma_{R V_{\text {idio }}}$ & 1.000000 & & & & & & & & & \\
\hline $\log S I Z E$ & -0.355033 & 1.000000 & & & & & & & & \\
\hline $\log B M$ & 0.431647 & -0.725132 & 1.000000 & & & & & & & \\
\hline$r_{t}$ & 0.144603 & -0.024243 & 0.020930 & 1.000000 & & & & & & \\
\hline$\beta_{j}$ & 0.300540 & -0.263507 & 0.229394 & 0.101288 & 1.000000 & & & & & \\
\hline$\sigma_{I V} i d i o, j, t$ & 0.763938 & -0.448155 & 0.544088 & 0.156685 & 0.204854 & 1.000000 & & & & \\
\hline$\sigma_{E G_{i d i o, j, t}}$ & 0.728031 & -0.489137 & 0.549225 & 0.295825 & 0.388249 & 0.770907 & 1.000000 & & & \\
\hline$\sigma_{\text {AR }}$ idio,j,t & 0.585937 & -0.278936 & 0.354787 & 0.168419 & 0.356123 & 0.571965 & 0.594942 & 1.000000 & & \\
\hline ORW $W_{\text {ratio }}$ & -0.491444 & 0.590756 & -0.564782 & -0.229442 & -0.464286 & -0.640379 & -0.647280 & -0.451029 & 1.000000 & \\
\hline$O I$ & 0.129430 & 0.416955 & -0.090692 & 0.071781 & 0.117763 & 0.087244 & 0.075560 & 0.147312 & 0.011836 & 1.000000 \\
\hline \multicolumn{11}{|c|}{ Phase 3} \\
\hline & $\sigma_{R V_{\text {idio }}}$ & $\log S I Z E$ & $\log B M$ & $r_{t}$ & $\beta_{j}$ & $\sigma_{I V}$ idio, $j, t$ & $\sigma_{E G_{\text {idio }, j, t}}$ & $\sigma_{A R_{i d i o}, j, t}$ & ORW $W_{\text {ratio }}$ & $O I$ \\
\hline$\sigma_{R V \text { idio }}$ & 1.000000 & & & & & & & & & \\
\hline $\log S I Z E$ & -0.208557 & 1.000000 & & & & & & & & \\
\hline $\log B M$ & 0.219872 & -0.681271 & 1.000000 & & & & & & & \\
\hline$r_{t}$ & -0.385748 & 0.170327 & -0.205406 & 1.000000 & & & & & & \\
\hline$\beta_{j}$ & 0.108634 & -0.297151 & 0.247101 & -0.244311 & 1.000000 & & & & & \\
\hline$\sigma_{I V_{i d i o, j, t}}$ & 0.790589 & -0.221563 & 0.288313 & -0.439922 & 0.304628 & 1.000000 & & & & \\
\hline$\sigma_{E G_{i d i o, j, t}}$ & 0.371477 & -0.382447 & 0.100347 & -0.186349 & 0.478958 & 0.601648 & 1.000000 & & & \\
\hline$\sigma_{A R_{i d i o, j, t}}$ & 0.347116 & -0.159337 & 0.149411 & -0.281451 & 0.516901 & 0.590842 & 0.732887 & 1.000000 & & \\
\hline ORW $W_{\text {ratio }}$ & -0.536015 & 0.329934 & -0.349136 & 0.390485 & -0.331697 & -0.745684 & -0.511888 & -0.492578 & 1.000000 & \\
\hline$O I$ & -0.118849 & 0.565305 & -0.187789 & -0.020633 & -0.002680 & -0.035278 & -0.178968 & 0.033626 & 0.091846 & 1.000000 \\
\hline \multicolumn{11}{|c|}{ Phase 4} \\
\hline & $\sigma_{R V_{\text {idio }}}$ & $\log S I Z E$ & $\log B M$ & $r_{t}$ & $\beta_{j}$ & $\sigma_{I V_{\text {idio }, j, t}}$ & $\sigma_{E G_{i d i o}, j, t}$ & $\sigma_{A R_{i d i o}, j, t}$ & ORW $W_{\text {ratio }}$ & $O I$ \\
\hline$\sigma_{R V_{i d i o}}$ & 1.000000 & & & & & & & & & \\
\hline $\log S I Z E$ & -0.337046 & 1.000000 & & & & & & & & \\
\hline $\log B M$ & 0.254729 & -0.603099 & 1.000000 & & & & & & & \\
\hline$r_{t}$ & -0.044713 & -0.027082 & -0.049930 & 1.000000 & & & & & & \\
\hline$\beta_{j}$ & 0.339843 & -0.398787 & 0.435616 & 0.052995 & 1.000000 & & & & & \\
\hline$\sigma_{I V i d i o, j, t}$ & 0.439021 & -0.254763 & 0.199714 & -0.110679 & 0.503602 & 1.000000 & & & & \\
\hline$\sigma_{E G_{i d i o, j, t}}$ & 0.405062 & -0.321828 & 0.320517 & 0.072957 & 0.695457 & 0.496532 & 1.000000 & & & \\
\hline$\sigma_{A R_{i d i o, j, t}}$ & 0.312785 & -0.227161 & 0.223750 & 0.177594 & 0.503214 & 0.331437 & 0.460357 & 1.000000 & & \\
\hline ORW $W_{\text {ratio }}$ & -0.027143 & 0.279875 & -0.163752 & 0.018982 & -0.248620 & -0.294034 & -0.131219 & -0.066631 & 1.000000 & \\
\hline OI & -0.011374 & 0.633731 & -0.103142 & -0.111298 & -0.092913 & -0.025403 & -0.023814 & -0.018353 & 0.144927 & 1.000000 \\
\hline
\end{tabular}




\subsubsection{Predictive regressions}

\subsubsection{Future realized volatility}

We first start by examining whether implied and realized volatilities from a specific month explain the realized volatility one month ahead. We test this relationship for both market (proxied by VIX and S\&P500) and at firm level. We apply every phases by equation 8 and 9, where:

$$
\sigma_{R V M, t+1}=\alpha_{t}+\xi_{1} \sigma_{I V}, t+\xi_{2} \sigma_{R V_{M, t}}+\varepsilon_{j_{t+1}}
$$

and,

$$
\sigma_{R V j, t+1}=\alpha_{j, t}+\xi_{1, j} \sigma_{I V}+t+\xi_{2, j} \sigma_{R V}+\varepsilon_{j, t+1}
$$

where, $\sigma_{R V_{M, t}}$ is the annualized realized monthly volatility in month $t$ for the S\&P 500 index, $\sigma_{I V_{M, t}}$ is the VIX index in month $t, \alpha$ is the constant term, $\xi_{1}$ and $\xi_{2}$ are estimated coefficients and $\varepsilon$ is the error term. The regression specification at individual/firm level is shown in equation (9). The equation is performed to each firm independently, whilst the mean and median coefficients are presented as well respective significance. $\sigma_{R V}, t$, represents the annualized realized monthly volatility in month $t$ for each unique firm, $\sigma_{I V j, t}$ is the implied volatility for each firm in month $t, \alpha$ is the constant term, $\xi_{1}$ and $\xi_{2}$ are estimated coefficients and $\varepsilon$ is the error term.

Tables 10.1 to 10.8 present following results. There is an evidence in panel A (market estimates) that implied volatility is a good predictor of future realized volatility with strong statistical significance for every sectors and phases except only Phase 3. These results are still aligned with Zhang and Shu (2010) which analysed the relationship between implied and realized volatility by using daily S\&P 500 index option prices over the period between January and December 1995. Even though, outcomes in phase 3 present that variables included both implied and realized volatilities cannot predict future realized volatility, observations are quite less 15 after sector allocation. Consequently, this results should be excluded. In summary, the implied volatility is eligible for future realized volatility predictability stronger than the historical volatility for all sectors at the market level. Moreover, at market level results of implied volatility for every sectors and phases support Christiansen and Prabhala (1998) findings that implied volatility is a proficient forecaster of future realized volatility even in the presence of past realized volatility. The implied volatility coefficient is divergent of one resulting that implied volatility is an upward biased forecaster of future realized volatility which highlight the existence of a robust volatility risk premium. 
In panel B (firm-level estimates), we find that implied and realized volatilities are strongly statistical significant predictors (at 1 percent level) of future realized volatility for every phases and sectors except Utilities which implied volatility is not significance in Phase 3 and realized volatility is meaningless in Phase 1 due to its return movement independently from the stock market and lowest Beta compared to other sectors. Especially an evidence of $R$-Squared shown in model including realized volatility higher than excluding indicates that when implied and realized volatilities are mutually employed, forecasting accuracy is higher. However, our results diverge from Bakshi and Kapadia (2003) and Stivers, Mayhew and Dennis (2006) which claims that implied volatility is an unbiased and proficient predictor of future realized volatility. In our study we find evidence that implied volatility is an upward biased forecaster of future volatility at both market and firm-levels for every sectors except Utilities.

Table 10: Future Realized Volatility forecast

Table 10.1: Basic Materials Sector

\begin{tabular}{|c|c|c|c|c|c|c|c|c|}
\hline \multicolumn{9}{|c|}{ Entire Phases } \\
\hline & \multicolumn{4}{|c|}{ Panel A } & \multicolumn{4}{|c|}{ Panel B } \\
\hline & \multicolumn{4}{|c|}{ Market Estimates } & \multicolumn{4}{|c|}{ Firm-level estimates } \\
\hline \multirow[t]{2}{*}{$\sigma_{I V}$} & 0.727000 & $* * *$ & 0.059800 & $* * *$ & 1.013491 & $* * *$ & 0.492672 & $* * *$ \\
\hline & $(10.140000)$ & & $(5.420000)$ & & $(75.942874)$ & & $(23.888542)$ & \\
\hline \multirow{2}{*}{$\sigma_{R V}$} & --- & & 0.160000 & & --- & & 0.447135 & $* * *$ \\
\hline & & & $(1.520000)$ & & & & $(31.582282)$ & \\
\hline \multirow[t]{2}{*}{ Constant } & -0.003000 & & -0.001000 & & -0.051770 & $* * *$ & -0.000213 & \\
\hline & $(0.210000)$ & & $(0.020000)$ & & $(8.347098)$ & & $(0.035642)$ & \\
\hline$R$-Squared & 0.664340 & & 0.685670 & & 0.482487 & & 0.554355 & \\
\hline \multicolumn{9}{|c|}{ Phase 1} \\
\hline & \multicolumn{4}{|c|}{ Panel A } & \multicolumn{4}{|c|}{ Panel B } \\
\hline & \multicolumn{4}{|c|}{ Market Estimates } & \multicolumn{4}{|c|}{ Firm-level estimates } \\
\hline \multirow[t]{2}{*}{$\sigma_{I V}$} & 0.781837 & $* *$ & 1.421075 & $* *$ & 0.966780 & $* * *$ & 0.781340 & $* * *$ \\
\hline & $(2.344392)$ & & $(2.347302)$ & & $(25.908420)$ & & (13.864299) & \\
\hline \multirow[t]{2}{*}{$\sigma_{R V}$} & --- & & -0.428699 & & --- & & 0.154402 & $* * *$ \\
\hline & & & $(1.257767)$ & & & & $(4.365613)$ & \\
\hline \multirow[t]{2}{*}{ Constant } & 0.067211 & & -0.065573 & & -0.034862 & $*$ & -0.012770 & \\
\hline & $(0.365152)$ & & $(0.312212)$ & & $(1.857006)$ & & $(0.661394)$ & \\
\hline \multirow[t]{4}{*}{$R$-Squared } & 0.207433 & & 0.265529 & & 0.359870 & & 0.369936 & \\
\hline & \multicolumn{4}{|c|}{ Phase 2} & & & & \\
\hline & \multicolumn{4}{|c|}{ Panel A } & \multicolumn{4}{|c|}{ Panel B } \\
\hline & \multicolumn{4}{|c|}{ Market Estimates } & \multicolumn{4}{|c|}{ Firm-level estimates } \\
\hline \multirow[t]{2}{*}{$\sigma_{I V}$} & 0.790700 & $* * *$ & 0.842444 & $* * *$ & 0.807762 & $* * *$ & 0.598736 & $* * *$ \\
\hline & $(9.063170)$ & & $(5.274629)$ & & $(56.959113)$ & & $(27.932130)$ & \\
\hline \multirow[t]{2}{*}{$\sigma_{R V}$} & --- & & -0.058818 & & --- & & 0.237285 & $* * *$ \\
\hline & & & $(0.388002)$ & & & & $(12.761447)$ & \\
\hline \multirow[t]{2}{*}{ Constant } & 0.007289 & & 0.005845 & & 0.016994 & $* * *$ & 0.018951 & $* * *$ \\
\hline & $(0.224974)$ & & $(0.177928)$ & & $(3.205499)$ & & $(3.664741)$ & \\
\hline$R$-Squared & 0.586131 & & 0.587221 & & 0.509929 & & 0.534262 & \\
\hline
\end{tabular}




\begin{tabular}{|c|c|c|c|c|c|c|c|c|}
\hline \multicolumn{9}{|c|}{ Phase 3} \\
\hline & \multicolumn{4}{|c|}{ Panel A } & \multicolumn{4}{|c|}{ Panel B } \\
\hline & \multicolumn{4}{|c|}{ Market Estimates } & \multicolumn{4}{|c|}{ Firm-level estimates } \\
\hline \multirow[t]{2}{*}{$\sigma_{I V}$} & 1.422542 & $* *$ & 0.259275 & & 1.419573 & $* * *$ & 0.613889 & $* * *$ \\
\hline & $(3.112067)$ & & $(0.097217)$ & & $(24.329024)$ & & $(4.688387)$ & \\
\hline \multirow[t]{2}{*}{$\sigma_{R V}$} & --- & & 0.570545 & & --- & & 0.434946 & $* * *$ \\
\hline & & & $(0.443312)$ & & & & $(6.816082)$ & \\
\hline \multirow[t]{2}{*}{ Constant } & -0.164642 & & 0.130726 & & -0.107374 & $* * *$ & 0.056065 & \\
\hline & $(0.669327)$ & & $(0.183104)$ & & (3.250189) & & $(1.405129)$ & \\
\hline$R$-Squared & 0.491998 & & 0.502854 & & 0.487603 & & 0.523268 & \\
\hline \multicolumn{9}{|c|}{ Phase 4} \\
\hline & \multicolumn{4}{|c|}{ Panel A } & \multicolumn{4}{|c|}{ Panel B } \\
\hline & \multicolumn{4}{|c|}{ Market Estimates } & \multicolumn{4}{|c|}{ Firm-level estimates } \\
\hline \multirow[t]{2}{*}{$\sigma_{I V}$} & 1.459938 & $* * *$ & 0.836533 & $* *$ & 0.957844 & $* * *$ & 0.401423 & $* * *$ \\
\hline & $(9.428729)$ & & $(2.511405)$ & & $(33.450198)$ & & $(10.446069)$ & \\
\hline \multirow[t]{2}{*}{$\sigma_{R V}$} & --- & & 0.413593 & $*$ & --- & & 0.510768 & $* * *$ \\
\hline & & & $(2.076705)$ & & & & (19.163786) & \\
\hline \multirow[t]{2}{*}{ Constant } & -0.357857 & $* * *$ & -0.207794 & $*$ & -0.085547 & $* * *$ & -0.018065 & \\
\hline & $(4.285214)$ & & $(1.956251)$ & & $(5.292117)$ & & $(1.233874)$ & \\
\hline$R$-Squared & 0.801625 & & 0.835423 & & 0.473131 & & 0.593145 & \\
\hline
\end{tabular}

$* * *, * *, *$ Statistical significant for 1,5 , and 10 percent levels

Table 10.2: Consumer Goods Sector

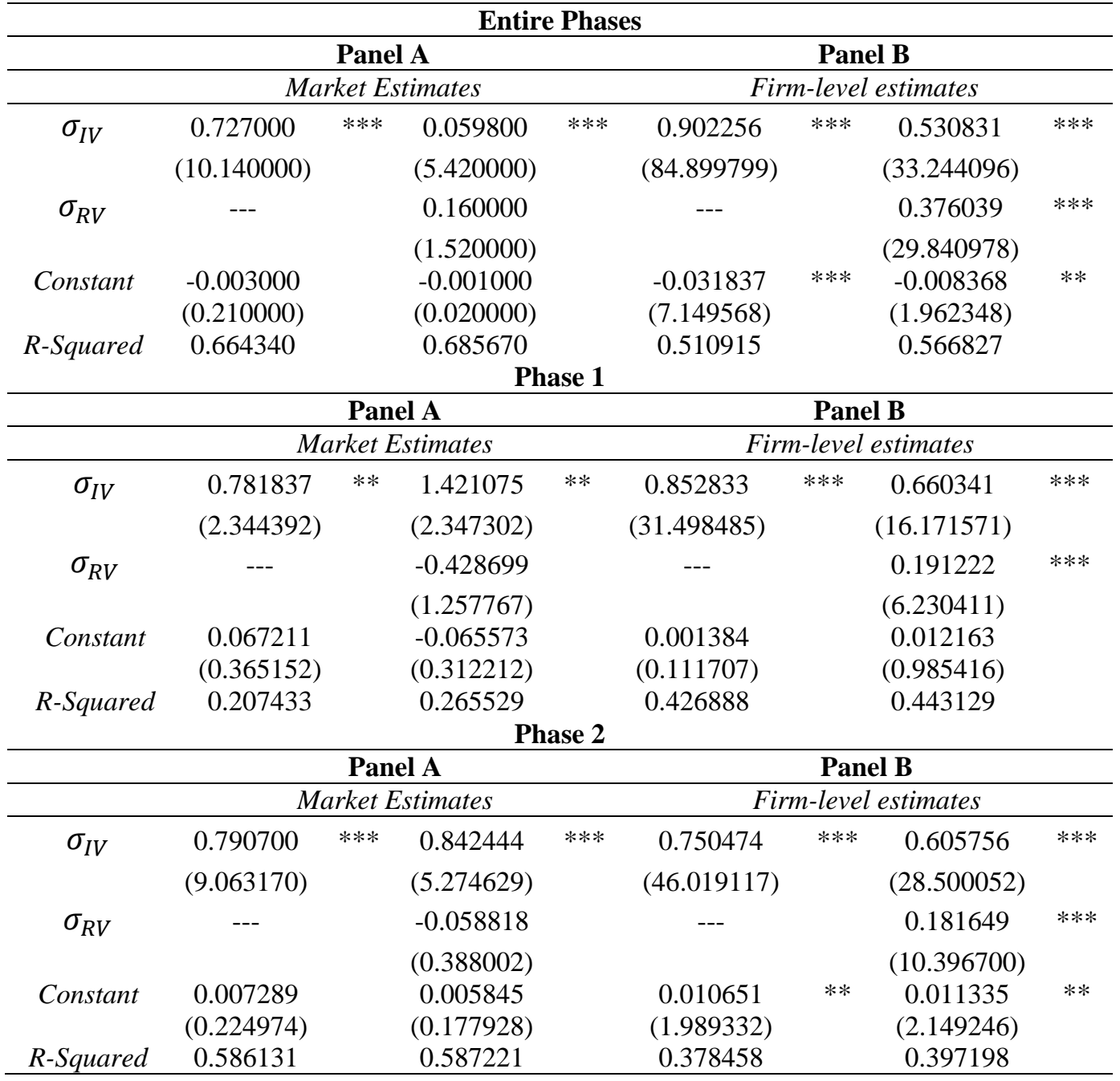




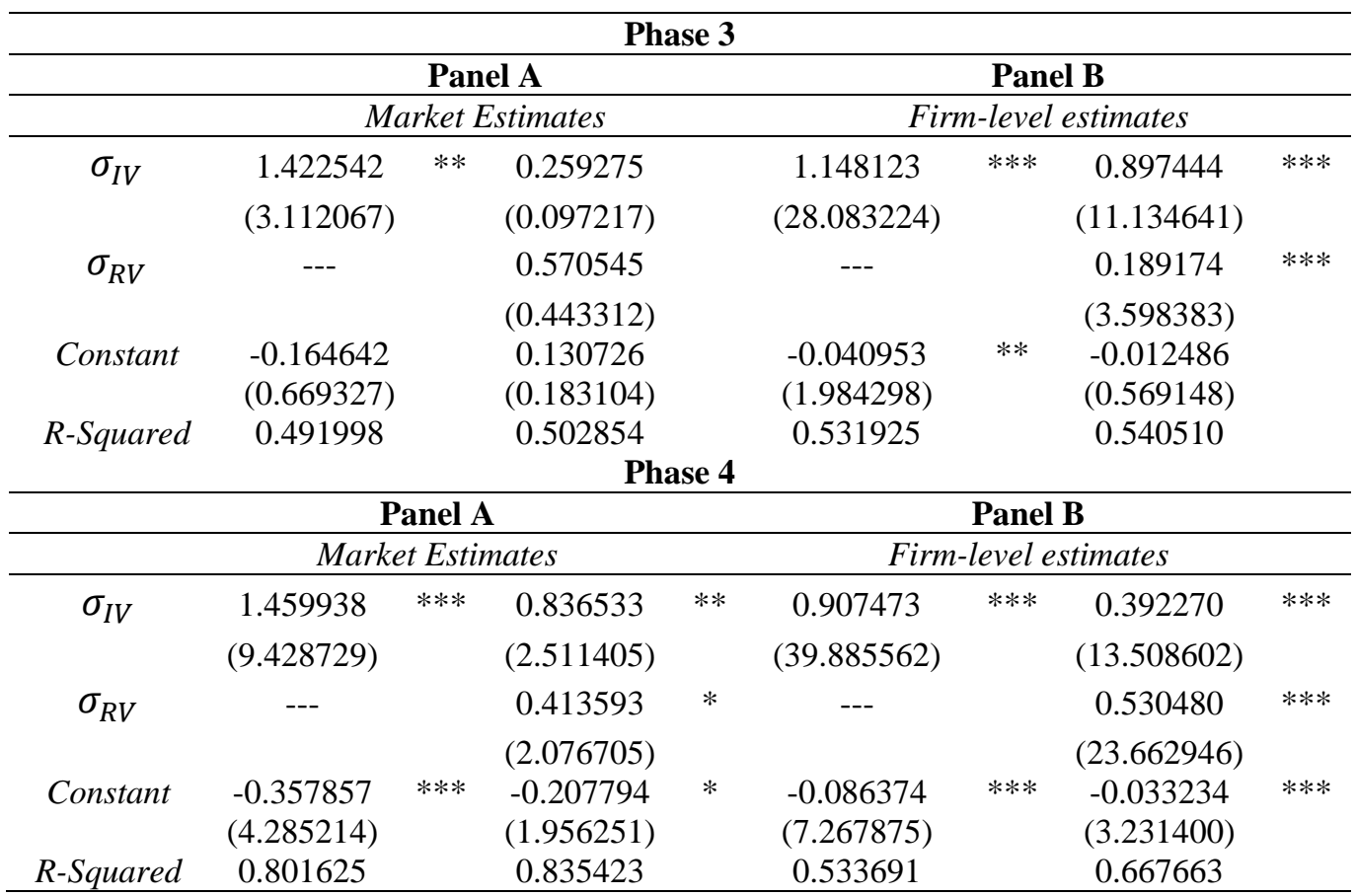

$* * *, * * *$ Statistical significant for 1, 5, and 10 percent levels

Table 10.3: Financial Sector

\begin{tabular}{|c|c|c|c|c|c|c|c|c|}
\hline \multicolumn{9}{|c|}{ Entire Phases } \\
\hline & \multicolumn{4}{|c|}{ Panel A } & \multicolumn{4}{|c|}{ Panel B } \\
\hline & \multicolumn{4}{|c|}{ Market Estimates } & \multicolumn{4}{|c|}{ Firm-level estimates } \\
\hline \multirow[t]{2}{*}{$\sigma_{I V}$} & 0.727000 & $* * *$ & 0.059800 & $* * *$ & 1.200745 & $* * *$ & 0.625076 & $* * *$ \\
\hline & $(10.140000)$ & & $(5.420000)$ & & (105.910808) & & $(30.419200)$ & \\
\hline \multirow[t]{2}{*}{$\sigma_{R V}$} & --- & & 0.160000 & & --- & & 0.441981 & $* * *$ \\
\hline & & & $(1.520000)$ & & & & $(32.621952)$ & \\
\hline \multirow{2}{*}{ Constant } & -0.003000 & & -0.001000 & & -0.131526 & $* * *$ & -0.055775 & $* * *$ \\
\hline & $(0.210000)$ & & $(0.020000)$ & & $(24.984651)$ & & $(10.305591)$ & \\
\hline \multirow[t]{4}{*}{$R$-Squared } & 0.664340 & & 0.685670 & & 0.627386 & & 0.678716 & \\
\hline & \multicolumn{4}{|c|}{$\begin{array}{r}\text { Phase } 1 \\
\end{array}$} & & & & \\
\hline & \multicolumn{4}{|c|}{ Panel A } & \multicolumn{4}{|c|}{ Panel B } \\
\hline & \multicolumn{4}{|c|}{ Market Estimates } & \multicolumn{4}{|c|}{ Firm-level estimates } \\
\hline \multirow[t]{2}{*}{$\sigma_{I V}$} & 0.781837 & $* *$ & 1.421075 & $* *$ & 0.780097 & $* * *$ & 0.523035 & $* * *$ \\
\hline & $(2.344392)$ & & $(2.347302)$ & & $(23.499727)$ & & (11.348794) & \\
\hline \multirow[t]{2}{*}{$\sigma_{R V}$} & --- & & -0.428699 & & --- & & 0.248124 & $* * *$ \\
\hline & & & $(1.257767)$ & & & & $(7.852345)$ & \\
\hline \multirow[t]{2}{*}{ Constant } & 0.067211 & & -0.065573 & & 0.013493 & & 0.033526 & $* *$ \\
\hline & $(0.365152)$ & & $(0.312212)$ & & $(0.974561)$ & & $(2.434977)$ & \\
\hline$R$-Squared & 0.207433 & & 0.265529 & & 0.300417 & & 0.332448 & \\
\hline
\end{tabular}




\begin{tabular}{|c|c|c|c|c|c|c|c|c|}
\hline \multicolumn{9}{|c|}{ Phase 2} \\
\hline & \multicolumn{4}{|c|}{ Panel A } & \multicolumn{4}{|c|}{ Panel B } \\
\hline & \multicolumn{4}{|c|}{ Market Estimates } & \multicolumn{4}{|c|}{ Firm-level estimates } \\
\hline \multirow[t]{2}{*}{$\sigma_{I V}$} & 0.790700 & $* * *$ & 0.842444 & $* * *$ & 0.718901 & $* * *$ & 0.442772 & $* * *$ \\
\hline & $(9.063170)$ & & $(5.274629)$ & & $(40.802835)$ & & $(20.583376)$ & \\
\hline \multirow[t]{2}{*}{$\sigma_{R V}$} & --- & & -0.058818 & & --- & & 0.362484 & $* * *$ \\
\hline & & & $(0.388002)$ & & & & $(20.246651)$ & \\
\hline \multirow[t]{2}{*}{ Constant } & 0.007289 & & 0.005845 & & 0.011148 & $* *$ & 0.012449 & $* *$ \\
\hline & $(0.224974)$ & & $(0.177928)$ & & $(2.046005)$ & & $(2.419641)$ & \\
\hline$R$-Squared & 0.586131 & & 0.587221 & & 0.331458 & & 0.404211 & \\
\hline \multicolumn{9}{|c|}{ Phase 3} \\
\hline
\end{tabular}

\begin{tabular}{|c|c|c|c|c|c|c|c|}
\hline & \multicolumn{3}{|c|}{ Panel A } & \multicolumn{4}{|c|}{ Panel B } \\
\hline & \multicolumn{3}{|c|}{ Market Estimates } & \multicolumn{4}{|c|}{ Firm-level estimates } \\
\hline \multirow[t]{2}{*}{$\sigma_{I V}$} & 1.422542 & $* *$ & 0.259275 & 1.278990 & $* * *$ & 0.719216 & $* * *$ \\
\hline & $(3.112067)$ & & $(0.097217)$ & $(25.416046)$ & & $(7.380569)$ & \\
\hline \multirow[t]{2}{*}{$\sigma_{R V}$} & --- & & 0.570545 & --- & & 0.355471 & $* * *$ \\
\hline & & & $(0.443312)$ & & & (6.635608) & \\
\hline \multirow[t]{2}{*}{ Constant } & -0.164642 & & 0.130726 & -0.034099 & & 0.056797 & \\
\hline & $(0.669327)$ & & $(0.183104)$ & $(1.008684)$ & & $(1.599126)$ & \\
\hline \multirow[t]{2}{*}{$R$-Squared } & 0.491998 & & 0.502854 & 0.490872 & & 0.522312 & \\
\hline & & & & & & & \\
\hline
\end{tabular}

\begin{tabular}{|c|c|c|c|c|c|c|c|c|}
\hline & \multicolumn{3}{|c|}{ Panel A } & \multicolumn{5}{|c|}{ Panel B } \\
\hline & \multicolumn{3}{|c|}{ Market Estimates } & \multicolumn{5}{|c|}{ Firm-level estimates } \\
\hline \multirow[t]{2}{*}{$\sigma_{I V}$} & 1.459938 & $* * *$ & 0.836533 & $* *$ & 1.361583 & $* * *$ & 0.810788 & $* * *$ \\
\hline & $(9.428729)$ & & $(2.511405)$ & & $(50.673990)$ & & $(17.128191)$ & \\
\hline \multirow[t]{2}{*}{$\sigma_{R V}$} & --- & & 0.413593 & $*$ & --- & & 0.381003 & $* * *$ \\
\hline & & & $(2.076705)$ & & & & (13.738239) & \\
\hline Constant & $\begin{array}{c}-0.357857 \\
(4.285214)\end{array}$ & $* * *$ & $\begin{array}{c}-0.207794 \\
(1.956251)\end{array}$ & $*$ & $\begin{array}{c}-0.283442 \\
(15.946790)\end{array}$ & $* * *$ & $\begin{array}{l}-0.166434 \\
(8.900215)\end{array}$ & $* * *$ \\
\hline$R$-Squared & 0.801625 & & 0.835423 & & 0.656765 & & 0.699113 & \\
\hline
\end{tabular}

$* * *, * * *$ Statistical significant for 1,5 , and 10 percent levels

Table 10.4: Healthcare Sector

\begin{tabular}{|c|c|c|c|c|c|c|c|c|}
\hline \multicolumn{9}{|c|}{ Entire Phases } \\
\hline & \multicolumn{4}{|c|}{ Panel A } & \multicolumn{4}{|c|}{ Panel B } \\
\hline & \multicolumn{4}{|c|}{ Market Estimates } & \multicolumn{4}{|c|}{ Firm-level estimates } \\
\hline \multirow[t]{2}{*}{$\sigma_{I V}$} & 0.727000 & $* * *$ & 0.059800 & $* * *$ & 0.841493 & $* * *$ & 0.590349 & $* * *$ \\
\hline & $(10.140000)$ & & $(5.420000)$ & & $(64.650424)$ & & $(32.253241)$ & \\
\hline \multirow[t]{2}{*}{$\sigma_{R V}$} & --- & & 0.160000 & & --- & & 0.265509 & $* * *$ \\
\hline & & & $(1.520000)$ & & & & $(18.952135)$ & \\
\hline \multirow[t]{2}{*}{ Constant } & -0.003000 & & -0.001000 & & -0.015216 & $* *$ & 0.001009 & \\
\hline & $(0.210000)$ & & $(0.020000)$ & & $(2.220267)$ & & $(0.150486)$ & \\
\hline$R$-Squared & 0.664340 & & 0.685670 & & 0.422630 & & 0.456806 & \\
\hline
\end{tabular}




\begin{tabular}{|c|c|c|c|c|c|c|c|c|}
\hline \multicolumn{9}{|c|}{ Phase 1} \\
\hline & \multicolumn{4}{|c|}{ Panel A } & \multicolumn{4}{|c|}{ Panel B } \\
\hline & \multicolumn{4}{|c|}{ Market Estimates } & \multicolumn{4}{|c|}{ Firm-level estimates } \\
\hline \multirow[t]{2}{*}{$\sigma_{I V}$} & 0.781837 & $* *$ & 1.421075 & $* *$ & 0.841192 & $* * *$ & 0.663062 & $* * *$ \\
\hline & $(2.344392)$ & & $(2.347302)$ & & $(26.993788)$ & & $(14.021601)$ & \\
\hline \multirow[t]{2}{*}{$\sigma_{R V}$} & --- & & -0.428699 & & --- & & 0.171121 & $* * *$ \\
\hline & & & $(1.257767)$ & & & & $(4.968143)$ & \\
\hline \multirow[t]{2}{*}{ Constant } & 0.067211 & & -0.065573 & & 0.014380 & & 0.028804 & \\
\hline & $(0.365152)$ & & $(0.312212)$ & & $(0.744945)$ & & $(1.491031)$ & \\
\hline$R$-Squared & 0.207433 & & 0.265529 & & 0.398033 & & 0.411232 & \\
\hline
\end{tabular}

Phase 2

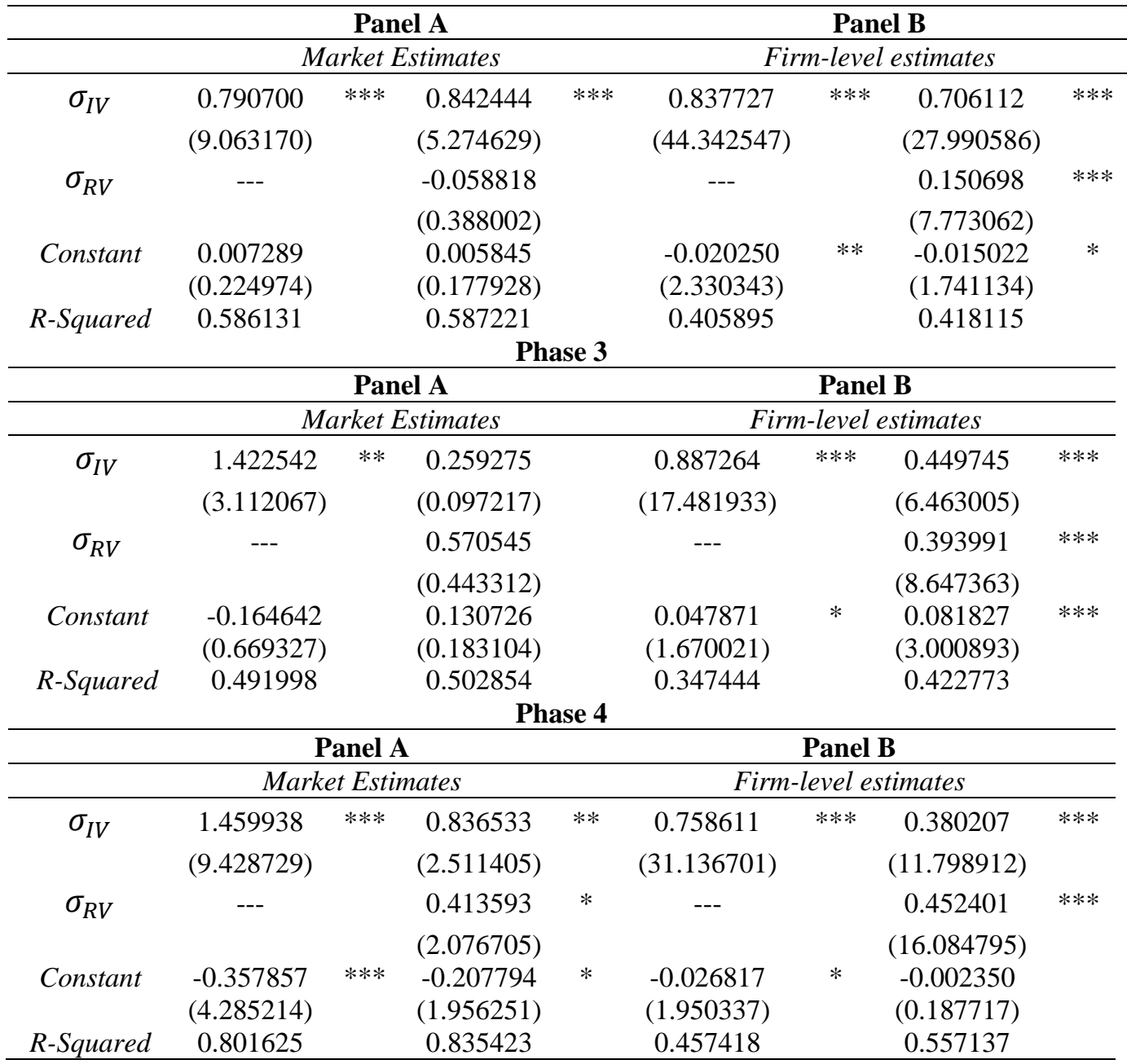

$* * *, * *, *$ Statistical significant for 1,5 , and 10 percent levels 
Table 10.5: Industrial Goods Sector

\begin{tabular}{|c|c|c|c|c|c|c|c|c|}
\hline \multicolumn{9}{|c|}{ Entire Phases } \\
\hline & \multicolumn{4}{|c|}{ Panel A } & \multicolumn{4}{|c|}{ Panel B } \\
\hline & \multicolumn{4}{|c|}{ Market Estimates } & \multicolumn{4}{|c|}{ Firm-level estimates } \\
\hline \multirow[t]{2}{*}{$\sigma_{I V}$} & 0.727000 & $* * *$ & 0.059800 & $* * *$ & 0.948269 & $* * *$ & 0.607475 & $* * *$ \\
\hline & $(10.140000)$ & & $(5.420000)$ & & $(70.463425)$ & & $(29.377645)$ & \\
\hline \multirow[t]{2}{*}{$\sigma_{R V}$} & --- & & 0.160000 & & --- & & 0.323461 & $* * *$ \\
\hline & & & $(1.520000)$ & & & & $(21.084660)$ & \\
\hline \multirow[t]{2}{*}{ Constant } & -0.003000 & & -0.001000 & & -0.035861 & $* * *$ & -0.010693 & $*$ \\
\hline & $(0.210000)$ & & $(0.020000)$ & & $(5.789199)$ & & $(1.765878)$ & \\
\hline$R$-Squared & 0.664340 & & 0.685670 & & 0.498449 & & 0.539439 & \\
\hline
\end{tabular}

Phase 1

\begin{tabular}{|c|c|c|c|c|c|c|c|c|}
\hline & \multicolumn{4}{|c|}{ Panel A } & \multicolumn{4}{|c|}{ Panel B } \\
\hline & \multicolumn{4}{|c|}{ Market Estimates } & \multicolumn{4}{|c|}{ Firm-level estimates } \\
\hline \multirow[t]{2}{*}{$\sigma_{I V}$} & 0.781837 & $* *$ & 1.421075 & $* *$ & 0.829083 & $* * *$ & 0.618257 & $* * *$ \\
\hline & $(2.344392)$ & & $(2.347302)$ & & $(17.380255)$ & & $(9.764081)$ & \\
\hline \multirow[t]{2}{*}{$\sigma_{R V}$} & --- & & -0.428699 & & --- & & 0.183014 & $* * *$ \\
\hline & & & $(1.257767)$ & & & & $(4.984795)$ & \\
\hline \multirow[t]{2}{*}{ Constant } & 0.067211 & & -0.065573 & & 0.029875 & & 0.050750 & $* *$ \\
\hline & $(0.365152)$ & & $(0.312212)$ & & $(1.259475)$ & & $(2.132042)$ & \\
\hline$R$-Squared & 0.207433 & & 0.265529 & & 0.238591 & & 0.257743 & \\
\hline
\end{tabular}

\begin{tabular}{|c|c|c|c|c|c|c|c|c|}
\hline \multirow[b]{3}{*}{$\sigma_{I V}$} & \multicolumn{4}{|c|}{ Panel A } & \multicolumn{4}{|c|}{ Panel B } \\
\hline & \multicolumn{4}{|c|}{ Market Estimates } & \multicolumn{4}{|c|}{ Firm-level estimates } \\
\hline & $\begin{array}{c}0.790700 \\
(9.063170)\end{array}$ & $* * *$ & $\begin{array}{c}0.842444 \\
(5.274629)\end{array}$ & $* * *$ & $\begin{array}{c}0.822012 \\
(52.608958)\end{array}$ & $* * *$ & $\begin{array}{c}0.693372 \\
(29.694474)\end{array}$ & $* * *$ \\
\hline$\sigma_{R V}$ & --- & & $\begin{array}{l}-0.058818 \\
(0.388002)\end{array}$ & & --- & & $\begin{array}{c}0.153266 \\
(7.352296)\end{array}$ & $* * *$ \\
\hline Constant & $\begin{array}{c}0.007289 \\
(0.224974)\end{array}$ & & $\begin{array}{c}0.005845 \\
(0.177928)\end{array}$ & & $\begin{array}{c}0.001906 \\
(0.327489)\end{array}$ & & $\begin{array}{c}0.002658 \\
(0.461359)\end{array}$ & \\
\hline$R$-Squared & 0.586131 & & 0.587221 & & 0.523621 & & 0.533636 & \\
\hline
\end{tabular}

\begin{tabular}{|c|c|c|c|c|c|c|c|}
\hline \multicolumn{8}{|c|}{ Phase 3} \\
\hline & \multicolumn{3}{|c|}{ Panel A } & \multicolumn{4}{|c|}{ Panel B } \\
\hline & \multicolumn{3}{|c|}{ Market Estimates } & \multicolumn{4}{|c|}{ Firm-level estimates } \\
\hline \multirow[t]{2}{*}{$\sigma_{I V}$} & 1.422542 & $* *$ & 0.259275 & 1.164361 & $* * *$ & 0.982086 & $* * *$ \\
\hline & (3.112067) & & $(0.097217)$ & $(23.916951)$ & & $(9.532862)$ & \\
\hline \multirow[t]{2}{*}{$\sigma_{R V}$} & --- & & 0.570545 & --- & & 0.129778 & $* *$ \\
\hline & & & $(0.443312)$ & & & $(2.005872)$ & \\
\hline \multirow[t]{2}{*}{ Constant } & -0.164642 & & 0.130726 & -0.028877 & & -0.005599 & \\
\hline & $(0.669327)$ & & $(0.183104)$ & $(1.059374)$ & & $(0.189470)$ & \\
\hline$R$-Squared & 0.491998 & & 0.502854 & 0.532597 & & 0.536321 & \\
\hline
\end{tabular}

***,**,* Statistical significant for 1,5 , and 10 percent levels 
Table 10.6: Services Sector

\begin{tabular}{|c|c|c|c|c|c|c|c|c|}
\hline \multicolumn{9}{|c|}{ Entire Phases } \\
\hline & \multicolumn{4}{|c|}{ Panel A } & \multicolumn{4}{|c|}{ Panel B } \\
\hline & \multicolumn{4}{|c|}{ Market Estimates } & \multicolumn{4}{|c|}{ Firm-level estimates } \\
\hline \multirow[t]{2}{*}{$\sigma_{I V}$} & 0.727000 & $* * *$ & 0.059800 & $* * *$ & 0.890318 & $* * *$ & 0.507830 & $* * *$ \\
\hline & $(10.140000)$ & & $(5.420000)$ & & $(99.913804)$ & & (41.271599) & \\
\hline \multirow[t]{2}{*}{$\sigma_{R V}$} & --- & & 0.160000 & & --- & & 0.387063 & $* * *$ \\
\hline & & & $(1.520000)$ & & & & $(42.238606)$ & \\
\hline \multirow[t]{2}{*}{ Constant } & -0.003000 & & -0.001000 & & -0.021167 & $* * *$ & 0.002293 & \\
\hline & $(0.210000)$ & & $(0.020000)$ & & $(5.057574)$ & & $(0.580104)$ & \\
\hline$R$-Squared & 0.664340 & & 0.685670 & & 0.446521 & & 0.516271 & \\
\hline
\end{tabular}

Phase 1

\begin{tabular}{|c|c|c|c|c|c|c|c|c|}
\hline \multirow{4}{*}{$\sigma_{I V}$} & \multicolumn{4}{|c|}{ Panel A } & \multicolumn{4}{|c|}{ Panel B } \\
\hline & \multicolumn{4}{|c|}{ Market Estimates } & \multicolumn{4}{|c|}{ Firm-level estimates } \\
\hline & 0.781837 & $* *$ & 1.421075 & $* *$ & 0.761635 & $* * *$ & 0.615849 & $* * *$ \\
\hline & $(2.344392)$ & & $(2.347302)$ & & $(33.045384)$ & & (19.239387) & \\
\hline \multirow[t]{2}{*}{$\sigma_{R V}$} & --- & & -0.428699 & & --- & & 0.148886 & $* * *$ \\
\hline & & & (1.257767) & & & & $(6.503981)$ & \\
\hline \multirow[t]{2}{*}{ Constant } & 0.067211 & & -0.065573 & & 0.058903 & $* * *$ & 0.065302 & $* * *$ \\
\hline & $(0.365152)$ & & $(0.312212)$ & & $(4.691816)$ & & $(5.229946)$ & \\
\hline$R$-Squared & 0.207433 & & 0.265529 & & 0.313612 & & 0.325555 & \\
\hline
\end{tabular}

\begin{tabular}{|c|c|c|c|c|c|c|c|c|}
\hline & & Pan & el A & & & Pan & I B & \\
\hline & & irket 1 & stimates & & Fir & -leve & estimates & \\
\hline$\sigma_{I V}$ & 0.790700 & $* * *$ & 0.842444 & $* * *$ & 0.711551 & $* * *$ & 0.564207 & $* * *$ \\
\hline & $(9.063170)$ & & $(5.274629)$ & & $(57.616420)$ & & $(36.526814)$ & \\
\hline$\sigma_{R V}$ & --- & & -0.058818 & & --- & & 0.198818 & $* * *$ \\
\hline & & & $(0.388002)$ & & & & $(15.392605)$ & \\
\hline Constant & 0.007289 & & 0.005845 & & 0.032025 & $* * *$ & 0.027688 & $* * *$ \\
\hline & $(0.224974)$ & & $(0.177928)$ & & $(7.006936)$ & & $(6.159425)$ & \\
\hline$R$-Squared & 0.586131 & & 0.587221 & & 0.347329 & & 0.371216 & \\
\hline
\end{tabular}

\begin{tabular}{|c|c|c|c|c|c|c|c|c|}
\hline \multicolumn{9}{|c|}{ Phase 3} \\
\hline & \multicolumn{4}{|c|}{ Panel A } & \multicolumn{4}{|c|}{ Panel B } \\
\hline & \multicolumn{4}{|c|}{ Market Estimates } & \multicolumn{4}{|c|}{ Firm-level estimates } \\
\hline \multirow[t]{2}{*}{$\sigma_{I V}$} & 1.422542 & $* *$ & 0.259275 & & 1.144438 & $* * *$ & 0.615864 & $* * *$ \\
\hline & (3.112067) & & $(0.097217)$ & & $(30.319579)$ & & $(10.018048)$ & \\
\hline \multirow[t]{2}{*}{$\sigma_{R V}$} & --- & & 0.570545 & & --- & & 0.376256 & $* * *$ \\
\hline & & & $(0.443312)$ & & & & $(10.631178)$ & \\
\hline \multirow[t]{2}{*}{ Constant } & -0.164642 & & 0.130726 & & -0.036299 & $*$ & 0.039095 & $*$ \\
\hline & $(0.669327)$ & & $(0.183104)$ & & $(1.729877)$ & & $(1.834216)$ & \\
\hline \multirow[t]{4}{*}{$R$-Squared } & 0.491998 & & 0.502854 & & 0.424554 & & 0.472446 & \\
\hline & \multicolumn{8}{|c|}{ Phase 4} \\
\hline & \multicolumn{4}{|c|}{ Panel A } & \multicolumn{4}{|c|}{ Panel B } \\
\hline & \multicolumn{4}{|c|}{ Market Estimates } & \multicolumn{4}{|c|}{ Firm-level estimates } \\
\hline \multirow[t]{2}{*}{$\sigma_{I V}$} & 1.459938 & $* * *$ & 0.836533 & $* *$ & 0.907449 & $* * *$ & 0.403153 & $* * *$ \\
\hline & $(9.428729)$ & & $(2.511405)$ & & $(43.606509)$ & & (17.016469) & \\
\hline$\sigma_{R V}$ & --- & & 0.413593 & $*$ & --- & & 0.525848 & $* * *$ \\
\hline Constant & $\begin{array}{l}-0.357857 \\
(4.285214)\end{array}$ & $* * *$ & $\begin{array}{c}(2.076705) \\
-0.207794 \\
(1.956251)\end{array}$ & $*$ & $\begin{array}{l}-0.077299 \\
(6.645122)\end{array}$ & $* * *$ & $\begin{array}{c}(31.724972) \\
-0.032536 \\
(3.279518)\end{array}$ & $* * *$ \\
\hline$R$-Squared & 0.801625 & & 0.835423 & & 0.432605 & & 0.595792 & \\
\hline
\end{tabular}

$* * *, * * *$ Statistical significant for 1,5 , and 10 percent levels 
Table 10.7: Technology Sector

\begin{tabular}{|c|c|c|c|c|c|c|c|c|}
\hline \multicolumn{9}{|c|}{ Entire Phases } \\
\hline & \multicolumn{4}{|c|}{ Panel A } & \multicolumn{4}{|c|}{ Panel B } \\
\hline & \multicolumn{4}{|c|}{ Market Estimates } & \multicolumn{4}{|c|}{ Firm-level estimates } \\
\hline \multirow[t]{2}{*}{$\sigma_{I V}$} & 0.727000 & $* * *$ & 0.059800 & $* * *$ & 1.004559 & $* * *$ & 0.712206 & $* * *$ \\
\hline & $(10.140000)$ & & $(5.420000)$ & & (117.382981) & & $(54.757154)$ & \\
\hline \multirow[t]{2}{*}{$\sigma_{R V}$} & --- & & 0.160000 & & --- & & 0.267781 & $* * *$ \\
\hline & & & $(1.520000)$ & & & & $(29.154685)$ & \\
\hline \multirow[t]{2}{*}{ Constant } & -0.003000 & & -0.001000 & & -0.055999 & $* * *$ & -0.030790 & $* * *$ \\
\hline & $(0.210000)$ & & $(0.020000)$ & & (12.013833) & & $(6.702224)$ & \\
\hline$R$-Squared & 0.664340 & & 0.685670 & & 0.522106 & & 0.552282 & \\
\hline
\end{tabular}

Phase 1

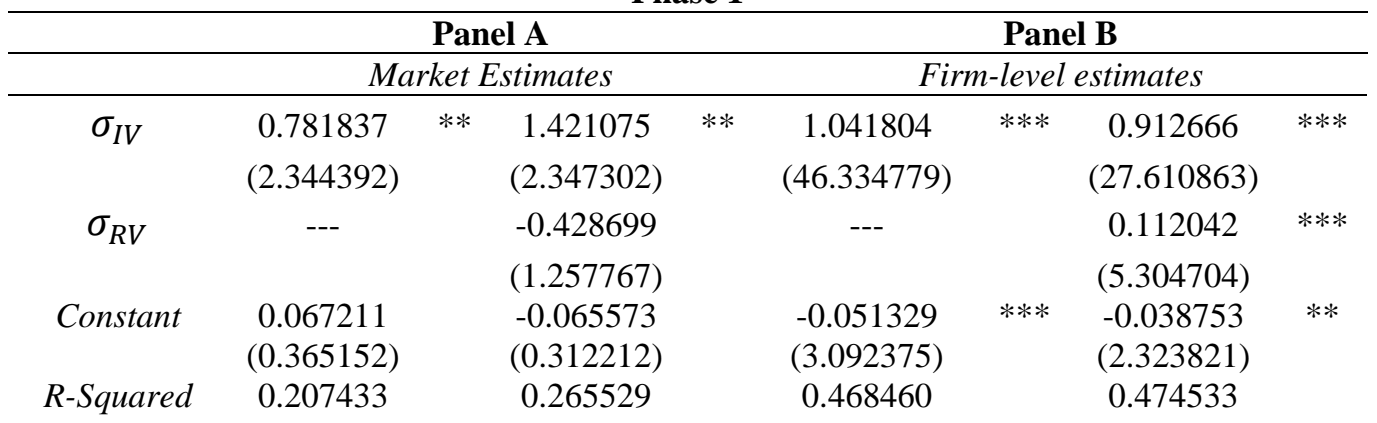

Phase 2

\begin{tabular}{|c|c|c|c|c|c|c|c|c|}
\hline & & Pan & $\mathbf{A}$ & & & Pan & $1 \mathrm{~B}$ & \\
\hline & & irket 1 & stimates & & Fir & -lever & estimates & \\
\hline$\sigma_{I V}$ & 0.790700 & $* * *$ & 0.842444 & $* * *$ & 0.796866 & $* * *$ & 0.757544 & $* * *$ \\
\hline & $(9.063170)$ & & $(5.274629)$ & & $(66.882541)$ & & $(46.358840)$ & \\
\hline$\sigma_{R V}$ & --- & & -0.058818 & & --- & & 0.045203 & $* * *$ \\
\hline & & & $(0.388002)$ & & & & $(3.512481)$ & \\
\hline Constant & 0.007289 & & 0.005845 & & 0.018511 & $* * *$ & 0.018906 & $* * *$ \\
\hline & $(0.224974)$ & & $(0.177928)$ & & $(3.454540)$ & & $(3.530685)$ & \\
\hline$R$-Squared & 0.586131 & & 0.587221 & & 0.412996 & & 0.414133 & \\
\hline
\end{tabular}

\begin{tabular}{|c|c|c|c|c|c|c|c|c|}
\hline \multicolumn{9}{|c|}{ Phase 3} \\
\hline & \multicolumn{4}{|c|}{ Panel A } & \multicolumn{4}{|c|}{ Panel B } \\
\hline & \multicolumn{4}{|c|}{ Market Estimates } & \multicolumn{4}{|c|}{ Firm-level estimates } \\
\hline \multirow[t]{2}{*}{$\sigma_{I V}$} & 1.422542 & $* *$ & 0.259275 & & 1.151329 & $* * *$ & 0.624075 & $* * *$ \\
\hline & (3.112067) & & $(0.097217)$ & & $(25.042615)$ & & $(10.017498)$ & \\
\hline \multirow[t]{2}{*}{$\sigma_{R V}$} & --- & & 0.570545 & & --- & & 0.379044 & $* * *$ \\
\hline & & & $(0.443312)$ & & & & (11.858768) & \\
\hline \multirow[t]{2}{*}{ Constant } & -0.164642 & & 0.130726 & & -0.023702 & & 0.044247 & $*$ \\
\hline & $(0.669327)$ & & $(0.183104)$ & & $(0.958027)$ & & $(1.830532)$ & \\
\hline \multirow[t]{4}{*}{$R$-Squared } & 0.491998 & & 0.502854 & & 0.330569 & & 0.397354 & \\
\hline & \multicolumn{4}{|c|}{ Phase 4} & & & & \\
\hline & \multicolumn{4}{|c|}{ Panel A } & \multicolumn{3}{|c|}{ Panel B } & \\
\hline & \multicolumn{4}{|c|}{ Market Estimates } & \multicolumn{4}{|c|}{ Firm-level estimates } \\
\hline \multirow[t]{2}{*}{$\sigma_{I V}$} & 1.459938 & $* * *$ & 0.836533 & $* *$ & 0.941105 & $* * *$ & 0.465105 & $* * *$ \\
\hline & $(9.428729)$ & & $(2.511405)$ & & $(44.884662)$ & & $(18.249363)$ & \\
\hline \multirow[t]{2}{*}{$\sigma_{R V}$} & --- & & 0.413593 & $*$ & --- & & 0.465633 & $* * *$ \\
\hline & & & $(2.076705)$ & & & & $(27.105536)$ & \\
\hline \multirow[t]{2}{*}{ Constant } & -0.357857 & $* * *$ & -0.207794 & $*$ & -0.070989 & $* * *$ & -0.027828 & $* * *$ \\
\hline & $(4.285214)$ & & $(1.956251)$ & & $(6.200192)$ & & $(2.725265)$ & \\
\hline$R$-Squared & 0.801625 & & 0.835423 & & 0.442132 & & 0.567256 & \\
\hline
\end{tabular}

***,**,* Statistical significant for 1,5 , and 10 percent levels 
Table 10.8: Utilities Sector

\begin{tabular}{|c|c|c|c|c|c|c|c|c|}
\hline \multicolumn{9}{|c|}{ Entire Phases } \\
\hline & \multicolumn{4}{|c|}{ Panel A } & \multicolumn{4}{|c|}{ Panel B } \\
\hline & \multicolumn{4}{|c|}{ Market Estimates } & \multicolumn{4}{|c|}{ Firm-level estimates } \\
\hline \multirow[t]{2}{*}{$\sigma_{I V}$} & 0.727000 & $* * *$ & 0.059800 & $* * *$ & 0.866866 & $* * *$ & 0.499326 & $* * *$ \\
\hline & $(10.140000)$ & & $(5.420000)$ & & $(39.196905)$ & & $(14.353253)$ & \\
\hline \multirow[t]{2}{*}{$\sigma_{R V}$} & --- & & 0.160000 & & --- & & 0.351576 & $* * *$ \\
\hline & & & $(1.520000)$ & & & & (13.288694) & \\
\hline \multirow[t]{2}{*}{ Constant } & -0.003000 & & -0.001000 & & -0.036779 & $* * *$ & -0.004844 & \\
\hline & $(0.210000)$ & & $(0.020000)$ & & (4.536709) & & $(0.598060)$ & \\
\hline$R$-Squared & 0.664340 & & 0.685670 & & 0.462854 & & 0.511284 & \\
\hline
\end{tabular}

Phase 1

\begin{tabular}{|c|c|c|c|c|c|c|c|c|}
\hline \multirow{4}{*}{$\sigma_{I V}$} & \multicolumn{4}{|c|}{ Panel A } & \multicolumn{4}{|c|}{ Panel B } \\
\hline & \multicolumn{4}{|c|}{ Market Estimates } & \multicolumn{4}{|c|}{ Firm-level estimates } \\
\hline & 0.781837 & $* *$ & 1.421075 & $* *$ & 0.954162 & $* * *$ & 0.904311 & $* * *$ \\
\hline & $(2.344392)$ & & $(2.347302)$ & & $(17.204333)$ & & $(9.194196)$ & \\
\hline \multirow[t]{2}{*}{$\sigma_{R V}$} & --- & & -0.428699 & & --- & & 0.041472 & \\
\hline & & & $(1.257767)$ & & & & $(0.613963)$ & \\
\hline \multirow[t]{2}{*}{ Constant } & 0.067211 & & -0.065573 & & -0.042748 & & -0.036931 & \\
\hline & $(0.365152)$ & & $(0.312212)$ & & $(1.513681)$ & & $(1.238781)$ & \\
\hline \multirow[t]{4}{*}{$R$-Squared } & 0.207433 & & 0.265529 & & 0.463215 & & 0.463806 & \\
\hline & \multicolumn{4}{|c|}{ Phase 2} & & & & \\
\hline & \multicolumn{4}{|c|}{ Panel A } & \multicolumn{4}{|c|}{ Panel B } \\
\hline & \multicolumn{4}{|c|}{ Market Estimates } & \multicolumn{4}{|c|}{ Firm-level estimates } \\
\hline \multirow[t]{2}{*}{$\sigma_{I V}$} & 0.790700 & $* * *$ & 0.842444 & $* * *$ & 0.650512 & $* * *$ & 0.313323 & $* * *$ \\
\hline & $(9.063170)$ & & $(5.274629)$ & & $(28.086850)$ & & (10.057907) & \\
\hline \multirow[t]{2}{*}{$\sigma_{R V}$} & --- & & -0.058818 & & --- & & 0.452579 & $* * *$ \\
\hline & & & $(0.388002)$ & & & & $(14.562802)$ & \\
\hline \multirow[t]{2}{*}{ Constant } & 0.007289 & & 0.005845 & & 0.012756 & $*$ & 0.017290 & $* * *$ \\
\hline & $(0.224974)$ & & $(0.177928)$ & & (1.900809) & & $(2.859441)$ & \\
\hline$R$-Squared & 0.586131 & & 0.587221 & & 0.467653 & & 0.569448 & \\
\hline
\end{tabular}

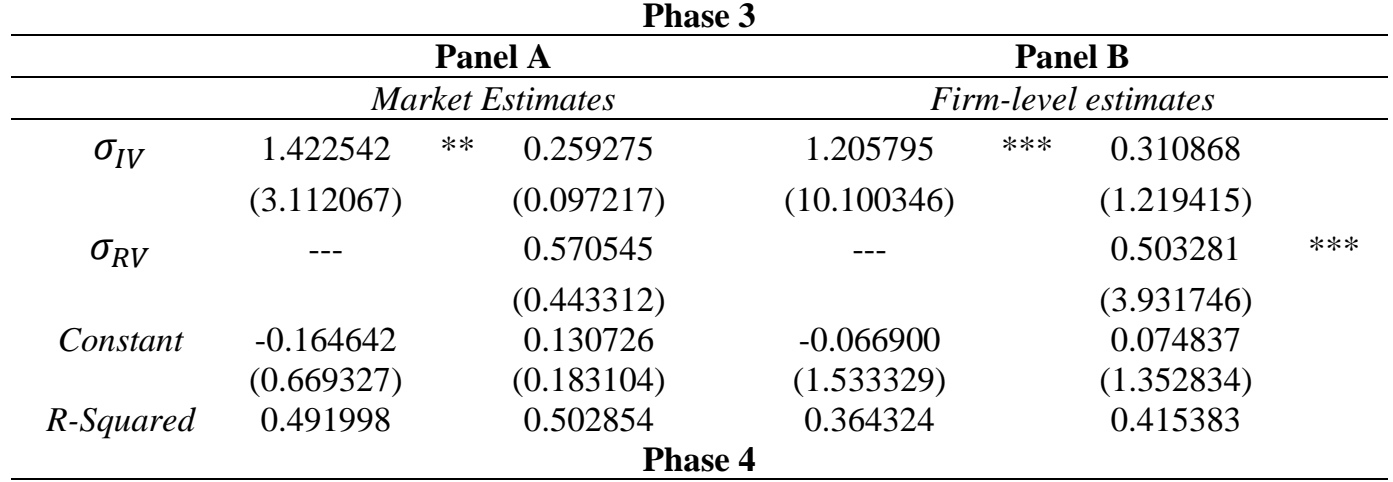

\begin{tabular}{|c|c|c|c|c|c|c|c|c|}
\hline & \multicolumn{4}{|c|}{ Panel A } & \multicolumn{4}{|c|}{ Panel B } \\
\hline & \multicolumn{3}{|c|}{ Market Estimates } & \multicolumn{5}{|c|}{ Firm-level estimates } \\
\hline \multirow[t]{2}{*}{$\sigma_{I V}$} & 1.459938 & $* * *$ & 0.836533 & $* *$ & 0.532848 & $* * *$ & 0.176532 & $* * *$ \\
\hline & $(9.428729)$ & & $(2.511405)$ & & (11.599153) & & $(3.809955)$ & \\
\hline \multirow[t]{2}{*}{$\sigma_{R V}$} & --- & & 0.413593 & $*$ & --- & & 0.569418 & $* * *$ \\
\hline & & & $(2.076705)$ & & & & $(13.221671)$ & \\
\hline \multirow[t]{2}{*}{ Constant } & -0.357857 & $* * *$ & -0.207794 & $*$ & 0.027604 & & 0.024047 & $*$ \\
\hline & $(4.285214)$ & & $(1.956251)$ & & (1.599588) & & $(1.698093)$ & \\
\hline$R$-Squared & 0.801625 & & 0.835423 & & 0.273156 & & 0.512078 & \\
\hline
\end{tabular}

***,**,* Statistical significant for 1,5 , and 10 percent levels 
As tables 11.1 to 11.8 , we next regress the idiosyncratic volatility in its different formulations with the realized volatility one month ahead, applying equation 10 for every phases as below:

$$
\sigma_{R V i d i o, j, t+1}=\alpha_{j}+\psi_{1, j} \sigma_{I V i d i o, j, t}+\psi_{2, j} \sigma_{E G_{i d i o, j, t}}+\psi_{3, j} \sigma_{A R i d i o, j, t}+\psi_{4, j} \sigma_{R V_{i d i o, j, t}}+\varepsilon_{j, t+1}
$$

where, $\sigma_{R V_{i d i o, j, t}}$ represents the realized idiosyncratic volatility in month $t$ for firm $j, \sigma_{I V i d i o, j, t}$, is the implied variance in its idiosyncratic part at month $t$ for firm $j, \sigma_{E G_{i d i o, j, t}}$, is conditional variance for firm $j$ in month $t$ is, $\sigma_{A R} i d i o, j, t$, is the idiosyncratic volatility estimation following Chua, Goh and Zhang (2005) autoregressive model in $2^{\text {nd }}$ order, $A R(2), \alpha$ is the constant term, $\psi$ 's estimated coefficients and $\varepsilon$ is the error term.

When every models examined after sector and sub period separations, results from every phases and sectors are same direction as entire phases that most idiosyncratic volatilities from almost sectors can predict future realized idiosyncratic volatility with strong statistical significant effects at 1 percent level. Moreover, $R$-Squared values from every models are same direction for every sectors and phases. In particular, model 4 has the highest $R$-Squared for every sectors and phases, as the result it is an evidence that the most accurate forecasting measure of idiosyncratic volatility is all mutual implied, realized, EGARCH, and AR Even though, some idiosyncratic volatilities such as EGARCH, and AR are shown to be low statistical significance or meaningless in some phases and sectors as model 4, these would be an effect of multicollinearity influencing some variables decreased in significant level. This causes from every idiosyncratic volatilities included in same model with mutually high correlation as reported in the correlation matrix.

Table 11: Realized idiosyncratic Volatility forecast

Table 11.1: Basic Materials Sector

\begin{tabular}{|c|c|c|c|c|c|c|c|c|}
\hline \multicolumn{9}{|c|}{ Entire Phases } \\
\hline & \multicolumn{2}{|c|}{ Model 1} & \multicolumn{2}{|c|}{ Model 2} & \multicolumn{2}{|l|}{ Model 3} & \multicolumn{2}{|c|}{ Model 4} \\
\hline$\sigma_{I V}$ idio, $, j, t$ & $\begin{array}{c}0.051954 \\
(14.187125)\end{array}$ & $* * *$ & --- & & --- & & $\begin{array}{c}0.041926 \\
(11.054009)\end{array}$ & $* * *$ \\
\hline$\sigma_{R V}$ idio, $j, t$ & $\begin{array}{c}0.622852 \\
(49.676057)\end{array}$ & $* * *$ & $\begin{array}{c}0.701156 \\
(75.582631)\end{array}$ & $* * *$ & $\begin{array}{c}0.718145 \\
(78.470836)\end{array}$ & $* * *$ & $\begin{array}{c}0.605203 \\
(48.061116)\end{array}$ & $* * *$ \\
\hline$\sigma_{E G_{i d i o, j, t}}$ & --- & & $\begin{array}{c}0.176847 \\
(12.995694)\end{array}$ & $* * *$ & --- & & $\begin{array}{c}0.128565 \\
(6.830836)\end{array}$ & $* * *$ \\
\hline$\sigma_{A R}$ idio $, j, t$ & --- & & --- & & $\begin{array}{c}0.119264 \\
(9.931046)\end{array}$ & $* * *$ & $\begin{array}{c}0.007540 \\
(0.459631)\end{array}$ & \\
\hline Constant & $\begin{array}{c}0.021029 \\
(24.657451)\end{array}$ & $* * *$ & $\begin{array}{c}0.009591 \\
(8.027572)\end{array}$ & $* * *$ & $\begin{array}{c}0.013046 \\
(11.471690)\end{array}$ & $* * *$ & $\begin{array}{c}0.012556 \\
(10.121661)\end{array}$ & $* * *$ \\
\hline$R$-Squared & 0.587540 & & 0.585438 & & 0.580802 & & 0.593601 & \\
\hline
\end{tabular}




\begin{tabular}{|c|c|c|c|c|c|c|c|c|}
\hline \multicolumn{9}{|c|}{ Phase 1} \\
\hline & \multicolumn{2}{|l|}{ Model 1} & \multicolumn{2}{|l|}{ Model 2} & \multicolumn{2}{|l|}{ Model 3} & \multicolumn{2}{|l|}{ Model 4} \\
\hline$\sigma_{I V} i d i o, j, t$ & $\begin{array}{c}0.095169 \\
(10.349555)\end{array}$ & $* * *$ & --- & & --- & & $\begin{array}{c}0.071557 \\
(7.456778)\end{array}$ & $* * *$ \\
\hline$\sigma_{R V i d i o, j, t}$ & $\begin{array}{c}0.298655 \\
(8.118964)\end{array}$ & $* * *$ & $\begin{array}{c}0.444398 \\
(16.245863)\end{array}$ & $* * *$ & $\begin{array}{c}0.485944 \\
(18.163197)\end{array}$ & $* * *$ & $\begin{array}{c}0.254537 \\
(6.954228)\end{array}$ & $* * *$ \\
\hline$\sigma_{E G_{i d i o, j, t}}$ & --- & & $\begin{array}{c}0.381364 \\
(10.012569)\end{array}$ & $* * *$ & --- & & $\begin{array}{c}0.235407 \\
(4.256378)\end{array}$ & $* * *$ \\
\hline$\sigma_{A R_{i d i o, j, t}}$ & --- & & --- & & $\begin{array}{c}0.295625 \\
(8.160040)\end{array}$ & $* * *$ & $\begin{array}{c}0.058452 \\
(1.150703)\end{array}$ & \\
\hline Constant & $\begin{array}{c}0.042705 \\
(16.706654)\end{array}$ & $* * *$ & $\begin{array}{c}0.017930 \\
(5.657400)\end{array}$ & $* * *$ & $\begin{array}{c}0.020961 \\
(6.474474)\end{array}$ & $* * *$ & $\begin{array}{c}0.026168 \\
(7.595723)\end{array}$ & $* * *$ \\
\hline$R$-Squared & 0.408720 & & 0.405583 & & 0.389696 & & 0.433118 & \\
\hline \multicolumn{9}{|c|}{ Phase 2} \\
\hline & \multicolumn{2}{|l|}{ Model 1} & \multicolumn{2}{|l|}{ Model 2} & \multicolumn{2}{|l|}{ Model 3} & \multicolumn{2}{|l|}{ Model 4} \\
\hline$\sigma_{I V_{i d i o, j, t}}$ & $\begin{array}{c}0.094897 \\
(20.916440)\end{array}$ & $* * *$ & --- & & --- & & $\begin{array}{c}0.073059 \\
(15.051877)\end{array}$ & $* * *$ \\
\hline$\sigma_{R V_{i d i o, j, t}}$ & $\begin{array}{c}0.422119 \\
(25.006258)\end{array}$ & $* * *$ & $\begin{array}{c}0.514657 \\
(34.278827)\end{array}$ & $* * *$ & $\begin{array}{c}0.525115 \\
(34.218011)\end{array}$ & $* * *$ & $\begin{array}{c}0.366024 \\
(21.236479)\end{array}$ & $* * *$ \\
\hline$\sigma_{E G_{i d i o, j, t}}$ & --- & & $\begin{array}{c}0.247833 \\
(17.860414)\end{array}$ & $* * *$ & --- & & $\begin{array}{c}0.142142 \\
(7.484020)\end{array}$ & $* * *$ \\
\hline$\sigma_{A R} i d i o, j, t$ & --- & & --- & & $\begin{array}{c}0.221746 \\
(15.902206)\end{array}$ & $* * *$ & $\begin{array}{c}0.037895 \\
(1.982529)\end{array}$ & $* *$ \\
\hline Constant & $\begin{array}{c}0.026067 \\
(28.075148)\end{array}$ & $* * *$ & $\begin{array}{c}0.011759 \\
(10.645535)\end{array}$ & $* * *$ & $\begin{array}{c}0.013017 \\
(11.733522)\end{array}$ & $* * *$ & $\begin{array}{c}0.017485 \\
(14.840155)\end{array}$ & $* * *$ \\
\hline$R$-Squared & 0.528782 & & 0.512531 & & 0.502967 & & 0.549065 & \\
\hline \multicolumn{9}{|c|}{ Phase 3} \\
\hline & Model 1 & & Model 2 & & Model 3 & & Model 4 & \\
\hline$\sigma_{I V_{i d i o, j, t}}$ & $\begin{array}{c}0.005198 \\
(0.294630)\end{array}$ & & --- & & --- & & $\begin{array}{c}-0.013737 \\
(0.754373)\end{array}$ & \\
\hline$\sigma_{R V} i d i o, j, t$ & $\begin{array}{c}0.738503 \\
(16.105847)\end{array}$ & $* * *$ & $\begin{array}{c}0.710748 \\
(25.135213)\end{array}$ & $* * *$ & $\begin{array}{c}0.726297 \\
(26.058256)\end{array}$ & $* * *$ & $\begin{array}{c}0.736880 \\
(16.205340)\end{array}$ & $* * *$ \\
\hline$\sigma_{E G_{i d i o, j, t}}$ & --- & & $\begin{array}{c}0.261121 \\
(3.640429)\end{array}$ & $* * *$ & --- & & $\begin{array}{c}0.261764 \\
(2.695399)\end{array}$ & $* * *$ \\
\hline$\sigma_{A R \text { idio }, j, t}$ & --- & & --- & & $\begin{array}{c}0.129724 \\
(2.545010)\end{array}$ & $* *$ & $\begin{array}{c}0.016316 \\
(0.242640)\end{array}$ & \\
\hline Constant & $\begin{array}{c}0.042686 \\
(9.457718)\end{array}$ & $* * *$ & $\begin{array}{c}0.023133 \\
(3.305168)\end{array}$ & $* * *$ & $\begin{array}{c}0.033361 \\
(5.741387)\end{array}$ & $* * *$ & $\begin{array}{c}0.022303 \\
(3.147412)\end{array}$ & $* * *$ \\
\hline$R$-Squared & 0.563586 & & 0.572645 & & 0.568031 & & 0.573073 & \\
\hline \multicolumn{9}{|c|}{ Phase 4} \\
\hline & Model 1 & & Model 2 & & Model 3 & & Model 4 & \\
\hline$\sigma_{I V_{i d i o, j, t}}$ & $\begin{array}{c}0.045306 \\
(7.585560)\end{array}$ & $* * *$ & --- & & --- & & $\begin{array}{c}0.041081 \\
(6.803092)\end{array}$ & $* * *$ \\
\hline$\sigma_{R V_{i d i o, j, t}}$ & $\begin{array}{c}0.654475 \\
(30.641563)\end{array}$ & $* * *$ & $\begin{array}{c}0.712307 \\
(38.358901)\end{array}$ & $* * *$ & $\begin{array}{c}0.735400 \\
(40.990325)\end{array}$ & $* * *$ & $\begin{array}{c}0.627601 \\
(28.329424)\end{array}$ & $* * *$ \\
\hline$\sigma_{E G_{i d i o, j, t}}$ & --- & & $\begin{array}{c}0.125470 \\
(5.458151)\end{array}$ & $* * *$ & --- & & $\begin{array}{c}0.106398 \\
(3.656396)\end{array}$ & $* * *$ \\
\hline$\sigma_{A R} i d i o, j, t$ & --- & & --- & & $\begin{array}{c}0.064788 \\
(3.488077)\end{array}$ & $* * *$ & $\begin{array}{c}-0.009607 \\
(0.411688)\end{array}$ & \\
\hline Constant & $\begin{array}{c}0.014523 \\
(7.461896)\end{array}$ & $* * *$ & $\begin{array}{c}0.011332 \\
(4.935662)\end{array}$ & $* * *$ & $\begin{array}{c}0.014563 \\
(6.611939)\end{array}$ & $* * *$ & $\begin{array}{c}0.009476 \\
(4.122897)\end{array}$ & $* * *$ \\
\hline$R$-Squared & 0.643931 & & 0.636181 & & 0.631080 & & 0.649245 & \\
\hline
\end{tabular}

$* * *, * * *$ Statistical significant for 1,5 , and 10 percent levels 
Table 11.2: Consumer Goods Sector

\begin{tabular}{|c|c|c|c|c|c|c|c|c|}
\hline \multicolumn{9}{|c|}{ Entire Phases } \\
\hline & \multicolumn{2}{|l|}{ Model 1} & \multicolumn{2}{|l|}{ Model 2} & \multicolumn{2}{|l|}{ Model 3} & \multicolumn{2}{|l|}{ Model 4} \\
\hline$\sigma_{I V_{i d i o, j, t}}$ & $\begin{array}{c}0.062295 \\
(20.307966)\end{array}$ & $* * *$ & --- & & --- & & $\begin{array}{c}0.055421 \\
(16.923937)\end{array}$ & $* * *$ \\
\hline$\sigma_{R V_{i d i o, j, t}}$ & $\begin{array}{c}0.576662 \\
(52.520926)\end{array}$ & $* * *$ & $\begin{array}{c}0.681242 \\
(75.711395)\end{array}$ & $* * *$ & $\begin{array}{c}0.698808 \\
(79.615723)\end{array}$ & $* * *$ & $\begin{array}{c}0.568842 \\
(51.546941)\end{array}$ & $* * *$ \\
\hline$\sigma_{E G_{i d i o, j, t}}$ & --- & & $\begin{array}{c}0.145520 \\
(12.494665)\end{array}$ & $* * *$ & --- & & $\begin{array}{c}0.072392 \\
(4.355517)\end{array}$ & $* * *$ \\
\hline$\sigma_{A R_{i d i o, j, t}}$ & --- & & --- & & $\begin{array}{c}0.092224 \\
(9.556818)\end{array}$ & $* * *$ & $\begin{array}{c}0.000493 \\
(0.036781)\end{array}$ & \\
\hline Constant & $\begin{array}{c}0.018799 \\
(27.632967)\end{array}$ & $* * *$ & $\begin{array}{c}0.011567 \\
(12.896862)\end{array}$ & $* * *$ & $\begin{array}{c}0.014086 \\
(16.646389)\end{array}$ & $* * *$ & $\begin{array}{c}0.015220 \\
(16.680447)\end{array}$ & $* * *$ \\
\hline$R$-Squared & 0.563272 & & 0.547407 & & 0.543212 & & 0.565519 & \\
\hline \multicolumn{9}{|c|}{$\begin{array}{r}\text { Phase 1 } \\
\end{array}$} \\
\hline & Model 1 & & Model 2 & & Model 3 & & Model 4 & \\
\hline$\sigma_{I V} i d i o, j, t$ & $\begin{array}{c}0.074443 \\
(11.409995)\end{array}$ & $* * *$ & --- & & --- & & $\begin{array}{c}0.059692 \\
(8.109003)\end{array}$ & $* * *$ \\
\hline$\sigma_{R V_{i d i o, j, t}}$ & $\begin{array}{c}0.413653 \\
(15.291400)\end{array}$ & $* * *$ & $\begin{array}{c}0.490445 \\
(19.616832)\end{array}$ & $* * *$ & $\begin{array}{c}0.547342 \\
(23.330596)\end{array}$ & $* * *$ & $\begin{array}{c}0.384521 \\
(13.881493)\end{array}$ & $* * *$ \\
\hline$\sigma_{E G_{i d i o, j, t}}$ & --- & & $\begin{array}{c}0.212185 \\
(9.014169)\end{array}$ & $* * *$ & --- & & $\begin{array}{c}0.101074 \\
(2.677351)\end{array}$ & $* * *$ \\
\hline$\sigma_{A R} i d i o, j, t$ & --- & & --- & & $\begin{array}{c}0.100689 \\
(6.624388)\end{array}$ & $* * *$ & $\begin{array}{c}0.009871 \\
(0.441437)\end{array}$ & \\
\hline Constant & $\begin{array}{c}0.031792 \\
(16.889963)\end{array}$ & $* * *$ & $\begin{array}{c}0.023995 \\
(11.922245)\end{array}$ & $* * *$ & $\begin{array}{c}0.027960 \\
(14.321602)\end{array}$ & $* * *$ & $\begin{array}{c}0.028448 \\
(13.765516)\end{array}$ & $* * *$ \\
\hline$R$-Squared & 0.455629 & & 0.436767 & & 0.421457 & & 0.463327 & \\
\hline \multicolumn{9}{|c|}{$\begin{array}{r}\text { Phase } 2 \\
\end{array}$} \\
\hline & Model 1 & & Model 2 & & Model 3 & & Model 4 & \\
\hline$\sigma_{I V} i d i o, j, t$ & $\begin{array}{c}0.128193 \\
(20.927867)\end{array}$ & $* * *$ & --- & & --- & & $\begin{array}{c}0.096956 \\
(14.358415)\end{array}$ & $* * *$ \\
\hline$\sigma_{R V_{i d i o, j, t}}$ & $\begin{array}{c}0.336899 \\
(20.135700)\end{array}$ & $* * *$ & $\begin{array}{c}0.422599 \\
(27.305047)\end{array}$ & $* * *$ & $\begin{array}{c}0.419234 \\
(26.993003)\end{array}$ & $* * *$ & $\begin{array}{c}0.297289 \\
(17.630826)\end{array}$ & $* * *$ \\
\hline$\sigma_{E G_{i d i o, j, t}}$ & --- & & $\begin{array}{c}0.257868 \\
(17.044788)\end{array}$ & $* * *$ & --- & & $\begin{array}{c}0.117869 \\
(5.502131)\end{array}$ & $* * *$ \\
\hline$\sigma_{A R_{i d i o, j, t}}$ & --- & & --- & & $\begin{array}{c}0.261120 \\
(17.195197)\end{array}$ & $* * *$ & $\begin{array}{c}0.070100 \\
(3.155399)\end{array}$ & $* * *$ \\
\hline Constant & $\begin{array}{c}0.022677 \\
(27.102033)\end{array}$ & $* * *$ & $\begin{array}{c}0.013905 \\
(13.056252)\end{array}$ & $* * *$ & $\begin{array}{c}0.013374 \\
(12.382204)\end{array}$ & $* * *$ & $\begin{array}{c}0.015081 \\
(13.841534)\end{array}$ & $* * *$ \\
\hline$R$-Squared & 0.376211 & & 0.351798 & & 0.352683 & & 0.396599 & \\
\hline \multicolumn{9}{|c|}{ Phase 3} \\
\hline & Model 1 & & Model 2 & & Model 3 & & Model 4 & \\
\hline$\sigma_{I V_{i d i o, j, t}}$ & $\begin{array}{c}0.031369 \\
(2.741746)\end{array}$ & $* * *$ & --- & & --- & & $\begin{array}{c}0.006123 \\
(0.476628)\end{array}$ & \\
\hline$\sigma_{R V_{i d i o, j, t}}$ & $\begin{array}{c}0.674654 \\
(18.413004)\end{array}$ & $* * *$ & $\begin{array}{c}0.699822 \\
(25.444431)\end{array}$ & $* * *$ & $\begin{array}{c}0.707987 \\
(25.479380)\end{array}$ & $* * *$ & $\begin{array}{c}0.685922 \\
(18.876022)\end{array}$ & $* * *$ \\
\hline$\sigma_{E G_{i d i o, j, t}}$ & --- & & $\begin{array}{c}0.278220 \\
(4.992554)\end{array}$ & $* * *$ & --- & & $\begin{array}{c}0.232842 \\
(2.898808)\end{array}$ & $* * *$ \\
\hline$\sigma_{A R_{i d i o, j, t}}$ & --- & & --- & & $\begin{array}{c}0.258856 \\
(3.923754)\end{array}$ & $* * *$ & $\begin{array}{c}0.053507 \\
(0.578552)\end{array}$ & \\
\hline Constant & $\begin{array}{c}0.033435 \\
(9.608044)\end{array}$ & $* * *$ & $\begin{array}{c}0.017636 \\
(3.735290)\end{array}$ & $* * *$ & $\begin{array}{c}0.018483 \\
(3.543374)\end{array}$ & $* * *$ & $\begin{array}{c}0.017033 \\
(3.061070)\end{array}$ & $* * *$ \\
\hline$R$-Squared & 0.538081 & & 0.549282 & & 0.543219 & & 0.549714 & \\
\hline
\end{tabular}




\begin{tabular}{|c|c|c|c|c|c|c|c|c|}
\hline \multicolumn{9}{|c|}{ Phase 4} \\
\hline & \multicolumn{2}{|c|}{ Model 1} & \multicolumn{2}{|l|}{ Model 2} & \multicolumn{2}{|c|}{ Model 3} & \multicolumn{2}{|c|}{ Model 4} \\
\hline$\sigma_{I V} i d i o, j, t$ & $\begin{array}{c}0.054857 \\
(10.285075)\end{array}$ & $* * *$ & --- & & --- & & $\begin{array}{c}0.053913 \\
(9.512665)\end{array}$ & $* * *$ \\
\hline$\sigma_{R V i d i o, j, t}$ & $\begin{array}{c}0.603475 \\
(29.456883)\end{array}$ & $* * *$ & $\begin{array}{c}0.713944 \\
(40.389051)\end{array}$ & $* * *$ & $\begin{array}{c}0.721140 \\
(42.066187)\end{array}$ & $* * *$ & $\begin{array}{c}0.601967 \\
(29.052507)\end{array}$ & $* * *$ \\
\hline$\sigma_{E G_{i d i o, j, t}}$ & --- & & $\begin{array}{c}0.081858 \\
(3.610903)\end{array}$ & $* * *$ & --- & & $\begin{array}{l}-0.001367 \\
(0.047254)\end{array}$ & \\
\hline$\sigma_{A R_{i d i o, j, t}}$ & --- & & --- & & $\begin{array}{c}0.063435 \\
(3.266946)\end{array}$ & $* * *$ & $\begin{array}{c}0.014044 \\
(0.579345)\end{array}$ & \\
\hline Constant & $\begin{array}{c}0.013730 \\
(8.756568)\end{array}$ & $* * *$ & $\begin{array}{c}0.013351 \\
(6.906650)\end{array}$ & $* * *$ & $\begin{array}{c}0.014078 \\
(7.506935)\end{array}$ & $* * *$ & $\begin{array}{c}0.013128 \\
(6.863459)\end{array}$ & $* * *$ \\
\hline$R$-Squared & 0.630779 & & 0.606356 & & 0.605690 & & 0.630905 & \\
\hline
\end{tabular}

Table 11.3: Financial Sector

\begin{tabular}{|c|c|c|c|c|c|c|c|c|}
\hline \multicolumn{9}{|c|}{ Entire Phases } \\
\hline & \multicolumn{2}{|l|}{ Model 1} & \multicolumn{2}{|l|}{ Model 2} & \multicolumn{2}{|l|}{ Model 3} & \multicolumn{2}{|l|}{ Model 4} \\
\hline$\sigma_{I V_{i d i o, j, t}}$ & $\begin{array}{c}0.067663 \\
(23.519072)\end{array}$ & $* * *$ & --- & & --- & & $\begin{array}{c}0.064401 \\
(21.206207)\end{array}$ & $* * *$ \\
\hline$\sigma_{R V_{i d i o, j, t}}$ & $\begin{array}{c}0.584673 \\
(49.574332)\end{array}$ & $* * *$ & $\begin{array}{c}0.753731 \\
(85.526449)\end{array}$ & $* * *$ & $\begin{array}{c}0.783522 \\
(95.321793)\end{array}$ & $* * *$ & $\begin{array}{c}0.576462 \\
(48.095395)\end{array}$ & $* * *$ \\
\hline$\sigma_{E G_{i d i o, j, t}}$ & --- & & $\begin{array}{c}0.145114 \\
(10.753615)\end{array}$ & $* * *$ & --- & & $\begin{array}{c}0.068697 \\
(4.311197)\end{array}$ & $* * *$ \\
\hline$\sigma_{A R_{i d i o, j, t}}$ & --- & & --- & & $\begin{array}{c}0.056209 \\
(6.434835)\end{array}$ & $* * *$ & $\begin{array}{c}-0.015832 \\
(1.568325)\end{array}$ & \\
\hline Constant & $\begin{array}{c}0.018528 \\
(24.109171)\end{array}$ & $* * *$ & $\begin{array}{c}0.009041 \\
(9.463146)\end{array}$ & $* * *$ & $\begin{array}{c}0.012739 \\
(14.849714)\end{array}$ & $* * *$ & $\begin{array}{c}0.016173 \\
(16.398774)\end{array}$ & $* * *$ \\
\hline$R$-Squared & 0.681032 & & 0.660439 & & 0.656678 & & 0.681944 & \\
\hline \multicolumn{9}{|c|}{ Phase 1} \\
\hline & \multicolumn{2}{|l|}{ Model 1} & \multicolumn{2}{|l|}{ Model 2} & \multicolumn{2}{|l|}{ Model 3} & \multicolumn{2}{|l|}{ Model 4} \\
\hline$\sigma_{I V_{i d i o, j, t}}$ & $\begin{array}{c}0.033104 \\
(4.031854)\end{array}$ & $* * *$ & --- & & --- & & $\begin{array}{c}0.024526 \\
(2.780762)\end{array}$ & $* * *$ \\
\hline$\sigma_{R V_{i d i o, j, t}}$ & $\begin{array}{c}0.553563 \\
(21.214200)\end{array}$ & $* * *$ & $\begin{array}{c}0.588124 \\
(25.957862)\end{array}$ & $* * *$ & $\begin{array}{c}0.592441 \\
(26.802370)\end{array}$ & $* * *$ & $\begin{array}{c}0.549605 \\
(21.091811)\end{array}$ & $* * *$ \\
\hline$\sigma_{E G_{i d i o, j, t}}$ & --- & & $\begin{array}{c}0.099470 \\
(3.584804)\end{array}$ & $* * *$ & --- & & $\begin{array}{c}0.020366 \\
(0.563563)\end{array}$ & \\
\hline$\sigma_{A R} i d i o, j, t$ & --- & & --- & & $\begin{array}{c}0.112409 \\
(4.131803)\end{array}$ & $* * *$ & $\begin{array}{c}0.078399 \\
(2.289036)\end{array}$ & $* *$ \\
\hline Constant & $\begin{array}{c}0.026827 \\
(14.594689)\end{array}$ & $* * *$ & $\begin{array}{c}0.023252 \\
(10.267718)\end{array}$ & $* * *$ & $\begin{array}{c}0.021759 \\
(9.159501)\end{array}$ & $* * *$ & $\begin{array}{c}0.021730 \\
(8.909753)\end{array}$ & $* * *$ \\
\hline$R$-Squared & 0.391031 & & 0.389434 & & 0.391413 & & 0.395924 & \\
\hline
\end{tabular}




\begin{tabular}{|c|c|c|c|c|c|c|c|c|}
\hline \multicolumn{9}{|c|}{ Phase 2} \\
\hline & \multicolumn{2}{|l|}{ Model 1} & \multicolumn{2}{|l|}{ Model 2} & \multicolumn{2}{|l|}{ Model 3} & \multicolumn{2}{|l|}{ Model 4} \\
\hline$\sigma_{I V} i d i o, j, t$ & $\begin{array}{c}0.088770 \\
(15.298547)\end{array}$ & $* * *$ & --- & & --- & & $\begin{array}{c}0.081261 \\
(12.941742)\end{array}$ & $* * *$ \\
\hline$\sigma_{R V_{i d i o, j, t}}$ & $\begin{array}{c}0.503170 \\
(31.288849)\end{array}$ & $* * *$ & $\begin{array}{c}0.602982 \\
(42.017004)\end{array}$ & $* * *$ & $\begin{array}{c}0.610146 \\
(42.755830)\end{array}$ & $* * *$ & $\begin{array}{c}0.495404 \\
(30.615898)\end{array}$ & $* * *$ \\
\hline$\sigma_{E G_{i d i o, j, t}}$ & --- & & $\begin{array}{c}0.136434 \\
(8.389639)\end{array}$ & $* * *$ & --- & & $\begin{array}{c}0.064962 \\
(3.136165)\end{array}$ & $* * *$ \\
\hline$\sigma_{\text {AR }}$ idio,j,t & --- & & --- & & $\begin{array}{c}0.113960 \\
(7.440364)\end{array}$ & $* * *$ & $\begin{array}{c}-0.001599 \\
(0.080838)\end{array}$ & \\
\hline Constant & $\begin{array}{c}0.017437 \\
(22.466836)\end{array}$ & $* * *$ & $\begin{array}{c}0.012634 \\
(11.925268)\end{array}$ & $* * *$ & $\begin{array}{c}0.013259 \\
(12.454410)\end{array}$ & $* * *$ & $\begin{array}{c}0.014790 \\
(13.319610)\end{array}$ & $* * *$ \\
\hline$R$-Squared & 0.442028 & & 0.415384 & & 0.412810 & & 0.444438 & \\
\hline \multicolumn{9}{|c|}{ Phase 3} \\
\hline & \multicolumn{2}{|l|}{ Model 1} & \multicolumn{2}{|l|}{ Model 2} & \multicolumn{2}{|l|}{ Model 3} & \multicolumn{2}{|l|}{ Model 4} \\
\hline$\sigma_{I V_{i d i o, j, t}}$ & $\begin{array}{c}0.042104 \\
(4.068697)\end{array}$ & $* * *$ & --- & & --- & & $\begin{array}{c}0.036323 \\
(3.395397)\end{array}$ & $* * *$ \\
\hline$\sigma_{R V_{i d i o, j, t}}$ & $\begin{array}{c}0.613512 \\
(14.475478)\end{array}$ & $* * *$ & $\begin{array}{c}0.700036 \\
(22.243158)\end{array}$ & $* * *$ & $\begin{array}{c}0.721674 \\
(24.493908)\end{array}$ & $* * *$ & $\begin{array}{c}0.595303 \\
(13.797852)\end{array}$ & $* * *$ \\
\hline$\sigma_{E G_{i d i o, j, t}}$ & --- & & $\begin{array}{c}0.151508 \\
(2.912513)\end{array}$ & $* * *$ & --- & & $\begin{array}{c}0.082566 \\
(1.404501)\end{array}$ & \\
\hline$\sigma_{A R}$ idio, $j, t$ & --- & & --- & & $\begin{array}{c}0.062878 \\
(2.192716)\end{array}$ & $* *$ & $\begin{array}{c}0.027965 \\
(0.885174)\end{array}$ & \\
\hline Constant & $\begin{array}{c}0.049422 \\
(9.523239)\end{array}$ & $* * *$ & $\begin{array}{c}0.040978 \\
(7.087675)\end{array}$ & $* * *$ & $\begin{array}{c}0.045688 \\
(8.528751)\end{array}$ & $* * *$ & $\begin{array}{c}0.044149 \\
(7.590281)\end{array}$ & $* * *$ \\
\hline$R$-Squared & 0.539708 & & 0.534224 & & 0.531684 & & 0.542860 & \\
\hline \multicolumn{9}{|c|}{ Phase 4} \\
\hline & \multicolumn{2}{|l|}{ Model 1} & \multicolumn{2}{|l|}{ Model 2} & \multicolumn{2}{|l|}{ Model 3} & \multicolumn{2}{|l|}{ Model 4} \\
\hline$\sigma_{I V} i d i o, j, t$ & $\begin{array}{c}0.083018 \\
(15.390150)\end{array}$ & $* * *$ & --- & & --- & & $\begin{array}{c}0.082521 \\
(14.627281)\end{array}$ & $* * *$ \\
\hline$\sigma_{R V_{i d i o, j, t}}$ & $\begin{array}{c}0.497668 \\
(21.258287)\end{array}$ & $* * *$ & $\begin{array}{c}0.719474 \\
(37.241955)\end{array}$ & $* * *$ & $\begin{array}{c}0.767757 \\
(43.384032)\end{array}$ & $* * *$ & $\begin{array}{c}0.490077 \\
(20.372856)\end{array}$ & $* * *$ \\
\hline$\sigma_{E G_{i d i o, j, t}}$ & --- & & $\begin{array}{c}0.146089 \\
(5.432284)\end{array}$ & $* * *$ & --- & & $\begin{array}{c}0.093673 \\
(2.993950)\end{array}$ & $* * *$ \\
\hline$\sigma_{A R i d i o, j, t}$ & --- & & --- & & $\begin{array}{c}0.030049 \\
(1.844024)\end{array}$ & $*$ & $\begin{array}{l}-0.059845 \\
(3.224901)\end{array}$ & $* * *$ \\
\hline Constant & $\begin{array}{c}0.018864 \\
(8.403623)\end{array}$ & $* * *$ & $\begin{array}{c}0.013993 \\
(5.265842)\end{array}$ & $* * *$ & $\begin{array}{c}0.018799 \\
(7.425247)\end{array}$ & $* * *$ & $\begin{array}{c}0.017557 \\
(7.082758)\end{array}$ & $* * *$ \\
\hline$R$-Squared & 0.709290 & & 0.665307 & & 0.658808 & & 0.711981 & \\
\hline
\end{tabular}


Table 11.4: Healthcare Sector

\begin{tabular}{|c|c|c|c|c|c|c|c|c|}
\hline \multicolumn{9}{|c|}{ Entire Phases } \\
\hline & \multicolumn{2}{|l|}{ Model 1} & \multicolumn{2}{|l|}{ Model 2} & \multicolumn{2}{|l|}{ Model 3} & \multicolumn{2}{|l|}{ Model 4} \\
\hline$\sigma_{I V_{i d i o, j, t}}$ & $\begin{array}{c}0.075581 \\
(25.876708)\end{array}$ & $* * *$ & --- & & --- & & $\begin{array}{c}0.060964 \\
(19.287290)\end{array}$ & $* * *$ \\
\hline$\sigma_{R V_{i d i o, j, t}}$ & $\begin{array}{c}0.395360 \\
(29.525945)\end{array}$ & $* * *$ & $\begin{array}{c}0.508597 \\
(43.662283)\end{array}$ & $* * *$ & $\begin{array}{c}0.547382 \\
(48.412960)\end{array}$ & $* * *$ & $\begin{array}{c}0.363632 \\
(26.892646)\end{array}$ & $* * *$ \\
\hline$\sigma_{E G_{i d i o, j, t}}$ & --- & & $\begin{array}{c}0.235923 \\
(20.324363)\end{array}$ & $* * *$ & --- & & $\begin{array}{c}0.133553 \\
(7.847846)\end{array}$ & $* * *$ \\
\hline$\sigma_{A R_{i d i o}, j, t}$ & --- & & --- & & $\begin{array}{c}0.171676 \\
(16.435207)\end{array}$ & $* * *$ & $\begin{array}{c}0.009881 \\
(0.665693)\end{array}$ & \\
\hline Constant & $\begin{array}{c}0.029131 \\
(29.449588)\end{array}$ & $* * *$ & $\begin{array}{c}0.016662 \\
(13.958206)\end{array}$ & $* * *$ & $\begin{array}{c}0.019384 \\
(16.206477)\end{array}$ & $* * *$ & $\begin{array}{c}0.021306 \\
(17.678899)\end{array}$ & $* * *$ \\
\hline$R$-Squared & 0.474043 & & 0.452004 & & 0.438901 & & 0.486086 & \\
\hline \multicolumn{9}{|c|}{$\begin{array}{r}\text { Phase 1 } \\
\end{array}$} \\
\hline & Model 1 & & Model 2 & & Model 3 & & Model 4 & \\
\hline$\sigma_{I V} i d i o, j, t$ & $\begin{array}{c}0.057174 \\
(9.506171)\end{array}$ & $* * *$ & --- & & --- & & $\begin{array}{c}0.037179 \\
(5.391210)\end{array}$ & $* * *$ \\
\hline$\sigma_{R V_{i d i o, j, t}}$ & $\begin{array}{c}0.388171 \\
(12.112541)\end{array}$ & $* * *$ & $\begin{array}{c}0.449666 \\
(16.259407)\end{array}$ & $* * *$ & $\begin{array}{c}0.496250 \\
(18.783368)\end{array}$ & $* * *$ & $\begin{array}{c}0.354666 \\
(11.029570)\end{array}$ & $* * *$ \\
\hline$\sigma_{E G_{i d i o, j, t}}$ & --- & & $\begin{array}{c}0.288458 \\
(9.545893)\end{array}$ & $* * *$ & --- & & $\begin{array}{c}0.164336 \\
(3.616465)\end{array}$ & $* * *$ \\
\hline$\sigma_{A R_{i d i o}, j, t}$ & --- & & --- & & $\begin{array}{c}0.229428 \\
(7.967988)\end{array}$ & $* * *$ & $\begin{array}{c}0.040133 \\
(0.973457)\end{array}$ & \\
\hline Constant & $\begin{array}{c}0.040484 \\
(14.885955)\end{array}$ & $* * *$ & $\begin{array}{c}0.024861 \\
(8.081966)\end{array}$ & $* * *$ & $\begin{array}{c}0.025831 \\
(8.109696)\end{array}$ & $* * *$ & $\begin{array}{c}0.029720 \\
(8.911485)\end{array}$ & $* * *$ \\
\hline$R$-Squared & 0.437813 & & 0.438170 & & 0.424837 & & 0.453969 & \\
\hline \multicolumn{9}{|c|}{ Phase 2} \\
\hline & Model 1 & & Model 2 & & Model 3 & & Model 4 & \\
\hline$\sigma_{I V_{i d i o, j, t}}$ & $\begin{array}{c}0.125959 \\
(28.362972)\end{array}$ & $* * *$ & --- & & --- & & $\begin{array}{c}0.101156 \\
(20.195522)\end{array}$ & $* * *$ \\
\hline$\sigma_{R V_{i d i o, j, t}}$ & $\begin{array}{c}0.151525 \\
(7.952563)\end{array}$ & $* * *$ & $\begin{array}{c}0.278532 \\
(15.208643)\end{array}$ & $* * *$ & $\begin{array}{c}0.371207 \\
(20.884820)\end{array}$ & $* * *$ & $\begin{array}{c}0.102648 \\
(5.338542)\end{array}$ & $* * *$ \\
\hline$\sigma_{E G_{i d i o, j, t}}$ & --- & & $\begin{array}{c}0.327000 \\
(21.844913)\end{array}$ & $* * *$ & --- & & $\begin{array}{c}0.189368 \\
(9.145281)\end{array}$ & $* * *$ \\
\hline$\sigma_{A R_{i d i o}, j, t}$ & --- & & --- & & $\begin{array}{c}0.205966 \\
(15.856179)\end{array}$ & $* * *$ & $\begin{array}{c}-0.022020 \\
(1.310584)\end{array}$ & \\
\hline Constant & $\begin{array}{c}0.033030 \\
(26.439313)\end{array}$ & $* * *$ & $\begin{array}{c}0.018099 \\
(12.036770)\end{array}$ & $* * *$ & $\begin{array}{c}0.022989 \\
(15.017378)\end{array}$ & $* * *$ & $\begin{array}{c}0.025106 \\
(17.089828)\end{array}$ & $* * *$ \\
\hline$R$-Squared & 0.421225 & & 0.364756 & & 0.318910 & & 0.444013 & \\
\hline \multicolumn{9}{|c|}{ Phase 3} \\
\hline & Model 1 & & Model 2 & & Model 3 & & Model 4 & \\
\hline$\sigma_{I V} i d i o, j, t$ & $\begin{array}{c}0.025900 \\
(2.680258)\end{array}$ & $* * *$ & --- & & --- & & $\begin{array}{c}0.012457 \\
(1.200167)\end{array}$ & \\
\hline$\sigma_{R V_{i d i o, j, t}}$ & $\begin{array}{c}0.658787 \\
(16.807119)\end{array}$ & $* * *$ & $\begin{array}{c}0.669574 \\
(20.566373)\end{array}$ & $* * *$ & $\begin{array}{c}0.668883 \\
(20.732780)\end{array}$ & $* * *$ & $\begin{array}{c}0.636906 \\
(16.157122)\end{array}$ & $* * *$ \\
\hline$\sigma_{E G_{i d i o, j, t}}$ & --- & & $\begin{array}{c}0.188594 \\
(3.869369)\end{array}$ & $* * *$ & --- & & $\begin{array}{c}0.068388 \\
(0.807579)\end{array}$ & \\
\hline$\sigma_{A R_{i d i o, j, t}}$ & --- & & --- & & $\begin{array}{c}0.184867 \\
(4.056354)\end{array}$ & $* * *$ & $\begin{array}{c}0.111311 \\
(1.408746)\end{array}$ & \\
\hline Constant & $\begin{array}{c}0.033230 \\
(8.647599)\end{array}$ & $* * *$ & $\begin{array}{c}0.021597 \\
(4.364082)\end{array}$ & $* * *$ & $\begin{array}{c}0.021343 \\
(4.362399)\end{array}$ & $* * *$ & $\begin{array}{c}0.021595 \\
(4.199601)\end{array}$ & $* * *$ \\
\hline$R$-Squared & 0.532994 & & 0.539180 & & 0.540338 & & 0.542269 & \\
\hline
\end{tabular}




\begin{tabular}{|c|c|c|c|c|c|c|c|c|}
\hline \multicolumn{9}{|c|}{ Phase 4} \\
\hline & \multicolumn{2}{|c|}{ Model 1} & \multicolumn{2}{|l|}{ Model 2} & \multicolumn{2}{|l|}{ Model 3} & \multicolumn{2}{|c|}{ Model 4} \\
\hline$\sigma_{I V_{i d i o, j, t}}$ & $\begin{array}{c}0.052409 \\
(9.441192)\end{array}$ & $* * *$ & --- & & --- & & $\begin{array}{c}0.042130 \\
(7.351883)\end{array}$ & $* * *$ \\
\hline$\sigma_{R V i d i o, j, t}$ & $\begin{array}{c}0.534506 \\
(19.972704)\end{array}$ & $* * *$ & $\begin{array}{c}0.601194 \\
(25.466521)\end{array}$ & $* * *$ & $\begin{array}{c}0.609622 \\
(25.747684)\end{array}$ & $* * *$ & $\begin{array}{c}0.480980 \\
(17.264910)\end{array}$ & $* * *$ \\
\hline$\sigma_{E G_{i d i o, j, t}}$ & --- & & $\begin{array}{c}0.184167 \\
(8.120200)\end{array}$ & $* * *$ & --- & & $\begin{array}{c}0.090777 \\
(2.685893)\end{array}$ & $* * *$ \\
\hline$\sigma_{A R}$ idio,j,t & --- & & --- & & $\begin{array}{c}0.164495 \\
(7.487177)\end{array}$ & $* * *$ & $\begin{array}{c}0.056238 \\
(1.741427)\end{array}$ & $*$ \\
\hline Constant & $\begin{array}{c}0.019713 \\
(9.933684)\end{array}$ & $* * *$ & $\begin{array}{c}0.012321 \\
(5.373406)\end{array}$ & $* * *$ & $\begin{array}{c}0.012974 \\
(5.630305)\end{array}$ & $* * *$ & $\begin{array}{c}0.012616 \\
(5.523237)\end{array}$ & $* * *$ \\
\hline$R$-Squared & 0.557735 & & 0.549290 & & 0.545595 & & 0.571334 & \\
\hline
\end{tabular}

$* * *, * * *$ Statistical significant for 1,5 , and 10 percent levels

Table 11.5: Industrial Goods Sector

\begin{tabular}{|c|c|c|c|c|c|c|c|c|}
\hline \multicolumn{9}{|c|}{ Entire Phases } \\
\hline & \multicolumn{2}{|l|}{ Model 1} & \multicolumn{2}{|l|}{ Model 2} & \multicolumn{2}{|l|}{ Model 3} & \multicolumn{2}{|l|}{ Model 4} \\
\hline$\sigma_{I V_{i d i o, j, t}}$ & $\begin{array}{c}0.061281 \\
(16.632642)\end{array}$ & $* * *$ & --- & & --- & & $\begin{array}{c}0.052216 \\
(13.413873)\end{array}$ & $* * *$ \\
\hline$\sigma_{R V_{i d i o, j, t}}$ & $\begin{array}{c}0.597481 \\
(45.066077)\end{array}$ & $* * *$ & $\begin{array}{c}0.725002 \\
(73.469551)\end{array}$ & $* * *$ & $\begin{array}{c}0.706485 \\
(69.588421)\end{array}$ & $* * *$ & $\begin{array}{c}0.587379 \\
(44.234120)\end{array}$ & $* * *$ \\
\hline$\sigma_{E G_{i d i o, j, t}}$ & --- & & $\begin{array}{c}0.100970 \\
(9.291601)\end{array}$ & $* * *$ & --- & & $\begin{array}{c}0.023460 \\
(1.670845)\end{array}$ & $*$ \\
\hline$\sigma_{A R_{i d i o}, j, t}$ & --- & & --- & & $\begin{array}{c}0.141254 \\
(11.754601)\end{array}$ & $* * *$ & $\begin{array}{c}0.068240 \\
(4.255197)\end{array}$ & $* * *$ \\
\hline Constant & $\begin{array}{c}0.020429 \\
(22.249168)\end{array}$ & $* * *$ & $\begin{array}{c}0.014476 \\
(13.313073)\end{array}$ & $* * *$ & $\begin{array}{c}0.012489 \\
(11.239806)\end{array}$ & $* * *$ & $\begin{array}{c}0.015653 \\
(13.704914)\end{array}$ & $* * *$ \\
\hline$R$-Squared & 0.600396 & & 0.585430 & & 0.589616 & & 0.604271 & \\
\hline \multicolumn{9}{|c|}{ Phase 1} \\
\hline & \multicolumn{2}{|l|}{ Model 1} & \multicolumn{2}{|l|}{ Model 2} & \multicolumn{2}{|l|}{ Model 3} & \multicolumn{2}{|l|}{ Model 4} \\
\hline$\sigma_{I V_{i d i o, j, t}}$ & $\begin{array}{c}0.066481 \\
(6.841282)\end{array}$ & $* * *$ & --- & & --- & & $\begin{array}{c}0.036627 \\
(3.397729)\end{array}$ & $* * *$ \\
\hline$\sigma_{R V_{i d i o, j, t}}$ & $\begin{array}{c}0.436382 \\
(12.364177)\end{array}$ & $* * *$ & $\begin{array}{c}0.500764 \\
(17.424609)\end{array}$ & $* * *$ & $\begin{array}{c}0.494952 \\
(17.836936)\end{array}$ & $* * *$ & $\begin{array}{c}0.416254 \\
(11.941829)\end{array}$ & $* * *$ \\
\hline$\sigma_{E G_{i d i o, j, t}}$ & --- & & $\begin{array}{c}0.186516 \\
(7.292510)\end{array}$ & $* * *$ & --- & & $\begin{array}{c}0.028020 \\
(0.727333)\end{array}$ & \\
\hline$\sigma_{A R_{i d i o, j, t}}$ & --- & & --- & & $\begin{array}{c}0.226328 \\
(8.590149)\end{array}$ & $* * *$ & $\begin{array}{c}0.161616 \\
(4.066911)\end{array}$ & $* * *$ \\
\hline Constant & $\begin{array}{c}0.035311 \\
(13.424047)\end{array}$ & $* * *$ & $\begin{array}{c}0.029193 \\
(10.578228)\end{array}$ & $* * *$ & $\begin{array}{c}0.025989 \\
(9.213545)\end{array}$ & $* * *$ & $\begin{array}{c}0.027669 \\
(9.705443)\end{array}$ & $* * *$ \\
\hline$R$-Squared & 0.404645 & & 0.408382 & & 0.420142 & & 0.428288 & \\
\hline
\end{tabular}




\begin{tabular}{|c|c|c|c|c|c|c|c|c|}
\hline \multicolumn{9}{|c|}{ Phase 2} \\
\hline & \multicolumn{2}{|l|}{ Model 1} & \multicolumn{2}{|l|}{ Model 2} & \multicolumn{2}{|l|}{ Model 3} & \multicolumn{2}{|l|}{ Model 4} \\
\hline$\sigma_{I V} i d i o, j, t$ & $\begin{array}{c}0.094606 \\
(21.715772)\end{array}$ & $* * *$ & --- & & --- & & $\begin{array}{c}0.070941 \\
(14.757456)\end{array}$ & $* * *$ \\
\hline$\sigma_{R V_{i d i o, j, t}}$ & $\begin{array}{c}0.397990 \\
(21.190462)\end{array}$ & $* * *$ & $\begin{array}{c}0.499559 \\
(28.514918)\end{array}$ & $* * *$ & $\begin{array}{c}0.500488 \\
(28.695995)\end{array}$ & $* * *$ & $\begin{array}{c}0.336926 \\
(17.543590)\end{array}$ & $* * *$ \\
\hline$\sigma_{E G_{i d i o, j, t}}$ & --- & & $\begin{array}{c}0.272056 \\
(17.123347)\end{array}$ & $* * *$ & --- & & $\begin{array}{c}0.115610 \\
(5.653647)\end{array}$ & $* * *$ \\
\hline$\sigma_{\text {AR }}$ idio,j,t & --- & & --- & & $\begin{array}{c}0.261255 \\
(17.231618)\end{array}$ & $* * *$ & $\begin{array}{c}0.081475 \\
(4.074986)\end{array}$ & $* * *$ \\
\hline Constant & $\begin{array}{c}0.026335 \\
(24.976746)\end{array}$ & $* * *$ & $\begin{array}{c}0.011777 \\
(9.888118)\end{array}$ & $* * *$ & $\begin{array}{c}0.012227 \\
(10.386958)\end{array}$ & $* * *$ & $\begin{array}{c}0.018288 \\
(14.393563)\end{array}$ & $* * *$ \\
\hline$R$-Squared & 0.538146 & & 0.508832 & & 0.509481 & & 0.558861 & \\
\hline \multicolumn{9}{|c|}{ Phase 3} \\
\hline & Model 1 & & Model 2 & & Model 3 & & Model 4 & \\
\hline$\sigma_{I V_{i d i o, j, t}}$ & $\begin{array}{c}0.009076 \\
(0.580925)\end{array}$ & & --- & & --- & & $\begin{array}{c}-0.009934 \\
(0.605528)\end{array}$ & \\
\hline$\sigma_{R V_{i d i o, j, t}}$ & $\begin{array}{c}0.699038 \\
(14.889625)\end{array}$ & $* * *$ & $\begin{array}{c}0.702621 \\
(22.358048)\end{array}$ & $* * *$ & $\begin{array}{c}0.672459 \\
(19.944349)\end{array}$ & $* * *$ & $\begin{array}{c}0.693050 \\
(14.861826)\end{array}$ & $* * *$ \\
\hline$\sigma_{E G_{i d i o, j, t}}$ & --- & & $\begin{array}{c}0.108971 \\
(2.635713)\end{array}$ & $* * *$ & --- & & $\begin{array}{c}0.053231 \\
(1.104894)\end{array}$ & \\
\hline$\sigma_{A R}$ idio, $j, t$ & --- & & --- & & $\begin{array}{c}0.211446 \\
(3.343620)\end{array}$ & $* * *$ & $\begin{array}{c}0.182625 \\
(2.385292)\end{array}$ & $* *$ \\
\hline Constant & $\begin{array}{c}0.043349 \\
(8.568173)\end{array}$ & $* * *$ & $\begin{array}{c}0.036886 \\
(6.573768)\end{array}$ & $* * *$ & $\begin{array}{c}0.031988 \\
(5.270889)\end{array}$ & $* * *$ & $\begin{array}{c}0.030486 \\
(4.909694)\end{array}$ & $* * *$ \\
\hline$R$-Squared & 0.518862 & & 0.525123 & & 0.529047 & & 0.530476 & \\
\hline \multicolumn{9}{|c|}{ Phase 4} \\
\hline & Model 1 & & Model 2 & & Model 3 & & Model 4 & \\
\hline$\sigma_{I V} i d i o, j, t$ & $\begin{array}{c}0.069322 \\
(10.849465)\end{array}$ & $* * *$ & --- & & --- & & $\begin{array}{c}0.068072 \\
(10.446513)\end{array}$ & $* * *$ \\
\hline$\sigma_{R V_{i d i o, j, t}}$ & $\begin{array}{c}0.634911 \\
(27.812358)\end{array}$ & $* * *$ & $\begin{array}{c}0.803590 \\
(44.887988)\end{array}$ & $* * *$ & $\begin{array}{c}0.788362 \\
(42.678207)\end{array}$ & $* * *$ & $\begin{array}{c}0.627510 \\
(26.748283)\end{array}$ & $* * *$ \\
\hline$\sigma_{E G_{i d i o, j, t}}$ & --- & & $\begin{array}{c}0.023538 \\
(1.296945)\end{array}$ & & --- & & $\begin{array}{c}0.008308 \\
(0.381566)\end{array}$ & \\
\hline$\sigma_{\text {AR idio }, j, t}$ & --- & & --- & & $\begin{array}{c}0.060776 \\
(3.030342)\end{array}$ & $* * *$ & $\begin{array}{c}0.021228 \\
(0.866761)\end{array}$ & \\
\hline Constant & $\begin{array}{c}0.009679 \\
(5.030415)\end{array}$ & $* * *$ & $\begin{array}{c}0.012530 \\
(5.709124)\end{array}$ & $* * *$ & $\begin{array}{c}0.010674 \\
(4.794653)\end{array}$ & $* * *$ & $\begin{array}{c}0.008268 \\
(3.824460)\end{array}$ & $* * *$ \\
\hline$R$-Squared & 0.726725 & & 0.695228 & & 0.697482 & & 0.727294 & \\
\hline
\end{tabular}


Table 11.6: Services Sector

\begin{tabular}{|c|c|c|c|c|c|c|c|c|}
\hline \multicolumn{9}{|c|}{ Entire Phases } \\
\hline & \multicolumn{2}{|l|}{ Model 1} & \multicolumn{2}{|l|}{ Model 2} & \multicolumn{2}{|l|}{ Model 3} & \multicolumn{2}{|l|}{ Model 4} \\
\hline$\sigma_{I V i d i o, j, t}$ & $\begin{array}{c}0.062572 \\
(26.537012)\end{array}$ & $* * *$ & --- & & --- & & $\begin{array}{c}0.052086 \\
(21.194540)\end{array}$ & $* * *$ \\
\hline$\sigma_{R V_{i d i o, j, t}}$ & $\begin{array}{c}0.567326 \\
(70.229489)\end{array}$ & $* * *$ & $\begin{array}{c}0.646714 \\
(93.600468)\end{array}$ & $* * *$ & $\begin{array}{c}0.661144 \\
(98.178300)\end{array}$ & $* * *$ & $\begin{array}{c}0.546190 \\
(66.929768)\end{array}$ & $* * *$ \\
\hline$\sigma_{E G_{i d i o, j, t}}$ & --- & & $\begin{array}{c}0.174090 \\
(19.917972)\end{array}$ & $* * *$ & --- & & $\begin{array}{c}0.090368 \\
(8.085756)\end{array}$ & $* * *$ \\
\hline$\sigma_{A R_{i d i o, j, t}}$ & --- & & --- & & $\begin{array}{c}0.132994 \\
(17.958603)\end{array}$ & $* * *$ & $\begin{array}{c}0.040623 \\
(4.310003)\end{array}$ & $* * *$ \\
\hline Constant & $\begin{array}{c}0.021637 \\
(34.234348)\end{array}$ & $* * *$ & $\begin{array}{c}0.013953 \\
(17.311799)\end{array}$ & $* * *$ & $\begin{array}{c}0.015921 \\
(20.554490)\end{array}$ & $* * *$ & $\begin{array}{c}0.014437 \\
(17.825824)\end{array}$ & $* * *$ \\
\hline$R$-Squared & 0.527480 & & 0.516102 & & 0.513274 & & 0.534903 & \\
\hline \multicolumn{9}{|c|}{$\begin{array}{r}\text { Phase } 1 \\
\end{array}$} \\
\hline & Model 1 & & Model 2 & & Model 3 & & Model 4 & \\
\hline$\sigma_{I V_{i d i o, j, t}}$ & $\begin{array}{c}0.060863 \\
(12.754168)\end{array}$ & $* * *$ & --- & & --- & & $\begin{array}{c}0.051589 \\
(10.455771)\end{array}$ & $* * *$ \\
\hline$\sigma_{R V_{i d i o, j, t}}$ & $\begin{array}{c}0.428371 \\
(20.979054)\end{array}$ & $* * *$ & $\begin{array}{c}0.541071 \\
(31.585463)\end{array}$ & $* * *$ & $\begin{array}{c}0.536340 \\
(30.984318)\end{array}$ & $* * *$ & $\begin{array}{c}0.403132 \\
(19.586510)\end{array}$ & $* * *$ \\
\hline$\sigma_{E G_{i d i o, j, t}}$ & --- & & $\begin{array}{c}0.136993 \\
(8.630705)\end{array}$ & $* * *$ & --- & & $\begin{array}{c}0.067029 \\
(3.570229)\end{array}$ & $* * *$ \\
\hline$\sigma_{\text {AR }}$ idio $, j, t$ & --- & & --- & & $\begin{array}{c}0.160285 \\
(8.716467)\end{array}$ & $* * *$ & $\begin{array}{c}0.064245 \\
(2.923209)\end{array}$ & $* * *$ \\
\hline Constant & $\begin{array}{c}0.037353 \\
(21.481009)\end{array}$ & $* * *$ & $\begin{array}{c}0.031443 \\
(16.076277)\end{array}$ & $* * *$ & $\begin{array}{c}0.030055 \\
(14.843023)\end{array}$ & $* * *$ & $\begin{array}{c}0.030550 \\
(15.200727)\end{array}$ & $* * *$ \\
\hline$R$-Squared & 0.403665 & & 0.382319 & & 0.382692 & & 0.414770 & \\
\hline \multicolumn{9}{|c|}{ Phase 2} \\
\hline & Model 1 & & Model 2 & & Model 3 & & Model 4 & \\
\hline$\sigma_{I V}$ idio,j,t & $\begin{array}{c}0.097038 \\
(26.562560)\end{array}$ & $* * *$ & --- & & --- & & $\begin{array}{c}0.075206 \\
(18.807442)\end{array}$ & $* * *$ \\
\hline$\sigma_{R V \text { idio }, j, t}$ & $\begin{array}{c}0.379024 \\
(31.642751)\end{array}$ & $* * *$ & $\begin{array}{c}0.442231 \\
(38.323968)\end{array}$ & $* * *$ & $\begin{array}{c}0.448380 \\
(39.086150)\end{array}$ & $* * *$ & $\begin{array}{c}0.335817 \\
(27.419940)\end{array}$ & $* * *$ \\
\hline$\sigma_{E G_{i d i o, j, t}}$ & --- & & $\begin{array}{c}0.234646 \\
(20.771400)\end{array}$ & $* * *$ & --- & & $\begin{array}{c}0.114313 \\
(7.951069)\end{array}$ & $* * *$ \\
\hline$\sigma_{A R}$ idio, $, t, t$ & --- & & --- & & $\begin{array}{c}0.214478 \\
(20.292304)\end{array}$ & $* * *$ & $\begin{array}{c}0.056620 \\
(4.098035)\end{array}$ & $* * *$ \\
\hline Constant & $\begin{array}{c}0.026267 \\
(36.662935)\end{array}$ & $* * *$ & $\begin{array}{c}0.016960 \\
(18.638424)\end{array}$ & $* * *$ & $\begin{array}{c}0.017265 \\
(18.981097)\end{array}$ & $* * *$ & $\begin{array}{c}0.018267 \\
(19.596633)\end{array}$ & $* * *$ \\
\hline$R$-Squared & 0.377620 & & 0.352036 & & 0.350119 & & 0.394943 & \\
\hline \multicolumn{9}{|c|}{ Phase 3} \\
\hline & Model 1 & & Model 2 & & Model 3 & & Model 4 & \\
\hline$\sigma_{I V} i d i o, j, t$ & $\begin{array}{c}0.006533 \\
(0.663214)\end{array}$ & & --- & & --- & & $\begin{array}{l}-0.030146 \\
(2.879821)\end{array}$ & $* * *$ \\
\hline$\sigma_{R V}$ idio,j,t & $\begin{array}{c}0.742048 \\
(27.566504)\end{array}$ & $* * *$ & $\begin{array}{c}0.699069 \\
(34.064521)\end{array}$ & $* * *$ & $\begin{array}{c}0.699606 \\
(35.274550)\end{array}$ & $* * *$ & $\begin{array}{c}0.741219 \\
(28.240463)\end{array}$ & $* * *$ \\
\hline$\sigma_{E G_{i d i o, j, t}}$ & --- & & $\begin{array}{c}0.280905 \\
(6.761617)\end{array}$ & $* * *$ & --- & & $\begin{array}{c}0.103193 \\
(1.714624)\end{array}$ & $*$ \\
\hline$\sigma_{A R_{i d i o}, j, t}$ & --- & & --- & & $\begin{array}{c}0.323062 \\
(8.169304)\end{array}$ & $* * *$ & $\begin{array}{c}0.298947 \\
(5.145638)\end{array}$ & $* * *$ \\
\hline Constant & $\begin{array}{c}0.036805 \\
(12.192100)\end{array}$ & $* * *$ & $\begin{array}{c}0.019168 \\
(4.864743)\end{array}$ & $* * *$ & $\begin{array}{c}0.015765 \\
(4.049389)\end{array}$ & $* * *$ & $\begin{array}{c}0.012727 \\
(3.129052)\end{array}$ & $* * *$ \\
\hline$R$-Squared & 0.555168 & & 0.570773 & & 0.577651 & & 0.581026 & \\
\hline
\end{tabular}




\begin{tabular}{|c|c|c|c|c|c|c|c|c|}
\hline \multicolumn{9}{|c|}{ Phase 4} \\
\hline & \multicolumn{2}{|c|}{ Model 1} & \multicolumn{2}{|l|}{ Model 2} & \multicolumn{2}{|l|}{ Model 3} & \multicolumn{2}{|c|}{ Model 4} \\
\hline$\sigma_{I V_{i d i o, j, t}}$ & $\begin{array}{c}0.070355 \\
(14.015469)\end{array}$ & $* * *$ & --- & & --- & & $\begin{array}{c}0.058000 \\
(11.181279)\end{array}$ & $* * *$ \\
\hline$\sigma_{R V_{i d i o, j, t}}$ & $\begin{array}{c}0.529135 \\
(31.924559)\end{array}$ & $* * *$ & $\begin{array}{c}0.574521 \\
(36.298646)\end{array}$ & $* * *$ & $\begin{array}{c}0.602077 \\
(39.472752)\end{array}$ & $* * *$ & $\begin{array}{c}0.490579 \\
(28.762161)\end{array}$ & $* * *$ \\
\hline$\sigma_{E G_{i d i o, j, t}}$ & --- & & $\begin{array}{c}0.213073 \\
(11.236831)\end{array}$ & $* * *$ & --- & & $\begin{array}{c}0.121552 \\
(4.923086)\end{array}$ & $* * *$ \\
\hline$\sigma_{A R_{i d i o, j, t}}$ & --- & & --- & & $\begin{array}{c}0.125195 \\
(9.526702)\end{array}$ & $* * *$ & $\begin{array}{c}0.032813 \\
(1.945021)\end{array}$ & $*$ \\
\hline Constant & $\begin{array}{c}0.018305 \\
(10.014266)\end{array}$ & $* * *$ & $\begin{array}{c}0.016402 \\
(8.185517)\end{array}$ & $* * *$ & $\begin{array}{c}0.021272 \\
(11.396488)\end{array}$ & $* * *$ & $\begin{array}{c}0.011545 \\
(5.777352)\end{array}$ & $* * *$ \\
\hline$R$-Squared & 0.494212 & & 0.480663 & & 0.473526 & & 0.507243 & \\
\hline
\end{tabular}

$* * *, * * *$ Statistical significant for 1,5 , and 10 percent levels

Table 11.7: Technology Sector

\begin{tabular}{|c|c|c|c|c|c|c|c|c|}
\hline \multicolumn{9}{|c|}{ Entire Phases } \\
\hline & \multicolumn{2}{|l|}{ Model 1} & \multicolumn{2}{|l|}{ Model 2} & \multicolumn{2}{|l|}{ Model 3} & \multicolumn{2}{|l|}{ Model 4} \\
\hline$\sigma_{I V_{i d i o, j, t}}$ & $\begin{array}{c}0.052717 \\
(24.628721)\end{array}$ & $* * *$ & --- & & --- & & $\begin{array}{c}0.043439 \\
(18.952235)\end{array}$ & $* * *$ \\
\hline$\sigma_{R V_{i d i o, j, t}}$ & $\begin{array}{c}0.602137 \\
(78.464664)\end{array}$ & $* * *$ & $\begin{array}{c}0.668999 \\
(99.537397)\end{array}$ & $* * *$ & $\begin{array}{c}0.681494 \\
(105.588409)\end{array}$ & $* * *$ & $\begin{array}{c}0.585328 \\
(75.559596)\end{array}$ & $* * *$ \\
\hline$\sigma_{E G_{i d i o, j, t}}$ & --- & & $\begin{array}{c}0.157237 \\
(17.583861)\end{array}$ & $* * *$ & --- & & $\begin{array}{c}0.046460 \\
(4.353744)\end{array}$ & $* * *$ \\
\hline$\sigma_{A R_{i d i o, j, t}}$ & --- & & --- & & $\begin{array}{c}0.122079 \\
(17.334804)\end{array}$ & $* * *$ & $\begin{array}{c}0.069443 \\
(8.625466)\end{array}$ & $* * *$ \\
\hline Constant & $\begin{array}{c}0.025023 \\
(33.069121)\end{array}$ & $* * *$ & $\begin{array}{c}0.017581 \\
(18.199957)\end{array}$ & $* * *$ & $\begin{array}{c}0.019261 \\
(21.080858)\end{array}$ & $* * *$ & $\begin{array}{c}0.017364 \\
(17.632372)\end{array}$ & $* * *$ \\
\hline$R$-Squared & 0.546186 & & 0.535741 & & 0.535428 & & 0.552005 & \\
\hline \multicolumn{9}{|c|}{ Phase 1} \\
\hline & Model 1 & & Model 2 & & Model 3 & & Model 4 & \\
\hline$\sigma_{I V_{i d i o, j, t}}$ & $\begin{array}{c}0.063727 \\
(14.435186)\end{array}$ & $* * *$ & --- & & --- & & $\begin{array}{c}0.056443 \\
(11.836860)\end{array}$ & $* * *$ \\
\hline$\sigma_{R V_{i d i o, j, t}}$ & $\begin{array}{c}0.448131 \\
(22.963050)\end{array}$ & $* * *$ & $\begin{array}{c}0.572890 \\
(33.788363)\end{array}$ & $* * *$ & $\begin{array}{c}0.583285 \\
(35.498092)\end{array}$ & $* * *$ & $\begin{array}{c}0.438638 \\
(22.351231)\end{array}$ & $* * *$ \\
\hline$\sigma_{E G_{i d i o, j, t}}$ & --- & & $\begin{array}{c}0.134976 \\
(7.894650)\end{array}$ & $* * *$ & --- & & $\begin{array}{c}0.029533 \\
(1.456816)\end{array}$ & \\
\hline$\sigma_{A R}$ idio,j,t & --- & & --- & & $\begin{array}{c}0.126267 \\
(7.964320)\end{array}$ & $* * *$ & $\begin{array}{c}0.050123 \\
(2.714075)\end{array}$ & $* * *$ \\
\hline Constant & $\begin{array}{c}0.042491 \\
(17.185809)\end{array}$ & $* * *$ & $\begin{array}{c}0.041756 \\
(15.220722)\end{array}$ & $* * *$ & $\begin{array}{c}0.042232 \\
(15.568010)\end{array}$ & $* * *$ & $\begin{array}{c}0.037839 \\
(13.921080)\end{array}$ & $* * *$ \\
\hline$R$-Squared & 0.446705 & & 0.414348 & & 0.414607 & & 0.450627 & \\
\hline
\end{tabular}




\begin{tabular}{|c|c|c|c|c|c|c|c|c|}
\hline \multicolumn{9}{|c|}{ Phase 2} \\
\hline & \multicolumn{2}{|l|}{ Model 1} & \multicolumn{2}{|l|}{ Model 2} & \multicolumn{2}{|l|}{ Model 3} & \multicolumn{2}{|l|}{ Model 4} \\
\hline$\sigma_{I V} i d i o, j, t$ & $\begin{array}{c}0.105157 \\
(30.345665)\end{array}$ & $* * *$ & --- & & --- & & $\begin{array}{c}0.080602 \\
(21.343083)\end{array}$ & $* * *$ \\
\hline$\sigma_{R V_{i d i o, j, t}}$ & $\begin{array}{c}0.299788 \\
(24.514509)\end{array}$ & $* * *$ & $\begin{array}{c}0.414081 \\
(36.665194)\end{array}$ & $* * *$ & $\begin{array}{c}0.395033 \\
(35.208910)\end{array}$ & $* * *$ & $\begin{array}{c}0.259562 \\
(21.085349)\end{array}$ & $* * *$ \\
\hline$\sigma_{E G_{i d i o, j, t}}$ & --- & & $\begin{array}{c}0.245802 \\
(21.441066)\end{array}$ & $* * *$ & --- & & $\begin{array}{c}0.056750 \\
(3.980641)\end{array}$ & $* * *$ \\
\hline$\sigma_{\text {AR }}$ idio,j,t & --- & & --- & & $\begin{array}{c}0.281930 \\
(24.806374)\end{array}$ & $* * *$ & $\begin{array}{c}0.143570 \\
(9.986782)\end{array}$ & $* * *$ \\
\hline Constant & $\begin{array}{c}0.035189 \\
(39.622279)\end{array}$ & $* * *$ & $\begin{array}{c}0.023622 \\
(20.906311)\end{array}$ & $* * *$ & $\begin{array}{c}0.019976 \\
(17.278444)\end{array}$ & $* * *$ & $\begin{array}{c}0.023401 \\
(20.024100)\end{array}$ & $* * *$ \\
\hline$R$-Squared & 0.379752 & & 0.337793 & & 0.352575 & & 0.401742 & \\
\hline \multicolumn{9}{|c|}{ Phase 3} \\
\hline & Model 1 & & Model 2 & & Model 3 & & Model 4 & \\
\hline$\sigma_{I V_{i d i o, j, t}}$ & $\begin{array}{c}0.004877 \\
(0.437120)\end{array}$ & & --- & & --- & & $\begin{array}{c}-0.011117 \\
(0.990900)\end{array}$ & \\
\hline$\sigma_{R V_{i d i o, j, t}}$ & $\begin{array}{c}0.731774 \\
(30.929730)\end{array}$ & $* * *$ & $\begin{array}{c}0.694246 \\
(33.252631)\end{array}$ & $* * *$ & $\begin{array}{c}0.690610 \\
(33.211494)\end{array}$ & $* * *$ & $\begin{array}{c}0.696922 \\
(29.222381)\end{array}$ & $* * *$ \\
\hline$\sigma_{E G_{i d i o, j, t}}$ & --- & & $\begin{array}{c}0.284499 \\
(5.919450)\end{array}$ & $* * *$ & --- & & $\begin{array}{c}0.122862 \\
(1.732100)\end{array}$ & $*$ \\
\hline$\sigma_{A R}$ idio, $j, t$ & --- & & --- & & $\begin{array}{c}0.328648 \\
(6.502343)\end{array}$ & $* * *$ & $\begin{array}{c}0.243728 \\
(3.240732)\end{array}$ & $* * *$ \\
\hline Constant & $\begin{array}{c}0.044778 \\
(11.882010)\end{array}$ & $* * *$ & $\begin{array}{c}0.023963 \\
(4.787198)\end{array}$ & $* * *$ & $\begin{array}{c}0.018237 \\
(3.367776)\end{array}$ & $* * *$ & $\begin{array}{c}0.017379 \\
(3.166310)\end{array}$ & $* * *$ \\
\hline$R$-Squared & 0.521515 & & 0.534301 & & 0.536873 & & 0.538275 & \\
\hline \multicolumn{9}{|c|}{ Phase 4} \\
\hline & Model 1 & & Model 2 & & Model 3 & & Model 4 & \\
\hline$\sigma_{I V} i d i o, j, t$ & $\begin{array}{c}0.048482 \\
(10.406975)\end{array}$ & $* * *$ & --- & & --- & & $\begin{array}{c}0.042051 \\
(8.870845)\end{array}$ & $* * *$ \\
\hline$\sigma_{R V_{i d i o, j, t}}$ & $\begin{array}{c}0.658955 \\
(47.381093)\end{array}$ & $* * *$ & $\begin{array}{c}0.694584 \\
(52.663975)\end{array}$ & $* * *$ & $\begin{array}{c}0.705236 \\
(57.292798)\end{array}$ & $* * *$ & $\begin{array}{c}0.626977 \\
(43.313179)\end{array}$ & $* * *$ \\
\hline$\sigma_{E G_{i d i o, j, t}}$ & --- & & $\begin{array}{c}0.141943 \\
(7.317373)\end{array}$ & $* * *$ & --- & & $\begin{array}{c}0.053180 \\
(2.540853)\end{array}$ & $* *$ \\
\hline$\sigma_{\text {AR idio }, j, t}$ & --- & & --- & & $\begin{array}{c}0.078586 \\
(8.572184)\end{array}$ & $* * *$ & $\begin{array}{c}0.060235 \\
(6.210033)\end{array}$ & $* * *$ \\
\hline Constant & $\begin{array}{c}0.016554 \\
(10.463008)\end{array}$ & $* * *$ & $\begin{array}{c}0.013741 \\
(7.206359)\end{array}$ & $* * *$ & $\begin{array}{c}0.017632 \\
(11.093779)\end{array}$ & $* * *$ & $\begin{array}{c}0.010424 \\
(5.515918)\end{array}$ & $* * *$ \\
\hline$R$-Squared & 0.621936 & & 0.613956 & & 0.616900 & & 0.631338 & \\
\hline
\end{tabular}


Table 11.8: Utilities Sector

\begin{tabular}{|c|c|c|c|c|c|c|c|c|}
\hline \multicolumn{9}{|c|}{ Entire Phases } \\
\hline & \multicolumn{2}{|l|}{ Model 1} & \multicolumn{2}{|l|}{ Model 2} & \multicolumn{2}{|l|}{ Model 3} & \multicolumn{2}{|l|}{ Model 4} \\
\hline$\sigma_{I V_{i d i o, j, t}}$ & $\begin{array}{c}0.068748 \\
(13.425003)\end{array}$ & $* * *$ & --- & & --- & & $\begin{array}{c}0.045288 \\
(7.791169)\end{array}$ & $* * *$ \\
\hline$\sigma_{R V_{i d i o, j, t}}$ & $\begin{array}{c}0.432968 \\
(17.991731)\end{array}$ & $* * *$ & $\begin{array}{c}0.501526 \\
(24.798878)\end{array}$ & $* * *$ & $\begin{array}{c}0.611351 \\
(34.688916)\end{array}$ & $* * *$ & $\begin{array}{c}0.394568 \\
(16.339281)\end{array}$ & $* * *$ \\
\hline$\sigma_{E G_{i d i o, j, t}}$ & --- & & $\begin{array}{c}0.343828 \\
(13.578201)\end{array}$ & $* * *$ & --- & & $\begin{array}{c}0.224331 \\
(6.738696)\end{array}$ & $* * *$ \\
\hline$\sigma_{A R_{i d i o, j, t}}$ & --- & & --- & & $\begin{array}{c}0.110136 \\
(8.741596)\end{array}$ & $* * *$ & $\begin{array}{c}0.007174 \\
(0.478323)\end{array}$ & \\
\hline Constant & $\begin{array}{c}0.018758 \\
(17.993245)\end{array}$ & $* * *$ & $\begin{array}{c}0.005301 \\
(4.284291)\end{array}$ & $* * *$ & $\begin{array}{c}0.012097 \\
(11.104482)\end{array}$ & $* * *$ & $\begin{array}{c}0.010922 \\
(7.744800)\end{array}$ & $* * *$ \\
\hline$R$-Squared & 0.557138 & & 0.558070 & & 0.532399 & & 0.572992 & \\
\hline \multicolumn{9}{|c|}{$\begin{array}{r}\text { Phase 1 } \\
\end{array}$} \\
\hline & Model 1 & & Model 2 & & Model 3 & & Model 4 & \\
\hline$\sigma_{I V} i d i o, j, t$ & $\begin{array}{c}0.099254 \\
(8.894467)\end{array}$ & $* * *$ & --- & & --- & & $\begin{array}{c}0.069797 \\
(5.561641)\end{array}$ & $* * *$ \\
\hline$\sigma_{R V_{i d i o, j, t}}$ & $\begin{array}{c}0.158301 \\
(2.599143)\end{array}$ & $* * *$ & $\begin{array}{c}0.296120 \\
(5.861629)\end{array}$ & $* * *$ & $\begin{array}{c}0.501518 \\
(11.546434)\end{array}$ & $* * *$ & $\begin{array}{c}0.079812 \\
(1.310290)\end{array}$ & \\
\hline$\sigma_{E G_{i d i o, j, t}}$ & --- & & $\begin{array}{c}0.541732 \\
(8.502573)\end{array}$ & $* * *$ & --- & & $\begin{array}{c}0.476447 \\
(5.032825)\end{array}$ & $* * *$ \\
\hline$\sigma_{A R}$ idio $, j, t$ & --- & & --- & & $\begin{array}{c}0.139141 \\
(4.727873)\end{array}$ & $* * *$ & $\begin{array}{l}-0.081513 \\
(2.110640)\end{array}$ & $* *$ \\
\hline Constant & $\begin{array}{c}0.041177 \\
(10.127328)\end{array}$ & $* * *$ & $\begin{array}{c}0.012474 \\
(2.806782)\end{array}$ & $* * *$ & $\begin{array}{c}0.026693 \\
(6.287810)\end{array}$ & $* * *$ & $\begin{array}{c}0.024385 \\
(4.824319)\end{array}$ & $* * *$ \\
\hline$R$-Squared & 0.509921 & & 0.501856 & & 0.433576 & & 0.547198 & \\
\hline \multicolumn{9}{|c|}{ Phase 2} \\
\hline & Model 1 & & Model 2 & & Model 3 & & Model 4 & \\
\hline$\sigma_{I V_{i d i o, j, t}}$ & $\begin{array}{c}0.077697 \\
(10.669588)\end{array}$ & $* * *$ & --- & & --- & & $\begin{array}{c}0.043662 \\
(5.432528)\end{array}$ & $* * *$ \\
\hline$\sigma_{R V_{i d i o, j, t}}$ & $\begin{array}{c}0.410538 \\
(12.899476)\end{array}$ & $* * *$ & $\begin{array}{c}0.414624 \\
(14.023171)\end{array}$ & $* * *$ & $\begin{array}{c}0.549132 \\
(21.114399)\end{array}$ & $* * *$ & $\begin{array}{c}0.295628 \\
(8.924499)\end{array}$ & $* * *$ \\
\hline$\sigma_{E G_{i d i o, j, t}}$ & --- & & $\begin{array}{c}0.308545 \\
(11.861401)\end{array}$ & $* * *$ & --- & & $\begin{array}{c}0.196266 \\
(6.619787)\end{array}$ & $* * *$ \\
\hline$\sigma_{A R_{i d i o, j, t}}$ & --- & & --- & & $\begin{array}{c}0.102273 \\
(7.928294)\end{array}$ & $* * *$ & $\begin{array}{c}0.055982 \\
(4.398349)\end{array}$ & $* * *$ \\
\hline Constant & $\begin{array}{c}0.015623 \\
(15.993581)\end{array}$ & $* * *$ & $\begin{array}{c}0.006436 \\
(6.261663)\end{array}$ & $* * *$ & $\begin{array}{c}0.011086 \\
(11.621115)\end{array}$ & $* * *$ & $\begin{array}{c}0.009895 \\
(8.417135)\end{array}$ & $* * *$ \\
\hline$R$-Squared & 0.567713 & & 0.578899 & & 0.544752 & & 0.603157 & \\
\hline \multicolumn{9}{|c|}{ Phase 3} \\
\hline & Model 1 & & Model 2 & & Model 3 & & Model 4 & \\
\hline$\sigma_{I V} i d i o, j, t$ & $\begin{array}{c}0.071361 \\
(2.039579)\end{array}$ & $* *$ & --- & & --- & & $\begin{array}{c}0.003032 \\
(0.070871)\end{array}$ & \\
\hline$\sigma_{R V_{i d i o, j, t}}$ & $\begin{array}{c}0.530702 \\
(5.776283)\end{array}$ & $* * *$ & $\begin{array}{c}0.617736 \\
(10.288051)\end{array}$ & $* * *$ & $\begin{array}{c}0.608018 \\
(10.354383)\end{array}$ & $* * *$ & $\begin{array}{c}0.597405 \\
(6.386094)\end{array}$ & $* * *$ \\
\hline$\sigma_{E G_{i d i o, j, t}}$ & --- & & $\begin{array}{c}0.474524 \\
(2.739913)\end{array}$ & $* * *$ & --- & & $\begin{array}{c}0.115128 \\
(0.465060)\end{array}$ & \\
\hline$\sigma_{A R_{i d i o, j, t}}$ & --- & & --- & & $\begin{array}{c}0.295457 \\
(3.475008)\end{array}$ & $* * *$ & $\begin{array}{c}0.251624 \\
(2.030510)\end{array}$ & $* *$ \\
\hline Constant & $\begin{array}{c}0.024796 \\
(5.523517)\end{array}$ & $* * *$ & $\begin{array}{c}0.005718 \\
(0.696889)\end{array}$ & & $\begin{array}{c}0.012621 \\
(2.259310)\end{array}$ & $* *$ & $\begin{array}{c}0.009824 \\
(1.053214)\end{array}$ & \\
\hline$R$-Squared & 0.458310 & & 0.468137 & & 0.480988 & & 0.481749 & \\
\hline
\end{tabular}




\begin{tabular}{|c|c|c|c|c|c|c|c|c|}
\hline \multicolumn{9}{|c|}{ Phase 4} \\
\hline & \multicolumn{2}{|c|}{ Model 1} & \multicolumn{2}{|c|}{ Model 2} & \multicolumn{2}{|l|}{ Model 3} & \multicolumn{2}{|l|}{ Model 4} \\
\hline$\sigma_{I V i d i o, j, t}$ & $\begin{array}{c}0.028395 \\
(3.253993)\end{array}$ & $* * *$ & --- & & --- & & $\begin{array}{c}0.021609 \\
(2.278190)\end{array}$ & $* *$ \\
\hline$\sigma_{R V i d i o, j, t}$ & $\begin{array}{c}0.614607 \\
(17.045880)\end{array}$ & $* * *$ & $\begin{array}{c}0.622701 \\
(17.539010)\end{array}$ & $* * *$ & $\begin{array}{c}0.654330 \\
(18.937829)\end{array}$ & $* * *$ & $\begin{array}{c}0.598812 \\
(16.041111)\end{array}$ & $* * *$ \\
\hline$\sigma_{E G_{i d i o, j, t}}$ & --- & & $\begin{array}{c}0.126693 \\
(3.018845)\end{array}$ & $* * *$ & --- & & $\begin{array}{c}0.091205 \\
(1.899422)\end{array}$ & $*$ \\
\hline$\sigma_{A R} i d i o, j, t$ & --- & & --- & & $\begin{array}{c}0.024949 \\
(1.090546)\end{array}$ & & $\begin{array}{l}-0.006666 \\
(0.272037)\end{array}$ & \\
\hline Constant & $\begin{array}{c}0.010908 \\
(6.263037)\end{array}$ & $* * *$ & $\begin{array}{c}0.008152 \\
(3.666127)\end{array}$ & $* * *$ & $\begin{array}{c}0.011717 \\
(6.271540)\end{array}$ & $* * *$ & $\begin{array}{c}0.008346 \\
(3.743393)\end{array}$ & $* * *$ \\
\hline$R$-Squared & 0.548320 & & 0.546500 & & 0.536468 & & 0.553040 & \\
\hline
\end{tabular}

$* * *, * *, *$ Statistical significant for 1,5 , and 10 percent levels 


\subsubsection{Realized returns}

In a following step we analyse in table 12 the predicting power of realized idiosyncratic volatility, other firm-specific characteristics and previous firm returns for every sectors and phases applied by monthly cross-sectional regressions using Fama-Macbeth (1973). As previously referred the variables SIZE and B/M ratio are calculated at the end of each month and the return variables are lagged 1, 11 and 36 months.

$r_{j, t+1}=\alpha_{j}+\lambda_{1} \sigma_{R V_{i d i o, j, t}}+\lambda_{2} \log S I Z E_{j, t}+\lambda_{3} \log B M_{j, t}+\lambda_{4} r_{j, t}+\lambda_{5} r_{j, t-11: t-1}+\lambda_{6} r_{j, t-35: t-12}+\lambda_{7} \beta_{j, t}+\varepsilon_{j, t+1}$

where, $r_{j, t}$ represents the stock return for firm for firm $j$ in month $t, \sigma_{R V \text { idio,j,t }}$, is the realized idiosyncratic volatility in month $t$ for firm $j, \log S I Z E_{j, t}$, is the logarithm of market value of equity (calculated by multiplying the company's current stock price by its number of outstanding shares.), $\log B M_{j, t}$, is the logarithm of the book-to-market ratio, $r_{j, t-11: t-1}$ and $r_{j, t-35: t-12}$, represents the stock return for firm $j$ one and three years before the current month, $\beta_{j, t}$, is firm $j$ equity Beta, $\alpha$ is the constant term, $\lambda$ 's estimated coefficients and $\varepsilon$ is the error term.

In results reported in tables 12.1 to 12.8 , does not show evidence of realized idiosyncratic volatility on firms realized returns. Although realized idiosyncratic volatility has a statistical significance at 1 percent level in only Services sector for every phases including entire phases, it is associated without certain direction both positive effect in Phase 1,2, and 4 and negative effect in Phase 3. Moreover, realized idiosyncratic volatilities for other sectors are statistical significance for only a few phases in each sector with no direction as well. Therefore, these cannot be employed to really predict their future stock returns. In terms of SIZE, B/M ratio, and Beta $(\beta)$, every sectors show statistical significance at different level both positive and negative effects in diffuse phases and cannot be summarized any certain direction. Our results are aligning with the ones from Ang et al. (2006) and Bali and Cakici (2007) in terms of the relation among future stock returns and idiosyncratic realized volatility. Additionally the return variables lagged 1 and 11 month $\left(r_{t}, r_{j, t-11: t-1}\right)$ cannot be found any certain direction to forecast the future return. $r_{t}$, shows a positive statistical significance in phase 2, 3, and 4 and a negative significant effect in Phase 1 for only Financial sector. Meanwhile, $r_{j, t-11: t-1}$ presents a positive statistical significance in phase 1, 3, and 4 and a negative significant effect in Phase 2 for only Technology sector. Eventually, we cannot find any measures in this model to really forecast future stock return for every sectors. 
Consequently, further study is applied to investigate other idiosyncratic volatilities for future stock return predictability other than realized idiosyncratic volatility.

Table 12: Fama-Macbeth Future returns estimation

Table 12.1: Basic Materials Sector

\begin{tabular}{|c|c|c|c|c|c|c|c|c|c|c|}
\hline Variables & \multicolumn{2}{|l|}{ Phase 1} & \multicolumn{2}{|l|}{ Phase 2} & \multicolumn{2}{|l|}{ Phase 3} & \multicolumn{2}{|l|}{ Phase 4} & \multicolumn{2}{|c|}{ Entire Phases } \\
\hline$\sigma_{R V \text { idio }}$ & 0.077439 & & 0.163238 & $* * *$ & 0.006669 & & -0.004126 & & -0.148661 & $* * *$ \\
\hline & (1.073010) & & (2.716673) & & $(0.087292)$ & & $(0.056856)$ & & $(5.087340)$ & \\
\hline $\log S I Z E$ & $\begin{array}{l}-0.008696 \\
(2.243466)\end{array}$ & $* *$ & $\begin{array}{c}0.000554 \\
(0.298822)\end{array}$ & & $\begin{array}{l}-0.005042 \\
(0.709581)\end{array}$ & & $\begin{array}{l}-0.009469 \\
(2.193948)\end{array}$ & $* *$ & $\begin{array}{l}-0.004255 \\
(2.656514)\end{array}$ & $* * *$ \\
\hline $\log B M$ & $\begin{array}{l}-0.004620 \\
(1.203364)\end{array}$ & & $\begin{array}{c}0.005716 \\
(2.910107)\end{array}$ & $* * *$ & $\begin{array}{l}-0.001392 \\
(0.181628)\end{array}$ & & $\begin{array}{c}0.005048 \\
(1.071141)\end{array}$ & & $\begin{array}{c}0.005780 \\
(3.317301)\end{array}$ & $* * *$ \\
\hline$r_{t}$ & $\begin{array}{c}-0.037609 \\
(1.294202)\end{array}$ & & $\begin{array}{c}-0.028002 \\
(1.572081)\end{array}$ & & $\begin{array}{c}0.263331 \\
(5.510294)\end{array}$ & $* * *$ & $\begin{array}{c}0.010866 \\
(0.393359)\end{array}$ & & $\begin{array}{c}0.058925 \\
(4.577868)\end{array}$ & $* * *$ \\
\hline$r_{j, t-11: t-1}$ & $\begin{array}{c}0.078212 \\
(3.026413)\end{array}$ & $* * *$ & $\begin{array}{l}-0.034139 \\
(2.109320)\end{array}$ & $* *$ & $\begin{array}{l}-0.043936 \\
(0.522147)\end{array}$ & & $\begin{array}{c}0.024073 \\
(1.055159)\end{array}$ & & $\begin{array}{c}0.009474 \\
(0.778085)\end{array}$ & \\
\hline$r_{j, t-35: t-12}$ & $\begin{array}{c}0.078012 \\
(3.548666)\end{array}$ & $* * *$ & $\begin{array}{l}-0.005569 \\
(0.399845)\end{array}$ & & $\begin{array}{c}0.136213 \\
(1.966599)\end{array}$ & $* *$ & $\begin{array}{l}-0.089159 \\
(2.042512)\end{array}$ & $* *$ & $\begin{array}{c}0.018164 \\
(1.455133)\end{array}$ & \\
\hline$\beta_{j}$ & $\begin{array}{c}-0.016113 \\
(1.561954)\end{array}$ & & $\begin{array}{l}-0.000570 \\
(0.174218)\end{array}$ & & $\begin{array}{c}0.008456 \\
(0.736006)\end{array}$ & & $\begin{array}{c}0.005233 \\
(0.630182)\end{array}$ & & $\begin{array}{c}0.005115 \\
(1.755017)\end{array}$ & $*$ \\
\hline Constant & $\begin{array}{c}0.134265 \\
(2.251674)\end{array}$ & $* *$ & $\begin{array}{c}0.007218 \\
(0.246557)\end{array}$ & & $\begin{array}{c}0.033629 \\
(0.293961)\end{array}$ & & $\begin{array}{c}0.178123 \\
(2.460644)\end{array}$ & $* *$ & $\begin{array}{c}0.087789 \\
(3.518895)\end{array}$ & $* * *$ \\
\hline$R$-Squared & 0.026262 & & 0.013133 & & 0.063014 & & 0.023411 & & 0.015855 & \\
\hline
\end{tabular}

***,**** Statistical significant for 1,5 , and 10 percent levels

Table 12.2: Consumer Goods Sector

\begin{tabular}{|c|c|c|c|c|c|c|c|c|c|c|}
\hline Variables & \multicolumn{2}{|l|}{ Phase 1} & \multicolumn{2}{|l|}{ Phase 2} & \multicolumn{2}{|l|}{ Phase 3} & \multicolumn{2}{|l|}{ Phase 4} & \multicolumn{2}{|c|}{ Entire Phases } \\
\hline$\sigma_{R V \text { idio }}$ & $\begin{array}{c}0.598987 \\
(6.806798)\end{array}$ & $* * *$ & $\begin{array}{c}0.170222 \\
(3.325476)\end{array}$ & $* * *$ & $\begin{array}{l}-0.274735 \\
(3.572008)\end{array}$ & $* * *$ & $\begin{array}{c}0.070367 \\
(0.908090)\end{array}$ & & $\begin{array}{c}0.007323 \\
(0.243390)\end{array}$ & \\
\hline $\log S I Z E$ & $\begin{array}{l}-0.006674 \\
(2.026652)\end{array}$ & $* *$ & $\begin{array}{c}0.000899 \\
(0.813847)\end{array}$ & & $\begin{array}{l}-0.002949 \\
(0.693553)\end{array}$ & & $\begin{array}{l}-0.001946 \\
(0.701957)\end{array}$ & & $\begin{array}{l}-0.002268 \\
(2.078860)\end{array}$ & $* *$ \\
\hline $\log B M$ & $\begin{array}{l}-0.002675 \\
(0.710203)\end{array}$ & & $\begin{array}{c}0.000861 \\
(0.744406)\end{array}$ & & $\begin{array}{c}0.004321 \\
(0.953496)\end{array}$ & & $\begin{array}{c}0.002118 \\
(0.779836)\end{array}$ & & $\begin{array}{c}0.001745 \\
(1.525108)\end{array}$ & \\
\hline$r_{t}$ & $\begin{array}{c}0.005761 \\
(0.221592)\end{array}$ & & $\begin{array}{c}0.033879 \\
(2.009579)\end{array}$ & $* *$ & $\begin{array}{l}-0.064579 \\
(1.442185)\end{array}$ & & $\begin{array}{c}-0.013969 \\
(0.530192)\end{array}$ & & $\begin{array}{c}0.039085 \\
(3.274802)\end{array}$ & $* * *$ \\
\hline$r_{j, t-11: t-1}$ & $\begin{array}{c}0.125304 \\
(5.352890)\end{array}$ & $* * *$ & $\begin{array}{c}-0.037055 \\
(2.457857)\end{array}$ & $* *$ & $\begin{array}{l}-0.041533 \\
(0.581482)\end{array}$ & & $\begin{array}{c}0.177851 \\
(7.607655)\end{array}$ & $* * *$ & $\begin{array}{c}0.096492 \\
(8.495134)\end{array}$ & $* * *$ \\
\hline$r_{j, t-35: t-12}$ & $\begin{array}{c}0.048194 \\
(1.744324)\end{array}$ & $*$ & $\begin{array}{c}0.055107 \\
(5.018299)\end{array}$ & $* * *$ & $\begin{array}{l}-0.057245 \\
(0.766089)\end{array}$ & & $\begin{array}{c}-0.015766 \\
(0.318358)\end{array}$ & & $\begin{array}{c}0.037709 \\
(3.106423)\end{array}$ & $* * *$ \\
\hline$\beta_{j}$ & $\begin{array}{l}-0.027448 \\
(3.228892)\end{array}$ & $* * *$ & $\begin{array}{l}-0.001864 \\
(0.730560)\end{array}$ & & $\begin{array}{l}-0.003853 \\
(0.373071)\end{array}$ & & $\begin{array}{c}0.016783 \\
(2.572988)\end{array}$ & $* *$ & $\begin{array}{c}0.003341 \\
(1.358761)\end{array}$ & \\
\hline Constant & $\begin{array}{c}0.074023 \\
(1.460442)\end{array}$ & & $\begin{array}{c}-0.011636 \\
(0.656127)\end{array}$ & & $\begin{array}{c}0.050105 \\
(0.731522)\end{array}$ & & $\begin{array}{c}0.035725 \\
(0.776406)\end{array}$ & & $\begin{array}{c}0.041233 \\
(2.372815)\end{array}$ & $* *$ \\
\hline$R$-Squared & 0.074663 & & 0.014126 & & 0.022254 & & 0.057201 & & 0.018459 & \\
\hline
\end{tabular}

***,**** Statistical significant for 1,5 , and 10 percent levels 
Table 12.3: Financial Sector

\begin{tabular}{|c|c|c|c|c|c|c|c|c|c|c|}
\hline Variables & \multicolumn{2}{|l|}{ Phase 1} & \multicolumn{2}{|l|}{ Phase 2} & \multicolumn{2}{|l|}{ Phase 3} & \multicolumn{2}{|l|}{ Phase 4} & \multicolumn{2}{|c|}{ Entire Phases } \\
\hline$\sigma_{R V \text { idio }}$ & $\begin{array}{c}0.103957 \\
(1.476488)\end{array}$ & & $\begin{array}{c}0.125865 \\
(2.913068)\end{array}$ & $* * *$ & $\begin{array}{c}-0.084144 \\
(1.364013)\end{array}$ & & $\begin{array}{c}0.078321 \\
(1.618189)\end{array}$ & & $\begin{array}{l}-0.019519 \\
(0.956957)\end{array}$ & \\
\hline $\log S I Z E$ & $\begin{array}{l}-0.008532 \\
(3.378187)\end{array}$ & $* * *$ & $\begin{array}{l}-0.002638 \\
(2.211196)\end{array}$ & $* *$ & $\begin{array}{l}-0.009608 \\
(1.478296)\end{array}$ & & $\begin{array}{l}-0.008690 \\
(1.957707)\end{array}$ & $*$ & $\begin{array}{l}-0.006139 \\
(4.483244)\end{array}$ & $* * *$ \\
\hline $\log B M$ & $\begin{array}{c}-0.002095 \\
(0.872675)\end{array}$ & & $\begin{array}{c}-0.000946 \\
(0.821781)\end{array}$ & & $\begin{array}{c}0.005732 \\
(0.957860)\end{array}$ & & $\begin{array}{c}0.001550 \\
(0.375132)\end{array}$ & & $\begin{array}{c}0.000910 \\
(0.706326)\end{array}$ & \\
\hline$r_{t}$ & $\begin{array}{l}-0.104835 \\
(3.788195)\end{array}$ & $* * *$ & $\begin{array}{c}0.061796 \\
(3.529046)\end{array}$ & $* * *$ & $\begin{array}{c}0.078002 \\
(1.775792)\end{array}$ & $*$ & $\begin{array}{c}0.075945 \\
(2.865853)\end{array}$ & $* * *$ & $\begin{array}{c}0.072688 \\
(5.931281)\end{array}$ & $* * *$ \\
\hline$r_{j, t-11: t-1}$ & $\begin{array}{c}0.001701 \\
(0.080087)\end{array}$ & & $\begin{array}{l}-0.050830 \\
(3.107892)\end{array}$ & $* * *$ & $\begin{array}{c}0.131405 \\
(1.428376)\end{array}$ & & $\begin{array}{c}0.083392 \\
(3.619610)\end{array}$ & $* * *$ & $\begin{array}{c}0.041654 \\
(3.505862)\end{array}$ & $* * *$ \\
\hline$r_{j, t-35: t-12}$ & $\begin{array}{c}0.027758 \\
(1.395309)\end{array}$ & & $\begin{array}{c}0.006092 \\
(0.514408)\end{array}$ & & $\begin{array}{c}-0.262668 \\
(2.121681)\end{array}$ & $* *$ & $\begin{array}{c}-0.114190 \\
(1.675224)\end{array}$ & $*$ & $\begin{array}{c}-0.012586 \\
(0.871440)\end{array}$ & \\
\hline$\beta_{j}$ & $\begin{array}{l}-0.011452 \\
(2.067934)\end{array}$ & $* *$ & $\begin{array}{c}0.002093 \\
(0.962622)\end{array}$ & & $\begin{array}{c}0.052332 \\
(3.474923)\end{array}$ & $* * *$ & $\begin{array}{c}0.024050 \\
(3.577562)\end{array}$ & $* * *$ & $\begin{array}{c}0.014223 \\
(5.930046)\end{array}$ & $* * *$ \\
\hline Constant & $\begin{array}{c}0.129969 \\
(3.236519)\end{array}$ & $* * *$ & $\begin{array}{c}0.041993 \\
(2.180871)\end{array}$ & $* *$ & $\begin{array}{c}0.076748 \\
(0.712669)\end{array}$ & & $\begin{array}{c}0.113457 \\
(1.589098)\end{array}$ & & $\begin{array}{c}0.088913 \\
(4.079734)\end{array}$ & $* * *$ \\
\hline$R$-Squared & 0.028381 & & 0.012318 & & 0.042346 & & 0.039989 & & 0.018836 & \\
\hline
\end{tabular}

***,**,* Statistical significant for 1,5 , and 10 percent levels

Table 12.4: Healthcare Sector

\begin{tabular}{|c|c|c|c|c|c|c|c|c|c|c|}
\hline \multirow{2}{*}{$\begin{array}{c}\text { Variables } \\
\sigma_{R V_{\text {idio }}}\end{array}$} & \multirow{2}{*}{$\begin{array}{r}\text { Phase 1 } \\
-0.025005 \\
(0.269757)\end{array}$} & & \multirow{2}{*}{$\begin{array}{r}\text { Phase 2 } \\
-0.013484 \\
(0.256317)\end{array}$} & & \multicolumn{2}{|l|}{ Phase 3} & \multirow{2}{*}{$\begin{array}{c}\text { Phase 4 } \\
0.063641 \\
(0.787274)\end{array}$} & & \multicolumn{2}{|c|}{ Entire Phases } \\
\hline & & & & & $\begin{array}{c}-0.267338 \\
(2.949650)\end{array}$ & $* * *$ & & & $\begin{array}{l}-0.103266 \\
(3.081032)\end{array}$ & $* * *$ \\
\hline $\log S I Z E$ & $\begin{array}{c}-0.006775 \\
(1.476500)\end{array}$ & & $\begin{array}{c}-0.003782 \\
(1.770089)\end{array}$ & $*$ & $\begin{array}{c}0.002880 \\
(0.575191)\end{array}$ & & $\begin{array}{c}-0.007098 \\
(2.307367)\end{array}$ & $* *$ & $\begin{array}{l}-0.004956 \\
(3.174711)\end{array}$ & $* * *$ \\
\hline $\log B M$ & $\begin{array}{c}-0.000144 \\
(0.036240)\end{array}$ & & $\begin{array}{c}0.002881 \\
(1.580252)\end{array}$ & & $\begin{array}{c}0.006561 \\
(1.357768)\end{array}$ & & $\begin{array}{c}0.000500 \\
(0.185963)\end{array}$ & & $\begin{array}{c}0.002709 \\
(2.006412)\end{array}$ & $* *$ \\
\hline$r_{t}$ & $\begin{array}{c}-0.049077 \\
(1.635759)\end{array}$ & & $\begin{array}{c}0.036342 \\
(1.925261)\end{array}$ & $*$ & $\begin{array}{c}0.039687 \\
(0.832180)\end{array}$ & & $\begin{array}{c}-0.023083 \\
(0.779421)\end{array}$ & & $\begin{array}{c}0.026730 \\
(2.035170)\end{array}$ & $* *$ \\
\hline$r_{j, t-11: t-1}$ & $\begin{array}{l}-0.024520 \\
(1.426319)\end{array}$ & & $\begin{array}{l}-0.070539 \\
(3.973511)\end{array}$ & $* * *$ & $\begin{array}{l}-0.164243 \\
(3.264366)\end{array}$ & $* * *$ & $\begin{array}{c}0.049603 \\
(1.971424)\end{array}$ & $* *$ & $\begin{array}{l}-0.037919 \\
(3.586906)\end{array}$ & $* * *$ \\
\hline$r_{j, t-35: t-12}$ & $\begin{array}{l}-0.055420 \\
(2.783262)\end{array}$ & $* * *$ & $\begin{array}{c}-0.045927 \\
(3.997106)\end{array}$ & $* * *$ & $\begin{array}{c}0.176474 \\
(3.361637)\end{array}$ & $* * *$ & $\begin{array}{l}-0.046451 \\
(1.353117)\end{array}$ & & $\begin{array}{l}-0.043605 \\
(4.587470)\end{array}$ & $* * *$ \\
\hline$\beta_{j}$ & $\begin{array}{c}-0.013793 \\
(1.723191)\end{array}$ & $*$ & $\begin{array}{c}-0.000864 \\
(0.251841)\end{array}$ & & $\begin{array}{c}0.016394 \\
(1.466510)\end{array}$ & & $\begin{array}{c}0.018766 \\
(1.992195)\end{array}$ & $* *$ & $\begin{array}{l}-0.000335 \\
(0.118514)\end{array}$ & \\
\hline Constant & $\begin{array}{c}0.116256 \\
(1.566365)\end{array}$ & & $\begin{array}{c}0.076047 \\
(2.156939)\end{array}$ & $* *$ & $\begin{array}{c}-0.055136 \\
(0.657372)\end{array}$ & & $\begin{array}{c}0.112898 \\
(2.100693)\end{array}$ & $* *$ & $\begin{array}{c}0.095232 \\
(3.667918)\end{array}$ & $* * *$ \\
\hline$R$-Squared & 0.017818 & & 0.018630 & & 0.061094 & & 0.034415 & & 0.013853 & \\
\hline
\end{tabular}

***,**,* Statistical significant for 1,5 , and 10 percent levels 
Table 12.5: Industrial Goods Sector

\begin{tabular}{|c|c|c|c|c|c|c|c|c|c|c|}
\hline Variables & \multicolumn{2}{|c|}{ Phase 1} & \multicolumn{2}{|c|}{ Phase 2} & \multicolumn{2}{|c|}{ Phase 3} & \multicolumn{2}{|c|}{ Phase 4} & \multicolumn{2}{|c|}{ Entire Phases } \\
\hline$\sigma_{R V \text { idio }}$ & $\begin{array}{c}0.257336 \\
(2.502342)\end{array}$ & $* *$ & $\begin{array}{c}0.109086 \\
(1.794454)\end{array}$ & $*$ & $\begin{array}{l}-0.193639 \\
(2.235019)\end{array}$ & $* *$ & $\begin{array}{c}0.008460 \\
(0.103046)\end{array}$ & & $\begin{array}{l}-0.083949 \\
(2.509880)\end{array}$ & $* *$ \\
\hline $\log S I Z E$ & $\begin{array}{c}-0.000621 \\
(0.147650)\end{array}$ & & $\begin{array}{l}-0.004837 \\
(2.578656)\end{array}$ & $* * *$ & $\begin{array}{c}-0.010436 \\
(1.525149)\end{array}$ & & $\begin{array}{l}-0.003572 \\
(0.814724)\end{array}$ & & $\begin{array}{l}-0.004927 \\
(3.015783)\end{array}$ & $* * *$ \\
\hline $\log B M$ & $\begin{array}{c}0.000726 \\
(0.155577)\end{array}$ & & $\begin{array}{c}0.003141 \\
(1.617291)\end{array}$ & & $\begin{array}{c}0.003569 \\
(0.470778)\end{array}$ & & $\begin{array}{c}0.004522 \\
(0.976954)\end{array}$ & & $\begin{array}{c}0.005171 \\
(2.892764)\end{array}$ & $* * *$ \\
\hline$r_{t}$ & $\begin{array}{c}0.027420 \\
(0.845353)\end{array}$ & & $\begin{array}{c}0.095850 \\
(4.886130)\end{array}$ & $* * *$ & $\begin{array}{c}0.046366 \\
(0.861713)\end{array}$ & & $\begin{array}{l}-0.010577 \\
(0.346255)\end{array}$ & & $\begin{array}{c}0.062324 \\
(4.389938)\end{array}$ & $* * *$ \\
\hline$r_{j, t-11: t-1}$ & $\begin{array}{c}0.084746 \\
(2.817032)\end{array}$ & $* * *$ & $\begin{array}{c}-0.068459 \\
(3.799224)\end{array}$ & $* * *$ & $\begin{array}{c}-0.048621 \\
(0.555117)\end{array}$ & & $\begin{array}{c}0.162239 \\
(6.027066)\end{array}$ & $* * *$ & $\begin{array}{c}0.055228 \\
(4.032812)\end{array}$ & $* * *$ \\
\hline$r_{j, t-35: t-12}$ & $\begin{array}{c}0.064517 \\
(1.994861)\end{array}$ & $* *$ & $\begin{array}{c}-0.013729 \\
(0.933519)\end{array}$ & & $\begin{array}{c}0.102170 \\
(1.168980)\end{array}$ & & $\begin{array}{c}-0.103236 \\
(1.802153)\end{array}$ & $*$ & $\begin{array}{c}-0.001862 \\
(0.125351)\end{array}$ & \\
\hline$\beta_{j}$ & $\begin{array}{c}-0.021670 \\
(1.894783)\end{array}$ & $*$ & $\begin{array}{c}-0.006888 \\
(2.303262)\end{array}$ & $* *$ & $\begin{array}{c}0.010743 \\
(0.850278)\end{array}$ & & $\begin{array}{c}0.015553 \\
(1.741356)\end{array}$ & $*$ & $\begin{array}{c}0.001710 \\
(0.602065)\end{array}$ & \\
\hline Constant & $\begin{array}{c}0.001423 \\
(0.020854)\end{array}$ & & $\begin{array}{c}0.093545 \\
(2.980315)\end{array}$ & $* * *$ & $\begin{array}{c}0.142980 \\
(1.234583)\end{array}$ & & $\begin{array}{c}0.060965 \\
(0.828267)\end{array}$ & & $\begin{array}{c}0.092475 \\
(3.456590)\end{array}$ & $* * *$ \\
\hline$R$-Squared & 0.025668 & & 0.031756 & & 0.025669 & & 0.050560 & & 0.016926 & \\
\hline
\end{tabular}

***,**,* Statistical significant for 1,5 , and 10 percent levels

Table 12.6: Services Sector

\begin{tabular}{|c|c|c|c|c|c|c|c|c|c|c|}
\hline \multirow{2}{*}{$\begin{array}{c}\text { Variables } \\
\sigma_{R V_{\text {idio }}}\end{array}$} & \multicolumn{2}{|c|}{ Phase 1} & \multicolumn{2}{|c|}{ Phase 2} & \multicolumn{2}{|c|}{ Phase 3} & \multicolumn{2}{|c|}{ Phase 4} & \multicolumn{2}{|c|}{ Entire Phases } \\
\hline & $\begin{array}{c}0.264364 \\
(4.210547)\end{array}$ & $* * *$ & $\begin{array}{c}0.171454 \\
(4.474419)\end{array}$ & $* * *$ & $\begin{array}{c}-0.255601 \\
(4.804743)\end{array}$ & $* * *$ & $\begin{array}{c}0.531439 \\
(11.915108)\end{array}$ & $* * *$ & $\begin{array}{c}0.103061 \\
(5.139128)\end{array}$ & $* * *$ \\
\hline $\log S I Z E$ & $\begin{array}{c}-0.007743 \\
(2.630355)\end{array}$ & $* * *$ & $\begin{array}{c}-0.000163 \\
(0.133919)\end{array}$ & & $\begin{array}{c}-0.000909 \\
(0.224049)\end{array}$ & & $\begin{array}{l}-0.001300 \\
(0.424517)\end{array}$ & & $\begin{array}{l}-0.002105 \\
(1.855930)\end{array}$ & $*$ \\
\hline $\log B M$ & $\begin{array}{c}0.000996 \\
(0.323328)\end{array}$ & & $\begin{array}{c}0.004334 \\
(3.221722)\end{array}$ & $* * *$ & $\begin{array}{c}0.004666 \\
(1.097166)\end{array}$ & & $\begin{array}{c}0.004387 \\
(1.327289)\end{array}$ & & $\begin{array}{c}0.005565 \\
(4.508628)\end{array}$ & $* * *$ \\
\hline$r_{t}$ & $\begin{array}{c}-0.010238 \\
(0.517188)\end{array}$ & & $\begin{array}{c}0.045054 \\
(3.585170)\end{array}$ & $* * *$ & $\begin{array}{c}0.034646 \\
(1.023123)\end{array}$ & & $\begin{array}{c}0.015878 \\
(0.822427)\end{array}$ & & $\begin{array}{c}0.071272 \\
(8.040593)\end{array}$ & $* * *$ \\
\hline$r_{j, t-11: t-1}$ & $\begin{array}{l}-0.016577 \\
(0.992962)\end{array}$ & & $\begin{array}{l}-0.034119 \\
(2.997048)\end{array}$ & $* * *$ & $\begin{array}{c}0.074909 \\
(1.455359)\end{array}$ & & $\begin{array}{c}0.119734 \\
(7.025965)\end{array}$ & $* * *$ & $\begin{array}{c}0.035796 \\
(4.291427)\end{array}$ & $* * *$ \\
\hline$r_{j, t-35: t-12}$ & $\begin{array}{c}0.064137 \\
(3.359077)\end{array}$ & $* * *$ & $\begin{array}{c}-0.000242 \\
(0.029302)\end{array}$ & & $\begin{array}{l}-0.061417 \\
(1.174310)\end{array}$ & & $\begin{array}{c}-0.065700 \\
(1.786296)\end{array}$ & $*$ & $\begin{array}{l}-0.000850 \\
(0.096894)\end{array}$ & \\
\hline$\beta_{j}$ & $\begin{array}{l}-0.019945 \\
(3.613767)\end{array}$ & $* * *$ & $\begin{array}{c}-0.001867 \\
(1.070040)\end{array}$ & & $\begin{array}{l}-0.001499 \\
(0.172503)\end{array}$ & & $\begin{array}{l}-0.000162 \\
(0.034028)\end{array}$ & & $\begin{array}{c}0.001534 \\
(0.872707)\end{array}$ & \\
\hline Constant & $\begin{array}{c}0.111348 \\
(2.457221)\end{array}$ & $* *$ & $\begin{array}{c}0.007788 \\
(0.405123)\end{array}$ & & $\begin{array}{c}0.022106 \\
(0.331435)\end{array}$ & & $\begin{array}{c}0.001857 \\
(0.037962)\end{array}$ & & $\begin{array}{c}0.033690 \\
(1.897452)\end{array}$ & $*$ \\
\hline$R$-Squared & 0.024348 & & 0.012475 & & 0.033098 & & 0.102978 & & 0.017504 & \\
\hline
\end{tabular}

***,**,* Statistical significant for 1,5 , and 10 percent levels 
Table 12.7: Technology Sector

\begin{tabular}{|c|c|c|c|c|c|c|c|c|c|c|}
\hline Variables & \multicolumn{2}{|c|}{ Phase 1} & \multicolumn{2}{|c|}{ Phase 2} & \multicolumn{2}{|l|}{ Phase 3} & \multicolumn{2}{|c|}{ Phase 4} & \multicolumn{2}{|c|}{ Entire Phases } \\
\hline$\sigma_{R V \text { idio }}$ & $\begin{array}{c}0.519852 \\
(7.370121)\end{array}$ & $* * *$ & $\begin{array}{c}0.244933 \\
(6.503414)\end{array}$ & $* * *$ & $\begin{array}{c}-0.029798 \\
(0.545018)\end{array}$ & & $\begin{array}{c}0.170761 \\
(3.747754)\end{array}$ & $* * *$ & $\begin{array}{c}0.031572 \\
(1.525295)\end{array}$ & \\
\hline $\log S I Z E$ & $\begin{array}{l}-0.000617 \\
(0.140012)\end{array}$ & & $\begin{array}{l}-0.000921 \\
(0.659326)\end{array}$ & & $\begin{array}{c}0.000561 \\
(0.105902)\end{array}$ & & $\begin{array}{l}-0.000231 \\
(0.081067)\end{array}$ & & $\begin{array}{c}-0.001655 \\
(1.219190)\end{array}$ & \\
\hline $\log B M$ & $\begin{array}{c}0.007318 \\
(1.553795)\end{array}$ & & $\begin{array}{c}0.000415 \\
(0.287255)\end{array}$ & & $\begin{array}{c}0.004259 \\
(0.768393)\end{array}$ & & $\begin{array}{c}0.006039 \\
(2.021207)\end{array}$ & $* *$ & $\begin{array}{c}0.004133 \\
(2.918110)\end{array}$ & $* * *$ \\
\hline$r_{t}$ & $\begin{array}{c}-0.097658 \\
(5.129968)\end{array}$ & $* * *$ & $\begin{array}{c}-0.003954 \\
(0.323117)\end{array}$ & & $\begin{array}{c}0.043526 \\
(1.121586)\end{array}$ & & $\begin{array}{l}-0.049027 \\
(2.767705)\end{array}$ & $* * *$ & $\begin{array}{c}-0.014521 \\
(1.668825)\end{array}$ & $*$ \\
\hline$r_{j, t-11: t-1}$ & $\begin{array}{c}0.033193 \\
(1.978314)\end{array}$ & $* *$ & $\begin{array}{l}-0.041606 \\
(4.166624)\end{array}$ & $* * *$ & $\begin{array}{c}0.223156 \\
(3.692538)\end{array}$ & $* * *$ & $\begin{array}{c}0.064634 \\
(4.189948)\end{array}$ & $* * *$ & $\begin{array}{c}0.021541 \\
(2.753735)\end{array}$ & $* * *$ \\
\hline$r_{j, t-35: t-12}$ & $\begin{array}{c}0.068272 \\
(3.195154)\end{array}$ & $* * *$ & $\begin{array}{c}-0.002815 \\
(0.405504)\end{array}$ & & $\begin{array}{c}0.049076 \\
(1.053129)\end{array}$ & & $\begin{array}{c}-0.095754 \\
(3.258633)\end{array}$ & $* * *$ & $\begin{array}{c}0.004663 \\
(0.617727)\end{array}$ & \\
\hline$\beta_{j}$ & $\begin{array}{l}-0.034228 \\
(4.819517)\end{array}$ & $* * *$ & $\begin{array}{l}-0.003987 \\
(2.175952)\end{array}$ & $* *$ & $\begin{array}{c}0.017933 \\
(2.178850)\end{array}$ & $* *$ & $\begin{array}{c}0.006175 \\
(1.128239)\end{array}$ & & $\begin{array}{c}-0.001064 \\
(0.619534)\end{array}$ & \\
\hline Constant & $\begin{array}{l}-0.019107 \\
(0.285033)\end{array}$ & & $\begin{array}{c}0.018218 \\
(0.823316)\end{array}$ & & $\begin{array}{c}-0.071401 \\
(0.851863)\end{array}$ & & $\begin{array}{c}0.013051 \\
(0.287085)\end{array}$ & & $\begin{array}{c}0.032187 \\
(1.513573)\end{array}$ & \\
\hline$R$-Squared & 0.043527 & & 0.010820 & & 0.022432 & & 0.035417 & & 0.005734 & \\
\hline
\end{tabular}

***,**,* Statistical significant for 1,5 , and 10 percent levels

Table 12.8: Utilities Sector

\begin{tabular}{|c|c|c|c|c|c|c|c|c|c|c|}
\hline \multirow{2}{*}{$\begin{array}{c}\text { Variables } \\
\sigma_{R V_{\text {idio }}}\end{array}$} & \multicolumn{2}{|c|}{ Phase 1} & \multicolumn{2}{|l|}{ Phase 2} & \multicolumn{2}{|l|}{ Phase 3} & \multicolumn{2}{|l|}{ Phase 4} & \multicolumn{2}{|c|}{ Entire Phases } \\
\hline & $\begin{array}{c}0.350178 \\
(2.839120)\end{array}$ & $* * *$ & $\begin{array}{c}0.052818 \\
(0.560215)\end{array}$ & & $\begin{array}{c}0.211050 \\
(1.762322)\end{array}$ & $*$ & $\begin{array}{c}0.128001 \\
(0.871011)\end{array}$ & & $\begin{array}{c}0.081683 \\
(1.748519)\end{array}$ & $*$ \\
\hline $\log S I Z E$ & $\begin{array}{c}0.002239 \\
(0.204981)\end{array}$ & & $\begin{array}{c}0.006454 \\
(1.662421)\end{array}$ & $*$ & $\begin{array}{c}0.009535 \\
(0.971947)\end{array}$ & & $\begin{array}{l}-0.004690 \\
(0.725629)\end{array}$ & & $\begin{array}{c}0.004451 \\
(1.348569)\end{array}$ & \\
\hline $\log B M$ & $\begin{array}{c}0.049100 \\
(2.640906)\end{array}$ & $* * *$ & $\begin{array}{c}0.034196 \\
(4.183153)\end{array}$ & $* * *$ & $\begin{array}{c}0.027590 \\
(1.554631)\end{array}$ & & $\begin{array}{c}0.023196 \\
(1.869152)\end{array}$ & $*$ & $\begin{array}{c}0.037186 \\
(6.050723)\end{array}$ & $* * *$ \\
\hline$r_{t}$ & $\begin{array}{c}-0.074348 \\
(1.338292)\end{array}$ & & $\begin{array}{c}0.226399 \\
(6.982309)\end{array}$ & $* * *$ & $\begin{array}{c}0.264114 \\
(3.143349)\end{array}$ & $* * *$ & $\begin{array}{c}0.109753 \\
(2.035960)\end{array}$ & $* *$ & $\begin{array}{c}0.096659 \\
(4.028566)\end{array}$ & $* * *$ \\
\hline$r_{j, t-11: t-1}$ & $\begin{array}{l}-0.001831 \\
(0.032318)\end{array}$ & & $\begin{array}{c}-0.014222 \\
(0.617234)\end{array}$ & & $\begin{array}{c}0.129796 \\
(1.196510)\end{array}$ & & $\begin{array}{c}0.141493 \\
(3.128605)\end{array}$ & $* * *$ & $\begin{array}{c}0.013248 \\
(0.621354)\end{array}$ & \\
\hline$r_{j, t-35: t-12}$ & $\begin{array}{c}0.020316 \\
(0.236526)\end{array}$ & & $\begin{array}{c}0.012721 \\
(0.722388)\end{array}$ & & $\begin{array}{c}0.192698 \\
(1.586049)\end{array}$ & & $\begin{array}{c}0.116349 \\
(1.411997)\end{array}$ & & $\begin{array}{c}0.014378 \\
(0.678959)\end{array}$ & \\
\hline$\beta_{j}$ & $\begin{array}{l}-0.065606 \\
(4.343308)\end{array}$ & $* * *$ & $\begin{array}{c}0.001675 \\
(0.568355)\end{array}$ & & $\begin{array}{l}-0.012342 \\
(0.834669)\end{array}$ & & $\begin{array}{l}-0.007062 \\
(0.486691)\end{array}$ & & $\begin{array}{c}-0.004414 \\
(1.386812)\end{array}$ & \\
\hline Constant & $\begin{array}{l}-0.049631 \\
(0.290899)\end{array}$ & & $\begin{array}{l}-0.084750 \\
(1.387413)\end{array}$ & & $\begin{array}{l}-0.174048 \\
(1.099563)\end{array}$ & & $\begin{array}{c}0.084849 \\
(0.798657)\end{array}$ & & $\begin{array}{l}-0.058169 \\
(1.107116)\end{array}$ & \\
\hline$R$-Squared & 0.102645 & & 0.088561 & & 0.086419 & & 0.067250 & & 0.035123 & \\
\hline
\end{tabular}

***,**,* Statistical significant for 1,5 , and 10 percent levels 
As the last step, tables 13.1 to 13.8 reports our analysis divided into eight different sectors in four sub periods (Phases) of bear and bull markets by applying monthly cross-sectional regressions using Fama-Macbeth (1973) as equation 12 with different combinations for the independent variables (models 1 to 10). Results show an overall of statistics that variables from different models in all sectors are both positive and negative statistical significance at different levels for certain phases. These outcomes support and associate to Chow test which determines when models are regressed and examined in different periods among breakpoints, correlations are unlike in different sub data groups. As the result, it is an evidence that there are different variable relations from all sectors in different phases embedded in the summary outcome in table 12 tested for full period in previous research study Mateus and Konsilp (2014) which is not totally complete and leads to further analyzed by breaking into sub periods.

Specifically, we enlarge five groups of highlight results showing effects of forecast model on future stock returns for every sectors and different phases compared to full period, such as a group of implied, realized, EGARCH and $A R(2)$ idiosyncratic volatilities $\left(\sigma_{I V_{i d i o}}, \sigma_{R V_{\text {idio }}}, \sigma_{E G_{i d i o}}, \sigma_{A R_{\text {idio }}}\right)$ in table 14 , the short-sales constraint and open-interest variables $\left(O R W_{\text {ratio }}, O I\right)$ in table 15 , crosssection firm-specific characteristics variables in term of $\log S I Z E$, and $\log B M$ in table 16 and 17 respectively. As well, Beta $\left(\beta_{j}\right)$ is shown in table 18 .

$$
\begin{aligned}
& r_{j, t+1}=\alpha_{j}+\lambda_{1} \sigma_{R V_{i d i o, j, t}}+\lambda_{2} \log S I Z E_{j, t}+\lambda_{3} \log B M_{j, t}+\lambda_{4} r_{j, t}+\lambda_{5} r_{j, t-11: t-1}+\lambda_{6} r_{j, t-35: t-12}+\lambda_{7} \beta_{j, t}+ \\
& +\lambda_{8} \sigma_{\text {IVidio }, j, t}+\lambda_{9} \sigma_{E G_{i d i o, j, t}}+\lambda_{10} \sigma_{A R 2} \text { idio }, j, t+\lambda_{11} O R W_{\text {ratio }_{j, t}}+\lambda_{12} O I_{j, t}+\varepsilon_{j, t+1}
\end{aligned}
$$

where, $r_{j, t}$ represents the stock return for firm for firm $j$ in month $t, \sigma_{R V_{\text {idio }, j, t}}$, is the realized idiosyncratic volatility in month $t$ for firm $j, \log S I Z E_{j, t}$, is the logarithm of market value of equity (calculated by multiplying the company's current stock price by its number of outstanding shares.), $\log B M_{j, t}$, is the logarithm of the book-to-market ratio, $r_{j, t-11: t-1}$ and $r_{j, t-35: t-12}$, represents the stock return for firm $j$ one and three years before the current month, $\beta_{j, t}$, is firm $j$ equity Beta, $\sigma_{I V i d i o, j, t}$, is the implied variance in its idiosyncratic part at month $t$ for firm $j, \sigma_{E G_{i d i o, j, t}}$, is conditional variance for firm $j$ in month $t$ is, $\sigma_{A R} i d i o, j, t$, is the idiosyncratic volatility estimation following Chua, Goh and Zhang (2005) autoregressive model in $2^{\text {nd }}$ order, $A R(2), O R W_{\text {ratio } j, t}$, is the $O R W$ Ratio following Ofek, Richardson, and Whitelaw (2004), $O I_{j, t}$, is the liquidity measure open-interest, $\alpha$ is the constant term, $\lambda$ 's estimated coefficients and $\varepsilon$ is the error term. 
Table 13: Fama-Macbeth future returns estimation with firm-specific characteristics

Table 13.1: Basic Materials Sector

\begin{tabular}{|c|c|c|c|c|c|c|c|c|c|c|}
\hline \multicolumn{11}{|c|}{ Entire Phases } \\
\hline Variables & Model 1 & Model 2 & Model 3 & Model 4 & Model 5 & Model 6 & Model 7 & Model 8 & Model 9 & Model 10 \\
\hline$\sigma_{R V i d i o, j, t}$ & --- & --- & $\begin{array}{c}-0.148661 * * * \\
(5.087340)\end{array}$ & & $\begin{array}{c}-0.287969 * * * \\
(7.161865)\end{array}$ & $\begin{array}{c}-0.156080 * * * \\
(5.030232)\end{array}$ & $\begin{array}{c}-0.132887 * * * \\
(4.343374)\end{array}$ & $\begin{array}{c}-0.281222 * * * \\
(6.931776)\end{array}$ & $\begin{array}{c}-0.296934 * * * \\
(7.335000)\end{array}$ & $\begin{array}{c}0.285573 * * * \\
(7.077395)\end{array}$ \\
\hline $\log S I Z E$ & $\begin{array}{c}-0.003214 * * \\
(2.044201)\end{array}$ & $\begin{array}{c}-0.003300 * * \\
(2.070817)\end{array}$ & $\begin{array}{c}-0.004255 * * * \\
(2.656514)\end{array}$ & $\begin{array}{c}-0.004393 * * * \\
(3.802923)\end{array}$ & $\begin{array}{c}-0.003624 * * \\
(2.260374)\end{array}$ & $\begin{array}{c}-0.004069 * * \\
(2.507267)\end{array}$ & $\begin{array}{c}-0.004697 * * * \\
(2.897041)\end{array}$ & $\begin{array}{c}-0.004032 * * \\
(2.482282)\end{array}$ & $\begin{array}{c}-0.005976 * * * \\
(3.150709)\end{array}$ & --- \\
\hline $\log B M$ & $\begin{array}{c}0.005091 * * * \\
(3.150757)\end{array}$ & $\begin{array}{c}0.004879 * * * \\
(2.809195)\end{array}$ & $\begin{array}{c}0.005780 * * * \\
(3.317301)\end{array}$ & $\begin{array}{c}0.000891 \\
(0.771785)\end{array}$ & $\begin{array}{c}0.004950 * * * \\
(2.833949)\end{array}$ & $\begin{array}{c}0.005592 * * * \\
(3.173039)\end{array}$ & $\begin{array}{c}0.006212 * * * \\
(3.530038)\end{array}$ & $\begin{array}{c}0.005318 * * * \\
(3.013778)\end{array}$ & $\begin{array}{c}0.004486 * * \\
(2.551317)\end{array}$ & $\begin{array}{c}0.007775 * * * \\
(5.491956)\end{array}$ \\
\hline$r_{t}$ & $\begin{array}{c}0.071870 * * * \\
(5.684933)\end{array}$ & $\begin{array}{c}0.071761 * * * \\
(5.673966)\end{array}$ & $\begin{array}{c}0.058925 * * * \\
(4.577868)\end{array}$ & $\begin{array}{l}0.015908 * \\
(1.794399)\end{array}$ & $\begin{array}{c}0.063604 * * * \\
(4.938129)\end{array}$ & $\begin{array}{c}0.057976 * * * \\
(4.479915)\end{array}$ & $\begin{array}{c}0.060686 * * * \\
(4.700875)\end{array}$ & $\begin{array}{c}0.064910 * * * \\
(5.005851)\end{array}$ & $\begin{array}{c}0.060991 * * * \\
(4.724482)\end{array}$ & $\begin{array}{c}0.063341 * * * \\
(4.911251)\end{array}$ \\
\hline$r_{j, t-11: t-1}$ & $\begin{array}{c}0.009176 \\
(0.752181)\end{array}$ & $\begin{array}{c}0.009146 \\
(0.749697)\end{array}$ & $\begin{array}{c}0.009474 \\
(0.778085)\end{array}$ & $\begin{array}{c}0.095848 * * * \\
(12.325570)\end{array}$ & $\begin{array}{c}0.010588 \\
(0.871172)\end{array}$ & $\begin{array}{c}0.009271 \\
(0.761218)\end{array}$ & $\begin{array}{c}0.009466 \\
(0.777585)\end{array}$ & $\begin{array}{c}0.010003 \\
(0.823080)\end{array}$ & $\begin{array}{c}0.011023 \\
(0.906966)\end{array}$ & $\begin{array}{c}0.011074 \\
(0.910482)\end{array}$ \\
\hline$r_{j, t-35: t-12}$ & $\begin{array}{c}0.018405 \\
(1.473552)\end{array}$ & $\begin{array}{c}0.018188 \\
(1.454155)\end{array}$ & $\begin{array}{c}0.018164 \\
(1.455133)\end{array}$ & $\begin{array}{c}-0.072837 * * * \\
(4.687945)\end{array}$ & $\begin{array}{c}0.017984 \\
(1.443552)\end{array}$ & $\begin{array}{c}0.017906 \\
(1.433833)\end{array}$ & $\begin{array}{c}0.018330 \\
(1.468652)\end{array}$ & $\begin{array}{c}0.017566 \\
(1.410112)\end{array}$ & $\begin{array}{c}0.017633 \\
(1.415911)\end{array}$ & $\begin{array}{c}0.017421 \\
(1.397887)\end{array}$ \\
\hline$\beta_{j}$ & --- & $\begin{array}{c}0.000930 \\
(0.331914)\end{array}$ & $\begin{array}{l}0.005115 * \\
(1.755017)\end{array}$ & $\begin{array}{c}0.011884 * * * \\
(5.294686)\end{array}$ & $\begin{array}{c}0.002724 \\
(0.924322)\end{array}$ & $\begin{array}{c}0.004679 \\
(1.571066)\end{array}$ & $\begin{array}{c}0.006093 * * \\
(2.052875)\end{array}$ & $\begin{array}{c}0.003501 \\
(1.166811)\end{array}$ & $\begin{array}{c}0.000483 \\
(0.157847)\end{array}$ & $\begin{array}{c}0.000311 \\
(0.101559)\end{array}$ \\
\hline$\sigma_{I V i d i o, j, t}$ & --- & --- & --- & $\begin{array}{c}0.048715^{* * *} \\
(8.750052)\end{array}$ & $\begin{array}{c}0.061108 * * * \\
(5.032830)\end{array}$ & --- & --- & $\begin{array}{c}0.063897 * * * \\
(5.162852)\end{array}$ & $\begin{array}{c}0.058395 * * * \\
(4.798069)\end{array}$ & $\begin{array}{c}0.061742 * * * \\
(5.088852)\end{array}$ \\
\hline$\sigma_{E G_{i d i o, j, t}}$ & --- & --- & --- & --- & --- & $\begin{array}{c}0.034218 \\
(0.711376)\end{array}$ & --- & $\begin{array}{l}0.104602 * \\
(1.696092)\end{array}$ & --- & --- \\
\hline$\sigma_{A R_{i d i o, j, t}}$ & --- & --- & --- & -- & --- & --- & $\begin{array}{c}-0.072403 * \\
(1.737202)\end{array}$ & $\begin{array}{c}-0.164268 * * * \\
(3.087997)\end{array}$ & --- & --- \\
\hline$O R W_{\text {ratio }}$ & --- & --- & --- & -- & --- & --- & --- & --- & $\begin{array}{c}-0.000582 * \\
(1.831629)\end{array}$ & $\begin{array}{c}-0.000618 * \\
(1.943502)\end{array}$ \\
\hline$O I$ & --- & --- & --- & -- & --- & --- & --- & --- & $\begin{array}{c}0.001886 * * \\
(2.495106)\end{array}$ & $\begin{array}{c}0.000617 \\
(0.964334)\end{array}$ \\
\hline Constant & $\begin{array}{c}0.063635 * * * \\
(2.594224)\end{array}$ & $\begin{array}{c}0.063990 * * * \\
(2.606034)\end{array}$ & $\begin{array}{c}0.087789 * * * \\
(3.518895)\end{array}$ & $\begin{array}{c}0.067373 * * * \\
(3.563526)\end{array}$ & $\begin{array}{c}0.079239 * * * \\
(3.175039)\end{array}$ & $\begin{array}{c}0.082923 * * * \\
(3.205480)\end{array}$ & $\begin{array}{c}0.098943 * * * \\
(3.841427)\end{array}$ & $\begin{array}{c}0.089283 * * * \\
(3.440558)\end{array}$ & $\begin{array}{c}0.108636^{* * * *} \\
(3.871794)\end{array}$ & $\begin{array}{c}0.021344 * * * \\
(4.808714)\end{array}$ \\
\hline
\end{tabular}




\begin{tabular}{|c|c|c|c|c|c|c|c|c|c|c|}
\hline \multicolumn{11}{|c|}{ Phase 1} \\
\hline Variables & Model 1 & Model 2 & Model 3 & Model 4 & Model 5 & Model 6 & Model 7 & Model 8 & Model 9 & Model 10 \\
\hline$\sigma_{R V \text { idioit }}$ & --- & --- & 0.077439 & --- & -0.095956 & $0.189915 * *$ & $0.229438 * * *$ & -0.025912 & -0.089046 & -0.074741 \\
\hline & & & (1.073010) & & $(0.910345)$ & $(2.400420)$ & (2.983987) & $(0.247764)$ & (0.841044) & (0.708107) \\
\hline $\log S I Z E$ & $\begin{array}{c}-0.010025 * * * \\
(2.655568)\end{array}$ & $\begin{array}{c}-0.009571 * * \\
(2.525388)\end{array}$ & $\begin{array}{c}-0.008696 * * \\
(2.243466)\end{array}$ & $\begin{array}{c}-0.007419 * \\
(1.904983)\end{array}$ & $\begin{array}{c}-0.007603 * \\
(1.949425)\end{array}$ & $\begin{array}{c}-0.011706^{* * *} \\
(2.956374)\end{array}$ & $\begin{array}{c}-0.013536 * * * \\
(3.435766)\end{array}$ & $\begin{array}{c}-0.012715 * * * \\
(3.224819)\end{array}$ & $\begin{array}{c}-0.006724 \\
(1.572654)\end{array}$ & --- \\
\hline $\log B M$ & $\begin{array}{l}-0.005964 \\
(1.641932)\end{array}$ & $\begin{array}{l}-0.004359 \\
(1.137488)\end{array}$ & $\begin{array}{l}-0.004620 \\
(1.203364)\end{array}$ & $\begin{array}{c}-0.004886 \\
(1.275292)\end{array}$ & $\begin{array}{l}-0.004783 \\
(1.247680)\end{array}$ & $\begin{array}{l}-0.002934 \\
(0.761087)\end{array}$ & $\begin{array}{l}-0.002520 \\
(0.660320)\end{array}$ & $\begin{array}{l}-0.002266 \\
(0.594413)\end{array}$ & $\begin{array}{l}-0.005006 \\
(1.304473)\end{array}$ & $\begin{array}{l}-0.001754 \\
(0.542270)\end{array}$ \\
\hline$r_{t}$ & $\begin{array}{l}-0.042450 \\
(1.479659)\end{array}$ & $\begin{array}{l}-0.042640 \\
(1.486732)\end{array}$ & $\begin{array}{l}-0.037609 \\
(1.294202)\end{array}$ & $\begin{array}{c}-0.029583 \\
(1.014031)\end{array}$ & $\begin{array}{c}-0.030357 \\
(1.040058)\end{array}$ & $\begin{array}{c}-0.038766 \\
(1.339812)\end{array}$ & $\begin{array}{c}-0.038252 \\
(1.331294)\end{array}$ & $\begin{array}{l}-0.026373 \\
(0.916376)\end{array}$ & $\begin{array}{l}-0.030251 \\
(1.035457)\end{array}$ & $\begin{array}{l}-0.026650 \\
(0.914459)\end{array}$ \\
\hline$r_{j, t-11: t-1}$ & $\begin{array}{c}0.079260 * * * \\
(3.067655)\end{array}$ & $\begin{array}{c}0.078114 * * * \\
(3.022479)\end{array}$ & $\begin{array}{c}0.078212 * * * \\
(3.026413)\end{array}$ & $\begin{array}{c}0.077437 * * * \\
(3.001634)\end{array}$ & $\begin{array}{c}0.077034 * * * \\
(2.985336)\end{array}$ & $\begin{array}{c}0.079167 * * * \\
(3.076762)\end{array}$ & $\begin{array}{c}0.082178 * * * \\
(3.214674)\end{array}$ & $\begin{array}{c}0.080687 * * * \\
(3.170876)\end{array}$ & $\begin{array}{c}0.079356 * * * \\
(3.067357)\end{array}$ & $\begin{array}{c}0.079405 * * * \\
(3.067320)\end{array}$ \\
\hline$r_{j, t-35: t-12}$ & $\begin{array}{c}0.074996 * * * \\
(3.421478)\end{array}$ & $\begin{array}{c}0.076790 * * * \\
(3.497552)\end{array}$ & $\begin{array}{c}0.078012 * * * \\
(3.548666)\end{array}$ & $\begin{array}{c}0.080710 * * * \\
(3.672052)\end{array}$ & $\begin{array}{c}0.080835 * * * \\
(3.677398)\end{array}$ & $\begin{array}{c}0.079613 * * * \\
(3.636661)\end{array}$ & $\begin{array}{c}0.080428 * * * \\
(3.699347)\end{array}$ & $\begin{array}{c}0.085702 * * * \\
(3.951753)\end{array}$ & $\begin{array}{c}0.081676^{* * *} \\
(3.715043)\end{array}$ & $\begin{array}{c}0.081864 * * * \\
(3.721319)\end{array}$ \\
\hline$\beta_{j}$ & --- & $\begin{array}{l}-0.012959 \\
(1.310443)\end{array}$ & $\begin{array}{l}-0.016113 \\
(1.561954)\end{array}$ & $\begin{array}{c}-0.018695 * \\
(1.837436)\end{array}$ & $\begin{array}{c}-0.017185 * \\
(1.666883)\end{array}$ & $\begin{array}{l}-0.010290 \\
(0.988164)\end{array}$ & $\begin{array}{l}-0.009372 \\
(0.911727)\end{array}$ & $\begin{array}{l}-0.009383 \\
(0.911554)\end{array}$ & $\begin{array}{l}-0.015833 \\
(1.503618)\end{array}$ & $\begin{array}{l}-0.016669 \\
(1.584000)\end{array}$ \\
\hline$\sigma_{I V_{i d i o, j, t}}$ & --- & --- & --- & $\begin{array}{c}0.041985 * * \\
(2.325129)\end{array}$ & $\begin{array}{c}0.059541 * * \\
(2.253635)\end{array}$ & --- & --- & $\begin{array}{c}0.100057 * * * \\
(3.658972)\end{array}$ & $\begin{array}{c}0.059849 * * \\
(2.246506)\end{array}$ & $\begin{array}{c}0.066708 * * \\
(2.536626)\end{array}$ \\
\hline$\sigma_{E G_{i d i o, j, t}}$ & --- & --- & --- & --- & --- & $\begin{array}{c}-0.399531 * * * \\
(3.396185)\end{array}$ & --- & $\begin{array}{l}-0.091086 \\
(0.569635)\end{array}$ & --- & --- \\
\hline$\sigma_{A R i d i o, j, t}$ & --- & --- & --- & --- & --- & --- & $\begin{array}{c}-0.573896 * * * \\
(5.308044)\end{array}$ & $\begin{array}{c}-0.613141 * * * \\
(4.229197)\end{array}$ & --- & --- \\
\hline$O R W_{\text {ratio }}$ & --- & --- & --- & --- & --- & --- & --- & --- & $\begin{array}{l}-0.000799 \\
(1.462863)\end{array}$ & $\begin{array}{l}-0.000807 \\
(1.477656)\end{array}$ \\
\hline$O I$ & --- & --- & --- & --- & --- & --- & --- & --- & $\begin{array}{l}-0.000727 \\
(0.436420)\end{array}$ & $\begin{array}{l}-0.001799 \\
(1.184230)\end{array}$ \\
\hline Constant & $\begin{array}{c}0.147903 * * * \\
(2.588667)\end{array}$ & $\begin{array}{c}0.152296 * * * \\
(2.661774)\end{array}$ & $\begin{array}{c}0.134265 * * \\
(2.251674)\end{array}$ & $\begin{array}{l}0.114157 * \\
(1.921205)\end{array}$ & $\begin{array}{c}0.120551 * * \\
(2.014646)\end{array}$ & $\begin{array}{c}0.199982 * * * \\
(3.202758)\end{array}$ & $\begin{array}{c}0.240116^{* * * *} \\
(3.857920)\end{array}$ & $\begin{array}{c}0.239290 * * * \\
(3.832356)\end{array}$ & $\begin{array}{l}0.108596 * \\
(1.694759)\end{array}$ & $\begin{array}{c}0.009278 \\
(0.855042)\end{array}$ \\
\hline
\end{tabular}




\begin{tabular}{|c|c|c|c|c|c|c|c|c|c|c|}
\hline \multicolumn{11}{|c|}{ Phase 2} \\
\hline Variables & Model 1 & Model 2 & Model 3 & Model 4 & Model 5 & Model 6 & Model 7 & Model 8 & Model 9 & Model 10 \\
\hline$\sigma_{R V_{i d i o, j, t}}$ & --- & --- & $\begin{array}{c}0.163238 * * * \\
(2.716673)\end{array}$ & --- & $\begin{array}{l}0.129650 * \\
(1.734308)\end{array}$ & $\begin{array}{c}0.074143 \\
(1.128752)\end{array}$ & $\begin{array}{c}0.108194 \\
(1.640067)\end{array}$ & $\begin{array}{c}0.084477 \\
(1.106848)\end{array}$ & $\begin{array}{l}0.146227 * \\
(1.907550)\end{array}$ & $\begin{array}{l}0.136239 * \\
(1.807810)\end{array}$ \\
\hline $\log S I Z E$ & $\begin{array}{l}-0.000085 \\
(0.046972)\end{array}$ & $\begin{array}{l}-0.000293 \\
(0.160159)\end{array}$ & $\begin{array}{c}0.000554 \\
(0.298822)\end{array}$ & $\begin{array}{c}0.000430 \\
(0.231424)\end{array}$ & $\begin{array}{c}0.000685 \\
(0.367955)\end{array}$ & $\begin{array}{c}0.001553 \\
(0.828313)\end{array}$ & $\begin{array}{c}0.001217 \\
(0.646823)\end{array}$ & $\begin{array}{c}0.001504 \\
(0.798169)\end{array}$ & $\begin{array}{c}0.001572 \\
(0.713365)\end{array}$ & --- \\
\hline $\log B M$ & $\begin{array}{c}0.007021 \\
(3.850770)\end{array}$ & $\begin{array}{c}0.006563 * * * \\
(3.380507)\end{array}$ & $\begin{array}{c}0.005716 * * * \\
(2.910107)\end{array}$ & $\begin{array}{c}0.005504 * * * \\
(2.754607)\end{array}$ & $\begin{array}{c}0.005443 * * * \\
(2.724670)\end{array}$ & $\begin{array}{c}0.004891 * * \\
(2.474516)\end{array}$ & $\begin{array}{c}0.005035 * * \\
(2.527481)\end{array}$ & $\begin{array}{c}0.004995 * * \\
(2.486517)\end{array}$ & $\begin{array}{c}0.005585 * * * \\
(2.784416)\end{array}$ & $\begin{array}{c}0.004794 * * * \\
(2.868920)\end{array}$ \\
\hline$r_{t}$ & $\begin{array}{l}-0.025544 \\
(1.435018)\end{array}$ & $\begin{array}{l}-0.026028 \\
(1.460966)\end{array}$ & $\begin{array}{c}-0.028002 \\
(1.572081)\end{array}$ & $\begin{array}{l}-0.025193 \\
(1.414672)\end{array}$ & $\begin{array}{l}-0.027243 \\
(1.526926)\end{array}$ & $\begin{array}{c}-0.033978 * \\
(1.900964)\end{array}$ & $\begin{array}{c}-0.030616 * \\
(1.715103)\end{array}$ & $\begin{array}{c}-0.034292 * \\
(1.909721)\end{array}$ & $\begin{array}{l}-0.026401 \\
(1.476833)\end{array}$ & $\begin{array}{l}-0.026669 \\
(1.492313)\end{array}$ \\
\hline$r_{j, t-11: t-1}$ & $\begin{array}{l}-0.032552 \\
(2.011596)\end{array}$ & $\begin{array}{c}-0.032981 * * \\
(2.036418)\end{array}$ & $\begin{array}{c}-0.034139 * * \\
(2.109320)\end{array}$ & $\begin{array}{c}-0.033280 * * \\
(2.056106)\end{array}$ & $\begin{array}{c}-0.034027 * * \\
(2.102179)\end{array}$ & $\begin{array}{c}-0.036037 * * \\
(2.228835)\end{array}$ & $\begin{array}{c}-0.034000 * * \\
(2.101752)\end{array}$ & $\begin{array}{c}-0.036207 * * \\
(2.236950)\end{array}$ & $\begin{array}{c}-0.033347 * * \\
(2.057726)\end{array}$ & $\begin{array}{c}-0.033470 * * \\
(2.065585)\end{array}$ \\
\hline$r_{j, t-35: t-12}$ & $\begin{array}{l}-0.004658 \\
(0.334538)\end{array}$ & $\begin{array}{l}-0.005099 \\
(0.365767)\end{array}$ & $\begin{array}{l}-0.005569 \\
(0.399845)\end{array}$ & $\begin{array}{l}-0.005115 \\
(0.367153)\end{array}$ & $\begin{array}{l}-0.005479 \\
(0.393352)\end{array}$ & $\begin{array}{l}-0.006928 \\
(0.498009)\end{array}$ & $\begin{array}{l}-0.006095 \\
(0.437761)\end{array}$ & $\begin{array}{l}-0.006982 \\
(0.501702)\end{array}$ & $\begin{array}{l}-0.005242 \\
(0.376395)\end{array}$ & $\begin{array}{l}-0.005272 \\
(0.378577)\end{array}$ \\
\hline$\beta_{j}$ & --- & $\begin{array}{c}0.002142 \\
(0.686873)\end{array}$ & $\begin{array}{l}-0.000570 \\
(0.174218)\end{array}$ & $\begin{array}{c}0.000686 \\
(0.215262)\end{array}$ & $\begin{array}{l}-0.000628 \\
(0.191761)\end{array}$ & $\begin{array}{l}-0.002408 \\
(0.726856)\end{array}$ & $\begin{array}{l}-0.001727 \\
(0.520190)\end{array}$ & $\begin{array}{l}-0.002379 \\
(0.714849)\end{array}$ & $\begin{array}{l}-0.000514 \\
(0.153445)\end{array}$ & $\begin{array}{l}-0.000361 \\
(0.107958)\end{array}$ \\
\hline$\sigma_{I V} i d i o, j, t$ & --- & --- & --- & $\begin{array}{c}0.036436 * * \\
(2.222327)\end{array}$ & $\begin{array}{c}0.015400 \\
(0.755285)\end{array}$ & --- & --- & $\begin{array}{l}-0.004535 \\
(0.210081)\end{array}$ & $\begin{array}{c}0.011965 \\
(0.583509)\end{array}$ & $\begin{array}{c}0.010841 \\
(0.530266)\end{array}$ \\
\hline$\sigma_{E G_{i d i o, j, t}}$ & --- & --- & --- & --- & --- & $\begin{array}{c}0.208221 * * * \\
(3.330091)\end{array}$ & --- & $\begin{array}{c}0.221537 * * * \\
(2.659847)\end{array}$ & --- & --- \\
\hline$\sigma_{A R} i d i o, j, t$ & --- & --- & --- & --- & --- & --- & $\begin{array}{c}0.128473 * * \\
(2.016659)\end{array}$ & $\begin{array}{l}-0.014332 \\
(0.168420)\end{array}$ & --- & --- \\
\hline ORW $W_{\text {ratio }}$ & --- & --- & --- & --- & --- & --- & --- & --- & $\begin{array}{l}-0.001148 \\
(1.628350)\end{array}$ & $\begin{array}{l}-0.001111 \\
(1.579351)\end{array}$ \\
\hline$O I$ & --- & --- & --- & --- & --- & --- & --- & --- & $\begin{array}{l}-0.000383 \\
(0.454982)\end{array}$ & $\begin{array}{l}-0.000067 \\
(0.093506)\end{array}$ \\
\hline Constant & $\begin{array}{c}0.027990 \\
(0.995864)\end{array}$ & $\begin{array}{c}0.029191 \\
(1.036510)\end{array}$ & $\begin{array}{c}0.007218 \\
(0.246557)\end{array}$ & $\begin{array}{c}0.013937 \\
(0.481097)\end{array}$ & $\begin{array}{c}0.005291 \\
(0.180067)\end{array}$ & $\begin{array}{l}-0.018417 \\
(0.609383)\end{array}$ & $\begin{array}{l}-0.009543 \\
(0.313740)\end{array}$ & $\begin{array}{l}-0.017620 \\
(0.576883)\end{array}$ & $\begin{array}{l}-0.007137 \\
(0.214905)\end{array}$ & $\begin{array}{c}0.016242 * * * \\
(3.030860)\end{array}$ \\
\hline
\end{tabular}




\begin{tabular}{|c|c|c|c|c|c|c|c|c|c|c|}
\hline \multicolumn{11}{|c|}{ Phase 3} \\
\hline Variables & Model 1 & Model 2 & Model 3 & Model 4 & Model 5 & Model 6 & Model 7 & Model 8 & Model 9 & Model 10 \\
\hline \multirow{2}{*}{$\sigma_{R V_{i d i o, j, t}}$} & --- & --- & 0.006669 & --- & -0.040436 & 0.043316 & 0.041614 & -0.024084 & -0.046964 & -0.042900 \\
\hline & & & $(0.087292)$ & & $(0.369874)$ & $(0.548644)$ & $(0.536806)$ & $(0.220681)$ & $(0.425262)$ & (0.388949) \\
\hline \multirow[t]{2}{*}{$\log S I Z E$} & -0.005009 & -0.005076 & -0.005042 & -0.004811 & -0.004805 & -0.006372 & -0.007042 & -0.006923 & -0.006852 & --- \\
\hline & $(0.706720)$ & $(0.715841)$ & $(0.709581)$ & $(0.676100)$ & $(0.674784)$ & $(0.893359)$ & $(0.987726)$ & $(0.968955)$ & $(0.824160)$ & \\
\hline \multirow[t]{2}{*}{$\log B M$} & 0.000043 & -0.001289 & -0.001392 & -0.001985 & -0.001906 & -0.000266 & 0.000509 & -0.000126 & -0.002647 & 0.001252 \\
\hline & $(0.005871)$ & $(0.170371)$ & $(0.181628)$ & $(0.257588)$ & $(0.247033)$ & $(0.034718)$ & $(0.066368)$ & $(0.016292)$ & $(0.335899)$ & (0.198719) \\
\hline$r_{t}$ & $\begin{array}{c}0.255980 * * * \\
(6.025029)\end{array}$ & $\begin{array}{c}0.261539 * * * \\
(6.065592)\end{array}$ & $\begin{array}{c}0.263331 * * * \\
(5.510294)\end{array}$ & $\begin{array}{c}0.272619 * * * \\
(5.581732)\end{array}$ & $\begin{array}{c}0.270415 * * * \\
(5.492065)\end{array}$ & $\begin{array}{c}0.273415 * * * \\
(5.692132)\end{array}$ & $\begin{array}{c}0.267434 * * * \\
(5.613439)\end{array}$ & $\begin{array}{c}0.282477 * * * \\
(5.677058)\end{array}$ & $\begin{array}{c}0.269524 * * * \\
(5.450810)\end{array}$ & $\begin{array}{c}0.270280 * * * \\
(5.468458)\end{array}$ \\
\hline \multirow[t]{2}{*}{$r_{j, t-11: t-1}$} & -0.031576 & -0.043859 & -0.043936 & -0.044510 & -0.044554 & -0.025939 & -0.016047 & -0.013588 & -0.045400 & -0.050908 \\
\hline & $(0.382769)$ & $(0.521683)$ & $(0.522147)$ & $(0.529035)$ & $(0.529187)$ & $(0.306637)$ & $(0.189565)$ & $(0.160246)$ & $(0.535747)$ & $(0.602780)$ \\
\hline \multirow[t]{2}{*}{$r_{j, t-35: t-12}$} & $0.136518 * *$ & $0.136144 * *$ & $0.136213 * *$ & $0.134865 *$ & $0.133443 *$ & $0.155311 * *$ & $0.138007 * *$ & $0.141276 * *$ & $0.130397 *$ & $0.130251 *$ \\
\hline & (1.973427) & (1.967305) & (1.966599) & (1.946208) & (1.921375) & $(2.220142)$ & (1.999840) & $(2.010073)$ & (1.864824) & $(1.863221)$ \\
\hline \multirow[t]{2}{*}{$\beta_{j}$} & --- & 0.008634 & 0.008456 & 0.006950 & 0.006710 & 0.016301 & 0.013729 & 0.013428 & 0.005286 & 0.006472 \\
\hline & & $(0.764167)$ & $(0.736006)$ & $(0.587519)$ & $(0.566028)$ & (1.327897) & (1.177402) & (1.078625) & $(0.424330)$ & $(0.523144)$ \\
\hline \multirow[t]{2}{*}{$\sigma_{I V_{i d i o, j, t}}$} & --- & --- & --- & 0.015492 & 0.027606 & --- & --- & 0.044502 & 0.028074 & 0.030512 \\
\hline & & & & $(0.484061)$ & (0.602645) & & & (0.957097) & (0.604196) & $(0.658168)$ \\
\hline \multirow[t]{2}{*}{$\sigma_{E G_{i d i o, j, t}}$} & --- & --- & --- & --- & --- & $-0.347825 *$ & --- & -0.145682 & --- & --- \\
\hline & & & & & & (1.792502) & & $(0.590131)$ & & \\
\hline \multirow[t]{2}{*}{$\sigma_{A R} i d i o, j, t$} & --- & --- & --- & --- & --- & --- & $-0.307242 * *$ & -0.262278 & --- & --- \\
\hline & & & & & & & $(2.372325)$ & (1.608095) & & \\
\hline \multirow[t]{2}{*}{ ORW $W_{\text {ratio }}$} & --- & --- & --- & --- & --- & --- & --- & --- & 0.000187 & 0.000173 \\
\hline & & & & & & & & & $(0.180776)$ & $(0.167037)$ \\
\hline \multirow[t]{2}{*}{$O I$} & --- & --- & -- & --- & --- & --- & -- & --- & 0.001783 & 0.000136 \\
\hline & & & & & & & & & $(0.455542)$ & $(0.040551)$ \\
\hline \multirow[t]{2}{*}{ Constant } & 0.044669 & 0.034814 & 0.033629 & 0.027957 & 0.029783 & 0.073463 & 0.084665 & 0.087681 & 0.052991 & $-0.047651 *$ \\
\hline & $(0.396263)$ & $(0.306738)$ & $(0.293961)$ & $(0.244275)$ & (0.259809) & $(0.631473)$ & $(0.729969)$ & $(0.751625)$ & $(0.425410)$ & (1.938874) \\
\hline
\end{tabular}




\begin{tabular}{|c|c|c|c|c|c|c|c|c|c|c|}
\hline \multicolumn{11}{|c|}{ Phase 4} \\
\hline Variables & Model 1 & Model 2 & Model 3 & Model 4 & Model 5 & Model 6 & Model 7 & Model 8 & Model 9 & Model 10 \\
\hline$\sigma_{R V_{i d i o, j, t}}$ & --- & --- & $\begin{array}{l}-0.004126 \\
(0.056856)\end{array}$ & --- & $\begin{array}{c}-0.226669 * * * \\
(2.598282)\end{array}$ & $\begin{array}{l}-0.008034 \\
(0.104936)\end{array}$ & $\begin{array}{l}-0.004110 \\
(0.054788)\end{array}$ & $\begin{array}{c}-0.222272 * * \\
(2.474185)\end{array}$ & $\begin{array}{c}-0.247773 * * * \\
(2.782853)\end{array}$ & $\begin{array}{c}-0.213266 * * \\
(2.431129)\end{array}$ \\
\hline $\log S I Z E$ & $\begin{array}{c}-0.009776 * * \\
(2.313201)\end{array}$ & $\begin{array}{c}-0.009431 * * \\
(2.212429)\end{array}$ & $\begin{array}{c}-0.009469 * * \\
(2.193948)\end{array}$ & $\begin{array}{l}-0.007046 \\
(1.642413)\end{array}$ & $\begin{array}{c}-0.007974 * \\
(1.856523)\end{array}$ & $\begin{array}{c}-0.009428 * * \\
(2.180002)\end{array}$ & $\begin{array}{c}-0.009469 * * \\
(2.191393)\end{array}$ & $\begin{array}{c}-0.008014 * \\
(1.861801)\end{array}$ & $\begin{array}{c}-0.011419 * * \\
(2.161862)\end{array}$ & --- \\
\hline $\log B M$ & $\begin{array}{c}0.006106 \\
(1.428373)\end{array}$ & $\begin{array}{c}0.004997 \\
(1.080359)\end{array}$ & $\begin{array}{c}0.005048 \\
(1.071141)\end{array}$ & $\begin{array}{c}0.002235 \\
(0.479299)\end{array}$ & $\begin{array}{c}0.003695 \\
(0.788591)\end{array}$ & $\begin{array}{c}0.004904 \\
(1.021984)\end{array}$ & $\begin{array}{c}0.005048 \\
(1.063384)\end{array}$ & $\begin{array}{c}0.003842 \\
(0.805522)\end{array}$ & $\begin{array}{c}0.002456 \\
(0.510948)\end{array}$ & $\begin{array}{c}0.008166 * * \\
(2.030063)\end{array}$ \\
\hline$r_{t}$ & $\begin{array}{c}0.013471 \\
(0.494007)\end{array}$ & $\begin{array}{c}0.010819 \\
(0.391998)\end{array}$ & $\begin{array}{c}0.010866 \\
(0.393359)\end{array}$ & $\begin{array}{c}0.012555 \\
(0.457133)\end{array}$ & $\begin{array}{c}0.015957 \\
(0.581678)\end{array}$ & $\begin{array}{c}0.010500 \\
(0.378678)\end{array}$ & $\begin{array}{c}0.010867 \\
(0.392367)\end{array}$ & $\begin{array}{c}0.016558 \\
(0.600742)\end{array}$ & $\begin{array}{c}0.015699 \\
(0.572139)\end{array}$ & $\begin{array}{c}0.016250 \\
(0.591348)\end{array}$ \\
\hline$r_{j, t-11: t-1}$ & $\begin{array}{c}0.023699 \\
(1.039817)\end{array}$ & $\begin{array}{c}0.024068 \\
(1.055380)\end{array}$ & $\begin{array}{c}0.024073 \\
(1.055159)\end{array}$ & $\begin{array}{c}0.023738 \\
(1.046167)\end{array}$ & $\begin{array}{c}0.023843 \\
(1.053218)\end{array}$ & $\begin{array}{c}0.024144 \\
(1.057690)\end{array}$ & $\begin{array}{c}0.024072 \\
(1.052955)\end{array}$ & $\begin{array}{c}0.023349 \\
(1.028810)\end{array}$ & $\begin{array}{c}0.024084 \\
(1.063605)\end{array}$ & $\begin{array}{c}0.023560 \\
(1.038989)\end{array}$ \\
\hline$r_{j, t-35: t-12}$ & $\begin{array}{c}-0.087504 * * \\
(2.012181)\end{array}$ & $\begin{array}{c}-0.089273 * * \\
(2.048091)\end{array}$ & $\begin{array}{c}-0.089159 * * \\
(2.042512)\end{array}$ & $\begin{array}{c}-0.108573 * * \\
(2.485456)\end{array}$ & $\begin{array}{c}-0.111606 * * \\
(2.559888)\end{array}$ & $\begin{array}{c}-0.089141 * * \\
(2.041282)\end{array}$ & $\begin{array}{c}-0.089160 * * \\
(2.041447)\end{array}$ & $\begin{array}{c}-0.112008 * * \\
(2.566355)\end{array}$ & $\begin{array}{c}-0.113347 * * * \\
(2.597636)\end{array}$ & $\begin{array}{c}-0.114652 * * * \\
(2.623917)\end{array}$ \\
\hline$\beta_{j}$ & --- & $\begin{array}{c}0.005217 \\
(0.628906)\end{array}$ & $\begin{array}{c}0.005233 \\
(0.630182)\end{array}$ & $\begin{array}{c}0.000921 \\
(0.110458)\end{array}$ & $\begin{array}{l}-0.000294 \\
(0.035268)\end{array}$ & $\begin{array}{c}0.005019 \\
(0.596640)\end{array}$ & $\begin{array}{c}0.005234 \\
(0.618379)\end{array}$ & $\begin{array}{c}0.000224 \\
(0.026347)\end{array}$ & $\begin{array}{l}-0.002496 \\
(0.291836)\end{array}$ & $\begin{array}{c}0.001530 \\
(0.183055)\end{array}$ \\
\hline$\sigma_{I V} i d i o, j, t$ & --- & --- & --- & $\begin{array}{c}0.076171 * * * \\
(3.687708)\end{array}$ & $\begin{array}{c}0.112804 * * * \\
(4.517748)\end{array}$ & --- & --- & $\begin{array}{c}0.113473 * * * \\
(4.524888)\end{array}$ & $\begin{array}{c}0.112958 * * * \\
(4.522831)\end{array}$ & $\begin{array}{c}0.116148 * * * \\
(4.651816)\end{array}$ \\
\hline$\sigma_{E G_{i d i o, j, t}}$ & --- & --- & --- & --- & --- & $\begin{array}{c}0.016119 \\
(0.160571)\end{array}$ & --- & $\begin{array}{c}0.007819 \\
(0.064750)\end{array}$ & --- & --- \\
\hline$\sigma_{A R} i d i o, j, t$ & --- & --- & --- & --- & --- & --- & $\begin{array}{l}-0.000065 \\
(0.000827)\end{array}$ & $\begin{array}{l}-0.031655 \\
(0.334307)\end{array}$ & --- & --- \\
\hline ORW $W_{\text {ratio }}$ & --- & --- & --- & --- & --- & --- & --- & --- & $\begin{array}{l}-0.000204 \\
(0.328717)\end{array}$ & $\begin{array}{l}-0.000288 \\
(0.463668)\end{array}$ \\
\hline$O I$ & --- & --- & --- & --- & --- & --- & --- & --- & $\begin{array}{c}0.002623 \\
(1.173520)\end{array}$ & $\begin{array}{l}-0.000160 \\
(0.087375)\end{array}$ \\
\hline Constant & $\begin{array}{c}0.189751 * * * \\
(2.818696)\end{array}$ & $\begin{array}{c}0.177138 * * \\
(2.521230)\end{array}$ & $\begin{array}{c}0.178123 \\
(2.460644)\end{array}$ & $\begin{array}{l}0.121585 * \\
(1.700273)\end{array}$ & $\begin{array}{c}0.148964 * * \\
(2.065555)\end{array}$ & $\begin{array}{c}0.176672 * * \\
(2.420903)\end{array}$ & $\begin{array}{c}0.178128 * * \\
(2.451150)\end{array}$ & $\begin{array}{c}0.150527 * * \\
(2.071056)\end{array}$ & $\begin{array}{c}0.190455 * * \\
(2.337226)\end{array}$ & $\begin{array}{c}0.018252 \\
(1.060541)\end{array}$ \\
\hline
\end{tabular}


Table 13.2: Consumer Goods Sector

\begin{tabular}{|c|c|c|c|c|c|c|c|c|c|c|}
\hline \multicolumn{11}{|c|}{ Entire Phases } \\
\hline Variables & Model 1 & Model 2 & Model 3 & Model 4 & Model 5 & Model 6 & Model 7 & Model 8 & Model 9 & Model 10 \\
\hline$\sigma_{R V_{i d i o, j, t}}$ & --- & --- & $\begin{array}{c}0.007323 \\
(0.243390)\end{array}$ & --- & $\begin{array}{c}-0.181433 * * * \\
(4.879336)\end{array}$ & $\begin{array}{l}-0.025247 \\
(0.808456)\end{array}$ & $\begin{array}{l}-0.029669 \\
(0.964877)\end{array}$ & $\begin{array}{c}-0.187324 * * * \\
(5.030321)\end{array}$ & $\begin{array}{c}-0.180523 * * * \\
(4.850420)\end{array}$ & $\begin{array}{c}-0.180699 * * * \\
(4.855644)\end{array}$ \\
\hline $\log S I Z E$ & $\begin{array}{c}-0.002494 * * \\
(2.311966)\end{array}$ & $\begin{array}{c}-0.002289 * * \\
(2.104690)\end{array}$ & $\begin{array}{c}-0.002268 * * \\
(2.078860)\end{array}$ & $\begin{array}{l}-0.001021 \\
(0.928923)\end{array}$ & $\begin{array}{l}-0.000890 \\
(0.810803)\end{array}$ & $\begin{array}{c}-0.001222 \\
(1.087474)\end{array}$ & $\begin{array}{l}-0.001066 \\
(0.960578)\end{array}$ & $\begin{array}{l}-0.000338 \\
(0.301278)\end{array}$ & $\begin{array}{c}-0.000602 \\
(0.492893)\end{array}$ & --- \\
\hline $\log B M$ & $\begin{array}{l}0.002109 * \\
(1.902630)\end{array}$ & $\begin{array}{c}0.001789 \\
(1.584763)\end{array}$ & $\begin{array}{c}0.001745 \\
(1.525108)\end{array}$ & $\begin{array}{c}0.001306 \\
(1.158506)\end{array}$ & $\begin{array}{l}0.002165 * \\
(1.900668)\end{array}$ & $\begin{array}{c}0.001816 \\
(1.588723)\end{array}$ & $\begin{array}{c}0.001601 \\
(1.402415)\end{array}$ & $\begin{array}{l}0.001983 * \\
(1.740897)\end{array}$ & $\begin{array}{l}0.002195 * \\
(1.925188)\end{array}$ & $\begin{array}{c}0.002535 * * * \\
(2.789643)\end{array}$ \\
\hline$r_{t}$ & $\begin{array}{c}0.039615 * * * \\
(3.330944)\end{array}$ & $\begin{array}{c}0.038873 * * * \\
(3.265970)\end{array}$ & $\begin{array}{c}0.039085 * * * \\
(3.274802)\end{array}$ & $\begin{array}{c}0.045603 * * * \\
(3.832254)\end{array}$ & $\begin{array}{c}0.043785 * * * \\
(3.683736)\end{array}$ & $\begin{array}{c}0.032596 * * * \\
(2.706775)\end{array}$ & $\begin{array}{c}0.029021 * * \\
(2.409187)\end{array}$ & $\begin{array}{c}0.037113 * * * \\
(3.076115)\end{array}$ & $\begin{array}{c}0.044013 * * * \\
(3.696465)\end{array}$ & $\begin{array}{c}0.044229 * * * \\
(3.717332)\end{array}$ \\
\hline$r_{j, t-11: t-1}$ & $\begin{array}{c}0.096600 * * * \\
(8.509484)\end{array}$ & $\begin{array}{c}0.096402 * * * \\
(8.492284)\end{array}$ & $\begin{array}{c}0.096492 * * * \\
(8.495134)\end{array}$ & $\begin{array}{c}0.100974 * * * \\
(8.911383)\end{array}$ & $\begin{array}{c}0.101099 * * * \\
(8.937113)\end{array}$ & $\begin{array}{c}0.096959 * * * \\
(8.544293)\end{array}$ & $\begin{array}{c}0.098788 * * * \\
(8.710387)\end{array}$ & $\begin{array}{c}0.102570 * * * \\
(9.070315)\end{array}$ & $\begin{array}{c}0.101227 * * * \\
(8.945448)\end{array}$ & $\begin{array}{c}0.101362^{* * * *} \\
(8.960489)\end{array}$ \\
\hline$r_{j, t-35: t-12}$ & $\begin{array}{c}0.038039 * * * \\
(3.134536)\end{array}$ & $\begin{array}{c}0.037665^{* * * *} \\
(3.103380)\end{array}$ & $\begin{array}{c}0.037709 * * * \\
(3.106423)\end{array}$ & $\begin{array}{c}0.039577 * * * \\
(3.271494)\end{array}$ & $\begin{array}{c}0.039475 * * * \\
(3.268401)\end{array}$ & $\begin{array}{c}0.037895 * * * \\
(3.124883)\end{array}$ & $\begin{array}{c}0.038460 * * * \\
(3.175022)\end{array}$ & $\begin{array}{c}0.039924 * * * \\
(3.308831)\end{array}$ & $\begin{array}{c}0.039557 * * * \\
(3.274632)\end{array}$ & $\begin{array}{c}0.039483 * * * \\
(3.268989)\end{array}$ \\
\hline$\beta_{j}$ & --- & $\begin{array}{c}0.003515 \\
(1.494008)\end{array}$ & $\begin{array}{c}0.003341 \\
(1.358761)\end{array}$ & $\begin{array}{l}-0.002842 \\
(1.130837)\end{array}$ & $\begin{array}{l}-0.001786 \\
(0.709277)\end{array}$ & $\begin{array}{c}0.000993 \\
(0.392245)\end{array}$ & $\begin{array}{c}0.000686 \\
(0.274469)\end{array}$ & $\begin{array}{l}-0.002835 \\
(1.107694)\end{array}$ & $\begin{array}{l}-0.001667 \\
(0.658283)\end{array}$ & $\begin{array}{l}-0.001545 \\
(0.613014)\end{array}$ \\
\hline$\sigma_{I V_{i d i o, j, t}}$ & --- & --- & --- & $\begin{array}{c}0.060405^{* * *} \\
(7.019715)\end{array}$ & $\begin{array}{c}0.091305^{* * *} \\
(8.554969)\end{array}$ & --- & --- & $\begin{array}{c}0.084473 * * * \\
(7.620304)\end{array}$ & $\begin{array}{c}0.091449 * * * \\
(8.484216)\end{array}$ & $\begin{array}{c}0.092355 * * * \\
(8.696146)\end{array}$ \\
\hline$\sigma_{E G_{i d i o, j, t}}$ & --- & --- & --- & --- & -- & $\begin{array}{c}0.162308 * * * \\
(3.843813)\end{array}$ & --- & $\begin{array}{l}-0.059889 \\
(1.063957)\end{array}$ & --- & --- \\
\hline$\sigma_{A R_{i d i o, j, t}}$ & --- & --- & --- & --- & --- & --- & $\begin{array}{c}0.189286^{* * *} \\
(5.564617)\end{array}$ & $\begin{array}{c}0.163905 * * * \\
(3.664049)\end{array}$ & --- & --- \\
\hline$O R W_{\text {ratio }}$ & --- & --- & --- & --- & -- & --- & --- & --- & $\begin{array}{l}-0.000099 \\
(0.372917)\end{array}$ & $\begin{array}{l}-0.000103 \\
(0.389417)\end{array}$ \\
\hline$O I$ & --- & --- & --- & --- & --- & --- & --- & --- & $\begin{array}{l}-0.000276 \\
(0.492292)\end{array}$ & $\begin{array}{l}-0.000397 \\
(0.787171)\end{array}$ \\
\hline Constant & $\begin{array}{c}0.048267 * * * \\
(2.910264)\end{array}$ & $\begin{array}{c}0.041968 * * \\
(2.452690)\end{array}$ & $\begin{array}{c}0.041233 * * \\
(2.372815)\end{array}$ & $\begin{array}{c}0.016330 \\
(0.936452)\end{array}$ & $\begin{array}{c}0.021440 \\
(1.229287)\end{array}$ & $\begin{array}{c}0.017256 \\
(0.935481)\end{array}$ & $\begin{array}{c}0.013032 \\
(0.721412)\end{array}$ & $\begin{array}{c}0.007349 \\
(0.399225)\end{array}$ & $\begin{array}{c}0.018049 \\
(0.974556)\end{array}$ & $\begin{array}{c}0.009093 * * \\
(2.535496)\end{array}$ \\
\hline
\end{tabular}




\begin{tabular}{|c|c|c|c|c|c|c|c|c|c|c|}
\hline \multicolumn{11}{|c|}{ Phase 1} \\
\hline Variables & Model 1 & Model 2 & Model 3 & Model 4 & Model 5 & Model 6 & Model 7 & Model 8 & Model 9 & Model 10 \\
\hline$\sigma_{R V_{i d i o, j, t}}$ & --- & --- & $\begin{array}{c}0.598987 * * * \\
(6.806798)\end{array}$ & --- & $\begin{array}{c}0.493716^{* * *} \\
(4.706961)\end{array}$ & $\begin{array}{c}0.486207 * * * \\
(4.930985)\end{array}$ & $\begin{array}{c}0.499804 * * * \\
(5.290286)\end{array}$ & $\begin{array}{c}0.445678 * * * \\
(4.164990)\end{array}$ & $\begin{array}{c}0.505508 * * * \\
(4.814886)\end{array}$ & $\begin{array}{c}0.507165 \\
(4.832167)\end{array}$ \\
\hline $\log S I Z E$ & $\begin{array}{c}-0.008001 * * \\
(2.392376)\end{array}$ & $\begin{array}{c}-0.008001 * * \\
(2.393326)\end{array}$ & $\begin{array}{c}-0.006674 * * \\
(2.026652)\end{array}$ & $\begin{array}{c}-0.005975 * \\
(1.792571)\end{array}$ & $\begin{array}{c}-0.006061 * \\
(1.832876)\end{array}$ & $\begin{array}{l}-0.005159 \\
(1.544007)\end{array}$ & $\begin{array}{c}-0.005773 * \\
(1.749649)\end{array}$ & $\begin{array}{l}-0.005363 \\
(1.603232)\end{array}$ & $\begin{array}{l}-0.003006 \\
(0.819049)\end{array}$ & --- \\
\hline $\log B M$ & $\begin{array}{c}0.001106 \\
(0.302599)\end{array}$ & $\begin{array}{c}0.002324 \\
(0.618730)\end{array}$ & $\begin{array}{l}-0.002675 \\
(0.710203)\end{array}$ & $\begin{array}{l}-0.000527 \\
(0.140220)\end{array}$ & $\begin{array}{l}-0.002987 \\
(0.792973)\end{array}$ & $\begin{array}{l}-0.002597 \\
(0.690997)\end{array}$ & $\begin{array}{l}-0.002795 \\
(0.744107)\end{array}$ & $\begin{array}{l}-0.002914 \\
(0.774134)\end{array}$ & $\begin{array}{l}-0.002195 \\
(0.579403)\end{array}$ & $\begin{array}{c}0.000043 \\
(0.016483)\end{array}$ \\
\hline$r_{t}$ & $\begin{array}{c}0.012149 \\
(0.459622)\end{array}$ & $\begin{array}{c}0.011873 \\
(0.449325)\end{array}$ & $\begin{array}{c}0.005761 \\
(0.221592)\end{array}$ & $\begin{array}{c}0.018473 \\
(0.705172)\end{array}$ & $\begin{array}{c}0.009591 \\
(0.368067)\end{array}$ & $\begin{array}{l}-0.011019 \\
(0.411297)\end{array}$ & $\begin{array}{l}-0.012792 \\
(0.478325)\end{array}$ & $\begin{array}{l}-0.009858 \\
(0.358799)\end{array}$ & $\begin{array}{c}0.012205 \\
(0.468089)\end{array}$ & $\begin{array}{c}0.013720 \\
(0.527577)\end{array}$ \\
\hline$r_{j, t-11: t-1}$ & $\begin{array}{c}0.128066 * * * \\
(5.387022)\end{array}$ & $\begin{array}{c}0.126143 * * * \\
(5.299078)\end{array}$ & $\begin{array}{c}0.125304 * * * \\
(5.352890)\end{array}$ & $\begin{array}{c}0.133759 * * * \\
(5.663394)\end{array}$ & $\begin{array}{c}0.128631 * * * \\
(5.483625)\end{array}$ & $\begin{array}{c}0.131203 * * * \\
(5.588076)\end{array}$ & $\begin{array}{c}0.132769 * * * \\
(5.651048)\end{array}$ & $\begin{array}{c}0.133947 * * * \\
(5.693275)\end{array}$ & $\begin{array}{c}0.130375 * * * \\
(5.557560)\end{array}$ & $\begin{array}{c}0.131251 * * * \\
(5.601430)\end{array}$ \\
\hline$r_{j, t-35: t-12}$ & $\begin{array}{c}0.034899 \\
(1.255888)\end{array}$ & $\begin{array}{c}0.040545 \\
(1.444257)\end{array}$ & $\begin{array}{l}0.048194 * \\
(1.744324)\end{array}$ & $\begin{array}{l}0.046006 * \\
(1.653717)\end{array}$ & $\begin{array}{l}0.049130 * \\
(1.779503)\end{array}$ & $\begin{array}{l}0.047113 * \\
(1.708427)\end{array}$ & $\begin{array}{l}0.049088 * \\
(1.781276)\end{array}$ & $\begin{array}{l}0.049155 * \\
(1.781300)\end{array}$ & $\begin{array}{l}0.048356 * \\
(1.751963)\end{array}$ & $\begin{array}{l}0.047391 * \\
(1.718798)\end{array}$ \\
\hline$\beta_{j}$ & --- & $\begin{array}{l}-0.011568 \\
(1.391597)\end{array}$ & $\begin{array}{c}-0.027448 * * * \\
(3.228892)\end{array}$ & $\begin{array}{c}-0.028848 * * * \\
(3.250992)\end{array}$ & $\begin{array}{c}-0.031873 * * * \\
(3.610838)\end{array}$ & $\begin{array}{c}-0.029876 * * * \\
(3.498967)\end{array}$ & $\begin{array}{c}-0.028847 * * * \\
(3.396702)\end{array}$ & $\begin{array}{c}-0.031301 * * * \\
(3.549772)\end{array}$ & $\begin{array}{c}-0.034026^{* * *} \\
(3.826579)\end{array}$ & $\begin{array}{c}-0.034706^{* * *} \\
(3.920593)\end{array}$ \\
\hline$\sigma_{I V_{i d i o, j, t}}$ & --- & --- & --- & $\begin{array}{c}0.116497 * * * \\
(5.216605)\end{array}$ & $\begin{array}{l}0.048644 * \\
(1.840303)\end{array}$ & --- & --- & $\begin{array}{c}0.025244 \\
(0.851992)\end{array}$ & $\begin{array}{c}0.059617 * * \\
(2.207798)\end{array}$ & $\begin{array}{c}0.063475 * * \\
(2.387549)\end{array}$ \\
\hline$\sigma_{E G_{i d i o, j, t}}$ & --- & --- & --- & --- & --- & $\begin{array}{c}0.237354 * * \\
(2.515746)\end{array}$ & --- & $\begin{array}{c}0.046794 \\
(0.318728)\end{array}$ & --- & --- \\
\hline$\sigma_{A R} i d i o, j, t$ & --- & --- & --- & --- & --- & --- & $\begin{array}{c}0.165199 * * * \\
(2.836243)\end{array}$ & $\begin{array}{c}0.127323 \\
(1.500527)\end{array}$ & --- & --- \\
\hline$O R W_{\text {ratio }}$ & --- & --- & --- & --- & --- & --- & --- & --- & $\begin{array}{c}0.000140 \\
(0.194163)\end{array}$ & $\begin{array}{c}0.000107 \\
(0.148978)\end{array}$ \\
\hline$O I$ & --- & --- & --- & --- & --- & --- & --- & --- & $\begin{array}{c}-0.002995 * \\
(1.955590)\end{array}$ & $\begin{array}{c}-0.003536 * * \\
(2.559313)\end{array}$ \\
\hline Constant & $\begin{array}{c}0.128947 * * \\
(2.561635)\end{array}$ & $\begin{array}{c}0.137233 * * * \\
(2.708306)\end{array}$ & $\begin{array}{c}0.074023 \\
(1.460442)\end{array}$ & $\begin{array}{l}0.090909 * \\
(1.784011)\end{array}$ & $\begin{array}{c}0.065789 \\
(1.294119)\end{array}$ & $\begin{array}{c}0.042760 \\
(0.820929)\end{array}$ & $\begin{array}{c}0.055835 \\
(1.095750)\end{array}$ & $\begin{array}{c}0.049569 \\
(0.949064)\end{array}$ & $\begin{array}{c}0.028661 \\
(0.526749)\end{array}$ & $\begin{array}{l}-0.015112 \\
(1.479657)\end{array}$ \\
\hline
\end{tabular}




\begin{tabular}{|c|c|c|c|c|c|c|c|c|c|c|}
\hline \multicolumn{11}{|c|}{ Phase 2} \\
\hline Variables & Model 1 & Model 2 & Model 3 & Model 4 & Model 5 & Model 6 & Model 7 & Model 8 & Model 9 & Model 10 \\
\hline$\sigma_{R V} i d i o, j, t$ & --- & --- & $\begin{array}{c}0.170222 * * * \\
(3.325476)\end{array}$ & --- & $\begin{array}{c}0.058757 \\
(1.029682)\end{array}$ & $\begin{array}{c}0.176776 * * * \\
(3.325057)\end{array}$ & $\begin{array}{c}0.155108 * * * \\
(2.938172)\end{array}$ & $\begin{array}{c}0.071933 \\
(1.249561)\end{array}$ & $\begin{array}{c}0.060924 \\
(1.065542)\end{array}$ & $\begin{array}{c}0.060137 \\
(1.051458)\end{array}$ \\
\hline $\log S I Z E$ & $\begin{array}{c}0.000580 \\
(0.529983)\end{array}$ & $\begin{array}{c}0.000622 \\
(0.564084)\end{array}$ & $\begin{array}{c}0.000899 \\
(0.813847)\end{array}$ & $\begin{array}{c}0.001870 * \\
(1.665591)\end{array}$ & $\begin{array}{c}0.001847 \\
(1.644608)\end{array}$ & $\begin{array}{c}0.000773 \\
(0.678683)\end{array}$ & $\begin{array}{c}0.001249 \\
(1.091391)\end{array}$ & $\begin{array}{c}0.001592 \\
(1.381983)\end{array}$ & $\begin{array}{l}0.002270 * \\
(1.822451)\end{array}$ & --- \\
\hline $\log B M$ & $\begin{array}{c}0.001602 \\
(1.449928)\end{array}$ & $\begin{array}{c}0.001511 \\
(1.323711)\end{array}$ & $\begin{array}{c}0.000861 \\
(0.744406)\end{array}$ & $\begin{array}{c}0.001198 \\
(1.052521)\end{array}$ & $\begin{array}{c}0.001003 \\
(0.869647)\end{array}$ & $\begin{array}{c}0.000881 \\
(0.761330)\end{array}$ & $\begin{array}{c}0.000749 \\
(0.645165)\end{array}$ & $\begin{array}{c}0.000997 \\
(0.859791)\end{array}$ & $\begin{array}{c}0.001026 \\
(0.888783)\end{array}$ & $\begin{array}{l}-0.000175 \\
(0.184076)\end{array}$ \\
\hline$r_{t}$ & $\begin{array}{c}0.033510 * * \\
(1.986576)\end{array}$ & $\begin{array}{c}0.033306 * * \\
(1.972812)\end{array}$ & $\begin{array}{c}0.033879 * * \\
(2.009579)\end{array}$ & $\begin{array}{c}0.041180 * * \\
(2.439970)\end{array}$ & $\begin{array}{c}0.040629 * * \\
(2.406106)\end{array}$ & $\begin{array}{c}0.034091 * * \\
(2.021161)\end{array}$ & $\begin{array}{c}0.033275 * * \\
(1.972936)\end{array}$ & $\begin{array}{c}0.041524 * * \\
(2.454353)\end{array}$ & $\begin{array}{c}0.041983 * * \\
(2.477378)\end{array}$ & $\begin{array}{c}0.041094 * * \\
(2.425135)\end{array}$ \\
\hline$r_{j, t-11: t-1}$ & $\begin{array}{c}-0.033729 * * \\
(2.240217)\end{array}$ & $\begin{array}{c}-0.033907 * * \\
(2.250213)\end{array}$ & $\begin{array}{c}-0.037055 * * \\
(2.457857)\end{array}$ & $\begin{array}{c}-0.038286 * * \\
(2.547396)\end{array}$ & $\begin{array}{c}-0.038956 * * * \\
(2.589575)\end{array}$ & $\begin{array}{c}-0.036935 * * \\
(2.449242)\end{array}$ & $\begin{array}{c}-0.037179 * * \\
(2.466154)\end{array}$ & $\begin{array}{c}-0.038529 * * \\
(2.561581)\end{array}$ & $\begin{array}{c}-0.038917 * * * \\
(2.585717)\end{array}$ & $\begin{array}{c}-0.039014 * * * \\
(2.591280)\end{array}$ \\
\hline$r_{j, t-35: t-12}$ & $\begin{array}{c}0.055805^{* * *} \\
(5.076180)\end{array}$ & $\begin{array}{c}0.055818 * * * \\
(5.076653)\end{array}$ & $\begin{array}{c}0.055107 * * * \\
(5.018299)\end{array}$ & $\begin{array}{c}0.056456 * * * \\
(5.155241)\end{array}$ & $\begin{array}{c}0.056150 * * * \\
(5.125438)\end{array}$ & $\begin{array}{c}0.055065 * * * \\
(5.013749)\end{array}$ & $\begin{array}{c}0.055089 * * * \\
(5.016946)\end{array}$ & $\begin{array}{c}0.055953 * * * \\
(5.108343)\end{array}$ & $\begin{array}{c}0.056234 * * * \\
(5.131504)\end{array}$ & $\begin{array}{c}0.055761 * * * \\
(5.088096)\end{array}$ \\
\hline$\beta_{j}$ & --- & $\begin{array}{c}0.000779 \\
(0.320617)\end{array}$ & $\begin{array}{l}-0.001864 \\
(0.730560)\end{array}$ & $\begin{array}{c}-0.004457 * \\
(1.710572)\end{array}$ & $\begin{array}{c}-0.004871 * \\
(1.847606)\end{array}$ & $\begin{array}{l}-0.001623 \\
(0.622876)\end{array}$ & $\begin{array}{l}-0.002684 \\
(1.014341)\end{array}$ & $\begin{array}{c}-0.004631 * \\
(1.725541)\end{array}$ & $\begin{array}{c}-0.004899 * \\
(1.857543)\end{array}$ & $\begin{array}{c}-0.005053 * \\
(1.915999)\end{array}$ \\
\hline$\sigma_{I V_{i d i o, j, t}}$ & --- & --- & --- & $\begin{array}{c}0.104875^{* * *} \\
(5.401764)\end{array}$ & $\begin{array}{c}0.094895 * * * \\
(4.373018)\end{array}$ & --- & --- & $\begin{array}{c}0.100415^{* * * *} \\
(4.359342)\end{array}$ & $\begin{array}{c}0.098609 * * * \\
(4.478606)\end{array}$ & $\begin{array}{c}0.089127 * * * \\
(4.164555)\end{array}$ \\
\hline$\sigma_{E G_{i d i o, j, t}}$ & --- & --- & --- & --- & --- & $\begin{array}{l}-0.024572 \\
(0.456919)\end{array}$ & --- & $\begin{array}{c}-0.139599 * \\
(1.956463)\end{array}$ & --- & --- \\
\hline$\sigma_{A R} i d i o, j, t$ & --- & --- & --- & --- & --- & --- & $\begin{array}{c}0.066300 \\
(1.169478)\end{array}$ & $\begin{array}{c}0.077106 \\
(1.005350)\end{array}$ & --- & --- \\
\hline ORW $W_{\text {ratio }}$ & --- & --- & --- & --- & --- & --- & --- & --- & $\begin{array}{c}0.000161 \\
(0.638774)\end{array}$ & $\begin{array}{c}0.000167 \\
(0.660569)\end{array}$ \\
\hline$O I$ & --- & --- & --- & --- & --- & --- & --- & --- & $\begin{array}{l}-0.000467 \\
(0.828940)\end{array}$ & $\begin{array}{l}-0.000024 \\
(0.047210)\end{array}$ \\
\hline Constant & $\begin{array}{c}0.001797 \\
(0.106301)\end{array}$ & $\begin{array}{c}0.000504 \\
(0.028976)\end{array}$ & $\begin{array}{l}-0.011636 \\
(0.656127)\end{array}$ & $\begin{array}{l}-0.026830 \\
(1.487743)\end{array}$ & $\begin{array}{l}-0.028419 \\
(1.570132)\end{array}$ & $\begin{array}{l}-0.008473 \\
(0.445033)\end{array}$ & $\begin{array}{c}-0.020495 \\
(1.062837)\end{array}$ & $\begin{array}{c}-0.021730 \\
(1.117808)\end{array}$ & $\begin{array}{c}-0.033383 * \\
(1.739388)\end{array}$ & $\begin{array}{c}0.000863 \\
(0.221002)\end{array}$ \\
\hline
\end{tabular}




\begin{tabular}{|c|c|c|c|c|c|c|c|c|c|c|}
\hline \multicolumn{11}{|c|}{ Phase 4} \\
\hline Variables & Model 1 & Model 2 & Model 3 & Model 4 & Model 5 & Model 6 & Model 7 & Model 8 & Model 9 & Model 10 \\
\hline$\sigma_{R V_{i d i o, j, t}}$ & --- & --- & $\begin{array}{c}0.070367 \\
(0.908090)\end{array}$ & & $\begin{array}{l}-0.118580 \\
(1.336089)\end{array}$ & $\begin{array}{c}0.043425 \\
(0.554005)\end{array}$ & $\begin{array}{c}0.047542 \\
(0.612135)\end{array}$ & $\begin{array}{l}-0.121374 \\
(1.368497)\end{array}$ & $\begin{array}{l}-0.115006 \\
(1.289243)\end{array}$ & $\begin{array}{l}-0.115636 \\
(1.297059)\end{array}$ \\
\hline $\log S I Z E$ & $\begin{array}{c}-0.004732 * \\
(1.792692)\end{array}$ & $\begin{array}{l}-0.002140 \\
(0.774027)\end{array}$ & $\begin{array}{l}-0.001946 \\
(0.701957)\end{array}$ & $\begin{array}{c}0.000463 \\
(0.164294)\end{array}$ & $\begin{array}{c}0.000615 \\
(0.218091)\end{array}$ & $\begin{array}{c}-0.000971 \\
(0.346040)\end{array}$ & $\begin{array}{l}-0.000580 \\
(0.206819)\end{array}$ & $\begin{array}{c}0.001506 \\
(0.529206)\end{array}$ & $\begin{array}{l}-0.001003 \\
(0.313787)\end{array}$ & --- \\
\hline $\log B M$ & $\begin{array}{c}0.002659 \\
(1.011683)\end{array}$ & $\begin{array}{c}0.002762 \\
(1.053993)\end{array}$ & $\begin{array}{c}0.002118 \\
(0.779836)\end{array}$ & $\begin{array}{c}0.001608 \\
(0.613595)\end{array}$ & $\begin{array}{c}0.002482 \\
(0.919363)\end{array}$ & $\begin{array}{c}0.002294 \\
(0.845522)\end{array}$ & $\begin{array}{c}0.002131 \\
(0.787065)\end{array}$ & $\begin{array}{c}0.002469 \\
(0.915131)\end{array}$ & $\begin{array}{c}0.002557 \\
(0.946560)\end{array}$ & $\begin{array}{c}0.002987 \\
(1.284708)\end{array}$ \\
\hline$r_{t}$ & $\begin{array}{c}0.001632 \\
(0.062847)\end{array}$ & $\begin{array}{l}-0.012268 \\
(0.466833)\end{array}$ & $\begin{array}{l}-0.013969 \\
(0.530192)\end{array}$ & $\begin{array}{l}-0.015259 \\
(0.583879)\end{array}$ & $\begin{array}{l}-0.012941 \\
(0.494246)\end{array}$ & $\begin{array}{l}-0.020852 \\
(0.786766)\end{array}$ & $\begin{array}{l}-0.020201 \\
(0.766344)\end{array}$ & $\begin{array}{l}-0.018190 \\
(0.689947)\end{array}$ & $\begin{array}{l}-0.015305 \\
(0.582954)\end{array}$ & $\begin{array}{l}-0.015278 \\
(0.582106)\end{array}$ \\
\hline$r_{j, t-11: t-1}$ & $\begin{array}{c}0.180331 * * * \\
(7.742239)\end{array}$ & $\begin{array}{c}0.175812 * * * \\
(7.555847)\end{array}$ & $\begin{array}{c}0.177851 * * * \\
(7.607655)\end{array}$ & $\begin{array}{c}0.184507 * * * \\
(7.944028)\end{array}$ & $\begin{array}{c}0.182667 * * * \\
(7.853269)\end{array}$ & $\begin{array}{c}0.179377 * * * \\
(7.679588)\end{array}$ & $\begin{array}{c}0.181726 * * * \\
(7.782310)\end{array}$ & $\begin{array}{c}0.185354 * * * \\
(7.968590)\end{array}$ & $\begin{array}{c}0.182107 * * * \\
(7.826845)\end{array}$ & $\begin{array}{c}0.182140 * * * \\
(7.830907)\end{array}$ \\
\hline$r_{j, t-35: t-12}$ & $\begin{array}{l}-0.017280 \\
(0.348323)\end{array}$ & $\begin{array}{l}-0.018015 \\
(0.364239)\end{array}$ & $\begin{array}{l}-0.015766 \\
(0.318358)\end{array}$ & $\begin{array}{l}-0.017046 \\
(0.346681)\end{array}$ & $\begin{array}{l}-0.020657 \\
(0.419613)\end{array}$ & $\begin{array}{l}-0.012500 \\
(0.252630)\end{array}$ & $\begin{array}{l}-0.008920 \\
(0.180407)\end{array}$ & $\begin{array}{l}-0.014741 \\
(0.299390)\end{array}$ & $\begin{array}{l}-0.021168 \\
(0.429189)\end{array}$ & $\begin{array}{l}-0.022034 \\
(0.447601)\end{array}$ \\
\hline$\beta_{j}$ & --- & $\begin{array}{c}0.018796 * * * \\
(3.064087)\end{array}$ & $\begin{array}{c}0.016783 * * \\
(2.572988)\end{array}$ & $\begin{array}{c}0.009604 \\
(1.480996)\end{array}$ & $\begin{array}{l}0.011308 * \\
(1.711523)\end{array}$ & $\begin{array}{c}0.010366 \\
(1.447999)\end{array}$ & $\begin{array}{c}0.010607 \\
(1.551413)\end{array}$ & $\begin{array}{c}0.006679 \\
(0.931664)\end{array}$ & $\begin{array}{c}0.009656 \\
(1.434723)\end{array}$ & $\begin{array}{c}0.010205 \\
(1.570842)\end{array}$ \\
\hline$\sigma_{I V}$ idio,j,t & --- & --- & --- & $\begin{array}{c}0.083368 * * * \\
(4.168898)\end{array}$ & $\begin{array}{c}0.098672 * * * \\
(4.282493)\end{array}$ & --- & --- & $\begin{array}{c}0.090225 * * * \\
(3.824556)\end{array}$ & $\begin{array}{c}0.096537 * * * \\
(4.141875)\end{array}$ & $\begin{array}{c}0.097836 * * * \\
(4.266818)\end{array}$ \\
\hline$\sigma_{E G_{i d i o, j, t}}$ & --- & --- & --- & --- & --- & $\begin{array}{c}0.223862 * * \\
(2.160869)\end{array}$ & --- & $\begin{array}{c}0.008923 \\
(0.072191)\end{array}$ & --- & --- \\
\hline$\sigma_{A R} i d i o, j, t$ & --- & --- & --- & --- & --- & --- & $\begin{array}{c}0.247135 * * * \\
(2.935476)\end{array}$ & $\begin{array}{l}0.193756 * \\
(1.950311)\end{array}$ & --- & --- \\
\hline ORW $W_{\text {ratio }}$ & --- & --- & --- & --- & --- & --- & --- & --- & $\begin{array}{l}-0.000485 \\
(0.550165)\end{array}$ & $\begin{array}{l}-0.000506 \\
(0.575100)\end{array}$ \\
\hline$O I$ & --- & --- & --- & --- & --- & --- & --- & --- & $\begin{array}{c}0.001979 \\
(1.237300)\end{array}$ & $\begin{array}{c}0.001752 \\
(1.228292)\end{array}$ \\
\hline Constant & $\begin{array}{c}0.103751 * * \\
(2.537428)\end{array}$ & $\begin{array}{c}0.042489 \\
(0.935797)\end{array}$ & $\begin{array}{c}0.035725 \\
(0.776406)\end{array}$ & $\begin{array}{l}-0.011046 \\
(0.235376)\end{array}$ & $\begin{array}{l}-0.009475 \\
(0.201903)\end{array}$ & $\begin{array}{c}0.013041 \\
(0.276667)\end{array}$ & $\begin{array}{c}0.004103 \\
(0.087051)\end{array}$ & $\begin{array}{c}-0.031302 \\
(0.652767)\end{array}$ & $\begin{array}{c}0.006716 \\
(0.134564)\end{array}$ & $\begin{array}{l}-0.008543 \\
(0.761144)\end{array}$ \\
\hline
\end{tabular}




\begin{tabular}{|c|c|c|c|c|c|c|c|c|c|c|}
\hline \multicolumn{11}{|c|}{ Phase 3} \\
\hline Variables & Model 1 & Model 2 & Model 3 & Model 4 & Model 5 & Model 6 & Model 7 & Model 8 & Model 9 & Model 10 \\
\hline$\sigma_{R V_{i d i o, j, t}}$ & --- & --- & $\begin{array}{c}-0.274735^{* * * *} \\
(3.572008)\end{array}$ & --- & $\begin{array}{c}-0.422617 * * * \\
(4.593333)\end{array}$ & $\begin{array}{c}-0.261553 * * * \\
(3.385402)\end{array}$ & $\begin{array}{c}-0.255486^{* * *} \\
(3.306753)\end{array}$ & $\begin{array}{c}-0.451041 * * * \\
(4.911004)\end{array}$ & $\begin{array}{c}-0.422307 * * * \\
(4.588542)\end{array}$ & $\begin{array}{c}-0.420540 * * * \\
(4.582565)\end{array}$ \\
\hline $\log S I Z E$ & $\begin{array}{l}-0.001959 \\
(0.463182)\end{array}$ & $\begin{array}{l}-0.002714 \\
(0.633027)\end{array}$ & $\begin{array}{l}-0.002949 \\
(0.693553)\end{array}$ & $\begin{array}{l}-0.002471 \\
(0.570463)\end{array}$ & $\begin{array}{l}-0.001018 \\
(0.237841)\end{array}$ & $\begin{array}{l}-0.005292 \\
(1.178777)\end{array}$ & $\begin{array}{l}-0.005238 \\
(1.196323)\end{array}$ & $\begin{array}{l}-0.005204 \\
(1.167895)\end{array}$ & $\begin{array}{c}0.001356 \\
(0.288393)\end{array}$ & --- \\
\hline $\log B M$ & $\begin{array}{c}0.000054 \\
(0.012381)\end{array}$ & $\begin{array}{c}0.001017 \\
(0.227270)\end{array}$ & $\begin{array}{c}0.004321 \\
(0.953496)\end{array}$ & $\begin{array}{c}0.000892 \\
(0.198816)\end{array}$ & $\begin{array}{c}0.005044 \\
(1.117300)\end{array}$ & $\begin{array}{c}0.003452 \\
(0.757195)\end{array}$ & $\begin{array}{c}0.004095 \\
(0.905569)\end{array}$ & $\begin{array}{c}0.004205 \\
(0.931262)\end{array}$ & $\begin{array}{c}0.005277 \\
(1.166816)\end{array}$ & $\begin{array}{c}0.004466 \\
(1.262097)\end{array}$ \\
\hline$r_{t}$ & $\begin{array}{l}-0.006348 \\
(0.150344)\end{array}$ & $\begin{array}{l}-0.014251 \\
(0.332464)\end{array}$ & $\begin{array}{l}-0.064579 \\
(1.442185)\end{array}$ & $\begin{array}{l}-0.007922 \\
(0.173539)\end{array}$ & $\begin{array}{l}-0.038082 \\
(0.837486)\end{array}$ & $\begin{array}{l}-0.065002 \\
(1.453302)\end{array}$ & $\begin{array}{l}-0.057876 \\
(1.292473)\end{array}$ & $\begin{array}{l}-0.019415 \\
(0.426102)\end{array}$ & $\begin{array}{l}-0.037243 \\
(0.818684)\end{array}$ & $\begin{array}{l}-0.037748 \\
(0.830955)\end{array}$ \\
\hline$r_{j, t-11: t-1}$ & $\begin{array}{l}-0.029245 \\
(0.408972)\end{array}$ & $\begin{array}{l}-0.022034 \\
(0.306781)\end{array}$ & $\begin{array}{l}-0.041533 \\
(0.581482)\end{array}$ & $\begin{array}{l}-0.019696 \\
(0.273189)\end{array}$ & $\begin{array}{l}-0.032239 \\
(0.453301)\end{array}$ & $\begin{array}{l}-0.037204 \\
(0.521109)\end{array}$ & $\begin{array}{l}-0.034582 \\
(0.484853)\end{array}$ & $\begin{array}{l}-0.015837 \\
(0.223712)\end{array}$ & $\begin{array}{l}-0.032802 \\
(0.460563)\end{array}$ & $\begin{array}{l}-0.030156 \\
(0.427261)\end{array}$ \\
\hline$r_{j, t-35: t-12}$ & $\begin{array}{l}-0.068126 \\
(0.904625)\end{array}$ & $\begin{array}{l}-0.066945 \\
(0.888933)\end{array}$ & $\begin{array}{l}-0.057245 \\
(0.766089)\end{array}$ & $\begin{array}{l}-0.066341 \\
(0.880207)\end{array}$ & $\begin{array}{l}-0.046912 \\
(0.630423)\end{array}$ & $\begin{array}{l}-0.057661 \\
(0.772544)\end{array}$ & $\begin{array}{l}-0.060657 \\
(0.813593)\end{array}$ & $\begin{array}{l}-0.046764 \\
(0.632658)\end{array}$ & $\begin{array}{l}-0.041144 \\
(0.551697)\end{array}$ & $\begin{array}{l}-0.039472 \\
(0.531246)\end{array}$ \\
\hline$\beta_{j}$ & --- & $\begin{array}{l}-0.010877 \\
(1.063886)\end{array}$ & $\begin{array}{l}-0.003853 \\
(0.373071)\end{array}$ & $\begin{array}{l}-0.012287 \\
(1.137072)\end{array}$ & $\begin{array}{l}-0.012013 \\
(1.127744)\end{array}$ & $\begin{array}{c}0.003510 \\
(0.311089)\end{array}$ & $\begin{array}{c}0.007335 \\
(0.633116)\end{array}$ & $\begin{array}{c}0.004794 \\
(0.410523)\end{array}$ & $\begin{array}{l}-0.010384 \\
(0.967280)\end{array}$ & $\begin{array}{l}-0.010850 \\
(1.022950)\end{array}$ \\
\hline$\sigma_{I V_{i d i o, j, t}}$ & --- & --- & --- & $\begin{array}{c}0.010377 \\
(0.405132)\end{array}$ & $\begin{array}{c}0.087853 * * * \\
(2.893386)\end{array}$ & --- & --- & $\begin{array}{c}0.125840 * * * \\
(3.901084)\end{array}$ & $\begin{array}{c}0.091348 * * * \\
(2.994132)\end{array}$ & $\begin{array}{c}0.089805^{* * *} \\
(2.991891)\end{array}$ \\
\hline$\sigma_{E G_{i d i o, j, t}}$ & --- & --- & --- & --- & --- & $\begin{array}{l}-0.268740 \\
(1.610764)\end{array}$ & --- & $\begin{array}{l}-0.276374 \\
(1.370538)\end{array}$ & --- & --- \\
\hline$\sigma_{A R_{i d i o}, j, t}$ & --- & --- & --- & --- & --- & --- & $\begin{array}{c}-0.423393 * * \\
(2.109469)\end{array}$ & $\begin{array}{c}-0.483031 * * \\
(2.014662)\end{array}$ & --- & --- \\
\hline$O R W_{\text {ratio }}$ & --- & --- & --- & --- & --- & --- & --- & --- & $\begin{array}{c}0.000190 \\
(0.213446)\end{array}$ & $\begin{array}{c}0.000197 \\
(0.221489)\end{array}$ \\
\hline$O I$ & --- & --- & --- & --- & --- & --- & --- & --- & $\begin{array}{l}-0.002977 \\
(1.247079)\end{array}$ & $\begin{array}{c}-0.002694 \\
(1.238633)\end{array}$ \\
\hline Constant & $\begin{array}{c}0.000687 \\
(0.010527)\end{array}$ & $\begin{array}{c}0.023374 \\
(0.340414)\end{array}$ & $\begin{array}{c}0.050105 \\
(0.731522)\end{array}$ & $\begin{array}{c}0.018430 \\
(0.264122)\end{array}$ & $\begin{array}{c}0.022641 \\
(0.329145)\end{array}$ & $\begin{array}{c}0.098308 \\
(1.316511)\end{array}$ & $\begin{array}{c}0.104893 \\
(1.435065)\end{array}$ & $\begin{array}{c}0.122844 \\
(1.643422)\end{array}$ & $\begin{array}{l}-0.000698 \\
(0.009759)\end{array}$ & $\begin{array}{c}0.019346 \\
(1.159714)\end{array}$ \\
\hline
\end{tabular}


Table 13.3: Financial Sector

\begin{tabular}{|c|c|c|c|c|c|c|c|c|c|c|}
\hline \multicolumn{11}{|c|}{ Entire Phases } \\
\hline Variables & Model 1 & Model 2 & Model 3 & Model 4 & Model 5 & Model 6 & Model 7 & Model 8 & Model 9 & Model 10 \\
\hline$\sigma_{R V i d i o, j, t}$ & --- & --- & $\begin{array}{l}-0.019519 \\
(0.956957)\end{array}$ & --- & $\begin{array}{c}-0.180444 * * * \\
(5.720938)\end{array}$ & $\begin{array}{c}-0.090668 * * * \\
(3.839654)\end{array}$ & $\begin{array}{c}-0.051781 * * \\
(2.324336)\end{array}$ & $\begin{array}{c}-0.201273 * * * \\
(6.306097)\end{array}$ & $\begin{array}{c}-0.184236 * * * \\
(5.817389)\end{array}$ & $\begin{array}{c}-0.176084 * * * \\
(5.563684)\end{array}$ \\
\hline $\log S I Z E$ & $\begin{array}{c}-0.004990 * * * \\
(3.680922)\end{array}$ & $\begin{array}{c}-0.006018 * * * \\
(4.413970)\end{array}$ & $\begin{array}{c}-0.006139 * * * \\
(4.483244)\end{array}$ & $\begin{array}{c}-0.005497 * * * \\
(4.011899)\end{array}$ & $\begin{array}{c}-0.005619 * * * \\
(4.110351)\end{array}$ & $\begin{array}{c}-0.005093 * * * \\
(3.698710)\end{array}$ & $\begin{array}{c}-0.005749 * * * \\
(4.189392)\end{array}$ & $\begin{array}{c}-0.004955 * * * \\
(3.603986)\end{array}$ & $\begin{array}{c}-0.006784 * * * \\
(4.177059)\end{array}$ & --- \\
\hline $\log B M$ & $\begin{array}{l}0.002188 * \\
(1.748350)\end{array}$ & $\begin{array}{c}0.000723 \\
(0.568033)\end{array}$ & $\begin{array}{c}0.000910 \\
(0.706326)\end{array}$ & $\begin{array}{l}-0.000072 \\
(0.055902)\end{array}$ & $\begin{array}{c}0.000140 \\
(0.108312)\end{array}$ & $\begin{array}{c}0.000468 \\
(0.363435)\end{array}$ & $\begin{array}{c}0.000703 \\
(0.545954)\end{array}$ & $\begin{array}{l}-0.000035 \\
(0.027043)\end{array}$ & $\begin{array}{l}-0.000132 \\
(0.100859)\end{array}$ & $\begin{array}{c}0.002971 * * * \\
(2.766313)\end{array}$ \\
\hline$r_{t}$ & $\begin{array}{c}0.078187 * * * \\
(6.412803)\end{array}$ & $\begin{array}{c}0.073961 * * * \\
(6.071148)\end{array}$ & $\begin{array}{c}0.072688 * * * \\
(5.931281)\end{array}$ & $\begin{array}{c}0.082373 * * * \\
(6.643438)\end{array}$ & $\begin{array}{c}0.086596 * * * \\
(6.988279)\end{array}$ & $\begin{array}{c}0.060824 * * * \\
(4.910770)\end{array}$ & $\begin{array}{c}0.068873 * * * \\
(5.603894)\end{array}$ & $\begin{array}{c}0.075213 * * * \\
(5.930811)\end{array}$ & $\begin{array}{c}0.085468 * * * \\
(6.880616)\end{array}$ & $\begin{array}{c}0.088451 * * * \\
(7.123780)\end{array}$ \\
\hline$r_{j, t-11: t-1}$ & $\begin{array}{c}0.042485 * * * \\
(3.586146)\end{array}$ & $\begin{array}{c}0.042832 * * * \\
(3.624636)\end{array}$ & $\begin{array}{c}0.041654 * * * \\
(3.505862)\end{array}$ & $\begin{array}{c}0.047263 * * * \\
(3.981039)\end{array}$ & $\begin{array}{c}0.044794 * * * \\
(3.779474)\end{array}$ & $\begin{array}{c}0.043967 * * * \\
(3.708046)\end{array}$ & $\begin{array}{c}0.043678 * * * \\
(3.675390)\end{array}$ & $\begin{array}{c}0.045908 * * * \\
(3.874893)\end{array}$ & $\begin{array}{c}0.044816^{* * *} \\
(3.779760)\end{array}$ & $\begin{array}{c}0.045300 * * * \\
(3.816089)\end{array}$ \\
\hline$r_{j, t-35: t-12}$ & $\begin{array}{l}-0.010867 \\
(0.750674)\end{array}$ & $\begin{array}{l}-0.012660 \\
(0.876588)\end{array}$ & $\begin{array}{l}-0.012586 \\
(0.871440)\end{array}$ & $\begin{array}{l}-0.012483 \\
(0.865091)\end{array}$ & $\begin{array}{l}-0.011462 \\
(0.796143)\end{array}$ & $\begin{array}{l}-0.011831 \\
(0.821224)\end{array}$ & $\begin{array}{l}-0.011783 \\
(0.816429)\end{array}$ & $\begin{array}{l}-0.011114 \\
(0.772741)\end{array}$ & $\begin{array}{l}-0.011428 \\
(0.793514)\end{array}$ & $\begin{array}{l}-0.010785 \\
(0.747993)\end{array}$ \\
\hline$\beta_{j}$ & --- & $\begin{array}{c}0.013548 * * * \\
(5.910003)\end{array}$ & $\begin{array}{c}0.014223 * * * \\
(5.930046)\end{array}$ & $\begin{array}{c}0.010738 * * * \\
(4.432279)\end{array}$ & $\begin{array}{c}0.011633 * * * \\
(4.803181)\end{array}$ & $\begin{array}{c}0.011230 * * * \\
(4.593477)\end{array}$ & $\begin{array}{c}0.012977 * * * \\
(5.359361)\end{array}$ & $\begin{array}{c}0.009944 * * * \\
(4.051887)\end{array}$ & $\begin{array}{c}0.011315 * * * \\
(4.630703)\end{array}$ & $\begin{array}{c}0.010568 * * * \\
(4.331488)\end{array}$ \\
\hline$\sigma_{I V} i d i o, j, t$ & --- & --- & --- & $\begin{array}{c}0.018279 * * * \\
(3.559193)\end{array}$ & $\begin{array}{c}0.053045^{* * * *} \\
(6.673501)\end{array}$ & --- & --- & $\begin{array}{c}0.042687 * * * \\
(5.103467)\end{array}$ & $\begin{array}{c}0.051726 * * * \\
(6.442140)\end{array}$ & $\begin{array}{c}0.055645 * * * \\
(6.969447)\end{array}$ \\
\hline$\sigma_{E G_{i d i o, j, t}}$ & --- & --- & --- & --- & --- & $\begin{array}{c}0.218533 * * * \\
(5.935799)\end{array}$ & --- & $\begin{array}{c}0.157596 * * * \\
(3.594785)\end{array}$ & --- & --- \\
\hline$\sigma_{A R}$ idio, $j, t$ & --- & --- & --- & --- & --- & --- & $\begin{array}{c}0.082451 * * * \\
(3.584903)\end{array}$ & $\begin{array}{c}0.002413 \\
(0.089780)\end{array}$ & --- & --- \\
\hline ORW $W_{\text {ratio }}$ & --- & --- & --- & --- & --- & --- & --- & --- & $\begin{array}{c}0.000054 \\
(0.306288)\end{array}$ & $\begin{array}{l}-0.000005 \\
(0.029433)\end{array}$ \\
\hline$O I$ & --- & --- & --- & --- & --- & --- & --- & --- & $\begin{array}{c}0.000807 \\
(1.284614)\end{array}$ & $\begin{array}{l}-0.000584 \\
(1.096423)\end{array}$ \\
\hline Constant & $\begin{array}{c}0.082121 * * * \\
(3.794402)\end{array}$ & $\begin{array}{c}0.086128 * * * \\
(3.987668)\end{array}$ & $\begin{array}{c}0.088913 * * * \\
(4.079734)\end{array}$ & $\begin{array}{c}0.076822 * * * \\
(3.534075)\end{array}$ & $\begin{array}{c}0.084875^{* * * *} \\
(3.905659)\end{array}$ & $\begin{array}{c}0.065441 * * * \\
(2.961814)\end{array}$ & $\begin{array}{c}0.080245 * * * \\
(3.662744)\end{array}$ & $\begin{array}{c}0.068483 * * * \\
(3.103216)\end{array}$ & $\begin{array}{c}0.100514 * * * \\
(4.068327)\end{array}$ & $\begin{array}{l}-0.001787 \\
(0.548466)\end{array}$ \\
\hline
\end{tabular}




\begin{tabular}{|c|c|c|c|c|c|c|c|c|c|c|}
\hline \multicolumn{11}{|c|}{ Phase 1} \\
\hline Variables & Model 1 & Model 2 & Model 3 & Model 4 & Model 5 & Model 6 & Model 7 & Model 8 & Model 9 & Model 10 \\
\hline$\sigma_{R V \text { idio }, t, t}$ & --- & --- & 0.103957 & --- & -0.020520 & 0.093773 & 0.115320 & -0.016845 & -0.024361 & -0.021845 \\
\hline & & & (1.476488) & & $(0.259604)$ & (1.301016) & (1.612351) & $(0.212794)$ & $(0.308164)$ & $(0.275214)$ \\
\hline $\log S I Z E$ & $\begin{array}{c}-0.008705 * * * \\
(3.449893)\end{array}$ & $\begin{array}{c}-0.008770 * * * \\
(3.477814)\end{array}$ & $\begin{array}{c}-0.008532 * * * \\
(3.378187)\end{array}$ & $\begin{array}{c}-0.007486 * * * \\
(2.955677)\end{array}$ & $\begin{array}{c}-0.007486^{* * *} \\
(2.954683)\end{array}$ & $\begin{array}{c}-0.008505^{* * *} \\
(3.366419)\end{array}$ & $\begin{array}{c}-0.008552 * * * \\
(3.385782)\end{array}$ & $\begin{array}{c}-0.007410 * * * \\
(2.926092)\end{array}$ & $\begin{array}{c}-0.009521 * * * \\
(3.406590)\end{array}$ & --- \\
\hline $\log B M$ & $\begin{array}{l}-0.002299 \\
(0.957910)\end{array}$ & $\begin{array}{c}-0.002078 \\
(0.865311)\end{array}$ & $\begin{array}{l}-0.002095 \\
(0.872675)\end{array}$ & $\begin{array}{c}-0.002074 \\
(0.867980)\end{array}$ & $\begin{array}{l}-0.002071 \\
(0.866208)\end{array}$ & $\begin{array}{l}-0.002228 \\
(0.924535)\end{array}$ & $\begin{array}{l}-0.002016 \\
(0.839041)\end{array}$ & $\begin{array}{l}-0.002072 \\
(0.864060)\end{array}$ & $\begin{array}{c}-0.002461 \\
(1.025415)\end{array}$ & $\begin{array}{c}0.002676 \\
(1.427416)\end{array}$ \\
\hline$r_{t}$ & $\begin{array}{c}-0.111444 * * * \\
(4.094554)\end{array}$ & $\begin{array}{c}-0.112434 * * * \\
(4.132973)\end{array}$ & $\begin{array}{c}-0.104835 * * * \\
(3.788195)\end{array}$ & $\begin{array}{c}-0.089254 * * * \\
(3.212868)\end{array}$ & $\begin{array}{c}-0.089910 * * * \\
(3.222010)\end{array}$ & $\begin{array}{c}-0.106428 * * * \\
(3.830525)\end{array}$ & $\begin{array}{c}-0.103718^{* * *} \\
(3.743845)\end{array}$ & $\begin{array}{c}-0.088270 * * * \\
(3.136823)\end{array}$ & $\begin{array}{c}-0.092588 * * * \\
(3.314254)\end{array}$ & $\begin{array}{c}-0.084325 * * * \\
(3.017435)\end{array}$ \\
\hline$r_{j, t-11: t-1}$ & $\begin{array}{c}0.001115 \\
(0.052582)\end{array}$ & $\begin{array}{l}-0.000136 \\
(0.006407)\end{array}$ & $\begin{array}{c}0.001701 \\
(0.080087)\end{array}$ & $\begin{array}{c}0.000338 \\
(0.016036)\end{array}$ & $\begin{array}{l}-0.000007 \\
(0.000322)\end{array}$ & $\begin{array}{c}0.001072 \\
(0.050437)\end{array}$ & $\begin{array}{c}0.002410 \\
(0.113409)\end{array}$ & $\begin{array}{c}0.000737 \\
(0.034819)\end{array}$ & $\begin{array}{l}-0.000562 \\
(0.026566)\end{array}$ & $\begin{array}{c}0.001572 \\
(0.074029)\end{array}$ \\
\hline$r_{j, t-35: t-12}$ & $\begin{array}{c}0.022090 \\
(1.129198)\end{array}$ & $\begin{array}{c}0.028380 \\
(1.426228)\end{array}$ & $\begin{array}{c}0.027758 \\
(1.395309)\end{array}$ & $\begin{array}{c}0.024275 \\
(1.224103)\end{array}$ & $\begin{array}{c}0.024249 \\
(1.222295)\end{array}$ & $\begin{array}{c}0.027295 \\
(1.370853)\end{array}$ & $\begin{array}{c}0.028788 \\
(1.444616)\end{array}$ & $\begin{array}{c}0.025977 \\
(1.308993)\end{array}$ & $\begin{array}{c}0.024697 \\
(1.244742)\end{array}$ & $\begin{array}{c}0.024106 \\
(1.209953)\end{array}$ \\
\hline$\beta_{j}$ & --- & $\begin{array}{c}-0.008906 * \\
(1.691529)\end{array}$ & $\begin{array}{c}-0.011452 * * \\
(2.067934)\end{array}$ & $\begin{array}{c}-0.019864 * * * \\
(3.303213)\end{array}$ & $\begin{array}{c}-0.019760 * * * \\
(3.277552)\end{array}$ & $\begin{array}{c}-0.012624 * * \\
(2.171334)\end{array}$ & $\begin{array}{c}-0.010862 * \\
(1.947784)\end{array}$ & $\begin{array}{c}-0.020773 * * * \\
(3.369174)\end{array}$ & $\begin{array}{c}-0.020425 * * * \\
(3.381615)\end{array}$ & $\begin{array}{c}-0.020842 * * * \\
(3.437134)\end{array}$ \\
\hline$\sigma_{I V_{i d i o, j, t}}$ & --- & --- & --- & $\begin{array}{c}0.091162 * * * \\
(3.712153)\end{array}$ & $\begin{array}{c}0.094481 * * * \\
(3.411641)\end{array}$ & --- & --- & $\begin{array}{c}0.102299 * * * \\
(3.530496)\end{array}$ & $\begin{array}{c}0.088776^{* * *} \\
(3.184856)\end{array}$ & $\begin{array}{c}0.103343^{* * *} \\
(3.736357)\end{array}$ \\
\hline$\sigma_{E G_{i d i o, j, t}}$ & --- & --- & --- & --- & --- & $\begin{array}{c}0.059318 \\
(0.663496)\end{array}$ & --- & $\begin{array}{c}0.097142 \\
(0.860522)\end{array}$ & --- & --- \\
\hline$\sigma_{\text {ARidio }, j, t}$ & --- & --- & --- & --- & --- & --- & $\begin{array}{l}-0.075366 \\
(0.905440)\end{array}$ & $\begin{array}{c}-0.203307 * \\
(1.956975)\end{array}$ & --- & --- \\
\hline ORW ratio & --- & --- & --- & --- & --- & --- & --- & --- & $\begin{array}{l}-0.000209 \\
(0.381947)\end{array}$ & $\begin{array}{l}-0.000238 \\
(0.433521)\end{array}$ \\
\hline$O I$ & --- & --- & --- & --- & --- & --- & --- & --- & $\begin{array}{l}0.001999 * \\
(1.749403)\end{array}$ & $\begin{array}{c}0.000357 \\
(0.343253)\end{array}$ \\
\hline Constant & $\begin{array}{c}0.131830 * * * \\
(3.345009)\end{array}$ & $\begin{array}{c}0.139558 * * * \\
(3.520045)\end{array}$ & $\begin{array}{c}0.129969 * * * \\
(3.236519)\end{array}$ & $\begin{array}{c}0.112115^{* * * *} \\
(2.793315)\end{array}$ & $\begin{array}{c}0.113009^{* * *} \\
(2.804267)\end{array}$ & $\begin{array}{c}0.127201 * * * \\
(3.149971)\end{array}$ & $\begin{array}{c}0.134258 * * * \\
(3.320075)\end{array}$ & $\begin{array}{c}0.118643 * * * \\
(2.933606)\end{array}$ & $\begin{array}{c}0.139393 * * * \\
(3.235129)\end{array}$ & $\begin{array}{l}-0.005549 \\
(0.812898)\end{array}$ \\
\hline
\end{tabular}




\begin{tabular}{|c|c|c|c|c|c|c|c|c|c|c|}
\hline \multicolumn{11}{|c|}{ Phase 2} \\
\hline Variables & Model 1 & Model 2 & Model 3 & Model 4 & Model 5 & Model 6 & Model 7 & Model 8 & Model 9 & Model 10 \\
\hline$\sigma_{R V_{i d i o, j, t}}$ & --- & --- & $\begin{array}{c}0.125865 * * * \\
(2.913068)\end{array}$ & --- & $\begin{array}{c}0.140523 * * * \\
(2.810908)\end{array}$ & $\begin{array}{c}0.133943 * * * \\
(2.993680)\end{array}$ & $\begin{array}{c}0.142677 * * * \\
(3.203876)\end{array}$ & $\begin{array}{c}0.143213 * * * \\
(2.853163)\end{array}$ & $\begin{array}{c}0.153159 * * * \\
(3.037149)\end{array}$ & $\begin{array}{c}0.158887 * * * \\
(3.175043)\end{array}$ \\
\hline $\log S I Z E$ & $\begin{array}{c}-0.002842 * * \\
(2.440743)\end{array}$ & $\begin{array}{c}-0.003207 * * * \\
(2.722833)\end{array}$ & $\begin{array}{c}-0.002638 * * \\
(2.211196)\end{array}$ & $\begin{array}{c}-0.002957 * * \\
(2.450408)\end{array}$ & $\begin{array}{c}-0.002747 * * \\
(2.274813)\end{array}$ & $\begin{array}{c}-0.002761 * * \\
(2.289439)\end{array}$ & $\begin{array}{c}-0.002981 * * \\
(2.457888)\end{array}$ & $\begin{array}{c}-0.002977 * * \\
(2.440380)\end{array}$ & $\begin{array}{l}-0.001319 \\
(0.920865)\end{array}$ & --- \\
\hline $\log B M$ & $\begin{array}{l}-0.000586 \\
(0.511672)\end{array}$ & $\begin{array}{l}-0.000851 \\
(0.738689)\end{array}$ & $\begin{array}{l}-0.000946 \\
(0.821781)\end{array}$ & $\begin{array}{c}-0.000874 \\
(0.758382)\end{array}$ & $\begin{array}{l}-0.000941 \\
(0.817336)\end{array}$ & $\begin{array}{l}-0.000915 \\
(0.794190)\end{array}$ & $\begin{array}{l}-0.000872 \\
(0.757215)\end{array}$ & $\begin{array}{l}-0.000880 \\
(0.763177)\end{array}$ & $\begin{array}{l}-0.000736 \\
(0.636013)\end{array}$ & $\begin{array}{l}-0.000163 \\
(0.167009)\end{array}$ \\
\hline$r_{t}$ & $\begin{array}{c}0.058187 * * * \\
(3.338065)\end{array}$ & $\begin{array}{c}0.056637 * * * \\
(3.247462)\end{array}$ & $\begin{array}{c}0.061796 * * * \\
(3.529046)\end{array}$ & $\begin{array}{c}0.059368 * * * \\
(3.359599)\end{array}$ & $\begin{array}{c}0.060479 * * * \\
(3.425141)\end{array}$ & $\begin{array}{c}0.062638 * * * \\
(3.568345)\end{array}$ & $\begin{array}{c}0.062604 * * * \\
(3.574352)\end{array}$ & $\begin{array}{c}0.061946 * * * \\
(3.486699)\end{array}$ & $\begin{array}{c}0.062386 * * * \\
(3.528764)\end{array}$ & $\begin{array}{c}0.063569 * * * \\
(3.605347)\end{array}$ \\
\hline$r_{j, t-11: t-1}$ & $\begin{array}{c}-0.048839 * * * \\
(2.984384)\end{array}$ & $\begin{array}{c}-0.050235 * * * \\
(3.068357)\end{array}$ & $\begin{array}{c}-0.050830 * * * \\
(3.107892)\end{array}$ & $\begin{array}{c}-0.050100 * * * \\
(3.059948)\end{array}$ & $\begin{array}{c}-0.050994 * * * \\
(3.117161)\end{array}$ & $\begin{array}{c}-0.050997 * * * \\
(3.117551)\end{array}$ & $\begin{array}{c}-0.052130 * * * \\
(3.183913)\end{array}$ & $\begin{array}{c}-0.052241 * * * \\
(3.189062)\end{array}$ & $\begin{array}{l}-0.050189 \\
(3.067862)\end{array}$ & $\begin{array}{c}-0.050026 * * * \\
(3.058174)\end{array}$ \\
\hline$r_{j, t-35: t-12}$ & $\begin{array}{c}0.007640 \\
(0.644720)\end{array}$ & $\begin{array}{c}0.007641 \\
(0.645127)\end{array}$ & $\begin{array}{c}0.006092 \\
(0.514408)\end{array}$ & $\begin{array}{c}0.007510 \\
(0.633980)\end{array}$ & $\begin{array}{c}0.006004 \\
(0.506878)\end{array}$ & $\begin{array}{c}0.005855 \\
(0.494137)\end{array}$ & $\begin{array}{c}0.005917 \\
(0.499677)\end{array}$ & $\begin{array}{c}0.006015 \\
(0.507557)\end{array}$ & $\begin{array}{c}0.006211 \\
(0.524382)\end{array}$ & $\begin{array}{c}0.006421 \\
(0.542235)\end{array}$ \\
\hline$\beta_{j}$ & --- & $\begin{array}{c}0.004148 * * \\
(2.014595)\end{array}$ & $\begin{array}{c}0.002093 \\
(0.962622)\end{array}$ & $\begin{array}{c}0.003464 \\
(1.589920)\end{array}$ & $\begin{array}{c}0.002334 \\
(1.054429)\end{array}$ & $\begin{array}{c}0.002432 \\
(1.091413)\end{array}$ & $\begin{array}{c}0.002657 \\
(1.205529)\end{array}$ & $\begin{array}{c}0.002583 \\
(1.149816)\end{array}$ & $\begin{array}{c}0.002478 \\
(1.119011)\end{array}$ & $\begin{array}{c}0.002123 \\
(0.973417)\end{array}$ \\
\hline$\sigma_{I V i d i o, j, t}$ & --- & --- & --- & $\begin{array}{c}0.015243 \\
(0.959770)\end{array}$ & $\begin{array}{l}-0.010703 \\
(0.583069)\end{array}$ & --- & --- & $\begin{array}{l}-0.002208 \\
(0.112740)\end{array}$ & $\begin{array}{l}-0.007730 \\
(0.419654)\end{array}$ & $\begin{array}{l}-0.004926 \\
(0.271185)\end{array}$ \\
\hline$\sigma_{E G_{i d i o, j, t}}$ & --- & --- & --- & --- & --- & $\begin{array}{l}-0.035208 \\
(0.696010)\end{array}$ & --- & $\begin{array}{c}0.020695 \\
(0.322676)\end{array}$ & --- & --- \\
\hline$\sigma_{A R i d i o, j, t}$ & --- & --- & --- & --- & --- & --- & $\begin{array}{l}-0.073719 \\
(1.553570)\end{array}$ & $\begin{array}{l}-0.083631 \\
(1.370650)\end{array}$ & --- & --- \\
\hline$O R W_{\text {ratio }}$ & --- & --- & --- & --- & --- & --- & --- & --- & $\begin{array}{c}0.000098 \\
(0.532070)\end{array}$ & $\begin{array}{c}0.000089 \\
(0.479454)\end{array}$ \\
\hline$O I$ & --- & --- & --- & --- & --- & --- & --- & --- & $\begin{array}{c}-0.001045 * \\
(1.940803)\end{array}$ & $\begin{array}{c}-0.001310 * * * \\
(2.871706)\end{array}$ \\
\hline Constant & $\begin{array}{c}0.053433 * * * \\
(2.866004)\end{array}$ & $\begin{array}{c}0.055894 * * * \\
(2.992939)\end{array}$ & $\begin{array}{c}0.041993 * * \\
(2.180871)\end{array}$ & $\begin{array}{c}0.050989 * * * \\
(2.633449)\end{array}$ & $\begin{array}{c}0.043818 * * \\
(2.245951)\end{array}$ & $\begin{array}{c}0.045354 * * \\
(2.284502)\end{array}$ & $\begin{array}{c}0.050736 * * \\
(2.529608)\end{array}$ & $\begin{array}{c}0.050312 * * \\
(2.494016)\end{array}$ & $\begin{array}{c}0.024453 \\
(1.104188)\end{array}$ & $\begin{array}{c}0.004254 \\
(1.394500)\end{array}$ \\
\hline
\end{tabular}




\begin{tabular}{|c|c|c|c|c|c|c|c|c|c|c|}
\hline \multicolumn{11}{|c|}{ Phase 3} \\
\hline Variables & Model 1 & Model 2 & Model 3 & Model 4 & Model 5 & Model 6 & Model 7 & Model 8 & Model 9 & Model 10 \\
\hline$\sigma_{R V_{i d i o, j, t}}$ & --- & --- & $\begin{array}{l}-0.084144 \\
(1.364013)\end{array}$ & --- & $\begin{array}{c}-0.228197 * * * \\
(2.617648)\end{array}$ & $\begin{array}{c}-0.187404 * * * \\
(2.750391)\end{array}$ & $\begin{array}{l}-0.089311 \\
(1.367585)\end{array}$ & $\begin{array}{c}-0.256716^{* * * *} \\
(2.920442)\end{array}$ & $\begin{array}{c}-0.231443 * * * \\
(2.649769)\end{array}$ & $\begin{array}{c}-0.223683 * * \\
(2.566212)\end{array}$ \\
\hline $\log S I Z E$ & $\begin{array}{c}-0.010401 \\
(1.603548)\end{array}$ & $\begin{array}{c}-0.008614 \\
(1.332849)\end{array}$ & $\begin{array}{c}-0.009608 \\
(1.478296)\end{array}$ & $\begin{array}{l}-0.008092 \\
(1.242622)\end{array}$ & $\begin{array}{c}-0.008751 \\
(1.348701)\end{array}$ & $\begin{array}{c}-0.007068 \\
(1.089236)\end{array}$ & $\begin{array}{c}-0.009584 \\
(1.473365)\end{array}$ & $\begin{array}{l}-0.006529 \\
(1.006530)\end{array}$ & $\begin{array}{l}-0.010209 \\
(1.257774)\end{array}$ & --- \\
\hline $\log B M$ & $\begin{array}{c}0.004594 \\
(0.771239)\end{array}$ & $\begin{array}{c}0.004460 \\
(0.754099)\end{array}$ & $\begin{array}{c}0.005732 \\
(0.957860)\end{array}$ & $\begin{array}{c}0.003701 \\
(0.614460)\end{array}$ & $\begin{array}{c}0.004187 \\
(0.697790)\end{array}$ & $\begin{array}{c}0.003467 \\
(0.580567)\end{array}$ & $\begin{array}{c}0.005648 \\
(0.941596)\end{array}$ & $\begin{array}{c}0.002842 \\
(0.474976)\end{array}$ & $\begin{array}{c}0.003684 \\
(0.605054)\end{array}$ & $\begin{array}{c}0.007619 \\
(1.457861)\end{array}$ \\
\hline$r_{t}$ & $\begin{array}{c}0.058003 \\
(1.360584)\end{array}$ & $\begin{array}{c}0.088135 * * \\
(2.034507)\end{array}$ & $\begin{array}{l}0.078002 * \\
(1.775792)\end{array}$ & $\begin{array}{c}0.097557 * * \\
(2.141405)\end{array}$ & $\begin{array}{c}0.106872 * * \\
(2.348968)\end{array}$ & $\begin{array}{c}0.041987 \\
(0.937059)\end{array}$ & $\begin{array}{l}0.076718 * \\
(1.732792)\end{array}$ & $\begin{array}{c}0.067209 \\
(1.414047)\end{array}$ & $\begin{array}{c}0.102496 * * \\
(2.245274)\end{array}$ & $\begin{array}{c}0.105844 * * \\
(2.321538)\end{array}$ \\
\hline$r_{j, t-11: t-1}$ & $\begin{array}{l}0.162390 * \\
(1.766261)\end{array}$ & $\begin{array}{c}0.146179 \\
(1.599065)\end{array}$ & $\begin{array}{c}0.131405 \\
(1.428376)\end{array}$ & $\begin{array}{l}0.153365 * \\
(1.665586)\end{array}$ & $\begin{array}{c}0.141360 \\
(1.540031)\end{array}$ & $\begin{array}{l}0.168597 * \\
(1.834787)\end{array}$ & $\begin{array}{c}0.134849 \\
(1.447649)\end{array}$ & $\begin{array}{l}0.156247 * \\
(1.691465)\end{array}$ & $\begin{array}{c}0.138331 \\
(1.505956)\end{array}$ & $\begin{array}{c}0.132709 \\
(1.445831)\end{array}$ \\
\hline$r_{j, t-35: t-12}$ & $\begin{array}{c}-0.241727 * \\
(1.941052)\end{array}$ & $\begin{array}{c}-0.265801 * * \\
(2.145970)\end{array}$ & $\begin{array}{c}-0.262668 * * \\
(2.121681)\end{array}$ & $\begin{array}{c}-0.265749 * * \\
(2.144655)\end{array}$ & $\begin{array}{c}-0.257045 * * \\
(2.082777)\end{array}$ & $\begin{array}{c}-0.241679 * * \\
(1.965634)\end{array}$ & $\begin{array}{c}-0.260505 * * \\
(2.097285)\end{array}$ & $\begin{array}{c}-0.249962 * * \\
(2.032540)\end{array}$ & $\begin{array}{c}-0.261355 * * \\
(2.117156)\end{array}$ & $\begin{array}{c}-0.262920 * * \\
(2.129007)\end{array}$ \\
\hline$\beta_{j}$ & --- & $\begin{array}{c}0.048165 * * * \\
(3.264023)\end{array}$ & $\begin{array}{c}0.052332 * * * \\
(3.474923)\end{array}$ & $\begin{array}{c}0.045645 * * * \\
(2.996488)\end{array}$ & $\begin{array}{c}0.047105 * * * \\
(3.103825)\end{array}$ & $\begin{array}{c}0.043180 * * * \\
(2.845920)\end{array}$ & $\begin{array}{c}0.052077 * * * \\
(3.447087)\end{array}$ & $\begin{array}{c}0.040828 * * * \\
(2.680712)\end{array}$ & $\begin{array}{c}0.048272 * * * \\
(3.176471)\end{array}$ & $\begin{array}{c}0.048603 * * * \\
(3.197370)\end{array}$ \\
\hline$\sigma_{I V_{i d i o, j, t}}$ & --- & --- & --- & $\begin{array}{c}0.010848 \\
(0.670778)\end{array}$ & $\begin{array}{c}0.053214 * * \\
(2.330888)\end{array}$ & --- & --- & $\begin{array}{c}0.035314 \\
(1.490842)\end{array}$ & $\begin{array}{c}0.054138 * * \\
(2.311777)\end{array}$ & $\begin{array}{c}0.059222 * * \\
(2.566293)\end{array}$ \\
\hline$\sigma_{E G_{i d i o, j, t}}$ & --- & --- & --- & --- & --- & $\begin{array}{c}0.388200 * * * \\
(3.444964)\end{array}$ & --- & $\begin{array}{c}0.405814 * * * \\
(3.195947)\end{array}$ & --- & --- \\
\hline$\sigma_{A R_{i d i o, j, t}}$ & --- & --- & --- & --- & --- & --- & $\begin{array}{c}0.014485 \\
(0.242506)\end{array}$ & $\begin{array}{l}-0.086830 \\
(1.339938)\end{array}$ & --- & --- \\
\hline$O R W_{\text {ratio }}$ & --- & --- & --- & --- & --- & --- & --- & --- & $\begin{array}{c}0.000905 \\
(1.552151)\end{array}$ & $\begin{array}{c}0.000781 \\
(1.358988)\end{array}$ \\
\hline$O I$ & --- & --- & --- & --- & --- & --- & --- & --- & $\begin{array}{l}-0.000732 \\
(0.220162)\end{array}$ & $\begin{array}{l}-0.003108 \\
(1.134603)\end{array}$ \\
\hline Constant & $\begin{array}{c}0.130656 \\
(1.249026)\end{array}$ & $\begin{array}{c}0.054101 \\
(0.508123)\end{array}$ & $\begin{array}{c}0.076748 \\
(0.712669)\end{array}$ & $\begin{array}{c}0.044574 \\
(0.414805)\end{array}$ & $\begin{array}{c}0.068788 \\
(0.640557)\end{array}$ & $\begin{array}{c}0.025168 \\
(0.233332)\end{array}$ & $\begin{array}{c}0.075976 \\
(0.704700)\end{array}$ & $\begin{array}{c}0.022169 \\
(0.205714)\end{array}$ & $\begin{array}{c}0.094697 \\
(0.761284)\end{array}$ & $\begin{array}{c}-0.059200 * * * \\
(2.640822)\end{array}$ \\
\hline
\end{tabular}




\begin{tabular}{|c|c|c|c|c|c|c|c|c|c|c|}
\hline \multicolumn{11}{|c|}{ Phase 4} \\
\hline Variables & Model 1 & Model 2 & Model 3 & Model 4 & Model 5 & Model 6 & Model 7 & Model 8 & Model 9 & Model 10 \\
\hline$\sigma_{R V_{i d i o, j, t}}$ & --- & --- & $\begin{array}{c}0.078321 \\
(1.618189)\end{array}$ & --- & $\begin{array}{c}-0.126742 * \\
(1.705244)\end{array}$ & $\begin{array}{l}-0.000577 \\
(0.010127)\end{array}$ & $\begin{array}{c}0.023574 \\
(0.448097)\end{array}$ & $\begin{array}{c}-0.152132 * * \\
(2.010076)\end{array}$ & $\begin{array}{c}-0.148058 * * \\
(1.972515)\end{array}$ & $\begin{array}{c}-0.131963 * \\
(1.761943)\end{array}$ \\
\hline $\log S I Z E$ & $\begin{array}{c}-0.007295 * \\
(1.662834)\end{array}$ & $\begin{array}{c}-0.009633 * * \\
(2.187960)\end{array}$ & $\begin{array}{c}-0.008690 * \\
(1.957707)\end{array}$ & $\begin{array}{l}-0.007015 \\
(1.578449)\end{array}$ & $\begin{array}{l}-0.007079 \\
(1.594093)\end{array}$ & $\begin{array}{c}-0.006075 \\
(1.338009)\end{array}$ & $\begin{array}{l}-0.006974 \\
(1.557852)\end{array}$ & $\begin{array}{l}-0.005425 \\
(1.197261)\end{array}$ & $\begin{array}{c}-0.012948 * * \\
(2.406955)\end{array}$ & --- \\
\hline $\log B M$ & $\begin{array}{c}0.004677 \\
(1.151527)\end{array}$ & $\begin{array}{c}0.002750 \\
(0.675863)\end{array}$ & $\begin{array}{c}0.001550 \\
(0.375132)\end{array}$ & $\begin{array}{c}0.000103 \\
(0.024903)\end{array}$ & $\begin{array}{c}0.000565 \\
(0.137038)\end{array}$ & $\begin{array}{c}0.001182 \\
(0.286439)\end{array}$ & $\begin{array}{c}0.001311 \\
(0.317766)\end{array}$ & $\begin{array}{c}0.000460 \\
(0.111561)\end{array}$ & $\begin{array}{l}-0.000585 \\
(0.140414)\end{array}$ & $\begin{array}{c}0.004962 \\
(1.427894)\end{array}$ \\
\hline$r_{t}$ & $\begin{array}{c}0.095126 * * * \\
(3.620500)\end{array}$ & $\begin{array}{c}0.077889 * * * \\
(2.940458)\end{array}$ & $\begin{array}{c}0.075945 * * * \\
(2.865853)\end{array}$ & $\begin{array}{c}0.087583 * * * \\
(3.303740)\end{array}$ & $\begin{array}{c}0.096143 * * * \\
(3.565761)\end{array}$ & $\begin{array}{c}0.064618 * * \\
(2.411648)\end{array}$ & $\begin{array}{c}0.072091 * * * \\
(2.722206)\end{array}$ & $\begin{array}{c}0.086352 * * * \\
(3.124341)\end{array}$ & $\begin{array}{c}0.092502 * * * \\
(3.426053)\end{array}$ & $\begin{array}{c}0.096024 * * * \\
(3.555333)\end{array}$ \\
\hline$r_{j, t-11: t-1}$ & $\begin{array}{c}0.081393 * * * \\
(3.533974)\end{array}$ & $\begin{array}{c}0.079274 * * * \\
(3.459935)\end{array}$ & $\begin{array}{c}0.083392 * * * \\
(3.619610)\end{array}$ & $\begin{array}{c}0.087913 * * * \\
(3.832633)\end{array}$ & $\begin{array}{c}0.086072 * * * \\
(3.750907)\end{array}$ & $\begin{array}{c}0.085927 * * * \\
(3.734441)\end{array}$ & $\begin{array}{c}0.086253 * * * \\
(3.747802)\end{array}$ & $\begin{array}{c}0.088131 * * * \\
(3.840002)\end{array}$ & $\begin{array}{c}0.085098 * * * \\
(3.704069)\end{array}$ & $\begin{array}{c}0.084729 * * * \\
(3.681463)\end{array}$ \\
\hline$r_{j, t-35: t-12}$ & $\begin{array}{c}-0.118062 * \\
(1.725026)\end{array}$ & $\begin{array}{l}-0.108373 \\
(1.591142)\end{array}$ & $\begin{array}{c}-0.114190 * \\
(1.675224)\end{array}$ & $\begin{array}{c}-0.123000 * \\
(1.810611)\end{array}$ & $\begin{array}{c}-0.121756 * \\
(1.793467)\end{array}$ & $\begin{array}{c}-0.116586 * \\
(1.713968)\end{array}$ & $\begin{array}{c}-0.113042 * \\
(1.662005)\end{array}$ & $\begin{array}{c}-0.120798 * \\
(1.780462)\end{array}$ & $\begin{array}{l}-0.111456 \\
(1.637837)\end{array}$ & $\begin{array}{c}-0.119157 * \\
(1.749797)\end{array}$ \\
\hline$\beta_{j}$ & --- & $\begin{array}{c}0.026187 * * * \\
(3.970505)\end{array}$ & $\begin{array}{c}0.024050 * * * \\
(3.577562)\end{array}$ & $\begin{array}{c}0.020556 * * * \\
(3.044540)\end{array}$ & $\begin{array}{c}0.020869 * * * \\
(3.092088)\end{array}$ & $\begin{array}{c}0.019475 * * * \\
(2.809539)\end{array}$ & $\begin{array}{c}0.019435 * * * \\
(2.802673)\end{array}$ & $\begin{array}{c}0.017171 * * \\
(2.458255)\end{array}$ & $\begin{array}{c}0.019279 * * * \\
(2.836982)\end{array}$ & $\begin{array}{c}0.017898 * * * \\
(2.638470)\end{array}$ \\
\hline$\sigma_{I V i d i o, j, t}$ & --- & --- & --- & $\begin{array}{c}0.040619 * * * \\
(3.584150)\end{array}$ & $\begin{array}{c}0.063301 * * * \\
(3.623537)\end{array}$ & --- & --- & $\begin{array}{c}0.052726 * * * \\
(2.883491)\end{array}$ & $\begin{array}{c}0.057965 * * * \\
(3.284399)\end{array}$ & $\begin{array}{c}0.064745 * * * \\
(3.709522)\end{array}$ \\
\hline$\sigma_{E G_{i d i o, j, t}}$ & --- & --- & --- & --- & --- & $\begin{array}{c}0.221359 * * * \\
(2.615824)\end{array}$ & --- & $\begin{array}{c}0.085049 \\
(0.834468)\end{array}$ & --- & --- \\
\hline$\sigma_{A R_{i d i o, j, t}}$ & --- & --- & --- & --- & --- & --- & $\begin{array}{c}0.129033 * * * \\
(2.624003)\end{array}$ & $\begin{array}{c}0.069137 \\
(1.186384)\end{array}$ & --- & --- \\
\hline ORW $W_{\text {ratio }}$ & --- & --- & --- & --- & --- & --- & --- & --- & $\begin{array}{l}-0.000168 \\
(0.397085)\end{array}$ & $\begin{array}{l}-0.000252 \\
(0.596073)\end{array}$ \\
\hline$O I$ & --- & --- & --- & --- & --- & --- & --- & --- & $\begin{array}{c}0.004164 * * \\
(2.027215)\end{array}$ & $\begin{array}{c}0.001424 \\
(0.831480)\end{array}$ \\
\hline Constant & $\begin{array}{l}0.130092 * \\
(1.838778)\end{array}$ & $\begin{array}{l}0.133413 * \\
(1.895969)\end{array}$ & $\begin{array}{c}0.113457 \\
(1.589098)\end{array}$ & $\begin{array}{c}0.085420 \\
(1.197605)\end{array}$ & $\begin{array}{c}0.090912 \\
(1.274224)\end{array}$ & $\begin{array}{c}0.068327 \\
(0.932136)\end{array}$ & $\begin{array}{c}0.086177 \\
(1.196987)\end{array}$ & $\begin{array}{c}0.062722 \\
(0.858094)\end{array}$ & $\begin{array}{c}0.166160 * * \\
(2.037671)\end{array}$ & $\begin{array}{c}-0.027615 * * \\
(2.125525)\end{array}$ \\
\hline
\end{tabular}


Table 13.4: Healthcare Sector

\begin{tabular}{|c|c|c|c|c|c|c|c|c|c|c|}
\hline \multicolumn{11}{|c|}{ Entire Phases } \\
\hline Variables & Model 1 & Model 2 & Model 3 & Model 4 & Model 5 & Model 6 & Model 7 & Model 8 & Model 9 & Model 10 \\
\hline$\sigma_{R V_{i d i o, j, t}}$ & --- & --- & $\begin{array}{c}-0.103266^{* * *} \\
(3.081032)\end{array}$ & --- & $\begin{array}{c}-0.213011^{* * *} \\
(5.275399)\end{array}$ & $\begin{array}{c}-0.175871 * * * \\
(4.936344)\end{array}$ & $\begin{array}{c}-0.128447 * * * \\
(3.684691)\end{array}$ & $\begin{array}{c}-0.245355^{* * *} \\
(5.998020)\end{array}$ & $\begin{array}{l}-0.208618 \\
(5.163627)\end{array}$ & $\begin{array}{c}-0.208084 * * * \\
(5.156711)\end{array}$ \\
\hline $\log S I Z E$ & $\begin{array}{c}-0.003354 * * \\
(2.498386)\end{array}$ & $\begin{array}{c}-0.004019 * * * \\
(2.622865)\end{array}$ & $\begin{array}{c}-0.004956^{* * *} \\
(3.174711)\end{array}$ & $\begin{array}{c}-0.002931 * \\
(1.826934)\end{array}$ & $\begin{array}{c}-0.003169 * * \\
(1.979237)\end{array}$ & $\begin{array}{l}-0.002255 \\
(1.389211)\end{array}$ & $\begin{array}{c}-0.003896 * * \\
(2.415981)\end{array}$ & $\begin{array}{l}-0.001557 \\
(0.945567)\end{array}$ & $\begin{array}{c}-0.000531 \\
(0.276802)\end{array}$ & --- \\
\hline $\log B M$ & $\begin{array}{l}0.002578 * \\
(1.912662)\end{array}$ & $\begin{array}{l}0.002520 * \\
(1.866912)\end{array}$ & $\begin{array}{c}0.002709 * * \\
(2.006412)\end{array}$ & $\begin{array}{l}0.002486 * \\
(1.842837)\end{array}$ & $\begin{array}{c}0.002825 * * \\
(2.096040)\end{array}$ & $\begin{array}{c}0.003135 * * \\
(2.325812)\end{array}$ & $\begin{array}{c}0.002773 * * \\
(2.054547)\end{array}$ & $\begin{array}{c}0.003221 * * \\
(2.391744)\end{array}$ & $\begin{array}{l}0.002521 * \\
(1.863930)\end{array}$ & $\begin{array}{c}0.002693 * * \\
(2.240549)\end{array}$ \\
\hline$r_{t}$ & $\begin{array}{c}0.027742 * * \\
(2.111824)\end{array}$ & $\begin{array}{c}0.027925 * * \\
(2.125496)\end{array}$ & $\begin{array}{c}0.026730 * * \\
(2.035170)\end{array}$ & $\begin{array}{c}0.030591 * * \\
(2.320128)\end{array}$ & $\begin{array}{c}0.032276 * * \\
(2.452942)\end{array}$ & $\begin{array}{c}0.018990 \\
(1.442798)\end{array}$ & $\begin{array}{l}0.024506 * \\
(1.862845)\end{array}$ & $\begin{array}{l}0.024370 * \\
(1.841766)\end{array}$ & $\begin{array}{c}0.033897 * * \\
(2.572274)\end{array}$ & $\begin{array}{c}0.034061 * * * \\
(2.587544)\end{array}$ \\
\hline$r_{j, t-11: t-1}$ & $\begin{array}{c}-0.038796 * * * \\
(3.670803)\end{array}$ & $\begin{array}{c}-0.038402 * * * \\
(3.630251)\end{array}$ & $\begin{array}{c}-0.037919 * * * \\
(3.586906)\end{array}$ & $\begin{array}{c}-0.038752 * * * \\
(3.664340)\end{array}$ & $\begin{array}{c}-0.038302 * * * \\
(3.630172)\end{array}$ & $\begin{array}{c}-0.037959 * * * \\
(3.601286)\end{array}$ & $\begin{array}{c}-0.037589 * * * \\
(3.557243)\end{array}$ & $\begin{array}{c}-0.038589 * * * \\
(3.664976)\end{array}$ & $\begin{array}{c}-0.038406^{* * *} \\
(3.641313)\end{array}$ & $\begin{array}{c}-0.038453 * * * \\
(3.646506)\end{array}$ \\
\hline$r_{j, t-35: t-12}$ & $\begin{array}{c}-0.044459 * * * \\
(4.679579)\end{array}$ & $\begin{array}{c}-0.044057 * * * \\
(4.632154)\end{array}$ & $\begin{array}{c}-0.043605^{* * *} \\
(4.587470)\end{array}$ & $\begin{array}{c}-0.045023 * * * \\
(4.730758)\end{array}$ & $\begin{array}{c}-0.045593 * * * \\
(4.801618)\end{array}$ & $\begin{array}{c}-0.043172 * * * \\
(4.555078)\end{array}$ & $\begin{array}{c}-0.043958 * * * \\
(4.626506)\end{array}$ & $\begin{array}{c}-0.044284 * * * \\
(4.671877)\end{array}$ & $\begin{array}{c}-0.045683 * * * \\
(4.810252)\end{array}$ & $\begin{array}{c}-0.045714 * * * \\
(4.814181)\end{array}$ \\
\hline$\beta_{j}$ & --- & $\begin{array}{l}-0.002471 \\
(0.900405)\end{array}$ & $\begin{array}{l}-0.000335 \\
(0.118514)\end{array}$ & $\begin{array}{l}-0.004678 \\
(1.608479)\end{array}$ & $\begin{array}{l}-0.003708 \\
(1.275327)\end{array}$ & $\begin{array}{l}-0.003421 \\
(1.192578)\end{array}$ & $\begin{array}{l}-0.001519 \\
(0.530655)\end{array}$ & $\begin{array}{c}-0.005268 * \\
(1.800552)\end{array}$ & $\begin{array}{c}-0.002668 \\
(0.908965)\end{array}$ & $\begin{array}{l}-0.002381 \\
(0.867147)\end{array}$ \\
\hline$\sigma_{I V i d i o, j, t}$ & --- & --- & --- & $\begin{array}{c}0.018794 * * \\
(2.285740)\end{array}$ & $\begin{array}{c}0.048051 * * * \\
(4.852703)\end{array}$ & --- & --- & $\begin{array}{c}0.036912 * * * \\
(3.618238)\end{array}$ & $\begin{array}{c}0.053244 * * * \\
(5.236237)\end{array}$ & $\begin{array}{c}0.054108 * * * \\
(5.591755)\end{array}$ \\
\hline$\sigma_{E G_{i d i o, j, t}}$ & --- & --- & --- & --- & --- & $\begin{array}{c}0.226432 * * * \\
(5.878756)\end{array}$ & --- & $\begin{array}{c}0.258740 * * * \\
(4.937136)\end{array}$ & --- & --- \\
\hline$\sigma_{A R_{i d i o, j, t}}$ & --- & --- & --- & --- & --- & --- & $\begin{array}{c}0.087926^{* * *} \\
(2.611577)\end{array}$ & $\begin{array}{c}-0.087920 * \\
(1.944991)\end{array}$ & --- & --- \\
\hline ORW ratio & --- & --- & --- & --- & --- & --- & --- & --- & $\begin{array}{c}-0.000333 \\
(0.841140)\end{array}$ & $\begin{array}{c}-0.000342 \\
(0.866830)\end{array}$ \\
\hline$O I$ & --- & --- & --- & --- & --- & --- & --- & --- & $\begin{array}{c}-0.002285 * * \\
(2.409307)\end{array}$ & $\begin{array}{c}-0.002428 * * * \\
(3.057437)\end{array}$ \\
\hline Constant & $\begin{array}{c}0.061655 * * * \\
(2.956164)\end{array}$ & $\begin{array}{c}0.074174 * * * \\
(2.959106)\end{array}$ & $\begin{array}{c}0.095232 * * * \\
(3.667918)\end{array}$ & $\begin{array}{c}0.054311 * * \\
(2.047834)\end{array}$ & $\begin{array}{c}0.066827 * * \\
(2.515582)\end{array}$ & $\begin{array}{c}0.039793 \\
(1.444322)\end{array}$ & $\begin{array}{c}0.073009 * * * \\
(2.673368)\end{array}$ & $\begin{array}{c}0.032284 \\
(1.157382)\end{array}$ & $\begin{array}{c}0.036337 \\
(1.245018)\end{array}$ & $\begin{array}{c}0.028408 * * * \\
(5.079588)\end{array}$ \\
\hline
\end{tabular}




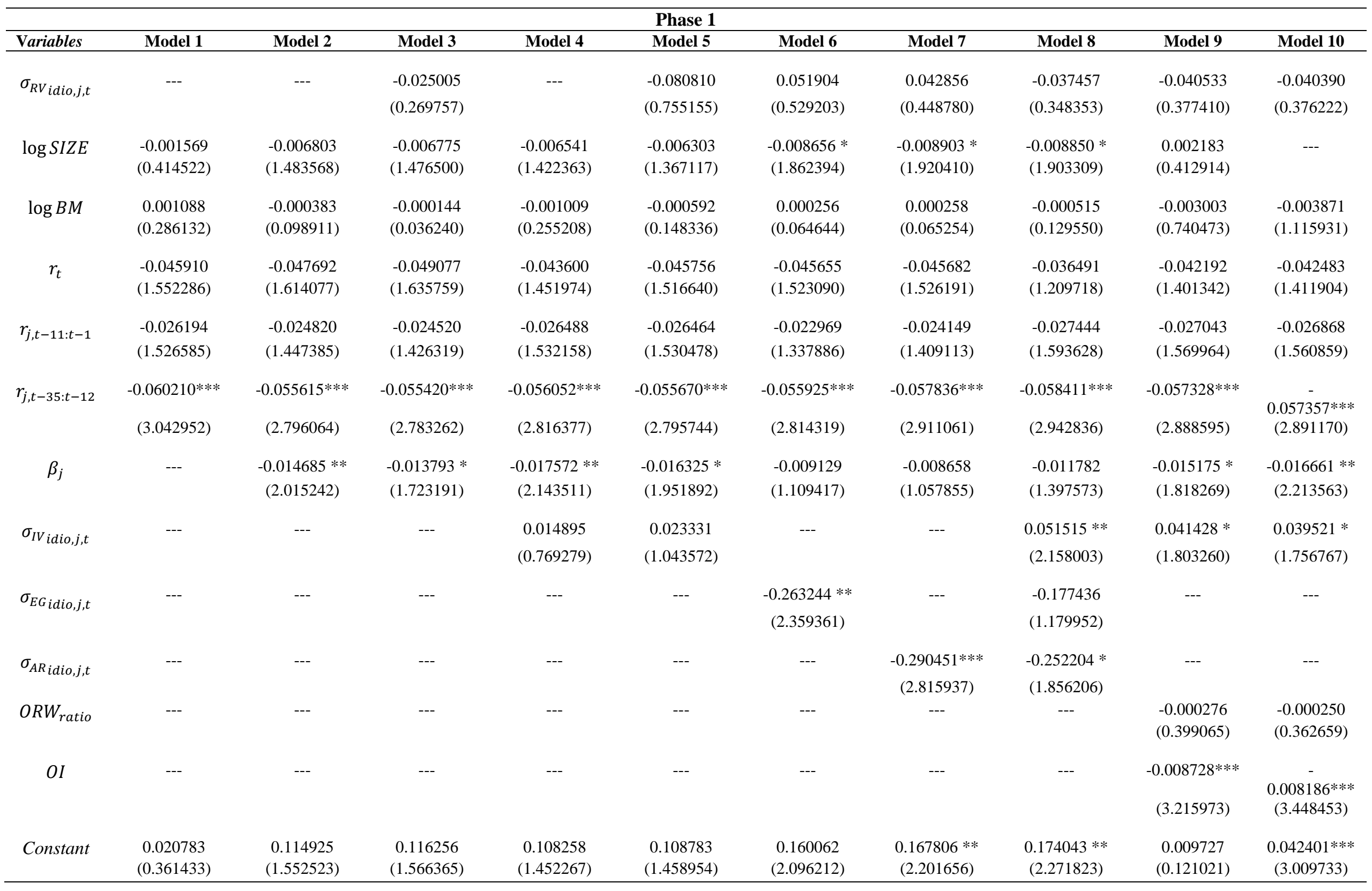




\begin{tabular}{|c|c|c|c|c|c|c|c|c|c|c|}
\hline \multicolumn{11}{|c|}{ Phase 2} \\
\hline Variables & Model 1 & Model 2 & Model 3 & Model 4 & Model 5 & Model 6 & Model 7 & Model 8 & Model 9 & Model 10 \\
\hline$\sigma_{R V_{i d i o, j, t}}$ & --- & --- & $\begin{array}{l}-0.013484 \\
(0.256317)\end{array}$ & --- & $\begin{array}{c}-0.164805^{* * * *} \\
(2.727879)\end{array}$ & $\begin{array}{c}-0.171317 * * * \\
(3.053780)\end{array}$ & $\begin{array}{l}-0.074538 \\
(1.366281)\end{array}$ & $\begin{array}{c}-0.239507 * * * \\
(3.915880)\end{array}$ & $\begin{array}{c}-0.146430 * * \\
(2.413946)\end{array}$ & $\begin{array}{c}-0.151750 * * \\
(2.507805)\end{array}$ \\
\hline $\log S I Z E$ & $\begin{array}{c}-0.003338 * \\
(1.822326)\end{array}$ & $\begin{array}{c}-0.003686 * \\
(1.752505)\end{array}$ & $\begin{array}{c}-0.003782 * \\
(1.770089)\end{array}$ & $\begin{array}{l}-0.000850 \\
(0.385791)\end{array}$ & $\begin{array}{l}-0.000964 \\
(0.437951)\end{array}$ & $\begin{array}{c}0.000612 \\
(0.278788)\end{array}$ & $\begin{array}{c}-0.001802 \\
(0.824546)\end{array}$ & $\begin{array}{c}0.001563 \\
(0.701352)\end{array}$ & $\begin{array}{c}0.003224 \\
(1.229895)\end{array}$ & --- \\
\hline $\log B M$ & $\begin{array}{c}0.002878 \\
(1.579674)\end{array}$ & $\begin{array}{c}0.002870 \\
(1.574673)\end{array}$ & $\begin{array}{c}0.002881 \\
(1.580252)\end{array}$ & $\begin{array}{l}0.003519 * \\
(1.929661)\end{array}$ & $\begin{array}{c}0.003900 * * \\
(2.134792)\end{array}$ & $\begin{array}{c}0.003841 * * \\
(2.122305)\end{array}$ & $\begin{array}{l}0.003156 * \\
(1.734631)\end{array}$ & $\begin{array}{c}0.004353 * * \\
(2.397130)\end{array}$ & $\begin{array}{l}0.003265 * \\
(1.777429)\end{array}$ & $\begin{array}{c}0.002222 \\
(1.363505)\end{array}$ \\
\hline$r_{t}$ & $\begin{array}{l}0.035211 * \\
(1.898012)\end{array}$ & $\begin{array}{l}0.035480 * \\
(1.910461)\end{array}$ & $\begin{array}{l}0.036342 * \\
(1.925261)\end{array}$ & $\begin{array}{c}0.036512 * * \\
(1.971582)\end{array}$ & $\begin{array}{c}0.047426 * * \\
(2.505869)\end{array}$ & $\begin{array}{c}0.028525 \\
(1.523631)\end{array}$ & $\begin{array}{l}0.033808 * \\
(1.794896)\end{array}$ & $\begin{array}{l}0.036100 * \\
(1.911360)\end{array}$ & $\begin{array}{c}0.048316 * * \\
(2.555539)\end{array}$ & $\begin{array}{c}0.048529 * * \\
(2.566692)\end{array}$ \\
\hline$r_{j, t-11: t-1}$ & $\begin{array}{c}-0.070805 * * * \\
(3.995638)\end{array}$ & $\begin{array}{c}-0.070487 * * * \\
(3.971469)\end{array}$ & $\begin{array}{c}-0.070539 * * * \\
(3.973511)\end{array}$ & $\begin{array}{c}-0.064331 * * * \\
(3.623003)\end{array}$ & $\begin{array}{c}-0.062691 * * * \\
(3.532570)\end{array}$ & $\begin{array}{c}-0.066532 * * * \\
(3.782748)\end{array}$ & $\begin{array}{c}-0.068059 * * * \\
(3.841941)\end{array}$ & $\begin{array}{c}-0.062764 * * * \\
(3.560477)\end{array}$ & $\begin{array}{c}-0.060406^{* * *} \\
(3.404677)\end{array}$ & $\begin{array}{c}-0.060794 * * * \\
(3.426802)\end{array}$ \\
\hline$r_{j, t-35: t-12}$ & $\begin{array}{c}-0.046048 * * * \\
(4.010082)\end{array}$ & $\begin{array}{c}-0.045979 * * * \\
(4.002884)\end{array}$ & $\begin{array}{c}-0.045927 * * * \\
(3.997106)\end{array}$ & $\begin{array}{c}-0.050114 * * * \\
(4.359753)\end{array}$ & $\begin{array}{c}-0.051012 * * * \\
(4.441067)\end{array}$ & $\begin{array}{c}-0.045127 * * * \\
(3.965718)\end{array}$ & $\begin{array}{c}-0.047494 * * * \\
(4.142334)\end{array}$ & $\begin{array}{c}-0.047553 * * * \\
(4.160841)\end{array}$ & $\begin{array}{c}-0.051083^{* * *} \\
(4.450995)\end{array}$ & $\begin{array}{c}-0.050872 * * * \\
(4.432756)\end{array}$ \\
\hline$\beta_{j}$ & --- & $\begin{array}{l}-0.001110 \\
(0.337222)\end{array}$ & $\begin{array}{l}-0.000864 \\
(0.251841)\end{array}$ & $\begin{array}{c}-0.008348 * * \\
(2.255319)\end{array}$ & $\begin{array}{c}-0.008020 * * \\
(2.167741)\end{array}$ & $\begin{array}{c}-0.006063 * \\
(1.749976)\end{array}$ & $\begin{array}{l}-0.003306 \\
(0.952334)\end{array}$ & $\begin{array}{c}-0.009441 * * \\
(2.562835)\end{array}$ & $\begin{array}{c}-0.007013 * \\
(1.889926)\end{array}$ & $\begin{array}{c}-0.008279 * * \\
(2.322263)\end{array}$ \\
\hline$\sigma_{I V} i d i o, j, t$ & --- & --- & --- & $\begin{array}{c}0.061780 * * * \\
(4.226452)\end{array}$ & $\begin{array}{c}0.084664 * * * \\
(5.027726)\end{array}$ & --- & --- & $\begin{array}{c}0.050789 * * * \\
(2.867368)\end{array}$ & $\begin{array}{c}0.100145^{* * *} \\
(5.687792)\end{array}$ & $\begin{array}{c}0.092339 * * * \\
(5.621920)\end{array}$ \\
\hline$\sigma_{E G_{i d i o, j, t}}$ & --- & --- & --- & --- & --- & $\begin{array}{c}0.371979 * * * \\
(7.582629)\end{array}$ & --- & $\begin{array}{c}0.375464 * * * \\
(5.742659)\end{array}$ & --- & --- \\
\hline$\sigma_{A R_{i d i o, j, t}}$ & --- & --- & --- & --- & --- & --- & $\begin{array}{c}0.164888 * * * \\
(4.079882)\end{array}$ & $\begin{array}{l}-0.064992 \\
(1.236980)\end{array}$ & --- & --- \\
\hline$O R W_{\text {ratio }}$ & --- & --- & --- & --- & --- & --- & --- & --- & $\begin{array}{c}0.000152 \\
(0.271669)\end{array}$ & $\begin{array}{c}0.000187 \\
(0.332942)\end{array}$ \\
\hline$O I$ & --- & --- & --- & --- & --- & --- & --- & --- & $\begin{array}{c}-0.003785^{* * *} \\
(2.969235)\end{array}$ & $\begin{array}{c}-0.002934 * * * \\
(2.740048)\end{array}$ \\
\hline Constant & $\begin{array}{c}0.067492 * * \\
(2.367499)\end{array}$ & $\begin{array}{c}0.073868 * * \\
(2.159176)\end{array}$ & $\begin{array}{c}0.076047 * * \\
(2.156939)\end{array}$ & $\begin{array}{c}0.023654 \\
(0.654841)\end{array}$ & $\begin{array}{c}0.031684 \\
(0.875227)\end{array}$ & $\begin{array}{c}-0.012894 \\
(0.350070)\end{array}$ & $\begin{array}{c}0.035155 \\
(0.961530)\end{array}$ & $\begin{array}{l}-0.024223 \\
(0.650022)\end{array}$ & $\begin{array}{c}-0.016183 \\
(0.407455)\end{array}$ & $\begin{array}{c}0.031859 * * * \\
(4.434370)\end{array}$ \\
\hline
\end{tabular}




\begin{tabular}{|c|c|c|c|c|c|c|c|c|c|c|}
\hline \multicolumn{11}{|c|}{ Phase 3} \\
\hline Variables & Model 1 & Model 2 & Model 3 & Model 4 & Model 5 & Model 6 & Model 7 & Model 8 & Model 9 & Model 10 \\
\hline$\sigma_{R V}{ }_{i d i o, j, t}$ & --- & --- & $\begin{array}{c}-0.267338 * * * \\
(2.949650)\end{array}$ & --- & $\begin{array}{c}-0.399581 * * * \\
(3.803024)\end{array}$ & $\begin{array}{c}-0.295041 * * * \\
(3.062955)\end{array}$ & $\begin{array}{c}-0.272747 * * * \\
(2.875267)\end{array}$ & $\begin{array}{c}-0.402747 * * * \\
(3.762045)\end{array}$ & $\begin{array}{c}-0.402200^{* * *} \\
(3.820691)\end{array}$ & $\begin{array}{c}-0.405899 * * * \\
(3.857286)\end{array}$ \\
\hline $\log S I Z E$ & $\begin{array}{c}0.003652 \\
(0.778242)\end{array}$ & $\begin{array}{c}0.005654 \\
(1.142131)\end{array}$ & $\begin{array}{c}0.002880 \\
(0.575191)\end{array}$ & $\begin{array}{c}0.006561 \\
(1.264198)\end{array}$ & $\begin{array}{c}0.005891 \\
(1.147716)\end{array}$ & $\begin{array}{c}0.004259 \\
(0.809196)\end{array}$ & $\begin{array}{c}0.003215 \\
(0.606859)\end{array}$ & $\begin{array}{c}0.005667 \\
(1.056972)\end{array}$ & $\begin{array}{c}0.006771 \\
(1.081565)\end{array}$ & --- \\
\hline $\log B M$ & $\begin{array}{c}0.005425 \\
(1.134303)\end{array}$ & $\begin{array}{c}0.004639 \\
(0.962468)\end{array}$ & $\begin{array}{c}0.006561 \\
(1.357768)\end{array}$ & $\begin{array}{c}0.004445 \\
(0.919487)\end{array}$ & $\begin{array}{c}0.006574 \\
(1.366407)\end{array}$ & $\begin{array}{c}0.006547 \\
(1.354530)\end{array}$ & $\begin{array}{c}0.006525 \\
(1.348138)\end{array}$ & $\begin{array}{c}0.006783 \\
(1.406098)\end{array}$ & $\begin{array}{c}0.006464 \\
(1.340712)\end{array}$ & $\begin{array}{c}0.004017 \\
(0.943360)\end{array}$ \\
\hline$r_{t}$ & $\begin{array}{c}0.096632 \\
(2.261242)\end{array}$ & $\begin{array}{c}0.102487 * * \\
(2.385525)\end{array}$ & $\begin{array}{c}0.039687 \\
(0.832180)\end{array}$ & $\begin{array}{c}0.110744 * * \\
(2.447796)\end{array}$ & $\begin{array}{c}0.048506 \\
(1.018685)\end{array}$ & $\begin{array}{c}0.033282 \\
(0.689173)\end{array}$ & $\begin{array}{c}0.038713 \\
(0.806671)\end{array}$ & $\begin{array}{c}0.045629 \\
(0.941645)\end{array}$ & $\begin{array}{c}0.047949 \\
(0.998685)\end{array}$ & $\begin{array}{c}0.041857 \\
(0.877726)\end{array}$ \\
\hline$r_{j, t-11: t-1}$ & $\begin{array}{l}-0.171378 \\
(3.394341)\end{array}$ & $\begin{array}{c}-0.174639 * * * \\
(3.456228)\end{array}$ & $\begin{array}{c}-0.164243 * * * \\
(3.264366)\end{array}$ & $\begin{array}{c}-0.175563 * * * \\
(3.470820)\end{array}$ & $\begin{array}{c}-0.163565 * * * \\
(3.265225)\end{array}$ & $\begin{array}{c}-0.167057 * * * \\
(3.312338)\end{array}$ & $\begin{array}{c}-0.164879 * * * \\
(3.267379)\end{array}$ & $\begin{array}{c}-0.163481 * * * \\
(3.251118)\end{array}$ & $\begin{array}{c}-0.158494 * * * \\
(3.126892)\end{array}$ & $\begin{array}{c}-0.160448 * * * \\
(3.166992)\end{array}$ \\
\hline$r_{j, t-35: t-12}$ & $\begin{array}{c}0.154941 \\
(2.955503)\end{array}$ & $\begin{array}{c}0.160036^{* * * *} \\
(3.045291)\end{array}$ & $\begin{array}{c}0.176474 * * * \\
(3.361637)\end{array}$ & $\begin{array}{c}0.158341 * * * \\
(3.006757)\end{array}$ & $\begin{array}{c}0.176421 * * * \\
(3.375490)\end{array}$ & $\begin{array}{c}0.174564 * * * \\
(3.321416)\end{array}$ & $\begin{array}{c}0.176257 * * * \\
(3.353903)\end{array}$ & $\begin{array}{c}0.175128 * * * \\
(3.343254)\end{array}$ & $\begin{array}{c}0.176617 * * * \\
(3.373105)\end{array}$ & $\begin{array}{c}0.180622 * * * \\
(3.457746)\end{array}$ \\
\hline$\beta_{j}$ & --- & $\begin{array}{c}0.014197 \\
(1.264255)\end{array}$ & $\begin{array}{c}0.016394 \\
(1.466510)\end{array}$ & $\begin{array}{c}0.013038 \\
(1.142834)\end{array}$ & $\begin{array}{c}0.011885 \\
(1.053657)\end{array}$ & $\begin{array}{c}0.015915 \\
(1.421470)\end{array}$ & $\begin{array}{c}0.016313 \\
(1.456994)\end{array}$ & $\begin{array}{c}0.011775 \\
(1.042582)\end{array}$ & $\begin{array}{c}0.012083 \\
(1.065378)\end{array}$ & $\begin{array}{c}0.008941 \\
(0.815463)\end{array}$ \\
\hline$\sigma_{I V} i d i o, j, t$ & --- & --- & --- & $\begin{array}{c}0.013540 \\
(0.585317)\end{array}$ & $\begin{array}{c}0.065409 * * \\
(2.456854)\end{array}$ & --- & --- & $\begin{array}{c}0.064751 * * \\
(2.351549)\end{array}$ & $\begin{array}{c}0.065359 * * \\
(2.347377)\end{array}$ & $\begin{array}{c}0.055002 * * \\
(2.103420)\end{array}$ \\
\hline$\sigma_{E G_{i d i o, j, t}}$ & --- & --- & --- & --- & --- & $\begin{array}{c}0.118968 \\
(0.850830)\end{array}$ & --- & $\begin{array}{c}0.165990 \\
(0.770916)\end{array}$ & --- & --- \\
\hline$\sigma_{A R_{i d i o, j, t}}$ & --- & --- & --- & --- & --- & --- & $\begin{array}{c}0.025925 \\
(0.194933)\end{array}$ & $\begin{array}{l}-0.163712 \\
(0.805557)\end{array}$ & --- & --- \\
\hline ORW $W_{\text {ratio }}$ & --- & --- & --- & --- & --- & --- & --- & --- & $\begin{array}{l}-0.001747 \\
(0.780927)\end{array}$ & $\begin{array}{l}-0.001421 \\
(0.641094)\end{array}$ \\
\hline$O I$ & --- & --- & --- & --- & --- & --- & --- & --- & $\begin{array}{c}-0.000338 \\
(0.101374)\end{array}$ & $\begin{array}{c}0.001684 \\
(0.610016)\end{array}$ \\
\hline Constant & $\begin{array}{c}-0.078393 \\
(1.064913)\end{array}$ & $\begin{array}{l}-0.122085 \\
(1.501877)\end{array}$ & $\begin{array}{l}-0.055136 \\
(0.657372)\end{array}$ & $\begin{array}{c}-0.139056 \\
(1.610400)\end{array}$ & $\begin{array}{l}-0.103999 \\
(1.211552)\end{array}$ & $\begin{array}{l}-0.085061 \\
(0.935069)\end{array}$ & $\begin{array}{c}-0.062365 \\
(0.679569)\end{array}$ & $\begin{array}{c}-0.099609 \\
(1.074860)\end{array}$ & $\begin{array}{l}-0.117181 \\
(1.236340)\end{array}$ & $\begin{array}{l}-0.017250 \\
(0.816162)\end{array}$ \\
\hline
\end{tabular}




\begin{tabular}{|c|c|c|c|c|c|c|c|c|c|c|}
\hline \multicolumn{11}{|c|}{ Phase 4} \\
\hline Variables & Model 1 & Model 2 & Model 3 & Model 4 & \begin{tabular}{|l|} 
Model 5 \\
\end{tabular} & Model 6 & Model 7 & Model 8 & Model 9 & Model 10 \\
\hline$\sigma_{R V \text { idio it }}$ & --- & --- & 0.063641 & --- & -0.034111 & 0.022491 & 0.064512 & -0.040108 & -0.022476 & -0.020234 \\
\hline & & & $(0.787274)$ & & $(0.365708)$ & $(0.261501)$ & $(0.749934)$ & $(0.415372)$ & $(0.239946)$ & $(0.218380)$ \\
\hline $\log S I Z E$ & $-0.011014 * * *$ & $-0.007882 * * *$ & $-0.007098 * *$ & -0.004913 & -0.005048 & -0.005427 & $-0.007131 * *$ & -0.004436 & -0.000712 & --- \\
\hline & (4.291586) & (2.708496) & (2.307367) & (1.534291) & (1.565498) & (1.644870) & (2.183197) & (1.302142) & $(0.166284)$ & \\
\hline $\log B M$ & $\begin{array}{l}-0.000596 \\
(0.226987)\end{array}$ & $\begin{array}{c}0.000666 \\
(0.248364)\end{array}$ & $\begin{array}{c}0.000500 \\
(0.185963)\end{array}$ & $\begin{array}{c}0.000078 \\
(0.029095)\end{array}$ & $\begin{array}{c}0.000111 \\
(0.041090)\end{array}$ & $\begin{array}{c}0.000947 \\
(0.349900)\end{array}$ & $\begin{array}{c}0.000497 \\
(0.184581)\end{array}$ & $\begin{array}{c}0.000737 \\
(0.270988)\end{array}$ & $\begin{array}{l}-0.000561 \\
(0.205237)\end{array}$ & $\begin{array}{l}-0.000439 \\
(0.166892)\end{array}$ \\
\hline$r_{t}$ & $\begin{array}{l}-0.012170 \\
(0.416560)\end{array}$ & $\begin{array}{l}-0.020145 \\
(0.685793)\end{array}$ & $\begin{array}{l}-0.023083 \\
(0.779421)\end{array}$ & $\begin{array}{l}-0.024385 \\
(0.829781)\end{array}$ & $\begin{array}{l}-0.023218 \\
(0.785140)\end{array}$ & $\begin{array}{l}-0.026584 \\
(0.894829)\end{array}$ & $\begin{array}{l}-0.023064 \\
(0.778283)\end{array}$ & $\begin{array}{l}-0.028237 \\
(0.950463)\end{array}$ & $\begin{array}{l}-0.021777 \\
(0.736016)\end{array}$ & $\begin{array}{l}-0.021761 \\
(0.735813)\end{array}$ \\
\hline$r_{j, t-11: t-1}$ & $\begin{array}{c}0.051659 * * \\
(2.054887)\end{array}$ & $\begin{array}{l}0.048671 * \\
(1.936857)\end{array}$ & $\begin{array}{c}0.049603 * * \\
(1.971424)\end{array}$ & $\begin{array}{c}0.052600 * * \\
(2.091502)\end{array}$ & $\begin{array}{c}0.052478 * * \\
(2.085678)\end{array}$ & $\begin{array}{l}0.048835 * \\
(1.941245)\end{array}$ & $\begin{array}{c}0.049615 * * \\
(1.970783)\end{array}$ & $\begin{array}{c}0.051706 * * \\
(2.055009)\end{array}$ & $\begin{array}{c}0.052153 * * \\
(2.072460)\end{array}$ & $\begin{array}{c}0.052163 * * \\
(2.073744)\end{array}$ \\
\hline$r_{j, t-35: t-12}$ & $\begin{array}{c}-0.047986 \\
(1.402680)\end{array}$ & $\begin{array}{l}-0.049144 \\
(1.438963)\end{array}$ & $\begin{array}{l}-0.046451 \\
(1.353117)\end{array}$ & $\begin{array}{l}-0.048679 \\
(1.427716)\end{array}$ & $\begin{array}{l}-0.050078 \\
(1.459040)\end{array}$ & $\begin{array}{l}-0.045528 \\
(1.326530)\end{array}$ & $\begin{array}{l}-0.046422 \\
(1.351101)\end{array}$ & $\begin{array}{l}-0.046090 \\
(1.340579)\end{array}$ & $\begin{array}{l}-0.052703 \\
(1.532738)\end{array}$ & $\begin{array}{l}-0.052849 \\
(1.538118)\end{array}$ \\
\hline$\beta_{j}$ & --- & $\begin{array}{c}0.020656 * * \\
(2.267951)\end{array}$ & $\begin{array}{c}0.018766 * * \\
(1.992195)\end{array}$ & $\begin{array}{l}0.016419 * \\
(1.766827)\end{array}$ & $\begin{array}{l}0.017025 * \\
(1.802923)\end{array}$ & $\begin{array}{c}0.018633 * * \\
(1.978724)\end{array}$ & $\begin{array}{c}0.018771 * * \\
(1.991541)\end{array}$ & $\begin{array}{l}0.017268 * \\
(1.829392)\end{array}$ & $\begin{array}{l}0.017845 * \\
(1.887363)\end{array}$ & $\begin{array}{c}0.018263 * * \\
(2.004541)\end{array}$ \\
\hline$\sigma_{I V i d i o, j, t}$ & --- & --- & --- & $\begin{array}{c}0.039114 * * \\
(2.205672)\end{array}$ & $\begin{array}{c}0.042870 * * \\
(2.091272)\end{array}$ & --- & --- & $\begin{array}{l}0.039013 * \\
(1.877764)\end{array}$ & $\begin{array}{c}0.053962 * * \\
(2.488464)\end{array}$ & $\begin{array}{c}0.055463 * * * \\
(2.814080)\end{array}$ \\
\hline$\sigma_{E G_{i d i o, j, t}}$ & --- & --- & --- & --- & --- & $\begin{array}{c}0.114056 \\
(1.396794)\end{array}$ & --- & $\begin{array}{l}0.204819 * \\
(1.763349)\end{array}$ & --- & --- \\
\hline$\sigma_{A R_{i d i o, j, t}}$ & --- & --- & --- & --- & --- & --- & $\begin{array}{l}-0.002333 \\
(0.029706)\end{array}$ & $\begin{array}{l}-0.158285 \\
(1.429031)\end{array}$ & --- & --- \\
\hline$O R W_{\text {ratio }}$ & --- & --- & --- & --- & --- & --- & --- & --- & $\begin{array}{l}-0.000107 \\
(0.089080)\end{array}$ & $\begin{array}{l}-0.000144 \\
(0.122221)\end{array}$ \\
\hline$O I$ & --- & --- & --- & --- & --- & --- & --- & --- & $\begin{array}{l}-0.003485 \\
(1.582740)\end{array}$ & $\begin{array}{c}-0.003719 * * \\
(2.197972)\end{array}$ \\
\hline Constant & $\begin{array}{c}0.195586 * * * \\
(4.852561)\end{array}$ & $\begin{array}{c}0.128543 * * \\
(2.574714)\end{array}$ & $\begin{array}{c}0.112898 * * \\
(2.100693)\end{array}$ & $\begin{array}{c}0.074531 \\
(1.342133)\end{array}$ & $\begin{array}{c}0.077730 \\
(1.382174)\end{array}$ & $\begin{array}{c}0.079314 \\
(1.347609)\end{array}$ & $\begin{array}{l}0.113561 * \\
(1.950410)\end{array}$ & $\begin{array}{c}0.065627 \\
(1.081805)\end{array}$ & $\begin{array}{c}0.026262 \\
(0.397862)\end{array}$ & $\begin{array}{c}0.015544 \\
(1.093634)\end{array}$ \\
\hline
\end{tabular}


Table 13.5: Industrial Goods Sector

\begin{tabular}{|c|c|c|c|c|c|c|c|c|c|c|}
\hline \multicolumn{11}{|c|}{ Entire Phases } \\
\hline Variables & Model 1 & Model 2 & Model 3 & Model 4 & Model 5 & Model 6 & Model 7 & Model 8 & Model 9 & Model 10 \\
\hline$\sigma_{R V_{i d i o, j, t}}$ & --- & --- & $\begin{array}{c}-0.083949 * * \\
(2.509880)\end{array}$ & --- & $\begin{array}{c}-0.215833 * * * \\
(4.999249)\end{array}$ & $\begin{array}{c}-0.065015 * \\
(1.910919)\end{array}$ & $\begin{array}{c}-0.076105 * * \\
(2.218192)\end{array}$ & $\begin{array}{c}-0.209161 * * * \\
(4.846875)\end{array}$ & $\begin{array}{c}-0.212136 * * * \\
(4.894938)\end{array}$ & $\begin{array}{c}-0.203503 * * * \\
(4.730524)\end{array}$ \\
\hline $\log S I Z E$ & $\begin{array}{c}-0.003884 * * \\
(2.560922)\end{array}$ & $\begin{array}{c}-0.003903 * * \\
(2.466056)\end{array}$ & $\begin{array}{c}-0.004927 * * * \\
(3.015783)\end{array}$ & $\begin{array}{c}-0.002950 * \\
(1.793363)\end{array}$ & $\begin{array}{c}-0.003742 * * \\
(2.269766)\end{array}$ & $\begin{array}{c}-0.005894 * * * \\
(3.540766)\end{array}$ & $\begin{array}{c}-0.005339 * * * \\
(3.173524)\end{array}$ & $\begin{array}{c}-0.004883 * * * \\
(2.895252)\end{array}$ & $\begin{array}{l}-0.003635 \\
(1.627570)\end{array}$ & --- \\
\hline $\log B M$ & $\begin{array}{c}0.004699 * * * \\
(2.646372)\end{array}$ & $\begin{array}{c}0.004695 * * * \\
(2.639767)\end{array}$ & $\begin{array}{c}0.005171 * * * \\
(2.892764)\end{array}$ & $\begin{array}{c}0.004237 * * \\
(2.365926)\end{array}$ & $\begin{array}{c}0.004579 * * \\
(2.561178)\end{array}$ & $\begin{array}{c}0.005597 * * * \\
(3.123119)\end{array}$ & $\begin{array}{c}0.005328 * * * \\
(2.969386)\end{array}$ & $\begin{array}{c}0.005066^{* * * *} \\
(2.828470)\end{array}$ & $\begin{array}{c}0.004638 * * \\
(2.525056)\end{array}$ & $\begin{array}{c}0.006331 * * * \\
(4.179903)\end{array}$ \\
\hline$r_{t}$ & $\begin{array}{c}0.067690 * * * \\
(4.821837)\end{array}$ & $\begin{array}{c}0.067701 * * * \\
(4.821354)\end{array}$ & $\begin{array}{c}0.062324 * * * \\
(4.389938)\end{array}$ & $\begin{array}{c}0.070873 * * * \\
(5.020631)\end{array}$ & $\begin{array}{c}0.063169 * * * \\
(4.459028)\end{array}$ & $\begin{array}{c}0.065905 * * * \\
(4.629155)\end{array}$ & $\begin{array}{c}0.063121 * * * \\
(4.439481)\end{array}$ & $\begin{array}{c}0.068008 * * * \\
(4.787841)\end{array}$ & $\begin{array}{c}0.062701 * * * \\
(4.421501)\end{array}$ & $\begin{array}{c}0.064163 * * * \\
(4.532926)\end{array}$ \\
\hline$r_{j, t-11: t-1}$ & $\begin{array}{c}0.057104 * * * \\
(4.174446)\end{array}$ & $\begin{array}{c}0.057097 * * * \\
(4.173300)\end{array}$ & $\begin{array}{c}0.055228 * * * \\
(4.032812)\end{array}$ & $\begin{array}{c}0.059043 * * * \\
(4.307345)\end{array}$ & $\begin{array}{c}0.057990 * * * \\
(4.240173)\end{array}$ & $\begin{array}{c}0.055746 * * * \\
(4.073574)\end{array}$ & $\begin{array}{c}0.055129 * * * \\
(4.025524)\end{array}$ & $\begin{array}{c}0.059029 * * * \\
(4.320683)\end{array}$ & $\begin{array}{c}0.059000 * * * \\
(4.310444)\end{array}$ & $\begin{array}{c}0.059712 * * * \\
(4.363948)\end{array}$ \\
\hline$r_{j, t-35: t-12}$ & $\begin{array}{l}-0.002250 \\
(0.151600)\end{array}$ & $\begin{array}{l}-0.002223 \\
(0.149572)\end{array}$ & $\begin{array}{l}-0.001862 \\
(0.125351)\end{array}$ & $\begin{array}{l}-0.002231 \\
(0.150195)\end{array}$ & $\begin{array}{l}-0.001320 \\
(0.089053)\end{array}$ & $\begin{array}{l}-0.001884 \\
(0.126954)\end{array}$ & $\begin{array}{l}-0.002257 \\
(0.151934)\end{array}$ & $\begin{array}{l}-0.001347 \\
(0.090947)\end{array}$ & $\begin{array}{l}-0.000380 \\
(0.025618)\end{array}$ & $\begin{array}{l}-0.000410 \\
(0.027649)\end{array}$ \\
\hline$\beta_{j}$ & --- & $\begin{array}{l}-0.000116 \\
(0.042146)\end{array}$ & $\begin{array}{c}0.001710 \\
(0.602065)\end{array}$ & $\begin{array}{l}-0.001487 \\
(0.527313)\end{array}$ & $\begin{array}{c}0.000560 \\
(0.196819)\end{array}$ & $\begin{array}{c}0.003217 \\
(1.115975)\end{array}$ & $\begin{array}{c}0.002502 \\
(0.850175)\end{array}$ & $\begin{array}{c}0.002468 \\
(0.841186)\end{array}$ & $\begin{array}{c}0.000076 \\
(0.025986)\end{array}$ & $\begin{array}{c}0.001403 \\
(0.499246)\end{array}$ \\
\hline$\sigma_{I V_{i d i o, j, t}}$ & --- & --- & --- & $\begin{array}{c}0.019872 * * \\
(2.121427)\end{array}$ & $\begin{array}{c}0.058210 * * * \\
(4.815296)\end{array}$ & --- & --- & $\begin{array}{c}0.066584 * * * \\
(5.334743)\end{array}$ & $\begin{array}{c}0.056072 * * * \\
(4.530756)\end{array}$ & $\begin{array}{c}0.060799 * * * \\
(5.053061)\end{array}$ \\
\hline$\sigma_{E G_{i d i o}, j, t}$ & --- & --- & --- & --- & --- & $\begin{array}{c}-0.108537 * * * \\
(2.973011)\end{array}$ & --- & $\begin{array}{c}-0.138307 * * * \\
(3.080178)\end{array}$ & --- & --- \\
\hline$\sigma_{A R i d i o, j, t}$ & --- & --- & --- & --- & --- & --- & $\begin{array}{l}-0.043409 \\
(1.026124)\end{array}$ & $\begin{array}{l}-0.008393 \\
(0.158500)\end{array}$ & --- & --- \\
\hline$O R W_{\text {ratio }}$ & --- & --- & --- & --- & --- & --- & --- & --- & $\begin{array}{c}-0.000915 * \\
(1.804034)\end{array}$ & $\begin{array}{c}-0.000923 * \\
(1.820228)\end{array}$ \\
\hline$O I$ & --- & --- & --- & --- & --- & --- & --- & --- & $\begin{array}{c}0.000035 \\
(0.038294)\end{array}$ & $\begin{array}{l}-0.000958 \\
(1.430600)\end{array}$ \\
\hline Constant & $\begin{array}{c}0.070879 * * * \\
(3.032464)\end{array}$ & $\begin{array}{c}0.071298 * * * \\
(2.806837)\end{array}$ & $\begin{array}{c}0.092475 * * * \\
(3.456590)\end{array}$ & $\begin{array}{c}0.053623 * * \\
(2.006541)\end{array}$ & $\begin{array}{c}0.073972 * * * \\
(2.742849)\end{array}$ & $\begin{array}{c}0.113066^{* * * *} \\
(4.094383)\end{array}$ & $\begin{array}{c}0.100979 * * * \\
(3.605448)\end{array}$ & $\begin{array}{c}0.099194 * * * \\
(3.532424)\end{array}$ & $\begin{array}{c}0.072566 * * \\
(2.157363)\end{array}$ & $\begin{array}{c}0.018420 * * * \\
(3.709931)\end{array}$ \\
\hline
\end{tabular}




\begin{tabular}{|c|c|c|c|c|c|c|c|c|c|c|}
\hline \multicolumn{11}{|c|}{ Phase 1} \\
\hline Variables & Model 1 & Model 2 & Model 3 & Model 4 & Model 5 & Model 6 & Model 7 & Model 8 & Model 9 & Model 10 \\
\hline$\sigma_{R V_{i d i o, j, t}}$ & --- & --- & $\begin{array}{c}0.257336 * * \\
(2.502342)\end{array}$ & --- & $\begin{array}{c}0.321675 * * * \\
(2.700318)\end{array}$ & $\begin{array}{c}0.385232 * * * \\
(3.637187)\end{array}$ & $\begin{array}{c}0.309905 * * * \\
(2.971618)\end{array}$ & $\begin{array}{c}0.363609 * * * \\
(3.065847)\end{array}$ & $\begin{array}{c}0.315152 * * * \\
(2.629459)\end{array}$ & $\begin{array}{c}0.327099 * * * \\
(2.760041)\end{array}$ \\
\hline $\log S I Z E$ & $\begin{array}{c}-0.000986 \\
(0.252980)\end{array}$ & $\begin{array}{c}-0.002622 \\
(0.633645)\end{array}$ & $\begin{array}{c}-0.000621 \\
(0.147650)\end{array}$ & $\begin{array}{l}-0.002345 \\
(0.555683)\end{array}$ & $\begin{array}{l}-0.001131 \\
(0.267285)\end{array}$ & $\begin{array}{l}-0.001642 \\
(0.393702)\end{array}$ & $\begin{array}{l}-0.002087 \\
(0.494127)\end{array}$ & $\begin{array}{l}-0.001249 \\
(0.295820)\end{array}$ & $\begin{array}{l}-0.003662 \\
(0.676492)\end{array}$ & --- \\
\hline$r_{t}$ & $\begin{array}{c}0.010233 \\
(0.323107)\end{array}$ & $\begin{array}{c}0.009044 \\
(0.285469)\end{array}$ & $\begin{array}{c}0.027420 \\
(0.845353)\end{array}$ & $\begin{array}{c}0.011345 \\
(0.349984)\end{array}$ & $\begin{array}{c}0.023624 \\
(0.724074)\end{array}$ & $\begin{array}{c}0.039794 \\
(1.233882)\end{array}$ & $\begin{array}{c}0.027450 \\
(0.849115)\end{array}$ & $\begin{array}{c}0.042927 \\
(1.312265)\end{array}$ & $\begin{array}{c}0.020986 \\
(0.640962)\end{array}$ & $\begin{array}{c}0.023093 \\
(0.708734)\end{array}$ \\
\hline$r_{j, t-11: t-1}$ & $\begin{array}{c}0.091579 * * * \\
(3.057225)\end{array}$ & $\begin{array}{c}0.087553 * * * \\
(2.904407)\end{array}$ & $\begin{array}{c}0.084746 * * * \\
(2.817032)\end{array}$ & $\begin{array}{c}0.087455 * * * \\
(2.899704)\end{array}$ & $\begin{array}{c}0.084399 * * * \\
(2.805561)\end{array}$ & $\begin{array}{c}0.085980 * * * \\
(2.885291)\end{array}$ & $\begin{array}{c}0.085602 * * * \\
(2.854904)\end{array}$ & $\begin{array}{c}0.086099 * * * \\
(2.886439)\end{array}$ & $\begin{array}{c}0.084921 * * * \\
(2.810323)\end{array}$ & $\begin{array}{c}0.086084 * * \\
(2.854257)\end{array}$ \\
\hline$r_{j, t-35: t-12}$ & $\begin{array}{c}0.064267 * * \\
(1.992061)\end{array}$ & $\begin{array}{c}0.067886 * * \\
(2.095100)\end{array}$ & $\begin{array}{c}0.064517 * * \\
(1.994861)\end{array}$ & $\begin{array}{c}0.068137 * * \\
(2.101334)\end{array}$ & $\begin{array}{l}0.062759 * \\
(1.938135)\end{array}$ & $\begin{array}{c}0.063817 * * \\
(1.992079)\end{array}$ & $\begin{array}{l}0.063126 * \\
(1.958151)\end{array}$ & $\begin{array}{c}0.064752 * * \\
(2.016624)\end{array}$ & $\begin{array}{c}0.064340 * * \\
(1.984467)\end{array}$ & $\begin{array}{c}0.063805 * * \\
(1.969114)\end{array}$ \\
\hline$\beta_{j}$ & --- & $\begin{array}{l}-0.012805 \\
(1.174382)\end{array}$ & $\begin{array}{c}-0.021670 * \\
(1.894783)\end{array}$ & $\begin{array}{l}-0.014527 \\
(1.207108)\end{array}$ & $\begin{array}{l}-0.017609 \\
(1.461432)\end{array}$ & $\begin{array}{l}-0.008622 \\
(0.736398)\end{array}$ & $\begin{array}{l}-0.012789 \\
(1.078880)\end{array}$ & $\begin{array}{l}-0.010535 \\
(0.866305)\end{array}$ & $\begin{array}{l}-0.017346 \\
(1.436522)\end{array}$ & $\begin{array}{l}-0.016319 \\
(1.362655)\end{array}$ \\
\hline$\sigma_{I V_{i d i o, j, t}}$ & --- & --- & --- & $\begin{array}{c}0.010401 \\
(0.338764)\end{array}$ & $\begin{array}{l}-0.037927 \\
(1.069847)\end{array}$ & --- & --- & $\begin{array}{c}0.015727 \\
(0.419182)\end{array}$ & $\begin{array}{l}-0.046201 \\
(1.271604)\end{array}$ & $\begin{array}{l}-0.041042 \\
(1.155679)\end{array}$ \\
\hline$\sigma_{E G_{i d i o, j, t}}$ & --- & --- & --- & --- & --- & $\begin{array}{c}-0.396714 * * * \\
(4.407799)\end{array}$ & --- & $\begin{array}{c}-0.446896 * * * \\
(3.487404)\end{array}$ & --- & --- \\
\hline$\sigma_{A R i d i o, j, t}$ & --- & --- & --- & --- & --- & --- & $\begin{array}{c}-0.262129 * * * \\
(2.728902)\end{array}$ & $\begin{array}{l}0.055459 \\
(0.415312)\end{array}$ & --- & --- \\
\hline$O R W_{\text {ratio }}$ & --- & --- & --- & --- & --- & --- & --- & --- & $\begin{array}{l}-0.000628 \\
(0.859419)\end{array}$ & $\begin{array}{l}-0.000640 \\
(0.876316)\end{array}$ \\
\hline$O I$ & --- & --- & --- & --- & --- & --- & --- & --- & $\begin{array}{c}0.001769 \\
(0.826979)\end{array}$ & $\begin{array}{c}0.000871 \\
(0.519297)\end{array}$ \\
\hline Constant & $\begin{array}{c}0.014763 \\
(0.251304)\end{array}$ & $\begin{array}{c}0.049333 \\
(0.750917)\end{array}$ & $\begin{array}{c}0.001423 \\
(0.020854)\end{array}$ & $\begin{array}{c}0.043852 \\
(0.647847)\end{array}$ & $\begin{array}{c}0.009431 \\
(0.137351)\end{array}$ & $\begin{array}{c}0.030102 \\
(0.443180)\end{array}$ & $\begin{array}{c}0.035425 \\
(0.512216)\end{array}$ & $\begin{array}{c}0.023216 \\
(0.336384)\end{array}$ & $\begin{array}{c}0.043488 \\
(0.528225)\end{array}$ & $\begin{array}{l}-0.011515 \\
(0.890684)\end{array}$ \\
\hline
\end{tabular}




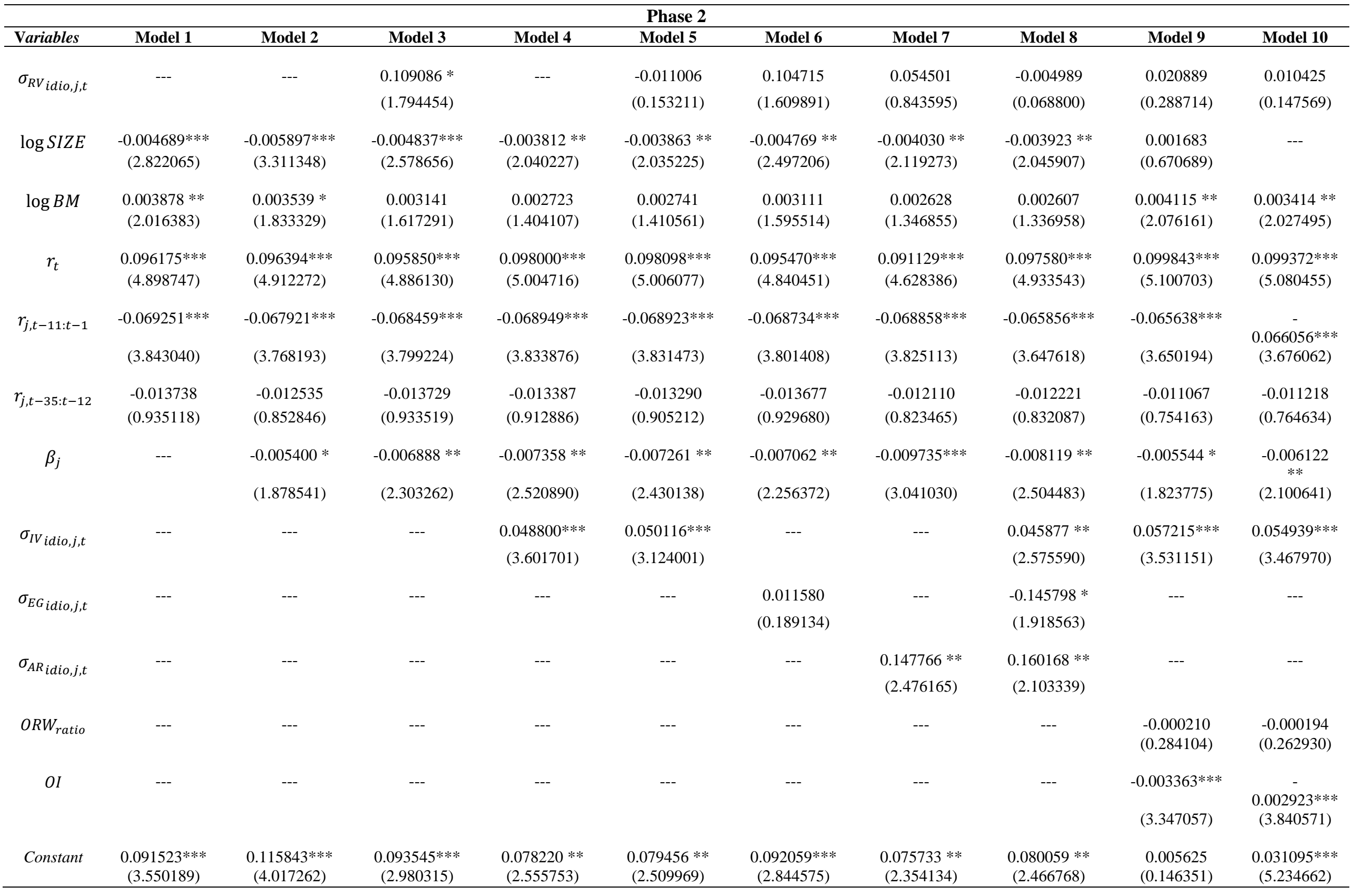




\begin{tabular}{|c|c|c|c|c|c|c|c|c|c|c|}
\hline \multicolumn{11}{|c|}{ Phase 3} \\
\hline Variables & Model 1 & Model 2 & Model 3 & Model 4 & Model 5 & Model 6 & Model 7 & Model 8 & Model 9 & Model 10 \\
\hline$\sigma_{R V} i d i o, j, t$ & --- & --- & $\begin{array}{c}-0.193639 * * \\
(2.235019)\end{array}$ & --- & $\begin{array}{c}-0.373032 * * * \\
(3.369281)\end{array}$ & $\begin{array}{c}-0.186742 * * \\
(2.150230)\end{array}$ & $\begin{array}{l}-0.140768 \\
(1.597242)\end{array}$ & $\begin{array}{c}-0.364624 * * * \\
(3.323575)\end{array}$ & $\begin{array}{c}-0.372210 * * * \\
(3.348442)\end{array}$ & $\begin{array}{c}-0.372897 * * * \\
(3.356683)\end{array}$ \\
\hline $\log S I Z E$ & $\begin{array}{l}-0.007979 \\
(1.299514)\end{array}$ & $\begin{array}{l}-0.006364 \\
(0.961020)\end{array}$ & $\begin{array}{l}-0.010436 \\
(1.525149)\end{array}$ & $\begin{array}{l}-0.004867 \\
(0.685774)\end{array}$ & $\begin{array}{c}-0.005872 \\
(0.835211)\end{array}$ & $\begin{array}{c}-0.012113 * \\
(1.728044)\end{array}$ & $\begin{array}{c}-0.016438 * * \\
(2.305043)\end{array}$ & $\begin{array}{c}-0.012131 * \\
(1.684624)\end{array}$ & $\begin{array}{l}-0.006607 \\
(0.662133)\end{array}$ & --- \\
\hline $\log B M$ & $\begin{array}{c}0.001595 \\
(0.211209)\end{array}$ & $\begin{array}{c}0.001524 \\
(0.201746)\end{array}$ & $\begin{array}{c}0.003569 \\
(0.470778)\end{array}$ & $\begin{array}{c}0.000864 \\
(0.113017)\end{array}$ & $\begin{array}{c}0.001785 \\
(0.235804)\end{array}$ & $\begin{array}{c}0.003077 \\
(0.405266)\end{array}$ & $\begin{array}{c}0.002925 \\
(0.388221)\end{array}$ & $\begin{array}{c}0.000349 \\
(0.046497)\end{array}$ & $\begin{array}{c}0.001600 \\
(0.206094)\end{array}$ & $\begin{array}{c}0.004011 \\
(0.585391)\end{array}$ \\
\hline$r_{t}$ & $\begin{array}{l}0.088587 * \\
(1.778452)\end{array}$ & $\begin{array}{l}0.091607 * \\
(1.830179)\end{array}$ & $\begin{array}{c}0.046366 \\
(0.861713)\end{array}$ & $\begin{array}{l}0.098922 * \\
(1.917013)\end{array}$ & $\begin{array}{c}0.045188 \\
(0.844575)\end{array}$ & $\begin{array}{c}0.051805 \\
(0.958953)\end{array}$ & $\begin{array}{c}0.061921 \\
(1.152295)\end{array}$ & $\begin{array}{c}0.064987 \\
(1.219024)\end{array}$ & $\begin{array}{c}0.044349 \\
(0.811817)\end{array}$ & $\begin{array}{c}0.052207 \\
(0.979604)\end{array}$ \\
\hline$r_{j, t-11: t-1}$ & $\begin{array}{l}-0.006818 \\
(0.080317)\end{array}$ & $\begin{array}{l}-0.018875 \\
(0.217159)\end{array}$ & $\begin{array}{l}-0.048621 \\
(0.555117)\end{array}$ & $\begin{array}{l}-0.009069 \\
(0.102410)\end{array}$ & $\begin{array}{l}-0.021572 \\
(0.245914)\end{array}$ & $\begin{array}{l}-0.055061 \\
(0.627370)\end{array}$ & $\begin{array}{l}-0.079220 \\
(0.903395)\end{array}$ & $\begin{array}{l}-0.052209 \\
(0.598466)\end{array}$ & $\begin{array}{l}-0.020466 \\
(0.229508)\end{array}$ & $\begin{array}{l}-0.032173 \\
(0.368312)\end{array}$ \\
\hline$r_{j, t-35: t-12}$ & $\begin{array}{c}0.116776 \\
(1.337421)\end{array}$ & $\begin{array}{c}0.112288 \\
(1.281324)\end{array}$ & $\begin{array}{c}0.102170 \\
(1.168980)\end{array}$ & $\begin{array}{c}0.109993 \\
(1.253080)\end{array}$ & $\begin{array}{c}0.080019 \\
(0.916282)\end{array}$ & $\begin{array}{c}0.105963 \\
(1.211677)\end{array}$ & $\begin{array}{c}0.105556 \\
(1.215771)\end{array}$ & $\begin{array}{c}0.076987 \\
(0.890342)\end{array}$ & $\begin{array}{c}0.079471 \\
(0.905804)\end{array}$ & $\begin{array}{c}0.080120 \\
(0.913781)\end{array}$ \\
\hline$\beta_{j}$ & --- & $\begin{array}{c}0.008256 \\
(0.653396)\end{array}$ & $\begin{array}{c}0.010743 \\
(0.850278)\end{array}$ & $\begin{array}{c}0.008581 \\
(0.678010)\end{array}$ & $\begin{array}{c}0.014855 \\
(1.173037)\end{array}$ & $\begin{array}{c}0.011896 \\
(0.938489)\end{array}$ & $\begin{array}{c}0.016159 \\
(1.272363)\end{array}$ & $\begin{array}{l}0.023265 * \\
(1.823486)\end{array}$ & $\begin{array}{c}0.014572 \\
(1.119344)\end{array}$ & $\begin{array}{c}0.018023 \\
(1.511640)\end{array}$ \\
\hline$\sigma_{I V i d i o, j, t}$ & --- & --- & --- & $\begin{array}{c}0.017352 \\
(0.589215)\end{array}$ & $\begin{array}{c}0.096628 * * \\
(2.579578)\end{array}$ & --- & --- & $\begin{array}{c}0.129056 * * * \\
(3.376780)\end{array}$ & $\begin{array}{c}0.094982 * * \\
(2.261655)\end{array}$ & $\begin{array}{c}0.107961 * * * \\
(2.908413)\end{array}$ \\
\hline$\sigma_{E G_{i d i o, j, t}}$ & --- & --- & --- & --- & --- & $\begin{array}{l}-0.106612 \\
(1.098469)\end{array}$ & --- & $\begin{array}{l}-0.000230 \\
(0.002156)\end{array}$ & --- & --- \\
\hline$\sigma_{A R_{i d i o, j, t}}$ & --- & --- & --- & --- & --- & --- & $\begin{array}{c}-0.440059 * * * \\
(2.780596)\end{array}$ & $\begin{array}{c}-0.570961 * * * \\
(3.200420)\end{array}$ & --- & --- \\
\hline ORW $W_{\text {ratio }}$ & --- & --- & --- & --- & --- & --- & --- & --- & $\begin{array}{c}0.000150 \\
(0.060009)\end{array}$ & $\begin{array}{c}0.000088 \\
(0.035502)\end{array}$ \\
\hline$O I$ & --- & --- & --- & --- & --- & --- & --- & --- & $\begin{array}{c}0.000433 \\
(0.100183)\end{array}$ & $\begin{array}{l}-0.001591 \\
(0.520019)\end{array}$ \\
\hline Constant & $\begin{array}{c}0.093767 \\
(0.987186)\end{array}$ & $\begin{array}{c}0.057830 \\
(0.526660)\end{array}$ & $\begin{array}{c}0.142980 \\
(1.234583)\end{array}$ & $\begin{array}{c}0.028546 \\
(0.236708)\end{array}$ & $\begin{array}{c}0.058793 \\
(0.491194)\end{array}$ & $\begin{array}{c}0.175565 \\
(1.468822)\end{array}$ & $\begin{array}{c}0.260511 * * \\
(2.125675)\end{array}$ & $\begin{array}{c}0.183101 \\
(1.476258)\end{array}$ & $\begin{array}{c}0.068471 \\
(0.451270)\end{array}$ & $\begin{array}{l}-0.030455 \\
(1.151652)\end{array}$ \\
\hline
\end{tabular}




\begin{tabular}{|c|c|c|c|c|c|c|c|c|c|c|}
\hline \multicolumn{11}{|c|}{ Phase 4} \\
\hline Variables & Model 1 & Model 2 & Model 3 & Model 4 & Model 5 & Model 6 & Model 7 & Model 8 & Model 9 & Model 10 \\
\hline$\sigma_{R V_{i d i o, j, t}}$ & --- & --- & $\begin{array}{c}0.008460 \\
(0.103046)\end{array}$ & --- & $\begin{array}{c}-0.220371 * * \\
(2.138278)\end{array}$ & $\begin{array}{c}0.016812 \\
(0.202863)\end{array}$ & $\begin{array}{c}0.009801 \\
(0.117677)\end{array}$ & $\begin{array}{c}-0.212240 * * \\
(2.043028)\end{array}$ & $\begin{array}{c}-0.194270 * \\
(1.840983)\end{array}$ & $\begin{array}{c}-0.179538 * \\
(1.739733)\end{array}$ \\
\hline $\log S I Z E$ & $\begin{array}{l}-0.006245 \\
(1.556925)\end{array}$ & $\begin{array}{l}-0.003686 \\
(0.869539)\end{array}$ & $\begin{array}{c}-0.003572 \\
(0.814724)\end{array}$ & $\begin{array}{l}-0.000456 \\
(0.104474)\end{array}$ & $\begin{array}{l}-0.001624 \\
(0.369842)\end{array}$ & $\begin{array}{l}-0.003968 \\
(0.898452)\end{array}$ & $\begin{array}{l}-0.003660 \\
(0.817246)\end{array}$ & $\begin{array}{l}-0.002113 \\
(0.472312)\end{array}$ & $\begin{array}{l}-0.004011 \\
(0.672603)\end{array}$ & --- \\
\hline $\log B M$ & $\begin{array}{c}0.004148 \\
(0.905202)\end{array}$ & $\begin{array}{c}0.004588 \\
(1.000939)\end{array}$ & $\begin{array}{c}0.004522 \\
(0.976954)\end{array}$ & $\begin{array}{c}0.003375 \\
(0.736212)\end{array}$ & $\begin{array}{c}0.004395 \\
(0.955117)\end{array}$ & $\begin{array}{c}0.004867 \\
(1.046074)\end{array}$ & $\begin{array}{c}0.004550 \\
(0.980598)\end{array}$ & $\begin{array}{c}0.004709 \\
(1.017729)\end{array}$ & $\begin{array}{c}0.003601 \\
(0.765823)\end{array}$ & $\begin{array}{c}0.005258 \\
(1.313137)\end{array}$ \\
\hline$r_{t}$ & $\begin{array}{l}-0.002733 \\
(0.090356)\end{array}$ & $\begin{array}{l}-0.010421 \\
(0.341737)\end{array}$ & $\begin{array}{l}-0.010577 \\
(0.346255)\end{array}$ & $\begin{array}{l}-0.012601 \\
(0.414695)\end{array}$ & $\begin{array}{l}-0.009760 \\
(0.321473)\end{array}$ & $\begin{array}{l}-0.009115 \\
(0.297731)\end{array}$ & $\begin{array}{l}-0.010585 \\
(0.346342)\end{array}$ & $\begin{array}{l}-0.008720 \\
(0.286090)\end{array}$ & $\begin{array}{l}-0.009316 \\
(0.307313)\end{array}$ & $\begin{array}{l}-0.010057 \\
(0.332059)\end{array}$ \\
\hline$r_{j, t-11: t-1}$ & $\begin{array}{c}0.161233 * * * \\
(5.993635)\end{array}$ & $\begin{array}{c}0.162102 * * * \\
(6.032273)\end{array}$ & $\begin{array}{c}0.162239 * * * \\
(6.027066)\end{array}$ & $\begin{array}{c}0.166549 * * * \\
(6.211365)\end{array}$ & $\begin{array}{c}0.165489 * * * \\
(6.181794)\end{array}$ & $\begin{array}{c}0.161536 * * * \\
(5.996027)\end{array}$ & $\begin{array}{c}0.162172 * * * \\
(6.019619)\end{array}$ & $\begin{array}{c}0.164835 * * * \\
(6.148900)\end{array}$ & $\begin{array}{c}0.166453 * * * \\
(6.227656)\end{array}$ & $\begin{array}{c}0.166473 * * * \\
(6.230105)\end{array}$ \\
\hline$r_{j, t-35: t-12}$ & $\begin{array}{c}-0.100164 * \\
(1.748579)\end{array}$ & $\begin{array}{c}-0.103375 * \\
(1.805974)\end{array}$ & $\begin{array}{c}-0.103236 * \\
(1.802153)\end{array}$ & $\begin{array}{c}-0.103469 * \\
(1.814493)\end{array}$ & $\begin{array}{c}-0.107144 * \\
(1.881426)\end{array}$ & $\begin{array}{c}-0.105096 * \\
(1.832512)\end{array}$ & $\begin{array}{c}-0.103584 * \\
(1.803843)\end{array}$ & $\begin{array}{c}-0.109344 * \\
(1.914542)\end{array}$ & $\begin{array}{l}-0.091182 \\
(1.593236)\end{array}$ & $\begin{array}{c}-0.095119 * \\
(1.671251)\end{array}$ \\
\hline$\beta_{j}$ & --- & $\begin{array}{l}0.015815 * \\
(1.848172)\end{array}$ & $\begin{array}{l}0.015553 * \\
(1.741356)\end{array}$ & $\begin{array}{c}0.010694 \\
(1.228989)\end{array}$ & $\begin{array}{l}0.014652 * \\
(1.649888)\end{array}$ & $\begin{array}{l}0.016370 * \\
(1.818982)\end{array}$ & $\begin{array}{l}0.015763 * \\
(1.714812)\end{array}$ & $\begin{array}{l}0.015745 * \\
(1.722474)\end{array}$ & $\begin{array}{c}0.009780 \\
(1.074177)\end{array}$ & $\begin{array}{c}0.011350 \\
(1.290011)\end{array}$ \\
\hline$\sigma_{I V_{i d i o, j, t}}$ & --- & --- & --- & $\begin{array}{c}0.063787 * * * \\
(2.936942)\end{array}$ & $\begin{array}{c}0.099542 * * * \\
(3.635646)\end{array}$ & --- & --- & $\begin{array}{c}0.100033 * * * \\
(3.600552)\end{array}$ & $\begin{array}{c}0.086818 * * * \\
(3.102055)\end{array}$ & $\begin{array}{c}0.090539 * * * \\
(3.301002)\end{array}$ \\
\hline$\sigma_{E G_{i d i o, j, t}}$ & --- & --- & --- & --- & --- & $\begin{array}{l}-0.057203 \\
(0.750647)\end{array}$ & --- & $\begin{array}{l}-0.041311 \\
(0.444827)\end{array}$ & --- & --- \\
\hline$\sigma_{A R i d i o, j, t}$ & --- & --- & --- & --- & --- & --- & $\begin{array}{l}-0.008612 \\
(0.097568)\end{array}$ & $\begin{array}{l}-0.020743 \\
(0.191457)\end{array}$ & --- & --- \\
\hline ORW $W_{\text {ratio }}$ & --- & --- & --- & --- & --- & --- & --- & --- & $\begin{array}{c}-0.004963 * * \\
(2.490517)\end{array}$ & $\begin{array}{c}-0.004947 * * \\
(2.483457)\end{array}$ \\
\hline$O I$ & --- & --- & --- & --- & --- & --- & --- & --- & $\begin{array}{c}0.002285 \\
(0.899324)\end{array}$ & $\begin{array}{c}0.001135 \\
(0.604040)\end{array}$ \\
\hline Constant & $\begin{array}{c}0.124347 * * \\
(2.002918)\end{array}$ & $\begin{array}{c}0.063207 \\
(0.899352)\end{array}$ & $\begin{array}{c}0.060965 \\
(0.828267)\end{array}$ & $\begin{array}{c}0.000591 \\
(0.008071)\end{array}$ & $\begin{array}{c}0.023896 \\
(0.323495)\end{array}$ & $\begin{array}{c}0.069821 \\
(0.936433)\end{array}$ & $\begin{array}{c}0.062660 \\
(0.828140)\end{array}$ & $\begin{array}{c}0.034191 \\
(0.451479)\end{array}$ & $\begin{array}{c}0.049832 \\
(0.549870)\end{array}$ & $\begin{array}{l}-0.010112 \\
(0.615400)\end{array}$ \\
\hline
\end{tabular}


Table 13.6: Services Sector

\begin{tabular}{|c|c|c|c|c|c|c|c|c|c|c|}
\hline \multicolumn{11}{|c|}{ Entire Phases } \\
\hline Variables & Model 1 & Model 2 & Model 3 & Model 4 & Model 5 & Model 6 & Model 7 & Model 8 & Model 9 & Model 10 \\
\hline$\sigma_{R V_{i d i o, j, t}}$ & --- & --- & $\begin{array}{c}0.103061 * * * \\
(5.139128)\end{array}$ & --- & $\begin{array}{c}0.039290 \\
(1.626337)\end{array}$ & $\begin{array}{c}0.095638 * * * \\
(4.564937)\end{array}$ & $\begin{array}{c}0.091744 * * * \\
(4.460356)\end{array}$ & $\begin{array}{c}0.037720 \\
(1.544724)\end{array}$ & $\begin{array}{l}0.046037 * \\
(1.898921)\end{array}$ & $\begin{array}{l}0.046714 * \\
(1.934553)\end{array}$ \\
\hline $\log S I Z E$ & $\begin{array}{c}-0.003560 * * * \\
(3.224066)\end{array}$ & $\begin{array}{c}-0.003285^{* * *} \\
(2.954091)\end{array}$ & $\begin{array}{c}-0.002105 * \\
(1.855930)\end{array}$ & $\begin{array}{l}-0.001169 \\
(1.013563)\end{array}$ & $\begin{array}{l}-0.001060 \\
(0.918072)\end{array}$ & $\begin{array}{l}-0.001778 \\
(1.525366)\end{array}$ & $\begin{array}{l}-0.001471 \\
(1.265387)\end{array}$ & $\begin{array}{l}-0.000790 \\
(0.667970)\end{array}$ & $\begin{array}{l}-0.000434 \\
(0.314638)\end{array}$ & --- \\
\hline $\log B M$ & $\begin{array}{c}0.006038 * * * \\
(4.904467)\end{array}$ & $\begin{array}{c}0.005844 * * * \\
(4.733983)\end{array}$ & $\begin{array}{c}0.005565 * * * \\
(4.508628)\end{array}$ & $\begin{array}{c}0.005687 * * * \\
(4.614764)\end{array}$ & $\begin{array}{c}0.005606 * * * \\
(4.545688)\end{array}$ & $\begin{array}{c}0.005539 * * * \\
(4.486975)\end{array}$ & $\begin{array}{c}0.005570 * * * \\
(4.513518)\end{array}$ & $\begin{array}{c}0.005625 * * * \\
(4.560336)\end{array}$ & $\begin{array}{c}0.005688 * * * \\
(4.585250)\end{array}$ & $\begin{array}{c}0.005921 * * * \\
(5.951187)\end{array}$ \\
\hline$r_{t}$ & $\begin{array}{c}0.070469 * * * \\
(7.958247)\end{array}$ & $\begin{array}{c}0.069488 * * * \\
(7.837239)\end{array}$ & $\begin{array}{c}0.071272 * * * \\
(8.040593)\end{array}$ & $\begin{array}{c}0.074983 * * * \\
(8.437313)\end{array}$ & $\begin{array}{c}0.074777 * * * \\
(8.413832)\end{array}$ & $\begin{array}{c}0.069700 * * * \\
(7.782198)\end{array}$ & $\begin{array}{c}0.069039 * * * \\
(7.749815)\end{array}$ & $\begin{array}{c}0.073747 * * * \\
(8.184654)\end{array}$ & $\begin{array}{c}0.074165 * * * \\
(8.345759)\end{array}$ & $\begin{array}{c}0.074261 * * * \\
(8.361793)\end{array}$ \\
\hline$r_{j, t-11: t-1}$ & $\begin{array}{c}0.034769 * * * \\
(4.166327)\end{array}$ & $\begin{array}{c}0.034428 * * * \\
(4.125206)\end{array}$ & $\begin{array}{c}0.035796 * * * \\
(4.291427)\end{array}$ & $\begin{array}{c}0.037234 * * * \\
(4.464110)\end{array}$ & $\begin{array}{c}0.037303 * * * \\
(4.472644)\end{array}$ & $\begin{array}{c}0.035931 * * * \\
(4.307215)\end{array}$ & $\begin{array}{c}0.036551 * * * \\
(4.379844)\end{array}$ & $\begin{array}{c}0.037781 * * * \\
(4.527669)\end{array}$ & $\begin{array}{c}0.037650 * * * \\
(4.516879)\end{array}$ & $\begin{array}{c}0.037700 * * * \\
(4.523932)\end{array}$ \\
\hline$r_{j, t-35: t-12}$ & $\begin{array}{l}-0.000078 \\
(0.008926)\end{array}$ & $\begin{array}{l}-0.000468 \\
(0.053373)\end{array}$ & $\begin{array}{l}-0.000850 \\
(0.096894)\end{array}$ & $\begin{array}{l}-0.001167 \\
(0.133236)\end{array}$ & $\begin{array}{l}-0.001200 \\
(0.136963)\end{array}$ & $\begin{array}{l}-0.000616 \\
(0.070287)\end{array}$ & $\begin{array}{l}-0.000407 \\
(0.046412)\end{array}$ & $\begin{array}{l}-0.000961 \\
(0.109668)\end{array}$ & $\begin{array}{l}-0.000337 \\
(0.038488)\end{array}$ & $\begin{array}{l}-0.000346 \\
(0.039562)\end{array}$ \\
\hline$\beta_{j}$ & --- & $\begin{array}{c}0.003560 * * \\
(2.075620)\end{array}$ & $\begin{array}{c}0.001534 \\
(0.872707)\end{array}$ & $\begin{array}{c}0.000191 \\
(0.106995)\end{array}$ & $\begin{array}{l}-0.000038 \\
(0.021317)\end{array}$ & $\begin{array}{c}0.001040 \\
(0.576285)\end{array}$ & $\begin{array}{c}0.000553 \\
(0.306957)\end{array}$ & $\begin{array}{l}-0.000467 \\
(0.254977)\end{array}$ & $\begin{array}{l}-0.000196 \\
(0.108207)\end{array}$ & $\begin{array}{l}-0.000137 \\
(0.076036)\end{array}$ \\
\hline$\sigma_{I V_{i d i o, j, t}}$ & --- & --- & --- & $\begin{array}{c}0.041600 * * * \\
(6.791839)\end{array}$ & $\begin{array}{c}0.034890 * * * \\
(4.724829)\end{array}$ & --- & --- & $\begin{array}{c}0.033176 * * * \\
(4.390390)\end{array}$ & $\begin{array}{c}0.031148 * * * \\
(4.135389)\end{array}$ & $\begin{array}{c}0.031696 * * * \\
(4.325390)\end{array}$ \\
\hline$\sigma_{E G_{i d i o, j, t}}$ & --- & --- & --- & --- & --- & $\begin{array}{c}0.034455 \\
(1.223964)\end{array}$ & --- & $\begin{array}{l}-0.022703 \\
(0.663825)\end{array}$ & --- & --- \\
\hline$\sigma_{A R_{i d i o, j, t}}$ & --- & --- & --- & --- & --- & --- & $\begin{array}{c}0.057784 * * \\
(2.465541)\end{array}$ & $\begin{array}{l}0.048989 * \\
(1.722242)\end{array}$ & --- & --- \\
\hline ORW ratio & --- & --- & --- & --- & --- & --- & --- & --- & $\begin{array}{c}-0.001293 * * * \\
(4.181770)\end{array}$ & $\begin{array}{c}-0.001297 * * * \\
(4.198275)\end{array}$ \\
\hline$O I$ & --- & --- & --- & --- & --- & --- & --- & --- & $\begin{array}{l}-0.000228 \\
(0.416417)\end{array}$ & $\begin{array}{l}-0.000323 \\
(0.701316)\end{array}$ \\
\hline Constant & $\begin{array}{c}0.066493 * * * \\
(3.990215)\end{array}$ & $\begin{array}{c}0.058448 * * * \\
(3.416681)\end{array}$ & $\begin{array}{l}0.033690 * \\
(1.897452)\end{array}$ & $\begin{array}{c}0.020127 \\
(1.119197)\end{array}$ & $\begin{array}{c}0.016869 \\
(0.932323)\end{array}$ & $\begin{array}{c}0.026854 \\
(1.442805)\end{array}$ & $\begin{array}{c}0.020856 \\
(1.127425)\end{array}$ & $\begin{array}{c}0.011319 \\
(0.598739)\end{array}$ & $\begin{array}{c}0.008342 \\
(0.409107)\end{array}$ & $\begin{array}{c}0.002005 \\
(0.628802)\end{array}$ \\
\hline
\end{tabular}




\begin{tabular}{|c|c|c|c|c|c|c|c|c|c|c|}
\hline \multicolumn{11}{|c|}{ Phase 1} \\
\hline Variables & Model 1 & Model 2 & Model 3 & Model 4 & Model 5 & Model 6 & Model 7 & Model 8 & Model 9 & Model 10 \\
\hline$\sigma_{R V_{i d i o, j, t}}$ & --- & --- & $\begin{array}{c}0.264364 * * * \\
(4.210547)\end{array}$ & --- & $\begin{array}{c}0.145992 * * \\
(2.011030)\end{array}$ & $\begin{array}{c}0.269649 * * * \\
(4.111423)\end{array}$ & $\begin{array}{c}0.265332 * * * \\
(4.036291)\end{array}$ & $\begin{array}{c}0.159443 * * \\
(2.157560)\end{array}$ & $\begin{array}{l}0.139948 * \\
(1.919771)\end{array}$ & $\begin{array}{c}0.146877 * * \\
(2.018690)\end{array}$ \\
\hline $\log S I Z E$ & $\begin{array}{c}-0.009312 * * * \\
(3.203517)\end{array}$ & $\begin{array}{c}-0.009802 * * * \\
(3.364888)\end{array}$ & $\begin{array}{c}-0.007743 * * * \\
(2.630355)\end{array}$ & $\begin{array}{c}-0.005433 * \\
(1.791891)\end{array}$ & $\begin{array}{c}-0.005341 * \\
(1.762483)\end{array}$ & $\begin{array}{c}-0.007938 * * * \\
(2.623340)\end{array}$ & $\begin{array}{c}-0.007792 * * \\
(2.506868)\end{array}$ & $\begin{array}{c}-0.006091 * \\
(1.931381)\end{array}$ & $\begin{array}{l}-0.004973 \\
(1.450897)\end{array}$ & --- \\
\hline $\log B M$ & $\begin{array}{c}0.001460 \\
(0.473348)\end{array}$ & $\begin{array}{c}0.001801 \\
(0.583682)\end{array}$ & $\begin{array}{c}0.000996 \\
(0.323328)\end{array}$ & $\begin{array}{c}0.002369 \\
(0.770907)\end{array}$ & $\begin{array}{c}0.001789 \\
(0.579862)\end{array}$ & $\begin{array}{c}0.000919 \\
(0.297074)\end{array}$ & $\begin{array}{c}0.000974 \\
(0.312675)\end{array}$ & $\begin{array}{c}0.001459 \\
(0.468766)\end{array}$ & $\begin{array}{c}0.001804 \\
(0.586216)\end{array}$ & $\begin{array}{l}0.004535 * \\
(1.862665)\end{array}$ \\
\hline$r_{t}$ & $\begin{array}{l}-0.017786 \\
(0.898990)\end{array}$ & $\begin{array}{l}-0.018411 \\
(0.931272)\end{array}$ & $\begin{array}{l}-0.010238 \\
(0.517188)\end{array}$ & $\begin{array}{l}-0.004210 \\
(0.211724)\end{array}$ & $\begin{array}{l}-0.003094 \\
(0.155627)\end{array}$ & $\begin{array}{l}-0.009536 \\
(0.477768)\end{array}$ & $\begin{array}{l}-0.010097 \\
(0.504831)\end{array}$ & $\begin{array}{c}0.000456 \\
(0.022547)\end{array}$ & $\begin{array}{l}-0.004436 \\
(0.223155)\end{array}$ & $\begin{array}{l}-0.001549 \\
(0.078308)\end{array}$ \\
\hline$r_{j, t-11: t-1}$ & $\begin{array}{l}-0.014707 \\
(0.877618)\end{array}$ & $\begin{array}{l}-0.015855 \\
(0.946468)\end{array}$ & $\begin{array}{l}-0.016577 \\
(0.992962)\end{array}$ & $\begin{array}{l}-0.019616 \\
(1.175429)\end{array}$ & $\begin{array}{l}-0.019115 \\
(1.146001)\end{array}$ & $\begin{array}{l}-0.016544 \\
(0.990789)\end{array}$ & $\begin{array}{l}-0.016558 \\
(0.991348)\end{array}$ & $\begin{array}{l}-0.019059 \\
(1.142251)\end{array}$ & $\begin{array}{l}-0.016551 \\
(0.993874)\end{array}$ & $\begin{array}{l}-0.016102 \\
(0.966813)\end{array}$ \\
\hline$r_{j, t-35: t-12}$ & $\begin{array}{c}0.056842 * * * \\
(3.011211)\end{array}$ & $\begin{array}{c}0.064318 * * * \\
(3.356836)\end{array}$ & $\begin{array}{c}0.064137 * * * \\
(3.359077)\end{array}$ & $\begin{array}{c}0.063115 * * * \\
(3.309737)\end{array}$ & $\begin{array}{c}0.063303 * * * \\
(3.321650)\end{array}$ & $\begin{array}{c}0.064042 * * * \\
(3.352967)\end{array}$ & $\begin{array}{c}0.064126 * * * \\
(3.357612)\end{array}$ & $\begin{array}{c}0.062902 * * * \\
(3.299152)\end{array}$ & $\begin{array}{c}0.064127 * * * \\
(3.373013)\end{array}$ & $\begin{array}{c}0.062962 * * * \\
(3.313911)\end{array}$ \\
\hline$\beta_{j}$ & --- & $\begin{array}{c}-0.011424 * * \\
(2.217122)\end{array}$ & $\begin{array}{c}-0.019945 * * * \\
(3.613767)\end{array}$ & $\begin{array}{c}-0.025236 * * * \\
(4.315638)\end{array}$ & $\begin{array}{c}-0.026638 * * * \\
(4.526157)\end{array}$ & $\begin{array}{c}-0.019922 * * * \\
(3.608391)\end{array}$ & $\begin{array}{c}-0.019933 * * * \\
(3.607309)\end{array}$ & $\begin{array}{c}-0.026964 * * * \\
(4.573274)\end{array}$ & $\begin{array}{c}-0.026577 * * * \\
(4.519446)\end{array}$ & $\begin{array}{c}-0.026935 * * * \\
(4.583120)\end{array}$ \\
\hline$\sigma_{I V i d i o, j, t}$ & --- & --- & --- & $\begin{array}{c}0.078876 * * * \\
(4.914542)\end{array}$ & $\begin{array}{c}0.060008 * * * \\
(3.229394)\end{array}$ & --- & --- & $\begin{array}{c}0.064374 * * * \\
(3.365373)\end{array}$ & $\begin{array}{c}0.056487 * * * \\
(2.982266)\end{array}$ & $\begin{array}{c}0.064847 * * * \\
(3.593110)\end{array}$ \\
\hline$\sigma_{E G_{i d i o, j, t}}$ & --- & --- & --- & --- & --- & $\begin{array}{l}-0.015910 \\
(0.279398)\end{array}$ & --- & $\begin{array}{l}-0.043307 \\
(0.650611)\end{array}$ & --- & --- \\
\hline$\sigma_{A R_{i d i o, j, t}}$ & --- & --- & --- & --- & --- & --- & $\begin{array}{l}-0.003395 \\
(0.049807)\end{array}$ & $\begin{array}{l}-0.026930 \\
(0.336873)\end{array}$ & --- & --- \\
\hline ORW $W_{\text {ratio }}$ & --- & --- & --- & --- & --- & --- & --- & --- & $\begin{array}{c}-0.002274 * * * \\
(3.702016)\end{array}$ & $\begin{array}{c}-0.002335 * * * \\
(3.808158)\end{array}$ \\
\hline$O I$ & --- & --- & --- & --- & --- & --- & --- & --- & $\begin{array}{c}0.000664 \\
(0.468220)\end{array}$ & $\begin{array}{l}-0.000288 \\
(0.229497)\end{array}$ \\
\hline Constant & $\begin{array}{c}0.144197 * * * \\
(3.341773)\end{array}$ & $\begin{array}{c}0.161904 * * * \\
(3.692383)\end{array}$ & $\begin{array}{c}0.111348 * * \\
(2.457221)\end{array}$ & $\begin{array}{l}0.084664 * \\
(1.825420)\end{array}$ & $\begin{array}{c}0.075222 \\
(1.614611)\end{array}$ & $\begin{array}{c}0.115201 * * \\
(2.431701)\end{array}$ & $\begin{array}{c}0.112292 * * \\
(2.285810)\end{array}$ & $\begin{array}{l}0.090566 * \\
(1.821001)\end{array}$ & $\begin{array}{c}0.067873 \\
(1.333310)\end{array}$ & $\begin{array}{l}-0.005076 \\
(0.636919)\end{array}$ \\
\hline
\end{tabular}




\begin{tabular}{|c|c|c|c|c|c|c|c|c|c|c|}
\hline \multicolumn{11}{|c|}{ Phase 2} \\
\hline Variables & Model 1 & Model 2 & Model 3 & Model 4 & Model 5 & Model 6 & Model 7 & Model 8 & Model 9 & Model 10 \\
\hline$\sigma_{R V_{i d i o, j, t}}$ & --- & --- & $\begin{array}{c}0.171454 * * * \\
(4.474419)\end{array}$ & --- & $\begin{array}{c}0.084565 * * \\
(2.007146)\end{array}$ & $\begin{array}{c}0.179071 * * * \\
(4.467796)\end{array}$ & $\begin{array}{c}0.164873 * * * \\
(4.131433)\end{array}$ & $\begin{array}{c}0.098795 * * \\
(2.299725)\end{array}$ & $\begin{array}{c}0.096552 * * \\
(2.268072)\end{array}$ & $\begin{array}{c}0.084751 * * \\
(2.014725)\end{array}$ \\
\hline $\log S I Z E$ & $\begin{array}{c}-0.001377 \\
(1.160417)\end{array}$ & $\begin{array}{l}-0.001366 \\
(1.148037)\end{array}$ & $\begin{array}{l}-0.000163 \\
(0.133919)\end{array}$ & $\begin{array}{c}0.001094 \\
(0.876591)\end{array}$ & $\begin{array}{c}0.001328 \\
(1.059529)\end{array}$ & $\begin{array}{l}-0.000360 \\
(0.286800)\end{array}$ & $\begin{array}{c}0.000037 \\
(0.029454)\end{array}$ & $\begin{array}{c}0.000899 \\
(0.699042)\end{array}$ & $\begin{array}{l}0.002667 * \\
(1.793348)\end{array}$ & --- \\
\hline $\log B M$ & $\begin{array}{c}0.004567 * * * \\
(3.398340)\end{array}$ & $\begin{array}{c}0.004558 * * * \\
(3.385988)\end{array}$ & $\begin{array}{c}0.004334 * * * \\
(3.221722)\end{array}$ & $\begin{array}{c}0.004281 * * * \\
(3.187930)\end{array}$ & $\begin{array}{c}0.004210 * * * \\
(3.135321)\end{array}$ & $\begin{array}{c}0.004406 * * * \\
(3.264043)\end{array}$ & $\begin{array}{c}0.004298 * * * \\
(3.192170)\end{array}$ & $\begin{array}{c}0.004400 * * * \\
(3.266586)\end{array}$ & $\begin{array}{c}0.004464 * * * \\
(3.309906)\end{array}$ & $\begin{array}{c}0.003038 * * * \\
(2.788353)\end{array}$ \\
\hline$r_{t}$ & $\begin{array}{c}0.045765 * * * \\
(3.637913)\end{array}$ & $\begin{array}{c}0.045727 * * * \\
(3.633434)\end{array}$ & $\begin{array}{c}0.045054 * * * \\
(3.585170)\end{array}$ & $\begin{array}{c}0.053966 * * * \\
(4.278669)\end{array}$ & $\begin{array}{c}0.052430 * * * \\
(4.150249)\end{array}$ & $\begin{array}{c}0.045443 * * * \\
(3.611840)\end{array}$ & $\begin{array}{c}0.044576^{* * *} \\
(3.539622)\end{array}$ & $\begin{array}{c}0.054101 * * * \\
(4.258674)\end{array}$ & $\begin{array}{c}0.052398 * * * \\
(4.147781)\end{array}$ & $\begin{array}{c}0.051879 * * * \\
(4.107039)\end{array}$ \\
\hline$r_{j, t-11: t-1}$ & $\begin{array}{c}-0.033526 * * * \\
(2.942608)\end{array}$ & $\begin{array}{c}-0.033573 * * * \\
(2.944751)\end{array}$ & $\begin{array}{c}-0.034119 * * * \\
(2.997048)\end{array}$ & $\begin{array}{c}-0.032642 * * * \\
(2.871859)\end{array}$ & $\begin{array}{c}-0.033047 * * * \\
(2.907778)\end{array}$ & $\begin{array}{c}-0.034194 * * * \\
(3.003370)\end{array}$ & $\begin{array}{c}-0.033990 * * * \\
(2.985036)\end{array}$ & $\begin{array}{c}-0.033172 * * * \\
(2.918726)\end{array}$ & $\begin{array}{c}-0.032493 * * * \\
(2.858648)\end{array}$ & $\begin{array}{c}-0.032631 * * * \\
(2.870342)\end{array}$ \\
\hline$r_{j, t-35: t-12}$ & $\begin{array}{c}0.000293 \\
(0.035350)\end{array}$ & $\begin{array}{c}0.000283 \\
(0.034153)\end{array}$ & $\begin{array}{l}-0.000242 \\
(0.029302)\end{array}$ & $\begin{array}{c}0.000540 \\
(0.065398)\end{array}$ & $\begin{array}{c}0.000243 \\
(0.029474)\end{array}$ & $\begin{array}{l}-0.000308 \\
(0.037286)\end{array}$ & $\begin{array}{l}-0.000182 \\
(0.021985)\end{array}$ & $\begin{array}{c}0.000098 \\
(0.011928)\end{array}$ & $\begin{array}{c}0.000545 \\
(0.065987)\end{array}$ & $\begin{array}{c}0.000216 \\
(0.026177)\end{array}$ \\
\hline$\beta_{j}$ & --- & $\begin{array}{c}0.000202 \\
(0.119615)\end{array}$ & $\begin{array}{l}-0.001867 \\
(1.070040)\end{array}$ & $\begin{array}{c}-0.003486 * * \\
(1.961245)\end{array}$ & $\begin{array}{c}-0.003967 * * \\
(2.212474)\end{array}$ & $\begin{array}{l}-0.001522 \\
(0.834132)\end{array}$ & $\begin{array}{l}-0.002167 \\
(1.192321)\end{array}$ & $\begin{array}{c}-0.003176 * \\
(1.708606)\end{array}$ & $\begin{array}{c}-0.003579 * * \\
(1.975164)\end{array}$ & $\begin{array}{c}-0.003707 * * \\
(2.047012)\end{array}$ \\
\hline$\sigma_{I V_{i d i o, j, t}}$ & --- & --- & --- & $\begin{array}{c}0.079568 * * * \\
(6.342359)\end{array}$ & $\begin{array}{c}0.067937 * * * \\
(4.917196)\end{array}$ & --- & --- & $\begin{array}{c}0.073358 * * * \\
(5.058054)\end{array}$ & $\begin{array}{c}0.066900 * * * \\
(4.795959)\end{array}$ & $\begin{array}{c}0.060800 * * * \\
(4.493521)\end{array}$ \\
\hline$\sigma_{E G_{i d i o, j, t}}$ & --- & --- & --- & --- & --- & $\begin{array}{l}-0.028062 \\
(0.648455)\end{array}$ & --- & $\begin{array}{l}-0.077586 \\
(1.504067)\end{array}$ & --- & --- \\
\hline$\sigma_{A R_{i d i o, j, t}}$ & --- & --- & --- & --- & --- & --- & $\begin{array}{c}0.023797 \\
(0.590732)\end{array}$ & $\begin{array}{l}-0.000374 \\
(0.007621)\end{array}$ & --- & --- \\
\hline$O R W_{\text {ratio }}$ & --- & --- & --- & --- & --- & --- & --- & --- & $\begin{array}{c}-0.000620 * \\
(1.847878)\end{array}$ & $\begin{array}{c}-0.000602 * \\
(1.797073)\end{array}$ \\
\hline$O I$ & --- & --- & --- & --- & --- & --- & --- & --- & $\begin{array}{l}-0.000863 \\
(1.519381)\end{array}$ & $\begin{array}{l}-0.000316 \\
(0.659771)\end{array}$ \\
\hline Constant & $\begin{array}{c}0.035690 * * \\
(1.987078)\end{array}$ & $\begin{array}{l}0.035311 * \\
(1.935894)\end{array}$ & $\begin{array}{c}0.007788 \\
(0.405123)\end{array}$ & $\begin{array}{c}-0.010094 \\
(0.516527)\end{array}$ & $\begin{array}{c}-0.017032 \\
(0.858458)\end{array}$ & $\begin{array}{c}0.012243 \\
(0.599702)\end{array}$ & $\begin{array}{c}0.003422 \\
(0.166131)\end{array}$ & $\begin{array}{l}-0.006626 \\
(0.315317)\end{array}$ & $\begin{array}{l}-0.034387 \\
(1.538221)\end{array}$ & $\begin{array}{c}0.005205 \\
(1.481682)\end{array}$ \\
\hline
\end{tabular}




\begin{tabular}{|c|c|c|c|c|c|c|c|c|c|c|}
\hline \multicolumn{11}{|c|}{ Phase 3} \\
\hline Variables & Model 1 & Model 2 & Model 3 & Model 4 & Model 5 & Model 6 & Model 7 & Model 8 & Model 9 & Model 10 \\
\hline$\sigma_{R V_{i d i o, j, t}}$ & --- & --- & $\begin{array}{c}-0.255601 * * * \\
(4.804743)\end{array}$ & --- & $\begin{array}{c}-0.553199 * * * \\
(8.638801)\end{array}$ & $\begin{array}{c}-0.236197 * * * \\
(4.300127)\end{array}$ & $\begin{array}{c}-0.231971 * * * \\
(4.255295)\end{array}$ & $\begin{array}{c}-0.547047 * * * \\
(8.595563)\end{array}$ & $\begin{array}{c}-0.553979 * * * \\
(8.648104)\end{array}$ & $\begin{array}{c}-0.559200 * * * \\
(8.752579)\end{array}$ \\
\hline $\log S I Z E$ & $\begin{array}{c}0.004072 \\
(1.064062)\end{array}$ & $\begin{array}{c}0.003770 \\
(0.949095)\end{array}$ & $\begin{array}{l}-0.000909 \\
(0.224049)\end{array}$ & $\begin{array}{l}0.007797 * \\
(1.891189)\end{array}$ & $\begin{array}{c}0.004744 \\
(1.179653)\end{array}$ & $\begin{array}{l}-0.002462 \\
(0.586033)\end{array}$ & $\begin{array}{l}-0.002860 \\
(0.685198)\end{array}$ & $\begin{array}{c}0.000440 \\
(0.107303)\end{array}$ & $\begin{array}{c}0.005518 \\
(1.106811)\end{array}$ & --- \\
\hline $\log B M$ & $\begin{array}{c}0.003408 \\
(0.797298)\end{array}$ & $\begin{array}{c}0.003475 \\
(0.811397)\end{array}$ & $\begin{array}{c}0.004666 \\
(1.097166)\end{array}$ & $\begin{array}{c}0.002464 \\
(0.576508)\end{array}$ & $\begin{array}{c}0.003266 \\
(0.786242)\end{array}$ & $\begin{array}{c}0.005277 \\
(1.235039)\end{array}$ & $\begin{array}{c}0.005061 \\
(1.190167)\end{array}$ & $\begin{array}{c}0.004367 \\
(1.055374)\end{array}$ & $\begin{array}{c}0.003275 \\
(0.776321)\end{array}$ & $\begin{array}{c}0.000894 \\
(0.246217)\end{array}$ \\
\hline$r_{t}$ & $\begin{array}{c}0.090898 * * * \\
(2.855007)\end{array}$ & $\begin{array}{c}0.089641 * * * \\
(2.788021)\end{array}$ & $\begin{array}{c}0.034646 \\
(1.023123)\end{array}$ & $\begin{array}{c}0.121280 * * * \\
(3.642275)\end{array}$ & $\begin{array}{l}0.057804 * \\
(1.742376)\end{array}$ & $\begin{array}{c}0.040475 \\
(1.186918)\end{array}$ & $\begin{array}{c}0.045582 \\
(1.329289)\end{array}$ & $\begin{array}{c}0.090341 * * * \\
(2.690103)\end{array}$ & $\begin{array}{l}0.057210 * \\
(1.720572)\end{array}$ & $\begin{array}{c}0.054400 \\
(1.640691)\end{array}$ \\
\hline$r_{j, t-11: t-1}$ & $\begin{array}{l}0.098113 * \\
(1.914752)\end{array}$ & $\begin{array}{l}0.099947 * \\
(1.934698)\end{array}$ & $\begin{array}{c}0.074909 \\
(1.455359)\end{array}$ & $\begin{array}{c}0.124402 * * \\
(2.396031)\end{array}$ & $\begin{array}{c}0.113149 * * \\
(2.242310)\end{array}$ & $\begin{array}{c}0.071907 \\
(1.396410)\end{array}$ & $\begin{array}{c}0.073776 \\
(1.434854)\end{array}$ & $\begin{array}{c}0.115763 * * \\
(2.311799)\end{array}$ & $\begin{array}{c}0.112232 * * \\
(2.220108)\end{array}$ & $\begin{array}{c}0.114823 * * \\
(2.273593)\end{array}$ \\
\hline$r_{j, t-35: t-12}$ & $\begin{array}{l}-0.053154 \\
(1.008429)\end{array}$ & $\begin{array}{l}-0.053425 \\
(1.013043)\end{array}$ & $\begin{array}{l}-0.061417 \\
(1.174310)\end{array}$ & $\begin{array}{l}-0.059712 \\
(1.136539)\end{array}$ & $\begin{array}{l}-0.088047 * \\
(1.721352)\end{array}$ & $\begin{array}{l}-0.059447 \\
(1.136689)\end{array}$ & $\begin{array}{l}-0.060729 \\
(1.162413)\end{array}$ & $\begin{array}{c}-0.090186 * \\
(1.777552)\end{array}$ & $\begin{array}{l}-0.086710 * \\
(1.694271)\end{array}$ & $\begin{array}{l}-0.084348 * \\
(1.649409)\end{array}$ \\
\hline$\beta_{j}$ & --- & $\begin{array}{l}-0.002503 \\
(0.285595)\end{array}$ & $\begin{array}{l}-0.001499 \\
(0.172503)\end{array}$ & $\begin{array}{l}-0.006350 \\
(0.721891)\end{array}$ & $\begin{array}{l}-0.010932 \\
(1.276668)\end{array}$ & $\begin{array}{c}0.002098 \\
(0.231776)\end{array}$ & $\begin{array}{c}0.003033 \\
(0.337425)\end{array}$ & $\begin{array}{l}-0.000196 \\
(0.022222)\end{array}$ & $\begin{array}{l}-0.010612 \\
(1.236114)\end{array}$ & $\begin{array}{l}-0.012672 \\
(1.511907)\end{array}$ \\
\hline$\sigma_{I V_{i d i o, j, t}}$ & --- & --- & --- & $\begin{array}{c}0.069857 * * * \\
(3.452112)\end{array}$ & $\begin{array}{c}0.192507 * * * \\
(7.938104)\end{array}$ & --- & --- & $\begin{array}{c}0.231596 * * * \\
(9.124018)\end{array}$ & $\begin{array}{c}0.196393 * * * \\
(7.877945)\end{array}$ & $\begin{array}{c}0.189077 * * * \\
(7.865304)\end{array}$ \\
\hline$\sigma_{E G_{i d i o, j, t}}$ & --- & --- & --- & --- & --- & $\begin{array}{l}-0.164228 \\
(1.410019)\end{array}$ & --- & $\begin{array}{l}-0.155273 \\
(1.052780)\end{array}$ & --- & --- \\
\hline$\sigma_{A R_{i d i o}, j, t}$ & --- & --- & --- & --- & --- & --- & $\begin{array}{c}-0.209966 * \\
(1.942078)\end{array}$ & $\begin{array}{c}-0.428588 * * * \\
(3.085363)\end{array}$ & --- & --- \\
\hline$O R W_{\text {ratio }}$ & --- & --- & --- & --- & --- & --- & --- & --- & $\begin{array}{c}0.001304 \\
(1.102532)\end{array}$ & $\begin{array}{c}0.001397 \\
(1.183744)\end{array}$ \\
\hline$O I$ & --- & --- & --- & --- & --- & --- & --- & --- & $\begin{array}{l}-0.000831 \\
(0.371563)\end{array}$ & $\begin{array}{c}0.000625 \\
(0.345298)\end{array}$ \\
\hline Constant & $\begin{array}{l}-0.086802 \\
(1.492191)\end{array}$ & $\begin{array}{l}-0.079311 \\
(1.242522)\end{array}$ & $\begin{array}{c}0.022106 \\
(0.331435)\end{array}$ & $\begin{array}{c}-0.157536 * * \\
(2.334882)\end{array}$ & $\begin{array}{l}-0.075382 \\
(1.138034)\end{array}$ & $\begin{array}{c}0.054579 \\
(0.773767)\end{array}$ & $\begin{array}{c}0.063041 \\
(0.902149)\end{array}$ & $\begin{array}{c}0.019083 \\
(0.276812)\end{array}$ & $\begin{array}{l}-0.083526 \\
(1.118708)\end{array}$ & $\begin{array}{l}-0.002801 \\
(0.175362)\end{array}$ \\
\hline
\end{tabular}




\begin{tabular}{|c|c|c|c|c|c|c|c|c|c|c|}
\hline \multicolumn{11}{|c|}{ Phase 4} \\
\hline Variables & Model 1 & Model 2 & Model 3 & Model 4 & Model 5 & Model 6 & Model 7 & Model 8 & Model 9 & Model 10 \\
\hline$\sigma_{R V_{i d i o, j, t}}$ & --- & --- & $\begin{array}{c}0.531439 * * * \\
(11.915108)\end{array}$ & --- & $\begin{array}{c}0.542783^{* * *} \\
(11.214855)\end{array}$ & $\begin{array}{c}0.514615 * * * \\
(11.246799)\end{array}$ & $\begin{array}{c}0.523524 * * * \\
(11.546068)\end{array}$ & $\begin{array}{c}0.529828 * * * \\
(10.820516)\end{array}$ & $\begin{array}{c}0.551268 * * * \\
(11.224743)\end{array}$ & $\begin{array}{c}0.551114 * * * \\
(11.292082)\end{array}$ \\
\hline $\log S I Z E$ & $\begin{array}{c}-0.010861 * * * \\
(3.662309)\end{array}$ & $\begin{array}{c}-0.008622 * * * \\
(2.796492)\end{array}$ & $\begin{array}{l}-0.001300 \\
(0.424517)\end{array}$ & $\begin{array}{l}-0.005215 \\
(1.634093)\end{array}$ & $\begin{array}{l}-0.001693 \\
(0.540731)\end{array}$ & $\begin{array}{l}-0.000435 \\
(0.140207)\end{array}$ & $\begin{array}{l}-0.000915 \\
(0.296427)\end{array}$ & $\begin{array}{l}-0.000937 \\
(0.296558)\end{array}$ & $\begin{array}{c}0.000108 \\
(0.028560)\end{array}$ & --- \\
\hline $\log B M$ & $\begin{array}{c}0.008288 * * \\
(2.450677)\end{array}$ & $\begin{array}{c}0.007722 * * \\
(2.281273)\end{array}$ & $\begin{array}{c}0.004387 \\
(1.327289)\end{array}$ & $\begin{array}{c}0.007259 * * \\
(2.149621)\end{array}$ & $\begin{array}{c}0.004390 \\
(1.328151)\end{array}$ & $\begin{array}{c}0.004184 \\
(1.265558)\end{array}$ & $\begin{array}{c}0.004331 \\
(1.310411)\end{array}$ & $\begin{array}{c}0.004172 \\
(1.261567)\end{array}$ & $\begin{array}{c}0.004769 \\
(1.431389)\end{array}$ & $\begin{array}{l}0.004715 * \\
(1.721539)\end{array}$ \\
\hline$r_{t}$ & $\begin{array}{c}0.071292 * * * \\
(3.727793)\end{array}$ & $\begin{array}{c}0.061730 * * * \\
(3.174226)\end{array}$ & $\begin{array}{c}0.015878 \\
(0.822427)\end{array}$ & $\begin{array}{c}0.060535 * * * \\
(3.121640)\end{array}$ & $\begin{array}{c}0.015092 \\
(0.779837)\end{array}$ & $\begin{array}{c}0.009777 \\
(0.497414)\end{array}$ & $\begin{array}{c}0.015311 \\
(0.792669)\end{array}$ & $\begin{array}{c}0.008151 \\
(0.410613)\end{array}$ & $\begin{array}{c}0.015514 \\
(0.801224)\end{array}$ & $\begin{array}{c}0.015519 \\
(0.801680)\end{array}$ \\
\hline$r_{j, t-11: t-1}$ & $\begin{array}{c}0.114428 * * * \\
(6.540294)\end{array}$ & $\begin{array}{c}0.111790 * * * \\
(6.386456)\end{array}$ & $\begin{array}{c}0.119734 * * * \\
(7.025965)\end{array}$ & $\begin{array}{c}0.120706 * * * \\
(6.859568)\end{array}$ & $\begin{array}{c}0.118466 * * * \\
(6.898544)\end{array}$ & $\begin{array}{c}0.121473 * * * \\
(7.116572)\end{array}$ & $\begin{array}{c}0.121436 * * * \\
(7.088319)\end{array}$ & $\begin{array}{c}0.119802 * * * \\
(6.952049)\end{array}$ & $\begin{array}{c}0.118289 * * * \\
(6.884012)\end{array}$ & $\begin{array}{c}0.118277 * * * \\
(6.886792)\end{array}$ \\
\hline$r_{j, t-35: t-12}$ & $\begin{array}{c}-0.064721 * \\
(1.713802)\end{array}$ & $\begin{array}{l}-0.058210 \\
(1.539892)\end{array}$ & $\begin{array}{c}-0.065700 * \\
(1.786296)\end{array}$ & $\begin{array}{l}-0.059492 \\
(1.578399)\end{array}$ & $\begin{array}{c}-0.065653 * \\
(1.784791)\end{array}$ & $\begin{array}{c}-0.062811 * \\
(1.706369)\end{array}$ & $\begin{array}{c}-0.064405 * \\
(1.749912)\end{array}$ & $\begin{array}{c}-0.062473 * \\
(1.696590)\end{array}$ & $\begin{array}{c}-0.064498 * \\
(1.749704)\end{array}$ & $\begin{array}{c}-0.064485 * \\
(1.749836)\end{array}$ \\
\hline$\beta_{j}$ & --- & $\begin{array}{c}0.012477 * * * \\
(2.620809)\end{array}$ & $\begin{array}{l}-0.000162 \\
(0.034028)\end{array}$ & $\begin{array}{c}0.007185 \\
(1.457213)\end{array}$ & $\begin{array}{c}0.000422 \\
(0.086997)\end{array}$ & $\begin{array}{l}-0.002423 \\
(0.489768)\end{array}$ & $\begin{array}{l}-0.001312 \\
(0.267954)\end{array}$ & $\begin{array}{l}-0.001776 \\
(0.353684)\end{array}$ & $\begin{array}{l}-0.000011 \\
(0.002338)\end{array}$ & $\begin{array}{l}-0.000034 \\
(0.006925)\end{array}$ \\
\hline$\sigma_{I V} i d i o, j, t$ & --- & --- & --- & $\begin{array}{c}0.055979 * * * \\
(3.966916)\end{array}$ & $\begin{array}{l}-0.009026 \\
(0.604150)\end{array}$ & --- & --- & $\begin{array}{l}-0.013366 \\
(0.881610)\end{array}$ & $\begin{array}{l}-0.010503 \\
(0.666370)\end{array}$ & $\begin{array}{l}-0.010615 \\
(0.695710)\end{array}$ \\
\hline$\sigma_{E G_{i d i o, j, t}}$ & --- & --- & --- & --- & --- & $\begin{array}{c}0.094424 \\
(1.636650)\end{array}$ & --- & $\begin{array}{c}0.101141 \\
(1.397102)\end{array}$ & --- & --- \\
\hline$\sigma_{A R} i d i o, j, t$ & --- & --- & --- & --- & --- & --- & $\begin{array}{c}0.036671 \\
(0.970484)\end{array}$ & $\begin{array}{c}0.001799 \\
(0.038079)\end{array}$ & --- & --- \\
\hline$O R W_{\text {ratio }}$ & --- & --- & --- & --- & --- & --- & --- & --- & $\begin{array}{l}-0.000907 \\
(0.820385)\end{array}$ & $\begin{array}{l}-0.000907 \\
(0.820348)\end{array}$ \\
\hline$O I$ & --- & --- & --- & --- & --- & --- & --- & --- & $\begin{array}{l}-0.001171 \\
(0.732221)\end{array}$ & $\begin{array}{l}-0.001145 \\
(0.862479)\end{array}$ \\
\hline Constant & $\begin{array}{c}0.197191 * * * \\
(4.381867)\end{array}$ & $\begin{array}{c}0.148329 * * * \\
(3.048169)\end{array}$ & $\begin{array}{c}0.001857 \\
(0.037962)\end{array}$ & $\begin{array}{l}0.085068 * \\
(1.665640)\end{array}$ & $\begin{array}{c}0.008931 \\
(0.177559)\end{array}$ & $\begin{array}{l}-0.015546 \\
(0.310687)\end{array}$ & $\begin{array}{l}-0.005419 \\
(0.109517)\end{array}$ & $\begin{array}{l}-0.006665 \\
(0.130516)\end{array}$ & $\begin{array}{l}-0.012917 \\
(0.230857)\end{array}$ & $\begin{array}{l}-0.011347 \\
(1.090597)\end{array}$ \\
\hline
\end{tabular}


Table 13.7: Technology Sector

\begin{tabular}{|c|c|c|c|c|c|c|c|c|c|c|}
\hline \multicolumn{11}{|c|}{ Entire Phases } \\
\hline Variables & Model 1 & Model 2 & Model 3 & Model 4 & Model 5 & Model 6 & Model 7 & Model 8 & Model 9 & Model 10 \\
\hline \multirow{2}{*}{$\sigma_{R V_{i d i o, j, t}}$} & --- & --- & 0.031572 & --- & -0.028230 & $0.040356 *$ & $0.042768 * *$ & -0.016702 & -0.024582 & -0.024545 \\
\hline & & & (1.525295) & & (1.117226) & (1.827355) & (1.997092) & $(0.654853)$ & $(0.967702)$ & $(0.970558)$ \\
\hline \multirow[t]{2}{*}{$\log S I Z E$} & -0.001912 & -0.001947 & -0.001655 & -0.000952 & -0.001030 & -0.001861 & -0.001921 & -0.001500 & -0.000024 & --- \\
\hline & (1.426408) & (1.449067) & $(1.219190)$ & $(0.698622)$ & $(0.754867)$ & (1.359260) & (1.409090) & (1.093367) & $(0.015436)$ & \\
\hline $\log B M$ & $\begin{array}{c}0.004043 * * * \\
(2.871974)\end{array}$ & $\begin{array}{c}0.004100 * * * \\
(2.894515)\end{array}$ & $\begin{array}{c}0.004133 * * * \\
(2.918110)\end{array}$ & $\begin{array}{c}0.004124 * * * \\
(2.913631)\end{array}$ & $\begin{array}{c}0.004098 * * * \\
(2.895154)\end{array}$ & $\begin{array}{c}0.004170 * * * \\
(2.943034)\end{array}$ & $\begin{array}{c}0.004242 * * * \\
(2.993349)\end{array}$ & $\begin{array}{c}0.004267 * * * \\
(3.013152)\end{array}$ & $\begin{array}{c}0.004338 * * * \\
(3.046738)\end{array}$ & $\begin{array}{c}0.004354 * * * \\
(4.757644)\end{array}$ \\
\hline$r_{t}$ & $\begin{array}{c}-0.015276 * \\
(1.758480)\end{array}$ & $\begin{array}{c}-0.015181 * \\
(1.746682)\end{array}$ & $\begin{array}{c}-0.014521 * \\
(1.668825)\end{array}$ & $\begin{array}{l}-0.011680 \\
(1.338737)\end{array}$ & $\begin{array}{l}-0.011624 \\
(1.332325)\end{array}$ & $\begin{array}{l}-0.013363 \\
(1.525414)\end{array}$ & $\begin{array}{l}-0.013643 \\
(1.566184)\end{array}$ & $\begin{array}{l}-0.008045 \\
(0.912104)\end{array}$ & $\begin{array}{l}-0.011356 \\
(1.301547)\end{array}$ & $\begin{array}{c}-0.011354 \\
(1.301560)\end{array}$ \\
\hline$r_{j, t-11: t-1}$ & $\begin{array}{c}0.021311 * * * \\
(2.724913)\end{array}$ & $\begin{array}{c}0.021354 * * * \\
(2.730016)\end{array}$ & $\begin{array}{c}0.021541 * * * \\
(2.753735)\end{array}$ & $\begin{array}{c}0.021664 * * * \\
(2.771471)\end{array}$ & $\begin{array}{c}0.021554 * * * \\
(2.757209)\end{array}$ & $\begin{array}{c}0.021657 * * * \\
(2.768438)\end{array}$ & $\begin{array}{c}0.021723 * * * \\
(2.777200)\end{array}$ & $\begin{array}{c}0.021946 * * * \\
(2.807983)\end{array}$ & $\begin{array}{c}0.021964 * * * \\
(2.809178)\end{array}$ & $\begin{array}{c}0.021965 * * * \\
(2.809440)\end{array}$ \\
\hline \multirow[t]{2}{*}{$r_{j, t-35: t-12}$} & 0.005547 & 0.005628 & 0.004663 & 0.001870 & 0.002039 & 0.004900 & 0.004642 & 0.001746 & 0.002048 & 0.002045 \\
\hline & $(0.737720)$ & $(0.748042)$ & $(0.617727)$ & $(0.246968)$ & $(0.269277)$ & $(0.648764)$ & $(0.614944)$ & $(0.230579)$ & $(0.270475)$ & $(0.270196)$ \\
\hline \multirow[t]{2}{*}{$\beta_{j}$} & --- & -0.000616 & -0.001064 & -0.001746 & -0.001554 & -0.000602 & -0.000348 & -0.000146 & -0.000783 & -0.000778 \\
\hline & & $(0.363948)$ & $(0.619534)$ & (1.020270) & $(0.903439)$ & $(0.341487)$ & (0.198439) & $(0.082091)$ & $(0.437167)$ & $(0.440521)$ \\
\hline \multirow[t]{2}{*}{$\sigma_{I V_{i d i o, j, t}}$} & --- & --- & --- & $0.025129 * * *$ & $0.029762 * * *$ & --- & --- & $0.037226 * * *$ & $0.029944 * * *$ & $0.029957 * * *$ \\
\hline & & & & (4.250448) & (4.121333) & & & $(4.863412)$ & (4.139084) & $(4.173021)$ \\
\hline \multirow[t]{2}{*}{$\sigma_{E G_{i d i o, j, t}}$} & --- & --- & --- & --- & --- & -0.035851 & --- & -0.058952 & --- & --- \\
\hline & & & & & & (1.140869) & & (1.623766) & & \\
\hline \multirow[t]{2}{*}{$\sigma_{\text {ARidio }, j, t}$} & --- & --- & --- & --- & --- & --- & $-0.049124 * *$ & $-0.053012 * *$ & --- & --- \\
\hline & & & & & & & $(2.035151)$ & (1.975677) & & \\
\hline ORW ratio & --- & --- & --- & --- & --- & --- & --- & --- & $\begin{array}{c}-0.000305 * \\
(1.801467)\end{array}$ & $\begin{array}{c}-0.000305 * \\
(1.802320)\end{array}$ \\
\hline$O I$ & --- & --- & --- & --- & --- & --- & --- & --- & $\begin{array}{l}-0.000734 \\
(1.235196)\end{array}$ & $\begin{array}{l}-0.000739 \\
(1.404834)\end{array}$ \\
\hline Constant & $\begin{array}{l}0.037382 * \\
(1.846314)\end{array}$ & $\begin{array}{l}0.039084 * \\
(1.880796)\end{array}$ & $\begin{array}{c}0.032187 \\
(1.513573)\end{array}$ & $\begin{array}{c}0.018681 \\
(0.876463)\end{array}$ & $\begin{array}{c}0.021086 \\
(0.984293)\end{array}$ & $\begin{array}{l}0.037187 * \\
(1.712714)\end{array}$ & $\begin{array}{l}0.038982 * \\
(1.811112)\end{array}$ & $\begin{array}{c}0.033856 \\
(1.554091)\end{array}$ & $\begin{array}{c}0.007863 \\
(0.338147)\end{array}$ & $\begin{array}{l}0.007510 * \\
(1.755129)\end{array}$ \\
\hline
\end{tabular}




\begin{tabular}{|c|c|c|c|c|c|c|c|c|c|c|}
\hline \multicolumn{11}{|c|}{ Phase 1} \\
\hline Variables & Model 1 & Model 2 & Model 3 & Model 4 & Model 5 & Model 6 & Model 7 & Model 8 & Model 9 & Model 10 \\
\hline$\sigma_{R V}{ }_{i d i o, j, t}$ & --- & --- & $\begin{array}{c}0.519852 * * * \\
(7.370121)\end{array}$ & --- & $\begin{array}{c}0.398817 * * * \\
(4.901875)\end{array}$ & $\begin{array}{c}0.579584 * * * \\
(7.976530)\end{array}$ & $\begin{array}{c}0.563480 * * * \\
(7.856866)\end{array}$ & $\begin{array}{c}0.427695 * * * \\
(5.266871)\end{array}$ & $\begin{array}{c}0.410903 * * * \\
(5.015231)\end{array}$ & $\begin{array}{c}0.403773 * * * \\
(4.966757)\end{array}$ \\
\hline $\log S I Z E$ & $\begin{array}{l}-0.005185 \\
(1.174791)\end{array}$ & $\begin{array}{l}-0.004807 \\
(1.087854)\end{array}$ & $\begin{array}{l}-0.000617 \\
(0.140012)\end{array}$ & $\begin{array}{l}-0.001439 \\
(0.325801)\end{array}$ & $\begin{array}{c}0.000251 \\
(0.056950)\end{array}$ & $\begin{array}{l}-0.002660 \\
(0.598840)\end{array}$ & $\begin{array}{l}-0.001917 \\
(0.433929)\end{array}$ & $\begin{array}{l}-0.002428 \\
(0.548763)\end{array}$ & $\begin{array}{c}0.003555 \\
(0.704504)\end{array}$ & --- \\
\hline $\log B M$ & $\begin{array}{c}0.005087 \\
(1.089616)\end{array}$ & $\begin{array}{c}0.006625 \\
(1.391774)\end{array}$ & $\begin{array}{c}0.007318 \\
(1.553795)\end{array}$ & $\begin{array}{c}0.005261 \\
(1.112536)\end{array}$ & $\begin{array}{c}0.006410 \\
(1.360242)\end{array}$ & $\begin{array}{c}0.007153 \\
(1.521767)\end{array}$ & $\begin{array}{c}0.007471 \\
(1.589105)\end{array}$ & $\begin{array}{c}0.005852 \\
(1.247115)\end{array}$ & $\begin{array}{c}0.006861 \\
(1.451057)\end{array}$ & $\begin{array}{c}0.004363 \\
(1.394911)\end{array}$ \\
\hline$r_{t}$ & $\begin{array}{c}-0.088185 * * * \\
(4.595551)\end{array}$ & $\begin{array}{c}-0.087241 * * * \\
(4.545870)\end{array}$ & $\begin{array}{c}-0.097658 * * * \\
(5.129968)\end{array}$ & $\begin{array}{c}-0.071867 * * * \\
(3.742638)\end{array}$ & $\begin{array}{c}-0.086815 * * * \\
(4.485736)\end{array}$ & $\begin{array}{c}-0.093078 * * * \\
(4.886500)\end{array}$ & $\begin{array}{c}-0.096409 * * * \\
(5.072831)\end{array}$ & $\begin{array}{c}-0.074947 * * * \\
(3.855697)\end{array}$ & $\begin{array}{c}-0.086550 * * * \\
(4.470134)\end{array}$ & $\begin{array}{c}-0.086675 * * * \\
(4.477209)\end{array}$ \\
\hline$r_{j, t-11: t-1}$ & $\begin{array}{c}0.035558 * * \\
(2.097211)\end{array}$ & $\begin{array}{c}0.034537 * * \\
(2.036323)\end{array}$ & $\begin{array}{c}0.033193 * * \\
(1.978314)\end{array}$ & $\begin{array}{l}0.029900 * \\
(1.774914)\end{array}$ & $\begin{array}{l}0.030967 * \\
(1.846784)\end{array}$ & $\begin{array}{c}0.034853 * * \\
(2.080619)\end{array}$ & $\begin{array}{c}0.036255 * * \\
(2.161342)\end{array}$ & $\begin{array}{c}0.033942 * * \\
(2.031400)\end{array}$ & $\begin{array}{l}0.031551 * \\
(1.880664)\end{array}$ & $\begin{array}{l}0.031166 * \\
(1.858862)\end{array}$ \\
\hline$r_{j, t-35: t-12}$ & $\begin{array}{c}0.067830 * * * \\
(3.193379)\end{array}$ & $\begin{array}{c}0.074191 * * * \\
(3.437159)\end{array}$ & $\begin{array}{c}0.068272 * * * \\
(3.195154)\end{array}$ & $\begin{array}{c}0.073654 * * * \\
(3.438723)\end{array}$ & $\begin{array}{c}0.069356 * * * \\
(3.250620)\end{array}$ & $\begin{array}{c}0.064879 * * * \\
(3.039097)\end{array}$ & $\begin{array}{c}0.064221 * * * \\
(3.005925)\end{array}$ & $\begin{array}{c}0.063139 * * * \\
(2.967695)\end{array}$ & $\begin{array}{c}0.067930 * * * \\
(3.179546)\end{array}$ & $\begin{array}{c}0.068888 * * * \\
(3.231246)\end{array}$ \\
\hline$\beta_{j}$ & --- & $\begin{array}{l}-0.010489 \\
(1.639287)\end{array}$ & $\begin{array}{c}-0.034228 * * * \\
(4.819517)\end{array}$ & $\begin{array}{c}-0.032991 * * * \\
(4.517922)\end{array}$ & $\begin{array}{c}-0.041021 * * * \\
(5.506028)\end{array}$ & $\begin{array}{c}-0.029635^{* * *} \\
(4.103677)\end{array}$ & $\begin{array}{c}-0.030100 * * * \\
(4.177297)\end{array}$ & $\begin{array}{c}-0.036740 * * * \\
(4.921388)\end{array}$ & $\begin{array}{c}-0.038761 * * * \\
(5.073853)\end{array}$ & $\begin{array}{c}-0.038790 * * * \\
(5.078150)\end{array}$ \\
\hline$\sigma_{I V} i d i o, j, t$ & --- & --- & --- & $\begin{array}{c}0.105602 * * * \\
(6.238603)\end{array}$ & $\begin{array}{c}0.057819 * * * \\
(2.970490)\end{array}$ & --- & --- & $\begin{array}{c}0.090533 * * * \\
(4.423858)\end{array}$ & $\begin{array}{c}0.062555^{* * *} \\
(3.161257)\end{array}$ & $\begin{array}{c}0.060654 * * * \\
(3.094410)\end{array}$ \\
\hline$\sigma_{E G_{i d i o, j, t}}$ & --- & --- & --- & --- & --- & $\begin{array}{c}-0.230813^{* * * *} \\
(3.314325)\end{array}$ & --- & $\begin{array}{c}-0.236915^{* * * *} \\
(2.888655)\end{array}$ & --- & --- \\
\hline$\sigma_{A R_{i d i o, j, t}}$ & --- & --- & --- & --- & --- & --- & $\begin{array}{c}-0.203386 * * * \\
(3.190247)\end{array}$ & $\begin{array}{c}-0.168053 * * \\
(2.275982)\end{array}$ & --- & --- \\
\hline ORW $W_{\text {ratio }}$ & --- & --- & --- & --- & --- & --- & --- & --- & $\begin{array}{c}0.000125 \\
(0.229173)\end{array}$ & $\begin{array}{c}0.000129 \\
(0.235560)\end{array}$ \\
\hline$O I$ & --- & --- & --- & --- & --- & --- & --- & --- & $\begin{array}{l}-0.002849 \\
(1.360812)\end{array}$ & $\begin{array}{c}-0.002134 \\
(1.165490)\end{array}$ \\
\hline Constant & $\begin{array}{c}0.060631 \\
(0.918240)\end{array}$ & $\begin{array}{c}0.074432 \\
(1.118595)\end{array}$ & $\begin{array}{l}-0.019107 \\
(0.285033)\end{array}$ & $\begin{array}{c}0.007457 \\
(0.111475)\end{array}$ & $\begin{array}{l}-0.033999 \\
(0.506573)\end{array}$ & $\begin{array}{c}0.024773 \\
(0.363264)\end{array}$ & $\begin{array}{c}0.011890 \\
(0.175858)\end{array}$ & $\begin{array}{c}0.028228 \\
(0.415110)\end{array}$ & $\begin{array}{l}-0.076796 \\
(1.033976)\end{array}$ & $\begin{array}{c}-0.025392 * \\
(1.830217)\end{array}$ \\
\hline
\end{tabular}




\begin{tabular}{|c|c|c|c|c|c|c|c|c|c|c|}
\hline \multicolumn{11}{|c|}{ Phase 2} \\
\hline Variables & Model 1 & Model 2 & Model 3 & Model 4 & Model 5 & Model 6 & Model 7 & Model 8 & Model 9 & Model 10 \\
\hline$\sigma_{R V_{i d i o, j, t}}$ & --- & --- & $\begin{array}{c}0.244933 * * * \\
(6.503414)\end{array}$ & --- & $\begin{array}{c}0.060893 \\
(1.402193)\end{array}$ & $\begin{array}{c}0.239301 * * * \\
(6.050850)\end{array}$ & $\begin{array}{c}0.250947 * * * \\
(6.355993)\end{array}$ & $\begin{array}{l}0.080335 * \\
(1.829126)\end{array}$ & $\begin{array}{l}0.073792 * \\
(1.682837)\end{array}$ & $\begin{array}{c}0.065629 \\
(1.507443)\end{array}$ \\
\hline $\log S I Z E$ & $\begin{array}{c}-0.002437 * \\
(1.769714)\end{array}$ & $\begin{array}{c}-0.002439 * \\
(1.765953)\end{array}$ & $\begin{array}{l}-0.000921 \\
(0.659326)\end{array}$ & $\begin{array}{c}0.000793 \\
(0.565163)\end{array}$ & $\begin{array}{c}0.000918 \\
(0.653052)\end{array}$ & $\begin{array}{l}-0.000809 \\
(0.570682)\end{array}$ & $\begin{array}{l}-0.001062 \\
(0.745599)\end{array}$ & $\begin{array}{c}0.000189 \\
(0.132414)\end{array}$ & $\begin{array}{c}0.002454 \\
(1.548393)\end{array}$ & --- \\
\hline $\log B M$ & $\begin{array}{l}-0.000096 \\
(0.067086)\end{array}$ & $\begin{array}{l}-0.000090 \\
(0.062043)\end{array}$ & $\begin{array}{c}0.000415 \\
(0.287255)\end{array}$ & $\begin{array}{l}-0.000237 \\
(0.165340)\end{array}$ & $\begin{array}{l}-0.000100 \\
(0.069705)\end{array}$ & $\begin{array}{c}0.000393 \\
(0.271869)\end{array}$ & $\begin{array}{c}0.000424 \\
(0.293232)\end{array}$ & $\begin{array}{l}-0.000083 \\
(0.057432)\end{array}$ & $\begin{array}{c}0.000154 \\
(0.106733)\end{array}$ & $\begin{array}{l}-0.001471 \\
(1.482992)\end{array}$ \\
\hline$r_{t}$ & $\begin{array}{l}-0.006089 \\
(0.496439)\end{array}$ & $\begin{array}{l}-0.006081 \\
(0.495520)\end{array}$ & $\begin{array}{l}-0.003954 \\
(0.323117)\end{array}$ & $\begin{array}{c}0.004797 \\
(0.392895)\end{array}$ & $\begin{array}{c}0.004477 \\
(0.366603)\end{array}$ & $\begin{array}{l}-0.004513 \\
(0.367082)\end{array}$ & $\begin{array}{l}-0.003571 \\
(0.291242)\end{array}$ & $\begin{array}{c}0.008478 \\
(0.688902)\end{array}$ & $\begin{array}{c}0.005353 \\
(0.438174)\end{array}$ & $\begin{array}{c}0.004758 \\
(0.389656)\end{array}$ \\
\hline$r_{j, t-11: t-1}$ & $\begin{array}{c}-0.041222 * * * \\
(4.116220)\end{array}$ & $\begin{array}{c}-0.041217 * * * \\
(4.114407)\end{array}$ & $\begin{array}{c}-0.041606 * * * \\
(4.166624)\end{array}$ & $\begin{array}{c}-0.038840 * * * \\
(3.909560)\end{array}$ & $\begin{array}{c}-0.039123 * * * \\
(3.937462)\end{array}$ & $\begin{array}{c}-0.041603 * * * \\
(4.166114)\end{array}$ & $\begin{array}{c}-0.041605 * * * \\
(4.166284)\end{array}$ & $\begin{array}{c}-0.038816^{* * * *} \\
(3.908823)\end{array}$ & $\begin{array}{c}-0.038454 * * * \\
(3.868161)\end{array}$ & $\begin{array}{c}-0.038609 * * * \\
(3.883552)\end{array}$ \\
\hline$r_{j, t-35: t-12}$ & $\begin{array}{c}0.000584 \\
(0.084136)\end{array}$ & $\begin{array}{c}0.000581 \\
(0.083672)\end{array}$ & $\begin{array}{l}-0.002815 \\
(0.405504)\end{array}$ & $\begin{array}{l}-0.005868 \\
(0.848740)\end{array}$ & $\begin{array}{l}-0.006208 \\
(0.897558)\end{array}$ & $\begin{array}{l}-0.002906 \\
(0.418440)\end{array}$ & $\begin{array}{l}-0.002763 \\
(0.397884)\end{array}$ & $\begin{array}{l}-0.006197 \\
(0.896360)\end{array}$ & $\begin{array}{l}-0.006128 \\
(0.886030)\end{array}$ & $\begin{array}{l}-0.006152 \\
(0.889389)\end{array}$ \\
\hline$\beta_{j}$ & --- & $\begin{array}{l}-0.000040 \\
(0.022967)\end{array}$ & $\begin{array}{c}-0.003987 * * \\
(2.175952)\end{array}$ & $\begin{array}{c}-0.005261 * * * \\
(2.939794)\end{array}$ & $\begin{array}{c}-0.005835^{* * *} \\
(3.178558)\end{array}$ & $\begin{array}{c}-0.004187 * * \\
(2.224988)\end{array}$ & $\begin{array}{c}-0.003719 * \\
(1.950685)\end{array}$ & $\begin{array}{c}-0.004265 * * \\
(2.240602)\end{array}$ & $\begin{array}{c}-0.004675 * * \\
(2.439827)\end{array}$ & $\begin{array}{c}-0.005063 * * * \\
(2.664889)\end{array}$ \\
\hline$\sigma_{I V_{i d i o, j, t}}$ & --- & --- & --- & $\begin{array}{c}0.117195 * * * \\
(10.532423)\end{array}$ & $\begin{array}{c}0.108044 * * * \\
(8.376160)\end{array}$ & --- & --- & $\begin{array}{c}0.121291 * * * \\
(8.886732)\end{array}$ & $\begin{array}{c}0.108546 * * * \\
(8.411699)\end{array}$ & $\begin{array}{c}0.105628 * * * \\
(8.273361)\end{array}$ \\
\hline$\sigma_{E G_{i d i o, j, t}}$ & --- & --- & --- & --- & --- & $\begin{array}{c}0.019980 \\
(0.467006)\end{array}$ & --- & $\begin{array}{l}-0.029068 \\
(0.570629)\end{array}$ & --- & --- \\
\hline$\sigma_{A R_{i d i o, j, t}}$ & --- & --- & --- & --- & --- & --- & $\begin{array}{l}-0.022201 \\
(0.507898)\end{array}$ & $\begin{array}{c}-0.124817 * * \\
(2.394932)\end{array}$ & --- & --- \\
\hline$O R W_{\text {ratio }}$ & --- & --- & --- & --- & --- & --- & --- & --- & $\begin{array}{c}0.000016 \\
(0.081366)\end{array}$ & $\begin{array}{c}0.000020 \\
(0.100777)\end{array}$ \\
\hline$O I$ & --- & --- & --- & --- & --- & --- & --- & --- & $\begin{array}{c}-0.001328 * * \\
(2.104907)\end{array}$ & $\begin{array}{l}-0.000878 \\
(1.568158)\end{array}$ \\
\hline Constant & $\begin{array}{c}0.052798 * * \\
(2.531379)\end{array}$ & $\begin{array}{c}0.052922 * * \\
(5.490517)\end{array}$ & $\begin{array}{c}0.018218 \\
(0.823316)\end{array}$ & $\begin{array}{l}-0.009237 \\
(0.416821)\end{array}$ & $\begin{array}{l}-0.013011 \\
(0.582894)\end{array}$ & $\begin{array}{c}0.015483 \\
(0.676369)\end{array}$ & $\begin{array}{c}0.021570 \\
(0.934077)\end{array}$ & $\begin{array}{c}0.005982 \\
(0.258262)\end{array}$ & $\begin{array}{l}-0.032600 \\
(1.347645)\end{array}$ & $\begin{array}{c}0.004141 \\
(0.880320)\end{array}$ \\
\hline
\end{tabular}




\begin{tabular}{|c|c|c|c|c|c|c|c|c|c|c|}
\hline \multicolumn{11}{|c|}{ Phase 3} \\
\hline Variables & Model 1 & Model 2 & Model 3 & Model 4 & Model 5 & Model 6 & Model 7 & Model 8 & Model 9 & Model 10 \\
\hline \multirow{2}{*}{$\sigma_{R V} i d i o, j, t$} & \multirow{2}{*}{--- } & \multirow{2}{*}{---} & -0.029798 & \multirow[t]{2}{*}{---} & -0.072253 & -0.064789 & -0.031664 & -0.091301 & -0.069691 & -0.072020 \\
\hline & & & $(0.545018)$ & & $(1.213842)$ & $(1.146771)$ & $(0.561705)$ & $(1.506135)$ & (1.169392) & (1.210093) \\
\hline \multirow[t]{2}{*}{$\log S I Z E$} & -0.001077 & 0.000720 & 0.000561 & 0.001129 & 0.000895 & 0.001323 & 0.000615 & 0.001078 & 0.004774 & \multirow[t]{2}{*}{---} \\
\hline & $(0.206042)$ & $(0.136057)$ & $(0.105902)$ & $(0.213160)$ & $(0.168864)$ & $(0.249767)$ & $(0.115672)$ & $(0.203617)$ & (0.799077) & \\
\hline \multirow[t]{2}{*}{$\log B M$} & 0.004840 & 0.004148 & 0.004259 & 0.003594 & 0.003660 & 0.002372 & 0.004163 & 0.002454 & 0.004822 & 0.001228 \\
\hline & $(0.874486)$ & $(0.749105)$ & $(0.768393)$ & $(0.647851)$ & $(0.659756)$ & $(0.424546)$ & $(0.744978)$ & $(0.439142)$ & $(0.860045)$ & $(0.366903)$ \\
\hline \multirow{2}{*}{$r_{t}$} & 0.055140 & 0.052657 & 0.043526 & 0.072757 & 0.057999 & 0.039174 & 0.043542 & 0.049790 & 0.056996 & 0.057094 \\
\hline & (1.574324) & $(1.504696)$ & (1.121586) & (1.930050) & $(1.464527)$ & (1.010227) & $(1.121561)$ & $(1.257133)$ & $(1.438559)$ & $(1.441242)$ \\
\hline \multirow{2}{*}{$r_{j, t-11: t-1}$} & $0.241989 * * *$ & $0.227380 * * *$ & $0.223156^{* * *}$ & $0.235395 * * *$ & $0.228095 * * *$ & $0.218573 * * *$ & $0.222685^{* * * *}$ & $0.229604 * * *$ & $0.226019 * * *$ & $0.230019 * * *$ \\
\hline & $(4.059565)$ & $(3.794827)$ & (3.692538) & (3.913124) & $(3.773665)$ & (3.621638) & (3.677357) & (3.801254) & (3.738249) & (3.818052) \\
\hline \multirow{2}{*}{$r_{j, t-35: t-12}$} & 0.044252 & 0.047531 & 0.049076 & 0.044126 & 0.046623 & 0.048996 & 0.049409 & 0.039998 & 0.046686 & 0.046568 \\
\hline & $(0.950824)$ & (1.022145) & (1.053129) & $(0.948078)$ & (1.000930) & (1.053367) & $(1.058420)$ & $(0.858812)$ & $(1.000891)$ & $(0.998501)$ \\
\hline \multirow{2}{*}{$\beta_{j}$} & --- & $0.017455 * *$ & $0.017933 * *$ & $0.016445 * *$ & $0.017233 * *$ & 0.013100 & $0.017600 * *$ & $0.015862 *$ & $0.019741 * *$ & $0.018215 * *$ \\
\hline & & $(2.133505)$ & $(2.178850)$ & $(2.003392)$ & $(2.093265)$ & $(1.548456)$ & $(2.049523)$ & (1.850713) & $(2.344616)$ & $(2.221619)$ \\
\hline \multirow[t]{2}{*}{$\sigma_{I V_{i d i o, j, t}}$} & --- & --- & --- & 0.036020 & $0.049250 *$ & --- & --- & $0.046965 *$ & $0.051813 *$ & $0.050349 *$ \\
\hline & & & & $(1.430525)$ & $(1.795275)$ & & & (1.697203) & (1.879007) & (1.830193) \\
\hline \multirow[t]{2}{*}{$\sigma_{E G_{i d i o, j, t}}$} & --- & --- & --- & --- & --- & $0.313047 * *$ & --- & $0.519226 * * *$ & --- & --- \\
\hline & & & & & & $(2.392642)$ & & $(2.998060)$ & & \\
\hline \multirow[t]{2}{*}{$\sigma_{A R} i d i o, j, t$} & --- & --- & --- & --- & --- & --- & 0.019221 & $-0.381254 * *$ & --- & --- \\
\hline & & & & & & & $(0.136743)$ & $(2.046640)$ & & \\
\hline \multirow[t]{2}{*}{ ORW $W_{\text {ratio }}$} & --- & --- & --- & --- & --- & --- & --- & --- & -0.000200 & -0.000191 \\
\hline & & & & & & & & & $(0.272514)$ & $(0.260892)$ \\
\hline \multirow[t]{2}{*}{$O I$} & --- & --- & --- & --- & --- & --- & --- & --- & -0.002991 & -0.002191 \\
\hline & & & & & & & & & $(1.374569)$ & $(1.134293)$ \\
\hline \multirow[t]{2}{*}{ Constant } & -0.020189 & -0.076811 & -0.071401 & -0.090806 & -0.082830 & -0.100614 & -0.073379 & -0.091517 & -0.130313 & $-0.059471 * * *$ \\
\hline & $(0.255650)$ & $(0.923147)$ & $(0.851863)$ & (1.084324) & $(0.986236)$ & (1.190026) & $(0.862384)$ & (1.077603) & (1.440374) & (3.296818) \\
\hline
\end{tabular}




\begin{tabular}{|c|c|c|c|c|c|c|c|c|c|c|}
\hline \multicolumn{11}{|c|}{ Phase 4} \\
\hline Variables & Model 1 & Model 2 & Model 3 & Model 4 & Model 5 & Model 6 & Model 7 & Model 8 & Model 9 & Model 10 \\
\hline$\sigma_{R V_{i d i o, j, t}}$ & --- & --- & $\begin{array}{c}0.170761 * * * \\
(3.747754)\end{array}$ & --- & $\begin{array}{c}0.111563 * * \\
(2.244814)\end{array}$ & $\begin{array}{c}0.122236 * * * \\
(2.618184)\end{array}$ & $\begin{array}{c}0.175319 * * * \\
(3.807761)\end{array}$ & $\begin{array}{l}0.086566 * \\
(1.720992)\end{array}$ & $\begin{array}{c}0.108679 * * \\
(2.177332)\end{array}$ & $\begin{array}{c}0.107534 * * \\
(2.157118)\end{array}$ \\
\hline $\log S I Z E$ & $\begin{array}{l}-0.003311 \\
(1.193493)\end{array}$ & $\begin{array}{c}-0.001383 \\
(0.486357)\end{array}$ & $\begin{array}{l}-0.000231 \\
(0.081067)\end{array}$ & $\begin{array}{c}0.001719 \\
(0.586789)\end{array}$ & $\begin{array}{c}0.001746 \\
(0.596490)\end{array}$ & $\begin{array}{c}0.000474 \\
(0.166567)\end{array}$ & $\begin{array}{l}-0.000212 \\
(0.074217)\end{array}$ & $\begin{array}{c}0.002144 \\
(0.734771)\end{array}$ & $\begin{array}{c}0.001607 \\
(0.487364)\end{array}$ & --- \\
\hline $\log B M$ & $\begin{array}{l}0.005737 * \\
(1.913005)\end{array}$ & $\begin{array}{c}0.005943 * * \\
(1.984144)\end{array}$ & $\begin{array}{c}0.006039 * * \\
(2.021207)\end{array}$ & $\begin{array}{c}0.006802 * * \\
(2.273263)\end{array}$ & $\begin{array}{c}0.006664 * * \\
(2.228283)\end{array}$ & $\begin{array}{c}0.004714 \\
(1.575791)\end{array}$ & $\begin{array}{c}0.006244 * * \\
(2.079426)\end{array}$ & $\begin{array}{l}0.005761 * \\
(1.916971)\end{array}$ & $\begin{array}{c}0.006728 * * \\
(2.232977)\end{array}$ & $\begin{array}{c}0.005564 * * * \\
(3.032060)\end{array}$ \\
\hline$r_{t}$ & $\begin{array}{c}-0.034317 * * \\
(1.961829)\end{array}$ & $\begin{array}{c}-0.042236 * * \\
(2.390771)\end{array}$ & $\begin{array}{c}-0.049027 * * * \\
(2.767705)\end{array}$ & $\begin{array}{c}-0.042742 * * \\
(2.427323)\end{array}$ & $\begin{array}{c}-0.047060 * * * \\
(2.658852)\end{array}$ & $\begin{array}{c}-0.065588 * * * \\
(3.636304)\end{array}$ & $\begin{array}{c}-0.048947 * * * \\
(2.762831)\end{array}$ & $\begin{array}{c}-0.064947 * * * \\
(3.591958)\end{array}$ & $\begin{array}{c}-0.047723 * * * \\
(2.696391)\end{array}$ & $\begin{array}{c}-0.047675 * * * \\
(2.694083)\end{array}$ \\
\hline$r_{j, t-11: t-1}$ & $\begin{array}{c}0.064314 * * * \\
(4.162109)\end{array}$ & $\begin{array}{c}0.061948 * * * \\
(4.009891)\end{array}$ & $\begin{array}{c}0.064634 * * * \\
(4.189948)\end{array}$ & $\begin{array}{c}0.066479 * * * \\
(4.306893)\end{array}$ & $\begin{array}{c}0.067174 * * * \\
(4.354494)\end{array}$ & $\begin{array}{c}0.066531 * * * \\
(4.327239)\end{array}$ & $\begin{array}{c}0.064171 * * * \\
(4.155640)\end{array}$ & $\begin{array}{c}0.067206 * * * \\
(4.368902)\end{array}$ & $\begin{array}{c}0.067799 * * * \\
(4.395543)\end{array}$ & $\begin{array}{c}0.067933 * * * \\
(4.405606)\end{array}$ \\
\hline$r_{j, t-35: t-12}$ & $\begin{array}{c}-0.091203 * * * \\
(3.092789)\end{array}$ & $\begin{array}{c}-0.092293 * * * \\
(3.134368)\end{array}$ & $\begin{array}{c}-0.095754 * * * \\
(3.258633)\end{array}$ & $\begin{array}{c}-0.101282 * * * \\
(3.441935)\end{array}$ & $\begin{array}{c}-0.101440 * * * \\
(3.450045)\end{array}$ & $\begin{array}{c}-0.096456 * * * \\
(3.294627)\end{array}$ & $\begin{array}{c}-0.095598 * * * \\
(3.252919)\end{array}$ & $\begin{array}{c}-0.100496 * * * \\
(3.430548)\end{array}$ & $\begin{array}{c}-0.097324 * * * \\
(3.302005)\end{array}$ & $\begin{array}{c}-0.096216^{* * * *} \\
(3.274658)\end{array}$ \\
\hline$\beta_{j}$ & --- & $\begin{array}{c}0.014821 * * * \\
(2.978384)\end{array}$ & $\begin{array}{c}0.006175 \\
(1.128239)\end{array}$ & $\begin{array}{l}0.008550 * \\
(1.651201)\end{array}$ & $\begin{array}{c}0.004368 \\
(0.794389)\end{array}$ & $\begin{array}{l}-0.000030 \\
(0.005276)\end{array}$ & $\begin{array}{c}0.006957 \\
(1.244716)\end{array}$ & $\begin{array}{c}0.000580 \\
(0.102111)\end{array}$ & $\begin{array}{c}0.005801 \\
(1.036234)\end{array}$ & $\begin{array}{c}0.005324 \\
(0.966129)\end{array}$ \\
\hline$\sigma_{I V_{i d i o, j, t}}$ & --- & --- & --- & $\begin{array}{c}0.063858 * * * \\
(4.216438)\end{array}$ & $\begin{array}{c}0.048921 * * * \\
(2.959262)\end{array}$ & --- & --- & $\begin{array}{c}0.038553 * * \\
(2.315276)\end{array}$ & $\begin{array}{c}0.047869 * * * \\
(2.894858)\end{array}$ & $\begin{array}{c}0.046163 * * * \\
(2.856862)\end{array}$ \\
\hline$\sigma_{E G_{i d i o, j, t}}$ & --- & --- & --- & --- & --- & $\begin{array}{c}0.313842 * * * \\
(4.449710)\end{array}$ & --- & $\begin{array}{c}0.335881 * * * \\
(4.504255)\end{array}$ & --- & --- \\
\hline$\sigma_{A R i d i o, j, t}$ & --- & --- & --- & --- & --- & --- & $\begin{array}{l}-0.021738 \\
(0.691498)\end{array}$ & $\begin{array}{c}-0.068642 * * \\
(2.094679)\end{array}$ & --- & --- \\
\hline$O R W_{\text {ratio }}$ & --- & --- & --- & --- & --- & --- & --- & --- & $\begin{array}{c}-0.000548 * * \\
(1.992538)\end{array}$ & $\begin{array}{c}-0.000542 * * \\
(1.970338)\end{array}$ \\
\hline$O I$ & --- & --- & --- & --- & --- & --- & --- & --- & $\begin{array}{c}0.000460 \\
(0.416350)\end{array}$ & $\begin{array}{c}0.000706 \\
(0.717318)\end{array}$ \\
\hline Constant & $\begin{array}{c}0.085517 \\
(2.031054)\end{array}$ & $\begin{array}{c}0.036536 \\
(0.809356)\end{array}$ & $\begin{array}{c}0.013051 \\
(0.287085)\end{array}$ & $\begin{array}{l}-0.020536 \\
(0.437084)\end{array}$ & $\begin{array}{l}-0.022530 \\
(0.479800)\end{array}$ & $\begin{array}{l}-0.012789 \\
(0.280080)\end{array}$ & $\begin{array}{c}0.013493 \\
(0.296747)\end{array}$ & $\begin{array}{l}-0.041248 \\
(0.878160)\end{array}$ & $\begin{array}{l}-0.024984 \\
(0.493225)\end{array}$ & $\begin{array}{l}-0.000679 \\
(0.076495)\end{array}$ \\
\hline
\end{tabular}


Table 13.8: Utilities Sector

\begin{tabular}{|c|c|c|c|c|c|c|c|c|c|c|}
\hline \multicolumn{11}{|c|}{ Entire Phases } \\
\hline Variables & Model 1 & Model 2 & Model 3 & Model 4 & Model 5 & Model 6 & Model 7 & Model 8 & Model 9 & Model 10 \\
\hline$\sigma_{R V_{i d i o, j, t}}$ & --- & --- & $\begin{array}{l}0.081683 * \\
(1.748519)\end{array}$ & --- & $\begin{array}{l}-0.029237 \\
(0.424864)\end{array}$ & $\begin{array}{l}0.117187 * \\
(1.911021)\end{array}$ & $\begin{array}{c}0.184022 * * * \\
(3.525716)\end{array}$ & $\begin{array}{c}0.009582 \\
(0.135795)\end{array}$ & $\begin{array}{l}-0.028565 \\
(0.413224)\end{array}$ & $\begin{array}{l}-0.038417 \\
(0.559448)\end{array}$ \\
\hline $\log S I Z E$ & $\begin{array}{c}0.003579 \\
(1.102467)\end{array}$ & $\begin{array}{c}0.003412 \\
(1.050393)\end{array}$ & $\begin{array}{c}0.004451 \\
(1.348569)\end{array}$ & $\begin{array}{c}0.004989 \\
(1.515491)\end{array}$ & $\begin{array}{c}0.004879 \\
(1.477137)\end{array}$ & $\begin{array}{c}0.003968 \\
(1.186392)\end{array}$ & $\begin{array}{c}0.004062 \\
(1.236473)\end{array}$ & $\begin{array}{c}0.004794 \\
(1.442471)\end{array}$ & $\begin{array}{c}0.005099 \\
(1.227376)\end{array}$ & --- \\
\hline $\log B M$ & $\begin{array}{c}0.036924 * * * \\
(6.136159)\end{array}$ & $\begin{array}{c}0.038282 * * * \\
(6.257976)\end{array}$ & $\begin{array}{c}0.037186 * * * \\
(6.050723)\end{array}$ & $\begin{array}{c}0.034640 * * * \\
(5.546634)\end{array}$ & $\begin{array}{c}0.034428 * * * \\
(5.493778)\end{array}$ & $\begin{array}{c}0.037578 * * * \\
(6.098583)\end{array}$ & $\begin{array}{c}0.039403 * * * \\
(6.420375)\end{array}$ & $\begin{array}{c}0.035040 * * * \\
(5.627731)\end{array}$ & $\begin{array}{c}0.034669 * * * \\
(5.341350)\end{array}$ & $\begin{array}{c}0.030124 * * * \\
(5.649904)\end{array}$ \\
\hline$r_{t}$ & $\begin{array}{c}0.085473 * * * \\
(3.671799)\end{array}$ & $\begin{array}{c}0.086475 * * * \\
(3.713100)\end{array}$ & $\begin{array}{c}0.096659 * * * \\
(4.028566)\end{array}$ & $\begin{array}{c}0.099375 * * * \\
(4.191986)\end{array}$ & $\begin{array}{c}0.097871 * * * \\
(4.082394)\end{array}$ & $\begin{array}{c}0.102497 * * * \\
(4.121674)\end{array}$ & $\begin{array}{c}0.121241 * * * \\
(4.939225)\end{array}$ & $\begin{array}{c}0.130392 * * * \\
(5.174232)\end{array}$ & $\begin{array}{c}0.098262 * * * \\
(4.091802)\end{array}$ & $\begin{array}{c}0.097393 * * * \\
(4.056803)\end{array}$ \\
\hline$r_{j, t-11: t-1}$ & $\begin{array}{c}0.010207 \\
(0.479481)\end{array}$ & $\begin{array}{c}0.010903 \\
(0.512053)\end{array}$ & $\begin{array}{c}0.013248 \\
(0.621354)\end{array}$ & $\begin{array}{c}0.016963 \\
(0.793991)\end{array}$ & $\begin{array}{c}0.017129 \\
(0.801462)\end{array}$ & $\begin{array}{c}0.013035 \\
(0.611284)\end{array}$ & $\begin{array}{c}0.006727 \\
(0.316232)\end{array}$ & $\begin{array}{c}0.011713 \\
(0.550609)\end{array}$ & $\begin{array}{c}0.016902 \\
(0.789976)\end{array}$ & $\begin{array}{c}0.016815 \\
(0.785831)\end{array}$ \\
\hline$r_{j, t-35: t-12}$ & $\begin{array}{c}0.012225 \\
(0.577819)\end{array}$ & $\begin{array}{c}0.013649 \\
(0.644291)\end{array}$ & $\begin{array}{c}0.014378 \\
(0.678959)\end{array}$ & $\begin{array}{c}0.012675 \\
(0.599353)\end{array}$ & $\begin{array}{c}0.012253 \\
(0.578596)\end{array}$ & $\begin{array}{c}0.015365 \\
(0.724540)\end{array}$ & $\begin{array}{c}0.019603 \\
(0.928722)\end{array}$ & $\begin{array}{c}0.017260 \\
(0.820198)\end{array}$ & $\begin{array}{c}0.012096 \\
(0.570624)\end{array}$ & $\begin{array}{c}0.013273 \\
(0.626685)\end{array}$ \\
\hline$\beta_{j}$ & --- & $\begin{array}{l}-0.003895 \\
(1.228336)\end{array}$ & $\begin{array}{c}-0.004414 \\
(1.386812)\end{array}$ & $\begin{array}{l}-0.004847 \\
(1.522810)\end{array}$ & $\begin{array}{l}-0.004820 \\
(1.513463)\end{array}$ & $\begin{array}{l}-0.003745 \\
(1.145433)\end{array}$ & $\begin{array}{l}-0.000807 \\
(0.246412)\end{array}$ & $\begin{array}{l}-0.000495 \\
(0.150178)\end{array}$ & $\begin{array}{l}-0.004646 \\
(1.408587)\end{array}$ & $\begin{array}{l}-0.005303 \\
(1.629267)\end{array}$ \\
\hline$\sigma_{I V} i d i o, j, t$ & --- & --- & --- & $\begin{array}{c}0.028611 * * * \\
(2.774291)\end{array}$ & $\begin{array}{c}0.033360 * * \\
(2.193120)\end{array}$ & --- & --- & $\begin{array}{c}0.060606^{* * *} \\
(3.512532)\end{array}$ & $\begin{array}{c}0.033826 * * \\
(2.208022)\end{array}$ & $\begin{array}{c}0.031871 * * \\
(2.091446)\end{array}$ \\
\hline$\sigma_{E G_{i d i o, j, t}}$ & --- & --- & --- & --- & --- & $\begin{array}{l}-0.071135 \\
(0.893837)\end{array}$ & --- & $\begin{array}{c}0.011766 \\
(0.118279)\end{array}$ & --- & --- \\
\hline$\sigma_{A R_{i d i o, j, t}}$ & --- & --- & --- & --- & --- & --- & $\begin{array}{c}-0.161406 * * * \\
(4.311895)\end{array}$ & $\begin{array}{c}-0.213359 * * * \\
(4.868696)\end{array}$ & --- & --- \\
\hline ORW $W_{\text {ratio }}$ & --- & --- & --- & --- & --- & --- & --- & --- & $\begin{array}{c}0.000228 \\
(0.332049)\end{array}$ & $\begin{array}{c}0.000290 \\
(0.423853)\end{array}$ \\
\hline$O I$ & --- & --- & --- & --- & --- & --- & --- & --- & $\begin{array}{l}-0.000126 \\
(0.104789)\end{array}$ & $\begin{array}{c}0.000768 \\
(0.801718)\end{array}$ \\
\hline Constant & $\begin{array}{l}-0.041979 \\
(0.822647)\end{array}$ & $\begin{array}{l}-0.037131 \\
(0.725581)\end{array}$ & $\begin{array}{l}-0.058169 \\
(1.107116)\end{array}$ & $\begin{array}{l}-0.067100 \\
(1.285240)\end{array}$ & $\begin{array}{l}-0.064545 \\
(1.227902)\end{array}$ & $\begin{array}{l}-0.048461 \\
(0.903189)\end{array}$ & $\begin{array}{l}-0.048260 \\
(0.922163)\end{array}$ & $\begin{array}{l}-0.058260 \\
(1.091483)\end{array}$ & $\begin{array}{l}-0.067563 \\
(1.067261)\end{array}$ & $\begin{array}{l}0.009844 * \\
(1.795434)\end{array}$ \\
\hline
\end{tabular}




\begin{tabular}{|c|c|c|c|c|c|c|c|c|c|c|}
\hline \multicolumn{11}{|c|}{ Phase 1} \\
\hline Variables & Model 1 & Model 2 & Model 3 & Model 4 & Model 5 & Model 6 & Model 7 & Model 8 & Model 9 & Model 10 \\
\hline$\sigma_{R V_{i d i o, j, t}}$ & --- & --- & $\begin{array}{c}0.350178 * * * \\
(2.839120)\end{array}$ & --- & $\begin{array}{c}0.145864 \\
(0.914003)\end{array}$ & $\begin{array}{c}0.455921 * * * \\
(3.166937)\end{array}$ & $\begin{array}{c}0.358563 * * * \\
(2.856254)\end{array}$ & $\begin{array}{c}0.248290 \\
(1.497736)\end{array}$ & $\begin{array}{c}0.171339 \\
(1.050181)\end{array}$ & $\begin{array}{c}0.167295 \\
(1.026586)\end{array}$ \\
\hline $\log S I Z E$ & $\begin{array}{c}0.005361 \\
(0.483649)\end{array}$ & $\begin{array}{c}0.000400 \\
(0.036283)\end{array}$ & $\begin{array}{c}0.002239 \\
(0.204981)\end{array}$ & $\begin{array}{c}0.006686 \\
(0.607123)\end{array}$ & $\begin{array}{c}0.006034 \\
(0.546657)\end{array}$ & $\begin{array}{c}0.003002 \\
(0.274877)\end{array}$ & $\begin{array}{c}0.002383 \\
(0.217773)\end{array}$ & $\begin{array}{c}0.008633 \\
(0.780810)\end{array}$ & $\begin{array}{c}0.009770 \\
(0.760616)\end{array}$ & --- \\
\hline $\log B M$ & $\begin{array}{c}0.057469 * * * \\
(3.160690)\end{array}$ & $\begin{array}{c}0.064053 * * * \\
(3.555411)\end{array}$ & $\begin{array}{c}0.049100 * * * \\
(2.640906)\end{array}$ & $\begin{array}{l}0.034095 * \\
(1.717203)\end{array}$ & $\begin{array}{l}0.034624 * \\
(1.742670)\end{array}$ & $\begin{array}{c}0.056164 * * * \\
(2.922065)\end{array}$ & $\begin{array}{c}0.050871 * * * \\
(2.647556)\end{array}$ & $\begin{array}{c}0.039797 * * \\
(1.977249)\end{array}$ & $\begin{array}{l}0.033485 * \\
(1.677008)\end{array}$ & $\begin{array}{c}0.028506 \\
(1.512124)\end{array}$ \\
\hline$r_{t}$ & $\begin{array}{c}-0.093762 * \\
(1.737880)\end{array}$ & $\begin{array}{c}-0.120132 * * \\
(2.236486)\end{array}$ & $\begin{array}{c}-0.074348 \\
(1.338292)\end{array}$ & $\begin{array}{c}-0.086557 \\
(1.607517)\end{array}$ & $\begin{array}{c}-0.075060 \\
(1.357117)\end{array}$ & $\begin{array}{l}-0.045899 \\
(0.778135)\end{array}$ & $\begin{array}{l}-0.066177 \\
(1.106640)\end{array}$ & $\begin{array}{l}-0.034027 \\
(0.562807)\end{array}$ & $\begin{array}{c}-0.074188 \\
(1.334064)\end{array}$ & $\begin{array}{c}-0.073481 \\
(1.322372)\end{array}$ \\
\hline$r_{j, t-11: t-1}$ & $\begin{array}{c}0.007121 \\
(0.123278)\end{array}$ & $\begin{array}{l}-0.011322 \\
(0.198078)\end{array}$ & $\begin{array}{l}-0.001831 \\
(0.032318)\end{array}$ & $\begin{array}{c}0.006393 \\
(0.113052)\end{array}$ & $\begin{array}{c}0.006351 \\
(0.112269)\end{array}$ & $\begin{array}{l}-0.003340 \\
(0.059024)\end{array}$ & $\begin{array}{l}-0.002919 \\
(0.051368)\end{array}$ & $\begin{array}{c}0.007932 \\
(0.140686)\end{array}$ & $\begin{array}{c}0.004303 \\
(0.075799)\end{array}$ & $\begin{array}{c}0.004411 \\
(0.077752)\end{array}$ \\
\hline$r_{j, t-35: t-12}$ & $\begin{array}{l}-0.020644 \\
(0.237234)\end{array}$ & $\begin{array}{c}0.024943 \\
(0.287458)\end{array}$ & $\begin{array}{c}0.020316 \\
(0.236526)\end{array}$ & $\begin{array}{c}0.012251 \\
(0.143182)\end{array}$ & $\begin{array}{c}0.013186 \\
(0.154070)\end{array}$ & $\begin{array}{c}0.032452 \\
(0.376510)\end{array}$ & $\begin{array}{c}0.022637 \\
(0.262518)\end{array}$ & $\begin{array}{c}0.029468 \\
(0.344286)\end{array}$ & $\begin{array}{c}0.011281 \\
(0.131498)\end{array}$ & $\begin{array}{c}0.014596 \\
(0.170463)\end{array}$ \\
\hline$\beta_{j}$ & --- & $\begin{array}{c}-0.045517 * * * \\
(3.375642)\end{array}$ & $\begin{array}{c}-0.065606^{* * *} \\
(4.343308)\end{array}$ & $\begin{array}{c}-0.078291 * * * \\
(4.753069)\end{array}$ & $\begin{array}{c}-0.079266^{* * *} \\
(4.801050)\end{array}$ & $\begin{array}{c}-0.047858 * * \\
(2.442020)\end{array}$ & $\begin{array}{c}-0.061829 * * * \\
(3.394622)\end{array}$ & $\begin{array}{c}-0.057085^{* * *} \\
(2.833892)\end{array}$ & $\begin{array}{c}-0.078486 * * * \\
(4.713114)\end{array}$ & $\begin{array}{c}-0.079308 * * * \\
(4.775481)\end{array}$ \\
\hline$\sigma_{I V_{i d i o, j, t}}$ & --- & --- & --- & $\begin{array}{c}0.092252 * * * \\
(3.364575)\end{array}$ & $\begin{array}{c}0.071443 * * \\
(2.004361)\end{array}$ & --- & --- & $\begin{array}{c}0.097955 * * * \\
(2.611427)\end{array}$ & $\begin{array}{c}0.076669 * * \\
(2.104879)\end{array}$ & $\begin{array}{c}0.070042 * * \\
(1.981679)\end{array}$ \\
\hline$\sigma_{E G_{i d i o, j, t}}$ & --- & --- & --- & --- & --- & $\begin{array}{l}-0.320727 \\
(1.418384)\end{array}$ & --- & $\begin{array}{c}-0.569252 * * \\
(2.103119)\end{array}$ & --- & --- \\
\hline$\sigma_{A R_{i d i o, j, t}}$ & --- & --- & --- & --- & --- & --- & $\begin{array}{l}-0.034362 \\
(0.372221)\end{array}$ & $\begin{array}{c}0.038674 \\
(0.365240)\end{array}$ & --- & --- \\
\hline ORW ratio & --- & --- & --- & --- & --- & --- & --- & --- & $\begin{array}{c}0.000456 \\
(0.415034)\end{array}$ & $\begin{array}{c}0.000565 \\
(0.518552)\end{array}$ \\
\hline$O I$ & --- & --- & --- & --- & --- & --- & --- & --- & $\begin{array}{l}-0.002589 \\
(0.648504)\end{array}$ & $\begin{array}{l}-0.001061 \\
(0.307590)\end{array}$ \\
\hline Constant & $\begin{array}{l}-0.070093 \\
(0.408155)\end{array}$ & $\begin{array}{c}0.012967 \\
(0.075856)\end{array}$ & $\begin{array}{l}-0.049631 \\
(0.290899)\end{array}$ & $\begin{array}{l}-0.120125 \\
(0.694479)\end{array}$ & $\begin{array}{c}-0.116178 \\
(0.671290)\end{array}$ & $\begin{array}{l}-0.042792 \\
(0.251089)\end{array}$ & $\begin{array}{c}-0.049121 \\
(0.287535)\end{array}$ & $\begin{array}{l}-0.129308 \\
(0.749921)\end{array}$ & $\begin{array}{l}-0.169281 \\
(0.861731)\end{array}$ & $\begin{array}{c}-0.020449 \\
(1.177888)\end{array}$ \\
\hline
\end{tabular}




\begin{tabular}{|c|c|c|c|c|c|c|c|c|c|c|}
\hline \multicolumn{11}{|c|}{ Phase 2} \\
\hline Variables & Model 1 & Model 2 & Model 3 & Model 4 & Model 5 & Model 6 & Model 7 & Model 8 & Model 9 & Model 10 \\
\hline$\sigma_{R V_{i d i o, j, t}}$ & --- & --- & $\begin{array}{c}0.052818 \\
(0.560215)\end{array}$ & --- & $\begin{array}{l}-0.071526 \\
(0.545761)\end{array}$ & $\begin{array}{c}-0.421955^{* * *} \\
(3.573045)\end{array}$ & $\begin{array}{c}0.252069 * * \\
(2.371218)\end{array}$ & $\begin{array}{l}-0.187364 \\
(1.390730)\end{array}$ & $\begin{array}{l}-0.051373 \\
(0.387468)\end{array}$ & $\begin{array}{l}-0.064901 \\
(0.489614)\end{array}$ \\
\hline $\log S I Z E$ & $\begin{array}{c}0.005974 \\
(1.557989)\end{array}$ & $\begin{array}{c}0.006375 \\
(1.643958)\end{array}$ & $\begin{array}{l}0.006454 * \\
(1.662421)\end{array}$ & $\begin{array}{l}0.006799 * \\
(1.748533)\end{array}$ & $\begin{array}{l}0.006856 * \\
(1.761867)\end{array}$ & $\begin{array}{c}0.009704 * * \\
(2.533487)\end{array}$ & $\begin{array}{l}0.007009 * \\
(1.818843)\end{array}$ & $\begin{array}{c}0.011011 * * * \\
(2.914697)\end{array}$ & $\begin{array}{l}0.009027 * \\
(1.833616)\end{array}$ & --- \\
\hline $\log B M$ & $\begin{array}{c}0.035747 * * * \\
(4.549006)\end{array}$ & $\begin{array}{c}0.035420 * * * \\
(4.498206)\end{array}$ & $\begin{array}{c}0.034196 * * * \\
(4.183153)\end{array}$ & $\begin{array}{c}0.031303 * * * \\
(3.716282)\end{array}$ & $\begin{array}{c}0.031377 * * * \\
(3.723096)\end{array}$ & $\begin{array}{c}0.022328 * * * \\
(2.721041)\end{array}$ & $\begin{array}{c}0.037698 * * * \\
(4.621309)\end{array}$ & $\begin{array}{c}0.025979 * * * \\
(3.172194)\end{array}$ & $\begin{array}{c}0.031383 * * * \\
(3.594715)\end{array}$ & $\begin{array}{c}0.021809 * * * \\
(3.112848)\end{array}$ \\
\hline$r_{t}$ & $\begin{array}{c}0.231444 * * * \\
(7.255009)\end{array}$ & $\begin{array}{c}0.228737 * * * \\
(7.116356)\end{array}$ & $\begin{array}{c}0.226399 * * * \\
(6.982309)\end{array}$ & $\begin{array}{c}0.222244 * * * \\
(6.843849)\end{array}$ & $\begin{array}{c}0.222912 * * * \\
(6.856863)\end{array}$ & $\begin{array}{c}0.161084 * * * \\
(4.837573)\end{array}$ & $\begin{array}{c}0.234095 * * * \\
(7.264922)\end{array}$ & $\begin{array}{c}0.158310 * * * \\
(4.825038)\end{array}$ & $\begin{array}{c}0.216246 * * * \\
(6.509376)\end{array}$ & $\begin{array}{c}0.219914 * * * \\
(6.623043)\end{array}$ \\
\hline$r_{j, t-11: t-1}$ & $\begin{array}{l}-0.012462 \\
(0.544245)\end{array}$ & $\begin{array}{l}-0.014160 \\
(0.614779)\end{array}$ & $\begin{array}{l}-0.014222 \\
(0.617234)\end{array}$ & $\begin{array}{l}-0.011672 \\
(0.505474)\end{array}$ & $\begin{array}{l}-0.010631 \\
(0.458649)\end{array}$ & $\begin{array}{l}-0.007033 \\
(0.311673)\end{array}$ & $\begin{array}{l}-0.030333 \\
(1.306431)\end{array}$ & $\begin{array}{l}-0.029689 \\
(1.314119)\end{array}$ & $\begin{array}{l}-0.011183 \\
(0.481997)\end{array}$ & $\begin{array}{l}-0.009610 \\
(0.413938)\end{array}$ \\
\hline$r_{j, t-35: t-12}$ & $\begin{array}{c}0.012911 \\
(0.733958)\end{array}$ & $\begin{array}{c}0.012602 \\
(0.715979)\end{array}$ & $\begin{array}{c}0.012721 \\
(0.722388)\end{array}$ & $\begin{array}{c}0.012144 \\
(0.690178)\end{array}$ & $\begin{array}{c}0.011807 \\
(0.670361)\end{array}$ & $\begin{array}{c}0.009113 \\
(0.528802)\end{array}$ & $\begin{array}{c}0.014589 \\
(0.834895)\end{array}$ & $\begin{array}{c}0.011367 \\
(0.670267)\end{array}$ & $\begin{array}{c}0.012901 \\
(0.729916)\end{array}$ & $\begin{array}{c}0.013628 \\
(0.770204)\end{array}$ \\
\hline$\beta_{j}$ & --- & $\begin{array}{c}0.002021 \\
(0.701828)\end{array}$ & $\begin{array}{c}0.001675 \\
(0.568355)\end{array}$ & $\begin{array}{c}0.001713 \\
(0.593320)\end{array}$ & $\begin{array}{c}0.002064 \\
(0.697436)\end{array}$ & $\begin{array}{l}-0.002340 \\
(0.793688)\end{array}$ & $\begin{array}{c}0.004463 \\
(1.484013)\end{array}$ & $\begin{array}{c}0.000352 \\
(0.116083)\end{array}$ & $\begin{array}{c}0.000928 \\
(0.281356)\end{array}$ & $\begin{array}{c}0.000321 \\
(0.097613)\end{array}$ \\
\hline$\sigma_{I V_{i d i o, j, t}}$ & --- & --- & --- & $\begin{array}{c}0.031428 \\
(1.371684)\end{array}$ & $\begin{array}{c}0.043518 \\
(1.365192)\end{array}$ & --- & -- & $\begin{array}{l}-0.024747 \\
(0.725553)\end{array}$ & $\begin{array}{c}0.029488 \\
(0.835695)\end{array}$ & $\begin{array}{c}0.030036 \\
(0.850128)\end{array}$ \\
\hline$\sigma_{E G_{i d i o, j, t}}$ & --- & --- & --- & --- & --- & $\begin{array}{c}0.784841 * * * \\
(6.435523)\end{array}$ & --- & $\begin{array}{c}0.970069 * * * \\
(7.264281)\end{array}$ & -- & -- \\
\hline$\sigma_{A R} i d i o, j, t$ & --- & --- & --- & --- & --- & -- & $\begin{array}{c}-0.207657 * * * \\
(3.942568)\end{array}$ & $\begin{array}{c}-0.287572 * * * \\
(5.449773)\end{array}$ & --- & --- \\
\hline$O R W_{\text {ratio }}$ & --- & --- & --- & --- & --- & --- & --- & --- & $\begin{array}{l}-0.006134 \\
(1.025342)\end{array}$ & $\begin{array}{l}-0.003011 \\
(0.524328)\end{array}$ \\
\hline$O I$ & --- & --- & --- & --- & --- & -- & --- & -- & $\begin{array}{l}-0.000438 \\
(0.355194)\end{array}$ & $\begin{array}{c}0.000835 \\
(0.817019)\end{array}$ \\
\hline Constant & $\begin{array}{l}-0.073640 \\
(1.232437)\end{array}$ & $\begin{array}{l}-0.081203 \\
(1.337069)\end{array}$ & $\begin{array}{l}-0.084750 \\
(1.387413)\end{array}$ & $\begin{array}{l}-0.091974 \\
(1.502637)\end{array}$ & $\begin{array}{l}-0.091315 \\
(1.490997)\end{array}$ & $\begin{array}{c}-0.159885 * * * \\
(2.626403)\end{array}$ & $\begin{array}{c}-0.089886 \\
(1.483107)\end{array}$ & $\begin{array}{c}-0.180998 * * * \\
(3.016448)\end{array}$ & $\begin{array}{c}-0.123752 * \\
(1.650442)\end{array}$ & $\begin{array}{c}0.013224 * * \\
(2.044696)\end{array}$ \\
\hline
\end{tabular}




\begin{tabular}{|c|c|c|c|c|c|c|c|c|c|c|}
\hline \multicolumn{11}{|c|}{ Phase 3} \\
\hline Variables & Model 1 & Model 2 & Model 3 & Model 4 & Model 5 & Model 6 & Model 7 & Model 8 & Model 9 & Model 10 \\
\hline$\sigma_{R V_{i d i o, j, t}}$ & --- & --- & $\begin{array}{l}0.211050 * \\
(1.762322)\end{array}$ & --- & $\begin{array}{c}0.171914 \\
(0.933785)\end{array}$ & $\begin{array}{c}0.264121 \\
(2.053982)\end{array}$ & $\begin{array}{c}0.303285 * * \\
(2.458435)\end{array}$ & $\begin{array}{c}0.080074 \\
(0.431769)\end{array}$ & $\begin{array}{c}0.172686 \\
(0.918854)\end{array}$ & $\begin{array}{c}0.164057 \\
(0.875329)\end{array}$ \\
\hline $\log S I Z E$ & $\begin{array}{c}0.009668 \\
(0.999237)\end{array}$ & $\begin{array}{c}0.008274 \\
(0.840529)\end{array}$ & $\begin{array}{c}0.009535 \\
(0.971947)\end{array}$ & $\begin{array}{c}0.007991 \\
(0.814619)\end{array}$ & $\begin{array}{c}0.009221 \\
(0.931357)\end{array}$ & $\begin{array}{c}0.004671 \\
(0.436097)\end{array}$ & $\begin{array}{c}0.010463 \\
(1.082528)\end{array}$ & $\begin{array}{c}0.009269 \\
(0.768331)\end{array}$ & $\begin{array}{c}0.010204 \\
(0.797641)\end{array}$ & --- \\
\hline $\log B M$ & $\begin{array}{c}0.027788 \\
(1.563742)\end{array}$ & $\begin{array}{c}0.028854 \\
(1.617347)\end{array}$ & $\begin{array}{c}0.027590 \\
(1.554631)\end{array}$ & $\begin{array}{c}0.025397 \\
(1.417305)\end{array}$ & $\begin{array}{c}0.026843 \\
(1.491906)\end{array}$ & $\begin{array}{c}0.020459 \\
(1.086668)\end{array}$ & $\begin{array}{c}0.026975 \\
(1.543744)\end{array}$ & $\begin{array}{c}0.022661 \\
(1.102424)\end{array}$ & $\begin{array}{c}0.027378 \\
(1.441939)\end{array}$ & $\begin{array}{c}0.017526 \\
(1.216663)\end{array}$ \\
\hline$r_{t}$ & $\begin{array}{c}0.230244 * * * \\
(2.950419)\end{array}$ & $\begin{array}{c}0.216463 * * * \\
(2.704555)\end{array}$ & $\begin{array}{c}0.264114 * * * \\
(3.143349)\end{array}$ & $\begin{array}{c}0.262535 * * * \\
(3.076533)\end{array}$ & $\begin{array}{c}0.268352 * * * \\
(3.135189)\end{array}$ & $\begin{array}{c}0.269700 * * * \\
(3.206775)\end{array}$ & $\begin{array}{c}0.251159 * * * \\
(3.030437)\end{array}$ & $\begin{array}{c}0.273101 * * * \\
(3.176694)\end{array}$ & $\begin{array}{c}0.268432 * * * \\
(3.097539)\end{array}$ & $\begin{array}{c}0.271506 * * * \\
(3.139473)\end{array}$ \\
\hline$r_{j, t-11: t-1}$ & $\begin{array}{c}0.111346 \\
(1.027506)\end{array}$ & $\begin{array}{c}0.119608 \\
(1.097497)\end{array}$ & $\begin{array}{c}0.129796 \\
(1.196510)\end{array}$ & $\begin{array}{c}0.131935 \\
(1.211745)\end{array}$ & $\begin{array}{c}0.131405 \\
(1.206414)\end{array}$ & $\begin{array}{c}0.134663 \\
(1.241363)\end{array}$ & $\begin{array}{c}0.137417 \\
(1.286179)\end{array}$ & $\begin{array}{c}0.150079 \\
(1.401027)\end{array}$ & $\begin{array}{c}0.132035 \\
(1.203849)\end{array}$ & $\begin{array}{c}0.135477 \\
(1.237509)\end{array}$ \\
\hline$r_{j, t-35: t-12}$ & $\begin{array}{c}0.125852 \\
(1.084055)\end{array}$ & $\begin{array}{c}0.148021 \\
(1.238230)\end{array}$ & $\begin{array}{c}0.192698 \\
(1.586049)\end{array}$ & $\begin{array}{c}0.172211 \\
(1.433168)\end{array}$ & $\begin{array}{c}0.191278 \\
(1.568780)\end{array}$ & $\begin{array}{c}0.190501 \\
(1.568991)\end{array}$ & $\begin{array}{c}0.183878 \\
(1.536615)\end{array}$ & $\begin{array}{c}0.171718 \\
(1.435085)\end{array}$ & $\begin{array}{c}0.191357 \\
(1.555776)\end{array}$ & $\begin{array}{c}0.193386 \\
(1.574290)\end{array}$ \\
\hline$\beta_{j}$ & --- & $\begin{array}{l}-0.011778 \\
(0.791935)\end{array}$ & $\begin{array}{l}-0.012342 \\
(0.834669)\end{array}$ & $\begin{array}{l}-0.016776 \\
(1.105172)\end{array}$ & $\begin{array}{l}-0.013656 \\
(0.878242)\end{array}$ & $\begin{array}{l}-0.003973 \\
(0.240296)\end{array}$ & $\begin{array}{c}0.008247 \\
(0.494997)\end{array}$ & $\begin{array}{c}0.006523 \\
(0.388030)\end{array}$ & $\begin{array}{l}-0.013512 \\
(0.850182)\end{array}$ & $\begin{array}{l}-0.016615 \\
(1.079379)\end{array}$ \\
\hline$\sigma_{I V i d i o, j, t}$ & --- & --- & --- & $\begin{array}{c}0.072391 \\
(1.515765)\end{array}$ & $\begin{array}{c}0.020542 \\
(0.280438)\end{array}$ & --- & --- & $\begin{array}{c}0.132163 \\
(1.479110)\end{array}$ & $\begin{array}{c}0.015731 \\
(0.176099)\end{array}$ & $\begin{array}{c}0.023665 \\
(0.266856)\end{array}$ \\
\hline$\sigma_{E G_{i d i o, j, t}}$ & --- & --- & --- & --- & --- & $\begin{array}{l}-0.465614 \\
(1.127338)\end{array}$ & --- & $\begin{array}{c}0.046655 \\
(0.077105)\end{array}$ & --- & --- \\
\hline$\sigma_{A R_{i d i o, j, t}}$ & --- & --- & --- & --- & --- & --- & $\begin{array}{c}-0.481546 * * \\
(2.540558)\end{array}$ & $\begin{array}{c}-0.658526 * * \\
(2.556398)\end{array}$ & --- & --- \\
\hline$O R W_{\text {ratio }}$ & --- & --- & --- & --- & --- & --- & --- & --- & $\begin{array}{l}-0.001077 \\
(0.104246)\end{array}$ & $\begin{array}{l}-0.000090 \\
(0.008779)\end{array}$ \\
\hline$O I$ & --- & --- & --- & --- & --- & --- & --- & --- & $\begin{array}{l}-0.000387 \\
(0.104642)\end{array}$ & $\begin{array}{c}0.001430 \\
(0.492055)\end{array}$ \\
\hline Constant & $\begin{array}{l}-0.170911 \\
(1.115206)\end{array}$ & $\begin{array}{c}-0.140659 \\
(0.889666)\end{array}$ & $\begin{array}{c}-0.174048 \\
(1.099563)\end{array}$ & $\begin{array}{c}-0.142508 \\
(0.904704)\end{array}$ & $\begin{array}{c}-0.168381 \\
(1.052414)\end{array}$ & $\begin{array}{l}-0.084025 \\
(0.474240)\end{array}$ & $\begin{array}{c}-0.182336 \\
(1.169789)\end{array}$ & $\begin{array}{l}-0.157943 \\
(0.775673)\end{array}$ & $\begin{array}{l}-0.181995 \\
(0.932500)\end{array}$ & $\begin{array}{c}-0.027215 \\
(1.304118)\end{array}$ \\
\hline
\end{tabular}




\begin{tabular}{|c|c|c|c|c|c|c|c|c|c|c|}
\hline \multicolumn{11}{|c|}{ Phase 4} \\
\hline Variables & Model 1 & Model 2 & Model 3 & Model 4 & Model 5 & Model 6 & Model 7 & Model 8 & Model 9 & Model 10 \\
\hline \multirow{2}{*}{$\sigma_{R V_{i d i o, j, t}}$} & --- & --- & 0.128001 & --- & 0.055943 & 0.097665 & 0.069264 & -0.001745 & 0.030278 & 0.067368 \\
\hline & & & $(0.871011)$ & & (0.361064) & (0.642784) & $(0.464368)$ & (0.010982) & $(0.186441)$ & $(0.436605)$ \\
\hline \multirow[t]{2}{*}{$\log S I Z E$} & -0.005478 & -0.005821 & -0.004690 & -0.004701 & -0.004290 & -0.004634 & -0.004783 & -0.004409 & -0.007282 & --- \\
\hline & $(0.882052)$ & (0.919763) & $(0.725629)$ & $(0.740423)$ & $(0.664205)$ & $(0.716650)$ & $(0.743237)$ & $(0.684378)$ & $(0.736901)$ & \\
\hline \multirow[t]{2}{*}{$\log B M$} & $0.022177 *$ & $0.023163 *$ & $0.023196 *$ & $0.024970 * *$ & $0.024850 * *$ & $0.023211 *$ & $0.022923 *$ & $0.024367 *$ & $0.022840 *$ & $0.029142 * * *$ \\
\hline & (1.860438) & $(1.867152)$ & $(1.869152)$ & $(2.009866)$ & (1.997059) & (1.869329) & (1.855168) & $(1.962762)$ & (1.657774) & $(2.699546)$ \\
\hline \multirow[t]{2}{*}{$r_{t}$} & $0.106057 * *$ & $0.106979 * *$ & $0.109753 * *$ & $0.121785 * *$ & $0.121900 * *$ & $0.107572 * *$ & $0.093818 *$ & $0.104376^{*}$ & $0.122399 * *$ & $0.122754 * *$ \\
\hline & (1.977474) & (1.988647) & $(2.035960)$ & $(2.238482)$ & $(2.237780)$ & (1.991844) & (1.729538) & (1.894170) & $(2.235612)$ & $(2.243659)$ \\
\hline \multirow[t]{2}{*}{$r_{j, t-11: t-1}$} & $0.139091 * * *$ & $0.138934 * * *$ & $0.141493 * * *$ & $0.136669 * * *$ & $0.137955^{* * *}$ & $0.138256 * * *$ & $0.135963 * * *$ & $0.131897 * * *$ & $0.141565^{* * *}$ & $0.141016 * * *$ \\
\hline & $(3.087266)$ & $(3.079582)$ & $(3.128605)$ & (3.035397) & $(3.050667)$ & $(3.043040)$ & (3.014016) & (2.911095) & (3.077775) & (3.068232) \\
\hline \multirow[t]{2}{*}{$r_{j, t-35: t-12}$} & 0.113460 & 0.114161 & 0.116349 & 0.112233 & 0.113333 & 0.112697 & 0.093477 & 0.090859 & 0.116232 & 0.112573 \\
\hline & (1.380416) & (1.386557) & (1.411997) & (1.366347) & (1.377083) & (1.364809) & (1.128778) & (1.095983) & (1.406363) & (1.365437) \\
\hline \multirow[t]{2}{*}{$\beta_{j}$} & --- & -0.004114 & -0.007062 & -0.016415 & -0.016792 & -0.015969 & -0.020227 & -0.031550 & -0.016375 & -0.015367 \\
\hline & & (0.291688) & $(0.486691)$ & (1.031318) & (1.051399) & $(0.869612)$ & (1.276869) & (1.615807) & (1.018584) & (0.959979) \\
\hline \multirow[t]{2}{*}{$\sigma_{I V_{i d i o, j, t}}$} & --- & --- & --- & $0.063008 *$ & 0.058335 & --- & --- & 0.050047 & 0.062654 & 0.063074 \\
\hline & & & & (1.653411) & $(1.447881)$ & & & (1.223838) & (1.508624) & (1.519861) \\
\hline \multirow[t]{2}{*}{$\sigma_{E G_{i d i o, j, t}}$} & --- & --- & --- & --- & --- & 0.181391 & --- & 0.078884 & --- & --- \\
\hline & & & & & & $(0.792147)$ & & $(0.338586)$ & & \\
\hline \multirow[t]{2}{*}{$\sigma_{A R_{i d i o, j, t}}$} & --- & --- & --- & --- & --- & --- & $0.215968 * *$ & $0.201251 *$ & --- & --- \\
\hline & & & & & & & $(2.025949)$ & (1.870263) & & \\
\hline \multirow[t]{2}{*}{ ORW ratio } & --- & --- & --- & --- & --- & --- & --- & --- & 0.001456 & 0.001057 \\
\hline & & & & & & & & & $(0.502653)$ & $(0.371764)$ \\
\hline \multirow[t]{2}{*}{$O I$} & --- & --- & --- & --- & --- & --- & --- & --- & 0.000847 & -0.000641 \\
\hline & & & & & & & & & $(0.310551)$ & (0.350218) \\
\hline \multirow[t]{2}{*}{ Constant } & 0.099097 & 0.107102 & 0.084849 & 0.087440 & 0.079173 & 0.081370 & 0.084667 & 0.078297 & 0.124320 & 0.012661 \\
\hline & (0.998576) & (1.038947) & $(0.798657)$ & $(0.844671)$ & (0.745878) & $(0.764852)$ & $(0.800451)$ & $(0.739040)$ & $(0.816972)$ & $(0.904372)$ \\
\hline
\end{tabular}


Tables 14.1 to 14.8 reports outcomes from effects of different idiosyncratic volatility measures on future stock returns for eight sectors in four phases compared to entire phase.

Table 14: Forecast model of implied, realized, $E G A R C H$ and $A R(2)$ idiosyncratic volatilities. Table 14.1: Basic Materials Sector

\begin{tabular}{|c|c|c|c|c|c|c|c|c|c|c|c|}
\hline \multirow{2}{*}{$\begin{array}{c}\text { Variables } \\
\sigma_{R V \text { idio }}\end{array}$} & \multirow{2}{*}{$\frac{\text { Model }}{\text { Model } 3}$} & \multicolumn{2}{|l|}{ Phase 1} & \multicolumn{2}{|l|}{ Phase 2} & \multicolumn{2}{|l|}{ Phase 3} & \multicolumn{2}{|l|}{ Phase 4} & \multicolumn{2}{|c|}{ Full Periods } \\
\hline & & 0.077439 & & 0.163238 & $* * *$ & 0.006669 & & -0.004126 & & -0.148661 & $* * *$ \\
\hline & & $(1.073010)$ & & $(2.716673)$ & & $(0.087292)$ & & $(0.056856)$ & & $(5.087340)$ & \\
\hline & Model 5 & -0.095956 & & 0.129650 & $*$ & -0.040436 & & -0.226669 & $* * *$ & -0.287969 & $* * *$ \\
\hline & & $(0.910345)$ & & (1.734308) & & $(0.369874)$ & & $(2.598282)$ & & $(7.161865)$ & \\
\hline & Model 6 & 0.189915 & $* *$ & 0.074143 & & 0.043316 & & -0.008034 & & -0.156080 & $* * *$ \\
\hline & & $(2.400420)$ & & $(1.128752)$ & & $(0.548644)$ & & $(0.104936)$ & & $(5.030232)$ & \\
\hline & Model 7 & 0.229438 & $* * *$ & 0.108194 & & 0.041614 & & -0.004110 & & -0.132887 & $* * *$ \\
\hline & & (2.983987) & & (1.640067) & & $(0.536806)$ & & $(0.054788)$ & & $(4.343374)$ & \\
\hline & Model 8 & -0.025912 & & 0.084477 & & -0.024084 & & -0.222272 & $* *$ & -0.281222 & $* * *$ \\
\hline & & $(0.247764)$ & & (1.106848) & & $(0.220681)$ & & $(2.474185)$ & & $(6.931776)$ & \\
\hline & Model 9 & -0.089046 & & 0.146227 & $*$ & -0.046964 & & -0.247773 & $* * *$ & -0.296934 & $* * *$ \\
\hline & & $(0.841044)$ & & (1.907550) & & $(0.425262)$ & & $(2.782853)$ & & $(7.335000)$ & \\
\hline & Model 10 & -0.074741 & & 0.136239 & $*$ & -0.042900 & & -0.213266 & $* *$ & -0.285573 & $* * *$ \\
\hline & & $(0.708107)$ & & $(1.807810)$ & & $(0.388949)$ & & $(2.431129)$ & & $(7.077395)$ & \\
\hline \multirow[t]{10}{*}{$\sigma_{I V i d i o, j, t}$} & Model 4 & 0.041985 & $* *$ & 0.036436 & $* *$ & 0.015492 & & 0.076171 & $* * *$ & 0.001245 & \\
\hline & & $(2.325129)$ & & $(2.222327)$ & & $(0.484061)$ & & $(3.687708)$ & & $(0.140800)$ & \\
\hline & Model 5 & 0.059541 & $* *$ & 0.015400 & & 0.027606 & & 0.112804 & $* * *$ & 0.061108 & $* * *$ \\
\hline & & $(2.253635)$ & & $(0.755285)$ & & $(0.602645)$ & & $(4.517748)$ & & $(5.032830)$ & \\
\hline & Model 8 & 0.100057 & $* * *$ & -0.004535 & & 0.044502 & & 0.113473 & $* * *$ & 0.063897 & $* * *$ \\
\hline & & $(3.658972)$ & & $(0.210081)$ & & $(0.957097)$ & & $(4.524888)$ & & $(5.162852)$ & \\
\hline & Model 9 & 0.059849 & $* *$ & 0.011965 & & 0.028074 & & 0.112958 & $* * *$ & 0.058395 & $* * *$ \\
\hline & & $(2.246506)$ & & $(0.583509)$ & & $(0.604196)$ & & $(4.522831)$ & & (4.798069) & \\
\hline & Model 10 & 0.066708 & $* *$ & 0.010841 & & 0.030512 & & 0.116148 & $* * *$ & 0.061742 & $* * *$ \\
\hline & & $(2.536626)$ & & $(0.530266)$ & & $(0.658168)$ & & $(4.651816)$ & & $(5.088852)$ & \\
\hline \multirow[t]{4}{*}{$\sigma_{E G_{i d i o, j, t}}$} & Model 6 & -0.399531 & $* * *$ & 0.208221 & $* * *$ & -0.347825 & $*$ & 0.016119 & & 0.034218 & \\
\hline & & $(3.396185)$ & & (3.330091) & & $(1.792502)$ & & $(0.160571)$ & & $(0.711376)$ & \\
\hline & Model 8 & -0.091086 & & 0.221537 & $* * *$ & -0.145682 & & 0.007819 & & 0.104602 & $*$ \\
\hline & & $(0.569635)$ & & $(2.659847)$ & & $(0.590131)$ & & $(0.064750)$ & & $(1.696092)$ & \\
\hline \multirow[t]{4}{*}{$\sigma_{\text {AR idio, } j, t}$} & Model 7 & -0.573896 & $* * *$ & 0.128473 & $* *$ & -0.307242 & $* *$ & -0.000065 & & -0.072403 & $*$ \\
\hline & & (5.308044) & & $(2.016659)$ & & $(2.372325)$ & & $(0.000827)$ & & $(1.737202)$ & \\
\hline & Model 8 & -0.613141 & $* * *$ & -0.014332 & & -0.262278 & & -0.031655 & & -0.164268 & $* * *$ \\
\hline & & (4.229197) & & $(0.168420)$ & & $(1.608095)$ & & $(0.334307)$ & & $(3.087997)$ & \\
\hline
\end{tabular}

For "Basic Materials" sector there is no consistent predictability from every idiosyncratic volatilities for this sector. The realized idiosyncratic volatility is no statistical significance in Phase 3, whilst the implied idiosyncratic volatility cannot work and has hardly been statistical significant in Phase 2 and 3. In fact, the $E G A R C H$ volatility forecast has no relation in Phase 3 and 4, while the $A R(2)$ volatility forecast is not statistical significant in Phase 4. In conclusion, 
results of Basic materials sector is not followed to all sectors for these idiosyncratic volatilities.

Table 14.2: Consumer Goods Sector

\begin{tabular}{|c|c|c|c|c|c|c|c|c|c|c|c|}
\hline \multirow{3}{*}{$\frac{\text { Variables }}{\sigma_{R V} \text { idio }}$} & \multirow{2}{*}{$\frac{\text { Model }}{\text { Model } 3}$} & \multicolumn{2}{|c|}{ Phase 1} & \multicolumn{2}{|l|}{ Phase 2} & \multicolumn{2}{|c|}{ Phase 3} & \multicolumn{2}{|l|}{ Phase 4} & \multicolumn{2}{|c|}{ Full Periods } \\
\hline & & 0.598987 & $* * *$ & 0.170222 & $* * *$ & -0.274735 & $* * *$ & 0.070367 & & 0.007323 & \\
\hline & & (6.806798) & & $(3.325476)$ & & (3.572008) & & (0.908090) & & $(0.243390)$ & \\
\hline & Model 5 & 0.493716 & $* * *$ & 0.058757 & & -0.422617 & $* * *$ & -0.118580 & & -0.181433 & $* * *$ \\
\hline & & $(4.706961)$ & & $(1.029682)$ & & $(4.593333)$ & & (1.336089) & & $(4.879336)$ & \\
\hline & Model 6 & 0.486207 & $* * *$ & 0.176776 & $* * *$ & -0.261553 & $* * *$ & 0.043425 & & -0.025247 & \\
\hline & & $(4.930985)$ & & $(3.325057)$ & & (3.385402) & & $(0.554005)$ & & $(0.808456)$ & \\
\hline & Model 7 & 0.499804 & $* * *$ & 0.155108 & $* * *$ & -0.255486 & $* * *$ & 0.047542 & & -0.029669 & \\
\hline & & $(5.290286)$ & & $(2.938172)$ & & $(3.306753)$ & & $(0.612135)$ & & $(0.964877)$ & \\
\hline & Model 8 & 0.445678 & $* * *$ & 0.071933 & & -0.451041 & $* * *$ & -0.121374 & & -0.187324 & $* * *$ \\
\hline & & $(4.164990)$ & & $(1.249561)$ & & $(4.911004)$ & & (1.368497) & & $(5.030321)$ & \\
\hline & Model 9 & 0.505508 & $* * *$ & 0.060924 & & -0.422307 & $* * *$ & -0.115006 & & -0.180523 & $* * *$ \\
\hline & & $(4.814886)$ & & $(1.065542)$ & & $(4.588542)$ & & (1.289243) & & $(4.850420)$ & \\
\hline & Model 10 & 0.507165 & $* * *$ & 0.060137 & & -0.420540 & $* * *$ & -0.115636 & & -0.180699 & $* * *$ \\
\hline & & $(4.832167)$ & & $(1.051458)$ & & $(4.582565)$ & & $(1.297059)$ & & $(4.855644)$ & \\
\hline \multirow[t]{10}{*}{$\sigma_{I V_{i d i o, j, t}}$} & Model 4 & 0.116497 & $* * *$ & 0.104875 & $* * *$ & 0.010377 & & 0.083368 & $* * *$ & 0.060405 & $* * *$ \\
\hline & & $(5.216605)$ & & (5.401764) & & $(0.405132)$ & & (4.168898) & & (7.019715) & \\
\hline & Model 5 & 0.048644 & * & 0.094895 & $* * *$ & 0.087853 & $* * *$ & 0.098672 & $* * *$ & 0.091305 & $* * *$ \\
\hline & & (1.840303) & & $(4.373018)$ & & $(2.893386)$ & & (4.282493) & & (8.554969) & \\
\hline & Model 8 & 0.025244 & & 0.100415 & $* * *$ & 0.125840 & $* * *$ & 0.090225 & $* * *$ & 0.084473 & $* * *$ \\
\hline & & $(0.851992)$ & & $(4.359342)$ & & (3.901084) & & $(3.824556)$ & & $(7.620304)$ & \\
\hline & Model 9 & 0.059617 & $* *$ & 0.098609 & $* * *$ & 0.091348 & $* * *$ & 0.096537 & $* * *$ & 0.091449 & $* * *$ \\
\hline & & $(2.207798)$ & & $(4.478606)$ & & $(2.994132)$ & & $(4.141875)$ & & $(8.484216)$ & \\
\hline & Model 10 & 0.063475 & $* *$ & 0.089127 & $* * *$ & 0.089805 & $* * *$ & 0.097836 & $* * *$ & 0.092355 & $* * *$ \\
\hline & & $(2.387549)$ & & $(4.164555)$ & & $(2.991891)$ & & $(4.266818)$ & & $(8.696146)$ & \\
\hline \multirow[t]{4}{*}{$\sigma_{E G_{i d i o, j, t}}$} & Model 6 & 0.237354 & $* *$ & -0.024572 & & -0.268740 & & 0.223862 & $* *$ & 0.162308 & $* * *$ \\
\hline & & $(2.515746)$ & & $(0.456919)$ & & (1.610764) & & (2.160869) & & $(3.843813)$ & \\
\hline & Model 8 & 0.046794 & & -0.139599 & $*$ & -0.276374 & & 0.008923 & & -0.059889 & \\
\hline & & $(0.318728)$ & & $(1.956463)$ & & $(1.370538)$ & & $(0.072191)$ & & $(1.063957)$ & \\
\hline \multirow[t]{4}{*}{$\sigma_{A R_{i d i o, j, t}}$} & Model 7 & 0.165199 & $* * *$ & 0.066300 & & -0.423393 & $* *$ & 0.247135 & $* * *$ & 0.189286 & $* * *$ \\
\hline & & $(2.836243)$ & & $(1.169478)$ & & (2.109469) & & (2.935476) & & $(5.564617)$ & \\
\hline & Model 8 & 0.127323 & & 0.077106 & & -0.483031 & $* *$ & 0.193756 & $*$ & 0.163905 & $* * *$ \\
\hline & & $(1.500527)$ & & $(1.005350)$ & & $(2.014662)$ & & $(1.950311)$ & & $(3.664049)$ & \\
\hline
\end{tabular}

For the "Consumer Goods" sector it is found in table 14.2 that the idiosyncratic volatility forecast is only the implied idiosyncratic volatility with a positive statistical significance for every phases. Moreover, the realized, $E G A R C H$, and $A R(2)$ idiosyncratic volatilities are not statistical significance in a Phase per each such as Phase 4, Phase 3, and Phase 2 respectively. To be concluded, their outcomes are associated to previous study of all sectors that the implied idiosyncratic volatility is the best predictor on future stock returns among other idiosyncratic 
volatilities.

Table 14.3: Financial Sector

\begin{tabular}{|c|c|c|c|c|c|c|c|c|c|c|c|}
\hline Variables & Model & Phase 1 & & Phase 2 & & Phase 3 & & Phase 4 & & Full Periods & \\
\hline \multirow[t]{14}{*}{$\sigma_{R V \text { idio }}$} & Model 3 & 0.103957 & & 0.125865 & $* * *$ & -0.084144 & & 0.078321 & & -0.019519 & \\
\hline & & (1.476488) & & (2.913068) & & $(1.364013)$ & & (1.618189) & & $(0.956957)$ & \\
\hline & Model 5 & -0.020520 & & 0.140523 & $* * *$ & -0.228197 & $* * *$ & -0.126742 & $*$ & -0.180444 & $* * *$ \\
\hline & & $(0.259604)$ & & $(2.810908)$ & & $(2.617648)$ & & $(1.705244)$ & & (5.720938) & \\
\hline & Model 6 & 0.093773 & & 0.133943 & $* * *$ & -0.187404 & $* * *$ & -0.000577 & & -0.090668 & $* * *$ \\
\hline & & (1.301016) & & $(2.993680)$ & & $(2.750391)$ & & $(0.010127)$ & & (3.839654) & \\
\hline & Model 7 & 0.115320 & & 0.142677 & $* * *$ & -0.089311 & & 0.023574 & & -0.051781 & $* *$ \\
\hline & & (1.612351) & & $(3.203876)$ & & $(1.367585)$ & & $(0.448097)$ & & $(2.324336)$ & \\
\hline & Model 8 & -0.016845 & & 0.143213 & $* * *$ & -0.256716 & $* * *$ & -0.152132 & $* *$ & -0.201273 & $* * *$ \\
\hline & & $(0.212794)$ & & $(2.853163)$ & & $(2.920442)$ & & $(2.010076)$ & & (6.306097) & \\
\hline & Model 9 & -0.024361 & & 0.153159 & $* * *$ & -0.231443 & $* * *$ & -0.148058 & $* *$ & -0.184236 & $* * *$ \\
\hline & & $(0.308164)$ & & (3.037149) & & $(2.649769)$ & & $(1.972515)$ & & $(5.817389)$ & \\
\hline & Model 10 & -0.021845 & & 0.158887 & $* * *$ & -0.223683 & $* *$ & -0.131963 & $*$ & -0.176084 & $* * *$ \\
\hline & & $(0.275214)$ & & $(3.175043)$ & & $(2.566212)$ & & $(1.761943)$ & & $(5.563684)$ & \\
\hline \multirow[t]{10}{*}{$\sigma_{I V} i d i o, j, t$} & Model 4 & 0.091162 & $* * *$ & 0.015243 & & 0.010848 & & 0.040619 & $* * *$ & 0.018279 & $* * *$ \\
\hline & & $(3.712153)$ & & $(0.959770)$ & & $(0.670778)$ & & $(3.584150)$ & & (3.559193) & \\
\hline & Model 5 & 0.094481 & $* * *$ & -0.010703 & & 0.053214 & $* *$ & 0.063301 & $* * *$ & 0.053045 & $* * *$ \\
\hline & & $(3.411641)$ & & $(0.583069)$ & & $(2.330888)$ & & $(3.623537)$ & & $(6.673501)$ & \\
\hline & Model 8 & 0.102299 & $* * *$ & -0.002208 & & 0.035314 & & 0.052726 & $* * *$ & 0.042687 & $* * *$ \\
\hline & & $(3.530496)$ & & $(0.112740)$ & & $(1.490842)$ & & $(2.883491)$ & & $(5.103467)$ & \\
\hline & Model 9 & 0.088776 & $* * *$ & -0.007730 & & 0.054138 & $* *$ & 0.057965 & $* * *$ & 0.051726 & $* * *$ \\
\hline & & $(3.184856)$ & & $(0.419654)$ & & $(2.311777)$ & & (3.284399) & & $(6.442140)$ & \\
\hline & Model 10 & 0.103343 & $* * *$ & -0.004926 & & 0.059222 & $* *$ & 0.064745 & $* * *$ & 0.055645 & $* * *$ \\
\hline & & $(3.736357)$ & & $(0.271185)$ & & $(2.566293)$ & & $(3.709522)$ & & $(6.969447)$ & \\
\hline \multirow[t]{4}{*}{$\sigma_{E G_{i d i o, j, t}}$} & Model 6 & 0.059318 & & -0.035208 & & 0.388200 & $* * *$ & 0.221359 & $* * *$ & 0.218533 & $* * *$ \\
\hline & & $(0.663496)$ & & $(0.696010)$ & & $(3.444964)$ & & $(2.615824)$ & & (5.935799) & \\
\hline & Model 8 & 0.097142 & & 0.020695 & & 0.405814 & $* * *$ & 0.085049 & & 0.157596 & $* * *$ \\
\hline & & $(0.860522)$ & & $(0.322676)$ & & $(3.195947)$ & & $(0.834468)$ & & $(3.594785)$ & \\
\hline \multirow[t]{4}{*}{$\sigma_{A R_{i d i o, j, t}}$} & Model 7 & -0.075366 & & -0.073719 & & 0.014485 & & 0.129033 & $* * *$ & 0.082451 & $* * *$ \\
\hline & & $(0.905440)$ & & $(1.553570)$ & & $(0.242506)$ & & $(2.624003)$ & & (3.584903) & \\
\hline & Mode 18 & -0.203307 & $*$ & -0.083631 & & -0.086830 & & 0.069137 & & 0.002413 & \\
\hline & & (1.956975) & & $(1.370650)$ & & (1.339938) & & (1.186384) & & $(0.089780)$ & \\
\hline
\end{tabular}

"Financials" sector (Table 14.3) reports that there is no consistent idiosyncratic volatility to forecast future returns for every phases. In fact, the implied, and realized, idiosyncratic volatilities are not statistical significance in a Phase per each such as Phase 2, and Phase 1 respectively. Furthermore, EGARCH idiosyncratic volatility cannot predict in Phase 1 and 2, while $A R(2)$ idiosyncratic volatility is not found any statistical significance in Phase 2 and 3. Eventually, results of financial sector for every idiosyncratic volatilities is not followed to all 
sectors' outcomes.

Table 14.4: Healthcare Sector

\begin{tabular}{|c|c|c|c|c|c|c|c|c|c|c|c|}
\hline \multirow{3}{*}{$\frac{\text { Variables }}{\sigma_{R V_{\text {idio }}}}$} & \multirow{2}{*}{$\begin{array}{c}\text { Model } \\
\text { Model } 3\end{array}$} & \multicolumn{2}{|l|}{ Phase 1} & \multicolumn{2}{|l|}{ Phase 2} & \multicolumn{2}{|c|}{ Phase 3} & \multicolumn{2}{|l|}{ Phase 4} & \multicolumn{2}{|c|}{ Full Periods } \\
\hline & & \multirow{2}{*}{\multicolumn{2}{|c|}{$\begin{array}{l}-0.025005 \\
(0.269757)\end{array}$}} & \multirow{2}{*}{\multicolumn{2}{|c|}{$\begin{array}{l}-0.013484 \\
(0.256317)\end{array}$}} & \multirow{2}{*}{$\begin{array}{l}-0.267338 \\
(2.949650)\end{array}$} & \multirow[t]{2}{*}{$* * *$} & \multirow{2}{*}{\multicolumn{2}{|c|}{$\begin{array}{c}0.063641 \\
(0.787274)\end{array}$}} & \multirow{2}{*}{$\begin{array}{l}-0.103266 \\
(3.081032)\end{array}$} & \multirow[t]{2}{*}{$* * *$} \\
\hline & & & & & & & & & & & \\
\hline & \multirow[t]{2}{*}{ Model 5} & \multirow{2}{*}{\multicolumn{2}{|c|}{$\begin{array}{l}-0.080810 \\
(0.755155)\end{array}$}} & -0.164805 & $* * *$ & -0.399581 & $* * *$ & \multirow{2}{*}{\multicolumn{2}{|c|}{$\begin{array}{l}-0.034111 \\
(0.365708)\end{array}$}} & -0.213011 & $* * *$ \\
\hline & & & & $(2.727879)$ & & (3.803024) & & & & (5.275399) & \\
\hline & Model 6 & \multirow{2}{*}{\multicolumn{2}{|c|}{$\begin{array}{c}0.051904 \\
(0.529203)\end{array}$}} & -0.171317 & $* * *$ & -0.295041 & $* * *$ & \multirow{2}{*}{\multicolumn{2}{|c|}{$\begin{array}{c}0.022491 \\
(0.261501)\end{array}$}} & -0.175871 & $* * *$ \\
\hline & & & & (3.053780) & & $(3.062955)$ & & & & (4.936344) & \\
\hline & Model 7 & \multirow{2}{*}{\multicolumn{2}{|c|}{$\begin{array}{c}0.042856 \\
(0.448780)\end{array}$}} & -0.074538 & & -0.272747 & $* * *$ & \multirow{2}{*}{\multicolumn{2}{|c|}{$\begin{array}{c}0.064512 \\
0749934)\end{array}$}} & -0.128447 & $* * *$ \\
\hline & & & & $(1.366281)$ & & $(2.875267)$ & & & & (3.684691) & \\
\hline & Model 8 & \multirow{2}{*}{\multicolumn{2}{|c|}{$\begin{array}{l}-0.037457 \\
(0.348353)\end{array}$}} & -0.239507 & $* * *$ & -0.402747 & $* * *$ & \multicolumn{2}{|l|}{-0.040108} & -0.245355 & $* * *$ \\
\hline & & & & $(3.915880)$ & & $(3.762045)$ & & $(0.415372)$ & & (5.998020) & \\
\hline & Model 9 & \multirow{2}{*}{\multicolumn{2}{|c|}{$\begin{array}{l}-0.040533 \\
(0.377410)\end{array}$}} & -0.146430 & $* *$ & -0.402200 & $* * *$ & \multicolumn{2}{|l|}{-0.022476} & -0.208618 & $* * *$ \\
\hline & & & & (2.413946) & & $(3.820691)$ & & & & (5.163627) & \\
\hline & Model 10 & \multirow{2}{*}{\multicolumn{2}{|c|}{$\begin{array}{l}-0.040390 \\
(0.376222) \\
\end{array}$}} & -0.151750 & $* *$ & -0.405899 & $* * *$ & \multirow{2}{*}{\multicolumn{2}{|c|}{$\begin{array}{l}-0.020234 \\
(0.218380)\end{array}$}} & -0.208084 & $* * *$ \\
\hline & & & & $(2.507805)$ & & $(3.857286)$ & & & & (5.156711) & \\
\hline$\sigma_{I V}$ & Model 4 & 0.014895 & & 0.061780 & $* * *$ & 0.013540 & & 0.039114 & $* *$ & 0.018794 & $* *$ \\
\hline & & $(0.769279)$ & & (4.226452) & & $(0.585317)$ & & $(2.205672)$ & & $(2.285740)$ & \\
\hline & Model 5 & 0.023331 & & 0.084664 & $* * *$ & 0.065409 & $* *$ & 0.042870 & $* *$ & 0.048051 & $* * *$ \\
\hline & & $(1.043572)$ & & (5.027726) & & $(2.456854)$ & & (2.091272) & & $(4.852703)$ & \\
\hline & Model 8 & 0.051515 & $* *$ & 0.050789 & $* * *$ & 0.064751 & $* *$ & 0.039013 & * & 0.036912 & $* * *$ \\
\hline & & (2.158003) & & $(2.867368)$ & & $(2.351549)$ & & (1.877764) & & (3.618238) & \\
\hline & Model 9 & 0.041428 & * & 0.100145 & $* * *$ & 0.065359 & $* *$ & 0.053962 & $* *$ & 0.053244 & $* * *$ \\
\hline & & $(1.803260)$ & & (5.687792) & & $(2.347377)$ & & (2.488464) & & $(5.236237)$ & \\
\hline & Model 10 & 0.039521 & * & 0.092339 & $* * *$ & 0.055002 & $* *$ & 0.055463 & **** & 0.054108 & $* * *$ \\
\hline & & $(1.756767)$ & & $(5.621920)$ & & $(2.103420)$ & & $(2.814080)$ & & $(5.591755)$ & \\
\hline$\sigma_{E G_{i d i o, j, t}}$ & Model 6 & -0.263244 & $* *$ & 0.371979 & $* * *$ & 0.118968 & & 0.114056 & & 0.226432 & $* * *$ \\
\hline & & $(2.359361)$ & & $(7.582629)$ & & $(0.850830)$ & & (1.396794) & & $(5.878756)$ & \\
\hline & Model 8 & -0.177436 & & 0.375464 & $* * *$ & 0.165990 & & 0.204819 & $*$ & 0.258740 & $* * *$ \\
\hline & & $(1.179952)$ & & $(5.742659)$ & & $(0.770916)$ & & $(1.763349)$ & & $(4.937136)$ & \\
\hline$\sigma_{A R_{i d i o, j, t}}$ & Model 7 & -0.290451 & $* * *$ & 0.164888 & $* * *$ & 0.025925 & & -0.002333 & & 0.087926 & $* * *$ \\
\hline & & (2.815937) & & (4.079882) & & $(0.194933)$ & & $(0.029706)$ & & (2.611577) & \\
\hline & Model 8 & -0.252204 & $*$ & -0.064992 & & -0.163712 & & -0.158285 & & -0.087920 & $*$ \\
\hline & & (1.856206) & & $(1.236980)$ & & $(0.805557)$ & & (1.429031) & & (1.944991) & \\
\hline
\end{tabular}

"Healthcare" sector results show that the implied idiosyncratic volatility can forecast on future stock returns with a positive statistical significant effect for every phases and entire phase, whereas realized, idiosyncratic volatilities are not statistical significance in Phase 1, and Phase 4. Furthermore, EGARCH idiosyncratic volatility cannot predict in Phase 3 and 4, while $A R(2)$ idiosyncratic volatility is not found any statistical significance in Phase 3 and 4 as well. Consequently, outcomes that the implied idiosyncratic volatility is the best predictor on future 
stock returns among other idiosyncratic volatilities, are analogous to previous study of all sectors

Table 14.5: Industrial Goods Sector

\begin{tabular}{|c|c|c|c|c|c|c|c|c|c|c|c|}
\hline \multirow{3}{*}{$\frac{\text { Variables }}{\sigma_{R V_{\text {idio }}}}$} & \multirow{2}{*}{$\frac{\text { Model }}{\text { Model } 3}$} & \multicolumn{2}{|c|}{ Phase 1} & \multicolumn{2}{|c|}{ Phase 2} & \multicolumn{2}{|c|}{ Phase 3} & \multicolumn{2}{|l|}{ Phase 4} & \multicolumn{2}{|c|}{ Full Periods } \\
\hline & & 0.257336 & $* *$ & 0.109086 & * & -0.193639 & $* *$ & 0.008460 & & -0.083949 & $* *$ \\
\hline & & $(2.502342)$ & & $(1.794454)$ & & $(2.235019)$ & & $(0.103046)$ & & $(2.509880)$ & \\
\hline & Model 5 & 0.321675 & $* * *$ & -0.011006 & & -0.373032 & $* * *$ & -0.220371 & $* *$ & -0.215833 & $* * *$ \\
\hline & & (2.700318) & & $(0.153211)$ & & (3.369281) & & (2.138278) & & (4.999249) & \\
\hline & Model 6 & 0.385232 & $* * *$ & 0.104715 & & -0.186742 & $* *$ & 0.016812 & & -0.065015 & $*$ \\
\hline & & $(3.637187)$ & & (1.609891) & & $(2.150230)$ & & $(0.202863)$ & & (1.910919) & \\
\hline & Model 7 & 0.309905 & $* * *$ & 0.054501 & & -0.140768 & & 0.009801 & & -0.076105 & $* *$ \\
\hline & & $(2.971618)$ & & $(0.843595)$ & & $(1.597242)$ & & $(0.117677)$ & & $(2.218192)$ & \\
\hline & Model 8 & 0.363609 & $* * *$ & -0.004989 & & -0.364624 & $* * *$ & -0.212240 & $* *$ & -0.209161 & $* * *$ \\
\hline & & $(3.065847)$ & & $(0.068800)$ & & $(3.323575)$ & & (2.043028) & & $(4.846875)$ & \\
\hline & Model 9 & 0.315152 & $* * *$ & 0.020889 & & -0.372210 & $* * *$ & -0.194270 & $*$ & -0.212136 & $* * *$ \\
\hline & & $(2.629459)$ & & $(0.288714)$ & & $(3.348442)$ & & (1.840983) & & $(4.894938)$ & \\
\hline & Model 10 & 0.327099 & $* * *$ & 0.010425 & & -0.372897 & $* * *$ & -0.179538 & $*$ & -0.203503 & $* * *$ \\
\hline & & $(2.760041)$ & & $(0.147569)$ & & $(3.356683)$ & & $(1.739733)$ & & $(4.730524)$ & \\
\hline \multirow[t]{10}{*}{$\sigma_{I V i d i o, j, t}$} & Model 4 & 0.010401 & & 0.048800 & $* * *$ & 0.017352 & & 0.063787 & $* * *$ & 0.019872 & $* *$ \\
\hline & & $(0.338764)$ & & (3.601701) & & $(0.589215)$ & & (2.936942) & & $(2.121427)$ & \\
\hline & Model 5 & -0.037927 & & 0.050116 & $* * *$ & 0.096628 & $* *$ & 0.099542 & $* * *$ & 0.058210 & $* * *$ \\
\hline & & (1.069847) & & $(3.124001)$ & & $(2.579578)$ & & (3.635646) & & $(4.815296)$ & \\
\hline & Model 8 & 0.015727 & & 0.045877 & $* *$ & 0.129056 & $* * *$ & 0.100033 & $* * *$ & 0.066584 & $* * *$ \\
\hline & & $(0.419182)$ & & $(2.575590)$ & & $(3.376780)$ & & (3.600552) & & $(5.334743)$ & \\
\hline & Model 9 & -0.046201 & & 0.057215 & $* * *$ & 0.094982 & $* *$ & 0.086818 & $* * *$ & 0.056072 & $* * *$ \\
\hline & & (1.271604) & & $(3.531151)$ & & $(2.261655)$ & & (3.102055) & & $(4.530756)$ & \\
\hline & Model 10 & -0.041042 & & 0.054939 & $* * *$ & 0.107961 & $* * *$ & 0.090539 & $* * *$ & 0.060799 & $* * *$ \\
\hline & & $(1.155679)$ & & $(3.467970)$ & & $(2.908413)$ & & $(3.301002)$ & & $(5.053061)$ & \\
\hline \multirow[t]{4}{*}{$\sigma_{E G_{i d i o, j, t}}$} & Model 6 & -0.396714 & $* * *$ & 0.011580 & & -0.106612 & & -0.057203 & & -0.108537 & $* * *$ \\
\hline & & (4.407799) & & $(0.189134)$ & & (1.098469) & & $(0.750647)$ & & $(2.973011)$ & \\
\hline & Model 8 & -0.446896 & $* * *$ & -0.145798 & $*$ & -0.000230 & & -0.041311 & & -0.138307 & $* * *$ \\
\hline & & $(3.487404)$ & & (1.918563) & & $(0.002156)$ & & $(0.444827)$ & & $(3.080178)$ & \\
\hline \multirow[t]{4}{*}{$\sigma_{A R_{i d i o, j, t}}$} & Model 7 & -0.262129 & $* * *$ & 0.147766 & $* *$ & -0.440059 & $* * *$ & -0.008612 & & -0.043409 & \\
\hline & & (2.728902) & & $(2.476165)$ & & $(2.780596)$ & & $(0.097568)$ & & (1.026124) & \\
\hline & Model 8 & 0.055459 & & 0.160168 & $* *$ & -0.570961 & $* * *$ & -0.020743 & & -0.008393 & \\
\hline & & $(0.415312)$ & & (2.103339) & & $(3.200420)$ & & $(0.191457)$ & & $(0.158500)$ & \\
\hline
\end{tabular}

"Industrial Goods" sector (Table 14.5) reports that there is no consistent idiosyncratic volatility to predict future stock returns in every phases. The implied, and realized, idiosyncratic volatilities are not statistical significance in one phase per each such as Phase 2, and Phase 1 respectively. Additionally, EGARCH idiosyncratic volatility cannot predict in Phase 3, while the $A R(2)$ idiosyncratic volatility is not found any statistical significance in 
Phase 3 and 4. In conclusion, results for Industrial Goods sector for every idiosyncratic volatilities is not associated to all sectors.

Table 14.6: Services Sector

\begin{tabular}{|c|c|c|c|c|c|c|c|c|c|c|c|}
\hline \multirow{2}{*}{$\frac{\text { Variables }}{\sigma_{R V \text { idio }}}$} & \multirow{2}{*}{$\frac{\text { Model }}{\text { Model } 3}$} & \multirow{2}{*}{$\begin{array}{c}\text { Phase 1 } \\
0.264364 \\
(4.210547)\end{array}$} & \multicolumn{3}{|c|}{ Phase 2} & \multicolumn{2}{|l|}{ Phase 3} & \multicolumn{2}{|l|}{ Phase 4} & \multicolumn{2}{|c|}{ Full Periods } \\
\hline & & & $* * *$ & $\begin{array}{c}0.171454 \\
(4.474419)\end{array}$ & $* * *$ & $\begin{array}{l}-0.255601 \\
(4.804743)\end{array}$ & $* * *$ & $\begin{array}{c}0.531439 \\
(11.915108)\end{array}$ & $* * *$ & $\begin{array}{c}0.103061 \\
(5.139128)\end{array}$ & $* * *$ \\
\hline & Model 5 & $\begin{array}{c}0.145992 \\
(2.011030)\end{array}$ & $* *$ & $\begin{array}{c}0.084565 \\
(2.007146)\end{array}$ & $* *$ & $\begin{array}{l}-0.553199 \\
(8.638801)\end{array}$ & $* * *$ & $\begin{array}{c}0.542783 \\
(11.214855)\end{array}$ & $* * *$ & $\begin{array}{c}0.039290 \\
(1.626337)\end{array}$ & \\
\hline & Model 6 & $\begin{array}{c}0.269649 \\
(4.111423)\end{array}$ & $* * *$ & $\begin{array}{c}0.179071 \\
(4.467796)\end{array}$ & $* * *$ & $\begin{array}{c}-0.236197 \\
(4.300127)\end{array}$ & $* * *$ & $\begin{array}{c}0.514615 \\
(11.246799)\end{array}$ & $* * *$ & $\begin{array}{c}0.095638 \\
(4.564937)\end{array}$ & $* * *$ \\
\hline & Model 7 & $\begin{array}{c}0.265332 \\
(4.036291)\end{array}$ & $* * *$ & $\begin{array}{c}0.164873 \\
(4.131433)\end{array}$ & $* * *$ & $\begin{array}{l}-0.231971 \\
(4.255295)\end{array}$ & $* * *$ & $\begin{array}{c}0.523524 \\
(11.546068)\end{array}$ & $* * *$ & $\begin{array}{c}0.091744 \\
(4.460356)\end{array}$ & $* * *$ \\
\hline & Model 8 & $\begin{array}{c}0.159443 \\
(2.157560)\end{array}$ & $* *$ & $\begin{array}{c}0.098795 \\
(2.299725)\end{array}$ & $* *$ & $\begin{array}{l}-0.547047 \\
(8.595563)\end{array}$ & $* * *$ & $\begin{array}{c}0.529828 \\
(10.820516)\end{array}$ & $* * *$ & $\begin{array}{c}0.037720 \\
(1.544724)\end{array}$ & \\
\hline & Model 9 & $\begin{array}{c}0.139948 \\
(1.919771)\end{array}$ & $*$ & $\begin{array}{c}0.096552 \\
(2.268072)\end{array}$ & $* *$ & $\begin{array}{l}-0.553979 \\
(8.648104)\end{array}$ & $* * *$ & $\begin{array}{c}0.551268 \\
(11.224743)\end{array}$ & $* * *$ & $\begin{array}{c}0.046037 \\
(1.898921)\end{array}$ & $*$ \\
\hline & Model 10 & $\begin{array}{c}0.146877 \\
(2.018690)\end{array}$ & $* *$ & $\begin{array}{c}0.084751 \\
(2.014725)\end{array}$ & $* *$ & $\begin{array}{l}-0.559200 \\
(8.752579)\end{array}$ & $* * *$ & $\begin{array}{c}0.551114 \\
(11.292082)\end{array}$ & $* * *$ & $\begin{array}{c}0.046714 \\
(1.934553)\end{array}$ & $*$ \\
\hline \multirow[t]{5}{*}{$\sigma_{I V} i d i o, j, t$} & Model 4 & $\begin{array}{c}0.078876 \\
(4.914542)\end{array}$ & $* * *$ & $\begin{array}{c}0.079568 \\
(6.342359)\end{array}$ & $* * *$ & $\begin{array}{c}0.069857 \\
(3.452112)\end{array}$ & $* * *$ & $\begin{array}{c}0.055979 \\
(3.966916)\end{array}$ & $* * *$ & $\begin{array}{c}0.041600 \\
(6.791839)\end{array}$ & $* * *$ \\
\hline & Model 5 & $\begin{array}{c}0.060008 \\
(3.229394)\end{array}$ & $* * *$ & $\begin{array}{c}0.067937 \\
(4.917196)\end{array}$ & $* * *$ & $\begin{array}{c}0.192507 \\
(7.938104)\end{array}$ & $* * *$ & $\begin{array}{l}-0.009026 \\
(0.604150)\end{array}$ & & $\begin{array}{c}0.034890 \\
(4.724829)\end{array}$ & $* * *$ \\
\hline & Model 8 & $\begin{array}{c}0.064374 \\
(3.365373)\end{array}$ & $* * *$ & $\begin{array}{c}0.073358 \\
(5.058054)\end{array}$ & $* * *$ & $\begin{array}{c}0.231596 \\
(9.124018)\end{array}$ & $* * *$ & $\begin{array}{l}-0.013366 \\
(0.881610)\end{array}$ & & $\begin{array}{c}0.033176 \\
(4.390390)\end{array}$ & $* * *$ \\
\hline & Model 9 & $\begin{array}{c}0.056487 \\
(2.982266)\end{array}$ & $* * *$ & $\begin{array}{c}0.066900 \\
(4.795959)\end{array}$ & $* * *$ & $\begin{array}{c}0.196393 \\
(7.877945)\end{array}$ & $* * *$ & $\begin{array}{l}-0.010503 \\
(0.666370)\end{array}$ & & $\begin{array}{c}0.031148 \\
(4.135389)\end{array}$ & $* * *$ \\
\hline & Model 10 & $\begin{array}{c}0.064847 \\
(3.593110) \\
\end{array}$ & $* * *$ & $\begin{array}{c}0.060800 \\
(4.493521) \\
\end{array}$ & $* * *$ & $\begin{array}{c}0.189077 \\
(7.865304) \\
\end{array}$ & $* * *$ & $\begin{array}{c}-0.010615 \\
(0.695710) \\
\end{array}$ & & $\begin{array}{c}0.031696 \\
(4.325390) \\
\end{array}$ & $* * *$ \\
\hline \multirow[t]{2}{*}{$\sigma_{E G_{i d i o, j, t}}$} & Model 6 & $\begin{array}{c}-0.015910 \\
(0.279398)\end{array}$ & & $\begin{array}{l}-0.028062 \\
(0.648455)\end{array}$ & & $\begin{array}{l}-0.164228 \\
(1.410019)\end{array}$ & & $\begin{array}{c}0.094424 \\
(1.636650)\end{array}$ & & $\begin{array}{c}0.034455 \\
(1.223964)\end{array}$ & \\
\hline & Model 8 & $\begin{array}{l}-0.043307 \\
(0.650611) \\
\end{array}$ & & $\begin{array}{c}-0.077586 \\
(1.504067) \\
\end{array}$ & & $\begin{array}{c}-0.155273 \\
(1.052780) \\
\end{array}$ & & $\begin{array}{c}0.101141 \\
(1.397102) \\
\end{array}$ & & $\begin{array}{c}-0.022703 \\
(0.663825) \\
\end{array}$ & \\
\hline \multirow[t]{2}{*}{$\sigma_{A R i d i o, j, t}$} & Model 7 & $\begin{array}{l}-0.003395 \\
(0.049807)\end{array}$ & & $\begin{array}{c}0.023797 \\
(0.590732)\end{array}$ & & $\begin{array}{l}-0.209966 \\
(1.942078)\end{array}$ & $*$ & $\begin{array}{c}0.036671 \\
(0.970484)\end{array}$ & & $\begin{array}{c}0.057784 \\
(2.465541)\end{array}$ & $* *$ \\
\hline & Model 8 & $\begin{array}{l}-0.026930 \\
(0.336873)\end{array}$ & & $\begin{array}{l}-0.000374 \\
(0.007621)\end{array}$ & & $\begin{array}{l}-0.428588 \\
(3.085363)\end{array}$ & $* * *$ & $\begin{array}{c}0.001799 \\
(0.038079)\end{array}$ & & $\begin{array}{c}0.048989 \\
(1.722242)\end{array}$ & $*$ \\
\hline
\end{tabular}

"Services" sector (Table 14.6) the results provide evidence the implied and realized idiosyncratic volatilities can forecast on future stock returns with strong statistical significant effects for every and entire phases, whereas EGARCH idiosyncratic volatility cannot predict for every phases. Additionally, $A R(2)$ idiosyncratic volatility is not found any statistical significance in Phase 1, 2, and 4. Although, realized idiosyncratic volatilities are statistical 
significance for every phases, Phase 1, 2, and 4 show positive statistical significant effects opposite to Phase 3 showing a negative effect. As the result, the realized idiosyncratic volatility cannot predict in certain direction for every phases. Whereas, the implied idiosyncratic volatility in phase which presents a statistical significance, is only positive effect with certain forecasting direction. Moreover, the implied idiosyncratic volatility forecast on future returns in Phase 4 is not found any statistical significance in every models except only Model 4 with a statistical significance at 1 percent level. This should be affected by the realized idiosyncratic volatility existed in every models (5, 8, 9, and 10) except Model 4. In fact, the implied idiosyncratic volatility with no statistical significance in Model 5, 8, 9, and 10, might cause by the multicollinearity issue which shows two variables with high correlation in same model, then a variable is decreased a statistical significant effect. It can find a conclusion that the implied and realized idiosyncratic volatilities should not be mutually employed to forecast the future stock return in this Services sector. In particular, the forecasting measure should be only the implied idiosyncratic volatility due to much more stable and consistent predictability direction than the realized idiosyncratic volatility. Eventually, outcomes that the implied idiosyncratic volatility is only the best predictor on future stock returns among other idiosyncratic volatilities, are same as previous study of all sectors.

The results for "Technologies" sector (Table 14.7) the implied and $A R(2)$ idiosyncratic volatilities can forecast on future stock returns with statistical significant effect for every and entire phases, whereas realized idiosyncratic volatilities are not statistical significance in Phase 3. Furthermore, EGARCH idiosyncratic volatility cannot predict in Phase 2. Although, $A R(2)$ idiosyncratic volatilities are statistical significance for every phases in Model 8, unfortunately Model 7 is not statistical significance in Phase 2 and 3. As the result, the $A R(2)$ idiosyncratic volatility cannot predict clearly for every phases. Inversely, the implied idiosyncratic volatility presents a positive statistical significance for every models and phases except only Model 4 in Phase 3 which is the period of recent financial crisis. At last, the implied idiosyncratic volatility can be the best predictor on future stock returns among other idiosyncratic volatilities, and this is analogous to previous study of all sectors 
Table 14.7: Technology Sector

\begin{tabular}{|c|c|c|c|c|c|c|c|c|c|c|c|}
\hline Variables & Model & Phase 1 & & Phase 2 & & Phase 3 & & Phase 4 & & Full Periods & \\
\hline \multirow[t]{14}{*}{$\sigma_{R V \text { idio }}$} & Model 3 & 0.519852 & $* * *$ & 0.244933 & $* * *$ & -0.029798 & & & $* * *$ & 0.031572 & \\
\hline & & (7.370121) & & $(6.503414)$ & & $(0.545018)$ & & $(3.747754)$ & & $(1.525295)$ & \\
\hline & Model 5 & 0.398817 & $* * *$ & 0.060893 & & -0.072253 & & 0.111563 & $* *$ & -0.028230 & \\
\hline & & (4.901875) & & (1.402193) & & $(1.213842)$ & & $(2.244814)$ & & $(1.117226)$ & \\
\hline & Model 6 & 0.579584 & $* * *$ & 0.239301 & $* * *$ & -0.064789 & & 0.122236 & $* * *$ & 0.040356 & $*$ \\
\hline & & $(7.976530)$ & & $(6.050850)$ & & $(1.146771)$ & & $(2.618184)$ & & $(1.827355)$ & \\
\hline & Model 7 & 0.563480 & $* * *$ & 0.250947 & $* * *$ & -0.031664 & & 0.175319 & $* * *$ & 0.042768 & $* *$ \\
\hline & & $(7.856866)$ & & (6.355993) & & $(0.561705)$ & & (3.807761) & & (1.997092) & \\
\hline & Model 8 & 0.427695 & $* * *$ & 0.080335 & * & -0.091301 & & 0.086566 & $*$ & -0.016702 & \\
\hline & & $(5.266871)$ & & $(1.829126)$ & & $(1.506135)$ & & $(1.720992)$ & & $(0.654853)$ & \\
\hline & Model 9 & 0.410903 & $* * *$ & 0.073792 & $*$ & -0.069691 & & 0.108679 & $* *$ & -0.024582 & \\
\hline & & $(5.015231)$ & & (1.682837) & & (1.169392) & & $(2.177332)$ & & $(0.967702)$ & \\
\hline & Model 10 & 0.403773 & $* * *$ & 0.065629 & & -0.072020 & & 0.107534 & $* *$ & -0.024545 & \\
\hline & & $(4.966757)$ & & $(1.507443)$ & & $(1.210093)$ & & $(2.157118)$ & & $(0.970558)$ & \\
\hline \multirow[t]{10}{*}{$\sigma_{I V i d i o, j, t}$} & Model 4 & 0.105602 & $* * *$ & 0.117195 & $* * *$ & 0.036020 & & 0.063858 & $* * *$ & 0.025129 & $* * *$ \\
\hline & & $(6.238603)$ & & $(10.532423)$ & & $(1.430525)$ & & $(4.216438)$ & & $(4.250448)$ & \\
\hline & Model 5 & 0.057819 & $* * *$ & 0.108044 & $* * *$ & 0.049250 & $*$ & 0.048921 & $* * *$ & 0.029762 & $* * *$ \\
\hline & & $(2.970490)$ & & $(8.376160)$ & & $(1.795275)$ & & $(2.959262)$ & & $(4.121333)$ & \\
\hline & Model 8 & 0.090533 & $* * *$ & 0.121291 & $* * *$ & 0.046965 & $*$ & 0.038553 & $* *$ & 0.037226 & $* * *$ \\
\hline & & (4.423858) & & $(8.886732)$ & & (1.697203) & & $(2.315276)$ & & $(4.863412)$ & \\
\hline & Model 9 & 0.062555 & $* * *$ & 0.108546 & $* * *$ & 0.051813 & $*$ & 0.047869 & $* * *$ & 0.029944 & $* * *$ \\
\hline & & $(3.161257)$ & & (8.411699) & & (1.879007) & & $(2.894858)$ & & $(4.139084)$ & \\
\hline & Model 10 & 0.060654 & $* * *$ & 0.105628 & $* * *$ & 0.050349 & $*$ & 0.046163 & $* * *$ & 0.029957 & $* * *$ \\
\hline & & $(3.094410)$ & & $(8.273361)$ & & $(1.830193)$ & & $(2.856862)$ & & $(4.173021)$ & \\
\hline \multirow[t]{4}{*}{$\sigma_{E G_{i d i o, j, t}}$} & Model 6 & -0.230813 & $* * *$ & 0.019980 & & 0.313047 & $* *$ & 0.313842 & $* * *$ & -0.035851 & \\
\hline & & $(3.314325)$ & & $(0.467006)$ & & $(2.392642)$ & & $(4.449710)$ & & (1.140869) & \\
\hline & Model 8 & -0.236915 & $* * *$ & -0.029068 & & 0.519226 & $* * *$ & 0.335881 & $* * *$ & -0.058952 & \\
\hline & & $(2.888655)$ & & $(0.570629)$ & & $(2.998060)$ & & $(4.504255)$ & & $(1.623766)$ & \\
\hline \multirow[t]{4}{*}{$\sigma_{A R_{i d i o, j, t}}$} & Model 7 & -0.203386 & $* * *$ & -0.022201 & & 0.019221 & & -0.021738 & & -0.049124 & $* *$ \\
\hline & & (3.190247) & & $(0.507898)$ & & $(0.136743)$ & & $(0.691498)$ & & $(2.035151)$ & \\
\hline & Model 8 & -0.168053 & $* *$ & -0.124817 & $* *$ & -0.381254 & $* *$ & -0.068642 & $* *$ & -0.053012 & $* *$ \\
\hline & & $(2.275982)$ & & $(2.394932)$ & & $(2.046640)$ & & $(2.094679)$ & & $(1.975677)$ & \\
\hline
\end{tabular}

For the "Utilities" sector in table 14.8, there is no consistent idiosyncratic volatility to forecast future stock returns in every phases. The implied idiosyncratic volatility is not statistical significance in Phase 2, 3, and 4, meanwhile the realized, idiosyncratic volatility cannot forecast in Phase 4. Additionally, EGARCH idiosyncratic volatility is not statistical significant in Phase 3, and 4, while $A R(2)$ idiosyncratic volatility is not found any statistical significance in Phase 1. In conclusion, results of Utilities sector for every idiosyncratic volatilities is not associated to all sectors' outcome in previous study. 
Table 14.8: Utilities Sector

\begin{tabular}{|c|c|c|c|c|c|c|c|c|c|c|c|}
\hline \multirow{3}{*}{$\begin{array}{c}\text { Variables } \\
\sigma_{R V_{\text {idio }}}\end{array}$} & \multirow{2}{*}{$\begin{array}{c}\text { Model } \\
\text { Model } 3\end{array}$} & \multicolumn{2}{|l|}{ Phase 1} & \multicolumn{2}{|l|}{ Phase 2} & \multicolumn{2}{|c|}{ Phase 3} & \multicolumn{2}{|l|}{ Phase 4} & \multicolumn{2}{|c|}{ Full Periods } \\
\hline & & 0.350178 & $* * *$ & 0.052818 & & 0.211050 & $*$ & 0.128001 & & 0.081683 & $*$ \\
\hline & & $(2.839120)$ & & $(0.560215)$ & & $(1.762322)$ & & $(0.871011)$ & & (1.748519) & \\
\hline & Model 5 & 0.145864 & & -0.071526 & & 0.171914 & & 0.055943 & & -0.029237 & \\
\hline & & $(0.914003)$ & & $(0.545761)$ & & $(0.933785)$ & & $(0.361064)$ & & $(0.424864)$ & \\
\hline & Model 6 & 0.455921 & $* * *$ & -0.421955 & $* * *$ & 0.264121 & $* *$ & 0.097665 & & 0.117187 & $*$ \\
\hline & & (3.166937) & & $(3.573045)$ & & $(2.053982)$ & & $(0.642784)$ & & $(1.911021)$ & \\
\hline & Model 7 & 0.358563 & $* * *$ & 0.252069 & $* *$ & 0.303285 & $* *$ & 0.069264 & & 0.184022 & $* * *$ \\
\hline & & $(2.856254)$ & & (2.371218) & & $(2.458435)$ & & $(0.464368)$ & & $(3.525716)$ & \\
\hline & Model 8 & 0.248290 & & -0.187364 & & 0.080074 & & -0.001745 & & 0.009582 & \\
\hline & & (1.497736) & & $(1.390730)$ & & $(0.431769)$ & & $(0.010982)$ & & $(0.135795)$ & \\
\hline & Model 9 & 0.171339 & & -0.051373 & & 0.172686 & & 0.030278 & & -0.028565 & \\
\hline & & (1.050181) & & $(0.387468)$ & & $(0.918854)$ & & $(0.186441)$ & & $(0.413224)$ & \\
\hline & Model 10 & 0.167295 & & -0.064901 & & 0.164057 & & 0.067368 & & -0.038417 & \\
\hline & & $(1.026586)$ & & $(0.489614)$ & & $(0.875329)$ & & $(0.436605)$ & & $(0.559448)$ & \\
\hline \multirow[t]{10}{*}{$\sigma_{I V i d i o, j, t}$} & Model 4 & 0.092252 & $* * *$ & 0.031428 & & 0.072391 & & 0.063008 & $*$ & 0.028611 & $* * *$ \\
\hline & & $(3.364575)$ & & (1.371684) & & (1.515765) & & (1.653411) & & $(2.774291)$ & \\
\hline & Model 5 & 0.071443 & $* *$ & 0.043518 & & 0.020542 & & 0.058335 & & 0.033360 & $* *$ \\
\hline & & $(2.004361)$ & & (1.365192) & & $(0.280438)$ & & $(1.447881)$ & & $(2.193120)$ & \\
\hline & Model 8 & 0.097955 & $* * *$ & -0.024747 & & 0.132163 & & 0.050047 & & 0.060606 & $* * *$ \\
\hline & & $(2.611427)$ & & $(0.725553)$ & & $(1.479110)$ & & (1.223838) & & $(3.512532)$ & \\
\hline & Model 9 & 0.076669 & $* *$ & 0.029488 & & 0.015731 & & 0.062654 & & 0.033826 & $* *$ \\
\hline & & $(2.104879)$ & & $(0.835695)$ & & $(0.176099)$ & & (1.508624) & & $(2.208022)$ & \\
\hline & Model 10 & 0.070042 & $* *$ & 0.030036 & & 0.023665 & & 0.063074 & & 0.031871 & $* *$ \\
\hline & & $(1.981679)$ & & $(0.850128)$ & & $(0.266856)$ & & $(1.519861)$ & & $(2.091446)$ & \\
\hline \multirow[t]{4}{*}{$\sigma_{E G_{i d i o, j, t}}$} & Model 6 & -0.320727 & & 0.784841 & $* * *$ & -0.465614 & & 0.181391 & & -0.071135 & \\
\hline & & (1.418384) & & $(6.435523)$ & & (1.127338) & & $(0.792147)$ & & $(0.893837)$ & \\
\hline & Model 8 & -0.569252 & $* *$ & 0.970069 & $* * *$ & 0.046655 & & 0.078884 & & 0.011766 & \\
\hline & & $(2.103119)$ & & $(7.264281)$ & & $(0.077105)$ & & $(0.338586)$ & & $(0.118279)$ & \\
\hline \multirow[t]{4}{*}{$\sigma_{A R_{i d i o, j, t}}$} & Model 7 & -0.034362 & & -0.207657 & $* * *$ & -0.481546 & $* *$ & 0.215968 & $* *$ & -0.161406 & $* * *$ \\
\hline & & $(0.372221)$ & & $(3.942568)$ & & $(2.540558)$ & & $(2.025949)$ & & $(4.311895)$ & \\
\hline & Model 8 & 0.038674 & & -0.287572 & $* * *$ & -0.658526 & $* *$ & 0.201251 & $*$ & -0.213359 & $* * *$ \\
\hline & & $(0.365240)$ & & $(5.449773)$ & & $(2.556398)$ & & $(1.870263)$ & & $(4.868696)$ & \\
\hline
\end{tabular}

In summary from table 14.1 to 14.8 ), we can find evidences that the best and most efficient idiosyncratic volatility predictor is the implied idiosyncratic volatility which can forecast future stock returns in every phases and periods for Consumer Goods, Healthcare, Services and Technology. Even though realized idiosyncratic volatilities are statistical significances between 1 and 10 percent levels in Services sector, they cannot be employed to forecast future return due to all phases consisted of both positive and negative effects without clear direction. In contrary, the implied idiosyncratic volatility can show much more stable and efficient results with strong statistical significance at 1 percent level in every phases for this Services sector. 
Moreover, $A R(2)$ idiosyncratic volatilities can be used in Model 8 to forecast future stock returns for every phases in Technology sector. Somehow, its predictability cannot be completely summarized, since it works in Model 7 for only Phase 1. In term of the EGARCH volatility forecast, all results from every sectors are unable to present the predictability in every phases and entire period. Eventually, the best idiosyncratic volatility measure for future stock return predictability is concluded to be the implied idiosyncratic volatility, however it cannot work for every sectors except only main sectors, namely Consumer Goods, Healthcare, Services, and Technology. These sectors cover over 65 percent of all stock samples and are majority from entire sectors, hence they affect the integrated outcome from all sectors to summarize that the implied idiosyncratic volatility can predict the best on future stock return with strong statistical significance compared to realized, EGARCH and $A R(2)$ idiosyncratic volatilities. After results concluded from total sectors, when different sectors are separated for further examination, we can find that the implied idiosyncratic volatility is still the best predictability on future stock returns among other idiosyncratic volatilities, whereas implied idiosyncratic volatility works to forecast for only main sectors and cannot cover every sectors. Table 15 from table 15.1 to 15.8 present the short-sales constraint $\left(O R W_{\text {ratio }}\right)$ and liquidity or open-interest $(O I)$ variables divided into eight sectors as the following results. These are also divided into Bear and Bull markets for four sub periods from two financial crises, namely the dotcom bubble and the recent financial crisis between January 2001 and December 2010.

Table 15: The short-sales constraint and liquidity or open-interest variables $\left(O R W_{\text {ratio }}, O I\right)$ Table 15.1: Basic Materials Sector

\begin{tabular}{|c|c|c|c|c|c|c|c|}
\hline Variables & Model & Phase 1 & Phase 2 & Phase 3 & Phase 4 & \multicolumn{2}{|c|}{ Full Periods } \\
\hline \multirow[t]{4}{*}{ ORW $W_{\text {ratio }}$} & Model 9 & -0.000799 & -0.001148 & 0.000187 & -0.000204 & -0.000582 & $*$ \\
\hline & & $(1.462863)$ & $(1.628350)$ & $(0.180776)$ & $(0.328717)$ & $(1.831629)$ & \\
\hline & Model10 & -0.000807 & -0.001111 & 0.000173 & -0.000288 & -0.000618 & $*$ \\
\hline & & $(1.477656)$ & $(1.579351)$ & $(0.167037)$ & $(0.463668)$ & $(1.943502)$ & \\
\hline \multirow[t]{4}{*}{$O I$} & Model 9 & -0.000727 & -0.000383 & 0.001783 & 0.002623 & 0.001886 & $* *$ \\
\hline & & $(0.436420)$ & $(0.454982)$ & $(0.455542)$ & (1.173520) & $(2.495106)$ & \\
\hline & Model10 & -0.001799 & -0.000067 & 0.000136 & -0.000160 & 0.000617 & \\
\hline & & $(1.184230)$ & $(0.093506)$ & $(0.040551)$ & $(0.087375)$ & $(0.964334)$ & \\
\hline
\end{tabular}


Table 15.2: Consumer Goods Sector

\begin{tabular}{|c|c|c|c|c|c|c|c|}
\hline Variables & Model & Phase 1 & & Phase 2 & Phase 3 & Phase 4 & Full Periods \\
\hline \multirow[t]{4}{*}{ ORW $W_{\text {ratio }}$} & Model 9 & 0.000140 & & 0.000161 & 0.000190 & -0.000485 & -0.000099 \\
\hline & & (0.194163) & & $(0.638774)$ & $(0.213446)$ & $(0.550165)$ & $(0.372917)$ \\
\hline & Model10 & 0.000107 & & 0.000167 & 0.000197 & -0.000506 & -0.000103 \\
\hline & & $(0.148978)$ & & $(0.660569)$ & $(0.221489)$ & $(0.575100)$ & $(0.389417)$ \\
\hline \multirow[t]{4}{*}{$O I$} & Model 9 & -0.002995 & $*$ & -0.000467 & -0.002977 & 0.001979 & -0.000276 \\
\hline & & (1.955590) & & $(0.828940)$ & (1.247079) & $(1.237300)$ & $(0.492292)$ \\
\hline & Model10 & -0.003536 & $* *$ & -0.000024 & -0.002694 & 0.001752 & -0.000397 \\
\hline & & $(2.559313)$ & & $(0.047210)$ & $(1.238633)$ & $(1.228292)$ & $(0.787171)$ \\
\hline
\end{tabular}

Table 15.3: Financial Sector

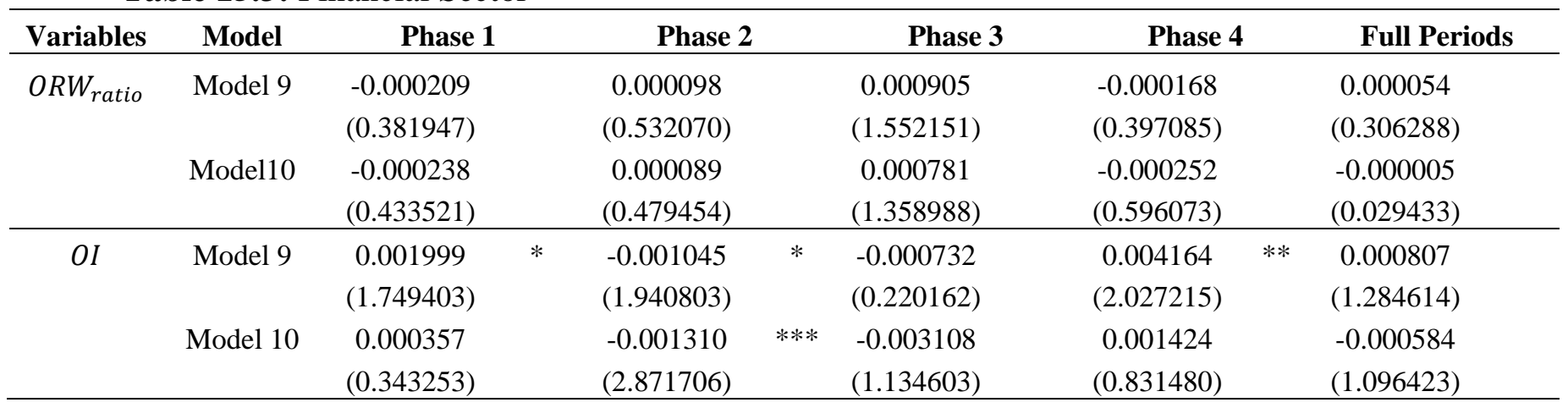

Table 15.4: Healthcare Sector

\begin{tabular}{|c|c|c|c|c|c|c|c|c|c|c|}
\hline Variables & Model & Phase 1 & & Phase 2 & & Phase 3 & Phase 4 & & Full Periods & \\
\hline \multirow[t]{4}{*}{ ORW $W_{\text {ratio }}$} & Model 9 & -0.000276 & & 0.000152 & & -0.001747 & -0.000107 & & -0.000333 & \\
\hline & & $(0.399065)$ & & $(0.271669)$ & & $(0.780927)$ & $(0.089080)$ & & $(0.841140)$ & \\
\hline & Model10 & -0.000250 & & 0.000187 & & -0.001421 & -0.000144 & & -0.000342 & \\
\hline & & $(0.362659)$ & & $(0.332942)$ & & $(0.641094)$ & $(0.122221)$ & & $(0.866830)$ & \\
\hline \multirow[t]{4}{*}{$O I$} & Model 9 & -0.008728 & $* * *$ & -0.003785 & $* * *$ & -0.000338 & -0.003485 & & -0.002285 & $* *$ \\
\hline & & (3.215973) & & $(2.969235)$ & & (0.101374) & (1.582740) & & (2.409307) & \\
\hline & Model 10 & -0.008186 & $* * *$ & -0.002934 & $* * *$ & 0.001684 & -0.003719 & $* *$ & -0.002428 & $* * *$ \\
\hline & & $(3.448453)$ & & $(2.740048)$ & & $(0.610016)$ & $(2.197972)$ & & (3.057437) & \\
\hline
\end{tabular}

Table 15.5: Industrial Goods Sector

\begin{tabular}{|c|c|c|c|c|c|c|c|c|c|}
\hline \multirow{2}{*}{$\begin{array}{l}\text { Variables } \\
R W_{\text {ratio }}\end{array}$} & \multirow{2}{*}{$\frac{\text { Model }}{\text { Model } 9}$} & \multirow{3}{*}{$\begin{array}{r}\text { Phase 1 } \\
-0.000628 \\
(0.859419)\end{array}$} & \multicolumn{2}{|l|}{ Phase 2} & \multirow{3}{*}{$\begin{array}{c}\text { Phase 3 } \\
0.000150 \\
(0.060009)\end{array}$} & \multicolumn{2}{|c|}{ Phase 4} & \multicolumn{2}{|c|}{ Full Periods } \\
\hline & & & -0.000210 & & & -0.004963 & $* *$ & -0.000915 & $*$ \\
\hline & & & $(0.284104)$ & & & $(2.490517)$ & & (1.804034) & \\
\hline & Model10 & -0.000640 & -0.000194 & & 0.000088 & -0.004947 & $* *$ & -0.000923 & $*$ \\
\hline & & $(0.876316)$ & $(0.262930)$ & & $(0.035502)$ & $(2.483457)$ & & $(1.820228)$ & \\
\hline \multirow[t]{4}{*}{$O I$} & Model 9 & 0.001769 & -0.003363 & $* * *$ & 0.000433 & 0.002285 & & 0.000035 & \\
\hline & & $(0.826979)$ & (3.347057) & & $(0.100183)$ & $(0.899324)$ & & $(0.038294)$ & \\
\hline & Model 10 & 0.000871 & -0.002923 & $* * *$ & -0.001591 & 0.001135 & & -0.000958 & \\
\hline & & $(0.519297)$ & $(3.840571)$ & & $(0.520019)$ & $(0.604040)$ & & $(1.430600)$ & \\
\hline
\end{tabular}


Table 15.6: Services Sector

\begin{tabular}{|c|c|c|c|c|c|c|c|c|c|}
\hline \multirow{3}{*}{$\frac{\text { Variables }}{\text { ORW }}$} & \multirow{2}{*}{$\frac{\text { Model }}{\text { Model } 9}$} & \multicolumn{2}{|c|}{ Phase 1} & \multicolumn{2}{|c|}{ Phase 2} & \multirow{3}{*}{$\begin{array}{c}\text { Phase 3 } \\
0.001304 \\
(1.102532)\end{array}$} & \multirow{3}{*}{$\begin{array}{r}\text { Phase } 4 \\
-0.000907 \\
(0.820385)\end{array}$} & \multicolumn{2}{|c|}{ Full Periods } \\
\hline & & -0.002274 & $* * *$ & -0.000620 & * & & & -0.001293 & $* * *$ \\
\hline & & $(3.702016)$ & & $(1.847878)$ & & & & (4.181770) & \\
\hline & Model10 & -0.002335 & $* * *$ & -0.000602 & $*$ & 0.001397 & -0.000907 & -0.001297 & $* * *$ \\
\hline & & $(3.808158)$ & & $(1.797073)$ & & (1.183744) & $(0.820348)$ & $(4.198275)$ & \\
\hline \multirow[t]{4}{*}{$O I$} & Model 9 & 0.000664 & & -0.000863 & & -0.000831 & -0.001171 & -0.000228 & \\
\hline & & $(0.468220)$ & & (1.519381) & & $(0.371563)$ & $(0.732221)$ & $(0.416417)$ & \\
\hline & Model 10 & -0.000288 & & -0.000316 & & 0.000625 & -0.001145 & -0.000323 & \\
\hline & & $(0.229497)$ & & $(0.659771)$ & & $(0.345298)$ & $(0.862479)$ & $(0.701316)$ & \\
\hline
\end{tabular}

Table 15.7: Technology Sector

\begin{tabular}{|c|c|c|c|c|c|c|c|c|c|}
\hline \multirow{2}{*}{$\frac{\text { Variables }}{O R W_{\text {ratio }}}$} & \multirow{2}{*}{$\frac{\text { Model }}{\text { Model } 9}$} & \multirow{2}{*}{$\begin{array}{c}\text { Phase 1 } \\
0.000125 \\
(0.229173)\end{array}$} & \multirow{2}{*}{$\begin{array}{c}\text { Phase 2 } \\
0.000016 \\
(0.081366)\end{array}$} & & \multirow{2}{*}{$\begin{array}{c}\text { Phase } 3 \\
-0.000200 \\
(0.272514)\end{array}$} & \multicolumn{2}{|c|}{ Phase 4} & \multicolumn{2}{|c|}{ Full Periods } \\
\hline & & & & & & $\begin{array}{l}-0.000548 \\
(1.992538)\end{array}$ & $* *$ & $\begin{array}{c}-0.000305 \\
(1.801467)\end{array}$ & $*$ \\
\hline & Model10 & $\begin{array}{c}0.000129 \\
(0.235560) \\
\end{array}$ & $\begin{array}{c}0.000020 \\
(0.100777) \\
\end{array}$ & & $\begin{array}{l}-0.000191 \\
(0.260892) \\
\end{array}$ & $\begin{array}{c}-0.000542 \\
(1.970338)\end{array}$ & $* *$ & $\begin{array}{c}-0.000305 \\
(1.802320) \\
\end{array}$ & $*$ \\
\hline$O I$ & Model 9 & $\begin{array}{l}-0.002849 \\
(1.360812)\end{array}$ & $\begin{array}{l}-0.001328 \\
(2.104907)\end{array}$ & $* *$ & $\begin{array}{l}-0.002991 \\
(1.374569)\end{array}$ & $\begin{array}{c}0.000460 \\
(0.416350)\end{array}$ & & $\begin{array}{l}-0.000734 \\
(1.235196)\end{array}$ & \\
\hline & Model 10 & $\begin{array}{l}-0.002134 \\
(1.165490)\end{array}$ & $\begin{array}{l}-0.000878 \\
(1.568158)\end{array}$ & & $\begin{array}{l}-0.002191 \\
(1.134293)\end{array}$ & $\begin{array}{c}0.000706 \\
(0.717318)\end{array}$ & & $\begin{array}{l}-0.000739 \\
(1.404834)\end{array}$ & \\
\hline
\end{tabular}

Table 15.8: Utilities Sector

\begin{tabular}{|c|c|c|c|c|c|c|}
\hline Variables & Model & Phase 1 & Phase 2 & Phase 3 & Phase 4 & Full Periods \\
\hline \multirow[t]{4}{*}{ ORW $W_{\text {ratio }}$} & Model 9 & 0.000456 & -0.006134 & -0.001077 & 0.001456 & 0.000228 \\
\hline & & $(0.415034)$ & (1.025342) & $(0.104246)$ & $(0.502653)$ & $(0.332049)$ \\
\hline & Model10 & 0.000565 & -0.003011 & -0.000090 & 0.001057 & 0.000290 \\
\hline & & $(0.518552)$ & $(0.524328)$ & $(0.008779)$ & $(0.371764)$ & $(0.423853)$ \\
\hline \multirow[t]{4}{*}{$O I$} & Model 9 & -0.002589 & -0.000438 & -0.000387 & 0.000847 & -0.000126 \\
\hline & & $(0.648504)$ & $(0.355194)$ & $(0.104642)$ & $(0.310551)$ & $(0.104789)$ \\
\hline & Model 10 & -0.001061 & 0.000835 & 0.001430 & -0.000641 & 0.000768 \\
\hline & & $(0.307590)$ & $(0.817019)$ & $(0.492055)$ & $(0.350218)$ & $(0.801718)$ \\
\hline
\end{tabular}

Tables15.1 to 15.8) present following results. After sector and phase classifications, the short-sales constraint $\left(O R W_{\text {ratio }}\right)$ is statistical significant for only a few phases and sectors due to U.S. equity market probably in completed market condition which is mostly without the short-sales constraint. Additionally, there is no statistical significance on future stock return in Phase 1, 2, and 3 for every sectors except Services sector with a negative statistical significance in Phase 1, and 2. In particular, Industrial Goods and Technology sectors is initially found a negative statistically significant effect in Phase 4, since investors anticipate to speculate in more call options, therefore the price of call option leads the price of stock and results lower short-sales constraint. Somehow, the higher stock price is not straightly affected by the short- 
sales constraint, because the tendency of $O R W_{\text {ratio }}$ is gradually decreased as descriptive statistic records. As the result, this outcome is related to the increasing implied idiosyncratic volatility in Phase 4 due to more speculation by investors. In conclusion, the short-sales constraint $\left(O R W_{\text {ratio }}\right)$ is meaningless to predict on future stock return for every sectors.

In relation to the open-interest variable $(O I)$ as a proxy for liquidity we find that Phase 1 and 2 show statistical significances by the open-interest (OI) for Consumer Goods, Financial, and Healthcare sectors and there is no statistical significance in Phase 3 for every sectors. Furthermore, Phase 4 presents statistical significant effects without certain and strong direction for Financial and Healthcare, since they are significance for only Model 9 in Financial and Model 10 in Healthcare. As the result, the open-interest $(O I)$ in Phase 4 is still unable to be obviously concluded for future stock return predictability in Financial and Healthcare. Finally, it is summarized that the liquidity in option market is enough for the U.S. equity market after Phase 3 and 4, consequently the liquidity is not affected to the future stock return from investment after Phase 3 and 4 and the open-interest (OI) should affect to the historical return for only certain sectors. Currently, the U.S. equity option market is enough high liquidity, and investors is under expectation any compensation returns from exposure in subject of option liquidity. Therefore, the open-interest $(O I)$ cannot be employed to predict any more future stock returns.

Table (16) from 16.1 to 16.8 in our analysis present, evidence with regard to firmspecific characteristics variable of $\log S I Z E$ divided into eight sectors as following results. These are separated for four sub periods both Bear and Bull markets through two financial crisis between January 2001 and December 2010. 
Table 16: The cross-section firm-specific characteristics variable in term of $\log S I Z E$ Table 16.1: Basic Materials Sector

\begin{tabular}{|c|c|c|c|c|c|c|c|c|c|}
\hline \multirow{2}{*}{ Variables } & \multirow{2}{*}{$\begin{array}{l}\text { Model } \\
\text { Model } 1\end{array}$} & \multicolumn{2}{|c|}{ Phase 1} & \multirow{3}{*}{$\begin{array}{r}\text { Phase 2 } \\
-0.000085 \\
(0.046972)\end{array}$} & \multirow{3}{*}{$\begin{array}{c}\text { Phase 3 } \\
-0.005009 \\
(0.706720)\end{array}$} & \multicolumn{2}{|c|}{ Phase 4} & \multicolumn{2}{|c|}{ Full Periods } \\
\hline & & -0.010025 & $* * *$ & & & -0.009776 & $* *$ & -0.003214 & $* *$ \\
\hline \multirow{17}{*}{$\log S I Z E$} & & (2.655568) & & & & $(2.313201)$ & & $(2.044201)$ & \\
\hline & Model 2 & -0.009571 & $* *$ & -0.000293 & -0.005076 & -0.009431 & $* *$ & -0.003300 & $* *$ \\
\hline & & $(2.525388)$ & & $(0.160159)$ & $(0.715841)$ & (2.212429) & & (2.070817) & \\
\hline & Model 3 & -0.008696 & $* *$ & 0.000554 & -0.005042 & -0.009469 & $* *$ & -0.004255 & $* * *$ \\
\hline & & $(2.243466)$ & & $(0.298822)$ & $(0.709581)$ & $(2.193948)$ & & $(2.656514)$ & \\
\hline & Model 4 & -0.007419 & $*$ & 0.000430 & -0.004811 & -0.007046 & & -0.003269 & $* *$ \\
\hline & & (1.904983) & & $(0.231424)$ & $(0.676100)$ & (1.642413) & & (2.031790) & \\
\hline & Model 5 & -0.007603 & $*$ & 0.000685 & -0.004805 & -0.007974 & $*$ & -0.003624 & $* *$ \\
\hline & & $(1.949425)$ & & $(0.367955)$ & $(0.674784)$ & $(1.856523)$ & & $(2.260374)$ & \\
\hline & Model 6 & -0.011706 & $* * *$ & 0.001553 & -0.006372 & -0.009428 & $* *$ & -0.004069 & $* *$ \\
\hline & & $(2.956374)$ & & $(0.828313)$ & $(0.893359)$ & (2.180002) & & $(2.507267)$ & \\
\hline & Model 7 & -0.013536 & $* * *$ & 0.001217 & -0.007042 & -0.009469 & $* *$ & -0.004697 & $* * *$ \\
\hline & & $(3.435766)$ & & $(0.646823)$ & $(0.987726)$ & $(2.191393)$ & & $(2.897041)$ & \\
\hline & Model 8 & -0.012715 & $* * *$ & 0.001504 & -0.006923 & -0.008014 & $*$ & -0.004032 & $* *$ \\
\hline & & (3.224819) & & $(0.798169)$ & $(0.968955)$ & (1.861801) & & $(2.482282)$ & \\
\hline & Model 9 & -0.006724 & & 0.001572 & -0.006852 & -0.011419 & $* *$ & -0.005976 & $* * *$ \\
\hline & & $(1.572654)$ & & $(0.713365)$ & $(0.824160)$ & $(2.161862)$ & & (3.150709) & \\
\hline
\end{tabular}

Table 16.2: Consumer Goods Sector

\begin{tabular}{|c|c|c|c|c|c|c|c|c|c|c|}
\hline \multirow[t]{2}{*}{ Variables } & \multirow{2}{*}{$\begin{array}{c}\text { Model } \\
\text { Model } 1\end{array}$} & \multicolumn{2}{|c|}{ Phase 1} & \multicolumn{2}{|l|}{ Phase 2} & \multirow{2}{*}{$\begin{array}{r}\text { Phase 3 } \\
-0.001959\end{array}$} & \multicolumn{2}{|c|}{ Phase 4} & \multicolumn{2}{|c|}{ Full Periods } \\
\hline & & -0.008001 & $* *$ & 0.000580 & & & -0.004732 & $*$ & -0.002494 & $* *$ \\
\hline \multirow{17}{*}{$\log S I Z E$} & & $(2.392376)$ & & (0.529983) & & $(0.463182)$ & (1.792692) & & $(2.311966)$ & \\
\hline & Model 2 & -0.008001 & $* *$ & 0.000622 & & -0.002714 & -0.002140 & & -0.002289 & $* *$ \\
\hline & & $(2.393326)$ & & $(0.564084)$ & & $(0.633027)$ & $(0.774027)$ & & (2.104690) & \\
\hline & Model 3 & -0.006674 & $* *$ & 0.000899 & & -0.002949 & -0.001946 & & -0.002268 & $* *$ \\
\hline & & $(2.026652)$ & & $(0.813847)$ & & $(0.693553)$ & $(0.701957)$ & & (2.078860) & \\
\hline & Model 4 & -0.005975 & $*$ & 0.001870 & $*$ & -0.002471 & 0.000463 & & -0.001021 & \\
\hline & & $(1.792571)$ & & (1.665591) & & $(0.570463)$ & $(0.164294)$ & & $(0.928923)$ & \\
\hline & Model 5 & -0.006061 & $*$ & 0.001847 & & -0.001018 & 0.000615 & & -0.000890 & \\
\hline & & $(1.832876)$ & & (1.644608) & & $(0.237841)$ & $(0.218091)$ & & $(0.810803)$ & \\
\hline & Model 6 & -0.005159 & & 0.000773 & & -0.005292 & -0.000971 & & -0.001222 & \\
\hline & & (1.544007) & & $(0.678683)$ & & (1.178777) & $(0.346040)$ & & (1.087474) & \\
\hline & Model 7 & -0.005773 & $*$ & 0.001249 & & -0.005238 & -0.000580 & & -0.001066 & \\
\hline & & $(1.749649)$ & & (1.091391) & & $(1.196323)$ & $(0.206819)$ & & $(0.960578)$ & \\
\hline & Model 8 & -0.005363 & & 0.001592 & & -0.005204 & 0.001506 & & -0.000338 & \\
\hline & & (1.603232) & & (1.381983) & & $(1.167895)$ & $(0.529206)$ & & $(0.301278)$ & \\
\hline & Model 9 & -0.003006 & & 0.002270 & $*$ & 0.001356 & -0.001003 & & -0.000602 & \\
\hline & & $(0.819049)$ & & $(1.822451)$ & & $(0.288393)$ & $(0.313787)$ & & $(0.492893)$ & \\
\hline
\end{tabular}


Table 16.3: Financial Sector

\begin{tabular}{|c|c|c|c|c|c|c|c|c|c|c|}
\hline Variables & $\frac{\text { Model }}{\text { Model } 1}$ & \multicolumn{2}{|c|}{ Phase 1} & \multicolumn{2}{|c|}{ Phase 2} & \multirow{2}{*}{$\begin{array}{c}\text { Phase 3 } \\
-0.010401 \\
(1.603548)\end{array}$} & \multicolumn{2}{|c|}{ Phase 4} & \multicolumn{2}{|c|}{ Full Periods } \\
\hline \multirow{9}{*}{$\log S I Z E$} & Model 1 & $\begin{array}{l}-0.008705 \\
(3.449893)\end{array}$ & $* * *$ & $\begin{array}{l}-0.002842 \\
(2.440743)\end{array}$ & $* *$ & & $\begin{array}{l}-0.007295 \\
(1.662834)\end{array}$ & $*$ & $\begin{array}{l}-0.004990 \\
(3.680922)\end{array}$ & $* * *$ \\
\hline & Model 2 & $\begin{array}{l}-0.008770 \\
(3.477814)\end{array}$ & $* * *$ & $\begin{array}{l}-0.003207 \\
(2.722833)\end{array}$ & $* * *$ & $\begin{array}{l}-0.008614 \\
(1.332849)\end{array}$ & $\begin{array}{l}-0.009633 \\
(2.187960)\end{array}$ & $* *$ & $\begin{array}{l}-0.006018 \\
(4.413970)\end{array}$ & $* * *$ \\
\hline & Model 3 & $\begin{array}{l}-0.008532 \\
(3.378187)\end{array}$ & $* * *$ & $\begin{array}{l}-0.002638 \\
(2.211196)\end{array}$ & $* *$ & $\begin{array}{l}-0.009608 \\
(1.478296)\end{array}$ & $\begin{array}{l}-0.008690 \\
(1.957707)\end{array}$ & $*$ & $\begin{array}{l}-0.006139 \\
(4.483244)\end{array}$ & $* * *$ \\
\hline & Model 4 & $\begin{array}{l}-0.007486 \\
(2.955677)\end{array}$ & $* * *$ & $\begin{array}{l}-0.002957 \\
(2.450408)\end{array}$ & $* *$ & $\begin{array}{l}-0.008092 \\
(1.242622)\end{array}$ & $\begin{array}{l}-0.007015 \\
(1.578449)\end{array}$ & & $\begin{array}{l}-0.005497 \\
(4.011899)\end{array}$ & $* * *$ \\
\hline & Model 5 & $\begin{array}{l}-0.007486 \\
(2.954683)\end{array}$ & $* * *$ & $\begin{array}{l}-0.002747 \\
(2.274813)\end{array}$ & $* *$ & $\begin{array}{l}-0.008751 \\
(1.348701)\end{array}$ & $\begin{array}{l}-0.007079 \\
(1.594093)\end{array}$ & & $\begin{array}{l}-0.005619 \\
(4.110351)\end{array}$ & $* * *$ \\
\hline & Model 6 & $\begin{array}{l}-0.008505 \\
(3.366419)\end{array}$ & $* * *$ & $\begin{array}{l}-0.002761 \\
(2.289439)\end{array}$ & $* *$ & $\begin{array}{l}-0.007068 \\
(1.089236)\end{array}$ & $\begin{array}{l}-0.006075 \\
(1.338009)\end{array}$ & & $\begin{array}{l}-0.005093 \\
(3.698710)\end{array}$ & $* * *$ \\
\hline & Model 7 & $\begin{array}{l}-0.008552 \\
(3.385782)\end{array}$ & $* * *$ & $\begin{array}{l}-0.002981 \\
(2.457888)\end{array}$ & $* *$ & $\begin{array}{l}-0.009584 \\
(1.473365)\end{array}$ & $\begin{array}{l}-0.006974 \\
(1.557852)\end{array}$ & & $\begin{array}{l}-0.005749 \\
(4.189392)\end{array}$ & $* * *$ \\
\hline & Model 8 & $\begin{array}{l}-0.007410 \\
(2.926092)\end{array}$ & $* * *$ & $\begin{array}{l}-0.002977 \\
(2.440380)\end{array}$ & $* *$ & $\begin{array}{l}-0.006529 \\
(1.006530)\end{array}$ & $\begin{array}{l}-0.005425 \\
(1.197261)\end{array}$ & & $\begin{array}{l}-0.004955 \\
(3.603986)\end{array}$ & $* * *$ \\
\hline & Model 9 & $\begin{array}{l}-0.009521 \\
(3.406590)\end{array}$ & $* * *$ & $\begin{array}{l}-0.001319 \\
(0.920865)\end{array}$ & & $\begin{array}{l}-0.010209 \\
(1.257774)\end{array}$ & $\begin{array}{l}-0.012948 \\
(2.406955)\end{array}$ & $* *$ & $\begin{array}{c}-0.006784 \\
(4.177059)\end{array}$ & $* * *$ \\
\hline
\end{tabular}

Table 16.4: Healthcare Sector

\begin{tabular}{|c|c|c|c|c|c|c|c|c|c|c|}
\hline \multirow{2}{*}{ Variables } & \multirow{2}{*}{$\frac{\text { Model }}{\text { Model } 1}$} & \multicolumn{2}{|l|}{ Phase 1} & \multicolumn{2}{|l|}{ Phase 2} & \multirow{2}{*}{$\begin{array}{c}\text { Phase 3 } \\
0.003652 \\
(0.778242)\end{array}$} & \multicolumn{2}{|c|}{ Phase 4} & \multicolumn{2}{|c|}{ Full Periods } \\
\hline & & $\begin{array}{l}-0.001569 \\
(0.414522)\end{array}$ & & $\begin{array}{l}-0.003338 \\
(1.822326)\end{array}$ & $*$ & & $\begin{array}{c}-0.011014 \\
(4.291586)\end{array}$ & $* * *$ & $\begin{array}{l}-0.003354 \\
(2.498386)\end{array}$ & $* *$ \\
\hline & Model 2 & $\begin{array}{l}-0.006803 \\
(1.483568)\end{array}$ & & $\begin{array}{l}-0.003686 \\
(1.752505)\end{array}$ & $*$ & $\begin{array}{c}0.005654 \\
(1.142131)\end{array}$ & $\begin{array}{l}-0.007882 \\
(2.708496)\end{array}$ & $* * *$ & $\begin{array}{l}-0.004019 \\
(2.622865)\end{array}$ & $* * *$ \\
\hline & Model 3 & $\begin{array}{l}-0.006775 \\
(1.476500)\end{array}$ & & $\begin{array}{l}-0.003782 \\
(1.770089)\end{array}$ & $*$ & $\begin{array}{c}0.002880 \\
(0.575191)\end{array}$ & $\begin{array}{l}-0.007098 \\
(2.307367)\end{array}$ & $* *$ & $\begin{array}{l}-0.004956 \\
(3.174711)\end{array}$ & $* * *$ \\
\hline & Model 4 & $\begin{array}{l}-0.006541 \\
(1.422363)\end{array}$ & & $\begin{array}{l}-0.000850 \\
(0.385791)\end{array}$ & & $\begin{array}{c}0.006561 \\
(1.264198)\end{array}$ & $\begin{array}{c}-0.004913 \\
(1.534291)\end{array}$ & & $\begin{array}{c}-0.002931 \\
(1.826934)\end{array}$ & $*$ \\
\hline \multirow[t]{5}{*}{$\log S I Z E$} & Model 5 & $\begin{array}{l}-0.006303 \\
(1.367117)\end{array}$ & & $\begin{array}{l}-0.000964 \\
(0.437951)\end{array}$ & & $\begin{array}{c}0.005891 \\
(1.147716)\end{array}$ & $\begin{array}{l}-0.005048 \\
(1.565498)\end{array}$ & & $\begin{array}{l}-0.003169 \\
(1.979237)\end{array}$ & $* *$ \\
\hline & Model 6 & $\begin{array}{l}-0.008656 \\
(1.862394)\end{array}$ & $*$ & $\begin{array}{c}0.000612 \\
(0.278788)\end{array}$ & & $\begin{array}{c}0.004259 \\
(0.809196)\end{array}$ & $\begin{array}{c}-0.005427 \\
(1.644870)\end{array}$ & & $\begin{array}{c}-0.002255 \\
(1.389211)\end{array}$ & \\
\hline & Model 7 & $\begin{array}{l}-0.008903 \\
(1.920410)\end{array}$ & $*$ & $\begin{array}{l}-0.001802 \\
(0.824546)\end{array}$ & & $\begin{array}{c}0.003215 \\
(0.606859)\end{array}$ & $\begin{array}{l}-0.007131 \\
(2.183197)\end{array}$ & $* *$ & $\begin{array}{l}-0.003896 \\
(2.415981)\end{array}$ & $* *$ \\
\hline & Model 8 & $\begin{array}{l}-0.008850 \\
(1.903309) \\
\end{array}$ & $*$ & $\begin{array}{c}0.001563 \\
(0.701352) \\
\end{array}$ & & $\begin{array}{c}0.005667 \\
(1.056972) \\
\end{array}$ & $\begin{array}{r}-0.004436 \\
(1.302142) \\
\end{array}$ & & $\begin{array}{r}-0.001557 \\
(0.945567) \\
\end{array}$ & \\
\hline & Model 9 & $\begin{array}{c}0.002183 \\
(0.412914) \\
\end{array}$ & & $\begin{array}{c}0.003224 \\
(1.229895) \\
\end{array}$ & & $\begin{array}{c}0.006771 \\
(1.081565) \\
\end{array}$ & $\begin{array}{r}-0.000712 \\
(0.166284) \\
\end{array}$ & & $\begin{array}{r}-0.000531 \\
(0.276802) \\
\end{array}$ & \\
\hline
\end{tabular}


Table 16.5: Industrial Goods Sector

\begin{tabular}{|c|c|c|c|c|c|c|c|c|c|}
\hline \multirow[t]{2}{*}{ Variables } & \multirow{2}{*}{$\frac{\text { Model }}{\text { Model } 1}$} & \multirow{3}{*}{$\begin{array}{r}\text { Phase 1 } \\
-0.000986 \\
(0.252980)\end{array}$} & \multicolumn{2}{|c|}{ Phase 2} & \multicolumn{2}{|l|}{ Phase 3} & \multirow{3}{*}{$\begin{array}{r}\text { Phase 4 } \\
-0.006245 \\
(1.556925)\end{array}$} & \multicolumn{2}{|c|}{ Full Periods } \\
\hline & & & -0.004689 & $* * *$ & -0.007979 & & & -0.003884 & $* *$ \\
\hline \multirow{17}{*}{$\log S I Z E$} & & & $(2.822065)$ & & (1.299514) & & & $(2.560922)$ & \\
\hline & Model 2 & -0.002622 & -0.005897 & $* * *$ & -0.006364 & & -0.003686 & -0.003903 & $* *$ \\
\hline & & $(0.633645)$ & $(3.311348)$ & & $(0.961020)$ & & $(0.869539)$ & $(2.466056)$ & \\
\hline & Model 3 & -0.000621 & -0.004837 & $* * *$ & -0.010436 & & -0.003572 & -0.004927 & $* * *$ \\
\hline & & $(0.147650)$ & $(2.578656)$ & & $(1.525149)$ & & $(0.814724)$ & $(3.015783)$ & \\
\hline & Model 4 & -0.002345 & -0.003812 & $* *$ & -0.004867 & & -0.000456 & -0.002950 & $*$ \\
\hline & & $(0.555683)$ & $(2.040227)$ & & $(0.685774)$ & & $(0.104474)$ & (1.793363) & \\
\hline & Model 5 & -0.001131 & -0.003863 & $* *$ & -0.005872 & & -0.001624 & -0.003742 & $* *$ \\
\hline & & $(0.267285)$ & $(2.035225)$ & & $(0.835211)$ & & $(0.369842)$ & $(2.269766)$ & \\
\hline & Model 6 & -0.001642 & -0.004769 & $* *$ & -0.012113 & $*$ & -0.003968 & -0.005894 & $* * *$ \\
\hline & & $(0.393702)$ & $(2.497206)$ & & (1.728044) & & $(0.898452)$ & $(3.540766)$ & \\
\hline & Model 7 & -0.002087 & -0.004030 & $* *$ & -0.016438 & $* *$ & -0.003660 & -0.005339 & $* * *$ \\
\hline & & $(0.494127)$ & $(2.119273)$ & & $(2.305043)$ & & $(0.817246)$ & (3.173524) & \\
\hline & Model 8 & -0.001249 & -0.003923 & $* *$ & -0.012131 & $*$ & -0.002113 & -0.004883 & $* * *$ \\
\hline & & $(0.295820)$ & $(2.045907)$ & & $(1.684624)$ & & $(0.472312)$ & $(2.895252)$ & \\
\hline & Model 9 & -0.003662 & 0.001683 & & -0.006607 & & -0.004011 & -0.003635 & \\
\hline & & $(0.676492)$ & $(0.670689)$ & & $(0.662133)$ & & $(0.672603)$ & $(1.627570)$ & \\
\hline
\end{tabular}

Table 16.6: Services Sector

\begin{tabular}{|c|c|c|c|c|c|c|c|c|c|c|c|}
\hline Variables & \multirow{2}{*}{$\frac{\text { Model }}{\text { Model } 1}$} & \multicolumn{2}{|c|}{ Phase 1} & \multicolumn{2}{|l|}{ 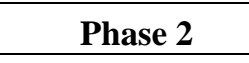 } & \multicolumn{2}{|l|}{ Phase 3} & \multicolumn{2}{|c|}{ Phase 4} & \multicolumn{2}{|c|}{ Full Periods } \\
\hline \multirow{18}{*}{$\log S I Z E$} & & -0.009312 & $* * *$ & -0.001377 & & 0.004072 & & -0.010861 & $* * *$ & -0.003560 & $* * *$ \\
\hline & & $(3.203517)$ & & (1.160417) & & $(1.064062)$ & & $(3.662309)$ & & $(3.224066)$ & \\
\hline & Model 2 & -0.009802 & $* * *$ & -0.001366 & & 0.003770 & & -0.008622 & $* * *$ & -0.003285 & $* * *$ \\
\hline & & $(3.364888)$ & & (1.148037) & & $(0.949095)$ & & $(2.796492)$ & & $(2.954091)$ & \\
\hline & Model 3 & -0.007743 & $* * *$ & -0.000163 & & -0.000909 & & -0.001300 & & -0.002105 & $*$ \\
\hline & & $(2.630355)$ & & (0.133919) & & $(0.224049)$ & & $(0.424517)$ & & (1.855930) & \\
\hline & Model 4 & -0.005433 & $*$ & 0.001094 & & 0.007797 & $*$ & -0.005215 & & -0.001169 & \\
\hline & & (1.791891) & & $(0.876591)$ & & (1.891189) & & (1.634093) & & $(1.013563)$ & \\
\hline & Model 5 & -0.005341 & $*$ & 0.001328 & & 0.004744 & & -0.001693 & & -0.001060 & \\
\hline & & $(1.762483)$ & & (1.059529) & & (1.179653) & & $(0.540731)$ & & $(0.918072)$ & \\
\hline & Model 6 & -0.007938 & $* * *$ & -0.000360 & & -0.002462 & & -0.000435 & & -0.001778 & \\
\hline & & $(2.623340)$ & & $(0.286800)$ & & $(0.586033)$ & & $(0.140207)$ & & $(1.525366)$ & \\
\hline & Model 7 & -0.007792 & $* *$ & 0.000037 & & -0.002860 & & -0.000915 & & -0.001471 & \\
\hline & & $(2.506868)$ & & $(0.029454)$ & & $(0.685198)$ & & $(0.296427)$ & & $(1.265387)$ & \\
\hline & Model 8 & -0.006091 & $*$ & 0.000899 & & 0.000440 & & -0.000937 & & -0.000790 & \\
\hline & & (1.931381) & & $(0.699042)$ & & $(0.107303)$ & & $(0.296558)$ & & $(0.667970)$ & \\
\hline & Model 9 & -0.004973 & & 0.002667 & $*$ & 0.005518 & & 0.000108 & & -0.000434 & \\
\hline & & (1.450897) & & (1.793348) & & $(1.106811)$ & & $(0.028560)$ & & $(0.314638)$ & \\
\hline
\end{tabular}


Table 16.7: Technology Sector

\begin{tabular}{|c|c|c|c|c|c|c|c|}
\hline Variables & Model & Phase 1 & Phase 2 & & Phase 3 & Phase 4 & Full Periods \\
\hline \multirow{18}{*}{$\log S I Z E$} & \multirow[t]{2}{*}{ Model 1} & -0.005185 & -0.002437 & $*$ & -0.001077 & -0.003311 & -0.001912 \\
\hline & & (1.174791) & $(1.769714)$ & & $(0.206042)$ & (1.193493) & $(1.426408)$ \\
\hline & \multirow[t]{2}{*}{ Model 2} & -0.004807 & -0.002439 & $*$ & 0.000720 & -0.001383 & -0.001947 \\
\hline & & (1.087854) & $(1.765953)$ & & $(0.136057)$ & $(0.486357)$ & (1.449067) \\
\hline & \multirow[t]{2}{*}{ Model 3} & -0.000617 & -0.000921 & & 0.000561 & -0.000231 & -0.001655 \\
\hline & & $(0.140012)$ & $(0.659326)$ & & $(0.105902)$ & $(0.081067)$ & (1.219190) \\
\hline & \multirow[t]{2}{*}{ Model 4} & -0.001439 & 0.000793 & & 0.001129 & 0.001719 & -0.000952 \\
\hline & & $(0.325801)$ & $(0.565163)$ & & $(0.213160)$ & $(0.586789)$ & $(0.698622)$ \\
\hline & \multirow[t]{2}{*}{ Model 5} & 0.000251 & 0.000918 & & 0.000895 & 0.001746 & -0.001030 \\
\hline & & $(0.056950)$ & $(0.653052)$ & & $(0.168864)$ & $(0.596490)$ & $(0.754867)$ \\
\hline & \multirow[t]{2}{*}{ Model 6} & -0.002660 & -0.000809 & & 0.001323 & 0.000474 & -0.001861 \\
\hline & & $(0.598840)$ & $(0.570682)$ & & $(0.249767)$ & $(0.166567)$ & $(1.359260)$ \\
\hline & \multirow[t]{2}{*}{ Model 7} & -0.001917 & -0.001062 & & 0.000615 & -0.000212 & -0.001921 \\
\hline & & $(0.433929)$ & $(0.745599)$ & & $(0.115672)$ & $(0.074217)$ & (1.409090) \\
\hline & \multirow[t]{2}{*}{ Model 8} & -0.002428 & 0.000189 & & 0.001078 & 0.002144 & -0.001500 \\
\hline & & $(0.548763)$ & $(0.132414)$ & & $(0.203617)$ & $(0.734771)$ & (1.093367) \\
\hline & \multirow[t]{2}{*}{ Model 9} & 0.003555 & 0.002454 & & 0.004774 & 0.001607 & -0.000024 \\
\hline & & $(0.704504)$ & (1.548393) & & $(0.799077)$ & $(0.487364)$ & $(0.015436)$ \\
\hline
\end{tabular}

Table 16.8: Utilities Sector

\begin{tabular}{|c|c|c|c|c|c|c|c|}
\hline Variables & Model & Phase 1 & Phase 2 & & Phase 3 & Phase 4 & Full Periods \\
\hline \multirow{18}{*}{$\log S I Z E$} & \multirow[t]{2}{*}{ Model 1} & 0.005361 & 0.005974 & & 0.009668 & -0.005478 & 0.003579 \\
\hline & & $(0.483649)$ & (1.557989) & & $(0.999237)$ & $(0.882052)$ & (1.102467) \\
\hline & \multirow[t]{2}{*}{ Model 2} & 0.000400 & 0.006375 & & 0.008274 & -0.005821 & 0.003412 \\
\hline & & $(0.036283)$ & (1.643958) & & $(0.840529)$ & $(0.919763)$ & (1.050393) \\
\hline & \multirow[t]{2}{*}{ Model 3} & 0.002239 & 0.006454 & $*$ & 0.009535 & -0.004690 & 0.004451 \\
\hline & & $(0.204981)$ & (1.662421) & & $(0.971947)$ & $(0.725629)$ & (1.348569) \\
\hline & \multirow[t]{2}{*}{ Model 4} & 0.006686 & 0.006799 & $*$ & 0.007991 & -0.004701 & 0.004989 \\
\hline & & $(0.607123)$ & (1.748533) & & $(0.814619)$ & $(0.740423)$ & $(1.515491)$ \\
\hline & \multirow[t]{2}{*}{ Model 5} & 0.006034 & 0.006856 & $*$ & 0.009221 & -0.004290 & 0.004879 \\
\hline & & $(0.546657)$ & (1.761867) & & $(0.931357)$ & $(0.664205)$ & (1.477137) \\
\hline & \multirow[t]{2}{*}{ Model 6} & 0.003002 & 0.009704 & $* *$ & 0.004671 & -0.004634 & 0.003968 \\
\hline & & $(0.274877)$ & $(2.533487)$ & & $(0.436097)$ & $(0.716650)$ & (1.186392) \\
\hline & \multirow[t]{2}{*}{ Model 7} & 0.002383 & 0.007009 & $*$ & 0.010463 & -0.004783 & 0.004062 \\
\hline & & $(0.217773)$ & (1.818843) & & (1.082528) & $(0.743237)$ & $(1.236473)$ \\
\hline & \multirow[t]{2}{*}{ Model 8} & 0.008633 & 0.011011 & $* * *$ & 0.009269 & -0.004409 & 0.004794 \\
\hline & & $(0.780810)$ & (2.914697) & & $(0.768331)$ & $(0.684378)$ & $(1.442471)$ \\
\hline & \multirow[t]{2}{*}{ Model 9} & 0.009770 & 0.009027 & $*$ & 0.010204 & -0.007282 & 0.005099 \\
\hline & & $(0.760616)$ & $(1.833616)$ & & $(0.797641)$ & $(0.736901)$ & $(1.227376)$ \\
\hline
\end{tabular}

Tables 16.1 to 16.8 report the results. There is an evidence after sector classification that a firm-specific characteristic variable in term of $\log S I Z E$ is not a statistical significance for every sectors in every models and periods. In particular, each model shows a statistical significant 
effect in certain phases between 1 and 10 percent level for only certain sectors. In summary, $\log S I Z E$ cannot be the predictor on future stock returns for every sectors separated.

Table 17 from 17.1 to 17.8 as following results show firm-specific characteristics variable in term of $\log B M$ divided into eight sectors. These are separated for four sub periods both Bear and Bull markets among the dotcom bubble and the recent financial crisis between January 2001 and December 2010.

Table 17: The cross-section firm-specific characteristics variable in term of $\log B M$ Table 17.1: Basic Materials Sector

\begin{tabular}{|c|c|c|c|c|c|c|c|c|c|}
\hline Variables & \multirow{2}{*}{$\frac{\text { Model }}{\text { Model } 1}$} & \multirow{2}{*}{$\begin{array}{r}\text { Phase 1 } \\
-0.005964\end{array}$} & \multicolumn{2}{|c|}{ Phase 2} & \multirow{2}{*}{$\begin{array}{r}\text { Phase 3 } \\
0.000043\end{array}$} & \multicolumn{2}{|l|}{ Phase 4} & \multicolumn{2}{|c|}{ Full Periods } \\
\hline \multirow{20}{*}{$\log B M$} & & & 0.007021 & $* * *$ & & 0.006106 & & 0.005091 & $* * *$ \\
\hline & & (1.641932) & $(3.850770)$ & & $(0.005871)$ & $(1.428373)$ & & (3.150757) & \\
\hline & Model 2 & -0.004359 & 0.006563 & $* * *$ & -0.001289 & 0.004997 & & 0.004879 & $* * *$ \\
\hline & & (1.137488) & $(3.380507)$ & & $(0.170371)$ & (1.080359) & & (2.809195) & \\
\hline & Model 3 & -0.004620 & 0.005716 & $* * *$ & -0.001392 & 0.005048 & & 0.005780 & $* * *$ \\
\hline & & (1.203364) & (2.910107) & & $(0.181628)$ & $(1.071141)$ & & (3.317301) & \\
\hline & Model 4 & -0.004886 & 0.005504 & $* * *$ & -0.001985 & 0.002235 & & 0.004845 & $* * *$ \\
\hline & & $(1.275292)$ & $(2.754607)$ & & $(0.257588)$ & $(0.479299)$ & & $(2.762603)$ & \\
\hline & Model 5 & -0.004783 & 0.005443 & $* * *$ & -0.001906 & 0.003695 & & 0.004950 & $* * *$ \\
\hline & & $(1.247680)$ & $(2.724670)$ & & $(0.247033)$ & $(0.788591)$ & & (2.833949) & \\
\hline & Model 6 & -0.002934 & 0.004891 & $* *$ & -0.000266 & 0.004904 & & 0.005592 & $* * *$ \\
\hline & & $(0.761087)$ & $(2.474516)$ & & $(0.034718)$ & (1.021984) & & (3.173039) & \\
\hline & Model 7 & -0.002520 & 0.005035 & $* *$ & 0.000509 & 0.005048 & & 0.006212 & $* * *$ \\
\hline & & $(0.660320)$ & $(2.527481)$ & & $(0.066368)$ & (1.063384) & & (3.530038) & \\
\hline & Model 8 & -0.002266 & 0.004995 & $* *$ & -0.000126 & 0.003842 & & 0.005318 & $* * *$ \\
\hline & & $(0.594413)$ & $(2.486517)$ & & $(0.016292)$ & $(0.805522)$ & & (3.013778) & \\
\hline & Model 9 & -0.005006 & 0.005585 & $* * *$ & -0.002647 & 0.002456 & & 0.004486 & $* *$ \\
\hline & & $(1.304473)$ & $(2.784416)$ & & $(0.335899)$ & $(0.510948)$ & & (2.551317) & \\
\hline & Model 10 & -0.001754 & 0.004794 & $* * *$ & 0.001252 & 0.008166 & $* *$ & 0.007775 & $* * *$ \\
\hline & & $(0.542270)$ & $(2.868920)$ & & $(0.198719)$ & $(2.030063)$ & & $(5.491956)$ & \\
\hline
\end{tabular}


Table 17.2: Consumer Goods Sector

\begin{tabular}{|c|c|c|c|c|c|c|c|}
\hline \multirow[t]{2}{*}{ Variables } & \multirow{2}{*}{$\frac{\text { Model }}{\text { Model } 1}$} & \multirow{3}{*}{$\begin{array}{c}\text { Phase 1 } \\
0.001106 \\
(0.302599)\end{array}$} & \multirow{3}{*}{$\begin{array}{c}\text { Phase 2 } \\
0.001602 \\
(1.449928)\end{array}$} & \multirow{3}{*}{$\begin{array}{c}\text { Phase 3 } \\
0.000054 \\
(0.012381)\end{array}$} & \multirow{3}{*}{$\begin{array}{c}\text { Phase 4 } \\
0.002659 \\
(1.011683)\end{array}$} & \multicolumn{2}{|c|}{ Full Periods } \\
\hline & & & & & & \multicolumn{2}{|c|}{$0.002109 *$} \\
\hline & & & & & & (1.902630) & \\
\hline & Model 2 & 0.002324 & 0.001511 & 0.001017 & 0.002762 & 0.001789 & \\
\hline & & $(0.618730)$ & $(1.323711)$ & $(0.227270)$ & $(1.053993)$ & $(1.584763)$ & \\
\hline & Model 3 & -0.002675 & 0.000861 & 0.004321 & 0.002118 & 0.001745 & \\
\hline & & $(0.710203)$ & $(0.744406)$ & $(0.953496)$ & $(0.779836)$ & $(1.525108)$ & \\
\hline & Model 4 & -0.000527 & 0.001198 & 0.000892 & 0.001608 & 0.001306 & \\
\hline & & $(0.140220)$ & $(1.052521)$ & $(0.198816)$ & $(0.613595)$ & (1.158506) & \\
\hline \multirow{12}{*}{$\log B M$} & Model 5 & -0.002987 & 0.001003 & 0.005044 & 0.002482 & 0.002165 & $*$ \\
\hline & & $(0.792973)$ & $(0.869647)$ & $(1.117300)$ & $(0.919363)$ & (1.900668) & \\
\hline & Model 6 & -0.002597 & 0.000881 & 0.003452 & 0.002294 & 0.001816 & \\
\hline & & $(0.690997)$ & $(0.761330)$ & $(0.757195)$ & $(0.845522)$ & (1.588723) & \\
\hline & Model 7 & -0.002795 & 0.000749 & 0.004095 & 0.002131 & 0.001601 & \\
\hline & & $(0.744107)$ & $(0.645165)$ & $(0.905569)$ & $(0.787065)$ & $(1.402415)$ & \\
\hline & Model 8 & -0.002914 & 0.000997 & 0.004205 & 0.002469 & 0.001983 & $*$ \\
\hline & & $(0.774134)$ & $(0.859791)$ & $(0.931262)$ & $(0.915131)$ & $(1.740897)$ & \\
\hline & Model 9 & -0.002195 & 0.001026 & 0.005277 & 0.002557 & 0.002195 & $*$ \\
\hline & & $(0.579403)$ & $(0.888783)$ & $(1.166816)$ & $(0.946560)$ & $(1.925188)$ & \\
\hline & Model 10 & 0.000043 & -0.000175 & 0.004466 & 0.002987 & 0.002535 & $* * *$ \\
\hline & & $(0.016483)$ & $(0.184076)$ & (1.262097) & $(1.284708)$ & $(2.789643)$ & \\
\hline
\end{tabular}

Table 17.3: Financial Sector

\begin{tabular}{|c|c|c|c|c|c|c|c|}
\hline Variables & Model & Phase 1 & Phase 2 & Phase 3 & Phase 4 & \multicolumn{2}{|c|}{ Full Periods } \\
\hline \multirow{20}{*}{$\log B M$} & Model 1 & -0.002299 & -0.000586 & 0.004594 & 0.004677 & \multicolumn{2}{|c|}{$0.002188 * *$} \\
\hline & & $(0.957910)$ & $(0.511672)$ & $(0.771239)$ & (1.151527) & $(1.748350)$ & \\
\hline & Model 2 & -0.002078 & -0.000851 & 0.004460 & 0.002750 & 0.000723 & \\
\hline & & $(0.865311)$ & $(0.738689)$ & $(0.754099)$ & $(0.675863)$ & $(0.568033)$ & \\
\hline & Model 3 & -0.002095 & -0.000946 & 0.005732 & 0.001550 & 0.000910 & \\
\hline & & $(0.872675)$ & $(0.821781)$ & $(0.957860)$ & $(0.375132)$ & $(0.706326)$ & \\
\hline & Model 4 & -0.002074 & -0.000874 & 0.003701 & 0.000103 & -0.000072 & \\
\hline & & $(0.867980)$ & $(0.758382)$ & $(0.614460)$ & $(0.024903)$ & $(0.055902)$ & \\
\hline & Model 5 & -0.002071 & -0.000941 & 0.004187 & 0.000565 & 0.000140 & \\
\hline & & $(0.866208)$ & $(0.817336)$ & $(0.697790)$ & $(0.137038)$ & $(0.108312)$ & \\
\hline & Model 6 & -0.002228 & -0.000915 & 0.003467 & 0.001182 & 0.000468 & \\
\hline & & $(0.924535)$ & (0.794190) & $(0.580567)$ & $(0.286439)$ & $(0.363435)$ & \\
\hline & Model 7 & -0.002016 & -0.000872 & 0.005648 & 0.001311 & 0.000703 & \\
\hline & & $(0.839041)$ & $(0.757215)$ & $(0.941596)$ & $(0.317766)$ & $(0.545954)$ & \\
\hline & Model 8 & -0.002072 & -0.000880 & 0.002842 & 0.000460 & -0.000035 & \\
\hline & & $(0.864060)$ & $(0.763177)$ & $(0.474976)$ & $(0.111561)$ & $(0.027043)$ & \\
\hline & Model 9 & -0.002461 & -0.000736 & 0.003684 & -0.000585 & -0.000132 & \\
\hline & & $(1.025415)$ & $(0.636013)$ & $(0.605054)$ & $(0.140414)$ & (0.100859) & \\
\hline & Model 10 & 0.002676 & -0.000163 & 0.007619 & 0.004962 & 0.002971 & $* * *$ \\
\hline & & $(1.427416)$ & $(0.167009)$ & $(1.457861)$ & (1.427894) & $(2.766313)$ & \\
\hline
\end{tabular}


Table 17.4: Healthcare Sector

\begin{tabular}{|c|c|c|c|c|c|c|c|c|}
\hline Variables & \multirow{2}{*}{$\frac{\text { Model }}{\text { Model } 1}$} & \multirow{3}{*}{$\begin{array}{c}\text { Phase 1 } \\
0.001088 \\
(0.286132)\end{array}$} & \multicolumn{2}{|l|}{ Phase 2} & \multirow{3}{*}{$\begin{array}{c}\text { Phase 3 } \\
0.005425 \\
(1.134303)\end{array}$} & \multirow{3}{*}{$\begin{array}{r}\text { Phase 4 } \\
-0.000596 \\
(0.226987)\end{array}$} & \multicolumn{2}{|c|}{ Full Periods } \\
\hline \multirow{20}{*}{$\log B M$} & & & 0.002878 & & & & 0.002578 & $*$ \\
\hline & & & (1.579674) & & & & (1.912662) & \\
\hline & Model 2 & -0.000383 & 0.002870 & & 0.004639 & 0.000666 & 0.002520 & $*$ \\
\hline & & $(0.098911)$ & (1.574673) & & $(0.962468)$ & $(0.248364)$ & $(1.866912)$ & \\
\hline & Model 3 & -0.000144 & 0.002881 & & 0.006561 & 0.000500 & 0.002709 & $* *$ \\
\hline & & $(0.036240)$ & $(1.580252)$ & & $(1.357768)$ & $(0.185963)$ & $(2.006412)$ & \\
\hline & Model 4 & -0.001009 & 0.003519 & $*$ & 0.004445 & 0.000078 & 0.002486 & $*$ \\
\hline & & $(0.255208)$ & (1.929661) & & $(0.919487)$ & $(0.029095)$ & (1.842837) & \\
\hline & Model 5 & -0.000592 & 0.003900 & $* *$ & 0.006574 & 0.000111 & 0.002825 & $* *$ \\
\hline & & $(0.148336)$ & $(2.134792)$ & & (1.366407) & $(0.041090)$ & $(2.096040)$ & \\
\hline & Model 6 & 0.000256 & 0.003841 & $* *$ & 0.006547 & 0.000947 & 0.003135 & $* *$ \\
\hline & & $(0.064644)$ & $(2.122305)$ & & $(1.354530)$ & $(0.349900)$ & $(2.325812)$ & \\
\hline & Model 7 & 0.000258 & 0.003156 & $*$ & 0.006525 & 0.000497 & 0.002773 & $* *$ \\
\hline & & $(0.065254)$ & $(1.734631)$ & & $(1.348138)$ & $(0.184581)$ & (2.054547) & \\
\hline & Model 8 & -0.000515 & 0.004353 & $* *$ & 0.006783 & 0.000737 & 0.003221 & $* *$ \\
\hline & & $(0.129550)$ & $(2.397130)$ & & (1.406098) & $(0.270988)$ & (2.391744) & \\
\hline & Model 9 & -0.003003 & 0.003265 & $*$ & 0.006464 & -0.000561 & 0.002521 & $*$ \\
\hline & & $(0.740473)$ & (1.777429) & & $(1.340712)$ & $(0.205237)$ & $(1.863930)$ & \\
\hline & Model 10 & -0.003871 & 0.002222 & & 0.004017 & -0.000439 & 0.002693 & $* *$ \\
\hline & & $(1.115931)$ & $(1.363505)$ & & $(0.943360)$ & $(0.166892)$ & $(2.240549)$ & \\
\hline
\end{tabular}

Table 17.5: Industrial Goods Sector

\begin{tabular}{|c|c|c|c|c|c|c|c|c|}
\hline Variables & Model & Phase 1 & Phase 2 & & Phase 3 & Phase 4 & Full Period & \\
\hline \multirow{20}{*}{$\log B M$} & \multirow[t]{2}{*}{ Model 1} & 0.004058 & 0.003878 & $* *$ & 0.001595 & 0.004148 & 0.004699 & $* * *$ \\
\hline & & $(0.898218)$ & (2.016383) & & (0.211209) & $(0.905202)$ & $(2.646372)$ & \\
\hline & \multirow[t]{2}{*}{ Model 2} & 0.003185 & 0.003539 & $*$ & 0.001524 & 0.004588 & 0.004695 & $* * *$ \\
\hline & & $(0.695925)$ & (1.833329) & & $(0.201746)$ & (1.000939) & $(2.639767)$ & \\
\hline & \multirow[t]{2}{*}{ Model 3} & 0.000726 & 0.003141 & & 0.003569 & 0.004522 & 0.005171 & $* * *$ \\
\hline & & $(0.155577)$ & (1.617291) & & $(0.470778)$ & $(0.976954)$ & $(2.892764)$ & \\
\hline & \multirow[t]{2}{*}{ Model 4} & 0.002772 & 0.002723 & & 0.000864 & 0.003375 & 0.004237 & $* *$ \\
\hline & & $(0.584934)$ & (1.404107) & & (0.113017) & $(0.736212)$ & $(2.365926)$ & \\
\hline & \multirow[t]{2}{*}{ Model 5} & 0.001619 & 0.002741 & & 0.001785 & 0.004395 & 0.004579 & $* *$ \\
\hline & & $(0.341338)$ & (1.410561) & & $(0.235804)$ & $(0.955117)$ & $(2.561178)$ & \\
\hline & \multirow[t]{2}{*}{ Model 6} & 0.004765 & 0.003111 & & 0.003077 & 0.004867 & 0.005597 & $* * *$ \\
\hline & & (1.010659) & (1.595514) & & $(0.405266)$ & $(1.046074)$ & $(3.123119)$ & \\
\hline & \multirow[t]{2}{*}{ Model 7} & 0.002940 & 0.002628 & & 0.002925 & 0.004550 & 0.005328 & $* * *$ \\
\hline & & $(0.622403)$ & $(1.346855)$ & & $(0.388221)$ & $(0.980598)$ & $(2.969386)$ & \\
\hline & \multirow[t]{2}{*}{ Model 8} & 0.004437 & 0.002607 & & 0.000349 & 0.004709 & 0.005066 & $* * *$ \\
\hline & & $(0.933383)$ & (1.336958) & & $(0.046497)$ & (1.017729) & $(2.828470)$ & \\
\hline & \multirow[t]{2}{*}{ Model 9} & 0.001151 & 0.004115 & $* *$ & 0.001600 & 0.003601 & 0.004638 & $* *$ \\
\hline & & $(0.238568)$ & $(2.076161)$ & & $(0.206094)$ & $(0.765823)$ & $(2.525056)$ & \\
\hline & \multirow[t]{2}{*}{ Model 10} & 0.003120 & 0.003414 & $* *$ & 0.004011 & 0.005258 & 0.006331 & $* * *$ \\
\hline & & $(0.810416)$ & $(2.027495)$ & & $(0.585391)$ & $(1.313137)$ & (4.179903) & \\
\hline
\end{tabular}


Table 17.6: Services Sector

\begin{tabular}{|c|c|c|c|c|c|c|c|c|c|c|}
\hline Variables & Model & \multirow{3}{*}{$\begin{array}{c}\text { Phase 1 } \\
0.001460 \\
(0.473348)\end{array}$} & & \multicolumn{2}{|c|}{ Phase 2} & Phase 3 & \multicolumn{2}{|c|}{ Phase 4} & \multicolumn{2}{|c|}{ Full Periods } \\
\hline \multirow{20}{*}{$\log B M$} & \multirow{2}{*}{ Model 1} & & & 0.004567 & $* * *$ & 0.003408 & 0.008288 & $* *$ & 0.006038 & $* * *$ \\
\hline & & & & (3.398340) & & $(0.797298)$ & (2.450677) & & (4.904467) & \\
\hline & \multirow[t]{2}{*}{ Model 2} & \multirow{2}{*}{\multicolumn{2}{|c|}{$\begin{array}{c}0.001801 \\
(0.583682)\end{array}$}} & 0.004558 & **** & 0.003475 & 0.007722 & $* *$ & 0.005844 & $* * *$ \\
\hline & & & & (3.385988) & & $(0.811397)$ & (2.281273) & & (4.733983) & \\
\hline & \multirow[t]{2}{*}{ Model 3} & \multirow{2}{*}{\multicolumn{2}{|c|}{$\begin{array}{c}0.000996 \\
(0.323328)\end{array}$}} & 0.004334 & $* * *$ & 0.004666 & 0.004387 & & 0.005565 & $* * *$ \\
\hline & & & & $(3.221722)$ & & (1.097166) & (1.327289) & & (4.508628) & \\
\hline & \multirow[t]{2}{*}{ Model 4} & \multirow{2}{*}{\multicolumn{2}{|c|}{$\begin{array}{c}0.002369 \\
(0.770907)\end{array}$}} & 0.004281 & **** & 0.002464 & 0.007259 & $* *$ & 0.005687 & $* * *$ \\
\hline & & & & (3.187930) & & $(0.576508)$ & $(2.149621)$ & & (4.614764) & \\
\hline & \multirow[t]{2}{*}{ Model 5} & \multirow{2}{*}{\multicolumn{2}{|c|}{$\begin{array}{c}0.001789 \\
(0.579862)\end{array}$}} & 0.004210 & $* * *$ & 0.003266 & 0.004390 & & 0.005606 & $* * *$ \\
\hline & & & & (3.135321) & & $(0.786242)$ & $(1.328151)$ & & (4.545688) & \\
\hline & \multirow[t]{2}{*}{ Model 6} & \multirow{2}{*}{\multicolumn{2}{|c|}{$\begin{array}{c}0.000919 \\
(0.297074)\end{array}$}} & 0.004406 & **** & 0.005277 & 0.004184 & & 0.005539 & $* * *$ \\
\hline & & & & $(3.264043)$ & & $(1.235039)$ & (1.265558) & & (4.486975) & \\
\hline & \multirow[t]{2}{*}{ Model 7} & \multirow{2}{*}{\multicolumn{2}{|c|}{$\begin{array}{c}0.000974 \\
(0.312675)\end{array}$}} & 0.004298 & **** & 0.005061 & 0.004331 & & 0.005570 & $* * *$ \\
\hline & & & & (3.192170) & & (1.190167) & $(1.310411)$ & & (4.513518) & \\
\hline & \multirow[t]{2}{*}{ Model 8} & \multirow{2}{*}{\multicolumn{2}{|c|}{$\begin{array}{c}0.001459 \\
(0.468766)\end{array}$}} & 0.004400 & $* * *$ & 0.004367 & 0.004172 & & 0.005625 & $* * *$ \\
\hline & & & & $(3.266586)$ & & $(1.055374)$ & (1.261567) & & (4.560336) & \\
\hline & \multirow[t]{2}{*}{ Model 9} & \multirow{2}{*}{\multicolumn{2}{|c|}{$\begin{array}{c}0.001804 \\
(0.586216)\end{array}$}} & 0.004464 & **** & 0.003275 & 0.004769 & & 0.005688 & $* * *$ \\
\hline & & & & (3.309906) & & $(0.776321)$ & (1.431389) & & (4.585250) & \\
\hline & \multirow[t]{2}{*}{ Model 10} & \multirow{2}{*}{\multicolumn{2}{|c|}{$\begin{array}{c}0.004535 \\
(1.862665)\end{array}$}} & 0.003038 & $* * *$ & 0.000894 & 0.004715 & $*$ & 0.005921 & $* * *$ \\
\hline & & & & (2.788353) & & $(0.246217)$ & (1.721539) & & (5.951187) & \\
\hline
\end{tabular}

Table 17.7: Technology Sector

\begin{tabular}{ccccccccc}
\hline Variables & Model & Phase 1 & Phase 2 & Phase 3 & Phase 4 & \multicolumn{2}{c}{ Full Periods } \\
\hline & Model 1 & 0.005087 & -0.000096 & 0.004840 & 0.005737 & $*$ & 0.004043 & $* * *$ \\
& & $(1.089616)$ & $(0.067086)$ & $(0.874486)$ & $(1.913005)$ & $(2.871974)$ & \\
& Model 2 & 0.006625 & -0.000090 & 0.004148 & 0.005943 & $* *$ & 0.004100 & $* * *$ \\
& $(1.391774)$ & $(0.062043)$ & $(0.749105)$ & $(1.984144)$ & & $(2.894515)$ & \\
& Model 3 & 0.007318 & 0.000415 & 0.004259 & 0.006039 & $* *$ & 0.004133 & $* * *$ \\
& $(1.553795)$ & $(0.287255)$ & $(0.768393)$ & $(2.021207)$ & & $(2.918110)$ & \\
& Model 4 & 0.005261 & -0.000237 & 0.003594 & 0.006802 & $* *$ & 0.004124 & $* * *$ \\
& & $(1.112536)$ & $(0.165340)$ & $(0.647851)$ & $(2.273263)$ & & $(2.913631)$ & \\
$\log B M$ & Model 5 & 0.006410 & -0.000100 & 0.003660 & 0.006664 & $* *$ & 0.004098 & $* * *$ \\
& & $(1.360242)$ & $(0.069705)$ & $(0.659756)$ & $(2.228283)$ & & $(2.895154)$ & \\
& \multirow{2}{*}{ Model 6 } & 0.007153 & 0.000393 & 0.002372 & 0.004714 & & 0.004170 & $* * *$ \\
& $(1.521767)$ & $(0.271869)$ & $(0.424546)$ & $(1.575791)$ & & $(2.943034)$ & \\
& Model 7 & 0.007471 & 0.000424 & 0.004163 & 0.006244 & $* *$ & 0.004242 & $* * *$ \\
& & $(1.589105)$ & $(0.293232)$ & $(0.744978)$ & $(2.079426)$ & & $(2.993349)$ & \\
& Model 8 & 0.005852 & -0.000083 & 0.002454 & 0.005761 & $*$ & 0.004267 & $* * *$ \\
& $(1.247115)$ & $(0.057432)$ & $(0.439142)$ & $(1.916971)$ & & $(3.013152)$ & \\
& Model 9 & 0.006861 & 0.000154 & 0.004822 & 0.006728 & $* *$ & 0.004338 & $* * *$ \\
& $(1.451057)$ & $(0.106733)$ & $(0.860045)$ & $(2.232977)$ & & $(3.046738)$ & \\
& Model 10 & 0.004363 & -0.001471 & 0.001228 & 0.005564 & $* * *$ & 0.004354 & $* * *$ \\
& $(1.394911)$ & $(1.482992)$ & $(0.366903)$ & $(3.032060)$ & & $(4.757644)$ & \\
\hline
\end{tabular}


Table 17.8: Utilities Sector

\begin{tabular}{|c|c|c|c|c|c|c|c|c|c|c|}
\hline \multirow[t]{2}{*}{ Variables } & \multirow{2}{*}{$\begin{array}{l}\text { Model } \\
\text { Model } 1\end{array}$} & \multicolumn{2}{|c|}{ Phase 1} & \multicolumn{2}{|l|}{ Phase 2} & \multirow{3}{*}{$\begin{array}{c}\text { Phase 3 } \\
0.027788 \\
(1.563742)\end{array}$} & \multicolumn{2}{|c|}{ Phase 4} & \multicolumn{2}{|c|}{ Full Periods } \\
\hline & & 0.057469 & $* * *$ & 0.035747 & $* * *$ & & 0.022177 & * & 0.036924 & $* * *$ \\
\hline \multirow{19}{*}{$\log B M$} & & (3.160690) & & $(4.549006)$ & & & $(1.860438)$ & & (6.136159) & \\
\hline & Model 2 & 0.064053 & $* * *$ & 0.035420 & $* * *$ & 0.028854 & 0.023163 & $*$ & 0.038282 & $* * *$ \\
\hline & & (3.555411) & & $(4.498206)$ & & (1.617347) & $(1.867152)$ & & (6.257976) & \\
\hline & Model 3 & 0.049100 & $* * *$ & 0.034196 & $* * *$ & 0.027590 & 0.023196 & $*$ & 0.037186 & $* * *$ \\
\hline & & (2.640906) & & $(4.183153)$ & & (1.554631) & $(1.869152)$ & & $(6.050723)$ & \\
\hline & Model 4 & 0.034095 & * & 0.031303 & $* * *$ & 0.025397 & 0.024970 & $* *$ & 0.034640 & $* * *$ \\
\hline & & (1.717203) & & $(3.716282)$ & & (1.417305) & (2.009866) & & (5.546634) & \\
\hline & Model 5 & 0.034624 & * & 0.031377 & $* * *$ & 0.026843 & 0.024850 & $* *$ & 0.034428 & $* * *$ \\
\hline & & $(1.742670)$ & & $(3.723096)$ & & (1.491906) & (1.997059) & & (5.493778) & \\
\hline & Model 6 & 0.056164 & $* * *$ & 0.022328 & $* * *$ & 0.020459 & 0.023211 & $*$ & 0.037578 & $* * *$ \\
\hline & & (2.922065) & & $(2.721041)$ & & (1.086668) & (1.869329) & & (6.098583) & \\
\hline & Model 7 & 0.050871 & $* * *$ & 0.037698 & $* * *$ & 0.026975 & 0.022923 & $*$ & 0.039403 & $* * *$ \\
\hline & & (2.647556) & & $(4.621309)$ & & (1.543744) & $(1.855168)$ & & $(6.420375)$ & \\
\hline & Model 8 & 0.039797 & $* *$ & 0.025979 & $* * *$ & 0.022661 & 0.024367 & * & 0.035040 & $* * *$ \\
\hline & & (1.977249) & & (3.172194) & & (1.102424) & $(1.962762)$ & & $(5.627731)$ & \\
\hline & Model 9 & 0.033485 & $*$ & 0.031383 & $* * *$ & 0.027378 & 0.022840 & $*$ & 0.034669 & $* * *$ \\
\hline & & (1.677008) & & $(3.594715)$ & & (1.441939) & (1.657774) & & $(5.341350)$ & \\
\hline & Model 10 & 0.028506 & & 0.021809 & $* * *$ & 0.017526 & 0.029142 & $* * *$ & 0.030124 & $* * *$ \\
\hline & & $(1.512124)$ & & $(3.112848)$ & & $(1.216663)$ & (2.699546) & & (5.649904) & \\
\hline
\end{tabular}

The results reported in tables 17.1 to 17.8 , we find after sector classification that a firm-specific characteristic variable in term of $\log B M$ is not a statistical significance for every sectors in every models and periods. In particular, each model shows a statistical significant effect for only certain sectors between 1 and 10 percent level in certain phases. In summary, $\log B M$ cannot be employed to forecast on future stock returns after sector separation as well.

Table (18) from 18.1 to 18.8 present following results regarding Beta $(\beta)$ variable. These are separated into eight sectors in both Bear and Bull markets during four sub periods among the dotcom bubble and the recent financial crisis between January 2001 and December 2010. 
Table 18: Variable in term of Beta $(\beta)$

Table 18.1: Basic Materials Sector

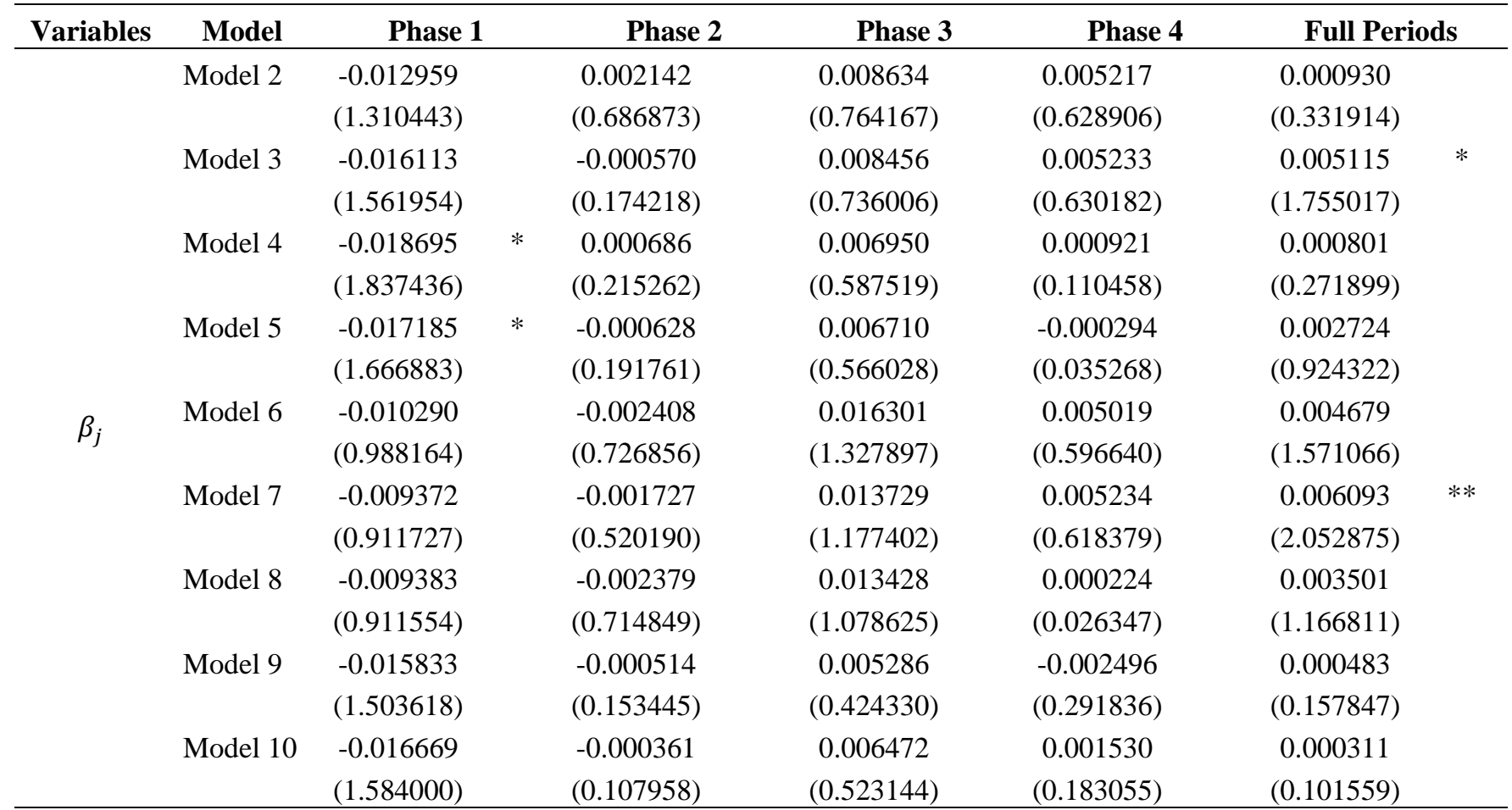

Table 18.2: Consumer Goods Sector

\begin{tabular}{|c|c|c|c|c|c|c|c|c|c|}
\hline Variables & Model & Phase 1 & & Phase 2 & & Phase 3 & Phase 4 & & Full Periods \\
\hline \multirow{18}{*}{$\beta_{j}$} & Model 2 & -0.011568 & & 0.000779 & & -0.010877 & 0.018796 & $* * *$ & 0.003515 \\
\hline & & (1.391597) & & $(0.320617)$ & & (1.063886) & (3.064087) & & (1.494008) \\
\hline & Model 3 & -0.027448 & $* * *$ & -0.001864 & & -0.003853 & 0.016783 & $* *$ & 0.003341 \\
\hline & & (3.228892) & & $(0.730560)$ & & $(0.373071)$ & $(2.572988)$ & & $(1.358761)$ \\
\hline & Model 4 & -0.028848 & $* * *$ & -0.004457 & $*$ & -0.012287 & 0.009604 & & -0.002842 \\
\hline & & $(3.250992)$ & & (1.710572) & & (1.137072) & (1.480996) & & (1.130837) \\
\hline & Model 5 & -0.031873 & $* * *$ & -0.004871 & $*$ & -0.012013 & 0.011308 & $*$ & -0.001786 \\
\hline & & (3.610838) & & (1.847606) & & (1.127744) & $(1.711523)$ & & $(0.709277)$ \\
\hline & Model 6 & -0.029876 & $* * *$ & -0.001623 & & 0.003510 & 0.010366 & & 0.000993 \\
\hline & & (3.498967) & & $(0.622876)$ & & (0.311089) & (1.447999) & & $(0.392245)$ \\
\hline & Model 7 & -0.028847 & $* * *$ & -0.002684 & & 0.007335 & 0.010607 & & 0.000686 \\
\hline & & (3.396702) & & (1.014341) & & $(0.633116)$ & (1.551413) & & $(0.274469)$ \\
\hline & Model 8 & -0.031301 & $* * *$ & -0.004631 & $*$ & 0.004794 & 0.006679 & & -0.002835 \\
\hline & & (3.549772) & & $(1.725541)$ & & $(0.410523)$ & $(0.931664)$ & & (1.107694) \\
\hline & Model 9 & -0.034026 & $* * *$ & -0.004899 & $*$ & -0.010384 & 0.009656 & & -0.001667 \\
\hline & & $(3.826579)$ & & $(1.857543)$ & & $(0.967280)$ & $(1.434723)$ & & $(0.658283)$ \\
\hline & Model 10 & -0.034706 & $* * *$ & -0.005053 & $*$ & -0.010850 & 0.010205 & & -0.001545 \\
\hline & & (3.920593) & & (1.915999) & & $(1.022950)$ & $(1.570842)$ & & $(0.613014)$ \\
\hline
\end{tabular}


Table 18.3: Financial Sector

\begin{tabular}{|c|c|c|c|c|c|c|c|c|c|c|c|}
\hline \multirow{2}{*}{ Variables } & \multirow{2}{*}{$\begin{array}{l}\text { Model } \\
\text { Model } 2\end{array}$} & \multicolumn{2}{|c|}{ Phase 1} & \multicolumn{2}{|c|}{ Phase 2} & \multicolumn{2}{|c|}{ Phase 3} & \multicolumn{2}{|l|}{ Phase 4} & \multicolumn{2}{|c|}{ Full Periods } \\
\hline & & $\begin{array}{l}-0.008906 \\
(1.691529)\end{array}$ & * & $\begin{array}{c}0.004148 \\
(2.014595)\end{array}$ & $* *$ & $\begin{array}{c}0.048165 \\
(3.264023)\end{array}$ & $* * *$ & $\begin{array}{c}0.026187 \\
(3.970505)\end{array}$ & $* * *$ & $\begin{array}{c}0.013548 \\
(5.910003)\end{array}$ & $* * *$ \\
\hline \multirow{8}{*}{$\beta_{j}$} & Model 3 & $\begin{array}{l}-0.011452 \\
(2.067934)\end{array}$ & $* *$ & $\begin{array}{c}0.002093 \\
(0.962622)\end{array}$ & & $\begin{array}{c}0.052332 \\
(3.474923)\end{array}$ & $* * *$ & $\begin{array}{c}0.024050 \\
(3.577562)\end{array}$ & $* * *$ & $\begin{array}{c}0.014223 \\
(5.930046)\end{array}$ & $* * *$ \\
\hline & Model 4 & $\begin{array}{l}-0.019864 \\
(3.303213)\end{array}$ & $* * *$ & $\begin{array}{c}0.003464 \\
(1.589920)\end{array}$ & & $\begin{array}{c}0.045645 \\
(2.996488)\end{array}$ & $* * *$ & $\begin{array}{c}0.020556 \\
(3.044540)\end{array}$ & $* * *$ & $\begin{array}{c}0.010738 \\
(4.432279)\end{array}$ & $* * *$ \\
\hline & Model 5 & $\begin{array}{l}-0.019760 \\
(3.277552)\end{array}$ & $* * *$ & $\begin{array}{c}0.002334 \\
(1.054429)\end{array}$ & & $\begin{array}{c}0.047105 \\
(3.103825)\end{array}$ & $* * *$ & $\begin{array}{c}0.020869 \\
(3.092088)\end{array}$ & $* * *$ & $\begin{array}{c}0.011633 \\
(4.803181)\end{array}$ & $* * *$ \\
\hline & Model 6 & $\begin{array}{l}-0.012624 \\
(2.171334)\end{array}$ & $* *$ & $\begin{array}{c}0.002432 \\
(1.091413)\end{array}$ & & $\begin{array}{c}0.043180 \\
(2.845920)\end{array}$ & $* * *$ & $\begin{array}{c}0.019475 \\
(2.809539)\end{array}$ & $* * *$ & $\begin{array}{c}0.011230 \\
(4.593477)\end{array}$ & $* * *$ \\
\hline & Model 7 & $\begin{array}{l}-0.010862 \\
(1.947784)\end{array}$ & $*$ & $\begin{array}{c}0.002657 \\
(1.205529)\end{array}$ & & $\begin{array}{c}0.052077 \\
(3.447087)\end{array}$ & $* * *$ & $\begin{array}{c}0.019435 \\
(2.802673)\end{array}$ & $* * *$ & $\begin{array}{c}0.012977 \\
(5.359361)\end{array}$ & $* * *$ \\
\hline & Model 8 & $\begin{array}{l}-0.020773 \\
(3.369174)\end{array}$ & $* * *$ & $\begin{array}{c}0.002583 \\
(1.149816)\end{array}$ & & $\begin{array}{c}0.040828 \\
(2.680712)\end{array}$ & $* * *$ & $\begin{array}{c}0.017171 \\
(2.458255)\end{array}$ & $* *$ & $\begin{array}{c}0.009944 \\
(4.051887)\end{array}$ & $* * *$ \\
\hline & Model 9 & $\begin{array}{l}-0.020425 \\
(3.381615)\end{array}$ & $* * *$ & $\begin{array}{c}0.002478 \\
(1.119011)\end{array}$ & & $\begin{array}{c}0.048272 \\
(3.176471)\end{array}$ & $* * *$ & $\begin{array}{c}0.019279 \\
(2.836982)\end{array}$ & $* * *$ & $\begin{array}{c}0.011315 \\
(4.630703)\end{array}$ & $* * *$ \\
\hline & Model 10 & $\begin{array}{l}-0.020842 \\
(3.437134)\end{array}$ & $* * *$ & $\begin{array}{c}0.002123 \\
(0.973417)\end{array}$ & & $\begin{array}{c}0.048603 \\
(3.197370)\end{array}$ & $* * *$ & $\begin{array}{c}0.017898 \\
(2.638470)\end{array}$ & $* * *$ & $\begin{array}{c}0.010568 \\
(4.331488)\end{array}$ & $* * *$ \\
\hline
\end{tabular}

Table 18.4: Healthcare Sector

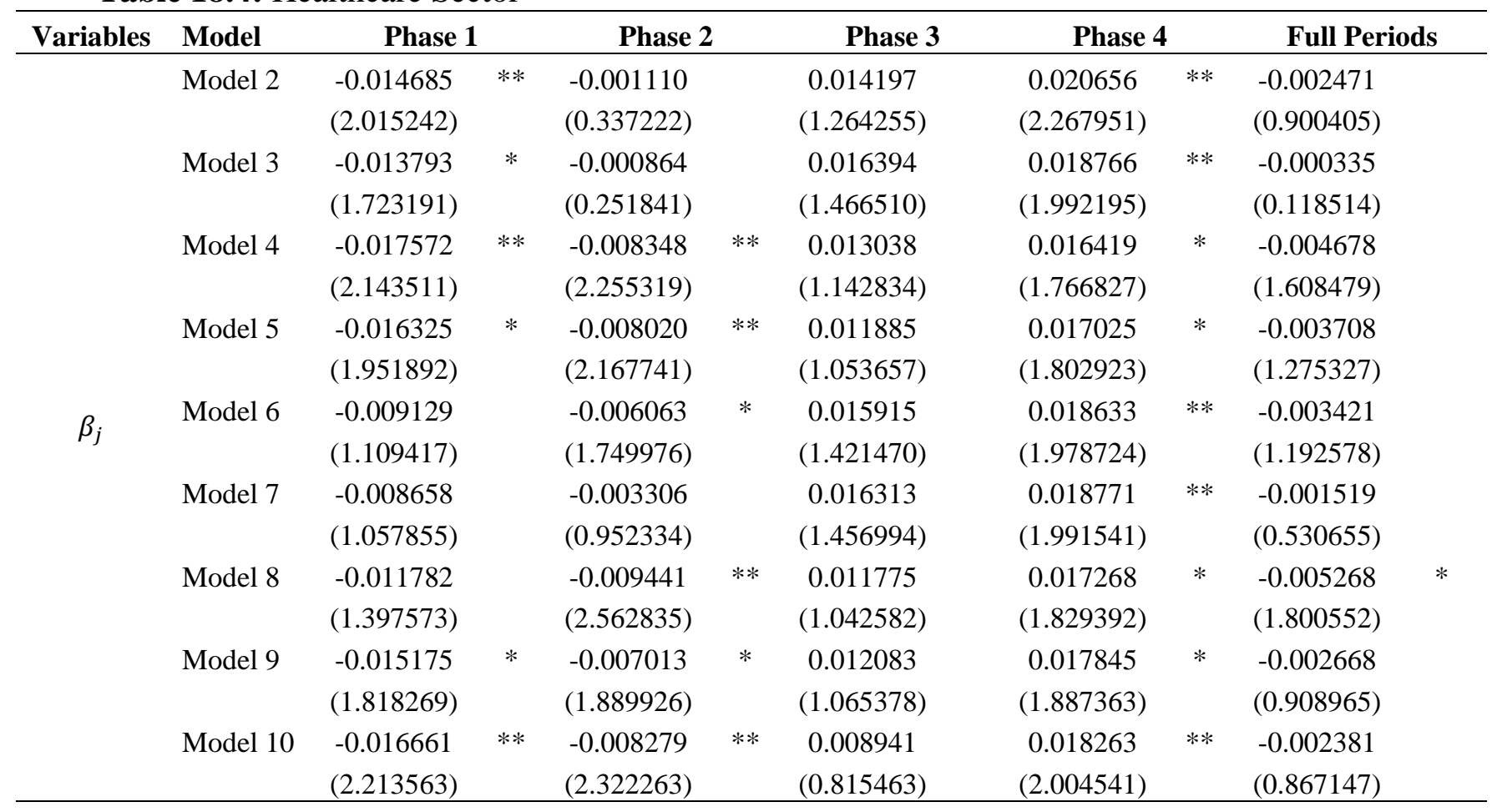


Table 18.5: Industrial Goods Sector

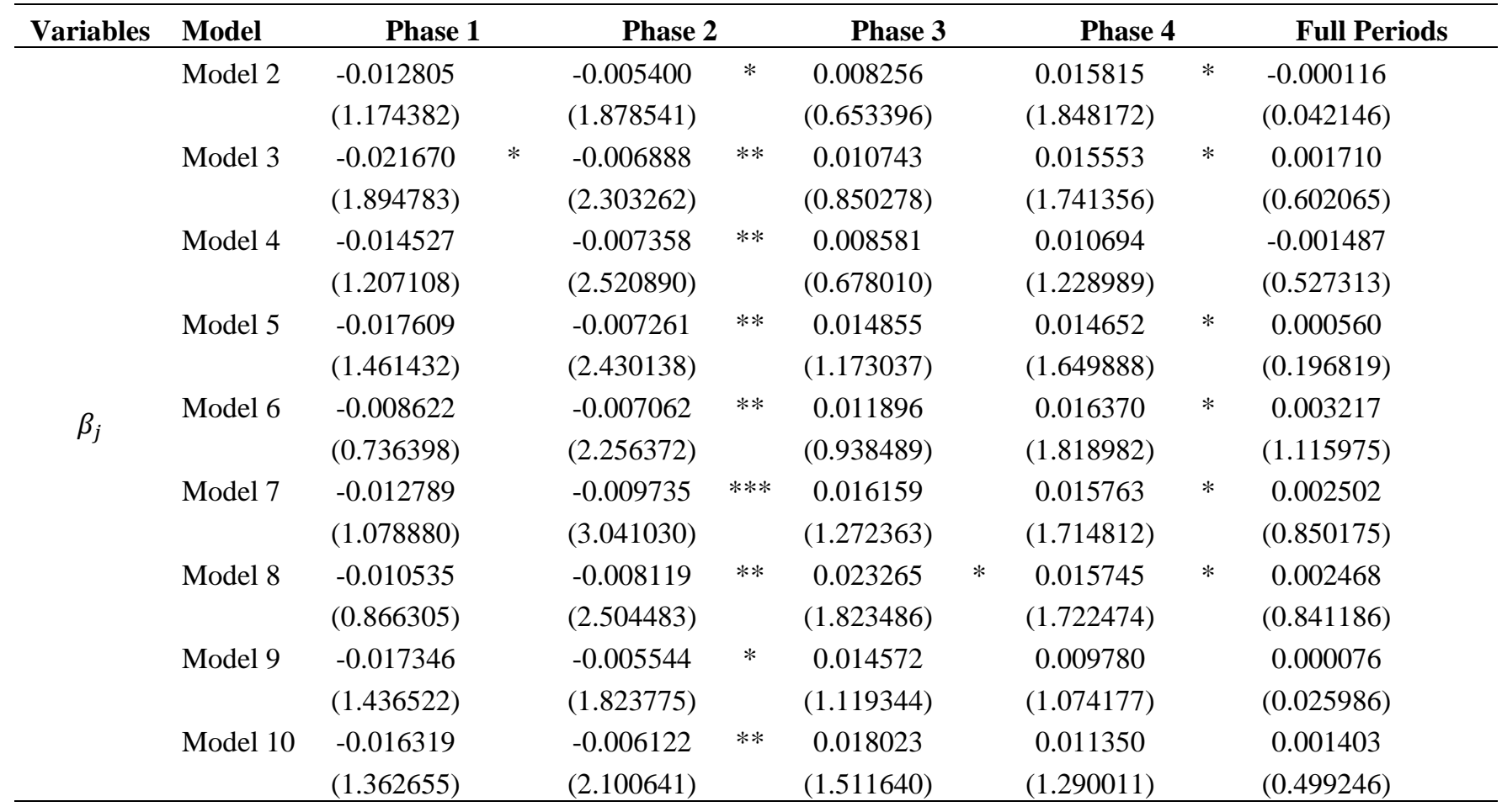

Table 18.6: Services Sector

\begin{tabular}{|c|c|c|c|c|c|c|c|c|c|c|}
\hline \multirow{2}{*}{ Variables } & \multirow{2}{*}{$\frac{\text { Model }}{\text { Model } 2}$} & \multicolumn{2}{|c|}{ Phase 1} & \multicolumn{2}{|l|}{ Phase 2} & \multirow{3}{*}{$\begin{array}{r}\text { Phase } 3 \\
-0.002503 \\
(0.285595)\end{array}$} & \multicolumn{2}{|c|}{ Phase 4} & \multicolumn{2}{|c|}{ Full Periods } \\
\hline & & -0.011424 & $* *$ & 0.000202 & & & 0.012477 & $* * *$ & 0.003560 & $* *$ \\
\hline \multirow{17}{*}{$\beta_{j}$} & & $(2.217122)$ & & $(0.119615)$ & & & (2.620809) & & $(2.075620)$ & \\
\hline & Model 3 & -0.019945 & $* * *$ & -0.001867 & & -0.001499 & -0.000162 & & 0.001534 & \\
\hline & & (3.613767) & & (1.070040) & & $(0.172503)$ & $(0.034028)$ & & $(0.872707)$ & \\
\hline & Model 4 & -0.025236 & $* * *$ & -0.003486 & $* *$ & -0.006350 & 0.007185 & & 0.000191 & \\
\hline & & $(4.315638)$ & & (1.961245) & & $(0.721891)$ & $(1.457213)$ & & $(0.106995)$ & \\
\hline & Model 5 & -0.026638 & $* * *$ & -0.003967 & $* *$ & -0.010932 & 0.000422 & & -0.000038 & \\
\hline & & $(4.526157)$ & & $(2.212474)$ & & $(1.276668)$ & $(0.086997)$ & & $(0.021317)$ & \\
\hline & Model 6 & -0.019922 & $* * *$ & -0.001522 & & 0.002098 & -0.002423 & & 0.001040 & \\
\hline & & (3.608391) & & $(0.834132)$ & & $(0.231776)$ & $(0.489768)$ & & $(0.576285)$ & \\
\hline & Model 7 & -0.019933 & $* * *$ & -0.002167 & & 0.003033 & -0.001312 & & 0.000553 & \\
\hline & & $(3.607309)$ & & $(1.192321)$ & & $(0.337425)$ & $(0.267954)$ & & $(0.306957)$ & \\
\hline & Model 8 & -0.026964 & $* * *$ & -0.003176 & $*$ & -0.000196 & -0.001776 & & -0.000467 & \\
\hline & & $(4.573274)$ & & (1.708606) & & $(0.022222)$ & $(0.353684)$ & & $(0.254977)$ & \\
\hline & Model 9 & -0.026577 & $* * *$ & -0.003579 & $* *$ & -0.010612 & -0.000011 & & -0.000196 & \\
\hline & & (4.519446) & & (1.975164) & & (1.236114) & $(0.002338)$ & & $(0.108207)$ & \\
\hline & Model 10 & -0.026935 & $* * *$ & -0.003707 & $* *$ & -0.012672 & -0.000034 & & -0.000137 & \\
\hline & & $(4.583120)$ & & $(2.047012)$ & & (1.511907) & $(0.006925)$ & & (0.076036) & \\
\hline
\end{tabular}


Table 18.7: Technology Sector

\begin{tabular}{|c|c|c|c|c|c|c|c|c|c|c|}
\hline Variables & \multirow{2}{*}{$\begin{array}{l}\text { Model } \\
\text { Model } 2\end{array}$} & \multicolumn{2}{|l|}{ Phase 1} & \multicolumn{2}{|l|}{ Phase 2} & \multicolumn{2}{|l|}{ Phase 3} & \multicolumn{2}{|l|}{ Phase 4} & \multirow{2}{*}{$\begin{array}{c}\text { Full Periods } \\
-0.000616\end{array}$} \\
\hline \multirow{18}{*}{$\beta_{j}$} & & -0.010489 & & -0.000040 & & 0.017455 & $* *$ & 0.014821 & $* * *$ & \\
\hline & & (1.639287) & & $(0.022967)$ & & $(2.133505)$ & & (2.978384) & & $(0.363948)$ \\
\hline & Model 3 & -0.034228 & $* * *$ & -0.003987 & $* *$ & 0.017933 & $* *$ & 0.006175 & & -0.001064 \\
\hline & & (4.819517) & & $(2.175952)$ & & $(2.178850)$ & & (1.128239) & & $(0.619534)$ \\
\hline & Model 4 & -0.032991 & $* * *$ & -0.005261 & $* * *$ & 0.016445 & $* *$ & 0.008550 & $*$ & -0.001746 \\
\hline & & $(4.517922)$ & & (2.939794) & & $(2.003392)$ & & (1.651201) & & $(1.020270)$ \\
\hline & Model 5 & -0.041021 & $* * *$ & -0.005835 & $* * *$ & 0.017233 & $* *$ & 0.004368 & & -0.001554 \\
\hline & & (5.506028) & & (3.178558) & & $(2.093265)$ & & (0.794389) & & $(0.903439)$ \\
\hline & Model 6 & -0.029635 & $* * *$ & -0.004187 & $* *$ & 0.013100 & & -0.000030 & & -0.000602 \\
\hline & & (4.103677) & & $(2.224988)$ & & $(1.548456)$ & & $(0.005276)$ & & $(0.341487)$ \\
\hline & Model 7 & -0.030100 & $* * *$ & -0.003719 & $*$ & 0.017600 & $* *$ & 0.006957 & & -0.000348 \\
\hline & & (4.177297) & & $(1.950685)$ & & $(2.049523)$ & & $(1.244716)$ & & $(0.198439)$ \\
\hline & Model 8 & -0.036740 & $* * *$ & -0.004265 & $* *$ & 0.015862 & $*$ & 0.000580 & & -0.000146 \\
\hline & & (4.921388) & & $(2.240602)$ & & $(1.850713)$ & & $(0.102111)$ & & $(0.082091)$ \\
\hline & Model 9 & -0.038761 & $* * *$ & -0.004675 & $* *$ & 0.019741 & $* *$ & 0.005801 & & -0.000783 \\
\hline & & (5.073853) & & $(2.439827)$ & & $(2.344616)$ & & (1.036234) & & $(0.437167)$ \\
\hline & Model 10 & -0.038790 & $* * *$ & -0.005063 & $* * *$ & 0.018215 & $* *$ & 0.005324 & & -0.000778 \\
\hline & & $(5.078150)$ & & (2.664889) & & $(2.221619)$ & & $(0.966129)$ & & $(0.440521)$ \\
\hline
\end{tabular}

Table 18.8: Utilities Sector

\begin{tabular}{|c|c|c|c|c|c|c|c|}
\hline Variables & Model & \multicolumn{2}{|l|}{ Phase 1} & Phase 2 & Phase 3 & Phase 4 & Full Periods \\
\hline \multirow{18}{*}{$\beta_{j}$} & \multirow[t]{2}{*}{ Model 2} & -0.045517 & $* * *$ & 0.002021 & -0.011778 & -0.004114 & -0.003895 \\
\hline & & $(3.375642)$ & & $(0.701828)$ & $(0.791935)$ & $(0.291688)$ & $(1.228336)$ \\
\hline & \multirow[t]{2}{*}{ Model 3} & -0.065606 & $* * *$ & 0.001675 & -0.012342 & -0.007062 & -0.004414 \\
\hline & & (4.343308) & & $(0.568355)$ & $(0.834669)$ & $(0.486691)$ & $(1.386812)$ \\
\hline & \multirow[t]{2}{*}{ Model 4} & -0.078291 & $* * *$ & 0.001713 & -0.016776 & -0.016415 & -0.004847 \\
\hline & & $(4.753069)$ & & $(0.593320)$ & (1.105172) & (1.031318) & $(1.522810)$ \\
\hline & \multirow[t]{2}{*}{ Model 5} & -0.079266 & $* * *$ & 0.002064 & -0.013656 & -0.016792 & -0.004820 \\
\hline & & $(4.801050)$ & & $(0.697436)$ & $(0.878242)$ & (1.051399) & $(1.513463)$ \\
\hline & \multirow[t]{2}{*}{ Model 6} & -0.047858 & $* *$ & -0.002340 & -0.003973 & -0.015969 & -0.003745 \\
\hline & & (2.442020) & & $(0.793688)$ & $(0.240296)$ & $(0.869612)$ & (1.145433) \\
\hline & \multirow[t]{2}{*}{ Model 7} & -0.061829 & $* * *$ & 0.004463 & 0.008247 & -0.020227 & -0.000807 \\
\hline & & $(3.394622)$ & & (1.484013) & $(0.494997)$ & (1.276869) & $(0.246412)$ \\
\hline & \multirow[t]{2}{*}{ Model 8} & -0.057085 & $* * *$ & 0.000352 & 0.006523 & -0.031550 & -0.000495 \\
\hline & & $(2.833892)$ & & $(0.116083)$ & $(0.388030)$ & (1.615807) & $(0.150178)$ \\
\hline & \multirow[t]{2}{*}{ Model 9} & -0.078486 & $* * *$ & 0.000928 & -0.013512 & -0.016375 & -0.004646 \\
\hline & & $(4.713114)$ & & $(0.281356)$ & $(0.850182)$ & (1.018584) & (1.408587) \\
\hline & \multirow[t]{2}{*}{ Model 10} & -0.079308 & $* * *$ & 0.000321 & -0.016615 & -0.015367 & -0.005303 \\
\hline & & $(4.775481)$ & & $(0.097613)$ & $(1.079379)$ & $(0.959979)$ & $(1.629267)$ \\
\hline
\end{tabular}

By last tables 18.1 to 18.2 in our analysis, an evidence is found after sector separation that "financials" sector in Model 2 and "Technology" in Model 4 present statistical significant effects for every phases. In "financial" sector, Phase 2 has no statistical significance in other models except only Model 2. Additionally, Phase 1 shows a positive statistical significant 
effect, whereas a negative effect is shown for other phases. As the result, equity beta is not employed to predict future stock return for "Financial" sector due to no certain significant direction. In regard to "Technology" sector, we find that Phase 4 has no statistical significance in other models except only Model 2 and 4. Especially, Model 2 presents no statistical significance in Phase 1 and 2, while Model 4 shows statistical significance at 1 percent level in Phase 1 and 2, 5 percent level in Phase 3 and 1 percent level in Phase 4 which is least. In addition, other models have no relation in Phase 4. In particular, Model 4 has no certain direction both negative statistical significant effect for Phase 1 and 2 and positive statistical significance for Phase 3 and 4. Consequently, equity beta is not eligible to forecast future return for "Technology" sector as well. Moreover, other sectors have no model of Beta with statistical significance for every phases. Eventually, Beta $(\beta)$ cannot be employed to predict future stock return after sector separation.

As a summary of the results from table 14 (14.1 to 14.8 ) to table 18 (table 18.1 to 18.8 ) with sector separation is that the implied idiosyncratic volatility is only measure to predict future stock returns in Consumer Goods, Healthcare, Services, and Technology sectors which are estimated to be over $65 \%$ of all stock samples. Moreover, the positive statistical significant effect is only shown in the implied idiosyncratic volatility, therefore it can affect to be a really stable predictor on future stock return. Other variables, namely short-sales constraint $\left(O R W_{\text {ratio }}\right)$, liquidity or open-interest $(O I)$, Beta $(\beta)$, firm-specific characteristics in term of $\log S I Z E$ and $\log B M$ cannot forecast future stock returns, even though there are certain models with statistical significances due to their uncertain direction both positive and negative effects over different phases. At last, the implied idiosyncratic volatility can predict future stock returns in sectors which are not the weak form of market efficiency such as Consumer Goods, Healthcare, Services, and Technology. Somehow, there is no variable including the implied idiosyncratic volatility in other remaining sectors for future stock return predictability, since efficiency of these sectors should be in weak form level affecting historical stock price, volume and other data to be meaningless to forecast future stock returns. Additionally, previous examinations for whole sectors show that the implied idiosyncratic volatility can forecast future stock returns the best due to most stocks estimated to be over $65 \%$ of samples and no stock group of weak form market efficiency. After sector separation, there is an additional evidence that the implied idiosyncratic volatility cannot forecast future returns for every sectors and effectively affects for only specific sectors which are not weak form market efficiency and 
consisted of Consumer Goods, Healthcare, Services, and Technology.

For all tables from Chow test in table 5 (table 5.1 to 5.8) to all variables examined in four period intervals and ten models in table 18 (table 18.1 to 18.8) after sector separation is that the future stock return predictability is studied in different terms of the idiosyncratic volatilities for all sectors, namely Basic Materials, Consumer Goods, Financial, Healthcare, Industrial Goods, Services, Technology, and Utilities in four sub periods such as Phase 1 between February 2001 and December 2002 (01/02/2001 and 31/12/2002), Phase 2 between January 2003 and December 2007 (01/01/2003 and 31/12/2007), Phase 3 between January 2008 and December 2008 (01/01/2008 and 31/12/2008), and Phase 4 between January 2009 and December 2010 (01/01/2009 and 31/12/2010). Specifically, all period intervals are analyzed in ten models according to Fama-Macbeth future returns estimation regression with firm-specific characteristics. In fact, after completed Chow test performance over breakpoints for whole sectors, it is found that coefficients examined and obtained from the equation of Fama-Macbeth future returns estimation with firm-specific characteristics are not consistent. Therefore, "these breakpoints" can be strongly confirmed to be effective and the sub periods are resulted to be divided into 4 intervals for further studies in all models. Eventually, the summary of study and analysis for all sectors in four intervals from ten models is as following: 1. "The implied idiosyncratic volatility $\left(\sigma_{I V}\right.$ idio $)$ " as Table 14 (table 14.1 to 14.8 ), shows the strong statistical significant effect between 90 and 99 percent for the future stock return predictability in specific sectors of Consumer Goods, Healthcare, Services, and Technology. Indeed, correlations are positive all periods for these sectors. Other remaining sectors present the statistical significant effects are not for every sub periods. 2. "The realized idiosyncratic volatility $\left(\sigma_{R V_{\text {idio }}}\right)$ " as Table 14 (table 14.1 to 14.8 ), illustrates the statistical significance between 90 and 99 percent for only Services sector. In particular, the correlation between the future stock return in a next month and realized idiosyncratic volatility is positive for period intervals such as phase 1 (year 2001-2002), phase 2 (year 2003-2007), and phase 4 (year 20092010) except phase 3 (year 2008) which occurred a recent financial crisis showing a negative statistical significance for the next month future stock return. Consequently, this realized idiosyncratic volatility $\left(\sigma_{R V_{i d i o}}\right)$ is ineligible for forecasting the future stock return in Services sector due to inconsistent correlation for both positive and negative. Meanwhile, other remaining sectors, namely Basic Materials, Consumer Goods, Financial, Healthcare, Industrial Goods, Technology, and Utilities are shown that the realized idiosyncratic volatility 
$\left(\sigma_{R V_{\text {idio }}}\right)$ has the statistical significance for only certain sub periods. At last, it is not eligible to be employed for the future stock return predictability in other remaining sectors as well. 3 . "EGARCH idiosyncratic volatility ( $\left.\sigma_{E G_{\text {idio }}}\right)$ " as Table 14 (table 14.1 to 14.8 ), shows that all sectors have sub periods which present no statistical significance to forecast for the future stock return. As the result, the $E G A R C H$ idiosyncratic volatility $\left(\sigma_{E G \text { idio }}\right)$ is ineligible for the future stock return predictability after sector divided. 4. $A R(2)$ idiosyncratic volatility $\left(\sigma_{A R \text { idio }}\right)$ as Table 14 (table 14.1 to 14.8), is able to forecast the future stock return for Technology sector in all sub periods by Model 8 (Fama-Macbeth future returns estimated regression with firmspecific characteristics except the short-sales constraint;ORW ratio and open-interest; OI variables). On the other hand, Model 7 (Fama-Macbeth future returns estimation regression with firm-specific characteristics except the implied and EGARCH idiosyncratic volatilities $\sigma_{I V_{i d i o}}$, and $\sigma_{E G_{i d i o}}$, the short-sales constraint ;ORW $W_{\text {ratio }}$ and open-interest; OI variables) can be employed to forecast for only Phase 1(Year 2001-2002). As the consequence, it is not clearly concluded that the $A R(2)$ idiosyncratic volatilities $\left(\sigma_{A R}\right.$ idio $)$ can be employed to forecast for Technology sector. More specifically, the $A R(2)$ idiosyncratic volatilities $\left(\sigma_{A R \text { idio }}\right)$ is found that there are sub periods showing no statistical significance to forecast the future stock return for other sectors, namely Basic Materials, Consumer Goods, Financial, Healthcare, Industrial Goods, Services, and Utilities. Finally, $A R(2)$ idiosyncratic volatility $\left(\sigma_{A R \text { idio }}\right)$ is ineligible for the future stock return predictability after sector separation. 5. other variables, such as the shortsales constraint and open-interest variables (ORW $W_{\text {ratio }}$, and $\left.O I\right)$ as Table 15 (table 15.1 to 15.8), cross-section firm-specific characteristics variables in term of $\log S I Z E$ as Table 16 (table 16.1 to 16.8 ), and $\log B M$ as Table 17 (table 17.1 to 17.8 ) including Beta $\left(\beta_{j}\right)$ as Table 18 (table 18.1 to 18.8), cannot forecast the future stock return after sectors divided, even though there are certain models and variables showing statistical significances which are not consistent directions. Indeed, all sub periods present both positive and negative statistical significant effects inconsistently between these variables and the future stock return. Although there are certain statistical significances with unsteady directions, these are ineligible to employ for future stock return predictability.

To be concluded in the end, after sector or industry divide, "the implied idiosyncratic volatility" shows the best stability and significant outcome to forecast the future stock return for all sub periods. In fact, sectors which are not weak form market efficiency such as Consumer Goods, Healthcare, Services, and Technology, present the strongly positive statistical significance between the implied idiosyncratic volatility and future stock return. On 
the contrary, other remaining sectors, which are efficient market in weak form level, namely Basic Materials, Financial, Industrial Goods, and Utilities are found that there is no historical factors and variable including price, volume, the implied idiosyncratic volatility and others to be able for forecasting the future stock return. 


\subsection{Conclusions}

This empirical essay investigates the role of volatility risk on stock returns predictability over the period of Global Financial Crises (included the dot-com bubble and recent financial crisis) with "Industry Specific Effects" during "Different market phases" both Bear and Bull markets from January 2001 to December 2010, for 596 sample stock options traded at the American Stock Exchange and the Chicago Board Options Exchange (CBOE). In fact, industries are classified into eight sectors, namely Basic Materials, Utilities, Industrial Goods, Financial, Consumer Goods, Healthcare, Services, and Technology.

More specifically, to our knowledge, it is the first research analyzing the effect of different idiosyncratic volatility measures and industry effect by stock sector classification for a period that involves both the dotcom bubble and the recent financial crisis with sub period extension. We shed light to the relation between idiosyncratic volatility and stock prices in all different sectors and periods both Bear and Bull markets over two financial crises when S\&P500 drop at least 20 percent.

The findings confirm that after sector separation, the best stock return predictor among different volatility measures used is the implied idiosyncratic volatility which is analogous to previous study before all sectors divided. Although, evidence is not shown its forecast for all sectors, it can effectively affect for most sectors which are not weak form market efficiency such as Consumer Goods, Healthcare, Services, and Technology with estimation to be over 65 percent of stocks examined. Unfortunately, other remaining sectors which are weak form, namely Basic Materials, Utilities, Industrial Goods, and Financial, cannot be predicted by all volatility measures including implied idiosyncratic volatility. Furthermore, there is a clear evidence of a return premium for carrying idiosyncratic volatility risk among different sectors and periods. Indeed, a one percent increase in the implied idiosyncratic volatility increases future returns between 0.01 and 0.08 percent.

Meanwhile, the clear evidence shows that after sector separation, other idiosyncratic volatilities consisted of realized, $E G A R C H$ and $A R(2)$ cannot present any strong evidence about their predictability. We also find that other variables, namely short-sales constraint $\left(O R W_{\text {ratio }}\right)$, liquidity or open-interest $(O I)$, Beta $(\beta)$ firm-specific characteristics in term of $\log S I Z E$ and $\log B M$ cannot certainly affect on future stock returns after sector separation, even though there are certain models with statistical significances due to their uncertain 
directions both positive and negative effects over different market phases.

Overall, we claim that this research provide a significant contribution to the existing evidence on volatility measures, volatility risk and stock return predictability in all terms of different industry effect and market phases both Bear and Bull markets over financial crises. Moreover, this research extend the work of Ang et al. (2006) by including and analyzing firmspecific characteristics and industry effect on Both different market characteristics which are Bear and Bull. 


\section{References}

Alber, N. (2013). Journal of Applied Finance \& Banking. 3(3), 29-43.

Ang, A., Hodrick, R. J., Xing, Y., \& Zhang, X. (2006). "The cross-section of volatility and expected returns". Journal of Finance, 61, 259-299.

Bakshi, G., \& Kapadia, N. (2003). "Delta-Hedged Gains and the Negative Market Volatility Risk Premium". Review of Financial Studies, 16(2), 527-566.

Bali, T. G., \& Cakici, N. (2008). "Idiosyncratic Volatility and the Cross Section of Expected Returns". Journal of Financial and Quantitative Analysis, 43(01), 29.

Bali, T. G., \& Peng, L. (2006, December). "Is There a Risk-Return Tradeoff? Evidence from High-Frequency Data". Journal of Applied Econometrics, 21(8), 1169-1198.

Banerjee, P., Doran, J., \& Peterson, D. (2007). "Implied volatility and future portfolio returns". Journal of Banking and Finance, 31, 3183-3199.

Barberis, N., \& Huang, M. (2001). "Mental Accounting, Loss Aversion, and Individual Stock Returns". The Journal of Finance, 56(4), 1247-1292.

Campbell, J. Y., \& Hentsche, L. (1992). "No news is good news: An asymmetric model of changing volatility in stock returns". Journal of Financial Economics, 31(3), 281-318.

Chow, G. C. (1960). "Tests of Equality Between Sets of Coefficients in Two Linear Regressions". Econometrica, 28(3), 591-605.

Christensen, B., \& Prabhala, N. (1998). "The relation between implied and realized volatility". Journal of Financial Economics, 50(2), 125-150.

Chua, C. T., Goh, J., \& Zhang, Z. (2010). "Expected Volatility, Unexpected Volatility, And The Cross-Section Of Stock Returns". Journal of Financial Research, 33(2), 103-123.

Copeland, M., \& Copeland, T. (1999). "Market timing: Style and size rotation using the VIX" . Financial Analysts Journal, 55, 73-81.

Coval, J. D., \& Shumway, T. (2001). "Expected Option Returns". The Journal of Finance, 56(3), 983-1009.

Dennis, P., Mayhew, S., \& Stivers, C. (2006). "Stock Returns, Implied Volatility Innovations, and the Asymmetric Volatility Phenomenon". Journal of Financial and Quantitative Analysis, 41(02), 381-406.

Doran, J. S., \& Ronn, E. I. (2006). "The bias in Black-Scholes/Black implied volatility: An analysis of equity and energy markets". Review of Derivatives Research, 8(3), 177-198.

Eleswarapu, V., \& Ashish, T. (1996). "Business cycles and stock market returns: Evidence using industry-based portfolios". Journal of Financial Research, 19, 121- 134.

Fama, E. F., \& French, K. R. (1993). "Common risk factors in the returns on stocks and bonds". Journal of Financial Economics, 33(1), 3-56.

Fama, E. F., \& Macbeth, J. D. (1973). "Risk, Return, and Equilibrium: Empirical Tests". Journal of Political Economy, 81(3), 607-636.

$\mathrm{Fu}, \mathrm{F}$. (2009). "Idiosyncratic risk and the cross-section of expected stock returns". Journal of Financial Economics, 9(1), 24-37.

Giot, P. (2005). "Relationships Between Implied Volatility Indexes and Stock Index Returns". The Journal of Portfolio Management, 31(3), 92-100.

Glosten, L. R., Jagannathan, R., \& Runkle, D. E. (1993). "On the Relation between the Expected Value and the Volatility of the Nominal Excess Return on Stocks". The Journal of Finance, 48(5), 1779-1801.

Goyal, A., \& Santa-Clara, P. (2003). "Idiosyncratic Risk Matters!". The Journal of Finance, 58(3), 975-1007.

Hentschel, L. (2003). "Errors in Implied Volatility Estimation". The Journal of Financial and Quantitative Analysis, 38(4), 779-810.

Hong, H., Torous, W., \& Valkanov, R. (2007, February). "Do Industries Lead Stock Markets?". Journal of Financial Economics, 83(2), 367-396. 
Jegadeesh, N., \& Titman, S. (1993). "Returns to Buying Winners and Selling Losers: Implications for Stock Market Efficiency". The Journal of Finance, 48(1), 65-91.

Jones, C. M., \& Rhodes-Kropf, M. (2003). "The Price of Diversifiable Risk in Venture Capital and Private Equity". SSRN Journal, Working paper, Columbia University.

Mateus, C., \& Konsilp, W. (2014). Implied Idiosyncratic Volatility and Stock Return Predictability. JMF Journal of Mathematical Finance, 04(05), 338-352.

Menzly, L., \& Oguzhan , O. (2004). "Cross-industry momentum". USC Working Paper.

Merton, R. C. (1973). An Intertemporal Capital Asset Pricing Model. Econometrica, 41(5), 867.

Ofek, E., Richardson, M., \& Whitelaw, R. F. (2004). "Limited arbitrage and short sales restrictions: evidence from the options markets". Journal of Financial Economics, 74(2), 305-342.

Pan, J., \& Poteshman, A. (2004). The Information in Option Volume for Future Stock Prices. MIT Working Paper.

Pástor, L., \& Stambaugh, R. F. (2003). "Liquidity Risk and Expected Stock Returns". Journal of Political Economy, 111(3), 642-685.

Pollet, J. (2002). "Predicting asset returns with expected oil price changes". Harvard University Working Paper.

Poon, S.-H., \& Granger, C. W. (2003). "Forecasting volatility in financial markets: A review". Journal of Economic Literature, 41(2), 478-539.

$\mathrm{Xu}$, Y., \& Malkiel, B. G. (2006). "Idiosyncratic Risk and Security Returns". SSRN Journal,Working paper,University of Texas at Dallas.

Zhang, J. E., Shu, J., \& Brenner, M. (2010). "The new market for volatility trading". Journal of Futures Markets, 30(9), 809-833. 


\title{
Chapter 5: Volatility Risk and Earnings Announcement Surprises
}

\begin{abstract}
This paper aims to analyze whether implied idiosyncratic volatility contains information about earnings announcement surprises. It contributes to the literature of earnings announcement surprises affected by implied idiosyncratic volatility of option prices. Our empirical results are obtained from a broad sample of stock options traded at the American Stock Exchange and the Chicago Board Options Exchange (CBOE), from January 2001 to December 2010. We find evidence that implied volatility should contain information about future earnings. There is a clear and robust empirical evidence that earnings announcement surprises are imbedded in option prices via implied idiosyncratic volatility prior to the announcement. Indeed, the implied idiosyncratic volatility at the end of month can forecast Standardized Unexpected Earnings (SUE) in the stock group of earning announcement date from $11^{\text {th }}$ till end of next month.
\end{abstract}

Keywords: Options, Risk Premium, stock, volatility, Standardized Unexpected Earnings JEL Classification: G10; G12; C53 


\subsubsection{Background}

Earnings surprises occur when company reports actual earnings that differ from consensus earnings estimates (American Association of Individual Investors, 2008). Public listed companies in U.S. are required to file quarterly reports with the Securities and Exchange Commission (SEC) within 40 days of the fiscal quarter end. Most companies announce earnings within one month after the end of the quarter (Livnat and Zhang, 2015) and the fiscal periods for most companies coincide with the calendar quarters (May, 1971 and Penman, 1987). Institutional investors and analysts work at a frenzied pace for about three weeks starting mid-month in January, April, July, and October as major companies report their earnings from the previous quarter. During the earnings reporting season, financial newspapers and websites provide daily reports on earnings announcements. Firms with significant earnings surprises are often highlighted.

Specifically, earnings surprises are either positive or negative: "Positive earnings surprises" occur when actual reported earnings are significantly above the forecasted earnings per share. Meanwhile, "Negative earnings surprises" occur when reported earnings per share are significantly below the earnings expectations. Indeed, the impact on stock prices is that price changes resulting from an earnings surprise can be felt immediately. Studies, namely Abraham and Harrington (2016) indicates that the stock prices of firms with significant positive earnings surprises show above-average performance, while those with negative surprises have below-average performance (Smart and Waldfogel, 1994). Although the surprise has an immediate impact on the stock's price, it may also have a long-term effect. In fact, studies found that the can persist for as long as a year after the announcement (Hee, 2008). That means it may not be too late to buy a stock that has had a positive earnings surprise, even though investors cannot act right at the time of the initial surprise. However, it also means that it does not make sense to buy a stock after the initial price decline of a negative earnings surprise, since there is a good chance that the stock will continue to underperform the market for some time. Not surprisingly, large firms tend to adjust to surprises faster than small firms (Ayers and Freeman, 2000)That's because larger firms are tracked by more analysts and portfolio managers, who tend to act quickly. Additionally, earnings surprises tend to follow the cockroach effect like cockroaches, investors rarely see just one earnings surprise. Lewellen, Kothari and Warner (2003), report that firms with a significant earnings surprise in one quarter will also often have earnings surprises in subsequent quarters. Since both positive and negative earnings surprises have lingering long-term effects, a rewarding investment tactic would be to avoid stocks investors believe will have negative earnings surprises or those that have had 
negative earnings surprises. Similarly, selecting positive earnings surprise stocks before and even after the earnings come in may be profitable.

Previous empirical work reveal that the implied idiosyncratic volatility is the best stock predictor among the different volatility measures (Kambouroudis, McMillan and Tsakou, 2016, Konsilp and Mateus, 2014 and Charles, ng and Swaminathan, 2008) leading to the idea that implied idiosyncratic volatility might also contain information about future earnings. Cao and Narayanamoorthy (2012) and Chung and Hrazdil (2011) show that post-earnings announcement drift (PEAD) ${ }^{26}$, and PEAD appears to be an enduring feature of stock returns ${ }^{27}$ and firms with lower earnings volatility have higher abnormal returns. However, the existing literature seems to be more concerned with the differences in stock returns between option and non-option firms, rather than the differences in returns to various option based strategies formed around earnings announcements. In particular, (Jennings and Laura , 1986) examine the stock price adjustment to the release of quarterly earnings using samples of firms with and without listed options. They find the two samples exhibit different adjustment processes, with the non-option firms requiring substantially more time to adjust. Their findings are consistent with the hypothesis that the common stock of firms with exchange listed options is associated with a different price adjustment process than that of non-option firms. Jennings and Laura (1986) results support the argument that option markets are useful in disseminating earnings news. .Easley, O'Hara, \& Srinivas (1998) investigate the informational role of transactions volume in options markets by developing and testing an asymmetric information model in which informed traders may trade in option or equity markets. Their main empirical results are that negative and positive option volumes contain information about future stock prices. In particular, they find that certain option volumes lead stock price changes, thus supporting the notion that options markets are an important venue for information based trading. Additionally, Diavatopoulos, Doran, and Peterson (2011) and Diavatopoulos D. , Doran, Fodor, and Peterson (2012) find a positive relation between implied volatility in stock option and expected returns, somehow their results show the limited support about correlation between implied volatility skew and unexpected future earnings. Overall, previous studies are more concerned about the earnings announcement itself, rather than the effect on the options market. For instance, Savor and Wilson (2016) test and find that the announcement premium is persistence across stocks, and early (late) announcers earn higher (lower) returns and no announcers' response to

\footnotetext{
${ }^{26}$ Post-earnings-announcement drift is the tendency for a stock's price to drift in the direction of an earnings surprise following an earnings announcement.

${ }^{27}$ See Foster, Olsen, Shevlin (1984), Bernard and Thomas (1989, 1990), and Freeman and Tse (1989).
} 
announcements is consistent with their systematic risk model, both over time and across firms. Chai and Tung (2002) also find that the magnitude of income-reducing abnormal accruals is related to the earnings announcement reporting lag. But a delay reaction to a surprise in the earnings announcement is an inefficiency in the market. One of encouragements for this research study is lighted up from findings from Konsilp and Mateus (2014) that option listing and subsequent trading do increase available information, consequently implied volatility might also contain information about future earnings. Specifically, this research investigates how the options price via the implied idiosyncratic volatility can anticipate unexpected earnings.

The purpose of this paper is the examination whether information about earnings announcement surprises is imbedded in option prices through implied idiosyncratic volatility prior to the announcement over a period that involves two global financial crises. We examine the role of volatility risk in the term of earnings announcement surprises imbedded in option prices (via implied idiosyncratic volatility) prior to the announcement.

We aim to contribute to contribute to the existing literature and previous research on volatility risk, future earnings contained in implied volatility, earnings per share (EPS) announcement surprises and predictability. First, to our knowledge, it is the first research analyzing the effect of the implied idiosyncratic volatility which can predict earnings per share (EPS) announcement surprises for a period that involves both the dotcom bubble and the recent financial crisis from January 2001 to December 2010. This will shed light to the relation between the implied idiosyncratic volatility and EPS announcement surprises in term of Standardized Unexpected Earnings (SUE) in periods when S\&P500 drop at least 20 percent. Second, the empirical findings will disclose more information on the best period of earning announcement date to be implemented by the result of implied idiosyncratic volatility predictability.

Our results show that, first a strong statistically significant evidence of implied idiosyncratic volatility on earnings per share (EPS) announcement surprises predictability. Second, the earnings announcements from the $11^{\text {th }}$ to the end of the month indicates the highest impact and predictability of implied idiosyncratic volatility on Standardized Unexpected Earnings (SUE). Therefore, our study provides a clear evidence of earnings announcement surprises carried by the idiosyncratic volatility risk.

The rest of the paper is organised as follows. The next section presents data sources, sample selection and methodology implemented. In Section 3, it is presented a brief overview 
of summary statistics for the variables used in this study followed by statistics of implied idiosyncratic volatility and standardized unexpected earnings whether are in different monthly period of earnings announcement. We finish by presenting correlations, equal mean and median analysis. Section 4 concludes the study. 


\subsection{Data and methodology}

\subsubsection{Sample}

Our sample represents the U.S. equity option market by comprising the stock options traded at the American Stock Exchange and the Chicago Board Options Exchange (CBOE) for the period from January 2001 to December 2010. The data to undertake the research was collected from different sources. 1) The daily implied volatility for each individual company and the option open interest were collected from Tick Data and OptionMetrics; 2) Stock returns, share prices, and the number of shares outstanding are from Tick Data and CRSP and equity book value are from Tick Data and Compustat; 3) daily returns for the the Carhart (1997) momentum factor (UMD) and three Fama and French (1993) factors (MKT, SMB, HML) were collected from Kenneth French's website, and, 4) actual quarterly earnings per share (EPS), EPS announcement dates, and quarterly consensus EPS forecasts ${ }^{28}$ are collected from the I/B/E/S database. More specifically, the monthly consensus forecast contains analysts' EPS forecasts up to the Thursday before the third Friday of every month. For each quarter, the monthly consensus forecast is used from the month closest to the earnings announcement date. For example, if the earnings announcement comes before the third Thursday of the month, then we use the monthly consensus forecast from the prior month. Indeed, the summary history file consists of a complete update of I/B/E/S historical data which includes the latest month's data and historical data adjusted for corporate actions and corrections, such as stock splits.

From CRSP the full data comprises 2,596 Tickers (or unique firms) for the period January 2001 to December 2010. We impose the following sample selection criteria: 1) Full information (daily basis) for trade options, 2) Daily stock returns for at least the five previous years. ${ }^{29}$ In order to confirm whether our sample represents the U.S. market as a whole, the sample average daily return was computed and the correlation between this average and the market return was calculated. The result shows a $90 \%$ of correlation which means that the data can represent the U.S. market as a whole ${ }^{30}$

Table 1 reports the initial number of firms per industry available in CRSP for the period January 2001 and December 2010 and the number of sampling firms after the previous presented selection criteria.

Table 1.1: Number of firms per industry

\begin{tabular}{cccc}
\hline Industry & Full Sample & Number unique & Sample/Full Data \\
\hline
\end{tabular}

\footnotetext{
${ }^{28}$ The consensus forecast is the average of analysts' EPS forecasts immediately prior to the earnings announcement and is contained in the $\mathrm{I} / \mathrm{B} / \mathrm{E} / \mathrm{S}$ summary history file.

${ }^{29}$ This condition is essential for the calculation of idiosyncratic realized, implied volatility and the firm's beta.

${ }^{30}$ Results are available upon request.
} 


\begin{tabular}{|c|c|c|c|}
\hline & & Firms & $(\%)$ \\
\hline Basic Materials & 275 & 62 & 22.5 \\
\hline Consumer Goods & 268 & 64 & 23.9 \\
\hline Financials & 352 & 79 & 22.4 \\
\hline Healthcare & 270 & 63 & 23.3 \\
\hline Industrial Goods & 216 & 50 & 23.1 \\
\hline Services & 520 & 117 & 22.5 \\
\hline Technology & 603 & 141 & 23.4 \\
\hline Utilities & 92 & 20 & 21.7 \\
\hline Total & 2,596 & 596 & 22.9 \\
\hline
\end{tabular}

Overall there are 596 unique firms in our sample which represents 22.9 percent of full data available in CRSP. There is no evidence of a single industry to be more represented in the sample. In fact, the percentage of unique firms per industry presented in the sample is very similar with values between 21.7 and 23.9 percent for Utilities and Consumer Goods, respectively.

\subsubsection{Implied idiosyncratic volatility}

Individual company monthly implied volatility, which is collected at-the money options from January 2001 through December 2010, are available from OptionMetrics ${ }^{31}$. For each firm, implied volatilities are calculated by OptionMetrics using American or European models where appropriate. A standardized implied volatility is calculated by employing the most weight on implied volatilities with at-the-money options. Indeed, our analysis divides into three groups of the earning announcement date period, namely: earning announcement date from the $1^{\text {st }}$ to $10^{\text {th }}$ of the month, from $11^{\text {th }}$ to $20^{\text {th }}$ of the month and from $21^{\text {st }}$ of month until the end of the month. More specifically, the main concern for dividing in three different time periods is due to anticipation that at 30 trading days prior to the earnings announcement information is not yet in stock prices. Somehow, we consider the 'transition' periods of 20 and 10 days prior to the announcement date because earnings information may not be priced into options 30 days before the announcement. Additionally, less 10 days before, earnings information may already be priced into both stock and option prices.

\footnotetext{
${ }^{31}$ OptionMetrics is a financial research and consulting firm specializing in econometric analysis of the options markets.
} 


\subsubsection{Earning Announcements and Standardized Unexpected Earnings}

The data used in this part is from different sources summarized in table 2. Table 1.2 reports the number of event observations per year and announcement date. Overall, there are 3,537 event observations for earnings announcement from the $1^{\text {st }}$ to $10^{\text {th }}$ of the month, 5,346 from $11^{\text {th }}$ to $20^{\text {th }}$ and 8,898 from the $21^{\text {st }}$ until the end of the month.

Table 1.2: Earnings announcements monthly period, year and industry

\begin{tabular}{|c|c|c|c|c|c|c|c|c|c|c|c|}
\hline Period & Total & 2001 & 2002 & 2003 & 2004 & 2005 & 2006 & 2007 & 2008 & 2009 & 2010 \\
\hline $1^{\text {st }}$ to $10^{\text {th }}$ & 3,537 & 239 & 246 & 266 & 354 & 399 & 437 & 413 & 409 & 434 & 340 \\
\hline $11^{\text {th }}$ to $20^{\text {th }}$ & 5,346 & 756 & 722 & 624 & 567 & 552 & 549 & 455 & 413 & 380 & 328 \\
\hline $21^{\text {st }}$ end of month & 8,898 & 771 & 813 & 898 & 897 & 858 & 843 & 958 & 1,019 & 1,043 & 798 \\
\hline Total & 17,781 & 1,766 & 1,781 & 1,788 & 1,818 & 1,809 & 1,829 & 1,826 & 1,841 & 1,857 & 1,466 \\
\hline Period & $\begin{array}{c}\text { Basic } \\
\text { Materials }\end{array}$ & \multicolumn{2}{|c|}{$\begin{array}{l}\text { Consumer } \\
\text { Goods }\end{array}$} & Financials & \multicolumn{2}{|c|}{ Healthcare } & $\begin{array}{l}\text { Industrial } \\
\text { Goods }\end{array}$ & Services & \multicolumn{2}{|c|}{ Technology } & Utilities \\
\hline $1^{\text {st }}$ to $10^{\text {th }}$ & 468 & \multicolumn{2}{|c|}{390} & 362 & \multicolumn{2}{|c|}{454} & 274 & 795 & \multicolumn{2}{|c|}{570} & 224 \\
\hline $11^{\text {th }}$ to $20^{\text {th }}$ & 309 & \multicolumn{2}{|c|}{602} & 770 & 42 & & 469 & 1,352 & \multicolumn{2}{|c|}{1,357} & 63 \\
\hline $21^{\text {st }}$ end of month & 1,175 & \multicolumn{2}{|c|}{1,031} & 809 & 91 & & 863 & 1,847 & \multicolumn{2}{|c|}{1,989} & 274 \\
\hline Total & 1,952 & \multicolumn{2}{|c|}{2,023} & 1,941 & $1,7 \varepsilon$ & & 1,606 & 3,994 & \multicolumn{2}{|c|}{3,916} & 561 \\
\hline
\end{tabular}

More specifically, as can be seen from an above Table 1.2, all annual numbers of event observations for entire security samples between 2001 and 2010 were similar and consistently increased between 1,766 in 2001 and 1,857 in 2009. Somehow, after a recent financial crisis, events reached the maximum at 1857 in 2009 were substantially fallen to 1,466 in 2010 for all earning announcement date periods used in this study. Overall there are earning announcement events total to be 17,781 from 596 unique firms in sample which data is available in CRSP as Table 1.1. Entire numbers of event observations for every industries are homologous as number of firms per industry. In fact, Services and Technology are industries to present maximum numbers of events at 3,994 and 3,916 respectively. On the other hand, Utilities shows minimum numbers of events as 561. Remaining industries, such as Industrial Goods, Healthcare, Financials, Basic Materials, and Consumer Goods have numbers of events to be 1,606, 1,788, $1,941,1,952$, and 2,023 in order. 


\subsubsection{Methodology}

\subsubsection{Beta, and Implied idiosyncratic volatility}

\subsection{Beta Calculation}

The firm's beta for each of the unique firms selected is calculated in a 60 months rolling basis. The Firm j's beta is estimated by the regression of stock returns $r$ on market returns Mret for each month with the use of the previous 60 months:

$$
r_{j, t}=\alpha_{j}+\beta_{j} \text { Mret }_{t}+\varepsilon_{j, t}
$$

where, Mret is the S\&P 500 value-weighted monthly returns collected from CRSP, $r$ is the stock monthly returns, $\alpha$ represents the constant term and $\varepsilon$ is the error term. Furthermore, the beta calculation robustness is verified by applying the Fama and French (1993) three factor model and a beta portfolio computed following $\mathrm{Fu}$ (2009) creating equal-weighted returns in a rolling monthly estimation for portfolios of $10 \times 10$ depending on firm's number and size betas. Then, the regression of these portfolios returns are performed on the S\&P 500 value-weighted monthly returns with one-month lag to determine portfolio betas for the individual firms based on their beta level and size.

\subsection{Implied idiosyncratic volatility calculation}

Data is gathered as refereed from OptionMetrics employing European and American models upon appropriated. The standardized implied volatility is estimated by using the option nearest to 30 days to maturity and at-the-money for both puts and calls to deduct the measurement error related to the conversion to attain implied volatilities from option prices. ${ }^{32}$

Analogous to Stivers, Mayhew and Dennis (2006) for the computation of the implied volatility in its idiosyncratic part the market implied volatility is demonstrated to be a market volatility function:

$$
\sigma_{I V j, t}^{2}=\beta_{j}^{2} \sigma_{I V}^{2}+\sigma_{I V}^{2} \text { idio,j,t }
$$

where, $\sigma_{I V}^{2}$ is the VIX implied market variance for day $t, \sigma_{I V}^{2}{ }_{j, t}$ is the total implied variance at time $t$ for firm $j, \beta^{2}{ }_{j}$ is the squared market beta from equation (1) and $\sigma_{I V i d i o, j, t}^{2}$ is the

\footnotetext{
${ }^{32}$ For details see Hentschel (2003).
} 
implied variance in the idiosyncratic part at time $t$ for firm $j$. Thus, the measurement of implied idiosyncratic volatility is the square root of the implied variance of the idiosyncratic part. In theory, this value would not be equal to zero or negative but it is possible empirically to occur. 33

\subsubsection{Standardized Unexpected Earnings}

Standardized unexpected earnings (SUE) is defined as actual quarterly earnings per share (EPS) from the IBES detail file minus expected quarterly earnings, divided by the absolute value of the consensus forecasts:

$$
S U E_{j, q}=\frac{E_{j, q}-\overline{\hat{E}}_{j, q}}{a b s\left(\overline{\hat{E}}_{j, q}\right)}
$$

where $S U E_{j, q}$ is standardized unexpected earnings measure for firm $\mathrm{j}$ in quarter $\mathrm{q}, E_{j, q}$ is the actual quarterly earnings per share (EPS) for firm $\mathrm{j}$ in quarter $\mathrm{q}, \overline{\hat{E}}_{j, q}$ is the quarterly consensus

EPS forecast, and abs $a b s\left(\overline{\hat{E}}_{j, q}\right.$ ) is the absolute value of the quarterly consensus EPS forecast obtained from the $\mathrm{I} / \mathrm{B} / \mathrm{E} / \mathrm{S}$ database. SUEs is calculated for every quarter over the period spanning January 2001 to December 2010. Observations are required to have at least three forecasts.

\subsubsection{Relationship between the implied idiosyncratic volatility and Standardized Unexpected Earnings (SUE)}

This research determines the hypothesis that information about earnings announcement surprises is imbedded in option prices via implied idiosyncratic volatility prior to the announcement. To examine this, the implied idiosyncratic volatility is tested whether the implied idiosyncratic volatility can forecast EPS announcement surprises in term of Standardized Unexpected Earnings (SUE). More specifically, stocks are sorted and divided into equal Quintiles based on the value of implied idiosyncratic volatility. The issue of 30 days prior is realized and used due to a reasonable starting point which earnings information may begin to appear in option prices. Following this, it is anticipated that at 30 trading days prior to the earnings announcement information is not yet in stock prices. However, we consider the 'transition' periods of 20 and 10 days prior to the announcement date because earnings information may not be priced into options 30 days before the announcement. Additionally, less 10 days before, earnings information may already be priced into both stock and option

${ }^{33}$ The small values are set equal to zero and there are non-positive values. 
prices. Finally, the relationship between the implied idiosyncratic volatility and Standardized Unexpected Earnings (SUE) is analyzed and examined as following main methods, namely the correlation test, the Equal Mean Statistical test, and the Equal Median Statistical test as Mood's. Indeed, after the quintile division from highest to lowest values these statistical tests also analyses the difference among the fifth quintile which has the highest value of implied idiosyncratic volatility and the first quintile which has the lowest value of implied idiosyncratic volatility for SUE's mean or median.

\subsection{The Correlation test}

Correlation is a bivariate analysis that measures the strengths of association between two variables. In statistics, the value of the correlation coefficient varies between +1 and -1 . When the value of the correlation coefficient lies around \pm 1 , then it is said to be a perfect degree of association between the two variables. In fact, 1 indicates a strong positive relationship, meanwhile -1 indicates a strong negative relationship. As the correlation coefficient value goes towards 0 , the relationship between the two variables will be weaker or no relationship at all. There are several different correlation techniques. Somehow, Pearson $r$ correlation is widely used in statistics to measure the degree of the relationship between linear related variables. The full name is the Pearson Product Moment Correlation or PPMC. It shows the linear relationship between two sets of data. It was developed by Karl Pearson from a related idea introduced by Francis Galton in the 1880s from Galton, F. (1886), Karl Pearson (1895), and Stigler, Stephen M. (1989). The following formula is used to calculate the Pearson r correlation:

$$
r=\frac{\left(\sum x y\right)-\left(\sum x\right)\left(\sum y\right)}{\sqrt{\left[n \sum x^{2}-\left(\sum x^{2}\right)\right]\left[n \sum y^{2}-\left(\sum y^{2}\right)\right]}}
$$

where $r$ is Pearson $r$ correlation coefficient, $n$ is number of value in each data set, $\sum x y$ is sum of the products of paired data, $\sum x$ is sum of x scores, $\sum y$ is sum of y data set, $\sum x^{2}$ is sum of squared $\mathrm{x}$ data set, and $\sum y^{2}$ is sum of squared y data set. Indeed, Pearson's correlation coefficient is the covariance of the two variables divided by the product of their standard deviations. The form of the definition involves a "product moment", that is, the mean (the first moment about the origin) of the product of the mean-adjusted random variables; hence the modifier product-moment in the name. Assumption for the Pearson $r$ correlation is that both variables should be normally distributed. Other assumptions include linearity and homoscedasticity. Linearity assumes a straight line relationship between each of the variables 
in the analysis and homoscedasticity assumes that data is normally distributed about the regression line.

\subsection{The Equal Mean Statistical test}

The purpose of this examination is to test, if two population means are equal or TwoSample t-Test for Equal Means. In fact, the two-sample t-test from Snedecor and Cochran, 1989 is used to determine if two population means are equal and sampling is from normally distributed populations. A common application is to test if a new process or treatment is superior to a current process or treatment. There are several variations on this test as following: 1.The data may either be paired or not paired. By paired, we mean that there is a one-to-one correspondence between the values in the two samples. That is, if $X_{1}, X_{2}, . . X_{n}$ and $Y_{1}, Y 2, \ldots$, $Y_{n}$ are the two samples, then $X_{i}$ corresponds to $Y_{i}$. For paired samples, the difference $X_{i}-Y_{i}$ is usually calculated. For unpaired samples, the sample sizes for the two samples may or may not be equal. The formulas for paired data are somewhat simpler than the formulas for unpaired data. 2. The variances of the two samples may be assumed to be equal or unequal. Equal variances yields somewhat simpler formulas, although with computers this is no longer a significant issue. 3. In some applications, it may be required to adopt a new process or treatment only if it exceeds the current treatment by some threshold. In this case, it can state the null hypothesis in the form that the difference between the two population's means is equal to some constant $\mu_{1}-\mu_{2}=d_{0}$ where the constant is the desired threshold.

Following this, definition is that the two-sample t-test for unpaired data is defined as:

$$
\begin{array}{ll}
\mathrm{H}_{0}: & \mu_{1}=\mu_{2} \\
\mathrm{H}_{a}: & \mu_{1} \neq \mu_{2}
\end{array}
$$

$$
\text { Test Statistic: } T=\frac{\bar{Y}_{1}-\bar{Y}_{2}}{\sqrt{S_{1}^{2} / N_{1}+S_{2}^{2} / N_{2}}}
$$

where, $N_{1}$ and $N_{2}$ are the sample sizes, $\bar{Y}_{1}$ and $\bar{Y}_{2}$ are the sample means, and $S_{1}^{2}$ and $S_{2}^{2}$ are the sample variances.

If equal variances are assumed, then the formula reduces to:

$$
T=\frac{\bar{Y}_{1}-\bar{Y}_{2}}{s_{p} \sqrt{1 / N_{1}+1 / N_{2}}}
$$

where,

$$
s_{p}^{2}=\frac{\left(N_{1}-1\right) s_{1}^{2}+\left(N_{2}-1\right) s_{2}^{2}}{N_{1}+N_{2}-2}
$$

Significance Level: $\alpha$ 
Critical Region: Reject the null hypothesis that the two means are equal if $|T|>t_{1-\alpha / 2, v}$ Where, $t_{1-\alpha / 2, v}$ is the critical value of the $\mathrm{t}$ distribution with $v$ degrees of freedom where

$$
v=\frac{\left(s_{1}^{2} / N_{1}+s_{2}^{2} / N_{2}\right)^{2}}{\left(s_{1}^{2} / N_{1}\right)^{2} /\left(N_{1}-1\right)+\left(s_{2}^{2} / N_{2}\right)^{2} /\left(N_{2}-1\right)}
$$

If equal variances are assumed, then $v=N_{1}+N_{2}-2$

In summary, the t-test and simple hypothesis test for equality of two mean values show an illustration of a hypothesis test which is frequently used in practice is provided by the t-test, one of several "difference-of-means" tests. In the t-test, two sample mean values, or a sample mean and a theoretical mean value, are compared as follows: 1. the null hypothesis is that the two mean values are equal, 2. while the alternative hypothesis is that the means are not equal (or that one is greater than or less than the other), 3. Test statistic is the t-statistic, and, 4. Significance level or $\mathrm{p}$-value is determined using the t-distribution.

\subsection{The Equal Median Statistical test}

In statistics, the equal median test is known in Mood's median test as Fligner, M. A., and Rust, S. W. (1982) and, Mood, A. M. (1954) which is a special case of Pearson's chisquared test. It is a nonparametric test that tests the null hypothesis that the medians of the populations from which two or more samples are drawn are identical. The data in each sample are assigned to two groups, one consisting of data whose values are higher than the median value in the two groups combined, and the other consisting of data whose values are at the median or below. A Pearson's chi-squared test is then used to determine whether the observed frequencies in each sample differ from expected frequencies derived from a distribution combining the two groups. In fact, nonparametric tests do not make assumptions about a specific distribution. Consequently, the Mood's median test which is a nonparametric test, can be used to test the equality of medians from two or more populations. If assumptions do not hold, nonparametric tests are a better safeguard against drawing wrong conclusions. Indeed, it provides a nonparametric alternative to the one-way ANOVA. The Mood's median test works when the $\mathrm{Y}$ variable is continuous, discrete-ordinal or discrete-count, and the $\mathrm{X}$ variable is discrete with two or more attributes. To summarize, Mood's median test determines assumptions as follow: 1. Observations are independent both within and between samples, i.e. the data are independent SRSes or the equivalent, and, 2. the distributions of the populations the samples were drawn from all have the same shape.

In addition to this, Mood's median test which is used to determine whether the medians of two 
or more groups differ, defines the hypotheses as follow: $\mathrm{H}_{0}$ : the population medians are all equal and $\mathrm{H}_{1}$ : the medians are not all equal. If the null hypothesis is true, any given observation will have probability 0.5 of being greater than the shared median, by definition and regardless of which population it is from. For each sample, therefore, the number of observations greater than the shared median would have a binomial distribution with $p=0.5$. Even if the null hypothesis is true, the shared population median is not known. It can be estimated, however, by the median of all the observations (i.e. the sample median if all the samples were combined into one).Following this, procedure can be simply performed as: 1. Determine the overall median, 2. For each sample, count how many observations are greater than the overall median, and how many are equal to or less than it, 3. Put the counts from step 2 into a $2 x k$ contingency table, and, 4. Perform a chi-square test on the table, testing the hypothesis that the probability of an observation being greater than the overall median is the same for all populations.

\begin{tabular}{lccc}
\hline & sample 1 & sample 2 & etc. \\
\hline equal to or less than overall median & & & \\
greater than overall median & & \\
\hline
\end{tabular}

Finally, we can conclude the robustness and power of this median test that it is very robust against outliers, and fairly robust against differences in the shapes of the distributions. Especially, the median test can have good relative power for heavy-tailed (outlier-rich) distributions.

\subsection{Data sources and description}

Table 2 below summarizes the data sources and equations description for each of the research steps detailed previously.

Table 2: Data Sources and Description

\begin{tabular}{llc}
\hline \multicolumn{2}{c}{ Variable } & Source and Description \\
\hline 1. & Index Return & CRSP \\
2. & Stock return & CRSP \\
3. & Realized Volatility Index & CRSP \\
4. & Realized Stock Volatility & OptionMetrics \\
5. & Implied Stock Volatility & OptionMetrics \\
6. & Realize Idiosyncratic Volatility & Calculated with (Stock Beta, Realized and Implied Stock Volatility) \\
7. & Implied Idiosyncratic Volatility & [Equations (4)] \\
& & The I/B/E/S database (Use to calculate SUE) [Equations (3)] \\
8. & Forecast earnings per share (EPS) & The I/B/E/S database (Use to calculate SUE) [Equations (3)] \\
9. & Actual earnings per share (EPS)
\end{tabular}




\subsection{Empirical Results}

In this section we first start by presenting a brief overview of summary statistics for the variables used in this study followed by Statistics of Implied idiosyncratic volatility and Standardized Unexpected Earnings whether are in different monthly period of earnings announcement. We finish by presenting correlations, Equal Mean and Median analysis.

\subsubsection{Descriptive statistics}

Table 3 reports year per year summary statistics for the 596 unique firms/stocks analysed. We can observe the increased volatility in 2001-2002 (dotcom bubble) ${ }^{34}$ and 2008-2009 (recent financial crisis). Although, the implied volatility annual standard deviation increases in the two cited periods with an evidence of the no-homogeneous increase in volatility among the different stocks in our sample, EPS earnings announcement surprises in term of Standardized Unexpected Earnings (SUE) are normally considered different in the periodical term of comparison prior to the earnings announcement date for all quarters of the year.

Table 3: Implied Volatility statistics

\begin{tabular}{cccccc}
\hline Year & $\begin{array}{c}\text { Implied Volatility } \\
\text { (Average monthly) }\end{array}$ & $\begin{array}{c}\text { Implied Volatility } \\
\text { (Median monthly) }\end{array}$ & $\begin{array}{c}\text { Std. Deviation Implied } \\
\text { Volatility }\end{array}$ & Maximum & Minimum \\
\hline 2001 & 0.567 & 0.510 & 0.231 & 1.672 & 0.085 \\
2002 & 0.533 & 0.482 & 0.223 & 1.953 & 0.111 \\
2003 & 0.435 & 0.396 & 0.179 & 1.751 & 0.134 \\
2004 & 0.366 & 0.333 & 0.137 & 1.002 & 0.122 \\
2005 & 0.337 & 0.311 & 0.125 & 1.746 & 0.117 \\
2006 & 0.334 & 0.316 & 0.117 & 1.147 & 0.116 \\
2007 & 0.356 & 0.332 & 0.131 & 1.616 & 0.117 \\
2008 & 0.544 & 0.494 & 0.222 & 2.114 & 0.137 \\
2009 & 0.574 & 0.532 & 0.221 & 1.988 & 0.167 \\
2010 & 0.465 & 0.444 & 0.151 & 1.436 & 0.135 \\
\hline
\end{tabular}

Figure 1 below presents the average monthly implied volatility per industry.

${ }^{34}$ S\&P500 index drops by 13.04 and 23.37 percent in 2001 and 2002, respectively. 
Figure 1: Monthly Implied Volatility

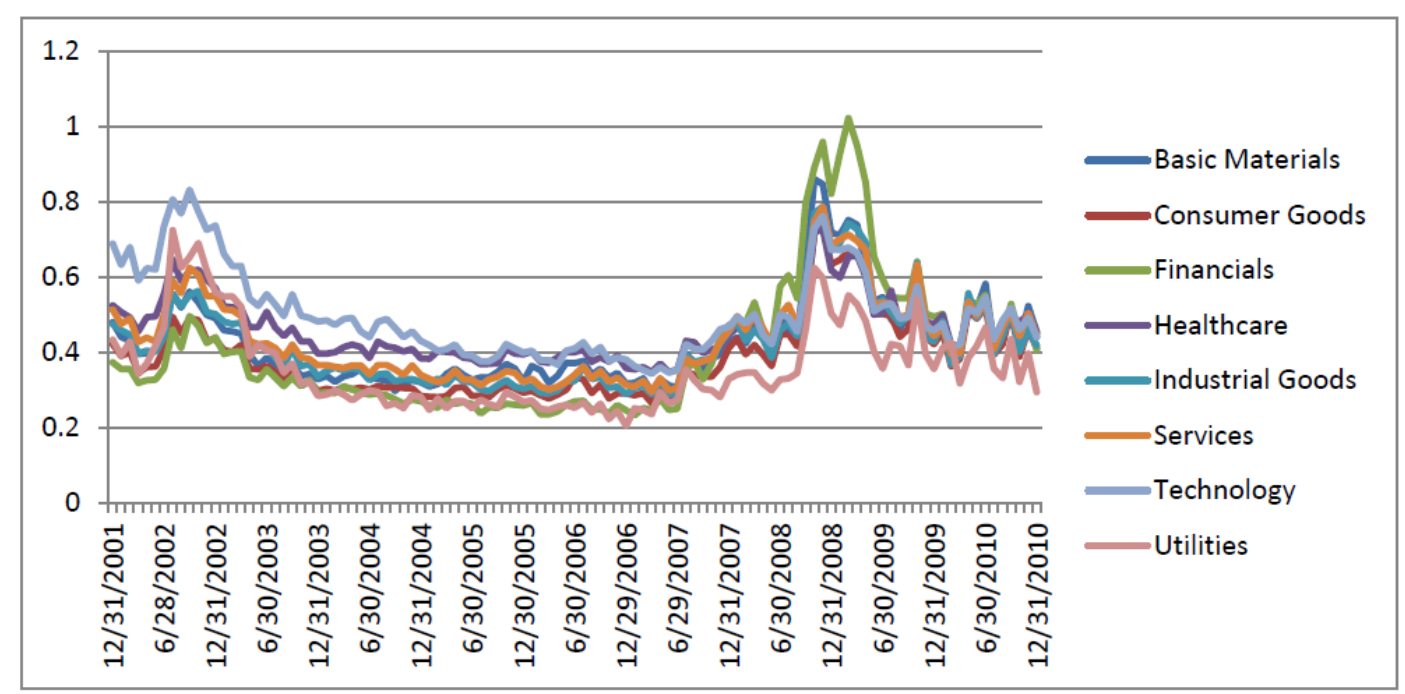

The volatility increase for the years 2001-2002 and 2008-2009 is observed independently of the industry analysed. There is evidence of higher implied volatility for technology firms in the period 2001-2002 and financials in 2008-2009 over the other industries. Somehow, all industries have highest range of implied volatility during the dot-com bubble in the yaers 20012001 and the recent financial crisis in the years 2008-2009.

In term of the correlation between "the implied idiosyncratic volatility at end of the month prior to the earnings announcement" and "Standardized Unexpected Earnings (SUE) at the earnings announcement date", this paper as discussed before classifies events of earning announcement into three different time periods, from the $1^{\text {st }}$ to $10^{\text {th }}$ of the month, from $11^{\text {th }}$ to $20^{\text {th }}$ of the month and from $21^{\text {st }}$ until the end of the month. Table 4 (Panels A to C) reports summary statistics for implied idiosyncratic volatility and standardized unexpected earnings for each of the periods and by for implied idiosyncratic volatility quintiles.

Table 4: Implied idiosyncratic volatility and Standardized Unexpected Earnings

Panel A: Earning announcement from the $1^{\text {st }}$ to $10^{\text {th }}$ of the month

\begin{tabular}{|c|c|c|c|c|c|c|c|}
\hline & Statistic & Entire Sample & 1st Quintile & 2nd Quintile & 3rd Quintile & 4th Quintile & 5th Quintile \\
\hline Number of Events & & 3,537 & 707 & 708 & 707 & 708 & 707 \\
\hline \multirow{6}{*}{$\begin{array}{c}\text { Implied Idiosyncratic } \\
\text { Volatility }\end{array}$} & Mean & 0.2414 & 0.0613 & 0.1112 & 0.1684 & 0.2640 & 0.6023 \\
\hline & Median & 0.1671 & 0.0631 & 0.1108 & 0.1671 & 0.2600 & 0.4996 \\
\hline & Maximum & 3.2703 & 0.0868 & 0.1372 & 0.2053 & 0.3387 & 3.2703 \\
\hline & Minimum & 0.0149 & 0.0149 & 0.0869 & 0.1372 & 0.2055 & 0.3388 \\
\hline & Standard Deviation. & 0.2387 & 0.0165 & 0.0142 & 0.0198 & 0.0371 & 0.3119 \\
\hline & Mean & 0.0260 & 0.0532 & 0.1458 & 0.0113 & -0.0982 & 0.0176 \\
\hline
\end{tabular}




\begin{tabular}{clcccccc} 
& Median & 0.0330 & 0.0318 & 0.0266 & 0.0360 & 0.0423 & 0.0253 \\
& Maximum & 78.0000 & 14.3000 & 58.3333 & 28.9429 & 71.0000 & 78.0000 \\
Standardized & Minimum & -79.0000 & -17.8955 & -8.0000 & -32.4286 & -79.0000 & -45.4500 \\
Unexpected Earnings & Standard Deviation. & 3.4098 & 0.9230 & 2.6150 & 2.0426 & 5.0591 & 4.5497 \\
(SUE) & Skewness & 2.7150 & -0.3878 & 0.0645 & 0.1799 & 0.2602 & 3.2104 \\
& Excess Kurtosis & 282.8467 & -0.6953 & -1.1243 & -1.1844 & -1.0833 & 16.8107 \\
& Jarque-Bera & $11,794,678.74$ & 31.96 & 37.78 & 45.13 & 42.61 & $9,539.39$ \\
& p-value & $0.0000^{* * *}$ & $0.0000^{* * *}$ & $0.0000^{* * *}$ & $0.0000^{* * *}$ & $0.0000^{* * *}$ & $0.0000^{* * *}$ \\
\hline
\end{tabular}

***,**** Statistical significant for 1,5 , and 10 percent levels, respectively

From the above we observe the presence for the Standardized Unexpected Earnings of a significant number of outliers for all the three time periods analysed. It is, therefore, anticipated the non-normality distribution. This should be caused by the SUE's calculation method which requires to be standardized. As the consequence that the firm with high earnings per share (EPS) might occur higher Unexpected Earnings than the firm with low earnings per share (EPS), this leads to be standardized by dividing with the absolute value of the quarterly EPS forecast. Whereas a problem in term of mathematics should occur in case of conflicting and different ideas among analysts. If there are both groups of analysts to forecast both positive and negative EPS, the average forecasting value will approach to be null. Consequently, SUE will be too much positive or negative after dividing by the absolute value of the average EPS forecast which is approaching zero. Following this, the SUE's outlier affects that mean should be inappropriate measure, on the other hand median measure can replace and be properly applied. Additionally, it is found from all three mentioned time period groups and data that the mean value of SUE and the implied idiosyncratic volatility have unclear and inconsistent correlation. Meanwhile, the correlation with median value of SUE for the two periods, $11^{\text {th }}$ to $20^{\text {th }}$ and beyond $21^{\text {st }}$ is consistent. If the value of implied idiosyncratic volatility increases, the median value of SUE will be also increased except only for the first time period implemented from the first to the tenth day of the month. Therefore, it can be anticipated that $S U E$ at the earnings announcement dates from $11^{\text {th }}$ to $20^{\text {th }}$ and beyond $21^{\text {st }}$ is possible to positively correlate to the implied idiosyncratic volatility at end of month prior to the earning announcement. Whereas SUE in an earnings announcement date between $1^{\text {st }}$ and $10^{\text {th }}$ might not correlate to the implied idiosyncratic volatility. However, this is an estimated summary and assumption from these data observations and the statistical examination will be definitely done in further empirical parts. More specifically, detailed explanation and description is provided next for Table 4 (panels A to C).

Table 4 (Panel A) presents all 3,537 events of earning announcement from the first time period analyzed. The announcements are further classified into 5 groups (quintiles) by the value 
of implied idiosyncratic volatility such as: a. first quintile group has the least value of implied idiosyncratic volatility and 707 total events. The mean value of implied idiosyncratic volatility is at 0.0613 and median at 0.631 . Meanwhile, the SUE's mean is 0.0532 and median at 0.0318 . b. the second quintile group has the value of implied idiosyncratic volatility higher than $1^{\text {st }}$ Quintile and 708 total events. The mean value of implied idiosyncratic volatility is at 0.1112 and median at 0.1108 . Meanwhile, the SUE's mean is 0.1458 and median at 0.0266 . c. the third quintile group has the value of implied idiosyncratic volatility higher than second quintile and 707 total events. The mean value of implied idiosyncratic volatility is at 0.1684 and median at 0.1671. Meanwhile, the SUE's mean is 0.0113 and median at 0.0360 . d. the fourth quintile group has the value of implied idiosyncratic volatility higher than third quintile and 708 total events. The mean value of implied idiosyncratic volatility is at 0.2640 and median at 0.2600 . Meanwhile, the SUE's mean is -0.0982 and median at 0.0423 . e. the fifth quintile group has the highest value of implied idiosyncratic volatility and 707 total events. The mean value of implied idiosyncratic volatility is at 0.6023 and median at 0.4996 . Meanwhile, the SUE's mean is 0.0176 and median at 0.0253 .

In actual fact, implied idiosyncratic volatilities from all quintiles have different means and medians in a small gap including insignificant different values of maximum and minimum as well. It can be anticipated that outlier of implied idiosyncratic volatilities should not be large. In the other hand, Standardized Unexpected Earnings (SUE) are found that each mean and median are substantially different as well as values of maximum and minimums are massively high gap for all quintiles. As a result, Standardized Unexpected Earnings (SUE) is possible that outliers are high indeed and its tendency is not normal distribution. In particular, the outcome of Jarque-Bera Test $^{35}$ is srong statistical significant at 1 percent for entire and each quintile levels. Finally, it can be concluded that Standardized Unexpected Earnings (SUE) is not normal distributed and caused by SUE calculation with standardized method dividing by the absolute value of the average EPS forecast which tend to zero. In fact, this problem in term of mathematics should occur due to case of conflicting and different ideas among analysts. If there are both groups of analysts to forecast both positive and negative EPS, the average forecasting value will approach zero. Hence, SUE will be too much positive or minus and cause outliers at the end. Besides, directions of SUE's means and medians are not consistent and found in both

\footnotetext{
35 Jarque-Bera Test is a test statistic for testing whether the series is normally distributed. The test statistic measures the difference of the skewness (measure of asymmetry of the distribution of the series around its mean) and Kurtosis (is the peakedness or flatness of the distribution of the series with those from the normal distribution) of the series with those from the normal distribution.
} 
of higher and lower values. Especially, SUE's means are 0.0532, 0.1458, 0.0113, -0.0982 and 0.0176 from first to fifth quintiles and SUE's medians are 0.0318, 0.0266, 0.0360, 0.0423, 0.0253 , respectively. As such, they are not associated with implied idiosyncratic volatilities. Additionally, the increase of implied idiosyncratic volatility in each quintile should not affect the direction of SUE. In summary, it is possible that there is no correlation between the implied idiosyncratic volatility and Standardized Unexpected Earnings (SUE) for the case of gap between Earning Announcement date and the implied idiosyncratic volatility during 1 to 10 days. Somehow, this is an estimation and the statistical examination will be exactly done further in regard to the linear relationship examination by the correlation test. Specifically, the Equal Mean test and the Nonparametric test (which has no requirements regarding the pattern of population distribution) by the Equal Mood's Median test shall be also performed further.

Table 4: Implied idiosyncratic volatility and Standardized Unexpected Earnings Panel B: Earnings announcement from $11^{\text {th }}$ to $20^{\text {th }}$ of the month

\begin{tabular}{|c|c|c|c|c|c|c|c|}
\hline & Statistic & Entire Sample & 1st Quintile & 2nd Quintile & 3rd Quintile & 4th Quintile & 5th Quintile \\
\hline Number of Events & & 5,346 & 1,069 & 1,069 & 1,070 & 1,069 & 1,069 \\
\hline \multirow{5}{*}{$\begin{array}{c}\text { Implied Idiosyncratic } \\
\text { Volatility }\end{array}$} & Mean & 0.2326 & 0.0591 & 0.1067 & 0.1601 & 0.2489 & 0.5882 \\
\hline & Median & 0.1583 & 0.0599 & 0.1066 & 0.1583 & 0.2436 & 0.4933 \\
\hline & Maximum & 2.7935 & 0.0835 & 0.1306 & 0.1937 & 0.3232 & 2.7935 \\
\hline & Minimum & 0.0139 & 0.0139 & 0.0836 & 0.1306 & 0.1938 & 0.3232 \\
\hline & Standard Deviation. & 0.2305 & 0.0151 & 0.0135 & 0.0183 & 0.0369 & 0.2927 \\
\hline \multirow{9}{*}{$\begin{array}{c}\text { Standardized } \\
\text { Unexpected Earnings } \\
(S U E)\end{array}$} & Mean & 0.0178 & -0.0178 & 0.0817 & 0.0505 & 0.0771 & -0.1025 \\
\hline & Median & 0.0322 & 0.0246 & 0.0284 & 0.0355 & 0.0414 & 0.0456 \\
\hline & Махітит & 33.0000 & 6.4000 & 33.0000 & 10.1429 & 19.6667 & 16.3333 \\
\hline & Minimum & -78.1111 & -48.0000 & -6.0000 & -12.6667 & -29.5000 & -78.1111 \\
\hline & Standard Deviation. & 1.8832 & 1.5549 & 1.0571 & 0.8580 & 1.8544 & 3.1646 \\
\hline & Skewness & -18.8748 & -0.2563 & 0.0117 & 0.1741 & 0.3268 & 2.2543 \\
\hline & Excess Kurtosis & 727.2700 & -0.8406 & -1.1737 & -1.1435 & -1.0719 & 7.1225 \\
\hline & Jarque-Bera & $118,134,725.15$ & 43.17 & 61.38 & 63.71 & 70.21 & $3,165.01$ \\
\hline & p-value & $0.0000 * * *$ & $0.0000^{* * *}$ & $0.0000^{* * *}$ & $0.0000 * * *$ & $0.0000 * * *$ & $0.0000 * * *$ \\
\hline
\end{tabular}

$* * *, * * *$ Statistical significant for 1,5 , and 10 percent levels, respectively

Table 4 (Panel B) reports all 5,346 events of earning announcement date from the $11^{\text {th }}$ to the $20^{\text {th }}$ of month from the entire stock sample. As shown they are classified into 5 groups equally by the value of implied idiosyncratic volatility namely. a. the first quintile group has the least value of implied idiosyncratic volatility and 1,069 total events. The mean value of implied idiosyncratic volatility is at 0.0591 and median at 0.0599 . Meanwhile, the SUE's mean is -0.0178 and median at 0.0246 . b. the second quintile group has the value of implied idiosyncratic volatility higher than the first quintile and 1,069 total events. The mean value of 
implied idiosyncratic volatility is at 0.1067 and median at 0.1066 . Meanwhile, the SUE's mean is 0.0817 and median at 0.0284 . c. the third quintile group has the value of implied idiosyncratic volatility higher than second quintile and 1,070 total events. The mean value of implied idiosyncratic volatility is at 0.1601 and median at 0.1583 . Meanwhile, the SUE's mean is 0.0505 and median at 0.0355 . d. the fourth quintile group has the value of implied idiosyncratic volatility higher than third quintile and 1,069 total events. The mean value of implied idiosyncratic volatility is at 0.2489 and median at 0.2436 . Meanwhile, the SUE's mean is 0.0771 and median at 0.0414 . e. the fifth quintile group has the highest value of implied idiosyncratic volatility and 1,069 total events. The mean value of implied idiosyncratic volatility is at 0.5882 and median at 0.4933 . Meanwhile, the SUE's mean is -0.1025 and median at 0.0456. In Table 4, Panel B, it is clear results that implied idiosyncratic volatilities from all quintiles have slightly different means and medians including insignificant different values of maximum and minimum as well. In addition, outlier of implied idiosyncratic volatilities are not anticipated to be large. In contrary, it is found that Standardized Unexpected Earnings (SUE)'s mean and median are substantially different as well as values of maximum and minimum are significantly high ranges for all quintiles. As the result, it is possible that outliers are extremely high and its Distribution should not be Normal. When Jarque-Bera Test is performed and results show all strong statistical significance at $1 \%$ for entire and each Quintile levels. Finally, Standardized Unexpected Earnings (SUE) can be concluded that it is not Normal Distribution. Likewise, SUE's means which are not consistent, are found to be upward and downward. Especially, SUE's means are -0.0178, 0.0817, 0.0505, 0.0771, -0.1025 from $1^{\text {st }}$ to $5^{\text {th }}$ Quintiles. Whereas SUE's medians are consistent from 0.0246, 0.0284, 0.0355, $0.0414,0.0456$ respectively. Consequently, it can be implied that when implied idiosyncratic volatilities are increased in higher Quintiles, SUE's medians are also higher homologous. Indeed, from this high outlier of data characteristic results that mean measure should not be appropriately used, in contrast median measure should be much more applied. To summarize, when it is considered in the term of SUE's median, the increasing implied idiosyncratic volatilities in higher Quintiles affect the enhancement of Standardized Unexpected Earnings (SUE) as well for the case of earnings announcement date after the implied idiosyncratic volatility spanning 11 to 20 days. Somehow, this is an estimation and the statistical examination will be exactly done in next empirical parts. 
Table 4: Implied idiosyncratic volatility and Standardized Unexpected Earnings

Panel C: Earnings announcement from $21^{\text {st }}$ until the end of the month

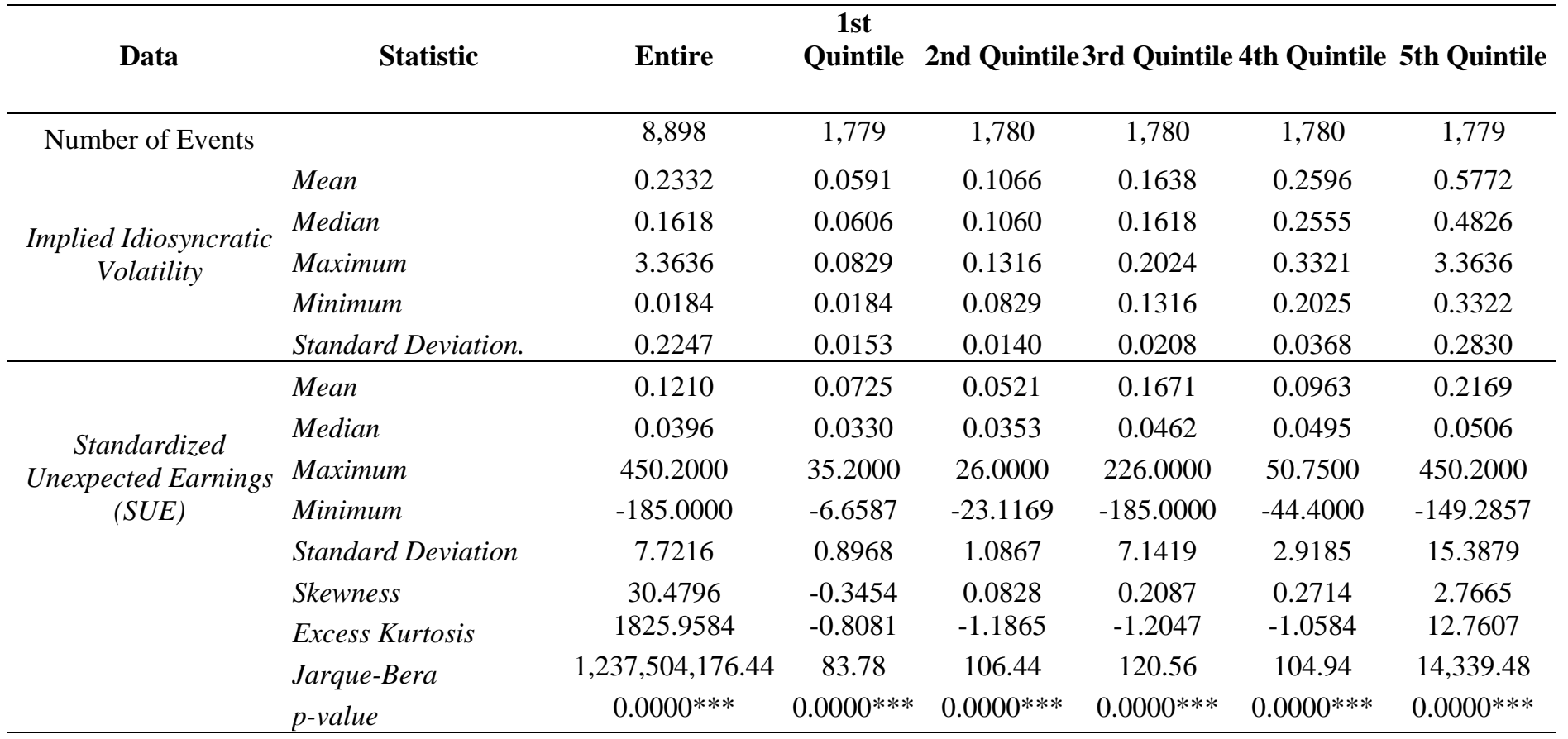

$* * *, * * *$ Statistical significant for 1,5 , and 10 percent levels, respectively

Table 4 (Panel C) details the 8,898 earnings announcement events from $21^{\text {st }}$ until the end of the month. The events are classified in 51uintile groups by theof implied idiosyncratic volatility such as: a. the first quintile group has the least value of implied idiosyncratic volatility and 1,779 total events. The mean value of implied idiosyncratic volatility is at 0.0591 and median at 0.0606 . Meanwhile, the SUE's mean is 0.0725 and median at 0.0330 ; $\mathbf{b}$. the second quintile has the value of implied idiosyncratic volatility higher than first Quintile and 1,780 total events. The mean value of implied idiosyncratic volatility is at 0.1066 and median at 0.1060 . Meanwhile, the SUE's mean is 0.0521 and median at 0.0353 ; c. the third quintile has the value of implied idiosyncratic volatility higher than second quintile and 1,780 total events. The mean value of implied idiosyncratic volatility is at 0.1638 and median at 0.1618 . Meanwhile, the SUE's mean is 0.1671 and median at 0.0462 ; d. the fourth quintile has the value of implied idiosyncratic volatility higher than third quintile and 1,780 total events. The mean value of implied idiosyncratic volatility is at 0.2596 and median at 0.2555 . Meanwhile, the SUE's mean is 0.0963 and median at 0.0495; and, e. fifth quintile group has the highest value of implied idiosyncratic volatility and 1,779 total events. The mean value of implied idiosyncratic volatility is at 0.5772 and median at 0.4826 . Meanwhile, the SUE's mean is 0.2169 and median at 0.0506. According to the results reported in Table 4 Panel $\mathrm{C}$, there is evidence that implied idiosyncratic volatilities from all quintiles have slightly different means and medians including 
insignificant different values of maximum and minimum as well. Hence, it can be estimated that outlier of implied idiosyncratic volatilities are not large. Conversely, Standardized Unexpected Earnings (SUE)'s means and medians are shown that they are substantially different as well as values of maximum and minimum are significantly high ranges for all quintiles. As the result, it is strongly tended that SUE's Distribution should not be Normal due to extremely high outlier. Indeed, when Jarque-Bera test is performed and results show all strong statistical significance at one percent level for entire and each quintile levels. In conclusion, Standardized Unexpected Earnings (SUE) is not normal distributed. Other than this, SUE's means are not consistent direction such as $0.0725,0.0521,0.1671,0.0963$ and 0.2169 from first to the fifth quintiles. In contrary, SUE's medians are consistent from 0.0330 , 0.0353, 0.0462, 0.0495 and 0.0506, respectively. As such, it can be implied that when implied idiosyncratic volatilities are increased in higher quintiles, SUE's medians are also higher homologously. In fact, from this high outlier of data characteristic results that mean measure should not be used, whereas median measure should be applied much more properly. To summarise from Table 7, when it is considered in term of SUE's median, the increasing implied idiosyncratic volatilities in higher quintiles affect Standardized Unexpected Earnings (SUE) to be enhanced as well for the case of different dates between Earning Announcement and the implied idiosyncratic volatility beyond 21 days. However, this is an anticipation and the statistical examination will be definitely done further.

In summary of descriptive statistics for this study regarding the correlation between the implied idiosyncratic volatility at end of month prior to the earning announcement and Standardized Unexpected Earnings (SUE) at the earnings announcement date for three different groups of earnings announcement dates (table 4, Panels A to C), we find that overall SUE outliers are highly much value for all groups. As the result, it is anticipated that SUE's distribution to be not normal. This should be caused by the SUE's calculation method which is required to perform standardized. As the consequence that the corporate with high earnings per share (EPS) might occur higher unexpected earnings than the corporate with low earnings per share (EPS), this leads to be standardized by dividing with the absolute value of the quarterly EPS forecast. Whereas a problem in term of mathematics should occur in case of conflicting and different ideas among analysts. If there are both groups of analysts to forecast both positive and negative EPS, the average forecasting value will approach zero. Consequently, SUE will be too much positive or minus after dividing by the absolute value of the average EPS forecast which will approach zero. Following this, the SUE's outlier affects 
that mean should be inappropriate measure, on the other hand median measure can replace and be properly applied. Additionally, it is found from all three mentioned groups and data that the mean value of SUE and the implied idiosyncratic volatility are unclear and inconsistent correlation. Meanwhile, the correlation with median value of SUE in the two period groups from $11^{\text {th }}$ to $20^{\text {th }}$ and beyond $21^{\text {st }}$ is consistent. If the value of implied idiosyncratic volatility increases, the median value of SUE will be also increased except only during the earnings announcement period from the $1^{\text {st }}$ to the $10^{\text {th }}$ of the month After this data observation it can be anticipated that SUE at the earning announcement date for the two periods from $11^{\text {th }}$ to $20^{\text {th }}$ and beyond $21^{\text {st }}$ is possible to positively correlate to the implied idiosyncratic volatility at end of month prior to the earning announcement. Whereas, SUE in an earnings announcement date between the $1^{\text {st }}$ and $10^{\text {th }}$ of the month might not correlate to the implied idiosyncratic volatility. However, this is an estimated summary and assumption from these data observations and the statistical examination will be definitely done further. 


\subsubsection{Implied idiosyncratic volatility and Standardized Unexpected Earnings (SUE)}

\subsubsection{The correlation test}

Next, we analyse whether the correlation between the implied idiosyncratic volatility at end of month prior to the earning announcement and Standardized Unexpected Earnings (SUE) at the earning announcement date can be the pattern of linear relationship or other. These events of earnings announcement are divided into three different time periods as defined previously. In table 5 (Panels A) we extend the correlation analysis regarding all data which present the announcement date from the first to the tenth of the month, with a total of 3,357 events.

Table 5: Correlation Test of Implied idiosyncratic volatility and SUE

Panel A: Earnings announcement from the $1^{\text {st }}$ to $10^{\text {th }}$ of the month

\begin{tabular}{ccccccc}
\hline & Entire & $\begin{array}{c}\text { 1st } \\
\text { Quintile }\end{array}$ & $\begin{array}{c}\text { 2nd } \\
\text { Quintile }\end{array}$ & $\begin{array}{c}\text { 3rd } \\
\text { Quintile }\end{array}$ & $\begin{array}{c}\text { 4th } \\
\text { Quintile }\end{array}$ & $\begin{array}{c}\text { 5th } \\
\text { Quintile }\end{array}$ \\
\hline Number of Event & 3,537 & 707 & 708 & 707 & 708 & 707 \\
Correlation & -0.0277 & -0.0300 & 0.0160 & 0.0473 & -0.0046 & -0.0627 \\
t-stat & -1.6497 & -0.7961 & 0.4243 & 1.2575 & -0.1218 & -1.6672 \\
p-value & 0.9505 & 0.7869 & 0.3357 & 0.1045 & 0.5485 & 0.9520 \\
\hline
\end{tabular}

***,**** Statistical significant for 1,5 , and 10 percent levels

The entire correlation between SUE and the implied idiosyncratic volatility of prior month ahead the earning announcement is at -0.0277 . Following this, they are classified by the value of implied idiosyncratic volatility into five equal quintile groups as following: a. first quintile has the least value of implied idiosyncratic volatility and 707 total events. The correlation between SUE and the implied idiosyncratic volatility of prior month ahead the earning announcement is at -0.0300 ; b. second quintile has 708 total events. The correlation between SUE and the implied idiosyncratic volatility of prior month ahead the earning announcement is at 0.0160 ; c. third quintile has 707 total events. The correlation between SUE and the implied idiosyncratic volatility of prior month ahead the earning announcement is at 0.0473 ; d. fourth quintile has 708 total events. The correlation between SUE and the implied idiosyncratic volatility of prior month ahead the earning announcement is at -0.0046 ; e. fifth quintile group has the most value of implied idiosyncratic volatility and 707 total events. The correlation between SUE and the implied idiosyncratic volatility of prior month ahead the earning announcement is at -0.0627 . To summarize, it is clear evidence that the Correlation value is too small and less 0.10. More specifically, when the statistical test is performed, there is no statistical significance for entire data and all quintiles. Finally, SUE of the earning announcement date group spanning from the first to the tenth of month is not linear relationship 
to the implied idiosyncratic volatility. Although, this correlation is not linear relationship, it might be possible to correlate in the term of non-linear relationship. As the result, it will be examined further later.

Table 5: Correlation Test of Implied idiosyncratic volatility and SUE

Panel B: Earnings announcement from $11^{\text {th }}$ to $20^{\text {th }}$ of the month

\begin{tabular}{ccccccc}
\hline & Entire & $\begin{array}{c}\text { 1st } \\
\text { Quintile }\end{array}$ & $\begin{array}{c}\text { 2nd } \\
\text { Quintile }\end{array}$ & $\begin{array}{c}\text { 3rd } \\
\text { Quintile }\end{array}$ & $\begin{array}{c}\text { 4th } \\
\text { Quintile }\end{array}$ & $\begin{array}{c}\text { 5th } \\
\text { Quintile }\end{array}$ \\
\hline Number of Event & 5,346 & 1,069 & 1,069 & 1,070 & 1,069 & 1,069 \\
Correlation & -0.0333 & -0.0015 & 0.0483 & 0.0222 & -0.0273 & -0.0274 \\
t-stat & -2.4358 & -0.0476 & 1.5786 & 0.7269 & -0.8916 & -0.8962 \\
p-value & 0.9926 & 0.5190 & $0.0574 *$ & 0.2337 & 0.8136 & 0.8148 \\
\hline ******* Stat
\end{tabular}

$* * *, * *, *$ Statistical significant for 1,5 , and 10 percent levels

Table 5, Panel B, reports on our analysis, for the announcement period between the $11^{\text {th }}$ and $20^{\text {th }}$ of month. There are 5,346 earnings announcement in such time period. Totally, the correlation between SUE and the implied idiosyncratic volatility of prior month ahead the earning announcement is at -0.0333 . Meanwhile, five quintiles are divided by the value of implied idiosyncratic volatility, namely: a. first quintile has the least value of implied idiosyncratic volatility and 1,069 total events. The correlation between SUE and the implied idiosyncratic volatility of prior month ahead the earning announcement is at -0.0015 ; $\mathbf{b}$. second group has 1,069 total events. The correlation between SUE and the implied idiosyncratic volatility of prior month ahead the earning announcement is at 0.0483 ; c. third quintile has 1,070 total events. The correlation between SUE and the implied idiosyncratic volatility of prior month ahead the earning announcement is at 0.0222 ; $\mathbf{d}$. fourth quintile group has 1,069 total events. The correlation between SUE and the implied idiosyncratic volatility of prior month ahead the earning announcement is at -0.0273 ; and, e. fifth quintile group has the most value of implied idiosyncratic volatility and 1,069 total events. The correlation between SUE and the implied idiosyncratic volatility of prior month ahead the earning announcement is at 0.0274. The results presented in Table 5, Panel B shows that the correlation value is too small and less 0.10 as well. Additionally, there is only second quintile showing a statistical significance at $10 \%$ after the statistical test performed. Hence, we can conclude that SUE of the earning announcement date from the $11^{\text {th }}$ to $20^{\text {th }}$ of the month is not a linear relationship to the implied idiosyncratic volatility. Even though, this correlation is not linear relationship, it is probable for the correlation in type of non-linear relationship. Specifically, it will be examined further.

Table 5, Panel C presents the results from earnings announcement from $21^{\text {st }}$ until the 
end of the month with 8,898 events.

Table 5: Correlation Test of Implied idiosyncratic volatility and SUE

Panel C: Earning announcement from $21^{\text {st }}$ until the end of the month

\begin{tabular}{ccccccc}
\hline & Entire & $\begin{array}{c}\text { 1st } \\
\text { Quintile }\end{array}$ & $\begin{array}{c}\text { 2nd } \\
\text { Quintile }\end{array}$ & $\begin{array}{c}\text { 3rd } \\
\text { Quintile }\end{array}$ & $\begin{array}{c}\text { 4th } \\
\text { Quintile }\end{array}$ & $\begin{array}{c}\text { 5th } \\
\text { Quintile }\end{array}$ \\
\hline Number of Event & 8,898 & 1,779 & 1,780 & 1,780 & 1,780 & 1,779 \\
Correlation & -0.0209 & -0.0155 & -0.0681 & 0.0045 & 0.0127 & -0.0524 \\
t-stat & -1.9692 & -0.6554 & -2.8761 & 0.1893 & 0.5347 & -2.2128 \\
p-value & 0.9755 & 0.7438 & 0.9980 & 0.4250 & 0.2965 & 0.9865 \\
\hline$* * * * * *$ Statistical significant for 1, 5, and 10 percent levels & & &
\end{tabular}

The total correlation between SUE and the implied idiosyncratic volatility of prior month ahead the earning announcement is at -0.0209 . After the implied idiosyncratic volatility equally divided into five quintiles: a. first quintile has the least value of implied idiosyncratic volatility and 1,779 total events. The correlation between SUE and the implied idiosyncratic volatility of prior month ahead the earning announcement is at -0.0015 ; b. second quintile group has 1,780 total events. The correlation between SUE and the implied idiosyncratic volatility of prior month ahead the earning announcement is at -0.0681 ; c. third quintile has 1,780 total events. The correlation between SUE and the implied idiosyncratic volatility of prior month ahead the earning announcement is at $0.0045 ; \mathrm{d}$. fourth quintile has 1,780 total events. The correlation between SUE and the implied idiosyncratic volatility of prior month ahead the earning announcement is at 0.0127 ; and, e. fifth quintile group has the most value of implied idiosyncratic volatility and 1,779 total events. The correlation between SUE and the implied idiosyncratic volatility of prior month ahead the earning announcement is at 0.0524. From the same correlation analysis, we find evidence that the correlation value, which is too small, is also less 0.10 . Moreover, there is no statistical significance for entire data and all quintiles, when the statistical test is performed. Finally, we can conclude that SUE of the earning announcement date from $21^{\text {st }}$ of month is not a linear relationship to the implied idiosyncratic volatility. Nevertheless, this linear correlation is not found, it is probable that the non-Linear correlation can be existing. After these results, further examination will be performed.

In summary of the correlation Test in all three earning announcement time period groups, the clear evidences show that there is no linear correlation between SUE and the implied idiosyncratic volatility. Specifically, it is not over our anticipation. Following in descriptive statistics, we find that the outlier of implied idiosyncratic volatility is not large, on the other hand it is too high for the outlier of SUE. Consequently, it can be anticipated from 
evidence in descriptive statistics that there should be no correlation between SUE and the implied idiosyncratic volatility in term of linear relationship. However, it is possible to find the non-linear correlation between the implied idiosyncratic volatility and SUE. This leads to further examination in the next section.

\subsubsection{The Equal Mean and Median tests}

We start by examining whether "Standardized Unexpected Earnings (SUE) for a group which has the maximum value of implied idiosyncratic volatility" or fifth quintile is equal to "SUE of group which has the minimum value of implied idiosyncratic volatility" or first quintile. Following this, "the Equal Mean test" is performed to test whether two means from two groups are equal when population variances are not equal. Meanwhile, "the Equal Median test" is done to test whether two medians from two groups are equal by the Mood's median test. Additionally, as before, we divide the events in three groups according to the day of the announcement. From Table 6, Panel A, the results for the first time period) from first to tenth of the month) is presented being divided by quintiles according to the implied idiosyncratic volatility value.

Table 6: Equal Mean and Median Tests

Panel A: Earnings announcement from the $1^{\text {st }}$ to $10^{\text {th }}$ of the month

\begin{tabular}{cccccccccc}
\hline & Entire & $\begin{array}{c}\text { 1st } \\
\text { Quintile }\end{array}$ & $\begin{array}{c}\text { 2nd } \\
\text { Quintile }\end{array}$ & $\begin{array}{c}\text { 3rd } \\
\text { Quintile }\end{array}$ & $\begin{array}{c}\text { 4th } \\
\text { Quintile }\end{array}$ & $\begin{array}{c}\text { 5th } \\
\text { Quintile }\end{array}$ & $\begin{array}{c}\text { 5th Quintile - } \\
\text { 1st Quintile }\end{array}$ & Statistic & p-value \\
\hline $\begin{array}{c}\text { Number of } \\
\text { Event }\end{array}$ & 3,537 & 707 & 708 & 707 & 708 & 707 & - & - & - \\
Max & 78.0000 & 14.3000 & 58.3333 & 28.9429 & 71.0000 & 78.0000 & - & - & - \\
Min & -79.0000 & -17.8955 & -8.0000 & -32.4286 & -79.0000 & -45.4500 & - & - & - \\
SD. & 3.4098 & 0.9230 & 2.6150 & 2.0426 & 5.0591 & 4.5497 & - & - & - \\
Mean & 0.0260 & 0.0532 & 0.1458 & 0.0113 & -0.0982 & 0.0176 & -0.0356 & -0.2038 & 0.5807 \\
Median & 0.0330 & 0.0318 & 0.0266 & 0.0360 & 0.0423 & 0.0253 & -0.0065 & 0.2291 & 0.6322 \\
\hline
\end{tabular}

$* * *, * * *$ Statistical significant for 1,5 , and 10 percent levels

The first quintile has the least value of implied idiosyncratic volatility and in total 707 events. The Standardized Unexpected Earnings (SUE)'s mean is at 0.0532 and median is at 0.0318 . The second quintile has a total of 708 events. The SUE's mean is at 0.1458 and median is at 0.0266. The third quintile has 707 events The SUE's mean is at 0.0113 and median is at 0.0360 . The fourth quintile has 708 events. The SUE's mean is at -0.0982 and median is at 0.0423 . e fifth quintile has the most value of implied idiosyncratic volatility and 707 events in total. The SUE's mean is at 0.0176 and median is at 0.0253 .

From the Equal Mean and Median analysis, there is evidence of no clear direction for correlation between the implied idiosyncratic volatility and mean or median of Standardized 
Unexpected Earnings (SUE). As the consequence that when quintile is higher, the implied idiosyncratic volatility is also increased. Whereas SUE's mean or median is not consistent and unclear direction. In addition to this, mean of SUE in fifth quintile subtracted by mean of SUE in first quintile is negative at -0.0065 . Especially, when the statistical test is performed, difference between fifth and first quintiles for SUE's mean or median is not statistical significant. To summarize, SUE of the earning announcement between the first and the tenth day of the month has no correlation with the implied idiosyncratic volatility of prior month ahead the earning announcement.

Table 6, Panel B presents the same Equal Mean and Median analysis regarding all 5,346 events for the announcement period between the $11^{\text {th }}$ and $20^{\text {th }}$ of month. We equally divide by quintiles following to the value of implied idiosyncratic volatilities.

Table 6: Equal Mean and Median Tests

Panel B: Earnings announcement from $11^{\text {th }}$ to $20^{\text {th }}$ of the month

\begin{tabular}{ccccccccc} 
Entire & $\begin{array}{c}\text { 1st } \\
\text { Quintile }\end{array}$ & $\begin{array}{c}\text { 2nd } \\
\text { Quintile }\end{array}$ & $\begin{array}{c}\text { 3rd } \\
\text { Quintile }\end{array}$ & $\begin{array}{c}\text { 4th } \\
\text { Quintile }\end{array}$ & $\begin{array}{c}\text { 5th } \\
\text { Quintile }\end{array}$ & $\begin{array}{c}\text { 5th } \\
\text { Quintile - } \\
\text { 1st } \\
\text { Quintile }\end{array}$ & Statistic & p-value \\
\hline 5,346 & 1,069 & 1,069 & 1,070 & 1,069 & 1,069 & - & - & - \\
33.0000 & 6.4000 & 33.0000 & 10.1429 & 19.6667 & 16.3333 & - & - & - \\
-78.1111 & -48.0000 & -6.0000 & -12.6667 & -29.5000 & -78.1111 & - & - & - \\
1.8832 & 1.5549 & 1.0571 & 0.8580 & 1.8544 & 3.1646 & - & - & - \\
0.0178 & -0.0178 & 0.0817 & 0.0505 & 0.0771 & -0.1025 & -0.0847 & -0.7850 & 0.7838 \\
0.0322 & 0.0246 & 0.0284 & 0.0355 & 0.0414 & 0.0456 & 0.0210 & $9.9701 * * *$ & 0.0016 \\
\hline
\end{tabular}

Median $\quad 0.0322, *$ Statistical significant for 1,5 , and 10 percent levels

The first quintile has the least value of implied idiosyncratic volatility and 1,069 events in total. The Standardized Unexpected Earnings (SUE)'s mean is at -0.0178 and median is at 0.0246. The second quintile has 1,069 events. The SUE's mean is at 0.0817 and median is at 0.0284. The third quintile has 1,070 events. The SUE's mean is at 0.0505 and median is at 0.0355. The fourth quintile has 1,069 events. The SUE's mean is at 0.0771 and median is at 0.0414. Finally, the fifth quintile has the most value of implied idiosyncratic volatility and 1,069 events in total. The SUE's mean is at -0.1025 and median is at 0.0456 .

Following the Equal Mean analysis, the evidence found in Table 6, Panel B is that the mean of Standardized Unexpected Earnings (SUE) is not correlated to the implied idiosyncratic volatility. In particular, implied idiosyncratic volatilities increase as higher quintiles, but means of SUE are not consistently higher with showing unclear directions both higher and lower. Furthermore, SUE's mean in fifth quintile subtracted by SUE's mean in first quintile is negative at -0.0847 . More specifically, there is no statistical significance for 
difference between fifth and first quintiles from SUE's mean. In fact, this is not over anticipation, since mean is not the appropriate average measure resulted by too much high outlier of SUE. Indeed, a condition and assumption for the Equal Mean test is required that data (SUE) is to be normal distributed. However, the SUE's distribution should not be normal due to the effect of much high outliers. As the result, the Equal Mean test cannot be a reliable and acceptable analysis for this case. Finally, the examination should not employ the Equal Mean test to be a measurement index for correlation between the implied idiosyncratic volatility and SUE.

On the other hand, we find clear evidence that SUE median is strongly correlated to the implied idiosyncratic volatility. When implied idiosyncratic volatilities increase as higher quintiles, SUE's medians are highly consistent and also rise in the clearly same direction. Moreover, median of SUE in fifth quintile subtracted by SUE's median in first quintile is at 0.0210 with a strongly statistical significance at 1 percent level In fact, the Equal Median analysis as Mood's Median test is a Nonparametric test which is no requirement in regard to the pattern of population distribution like as the Equal Mean test. It can conclude that the median between fifth and first quintiles of SUE is significantly different. Consequently, when the implied idiosyncratic volatility at the end of month before the earning announcement is higher, it will affect higher Standardized Unexpected Earnings (SUE) in same direction as well for the group of the earning announcement from $11^{\text {th }}$ to $20^{\text {th }}$ of the month.

By last in Table 6, Panel C, it is presented the results from earnings announcement from $21^{\text {st }}$ until the end of the month. There are 8,898 events and data is divided in quintiles by the value of implied idiosyncratic volatility.

Table 6: Equal Mean and Median Tests

Panel C: Earning announcement from $21^{\text {st }}$ until the end of the month

\begin{tabular}{cccccccccc}
\hline & Entire & $\begin{array}{c}\text { 1st } \\
\text { Quintile }\end{array}$ & $\begin{array}{c}\text { 2nd } \\
\text { Quintile }\end{array}$ & $\begin{array}{c}\text { 3rd } \\
\text { Quintile }\end{array}$ & $\begin{array}{c}\text { 4th } \\
\text { Quintile }\end{array}$ & $\begin{array}{c}\text { 5th } \\
\text { Quintile }\end{array}$ & $\begin{array}{c}\text { 5th } \\
\text { Quintile - } \\
\text { 1st } \\
\text { Quintile }\end{array}$ & Statistic & p-value \\
\hline $\begin{array}{c}\text { Number of } \\
\text { Event }\end{array}$ & 8,898 & 1,779 & 1,780 & 1,780 & 1,780 & 1,779 & - & - & - \\
Max & 450.2000 & 35.2000 & 26.0000 & 226.0000 & 50.7500 & 450.2000 & - & - & - \\
Min & -185.0000 & -6.6587 & -23.1169 & -185.0000 & -44.4000 & -149.2857 & - & - & - \\
SD. & 7.7216 & 0.8968 & 1.0867 & 7.1419 & 2.9185 & 15.3879 & - & - & - \\
Mean & 0.1210 & 0.0725 & 0.0521 & 0.1671 & 0.0963 & 0.2169 & 0.1444 & 0.3950 & 0.3464 \\
Median & 0.0396 & 0.0330 & 0.0353 & 0.0462 & 0.0495 & 0.0506 & 0.0177 & $10.1461 * * *$ & 0.0014 \\
\hline
\end{tabular}

$* * * * * *$ Statistical significant for 1,5 , and 10 percent levels

The first quintile has the least value of implied idiosyncratic volatility and totally 1,779 events. 
The Standardized Unexpected Earnings (SUE)'s mean is at 0.0725 and median is at 0.0330 . The second quintile has 1,780 events. The SUE's mean is at 0.0521 and median is at 0.0353 . The third quintile has 1,780 events. The SUE's mean is at 0.1671 and median is at 0.0462 . The fourth quintile has 1,780 events. The SUE's mean is at 0.0963 and median is at 0.0495. Finally, the fifth quintile has the most value of implied idiosyncratic volatility and 1,779 events in total. The SUE's mean is at 0.2169 and median is at 0.0506 .

As the Equal Mean analysis, it is found that there is no correlation between mean of Standardized Unexpected Earnings (SUE) and the implied idiosyncratic volatility. When implied idiosyncratic volatilities increase as higher quintiles, in contrast means of SUE are not consistently higher with showing unclear directions both higher and lower. Moreover, there is no statistical significance for difference between fifth and first quintiles from SUE's mean. Other than, SUE's mean in fifth quintile subtracted by SUE's mean in first quintile is at 0.1444. In fact, the issue of much high outlier of SUE affects that mean is not the appropriate average measure. In addition, the Equal Mean test requires an assumption with condition that data (SUE) is essential to be normal distributed. Somehow, the effect of much high outlier's results that SUE should not be normal distributed. As the result, the Equal Mean test cannot be a reliable and acceptable analysis for this case. Eventually, the Equal Mean test should not use for a measurement index to examine the correlation between the implied idiosyncratic volatility and SUE.

In contrary, the evidence found that the correlation between the implied idiosyncratic volatility and median of SUE is quite strong and clear. Particularly, SUE's medians are highly consistent and rise in the same direction as well as implied idiosyncratic volatilities increase as higher quintiles. Additionally, median of SUE in fifth quintile subtracted by SUE's median in first quintile is at 0.0177 with a strongly statistical significance at 1 percent level. Indeed, the Equal Median analysis as Mood's Median test is a nonparametric test which is no requirement regarding the pattern of population distribution like as the Equal Mean test. To conclude, it is significant difference for medians between fifth and first quintiles of SUE. Finally, Standardized Unexpected Earnings (SUE) will be affected higher, if the implied idiosyncratic volatility at the end of month before the earning announcement is higher for the group of the earning announcement date from $21^{\text {st }}$ of month.

In summary of the Equal Mean and Median tests, it is found in the Equal Mean test for three groups of the earning announcement period dates that difference between SUE's mean of fifth and first quintiles is not statistical significant in all groups. This affect from much high outlier of SUE. As the result, SUE's distribution is not normal and unable to comply as an 
assumption and condition for the Equal Mean test. In fact, mean cannot appropriately represent every quintiles. Finally, the Equal Mean test should be used for analysis and examination in the correlation between the implied idiosyncratic volatility at the end of month and Standardized Unexpected Earnings (SUE) of next month. Meanwhile, we can conclude in following details about the Equal Median analysis as Mood's median test which is a nonparametric test and no requirement regarding the pattern of population distribution. Firstly, both groups of the earning announcement from $11^{\text {th }}$ to $20^{\text {th }}$ of the month and beyond $21^{\text {st }}$ have median of SUE in fifth quintile subtracted by SUE's median in first quintile with a strongly statistical significance at one percent level. Indeed, fifth quintile, which has the most value of implied idiosyncratic volatility, shows the highest median of Standardized Unexpected Earnings (SUE) and first quintile, which has the least value of implied idiosyncratic volatility, also indicates the lowest median of SUE. As the result, it can be highlighted that the implied idiosyncratic volatility at the end of prior month is correlated to SUE of next month in the earning announcement date from the $11^{\text {th }}$ to end of month. Somehow, the sub-sample of earnings announcement from the first to the tenth of the month displays no statistical significance for difference between SUE's mean of fifth and first quintiles. Hence, it can conclude that there is no correlation between the implied idiosyncratic volatility at the end of prior month and Standardized Unexpected Earnings (SUE) for the time period above. Particularly, it can be prior anticipated by the cause that SUE is calculated by the average of forecast EPS till the last day of month as same as the date of implied idiosyncratic volatility. Following this, a gap between dates of forecast EPS noticed by analyst and actual EPS is not over 10 days. As the result, the analyst's missing or unexpected is affected without pattern or random pattern which is no correlation with any factor. Indeed, there is no factor to forecast SUE which occurs within 10 days. In term of the earning announcement starting on the tenth of the month, it can find the correlation between the implied idiosyncratic volatility and Standardized Unexpected Earnings (SUE) due to the analyst's error or unexpected to be pattern caused by the forecast beyond over 10 days. In fact, those error or unexpected patterns are reflected in the implied idiosyncratic volatility. Finally, the implied idiosyncratic volatility at the end of month can forecast Standardized Unexpected Earnings (SUE) at the earning announcement date over 10 days ahead. 


\subsection{Conclusions}

In this paper we investigate the role of volatility risk on stock returns predictability for 596 stock options traded at the American Stock Exchange and the Chicago Board Options Exchange (CBOE) for the period from January 2001 to December 2010. Using a time period that incorporates both the dotcom bubble and the recent financial crisis we shed light in this first research as our knowledge to the relation between implied idiosyncratic volatility and Standardized Unexpected Earnings over periods when S\&P500 drop at least 20 percent in the term of earnings announcement surprises imbedded in option prices (via implied idiosyncratic volatility) prior to the announcement.

The findings confirm that mean measure is not well represent in the analysis of correlation between implied idiosyncratic volatility and Standardized Unexpected Earnings (SUE) due to much high outlier of SUE. Consequently, median is used to represent this analysis instead. The analysis is divided in three time periods: 1. Earnings announcements between the first and tenth of month; 2 . between eleventh and twentieth and, 3. From twenty first until the end of the month.

We found clear evidence that both groups of earning announcement date between $11^{\text {th }}$ to the $20^{\text {th }}$ and from $21^{\text {st }}$ of month have the correlation between the implied idiosyncratic volatility at the end of month and Standardized Unexpected Earnings (SUE) of next month. This is resulted by a strong statistical significance at 1 percent for difference between SUE's median of fifth and first quintiles which have most and least values of implied idiosyncratic volatilities respectively, even though the correlation between the implied idiosyncratic volatility and SUE is nonlinear relationship. In fact, the analyst's error or unexpectation is a pattern which is caused by the forecast beyond over 10 days and reflected in the implied idiosyncratic volatility. Finally, the implied idiosyncratic volatility at the end of month can forecast SUE at the earning announcement date over 10 days ahead.

We also discover that a group of earning announcement date spanning from $1^{\text {st }}$ to $10^{\text {th }}$ of month has no correlation between the implied idiosyncratic volatility at the end of month and SUE of next month due to no statistical significance for difference between SUE's mean of $5^{\text {th }}$ and $1^{\text {st }}$ Quintiles. Indeed, there is no factor to forecast SUE which occurs within 10 days.

Overall, we claim that this research provide a significant contribution to the existing evidence on earnings announcement surprises imbedded in option prices (via implied idiosyncratic volatility) prior to the announcement, and earning predictability. To our 
knowledge it is also the first time that a period that involves both the dotcom bubble and the recent financial crisis is analyzed.

The volatile market environment and depressed expected returns and earnings of the past several years have increased the use of volatility strategies. Now that volatility has emerged not only as a concept but an investment in its own right, this study brings light to the accuracy of the implied idiosyncratic volatility to forecast Standardized Unexpected Earnings (SUE). 


\section{References}

AAII. (2008, April). "Great Expectations: Earnings Estimates and Their Impact on Stock Prices". American Association of Individual Investors (AAII) Journal.

Ang, A., Hodrick, R. J., Xing, Y., \& Zhang, X. (2006). "The cross-section of volatility and expected returns". Journal of Finance, 61, 259-299.

Bakshi, G., \& Kapadia, N. (2003). "Delta-Hedged Gains and the Negative Market Volatility Risk Premium". Review of Financial Studies, 16(2), 527-566.

Bali, T. G., \& Cakici, N. (2008). "Idiosyncratic Volatility and the Cross Section of Expected Returns". Journal of Financial and Quantitative Analysis, 43(01), 29.

Bali, T. G., \& Hovakimian, A. (2009). "Volatility Spreads and Expected Stock Returns". Management Science, 1797-1812.

Barberis, N., \& Huang, M. (2001). "Mental Accounting, Loss Aversion, and Individual Stock Returns". The Journal of Finance, 56(4), 1247-1292.

Bollerslev, T., Tauchen, G., \& Zhou, H. (2009). Expected Stock Returns and Variance Risk Premia. Rev. Financ. Stud. Review of Financial Studies, 22(11), 4463-4492.

Campbell, J. Y. (1993). Intertemporal asset pricing without consumption data. American Economic Review, 83(3), 487-512.

Campbell, J. Y. (1996). Understanding Risk and Return. Journal of Political Economy, 104(2), 298-345.

Campbell, J. Y., \& Hentsche, L. (1992). "No news is good news: An asymmetric model of changing volatility in stock returns". Journal of Financial Economics, 31(3), 281-318.

Chow, G. C. (1960). "Tests of Equality Between Sets of Coefficients in Two Linear Regressions". Econometrica, 28(3), 591-605.

Christensen, B., \& Prabhala, N. (1998). "The relation between implied and realized volatility". Journal of Financial Economics, 50(2), 125-150.

Chua, C. T., Goh, J., \& Zhang, Z. (2010). "Expected Volatility, Unexpected Volatility, And The Cross-Section Of Stock Returns". Journal of Financial Research, 33(2), 103-123.

Coval, J. D., \& Shumway, T. (2001). "Expected Option Returns". The Journal of Finance, 56(3), 983-1009.

Dangland, T., \& Halling, M. (2012). Predictive regressions with time-varying coefficients. Journal of Financial Economics, 106(1), 157-181.

Dennis, P., Mayhew, S., \& Stivers, C. (2006). "Stock Returns, Implied Volatility Innovations, and the Asymmetric Volatility Phenomenon". Journal of Financial and Quantitative Analysis, 41(02), 381-406.

Diavatopoulos, C., Doran, J. S., \& Peterson, D. R. (2011). Two essays on the predictive ability of implied volatility. ProQuest.

Diavatopoulos, D., Doran, J. S., \& Peterson, D. R. (2008). The information content in implied idiosyncratic volatility and the cross-section of stock returns: Evidence from the option markets. J. Fut. Mark. Journal of Futures Markets, 1013-1039.

Diavatopoulos, D., Doran, J. S., Fodor, A., \& Peterson, D. R. (2012). The information content of implied skewness and kurtosis changes prior to earnings announcements for stock and option returns. Journal of Banking \& Finance, 36(3), 786-802.

Doran, J. S., \& Ronn, E. I. (2006). "The bias in Black-Scholes/Black implied volatility: An analysis of equity and energy markets". Review of Derivatives Research, 8(3), 177198.

Easley, D., O'Hara, M., \& Srinivas, P. S. (1998, April). "Option Volume and Stock Prices: Evidence on Where Informed Traders Trade". Journal of Finance, 53(2).

Fama, E. F., \& French, K. R. (1993). "Common risk factors in the returns on stocks and bonds". Journal of Financial Economics, 33(1), 3-56.

Fama, E. F., \& Macbeth, J. D. (1973). "Risk, Return, and Equilibrium: Empirical Tests". 
Journal of Political Economy, 81(3), 607-636.

Fligner, M. A., \& Rust, S. W. (1982). "A modification of the Mood's median test for the generalized Behrens-Fisher problem". Biometrika, 69, 221-226.

Fu, F. (2009). "Idiosyncratic risk and the cross-section of expected stock returns". Journal of Financial Economics, 9(1), 24-37.

Galton, F. (1886). "Regression towards mediocrity in hereditary stature". Journal of the Anthropological Institute of Great Britain and Ireland, 15, 246-263.

Giot, P. (2005). "Relationships Between Implied Volatility Indexes and Stock Index Returns". The Journal of Portfolio Management, 31(3), 92-100.

Glosten, L. R., Jagannathan, R., \& Runkle, D. E. (1993). "On the Relation between the Expected Value and the Volatility of the Nominal Excess Return on Stocks". The Journal of Finance, 48(5), 1779-1801.

Goyal, A., \& Santa-Clara, P. (2003). "Idiosyncratic Risk Matters!". The Journal of Finance, 58(3), 975-1007.

Henkel, S. J., Martin, J. S., \& Nardari, F. (2011). Time-varying short-horizon predictability. Journal of Financial Economics, 99(3), 560-580.

Hentschel, L. (2003). "Errors in Implied Volatility Estimation". The Journal of Financial and Quantitative Analysis, 38(4), 779-810.

Huang, D., Jiang, F., Tu, J., \& Zhou, G. (2015). Investor Sentiment Aligned: A Powerful Predictor of Stock Returns. Review of Financial Studies, 28(3), 791-837.

Jegadeesh, N., \& Titman, S. (1993). "Returns to Buying Winners and Selling Losers: Implications for Stock Market Efficiency". The Journal of Finance, 48(1), 65-91.

Jennings, R., \& Laura, S. (1986). "Earnings Announcements, Stock Price Adjustment, and the Existence of Option Markets" . The Journal of Finance, 41, 107-125.

Jiang, F., Huang, D., Tu, J., \& Zhou, G. (2016, January 31). Forecasting Stock Returns in Good and Bad Times: The Role of Market States. Asian Finance Association (AsianFA) 2016 Conference. SSRN.

Jones, C. M., \& Rhodes-Kropf, M. (2003). "The Price of Diversifiable Risk in Venture Capital and Private Equity". SSRN Journal,Working paper, Columbia University.

Karl , P. (1895, June 20). "Notes on regression and inheritance in the case of two parents". Proceedings of the Royal Society of London, 58, 240-242.

Kumar, A., \& Lee , C. (2006). "Retail investor sentiment and return comovements". Journal of Finance, 61(5), 2451-2486.

Lemmon, M. L., \& Portniaguina, E. V. (2006). "Consumer Confidence and Asset Prices: Some Empirical Evidence". Review of Financial studies, Forthcoming.

Mateus, C., \& Konsilp, W. (2014). Implied Idiosyncratic Volatility and Stock Return Predictability. JMF Journal of Mathematical Finance, 04(05), 338-352.

Merton, R. C. (1973). An Intertemporal Capital Asset Pricing Model. Econometrica, 41(5), 867.

Mood, A. M. (1954). "On the asymptotic efficiency of certain non-parametric two-sample tests". Annals of Mathematical Statistics, 25, 514-522.

Ofek, E., Richardson, M., \& Whitelaw, R. F. (2004). "Limited arbitrage and short sales restrictions: evidence from the options markets". Journal of Financial Economics, 74(2), 305-342.

Pástor, L., \& Stambaugh, R. F. (2003). "Liquidity Risk and Expected Stock Returns". Journal of Political Economy, 111(3), 642-685.

Poon, S.-H., \& Granger, C. W. (2003). "Forecasting volatility in financial markets: A review". Journal of Economic Literature, 41(2), 478-539.

Rapach, D. E., Strauss, J. K., \& Zhou, G. (2009). Out-of-Sample Equity Premium Prediction: Combination Forecasts and Links to the Real Economy. Rev. Financ. Stud. Review of 
Financial Studies, 23(2), 821-862.

Schmalensee, R., \& Trippi, R. (1978). "Common Stock Volatility Expectations Implied by Option Premia”. Journal of Finance, 33(1), 129-47.

Schwartz, E. S. (1997). "The stochastic behavior of commodity prices: Implications for valuation and hedging" . Journal of Finance, 52, 923-973.

Schwartz, E. S., \& Smith, J. E. (2000, July ). "Short-Term Variations and Long-Term Dynamics in Commodity Prices". Management Science, 46, 893-911.

Scruggs, J. T. (1998). "Resolving the Puzzling Intertemporal Relation between the Market Risk Premium and Conditional Market Variance: A Two-Factor Approach”. Journal of Finance, 53, 575-603.

Sharpe, W. (1964). "Capital asset prices: A theory of market equilibrium under conditions of risk". Journal of Finance, 19, 425-442.

Snedecor, G. W., \& Cochran, W. G. (1989). Statistical Methods, Eighth Edition. Iowa State University Press.

Stigler, S. M. (1989). "Francis Galton's Account of the Invention of Correlation". Statistical Science, 4(2), 73-79.

Xu, Y., \& Malkiel, B. G. (2006). "Idiosyncratic Risk and Security Returns". SSRN Journal, Working paper,University of Texas at Dallas.

Zhang, J. E., Shu, J., \& Brenner, M. (2010). "The new market for volatility trading". Journal of Futures Markets, 30(9), 809-833. 


\section{Chapter 6: Summary of Conclusions}

In this dissertation consisted of three essays, we investigate the role of volatility risk in stock returns predictability for 596 stock options traded at the American Stock Exchange and the Chicago Board Options Exchange (CBOE) for the full period from January 2001 to December 2010 including two global financial crises (Dotcom Bubble and recent financial crisis). To conclude, we study and research in three main essays. First essay, we examine "different idiosyncratic volatility forecasting measures on future stock returns in four different periods (bear and bull markets)". Second essay enlarged in term of industry specific effects, we examine "different idiosyncratic volatility forecasting measures on future stock returns in four different periods (bear and bull markets) with eight stock sector classification". Meanwhile, Third essay in term of earnings announcement surprises, we further study and examine "earnings announcement surprises imbedded in option prices (via implied idiosyncratic volatility prior to the announcement." as the robust results from our previous research parts that implied volatility might also contain information about future earnings.

According to the first empirical essay, to our knowledge, it is the first research analyzing the effect of different idiosyncratic volatility measures for a period that involves both the dotcom bubble and the recent financial crisis with sub period extension. This will shed light to the relation between idiosyncratic volatility and stock prices in sub periods when S\&P500 drop at least 20 percent in Bear markets and also recover in Bull markets. At the end, the results of $1^{\text {st }}$ essay can be summarized as follows for four sub periods divided both Bear and Bull markets over two global financial crises. First, we find strong statistically significant evidence of idiosyncratic volatility on stock returns predictability. Second, the results show that implied idiosyncratic volatility is the best predictor among the different volatility measures used. There is clear evidence of a return premium for carrying idiosyncratic volatility risk. Third, we provide evidence of cross-section firm-specific characteristics on stock returns for different periods(bear and bull markets). Finally, we confirm that short selling constraints and liquidity is meaningless on stock returns for both bear and bull markets after the recent financial crisis.

As shown in the second empirical essay, to our knowledge, it is the first research analyzing the effect of different idiosyncratic volatility measures and industry effect by stock sector classification, for a period that involves both the dotcom bubble and the recent financial crisis with sub period extension. At last, the results of second empirical essay are summarized 
as follows for four sub periods divided both Bear and Bull markets over two global financial crises in term of industry effect with stock sector classification. First we find clear and robust empirical evidence that the implied idiosyncratic volatility is the best stock return predictor for every sub periods both bear and bull markets among different sectors. Second, the crosssection firm-specific characteristics uncertainly effect on stock returns forecast in mixed positive and negative effects for different sectors in bear and bull markets. Third, we provide evidence that short selling constraints and liquidity are meaningless to impact on future stock returns after sector classification.

In the third empirical essay, to our knowledge, it is the first research analyzing the effect of the implied idiosyncratic volatility which can predict earnings per share (EPS) announcement surprises for a period that involves both the dotcom bubble and the recent financial crisis. This will shed light to the relation between the implied idiosyncratic volatility and EPS announcement surprises in term of Standardized Unexpected Earnings (SUE) in periods when S\&P500 drop at least 20 percent. In fact, the result summary of $3^{\text {rd }}$ essay is as follows. First, we find strong statistically significant evidence of implied idiosyncratic volatility on earnings per share (EPS) announcement surprises predictability. Second, the results show that the best monthly period of earning announcement date spanning $11^{\text {th }}$ to end of month indicates the impact and predictability of implied idiosyncratic volatility on Standardized Unexpected Earnings(SUE). There is clear evidence of earnings announcement surprises carried by the idiosyncratic volatility risk. 


\section{References}

Amin, Kaushik I, and Charles M.C. Lee (1997) "Option trading, price discovery, and earnings news dissemination", Contemporary Accounting Research 14, 153-192

Amihud, Y., \& Mendelson, H. (1986) "Asset pricing and the bid-ask spread", .Journal of financial Economics, 17(2), 223-249

Ang, A., Hodrick, J., Xing, Y., Zhang, X. (2006) "The cross-section of volatility and expected returns", Journal of Finance, 61, 259-299

Ang, A., \& Chen, J. (2002) "Asymmetric correlations of equity portfolios", Journal of Financial Economics, 63(3), 443-494

Bakshi, G., and Kapadia, N. (2003) "Delta-hedged gains and the negative market volatility risk premium", Review of Financial Studies, 16, 527-566

Bakshi, G., Kapadia, N., and D. Madan (2003) "Stock Return Characteristics, Skew Laws, and Differential Pricing of Individual Equity Options", Review of Financial Studies, 101143

Bali, T. G., \& Cakici, N. (2008) "Idiosyncratic volatility and the cross section of expected returns“", Journal of Financial and Quantitative Analysis,43(1), 29

Banerjee, P., Doran, J., and Peterson, D. (2007) "Implied volatility and future portfolio returns", Journal of Banking and Finance, 31, 3183-3199

Barberis, N., and Huang, M. (2001) "Mental accounting, loss aversion, and individual stock returns", Journal of Finance, 56, 1247-1292

Battalio, Robert H., and Richard R. Mendenhall, 2005, Earnings expectations, investor trade size, and anomalous returns around earnings announcements, Journal of Financial Economics 77, 289-319.

Bates, D., (2000) "Post-'87 crash fears in S\&P500 futures options", Journal of Econometrics, 94, 181-238

Battalio, R., \& Schultz, P. (2006). Options and the bubble. The Journal of Finance, 61(5), 2071-2102.

Banerjee, P. S., Doran, J. S. and Peterson, D. R. (2007) "Implied volatility and future portfolio returns", Journal of Banking \& Finance, 31(10), 3183-3199

Beckers, S. (1981) "Standard deviations implied in option prices as predictors of future stock price variability", Journal of Banking \& Finance, 5(3), 363-381

Bernard, Victor L., and Jacob K. Thomas (1990) "Evidence that stock prices do not fully reflect the implications of current earnings for future earnings", Journal of Accounting and Economics 13, 305-340

Bernard, Victor L., and Jacob K. Thomas 1(989) "Post Earnings Announcement Drift: Delayed Price Response or Risk Premium?”, Journal of Accounting Research, 27(Supplement), $1-36$

Black, Fischer., (1975) "Fact and Fantasy in the use of Options", Financial Analysts Journal, 31, 36-41

Blair B. J., S.H. Poon, S.J. Taylor, (2001) "Forecasting S\&P 100 volatility: The incremental information content of implied volatilities and high Frequency index Returns", Journal of Econometrics, Vol. 105(1), pp. 5-26

Bliss R., N. Panigirtzoglou, (2004), “Option Implied Risk Aversion Estimates", Journal of Finance, Vol. 59(1), pp. 407-446

Boehme, R. D., Danielsen, B. R., Kumar, P., \& Sorescu, S. M. (2006) "Idiosyncratic risk and the cross-section of stock returns: Merton (1987) meets Miller (1977)" Texas A \& M Working paper

Bollerslev T., M.Gibson and H.Zhou, (2004), "Dynamic estimation of volatility risk premia and investor risk aversion from option-implied and realized volatilities", Finance and 
Economics Discussion Series 2004-56, Board of Governors of the Federal Reserve System (U.S.)

Brandt, M., and Q. Kang (2004) "On the Relationship between the Conditional Mean and Volatility of Stock Returns: A Latent VAR Approach", Journal of Financial Economics, Vol. 72, pp. 217-257

Branger N., C Schlag (2004) "Can Tests Based on Option Hedging Errors Correctly Identify Volatility Risk Premia- Unpublished Manuscript, Goethe University

Brown G. W., M.T. Cliff (2004) “Investor Sentiment and the near-term Stock Market”, Journal of Empirical Finance, Vol. 11, pp. 1-27

Brown G. W., M.T. Cliff (2005) "Investor Sentiment and Asset Valuation", Journal of Business, Vol. 78(2), pp. 405-440

Buraschi A., J. Jackwerth (2001), "The price of a smile: hedging and spanning in option markets", Review of Financial Studies, Vol. 14(2), pp. 495-527

Buraschi A, A. Jiltsov (2006), "Model Uncertainty and Option Markets with Heterogeneous Agents", Journal of Finance, 61.6, pp. 2841-2897

Black, F., Myron S. (1973), "The Pricing of Options and Corporate Liabilities", Journal of Political Economy, Volume 81(3), pp. 637-654

Black, F. (1975) "Fact and Fantasy in the Use of Options" Financial Analysts Journal, 36-72

Black F. (1986), "Noise", Journal of Finance, Vol. XLI (3), pp. 529-543

Campa J. M., K. Chang, R. Reider (1998) "Implied Exchange Rate Distributions: Evidence from OTC Option Markets", Journal of international Money and Finance, Vol. 17(1), pp. $117-160$

Campbell, J.Y. (1987), "Stock Returns and the Term Structure", Journal of Financial Economics, Vol.18 (2), pp.373-399

Canina, L. and Figlewski, S. (1993), "The informational content of implied volatility" Review of Financial studies, 6(3), 659-681

Carhart, M. (1997) "On persistence in mutual fund performance”, Journal of Finance, 52, 5782

Carr, P. and L. Wu (2004), "A Tale of Two Indices", 20th Annual Risk Management Conference

Chakravarty, S., Gulen, H.and Mayhew, S. (2004) 2Informed trading in stock and option markets", Journal of Finance, 59(3), 1235-1258

Chan, K. (1992) "A further analysis of the lead-lag relationship between the cash market and stock index futures market" Review of financial studies, 5(1), 123-152

Chiras, D. P., \& Manaster, S. (1978) "The information content of option prices and a test of market efficiency" Journal of Financial Economics, 6(2), 213-234

Chow, G.C. (1960) "'Tests of Equality Between Sets of Coefficients in Two Linear Regressions"', Econometrica, vol. 28, no. 3, pp. 591-605.

Christensen, B. J. and Hansen, C. S. (2002) "New evidence on the implied-realized volatility relation" The European Journal of Finance, 8(2), 187-205

Christensen, B., and Prabhala, N (1998) "The relation between implied and realized volatility", Journal of Financial Economics, 50, 125-150

Chua, C., Goh, J., and Zhang, Z. (2005), "Idiosyncratic volatility matters for the cross-section of returns - In more ways than one!" Working paper

Copeland, M. and Copeland, T. (1999), "Market timing: Style and size rotation using the VIX" Financial Analysts Journal, 55, 73-81

Conover, Mitchell C., and David R. Peterson (1999), “The Lead-Lag Relationship Between the Option and Stock Markets Prior to Substantial Earnings Surprises and the Effect of Securities Regulation", Journal of Financial and Strategic Decisions, 12, 41-52 
Coval, Joshua D., and Tyler Shumway (2001)," Expected Option Returns", Journal of Finance 56, 983-1009

Day, T. E., \& Lewis, C. M. (1992) "Stock market volatility and the information content of stock index options" Journal of Econometrics, 52(1), 267-287

De Long J., A Shleifer, L.H. Summers, R.J. Waldmann (1990), "Noise Trader Risk in Financial Markets", The Journal of Political Economy, Vol. 98(4), pp. 703-38

Dennis, P., Mayhew, S., and Stivers, C. (2006) "Stock returns, implied volatility innovations, and the asymmetric volatility phenomena" Journal of Financial and Quantitative Analysis, 41, 381- 406

Deuskar P., (2006), "Extrapolative Expectations: Implications for Volatility and Liquidity" Job Market Paper, NYU 2006

Diavatopoulos, C., Doran, J. S., \& Peterson, D. R. (2011). Two essays on the predictive ability of implied volatility. ProQQuest, UMI Publishing

Diavatopoulos, D., Doran, J. S., \& Peterson, D. R. (2008). The information content in implied idiosyncratic volatility and the cross-section of stock returns: Evidence from the option markets. J. Fut. Mark. Journal of Futures Markets, 1013-1039.

Diavatopoulos, D., Doran, J. S., Fodor, A., \& Peterson, D. R. (2012). The information content of implied skewness and kurtosis changes prior to earnings announcements for stock and option returns. Journal of Banking \& Finance, 36(3), 786-802.

Diz F., T.J. Finucane (1993), “Do the Options Markets Really Overreact?” Journal of Futures Markets, Vol.13, 298-312

Doran, J., and Ronn, E. (2006) "The bias in Black-Scholes/Black implied volatility: An analysis of equity and energy markets" Review of Derivatives Research, 8, 177-198

Doran, J. S. (2006) "The influence of tracking error on volatility premium estimation", Available at SSRN 670223

Douglas, G. (1969) "Risk in the equity markets: An empirical appraisal of market efficiency", Yale Economic Essays, 9, 3-45

Duan, Y., Hu, G., and McLean, D. (2007) "Costly arbitrage and idiosyncratic risk: Evidence from short sellers" Working paper

Easley, D., O'Hara, M., \& Srinivas, P. S. (1998) "Option volume and stock prices: Evidence on where informed traders trade" Journal of Finance, 53(2), 431-465

Easley, D., and O'Hara, M. (1987) "Price, trade size, and information in securities markets" Journal of Financial economics, 19(1), 69-90

Fama, E. and French, K. (1992) "The cross-section of expected stock returns" Journal of Finance, 47, 427-465

Fama, E., and French, K. (1993) "Common risk factors in the returns on stocks and bonds" Journal of Financial Economics, 33, 3-56

Fama, E. and MacBeth, J. (1973), "Risk, return, and equilibrium: Empirical tests" Journal of Political Economy, 81, 607-636

Fama, Eugene F. (1998), "Market efficiency, long-term returns, and behavioral finance", Journal of Financial Economics, 49, 283-306

Fleming, J. (1998) "The quality of market volatility forecasts implied by S\&P 100 index option prices", .Journal of Empirical Finance, 5(4), 317-345

Fligner, M. A., and Rust, S. W. (1982). A modification of the Mood's median test for the generalized Behrens-Fisher problem. Biometrika, 69, 221-226.

Fleming J., B. Ostdiek, R. Whaley (1995), "Predicting stock market volatility: A new measure", Journal of Futures Markets, Vol.15 (3) pp.265-302

Florackis, C, Gregoriou, A \& Kostakis, A (2011), 'Trading frequency and asset pricing on the London Stock Exchange: Evidence from a new price impact ratio", Journal of Banking and Finance, 35(12), 3335-3350. 
Foster, George., Chris Olsen, and Terry Shevlin (1984) "Earnings releases, anomalies, and the behavior of security returns", The Accounting Review, 59, 574-603

Freeman, Robert N., and Senyo Tse (1989) "The Multi period Information Content of Accounting Earnings: Confirmations and Contradictions of Previous Earnings Reports", Journal of Accounting Research 27(Supplement), 49-79

French, D.W., D.A. Dubofsky (1986), "Stock Splits and Implied Stock Price Volatility", The Journal of Portfolio Management, Vol. 12 (4), pp.55-59

$\mathrm{Fu}, \mathrm{F}$. (2009) "Idiosyncratic risk and the cross-section of expected stock returns" Journal of Financial Economics, 91(1), 24-37

Galton, F. (1886) "Regression towards mediocrity in hereditary stature," Journal of the Anthropological Institute of Great Britain and Ireland, 15 : 246-263.

Giot, P. (2005) "Relationships between implied volatility indexes and stock returns" Journal of Portfolio Management, 26, 12-17

Gatheral J., (2003) "Modeling the Implied Volatility Surface", Global Derivatives and Risk Management2003, Barcelona

Giot, P. (2005) "Relationships between implied volatility indexes and stock index returns", Journal of Portfolio Management, 31(3), 92-100

Glosten, R., Jagannathan, R. and D. Runkle (1993), "On the Relation Between the Expected Value and the Volatility of the Nominal Excess Return on Stocks", Journal of Finance, vol. 48(5), pp. 1779-1801

Glosten, L. R., \& Harris, L. E. (1988) "Estimating the components of the bid/ask spread" Journal of Financial Economics, 21(1), 123-142

Goyal, A., and Santa-Clara, P. (2003), "Idiosyncratic risk matters!" Journal of Finance, 58, 975- 1008

Guo, H., \& Whitelaw, R. F. (2006) "Uncovering the risk-return relation in the stock market", Journal of Finance, 61(3), 1433-1463

Han B., (2006)," Limits of Arbitrage, Sentiment and Pricing Kernel: Evidence from S\&P 500 Index Options", Working Paper, OSU

Hansen, B. E. (1999) "Threshold effects in non-dynamic panels: Estimation, testing, and inference", Journal of econometrics, 93(2), 345-368

Harvey, C. R. (1989), Time-Varying Conditional Covariances in Tests of Asset Pricing Models", Journal of Financial Economics, Vol. 24, pp. 289-317

Haugen, R. A., \& Lakonishok, J. (1987) "The incredible January effect: The stock market's unsolved mystery" Dow Jones-Irwin

Hentschel, L. (2003) "Errors in implied volatility estimation" Journal of Financial and Quantitative Analysis, 38, 779-810

Heston, S.L. (1993), "A closed-form solution for options with stochastic volatility with applications to bond and currency options", Review of Financial Studies, Vol.6 (2), pp327-343

Ho, Li-Chin Jennifer (1993), "Option trading and the relation between price and earnings: a cross- sectional analysis", The Accounting Review, 68, 368-384

Hull J., A.White (1987), "The Pricing of Options on Assets with Stochastic Volatilities", Journal of Finance, Vol. 42(2), pp281-300

Jackwerth, J. C., \& Rubinstein, M. (1996), "Recovering probability distributions from option prices" Journal of Finance, 51(5), 1611-1631

Jennings, Robert and Laura Starks (1986), "Earnings Announcements, Stock Price Adjustment, and the Existence of Option Markets", Journal of Finance, 41, 107-125

Jones, C., and Rhodes-Kropf, M. (2003) "The price of diversifiable risk in venture capital and private equity", Working paper, Columbia University

Jones, S. L., \& Singh, M. K. (1997) "The Distribution of Stock Returns Implied in Their 
Options at the Turn-of-the-Year: A Test of Seasonal Volatility" The Journal of Business, 70(2), 281-311

Karl Pearson (20 June 1895) "Notes on regression and inheritance in the case of two parents," Proceedings of the Royal Society of London, 58 : 240-242.

Kawaller, I. G., Koch, P. D. and Koch, T. W (1987) "The temporal price relationship between S\&P 500 futures and the S\&P 500 index" Journal of Finance, 42(5), 1309-1329

Keim, D. B. (1983) "Size-related anomalies and stock return seasonality: Further empirical evidence", Journal of Financial Economics, 12(1), 13-32

Klein, L, D. R. Peterson (1988), "Investor Expectations of Volatility Increases Around Large Stock Splits As Implied in Call Option Premia”, The Journal of Financial Research, Vol. 11(1) pp 71- 86

Kyle, A. S. (1985), "Continuous auctions and insider trading", Econometrica, Journal of the Econometric Society, 1315-1335

Kumar, S. M, A. Persaud (2002), "Pure Contagion and Investors Shifting Risk Appetite: Analytical Issues and Empirical Evidence", International Finance, Vol 5(3)

Kumar, A., \& Lee, C. (2006), "Retail investor sentiment and return comovements", Journal of Finance, 61(5), 2451-2486

Kumar, P., \& Seppi, D. J. (1994), "Information and index arbitrage”, Journal of Business, 481509

Lakonishok, J., Shleifer, A., Thaler, R. and Vishny, R. (1991), "Window dressing by pension fund managers" National Bureau of Economic Research, w3617

Lamoureux C.G. and W.D. Lastrapes (1993), "Forecasting Stock-Return Variance: Toward an Understanding of Stochastic Implied Volatilities", The Review of Financial Studies, Vol. 6(2) pp.293-326

Latane, H.A., R.J. Rendleman, Jr. (1976), "Standard Deviations of Stock Price Ratios Implied in Option Prices", Journal of Finance, Vol. 31(2), pp369-81

Lee, C. M., Mucklow, B., Ready, M. J. (1993) "Spreads, depths, and the impact of earnings information: An intraday analysis", Review of Financial Studies, 6(2), 345-374

Lemmon, M.L., E.V, Portniaguina (2006), "Consumer Confidence and Asset Prices: Some Empirical Evidence", Review of Financial studies, Forthcoming

Lehmann, B. (1990) "Residual risk revisited", Journal of Econometrics, 45, 71-97

Li, S., \& Yang, Q. (2009) "The relationship between implied and realized volatility: evidence from the Australian stock index option market", Review of Quantitative Finance and Accounting, 32(4), 405-419

Lintner, J. (1965) "The valuation of risk assets and the selection of risky investments in stock portfolios and capital budgets", The review of economics and statistics, 13-37

Low Cheekiat, (2004), "The Fear and Exuberance from Implied Volatility of S\&P 100 Index Options", Journal of Business, Vol. 77, pp. 527-546

Malkiel, B., and $\mathrm{Xu}, \mathrm{Y}$. (2006), "Idiosyncratic risk and security returns" Working paper, University of Texas at Dallas

Maloney, K. J. and Rogalski, R. J. (1989) "Call-option pricing and the turn of the year", Journal of Business, 539-552

Manaster, S. and Rendleman, Jr. R. (1982), "Option Prices as Predictors of Equilibrium Stock Prices", Journal of Finance, 37, 1043-1057

Mateus, C. and Konsilp, W. (2014) 'Implied Idiosyncratic Volatility and Stock Return Predictability', Journal of Mathematical Finance Journal of Mathematical Finance, vol. 04, no. 05, pp. 338-352.

Mayhew S. (1995), "Implied Volatility", Financial Analysts Journal, Vol. 51(4), pp.8-20

Mendenhall, Richard (2004), "Arbitrage risk and post-earnings-announcement drift", Journal of Business, 77, 875-894 
Mendenhall, R. and Fehrs D. (1999), "Option listing and the stock-price response to earnings announcements, Journal of Accounting \& Economics, 27, 57-87

Merton, R. (1987) "Presidential address: A simple model of capital market equilibrium with incomplete information", Journal of Finance, 42, 483-510

Merton, R., (1980), "On Estimating the Expected Return on the Market: An Exploratory Investigation", Journal Financial Economics, Vol. 8

Mood, A. M. (1954). On the asymptotic efficiency of certain non-parametric two-sample tests. Annals of Mathematical Statistics, 25, 514-522.

Moskowitz. T, ( 2003), “An Analysis of Covariance Risk and Pricing Anomalies”, Review of Financial Studies, Vol. 16 (2), pp. 417-457

Miller, E. (1977) "Risk, uncertainty, and divergence of opinion", Journal of Finance, 32, 11511168

Moll, C. R. (2010), "Tests of the Information Content Of Derivatives Prices: The Case Of Options And Single Stock Futures"

Nelson, D. (1991), "Conditional heteroskedasticity in asset returns: A new approach", Econometrica, 59, 347-370

Nelson, C. R., Startz, R., and C. M. Turner (1989), “A Markov Model of Heteroskedasticity, Risk, and Learning in the Stock Market”, Journal of Financial Economics, Vol. 25 (1), pp. 3-25

Newey, W. and K. West (1987), "A Simple, Positive Semi-Definite, Heteroskedasticity and Autocorrelation Consistent Covariance Matrix", Econometrica, Vol. 55(3)

Ng, L. and Wang, Q. (2004), "Institutional trading and the turn-of-the-year effect" Journal of Financial Economics, 74(2), 343-366

Ofek, E., Richardson, M., and Whitelaw, R. (2004), "Limited arbitrage and short sales restrictions: Evidence from the options markets", Journal of Financial Economics, 74, 305-342

Pan, J. (2000), “The Jump-Risk Premia Implicit in Options: Evidence from an Integrated TimeSeries Study", Journal of Financial Economics, 63(1), 3-50

Patell, James M., and Mark A. Wolfson (1981), "The Ex Ante and Ex Post Price Effects of Quarterly Earnings Announcements Reflected in Option and Stock Prices”, Journal of Accounting Research, 19, 434-458

Patell, James M., and Mark A. Wolfson (1979), "Anticipated Information Releases Reflected in Call Option Prices", Journal of Accounting and Economics, 1, 117-140

Poon, S. H., and Granger, C. W. (2003) "Forecasting volatility in financial markets: A review", Journal of Economic Literature, 41(2), 478-539

Poterba, James M., L.H. Summers (1986), "The Persistence of Volatility and Stock Market Fluctuations", The American Economic Review, Vol. 76 (5) pp.1142-51

Poteshman, A.M.( 2001),"Underreaction, Overreaction, and Increasing Misreaction to Information in the Options Market", Journal of Finance, Vol. 56 (3), pp. 851-876

Ritter, J. R., and Chopra, N. (1989), "Portfolio Rebalancing and the Turn-of-the-Year Effect", The Journal of Finance, 44(1), 149-166

Rogalski, R. J., \& Tinic, S. M. (1986), "The January size effect: anomaly or risk mismeasurement?", Financial Analysts Journal, 63-70

Roll, R. (1983), "On computing mean returns and the small firm premium", .Journal of Financial Economics, 12(3), 371-386

Roll, R., Schwartz, E. and Subrahmanyam, A. (2007), "Liquidity and the Law of One Price: The Case of the Futures-Cash Basis" Journal of Finance, 62(5), 2201-2234

Ross, S. (1976), "The arbitrage theory of capital asset pricing", Journal of Economic Theory, $13,341-360$

Rozeff, M. S.and Kinney Jr, W. R. (1976)," Capital market seasonality: The case of stock 
returns", Journal of Financial Economics, 3(4), 379-402

Sharpe, W. F. (1964) "Capital asset prices: A theory of market equilibrium under conditions of risk", Journal of Finance, 19(3), 425-442

Shastri, K., Thirumalai, R. S. and Zutter, C. J. (2008), "Information revelation in the futures market: Evidence from single stock futures", Journal of Futures Markets, 28(4), 335353

Schmalensee R., R. Trippi, (1978), "Common Stock Volatility Expectations Implied by Option Premia”, Journal of Finance, Vol. 33(1) pp.129-47

Scruggs, J.T. (1998), "Resolving the Puzzling Intertemporal Relation between the Market Risk Premium and Conditional Market Variance: A Two-Factor Approach", Journal of Finance, Vol. 53, pp. 575-603

Schwartz, E. S., (1997), "The stochastic behavior of commodity prices: Implications for valuation and hedging." Journal of Finance, 52, 923-973

Schwartz, E. S., and J.E. Smith (2000), "Short-Term Variations and Long-Term Dynamics in Commodity Prices", Management Science, Vol. 46, July 2000, 893-911

Sharpe, W. (1964) "Capital asset prices: A theory of market equilibrium under conditions of risk", Journal of Finance, 19, 425-442

Sheikh, Aamir M., and Ehud I. Ronn (1994), "A characterization of the daily and intraday behavior of returns on options", Journal of Finance, 49, 557-580

Shleifer A., L.H. Summers, (1990), "The Noise Trader Approach to Finance", The Journal of Economic Perspectives, Vol. 4(2), pp. 19-33

Shu, J., and Zhang, J. E. (2003), "The relationship between implied and realized volatility of S\&P 500 index", Wilmott magazine, 4, 83-91

Simon D. P. and RA Wiggins (2001), "S\&P futures returns and contrary sentiment indicators", Journal of Futures Markets, Vol. 1(5), pp. 447-462

Skinner, Douglas J. (1990), "Options markets and the information content of accounting earnings releases", Journal of Accounting and Economics, 13, 191-211

Snedecor, George W. and Cochran, William G. (1989), Statistical Methods, Eighth Edition, Iowa State University Press.

Spiegel, M. and Wang, X. (2007), "Cross-sectional variation in stock returns: Liquidity and idiosyncratic risk", Yale Working Paper

Stephan, Jens A., and Robert E. Whaley, (1990), "Intraday price change and trading volume relations in the stock and stock option markets", Journal of Finance, 45, 191-220

Stein, J. (1989), "Overreactions in the options market", Journal of Finance, Vol. 44(4), pp. 1011-1023

Stigler, Stephen M. (1989). "Francis Galton's Account of the Invention of Correlation". Statistical Science 4 (2):

73-79.

Stoll, H. R., and Whaley, R. E. (1990) "The dynamics of stock index and stock index futures returns", Journal of Financial and Quantitative Analysis, 25(04), 441-468

Szakmary, A., Ors, E., Kyoung Kim, J.and Davidson III, W. N. (2003), "The predictive power of implied volatility: Evidence from 35 futures markets", Journal of Banking \& Finance, 27(11), 2151-2175

Tinic, S. M. and West, R. R. (1984), "Risk and return: January vs. the rest of the year", Journal of Financial Economics, 13(4), 561-574

Tse, Y. (1999), "Price discovery and volatility spillovers in the DJIA index and futures markets", Journal of Futures markets, 19(8), 911-930

Vijh, Anand M. (1988), "Potential biases from using only trade prices of related securities on different exchanges", Journal of Finance, 43, 1049-1055 
Vlad D. G. (2004), "Investors' beliefs and their implications on asset pricing, excess returns, and volatilities in financial markets", Ph.D. Thesis, Southern Illinois University at Carbondale

Whaley, R. E. (2000), “The investor fear gauge”, Journal of Portfolio Management, 26(3), 12-17

$\mathrm{Xu}$, Y., \& Malkiel, B. G. (2006). "Idiosyncratic Risk and Security Returns". SSRN Journal, Working paper,University of Texas at Dallas.

Zhang, J. E., Shu, J., \& Brenner, M. (2010). "The new market for volatility trading". Journal of Futures Markets, 30(9), 809-833. 